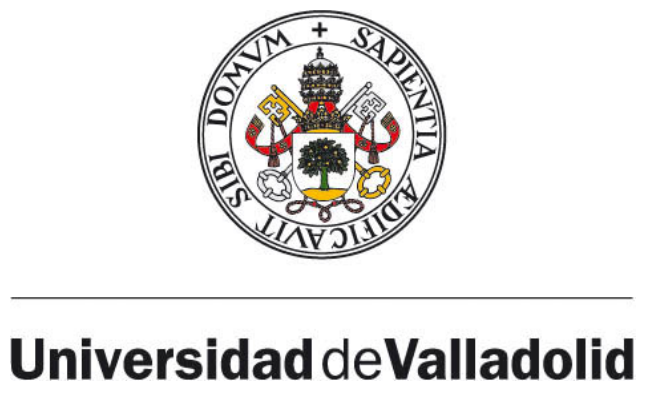

FACULTAD DE CIENCIAS

DEPARTAMENTO DE FÍSICA APLICADA

TESIS DOCTORAL:

\title{
Solar Irradiance and Actinic Flux in the UV Range: Advances in the Characterization of the Cloudy Scenario
}

Presentada por David Mateos Villán para optar al grado de doctor por la Universidad de Valladolid

\author{
Dirigida por: \\ Dr. Julia Bilbao Santos \\ Dr. Alcide di Sarra \\ Dr. Argimiro de Miguel Castrillo
}





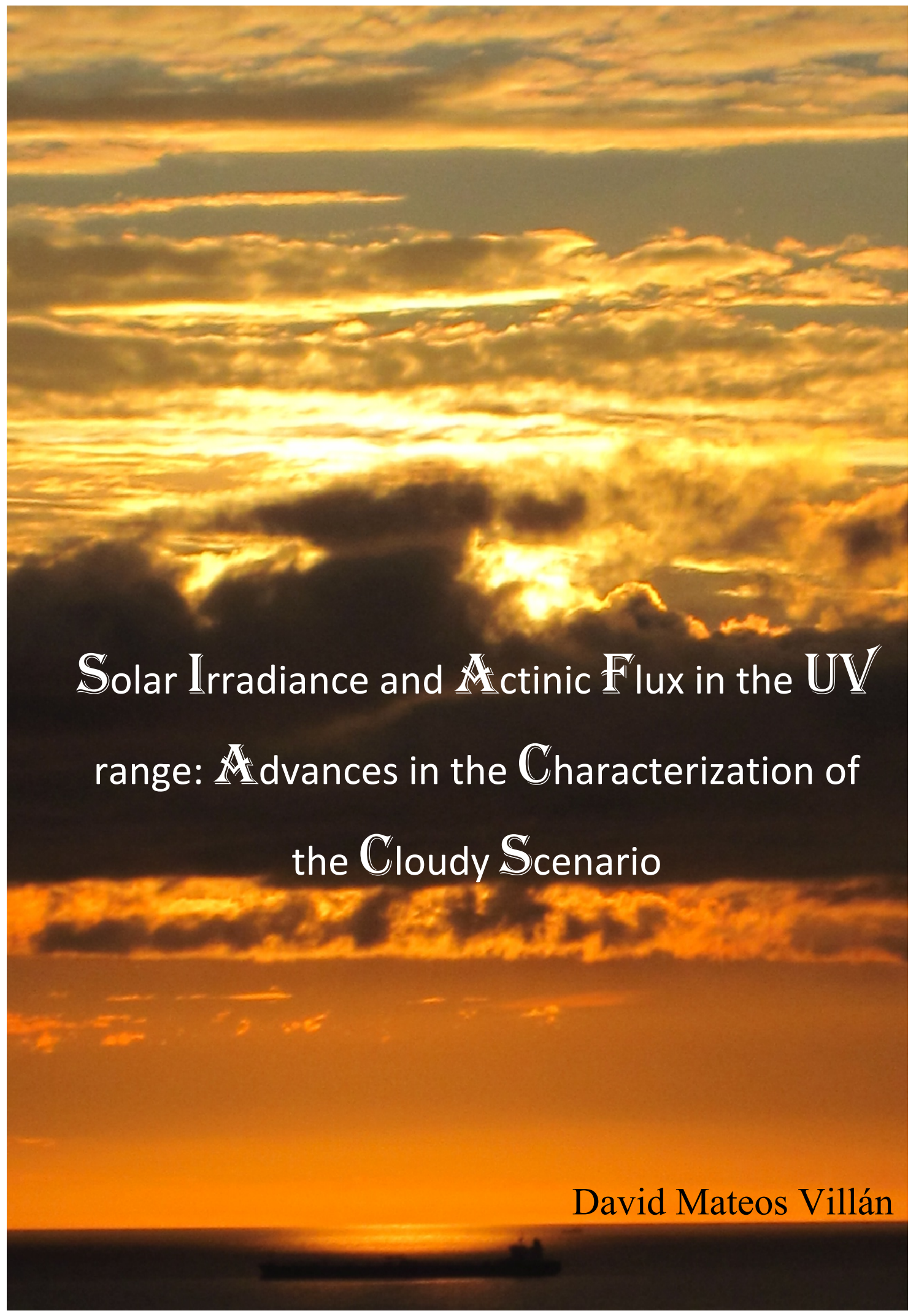





\section{Certificate}

Dra. Julia Bilbao Santos y Dr. Argimiro de Miguel Castrillo, ambos profesores titulares del área de Física Aplicada de la Universidad de Valladolid, junto con Dr. Alcide di Sarra cotutor de este trabajo de investigación y director de la unidad UTMEA-TER de la agencia de investigación italiana ENEA,

\section{CERTIFICAN:}

Que la presente memoria titulada: "Solar irradiance and actinic flux in the UV range: advances in the characterization of the cloudy scenario", presentada por D. David Mateos Villán para optar al grado de Doctor en Física, ha sido realizada bajo nuestra dirección en el Departamento de Física Aplicada de la Universidad de Valladolid con estancias de investigación en la unidad UTMEA-TER.

Y para que así conste, en cumplimiento de la legislación vigente, firmamos el presente certificado en Valladolid, a 11 de julio de 2012.

Fdo.: Dra. Julia Bilbao Santos

Fdo.: Dr. Alcide di Sarra

Fdo.: Argimiro de Miguel Castrillo 



\section{Acknowledgments}

This thesis was written thanks to a pre-doctoral scholarship (PIF-UVa) from the University of Valladolid.

I would particularly like to thank Dra. Julia Bilbao and Dr. Argimiro de Miguel for their guidance, trust and understanding throughout the whole of this PhD. I also wish to thank Dr. Alcide di Sarra for his help during my academic visits to Italy and for having welcomed me as one of his $\mathrm{PhD}$ students. I have been fortunate to have the opportunity to learn from the expertise and research of these three scientists.

Most of the studies presented in this thesis were partly undertaken during the experimental campaign of the MINNI and MORE projects, which was supported by the UTMEA unit of the Italian agency ENEA. I would also like to extend my gratitude to Dr. Giandomenico Pace for HATPRO data, to Dr. Giampietro Casasanta for actinic flux data, and to Dr. Marco Cacciani for LIDAR plots.

En lo que respecta a la parte personal, he decidido aprovechar esta oportunidad para expresar esas cosas que no se suelen decir pero que están ahí día tras día. Aquí van mis sentimientos durante estos cinco últimos años de mi vida:

En primer lugar, agradecer a mis padres, Mercedes y José Antonio, porque a ellos se lo debo todo. Me han enseñado tantas cosas de la vida que es imposible enumerarlas todas. Educación, respeto, honradez, generosidad,... tanto que aprender de vosotros, que espero poder demostrarlo a lo largo de mi vida. Si he podido hacer esta tesis, ha sido gracias a vosotros que me habéis ayudado, aconsejado, calmado,... en definitiva, esta tesis va por vosotros.

A mi prima Elisa, por estar siempre ahí, y porque la siento más como hermana que como prima. Hemos vivido muchas cosas, y siempre juntos, lo que ha hecho más llevaderos los malos momentos. A mis tíos Piluchi y Vicente, porque cada reunión familiar me hace sentir más feliz de teneros cerca. Sois únicos e irrepetibles.

Un gran trozo de esta tesis va dirigido a Natzaret, que en este momento tiene 4 años y medio. No puedo olvidar la sensación que viví aquel 24 de enero cuando me llegó tu foto recién nacida. Después de los que fueron los meses más duros de toda mi vida, pude por fin volver a experimentar lo que era la felicidad. No me puedo olvidar de tus padres (mis primos), Isa y Alexis, y de tus abuelos (mis tíos), Isabel y Carlos, que siempre han estado cerca de mí y de mis padres. Mención especial merece Celes, que desde la distancia, nos muestra siempre su cariño.

No puedo tardar más en mencionar a la gente que estuvo y que ya no está, porque no han dejado de ser importantes para mí, así que aquí van mis agradecimientos para ellos. A mi abuela Pilar, porque es muy difícil explicar cómo cada día echo de menos sus besos, abrazos y sonrisas que durante un gran tiempo fueron el motor de mi vida. A mi abuelo Julián, porque fue muy grande en todo, y porque sé, que el día que defienda esta tesis se sentirá muy orgulloso de mí. A mi abuela Soledad y a mi prima Ana, porque las dos me enseñaron lo que era la fuerza de la lucha por sobrevivir día tras día, y siempre con una sonrisa; me gustaría poder tener un poco de la fortaleza que ambas mostrasteis. A mi tío Ramón, porque no me acabo de acostumbrar a no verte al entrar en tu casa de Malva y oírte contar las historias de cuando yo era pequeño, y porque fuiste simple y llanamente Ramón. Y también mi recuerdo a Juan, la última adquisición de la familia, porque revitalizaste a una familia tocada por las ausencias y además, nos abriste la puerta a una nueva.

A mi (nuestra) nueva familia, Mari Carmen, Julio, Juanjo y familia. El cariño que recibimos de vosotros es tan grande, que espero que nos sigamos reuniendo para poder disfrutar de vosotros.

También quiero expresar mi agradecimiento al resto de mis tíos, primos y demás familia. 
Y aunque sean much@s, intentaré no olvidarme de ningun@ de mis amig@s. Primero las de más antigüedad (¡qué de años juntos!): Lara G., porque te debo más de lo que imaginas y porque siempre estás dispuesta a escuchar (aunque te llame pidiendo SOS sobre narcos). Iris, porque eres única y siempre consigues hacerme reír. Silvia, porque da igual cuando, siempre estás. Y por último, María y Lara M., porque siempre estáis preocupándoos por mí, y eso se agradece. Y ahora los más nuev@s, pero no menos importantes: Jose, mi 'primo', si se pudiese elegir a la familia, ten por seguro que te elegiría. Pacho, por la paciencia que has tenido y por los buenos ratos que nos quedan por pasar en ese sitio de cuyo nombre no quiero acordarme. Lobo, quién iba a decir que un tío tan grande podría ser tan majo (ah! Y gracias por haberme llevado tantas veces en tu coche). Nieto, por la habilidad de convertir cualquier rato en un gran rato (y por esa caricatura que está en proceso). Tampoco me puedo olvidar de Nuria y Vargas (sois muy grandes); Vero y Ketex (mis últimos descubrimientos); Lázaro, Héctor, Alfonso, Eva y Luis (la cara B también importa); Jesús, Kike, Rober y Molina (por los buenos ratos pasados); y Benja, Mariana y Banana (qué pena no veros más). Tampoco me olvido de tod@s a 1@s que, por circunstancias de la vida, ya no veo tanto: Edu, Ana I., Ana P., Medina, Virginias (rubia y morena)... Y también Marcos (y familia), que desde la infancia siempre es grato poder tener a un amigo así.

A Tamara y Amador, por la comprensión y el aguante que habéis tenido conmigo. Los cafés, comidas, cenas, timbas, noches de XBOX y juego de tronos... no se me van a olvidar nunca. No sé dónde nos llevará la vida, pero si no estáis cerca, os echaré de menos.

Y moviendo mi cabeza en el despacho, veo a Roberto, que ha sido de gran ayuda en momentos cruciales de atasco y atolladero, y porque siempre ha respondido a las temibles frases que comenzaban con un "Roberto...". Sin duda, ha sido fundamental durante estos años. También veo a Carmen, que siempre ha estado dispuesta a echar una mano, ya se pidiese desde la mesa de enfrente o desde miles de kilómetros. También agradecer a Rubén y a Juanfran por esos 'ratos científicos' que siempre han hecho que termine doblado de reír.

Non posso dimenticare tutti quelli che mi sono stati vicini nei miei soggiorni in Italia. Per prima cosa voglio ringranziare tutta l'unitá UTMEA-TER dell' ENEA-Casaccia per la sua ospitalità: Giando e Daniela (i vostri contributi a questa tesi hanno un valore inestimabile), Claudia, Giampiettro, Claudio, Paolo, Lorenzo, Bianca, Toni, Daniele, Irene, e Simone. Della stessa unitá dedico un ringraziamento speciale a José Luis, que me ayudó mucho en esos primeros días en los que el italiano me parecía ruso y consiguió que tuviese un aterrizaje mucho más suave. Voglio ringraziare tutti quelli della campagna di ENEA-Trisaia: il gruppo G-24 della Università della Sapienza per il loro aiuto, da Marco a Giampietro, Nicoletta, Vincenzo, a tutte le persone di ENEA-Bologna perché grazie a loro la campagna è diventata molto più divertente, e tutti quelli dell' ENEA-Trisaia che mi hanno fatto sentire a casa durante quei 2 mesi.

Fuori del lavoro, ho avuto la fortuna di trovare Carlos, il mio 'roma's brother'. Sin duda, eres la persona más generosa que he conocido nunca, sin ti Roma no hubiese sido lo mismo. Gracias, de verdad, por todo. Da también mis gracias a Lina, Ludovico, Valentina, Livia, etc. E in fine voglio ringraziare tre amici scoperti durante il mio primo viaggio a Roma, Tsugu, Tobias ed Andrea, che hanno fatto si che vivessi la mia esperienza in modo incredibile.

Thank you everybody for everything,

Per tutto questo, grazie a tutti,

Por todo esto, gracias a tod@s, y... 
A mis padres 



\section{Table of contents}

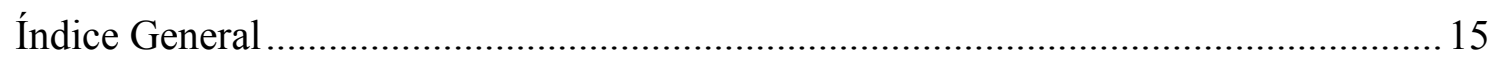

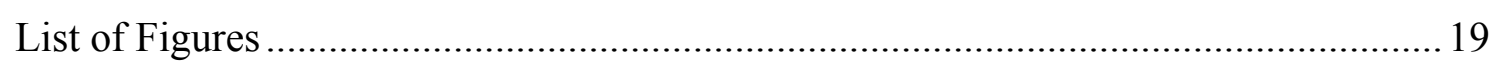

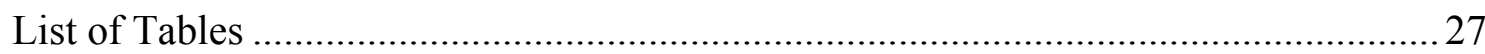

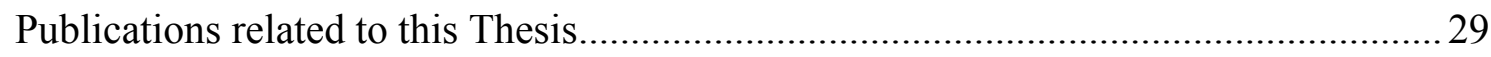

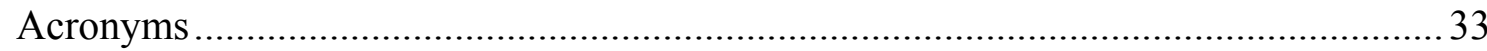

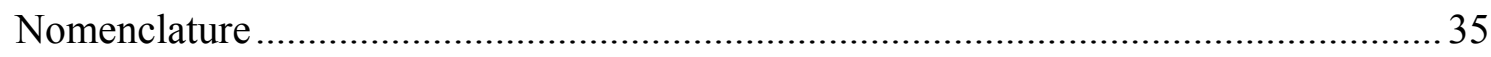

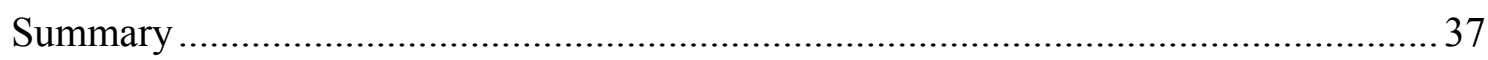

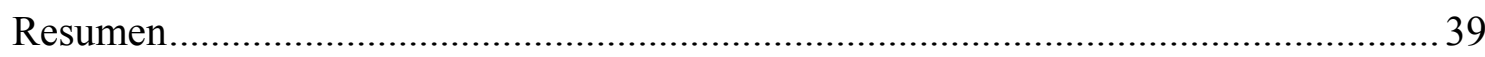

Introduction, Objectives and Thesis Structure........................................................... 41

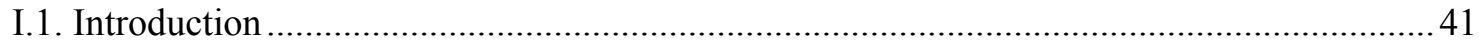

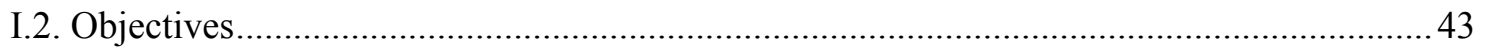

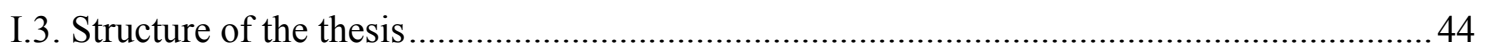

1. The radiative field and the factors controlling its levels at the surface ....................47

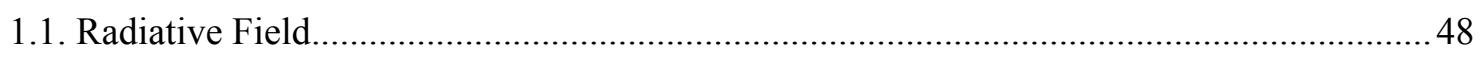

1.1.1. Introduction and definitions........................................................................................ 48

1.1.2. Integrated radiation quantities .............................................................................. 51

1.2. Factors controlling the UV radiative flux....................................................................5

1.2.1. Reflection, absorption and scattering …………………………………………….... 55

1.2.2. Main factors affecting the solar radiative flux in the ultraviolet range …………..........62

1.3. What is the effect of clouds on the UV radiative flux? .................................................. 70

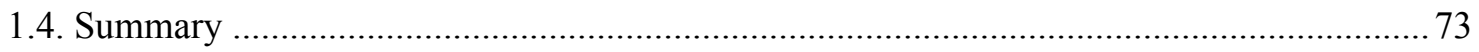

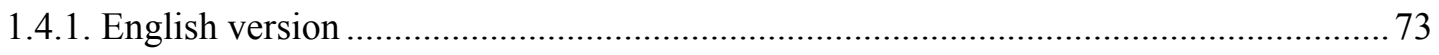

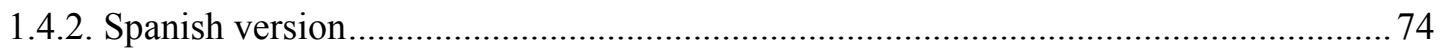

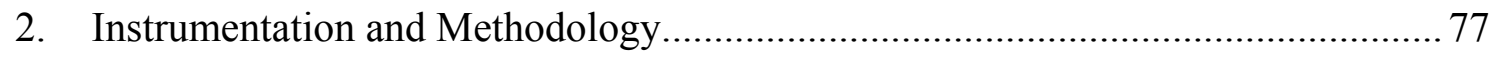

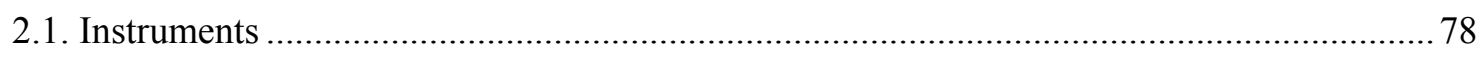

2.1.1. Broadband UVI measurements: UVB-1 ....................................................................

2.1.2. Spectral irradiance and UVI: UV-MFRSR .................................................................. 84

2.1.3. Spectral irradiance: BREWER ................................................................................... 88 


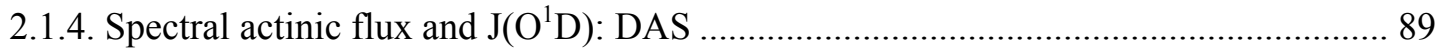

2.1.5. Cloud microphysical properties: HATPRO ........................................................... 90

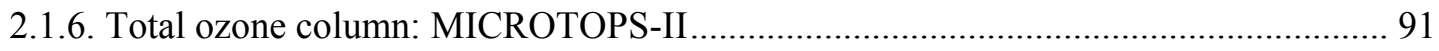

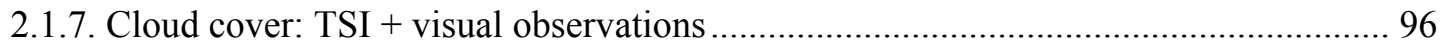

2.1.8. Total SW measurements: CMP21 / CM 6B / PSP ..................................................... 98

2.1.9. Aerosol and cloud vertical distribution: LIDAR .......................................................... 99

2.1.10. Aerosol optical properties: VIS-MFRSR ……................................................... 100

2.1.11. Remote sensing data: OMI - GOME/GOME2 - MODIS ……………….............. 100

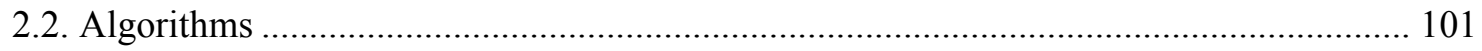

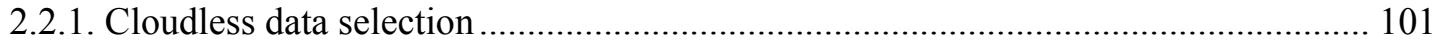

2.2.2. Algorithms to retrieve fractional sky cover ............................................................ 102

2.2.3. Algorithm to retrieve Cloud Optical Thickness ........................................................ 105

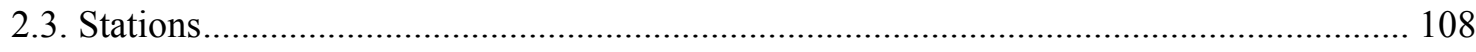

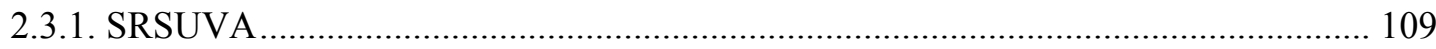

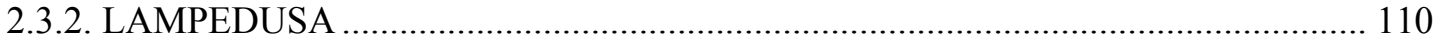

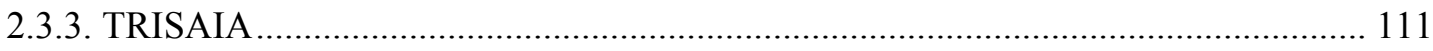

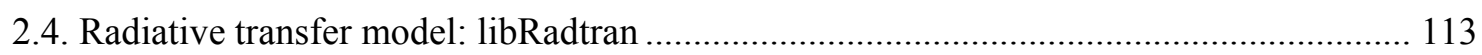

2.4.1. Radiative Transfer Equation (RTE) and Discrete Ordinate Approximation.............. 113

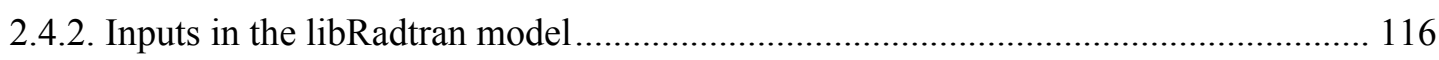

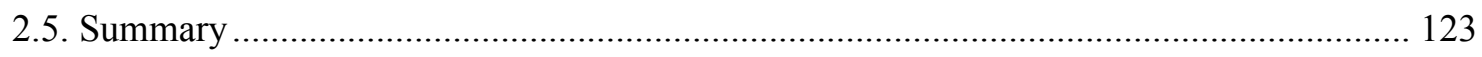

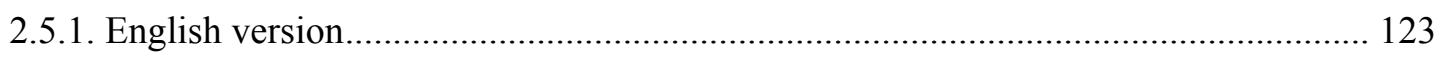

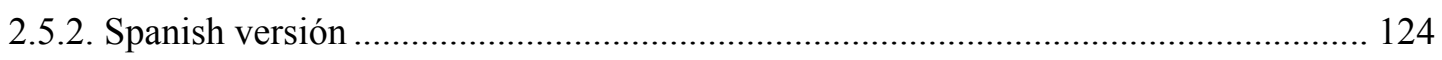

3. Characterization of UV Index and Ozone Photolysis Rate in the Cloudy Scenario127

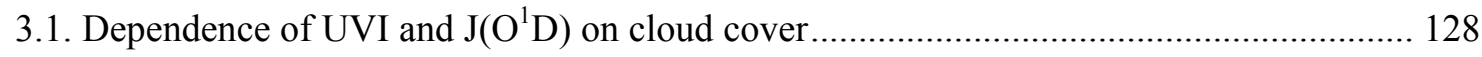

3.1.1. UVI dependence on cloud cover and solar zenith angle ........................................ 128

3.1.2. $\mathrm{J}\left(\mathrm{O}^{1} \mathrm{D}\right)$ dependence on cloud cover and solar zenith angle..................................... 131

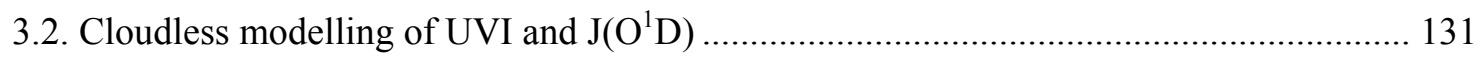

3.2.1. UVI under cloudless conditions: measurements vs simulations ................................ 132

3.2.2. $\mathrm{J}\left(\mathrm{O}^{1} \mathrm{D}\right)$ under cloudless conditions: measurements vs simulations ........................... 136

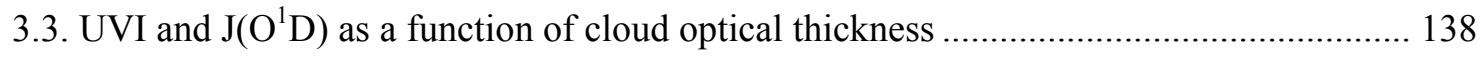

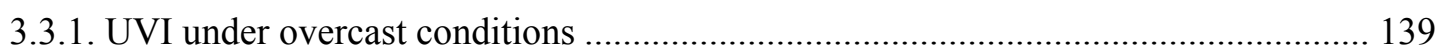

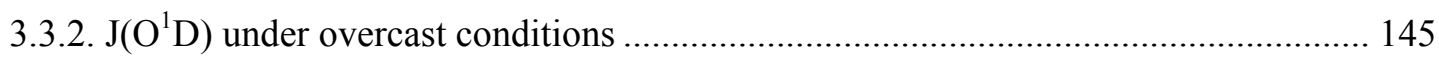

3.4. Evaluation of cloud modification factors for UVI and $\mathrm{J}\left(\mathrm{O}^{1} \mathrm{D}\right)$ and their dependence on cloud optical thickness 


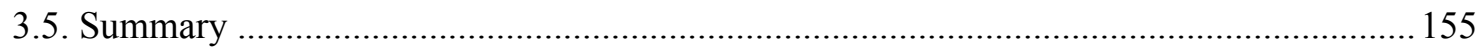

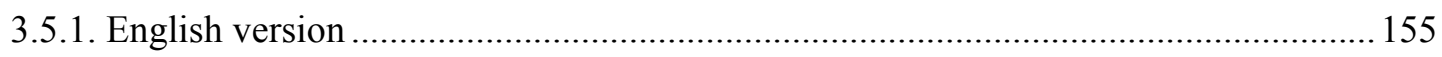

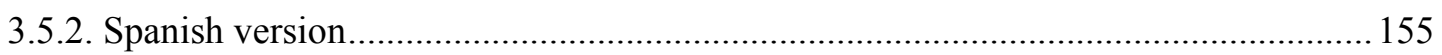

4. Characterization of Spectral Cloud Modification Factors as a function of Cloud Optical Thickness..

4.1. Dependence of global irradiance CMF on cloud cover, cloud optical thickness and solar zenith angle.

4.2. Spectral dependence of actinic flux CMF on cloud optical thickness and solar zenith angle

4.3. Spectral CMF of global and diffuse irradiances as a function of cloud optical properties

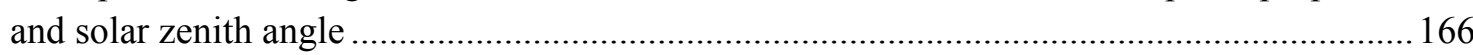

4.4. Physical interpretation of the spectral effects under overcast conditions ............................. 171

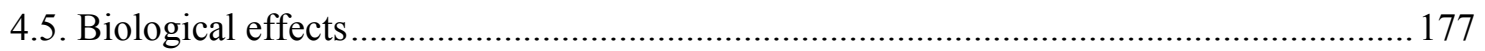

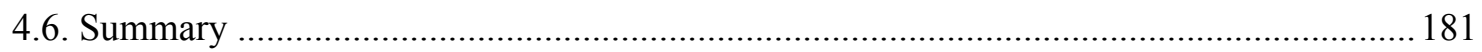

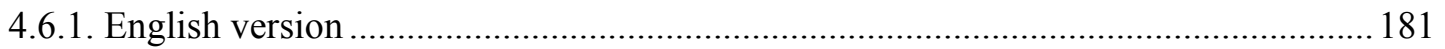

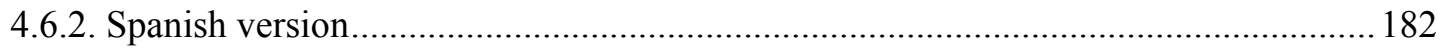

5. Dependence of UV Cloud Modification Factors on Water Cloud Microphysical Properties

5.1. Dependence of integrated UV radiative flux on water cloud microphysical properties.... 184

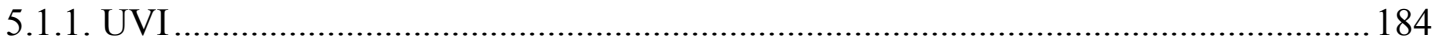

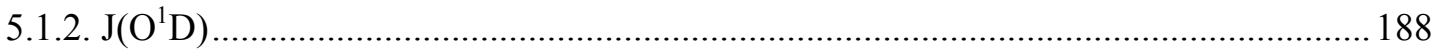

5.2. Dependence of spectral UV radiative flux on water cloud microphysical properties ........ 193

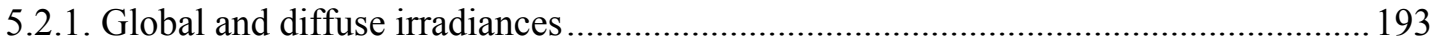

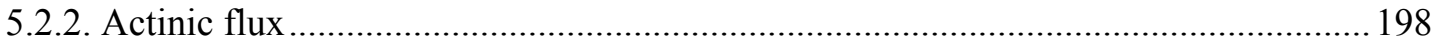

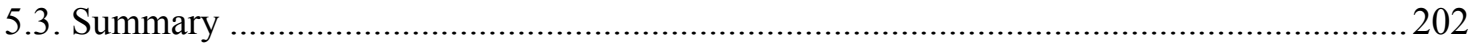

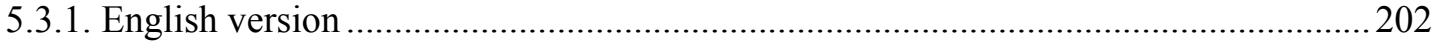

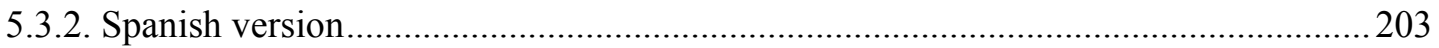

6. Case Study: Role of an Aerosol Layer below the Cloud. Model Sensitivity Analysis

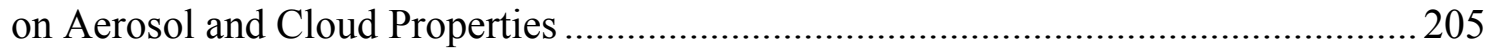

6.1. Case study and inputs to the radiative transfer model ………............................................206

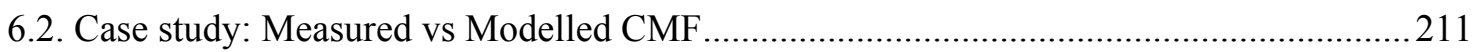

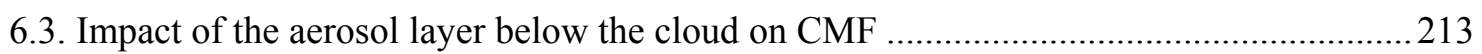

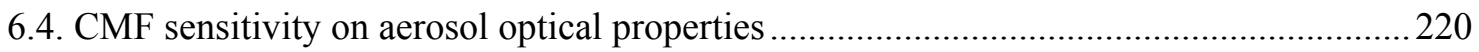




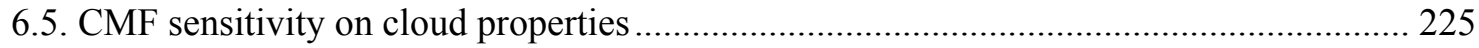

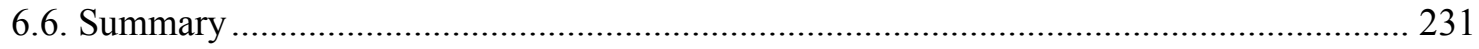

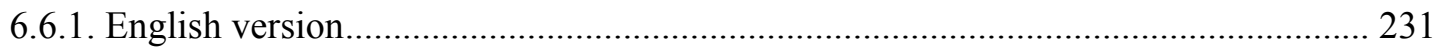

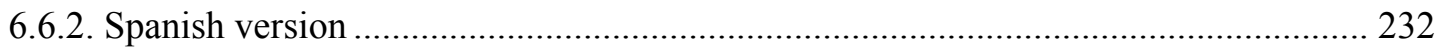

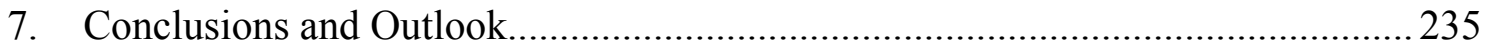

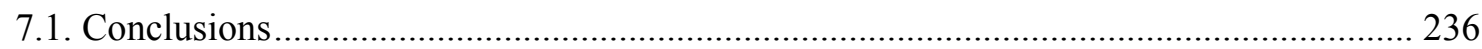

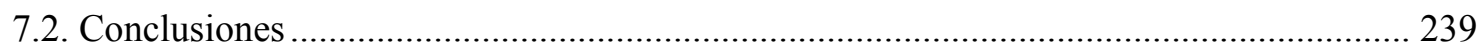

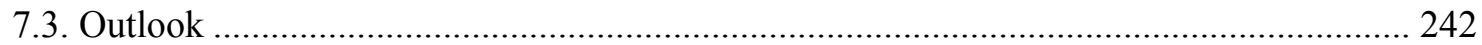

Annex A: Definitions of the statistical parameters used in the comparison between two

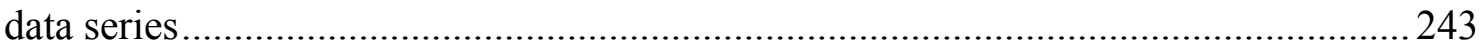

Annex B: Cloud radiative effect for erythemal radiation ..........................................24 247

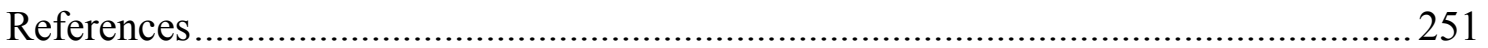




\section{Índice General}

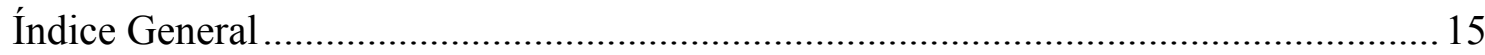

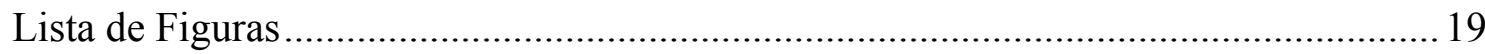

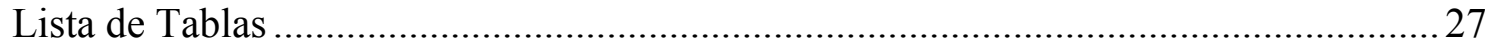

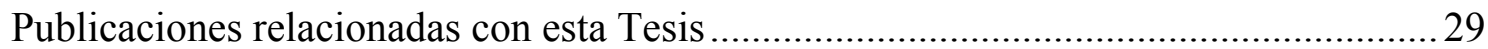

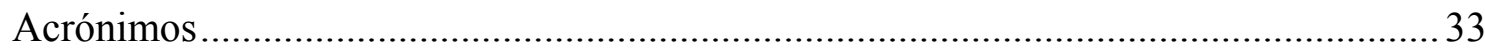

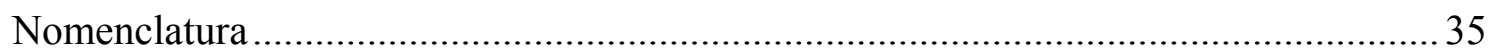

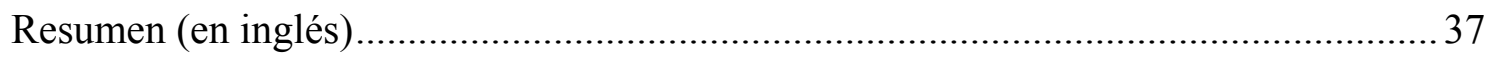

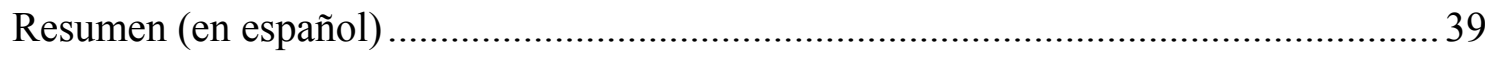

Introducción, Objetivos y Estructura de la Tesis ............................................................... 41

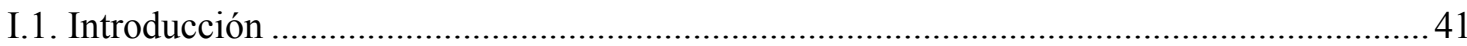

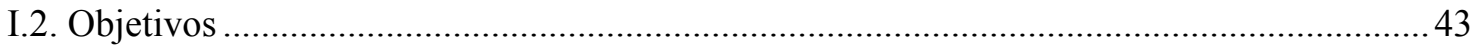

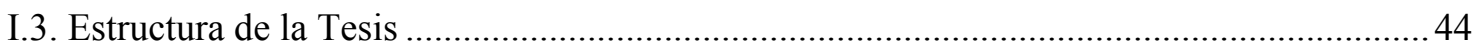

1. El campo radiativo y los factores que controlan sus niveles en superficie...............47

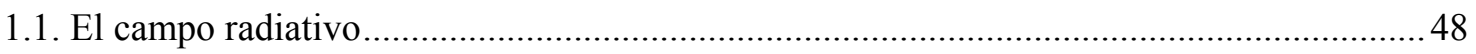

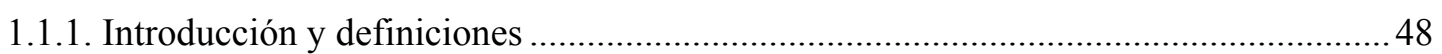

1.1.2. Variables de radiación integradas................................................................................... 51

1.2. Factores que controlan el flujo radiativo ………………………………………………....5

1.2.1. Reflexión, absorción y dispersión ................................................................................. 55

1.2.2. Principales factores que afectan al flujo radiativo solar en la región espectral del

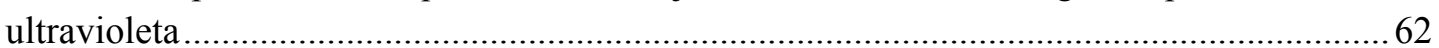

1.3. ¿Cuál es el efecto de las nubes sobre el flujo radiativo en el UV? ..................................... 70

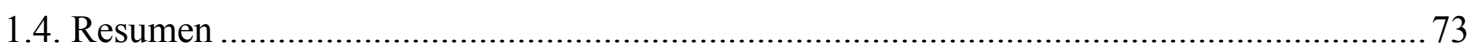

1.4.1. Versión en inglés ……………………………………………………………......

1.4.2. Versión en español ...................................................................................................

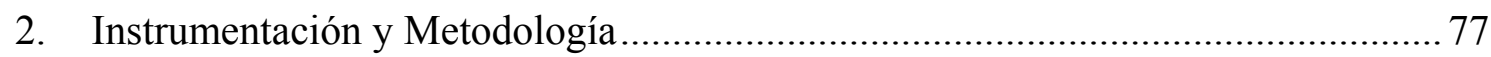

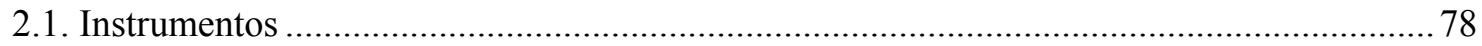

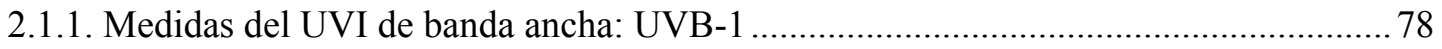

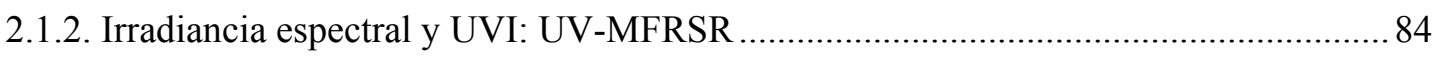

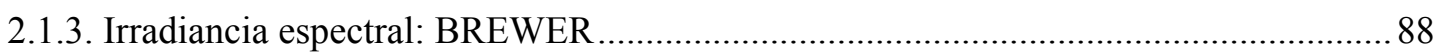




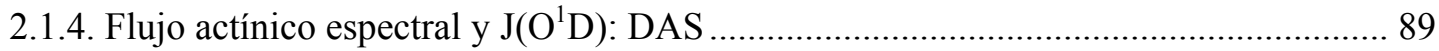

2.1.5. Propiedades microfísicas de nubes: HATPRO ………………..................................... 90

2.1.6. Columna total de ozono: MICROTOPS-II ............................................................... 91

2.1.7. Cobertura de nubes: TSI + observaciones visuales.................................................. 96

2.1.8. Radiación de onda corta: CMP21 / CM 6B / PSP ....................................................... 98

2.1.9. Distribución vertical de nubes y aerosol: LIDAR ......................................................... 99

2.1.10. Propiedades ópticas del aerosol: VIS-MFRSR .................................................... 100

2.1.11. Instrumentos a bordo de satélites: OMI - GOME/GOME2 - MODIS .................... 100

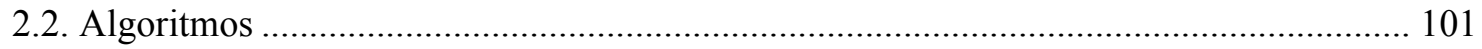

2.2.1. Selección de datos despejados ............................................................................... 101

2.2.2. Algoritmos para obtener la fracción de cobertura nubosa .......................................... 102

2.2.3. Algoritmo para obtener el espesor óptico de nubes ................................................... 105

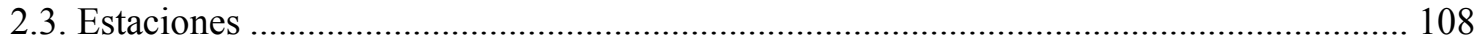

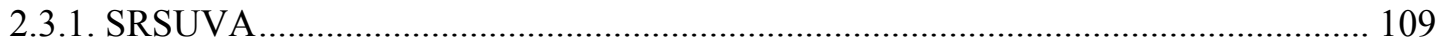

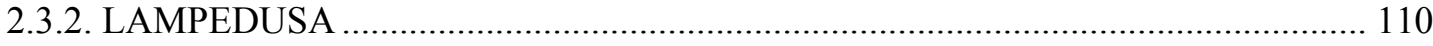

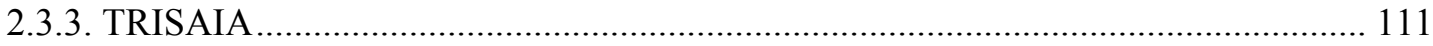

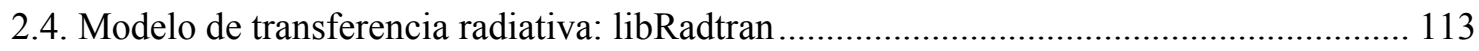

2.4.1. La Ecuación de Transferencia radiativa (RTE) y la Aproximación de las Ordenadas

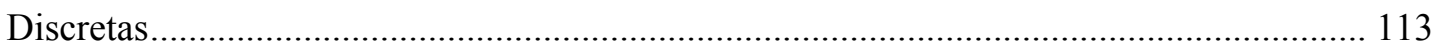

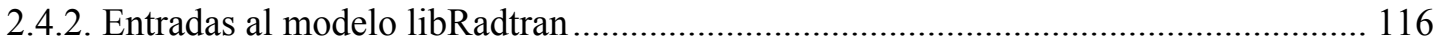

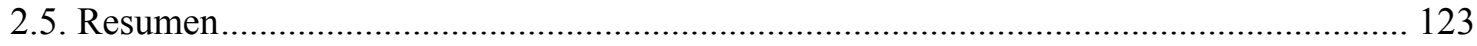

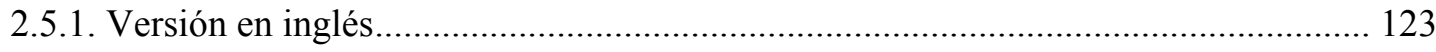

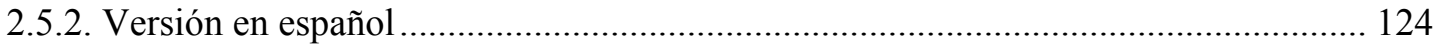

3. Caracterización del índice UV y del índice de fotodisociación del ozono en el

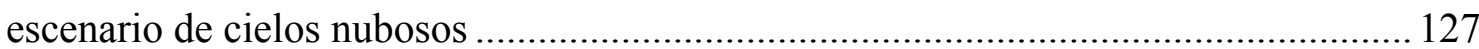

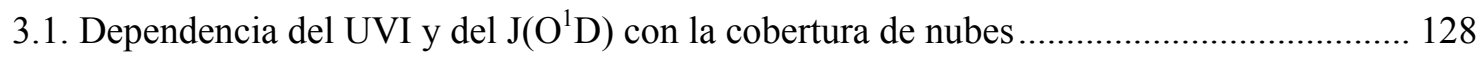

3.1.1. Dependencia del UVI con la cobertura de nubes y el ángulo cenital solar................. 128

3.1.2. Dependencia del $\mathrm{J}\left(\mathrm{O}^{1} \mathrm{D}\right)$ con la cobertura de nubes y el ángulo cenital solar............ 131

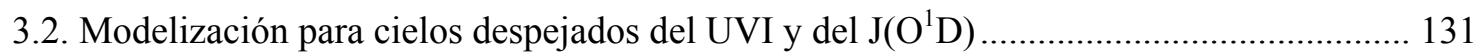

3.2.1. UVI en condiciones de cielos despejados: medidas vs simulaciones ....................... 132

3.2.2. $\mathrm{J}\left(\mathrm{O}^{1} \mathrm{D}\right)$ en condiciones de cielos despejados: medidas vs simulaciones .................... 136

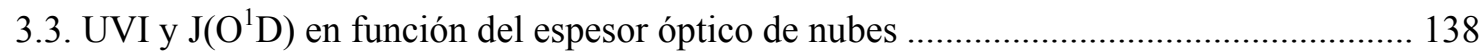

3.3.1. UVI en condiciones de cielos totalmente cubiertos ................................................ 139

3.3.2. $\mathrm{J}\left(\mathrm{O}^{1} \mathrm{D}\right)$ en condiciones de cielos totalmente cubiertos ............................................. 145 
3.4. Cálculo de los factores de modificación de nubes para el UVI y el $\mathrm{J}\left(\mathrm{O}^{1} \mathrm{D}\right)$ y su dependencia

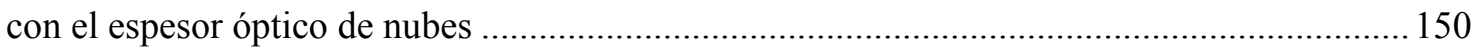

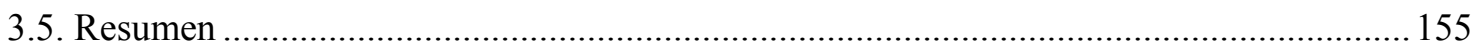

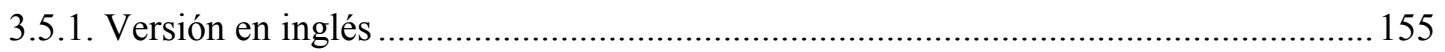

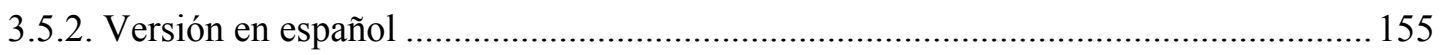

4. Caracterización espectral de los factores de modificación de nubes en función del espesor óptico de nubes

4.1. Dependencia del CMF para la irradiancia global con la cobertura de nubes, espesor óptico de nubes y ángulo cenital solar...

4.2. Dependencia espectral del CMF para el flujo actínico con el espesor óptico de nubes y el ángulo cenital solar.

4.3. Dependencia espectral del CMF para la irradiancia global y difusa con el espesor óptico de

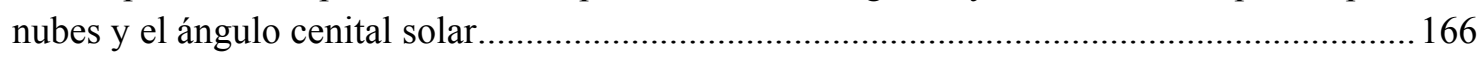

4.4. Interpretación física de los efectos espectrales en condiciones de cielos totalmente

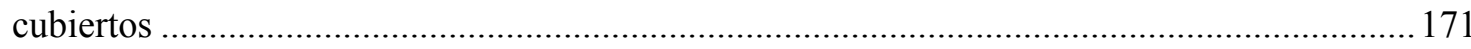

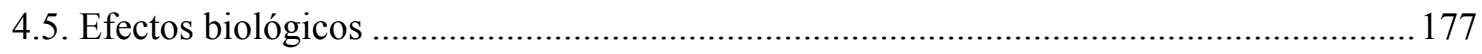

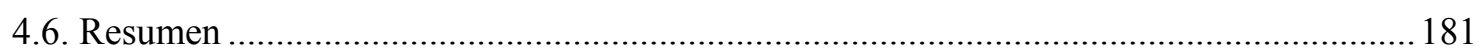

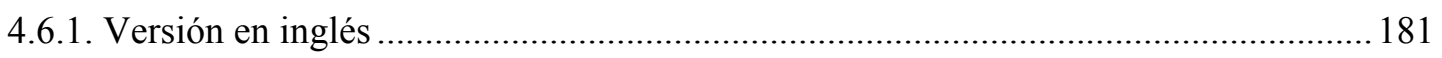

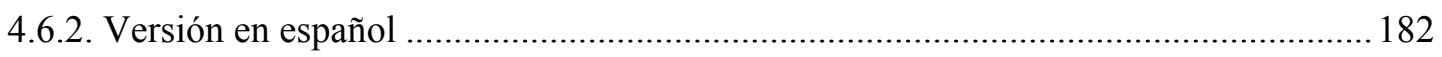

5. Dependencia de los factores de modificación de nubes en el UV con las propiedades microfísicas de las nubes de agua

183

5.1. Dependencia del flujo radiativo del UV con las propiedades microfísicas de las nubes de

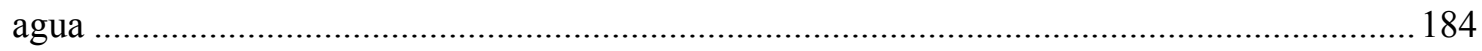

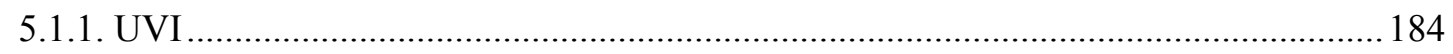

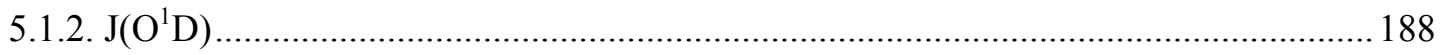

5.2. Dependencia del flujo radiativo espectral con las propiedades microfísicas de las nubes de

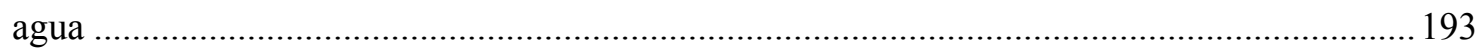

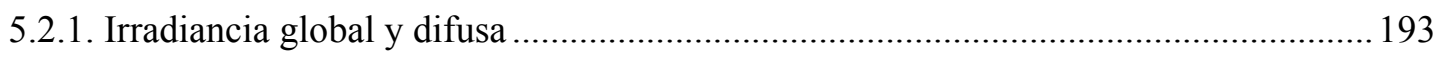

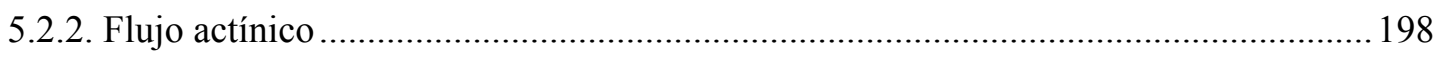

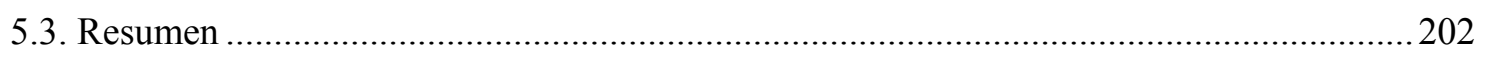

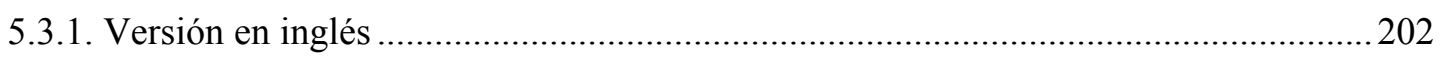

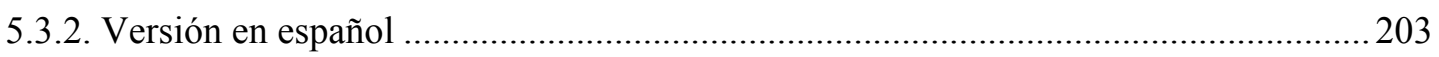


6. Caso de estudio: Papel de una capa de aerosol debajo de una nube. Estudio de sensibilidad a propiedades de nubes y aerosol.......................................................... 205

6.1. Caso de estudio y entradas al modelo de transferencia radiativa....................................... 206

6.2. Caso de estudio: Medidas vs Modelo del CMF ................................................................... 211

6.3. Impacto de una capa de aerosol debajo de una nube sobre el CMF................................. 213

6.4. Sensibilidad del CMF a propiedades ópticas del aerosol................................................ 220

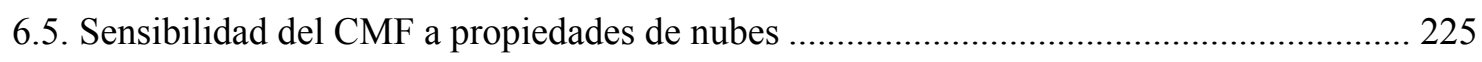

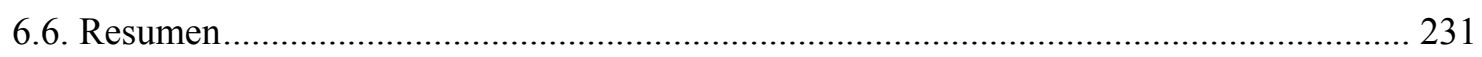

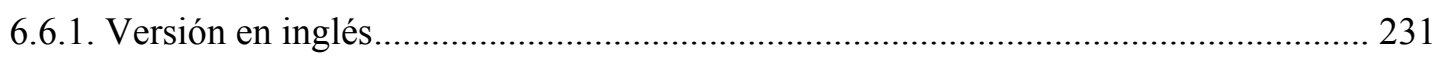

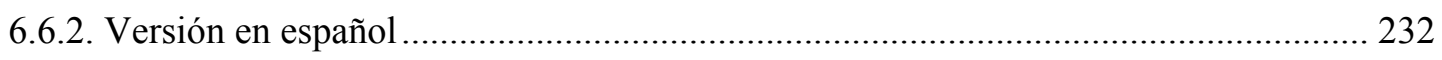

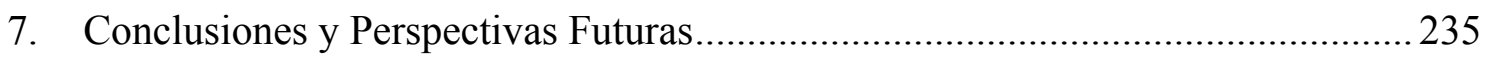

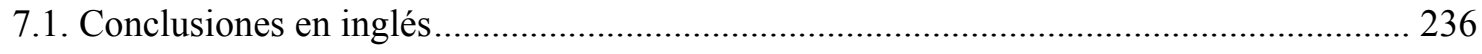

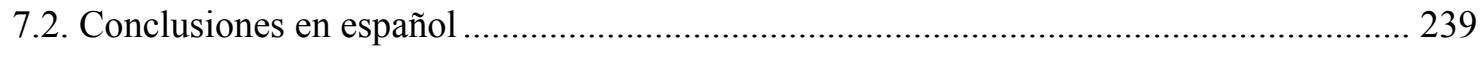

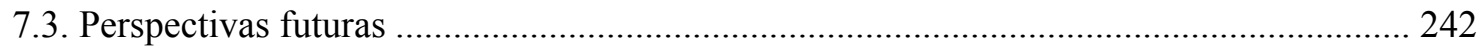

Anexo A: Definiciones de los parámetros estadísticos usados en la comparación entre dos

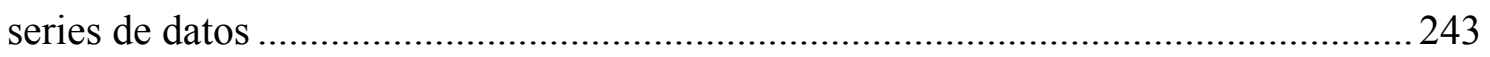

Anexo B: Efecto radiativo de las nubes para la radiación eritemática ........................247

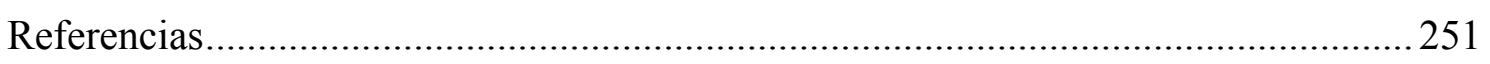




\section{List of Figures}

\section{Chapter 1}

Figure 1.1. Dependence of radiation at the top of the atmosphere on wavelength following the

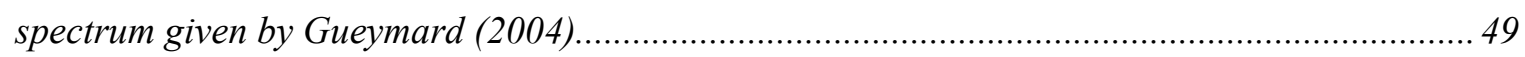

Figure 1.2. Difference between irradiance (a) and actinic flux (b) ............................................. 51

Figure 1.3. a) Erythemal Actium spectrum, $S_{\text {er }}$ b) its application to obtain erythemal UV radiation, $U V E R_{0}$, for the solar spectrum at the top of the atmosphere in the $U V, U V_{0} \ldots \ldots \ldots \ldots . . . . . .52$ Figure 1.4. Recommended Sun protection scheme, taken from WHO (2002).................................53

Figure 1.5. a) Lambertian reflectance; b) reflection by clouds ................................................... 55

Figure 1.6. Definition of absorption: a radiation beam of radiance $L$ crosses a perpendicular layer of thickness $d x$ (without scattering processes). Adapted from Lenoble (1993)..................... 56

Figure 1.7. Scattering function. Adapted from Lenoble (1993). .................................................... 58

Figure 1.8. Rayleigh scattering (a), Mie scattering (b) and Mie scattering for larger particles (c).

Figure 1.9. Definitions of Solar Zenith Angle (SZA) and other solar parameters. .........................63 63

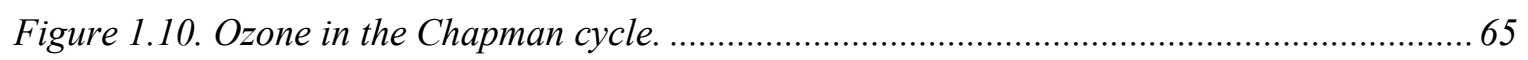

Figure 1.11. Spectral AOT dependence for different values of $\alpha$ and $\beta$ coefficients...................... 67

Figure 1.12. Transmittance of a homogeneous cloud layer at Garmisch-Partenkirchen on 22

October, 1995 as a function of wavelength (Seckmeyer et al.,1996; Kylling et al.,1997). ............ 72

Figure 1.13. CMF for the actinic flux versus wavelength at several solar zenith angles obtained

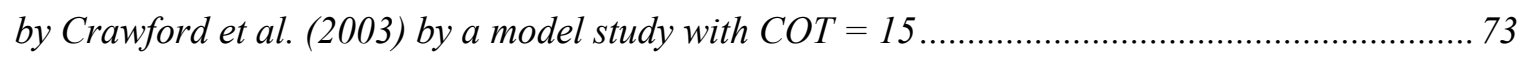

\section{Chapter 2}

Figure 2.1. UVB-1 YES pyranometer.

Figure 2.2. UVB-1 pyranometer (SN 090503) spectral response measured in one calibration on 1 October 2009 (black circles) and the erythemal actium spectrum $\left(S_{\text {er }}\right.$, red line).......................... 79

Figure 2.3. Schematic block diagram of the UVB-1 pyranometer. ............................................... 79

Figure 2.4. a) $f_{n}(S Z A, T O C)$ and b) Coscor(SZA) obtained in the calibration performed in the PMOD-WRC of the UVB-1 \#090503 on 1 October 2009.

Figure 2.5. Comparison between UVER data obtained with the UVB-1 pyranometer and the BREWER spectroradiometer.

Figure 2.6. Dependence of the ratio between UVB-1 and BREWER measurements on SZA (a) and TOC (b) values. Blue lines indicate perfect agreement and red lines limit the area to within an error of $\pm 10 \%$.

Figure 2.7. UV-MFRSR YES shadowband radiometer. 
Figure 2.8. Comparison of UVER obtained by the UV-MFRSR using seven (a) and four (b) channels and UVB-1 instruments. Red and orange lines are the linear fits and blue dashed lines indicate the 1:1 line. 87

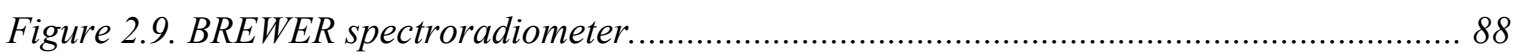

Figure 2.10. Several processes in BREWER calibration performed at LAMPEDUSA in November

2009. 88

Figure 2.11. METCON-DAS actinometer. 89

Figure 2.12. Spectral dependence of ozone cross section (a) and quantum yield (b) to determine $J\left(O^{l} D\right)$ at a fixed temperature of $295 \mathrm{~K}$. 90

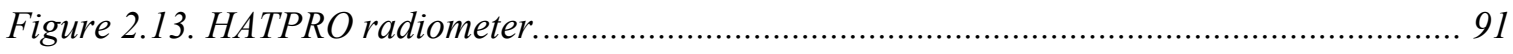

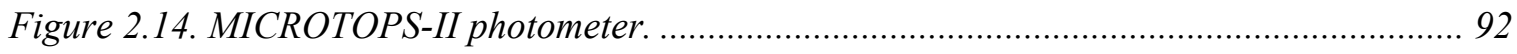

Figure 2.15. TOC database of MICROTOPS-II photometer at the SRSUVA station.................... 94

Figure 2.16. Comparison of TOC obtained by the MICROTOPS-II and OMI instruments. The red line is the linear fit and the blue dashed line indicates the 1:1 line ............................................. 95

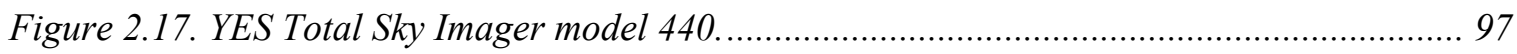

Figure 2.18. Three samples of bad estimation of cloud cover from the TSI's automatic algorithm.

Figure 2.19. Three different pictures at the TRISAIA station ……............................................. 98

Figure 2.20. Three different models of pyranometers used in this thesis to record SW radiation. 99

Figure 2.21. Top view of the LIDAR instrument used at the TRISAIA station: CaBLE ............... 99

Figure 2.22. VIS-MFRSR YES shadowband radiometer....................................................... 100

Figure 2.23. Main steps of the Long et al. (2006) algorithm.................................................. 102

Figure 2.24. Comparison of the fractional sky cover obtained by the algorithms proposed by Long et al. (2006), $\left(S_{C V}\right)_{L O N G}$, by Min et al. (2008), $\left(S_{C V}\right)_{M I N}$, and the visual observations, $\left(S_{C V}\right)_{V I S U A L}$ at

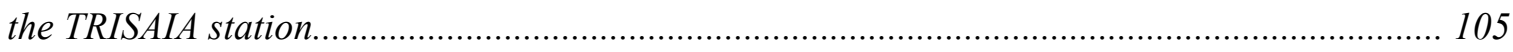

Figure 2.25. Surface albedo measurements by an aircraft at the TRISAIA station..................... 107

Figure 2.26. COT estimations by Equations (2.18) and (2.19) for different surface albedo (a) and

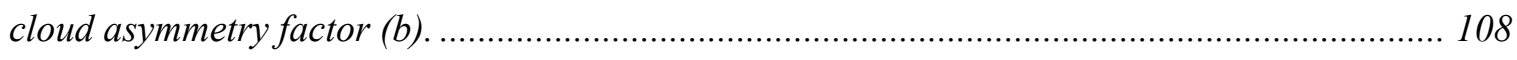

Figure 2.27. Location of the three stations used in this thesis.................................................. 108

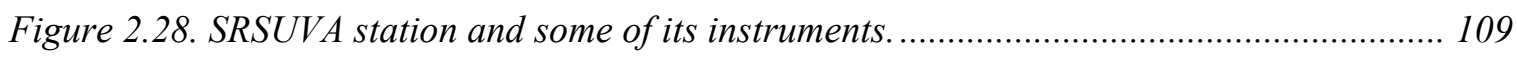

Figure 2.29. LAMPEDUSA station and some of its instruments............................................ 110

Figure 2.30. Some of the instruments at the TRISAIA station. .................................................. 112

Figure 2.31. Definition of radiance, adapted from Lenoble (1993)......................................... 113

Figure 2.32. Establishing the radiative transfer equation, adapted from Lenoble (1993)......... 114

Figure 2.33. Structure of the uvspec model, adapted from Mayer and Kylling (2005).............. 117

Figure 2.34. Surface albedo (A) values used in the radiative transfer simulations for each station.

Figure 2.35. Temperature (a) and ozone density (b) profiles for the midlatitude summer (LMS) and standard atmosphere in the US (US).

Figure 2.36. Radiation at the top of the atmosphere taken from ATLAS and MODTRAN spectra. 


\section{Chapter 3}

Figure 3.1. Dependence of $U V$ index values on total cloud cover for different solar zenith angles $\left(S Z A \leq 30^{\circ}\right.$, in black, $30^{\circ}<S Z A<45^{\circ}$, in blue, $45^{\circ}<S Z A<60^{\circ}$, in purple, and $60^{\circ}<S Z A<75^{\circ}$, in red) at the SRSUVA (a), TRISAIA (b) and LAMPEDUSA (c) stations. The bars indicate the standard deviation.

Figure 3.2. Dependence of $U V$ index values on total cloud cover for different solar zenith angles $\left(S Z A \leq 30^{\circ}, 30^{\circ}<S Z A<45^{\circ}, 45^{\circ}<S Z A<60^{\circ}\right.$, and $\left.60^{\circ}<S Z A<75^{\circ}\right)$ and TOC values $(290 \mathrm{DU}<$ TOC1 $<310 D U$ and $330 D U<T O C 2<350 D U)$ at the SRSUVA station. 130

Figure 3.3. Dependence of $J\left(O^{l} D\right)$ values on total cloud cover for different solar zenith angles $\left(S Z A \leq 30^{\circ}\right.$, in black, $30^{\circ}<S Z A<45^{\circ}$, in blue, $45^{\circ}<S Z A<60^{\circ}$, in purple, and $60^{\circ}<S Z A<75^{\circ}$, in red) at the TRISAIA station. The bars indicate the standard deviation.

Figure 3.4. Look-up-Tables obtained by model (a) and experimental (b) data for UVI values under cloudless conditions at the SRSUVA station.

Figure 3.5. Look-up-Tables obtained by model (a) and experimental (b) data for UVI values under cloudless conditions at the TRISAIA station.

Figure 3.6. Look-up-Tables obtained by model (a) and experimental (b) data for UVI values under cloudless conditions at the LAMPEDUSA station.

Figure 3.7. Comparison between UVI values obtained by the libRadtran Look-up-Table and experimental data under cloudless conditions at the TRISAIA station: a) considering a fixed $A O T_{550 n m}$ of 0.25 in the model, b) using the average $A_{O T_{55 n m}}$ value for each point. The blue dashed lines indicate the 1:1 line; the black and red lines are the linear fits.

Figure 3.8. Dependence of ratio between the UVI estimated with the libRadtran model and that obtained by the measurements on SZA (a) and TOC (b), considering a fixed AOT ${ }_{550 \mathrm{~nm}}$ of 0.25 in the model (grey points), and using the average $A_{O S T_{50 n m}}$ value for each point (black points). The blue dashed lines indicate perfect agreement and the red ones a deviation of $\pm 5 \%$.

Figure 3.9. Look-up-Tables obtained by model (a) and experimental (b) data for $J\left(O^{l} D\right)$ values under cloudless conditions at the TRISAIA station.

Figure 3.10. Comparison between $J\left(O^{I} D\right)$ values obtained by the libRadtran Look-up-Table and experimental data under cloudless conditions at the TRISAIA station for three different conditions (see text). The blue dashed line indicates the 1:1 line.

Figure 3.11. Dependence of the ratio between $J\left(O^{l} D\right)$ estimated with the libRadtran model and the measured one versus SZA (a) and TOC (b), considering in the model a fixed AOT $550 \mathrm{~nm}$ of 0.25 (black points), using the average $A O T_{550 n m}$ value for each point (red points), and considering twice the amount of tropospheric ozone (TCOx2, purple points). Blue dashed lines indicate perfect agreement and the red solid lines a deviation of $\pm 10 \%$.

Figure 3.12. UVI values in overcast skies (8 octas) as a function of the cloud optical thickness for the SRSUVA (a), TRISAIA (b), and LAMPEDUSA (c) stations.

Figure 3.13. UVI values in overcast skies (8 octas) as a function of the solar zenith angle for different cloud optical thicknesses for measurements (left panel) and radiative transfer simulations (right panel) at a fixed interval of TOC for the TRISAIA database. 
Figure 3.14. Absolute and relative differences between $U V I$ at $S Z A=10^{\circ}$ and $S Z A=80^{\circ}$ as a function of the COT obtained with radiative transfer simulations.

Figure 3.15. UVI values in overcast skies (8 octas) as a function of the total ozone column for different cloud optical thicknesses for measurements (left panels) and radiative transfer simulations (right panels) at two fixed intervals of SZA for the TRISAIA database.

Figure 3.16. Absolute and relative differences between UVI at TOC $=200 \mathrm{DU}$ and TOC $=500$

$D U$ as a function of the COT obtained with radiative transfer simulations at $S Z A=30^{\circ}(a)$ and $S Z A=60^{\circ}(b)$, and with $A O T_{550 \mathrm{~nm}}=0.25$.

Figure 3.17. Simulated UVI values in overcast skies (8 octas) as a function of the aerosol optical thickness at $550 \mathrm{~nm}$ for different cloud optical thicknesses for the TRISAIA station at a fixed TOC $=300$ DU for two different SZAs: $30^{\circ}(a)$ and $60^{\circ}(b)$. 144

Figure 3.18. Absolute and relative differences between UVI at $A O T_{550 \mathrm{~nm}}=0.05$ and $A O T_{550 \mathrm{~nm}}=$ 0.85 as a function of the COT obtained with radiative transfer simulations at $S Z A=30^{\circ}$ (a) and $S Z A=60^{\circ}(b)$, and $T O C=300 D U$. 145

Figure 3.19. $J\left(O^{I} D\right)$ values in overcast skies (8 octas) as a function of the cloud optical thickness for the TRISAIA station. 145

Figure 3.20. $J\left(O^{l} D\right)$ values in overcast skies (8 octas) as a function of the solar zenith angle for different cloud optical thicknesses for measurements (left panel) and radiative transfer simulations (right panel) at a fixed interval of TOC for the TRISAIA database. 146

Figure 3.21. J $\left(O^{I} D\right)$ values in overcast skies (8 octas) as a function of total ozone column for different cloud optical thicknesses for measurements (left panels) and radiative transfer simulations (right panels) at two fixed intervals of SZA for the TRISAIA database.

Figure 3.22. Simulated $J\left(O^{I} D\right)$ values in overcast skies (8 octas) as a function of aerosol optical thickness at $550 \mathrm{~nm}$ for different cloud optical thicknesses for the TRISAIA station at a fixed TOC $=300$ DU for two different SZAs: $30^{\circ}(a)$ and $60^{\circ}(b)$. 148

Figure 3.23. Absolute and relative differences between $J\left(O^{l} D\right)$ at $S Z A$ of $10^{\circ}$ and $80^{\circ}(a)$, TOC of 200 and $500 \mathrm{DU}(\mathrm{b})$, and $A O T_{550 \mathrm{~mm}}$ of 0.05 and 0.85 (c) as a function of the COT obtained with radiative transfer simulations.

Figure 3.24. $C M F_{U V I}$ values (measurements and simulations in grey and orange, respectively) in overcast skies (8 octas) as a function of cloud optical thickness at the SRSUVA (a), TRISAIA (b), and LAMPEDUSA (c) stations. The green dash and the blue solid lines are fits made with the measured and modelled data, respectively.

Figure 3.25. $C M F_{U V I}=\left(1+c_{1} C O T\right)^{-1}$ with the coefficients of Table 3.1 for the three stations (SRSUVA, TRISAIA and LAMPEDUSA, labelled LAMPE in the legend), for both experimental (solid lines) and model (dashed lines) results.

Figure 3.26. $C M F_{J(O I D)}$ values (measurements and simulations in grey and orange, respectively) in overcast skies (8 octas) as a function of cloud optical thickness at the TRISAIA station. The green dash and the blue solid lines are fits made with the measured and modelled data, respectively.

Figure 3.27. $C M F=\left(1+c_{1} C O T\right)^{-1}$ for UVI and $J\left(O^{l} D\right)$ with the coefficients of Table 3.1 and Table 3.2 of the TRISAIA station for both experimental (solid lines) and model (dashed lines) results. 


\section{Chapter 4}

Figure 4.1. Irradiance CMF spectral dependence for 0-2 octas (a), and overcast (8 octas, b) cloud cover as a function of the solar zenith angle (SZA) at the LAMPEDUSA station.

Figure 4.2. Measured ( $a, c, e)$ and modelled $(b, d, f) C M F$ versus wavelength as a function of the solar zenith angle for different cloud optical thickness values. Dashed bold lines in the right panels relate to simulations with twice the amount of tropospheric ozone at $30^{\circ}, 50^{\circ}$, and $70^{\circ}$ $S Z A$, respectively in $b$ ), $d$ ), and $f$ ).

Figure 4.3. Measured (left panels) and modelled (right panels) values of actinic flux CMF versus wavelength as a function of the solar zenith angle for different cloud optical thickness values. 164 Figure 4.4. $C M F$ for the irradiance (CMF , dashed lines) and the actinic flux (CMF $F_{F}$, solid lines) calculated with the libRadtran model for COT $=15, T O C=300 \mathrm{DU}$ and $A O T_{550 \mathrm{~nm}}=0.25$ at several SZAs.

Figure 4.5. Global (left panels) and diffuse (right panels) experimental values of irradiance CMF versus wavelength as a function of the solar zenith angle for different cloud optical thickness values.

Figure 4.6. Global (solid lines, right panels) and diffuse (dashed lines, left panels) values of irradiance CMF versus wavelength as a function of the solar zenith angle for different cloud optical thickness values evaluated using the libRadtran model.

Figure 4.7. Evolution of the $U V_{\text {DIRECT }}(\lambda) / U V_{\text {DIFFUSE }}(\lambda)$ ratio under cloudless conditions for two different solar zenith angles.

Figure 4.8. Figure 2 at Lindfors and Arola (2008) and the analyzed scenario.

Figure 4.9. Profiles of air density (a) and pressure (b) for the normal scenario and the DENS option (see text).

Figure 4.10. Spectral CMF of global (a) and diffuse (b) components for two different scenarios: normal case and the new density profile explained in the test for two different solar zenith angles.

Figure 4.11. Normalized radiance compared to the maximum value among all the directions between $0^{\circ}$ and $90^{\circ}$ polar angle at the zenith (solid lines) and $20.5^{\circ}$ and $70.5^{\circ}$ (dashed lines) of polar angle at $S Z A=20^{\circ}(a, b)$ and $S Z A=70^{\circ}(c, d)$, respectively. Cloud-free $(a, c)$ and overcast $(b, d)$ conditions are considered.

Figure 4.12. The five action spectra used to calculate the BEUVD dose: plant damage (1), erythemal (2), phytoplankton inhibition (3), DNA damage (4), and vitamin D synthesis (5)..... 178 Figure 4.13. (a) Dependence of UV index on cloud optical thickness at two solar zenith angles. Solid lines reflect the real case, and the dashed ones the assumption of constant CMF. (b) Differences between the two derived values of UVI versus COT.....

Figure 4.14. Differences between the UV irradiance weighted for various biological action spectra calculated with the derived CMF and with constant CMF: (a) plant damage, (b) inhibition of phytoplankton, (c) DNA damage, and (d) vitamin D synthesis. 


\section{Chapter 5}

Figure 5.1. $C M F_{U V I}$ as a function of the LWP for different cloud droplet radii. Dots are the experimental data (different symbols correspond to different days) and lines are the radiative transfer simulations at $S Z A=18^{\circ}$ (solid lines) and $S Z A=75^{\circ}$ (dashed lines).

Figure 5.2. $C M F_{U V I}$ as a function of LWP for different cloud droplet radii and for different cloud base heights. Dots are the experimental data and solid lines are the radiative transfer simulations at $S Z A=18^{\circ}$.

Figure 5.3. $C M F_{J(O I D)}$ as a function of the LWP for different cloud droplet radii for three SZA intervals. Dots are the experimental data (different symbols correspond to different days). In each plot, solid lines refer to results of simulations at the smallest $S Z A$ in the range $\left(18^{\circ}\right.$ in graph a; $42^{\circ}$ in graph $b ; 63^{\circ}$ in graph c), and dashed lines refer to simulations at the largest SZA in the range.

Figure 5.4. Dependence of modelled $C M F_{J(O I D)}$ on solar zenith angle for three values of $L W P$ and two different effective radii: a) $2.5 \mu \mathrm{m}$, and b) $10 \mu \mathrm{m}$.. 190 Figure 5.5. Dependence of $C M F_{U V I}$ (purple lines) and $C M F_{J(O I D)}$ (red lines) on LWP at 18 a) and c), and $\left.75^{\circ}, b\right)$ and d), of SZA for two fixed cloud droplet radii of $2.5 \mu \mathrm{m}$, a) and b), and $10 \mu \mathrm{m}, c$ ) and $d$ ). 191

Figure 5.6. Dependence on SZA of the ratio between diffuse and global components for the UVI (purple line) and $J\left(O^{l} D\right)$ (red line) calculated with the libRadtran model for cloudless conditions.

Figure 5.7. CMF for the global and diffuse spectral irradiances at two wavelengths as a function of LWP for different cloud droplet radii in the SZA interval $\left(18^{\circ}, 30^{\circ}\right)$. Dots are the experimental data and lines are the radiative transfer simulations at $S Z A=18^{\circ}$ (solid lines) and $S Z A=30^{\circ}$ (dashed lines).

Figure 5.8. CMF for the global and diffuse spectral irradiances at two wavelengths as a function of LWP for different cloud droplet radii in the SZA interval $\left(42^{\circ}, 54^{\circ}\right)$. Dots are the experimental data and lines are the radiative transfer simulations at $S Z A=42^{\circ}$ (solid lines) and $S Z A=54^{\circ}$ (dashed lines).

Figure 5.9. CMF for the global and diffuse spectral irradiances at two wavelengths as a function of LWP for different cloud droplet radii in the SZA interval $\left(63^{\circ}, 75^{\circ}\right)$. Dots are the experimental data and lines are the radiative transfer simulations at $S Z A=63^{\circ}$ (solid lines) and $S Z A=75^{\circ}$ (dashed lines).

Figure 5.10. CMF for the actinic flux at two wavelengths as a function of LWP for different cloud droplet radii in the three SZA intervals. Dots are the experimental data and lines are the radiative transfer simulations at the smallest (solid lines) and highest (dashed lines) SZAs in each panel.

Figure 5.11. $C M F$ for the global irradiance (CMF , purple lines) and actinic flux $\left(C M F_{F}\right.$, red lines) at $S Z A=18^{\circ}$ (solid lines) and $S Z A=63^{\circ}$ (dashed lines) at $304.7 \mathrm{~nm}$, a) and c), and 367.2 $n m, b)$ and d), for fixed $r_{\text {eff }}$ of $5, a$ ) and b), and $\left.15, c\right)$ and $d$ ), $\mu m$....... 
Figure 5.12. Spectral ratios between diffuse and global components for the irradiance (purple lines) and actinic flux (red lines) at $18^{\circ}$ (solid lines) and $75^{\circ}$ (dashed lines) calculated with the libRadtran model for cloudless conditions.

\section{Chapter 6}

Figure 6.1. Frequency of overcast events as a function of their length in hours.

Figure 6.2. Vertical distribution of Aerosol Backscatter Ratio at $532 \mathrm{~nm}$ on 30 May 2010 at the TRISAIA station.

Figure 6.3. Ozone profiles in the standard mid-latitude summer atmosphere (red line) and in the new profile to produce more realistic values of ozone at surface (blue line).

Figure 6.4. Three-day trajectories ending at the TRISAIA station at 14:00 UT 30 May 2010 for three different heights: 500 (red), 1500 (blue), and 2500 (green) $m$ a.s.l. Source: NOAA Air Resources Laboratory (ARL) and READY website (http://ready.arl.noaa.gov).

Figure 6.5. a-b) Comparison between modelled (green lines) and measured (black lines) spectral CMF values. c-d) Spectral ratios between CMF calculated by the libRadtran model and experimental data; horizontal grey lines indicate a difference of 5\% (dashed) and perfect agreement (solid). Left and right panels correspond to global and diffuse components, respectively.

Figure 6.6. a) Comparison between measured (black lines) and modelled (green lines) spectral actinic flux CMF values. b) Spectral ratios between CMF calculated by the libRadtran model and experimental data; horizontal grey lines indicate a difference of $5 \%$ (dashed) and perfect agreement (solid).

Figure 6.7. Spectral CMF for the irradiance (purple line) and the actinic flux (red line) obtained by experimental (a) and model (b) data.

Figure 6.8. Heights at which irradiances are simulated with the libRadtran for the case study. 213 Figure 6.9. Spectral $C M F_{\text {aer }} / C M F_{\text {NOaer }}$ ratio for global (a) and diffuse (b) components at five different heights.

Figure 6.10. Spectral ratios of Equation (6.1) for global (a) and diffuse (b) components at the surface for a desert dust aerosol layer.

Figure 6.11. Spectral $C M F_{\text {aer }} / C M F_{\text {NOaer }}$ ratio for global (a) and diffuse (b) components at five different heights considering a maritime clean aerosol layer.

Figure 6.12. Spectral ratios of Equation (6.1) for the global (a) and diffuse (b) components at the surface for a maritime clean aerosol layer.

Figure 6.13. a-b) Spectral $C M F_{a e r} / C M F_{\text {NOaer }}$ ratio for global (a) and diffuse (b) components at five different heights for an urban aerosol layer. c-d) Spectral ratios of Equation (6.1) for global (c) and diffuse (d) components at surface for an urban aerosol layer.

Figure 6.14. Profiles of single scattering albedo, aerosol optical thickness and a Ängström exponent for two wavelengths, 550 (black lines) and 305 (red lines) for three different types of aerosol: desert dust (DESERT, upper panels), maritime clean (MARcle, middle panels), and urban (URBAN, lower panels). 
Figure 6.15. Sensitivity analysis of the CMF for global (solid lines) and diffuse (dashed lines) components for two aerosol optical thickness values.

Figure 6.16. Sensitivity analysis of the CMF for global (solid lines) and diffuse (dashed lines) components for two aerosol asymmetry factor values.

Figure 6.17. Ratios between the simulated irradiances, global (a) and diffuse (b), for $g=0.65$ and $g=0.95$ in cloudless (blue lines) and overcast (black lines) conditions.

Figure 6.18. Sensitivity analysis of the CMF for global (solid lines) and diffuse (dashed lines) components for two aerosol single scattering albedo values.

Figure 6.19. Ratios between the simulated irradiances, global (a) and diffuse (b), for $\omega_{0}=0.6$ and $\omega_{0}=0.99$ in cloudless (blue lines) and overcast (black lines) conditions.

Figure 6.20. Sensitivity analysis of the CMF for global (solid lines) and diffuse (dashed lines) components for two cloud asymmetry factor values.

Figure 6.21. Sensitivity analysis of the CMF for global (solid lines) and diffuse (dashed lines) components for two cloud single scattering albedo values.

Figure 6.22. Diagram for the two situations analyzed with regard to cloud geometric thickness.

Figure 6.23. Spectral CMF dependence for global (solid lines) and diffuse (dashed lines) components for one (red lines) and two (blue lines) cloud layers at the seven heights indicated in Figure 6.22.

Figure 6.24. Effect of cloud base height on spectral CMF for global (solid lines) and diffuse (dashed lines) components for three different SZAs at 305 (a-b) and 367 (c-d) nm. 230 


\section{List of Tables}

\section{Chapter 1}

Table 1.1. Some photochemical reactions occurring in the atmosphere in the UV range.

\section{Chapter 2}

Table 2.1. Statistical indexes of the comparison between UVB-1 and BREWER measurements of UVER carried out at Lampedusa Island in 2010 during 56 days: $n$ is the number of data, UVER ave represents the average of all the experimental data, MBE and RMSE are the mean bias error and the root mean square error, respectively, and $W_{i}$ is the percent of cases whose deviation falls below the $\pm i \%$ difference.

Table 2.2. Coefficients of Equation (2.6) obtained for the UV-MFRSR. $a_{i}$ coefficients are unitless, while $b_{i}$ are in $\mathrm{m}^{2} \mathrm{~nm} \mathrm{~W}^{1}$. 86

Table 2.3. Statistical indexes of the comparison between UVER data obtained by the UV-MFRSR using seven and four channels and the UVB-1 pyranometer. $n$ is the number of data, UVER ave represents the average of all the experimental data, MBE and RMSE are the mean bias error and the root mean square error, respectively, and $W_{i}$ is the number of cases falling below the $\pm i \%$ error.

Table 2.4. Statistical indexes of the comparison between TOC data obtained by the MICROTOPSII and OMI and BREWER instruments. $n$ is the number of data, TOC ave represents the average of all the experimental data, MBE and RMSE are the mean bias error and the root mean square error, respectively, and $W_{i}$ is the number of cases falling below the $\pm i \%$ error.

Table 2.5. SRSUVA station instruments used, the variables they record and the time period used for the thesis.

Table 2.6. LAMPEDUSA station instruments used, the variables they record and the time period used for the thesis.

Table 2.7. TRISAIA station instruments used, the variables they record and the time period used for the thesis.

\section{Chapter 3}

Table 3.1. $c_{1}$ coefficient of Equation (3.1), its standard error (SE), and correlation coefficient (r) for the three stations.

Table 3.2. $c_{1}$ coefficient of Equation (3.1) but for the $C M F_{J(O I D)}$, its standard error (SE), and the correlation coefficient ( $r$ ) at the TRISAIA station. 


\section{Chapter 4}

Table 4.1. Number of UV spectra at 8 octas for the three ranges of cloud optical thickness (COT) as a function of the solar zenith angle (SZA) at the LAMPEDUSA station. 162

Table 4.2. Number of actinic flux spectra at 8 octas for the three values of COT as a function of the SZA at the TRISAIA station.

Table 4.3. Number of irradiance (global and diffuse) spectra at 8 octas for the three values of COT as a function of the SZA at the TRISAIA station. 166

Table 4.4. Correction factors for taking into account the 363.5-400 $\mathrm{nm}$ range in UVI calculations.

\section{Chapter 6}

Table 6.1. Atmospheric and meteorological conditions recorded at 14:00h UT 30 May 2010 at the TRISAIA station. 208

Table 6.2. Integrated values of aerosol optical properties considering three different aerosol types in the 0-2 km and free tropospheric type in the 2-12 km height range. 218 


\title{
Publications related to this Thesis
}

\author{
Manuscripts
}

Mateos, D., Bilbao, J., Kudish, A.I., Parisi, A.V., Carbajal, G., di Sarra, A., Román, R., and de Miguel, A., 2012, Validation of satellite erythemal radiation retrievals using ground-based measurements in five Countries, Remote Sensing of Environment, Under Review.

Román, R., Mateos, D., de Miguel, A., Bilbao, J., Pérez-Burgos, A., Rodrigo, R., and Cachorro, V.E., 2012, Atmospheric effects on the ultraviolet erythemal and total shortwave solar radiation in Valladolid, Spain, Óptica Pura y Aplicada 45(1), 17-21.

Mateos, D., Román, R., Bilbao, J., de Miguel, A., and Pérez-Burgos, A., 2012, Cloud modulation of shortwave and ultraviolet solar irradiances at surface, Óptica Pura y Aplicada 45(1), 29-32.

Bilbao, J., Román, R., de Miguel, A., and D. Mateos, 2011, Long-term solar erythemal UV irradiance data reconstruction in Spain using a semi-empirical method, Journal of Geophysical Research 116, D22211, doi:10.1029/2011JD015836.

De Miguel, A., Bilbao, J., Román, R., and Mateos, D., 2011, Measurements and attenuation of erythemal radiation in Central Spain, International Journal of Climatology, Published on-line, doi: $10.1002 /$ joc. 2319 .

Mateos, D., di Sarra, A., Meloni, D., Di Biagio, C., and Sferlazzo, D.M., 2011, Experimental determination of cloud influence on the spectral UV radiation and implications for biological effects, Journal of Atmospheric and Solar-Terrestrial Physics 73, 1739-1746, doi:10.1016/j.jastp.2011.04.003.

de Miguel, A., Mateos, D., Bilbao, J., and Román, R., 2011, Sensitivity analysis of ratio between ultraviolet and total shortwave solar radiation to cloudiness, ozone, aerosols and precipitable water, Atmospheric Research 102, 136-144, doi:10.1016/j.atmosres.2011.06.019.

de Miguel, A., Román, R., Bilbao, J., and Mateos, D., 2011, Evolution of erythemal and total shortwave solar radiation in Valladolid, Spain: Effects of atmospheric factors, Journal of Atmospheric and SolarTerrestrial Physics 73, 578-586, doi:10.1016/j.jastp.2010.11.021.

Bilbao, J., Mateos, D., and de Miguel, A., 2011, Analysis and cloudiness influence on UV total irradiation, International Journal of Climatology 31 (3), 451-460, doi:10.1002/joc.2072.

Mateos, D., de Miguel, A., and Bilbao, J., 2010, Empirical models of UV total radiation and cloud effect study, International Journal of Climatology 30, 1407-1415, doi:10.1002/joc.1983.

Mateos, D., Bilbao, J., de Miguel, A., and Pérez-Burgos, A., 2010, Dependence of ultraviolet (erythemal and total) radiation and CMF values on total and low cloud covers in Central Spain, Atmospheric Research 98, 21-27, doi:10.1016/j.atmosres.2010.05.002.

Mateos, D., 2008, Medida, Análisis Climatológico y Modelización de la Radiación Solar Ultravioleta Total en Valladolid, Minor Thesis, Doctorate in Science Physics, University of Valladolid. 


\section{Conferences}

Mateos, D., di Sarra, A., Bilbao, J., Cacciani, M., Casasanta, G., Meloni, D., Pace, G., and de Miguel, A., Experimental and modelled characterization of diffuse spectral UV irradiance under cloudy conditions: impact of aerosol properties, European Aerosol Conference, Granada Spain, 2-7 September 2012.

Mateos, D., di Sarra, A., Bilbao, J., Pace, G., Meloni, D., de Miguel, A., Casasanta, G., and Min, Q., Wavelength dependence of diffuse and total Cloud Modification Factors for UV irradiance and actinic flux for different cloud optical and microphysical properties, International Radiation Symposium, Berlin, Germany, 6-10 August 2012.

Mateos, D., Bilbao, J., Kudish, A.I., Parisi, A.V., Carbajal, G., di Sarra, A., Román, R., and, de Miguel, A., Daily erythemal radiation validation of satellite retrievals using 14 ground-based stations in both hemispheres, International Radiation Symposium, Berlin, Germany, 6-10 August 2012.

Román, R., Bilbao, J., de Miguel, A., and Mateos, D., Analysis of erythemal radiation evolution along twenty years in Central Spain, International Radiation Symposium, Berlin, Germany, 6-10 August 2012.

Mateos, D., Bilbao, J., de Miguel, A., Román, R., and Pérez-Burgos, A., Satellite Radiation Retrieval Validation in Spain: Impact of Ozone, Clouds and Aerosols, V Reunión Española de Ciencia y Tecnología de Aerosoles - RECTA 2011, Madrid, Spain, 27-29 June 2011.

Román, R., Bilbao, J., de Miguel, A., Mateos, D., and Pérez-Burgos, A., Influence of aerosol optical depth on ultraviolet erythemal radiation, V Reunión Española de Ciencia y Tecnología de Aerosoles - RECTA 2011, Madrid, Spain, 27-29 June 2011.

Mateos, D., Bilbao, J., de Miguel, A., and Román, R., Aerosol, cloud and water effects on the relationship between UV and total shortwave radiant fluxes, WAVACS-COST winter school Water Vapour in the Climate System, Venice, Italy, 6-12 February 2011.

Pérez-Burgos, A., De Miguel, A., Bilbao, J., and Mateos, D., Prediction of Solar Irradiance and Illuminance Using REST2 Model, EuroSun 2010, Graz, Austria, 28 September - 1 October 2010.

Mateos, D., de Miguel, A., Bilbao, J., and Román, R., 2010, What effect does the presence of clouds on UV solar radiation attenuation?, 37th Annual European Meeting on Atmospheric Studies by Optical Methods, Valladolid, Spain, 23-27 August 2010.

de Miguel, A., Mateos, D., Bilbao, J., Román, R., and Pérez-Burgos, A., 2010, Dependence on cloudiness of CMF values in the UV range, 37th Annual European Meeting on Atmospheric Studies by Optical Methods, Valladolid, Spain, 23-27 August 2010.

de Miguel, A., Román, R., Mateos, D., Bilbao, J., Pérez-Burgos, A., Cachorro, V.E., and Rodrigo, R., Atmospheric effects on the erythemal ultraviolet and total shortwave solar radiation in Valladolid, Spain, 37th Annual European Meeting on Atmospheric Studies by Optical Methods, Valladolid, Spain, 23-27 August 2010.

Román, R., de Miguel, A., Bilbao, J., and Mateos, D., Proposal of a new method to obtain erythemal UV irradiance values in the past, 37th Annual European Meeting on Atmospheric Studies by Optical Methods, Valladolid, Spain, 23-27 August 2010. 
Mateos, D., de Miguel, A., and Bilbao, J., Climatological study of total ozone column in central Spain, MOCA-09: IAMAS Simposia, Montreal, Canada, 19-29 July 2009.

Bilbao, J., de Miguel, A., and Mateos, D., Daily solar UV-B radiation evaluated from meteorological variables, MOCA-09: IAMAS Simposia, Montreal, Canada, 19-29 July 2009.

Mateos, D., Bilbao, J., and de Miguel, A., Empirical models of ultraviolet total solar radiation, MOCA-09: IAMAS Simposia, MOCA-09: IAMAS Simposia, Montreal, Canada, 19-29 July 2009.

Mateos, D., de Miguel, A., and Bilbao, J., The cloudiness effect on UV radiation, EGU General Assembly 2009, Vienna, Austria, 19-24 April 2009.

Mateos, D., de Miguel, A., and Bilbao, J., Climatology of Ultraviolet Global Solar Irradiation, $6^{\circ}$ Simpósio de Meteorologia e Geofísica da APMG / $10^{\circ}$ Encontro Luso-Espanhol de Meteorologia, Aldeia dos Capuchos, Portugal, 16-18 March 2009.

Mateos, D., Bilbao, J., de Miguel, A., and Cachorro, V.E., Comparison of total ozone column, precipitable water and aerosol optical thickness in central Spain, EGU General Assembly 2008, Vienna, Austria, 1318 April 2008.

Mateos, D., Bilbao, J., and de Miguel, A., Radiación solar UV, ozono y nubosidad en Valladolid, España, $6^{\text {a }}$ Asamblea Hispano Portuguesa de Geodesia y Geofísica, Tomar, Portugal, 11-14 February 2008. 



\section{Acronyms}

\begin{tabular}{|c|c|}
\hline AEMet & Spanish Meteorological Agency \\
\hline AERONET & Aerosol RObotic NETwork \\
\hline CIE & International Commission on Illumination \\
\hline COST 726 & Long Term changes and Climatology of UV Radiation over Europe \\
\hline DAS & Diode Array Spectrometer \\
\hline DU & Dobson Unit \\
\hline ENEA & Agenzia Nazionale per le Nuove Tecnologie, l'Energia e lo Svilippo \\
\hline & Economico Sostenibile \\
\hline GAW & Global Atmospheric Watch \\
\hline GOME & Global Ozone Monitoring Experiment \\
\hline HATPRO & Humidity and Temperature Profiler \\
\hline ICNIRP & International Commission on Non-Ionizing Radiation Protection \\
\hline INTA & National Institute for Aerospace Technology \\
\hline IPCC & Intergovernmental Panel on Climate Change \\
\hline LAMPEDUSA & Referred to the ENEA station placed in Lampedusa island \\
\hline LIDAR & Light Detection and Ranging \\
\hline LUT & Look-Up-Table \\
\hline GMT & Greenwich Mean Time \\
\hline MODIS & Moderate Resolution Imaging Spectroradiometer \\
\hline NASA & National Aeronautics and Space Administration \\
\hline NCEP & National Centres for Environmental Prediction \\
\hline OMI & Ozone Monitoring Instrument \\
\hline PMOD-WRC & World Radiometric Centre \\
\hline RTE & Radiative Transfer Equation \\
\hline SRSUVA & Solar Radiometric Station of the University of Valladolid \\
\hline TOMS & Total Ozone Mapping Spectrometer \\
\hline TRISAIA & Referred to the measurement campaign the ENEA-Trisaia centre \\
\hline TSI & Total Sky Imager of Yankee Environmental Systems model 440 \\
\hline UNEP & United Nations Environment Programme \\
\hline UVA & University of Valladolid \\
\hline UV-MFRSR & Multifilter Shadowband Radiometer for the ultraviolet range \\
\hline VIS-MFRSR & Multifilter Shadowband Radiometer for the visible range \\
\hline WHO & World Health Organization \\
\hline WMO & World Meteorological Organization \\
\hline YES & Yankee Environmental Systems, Inc \\
\hline
\end{tabular}





\section{Nomenclature}

\begin{tabular}{|c|c|}
\hline$\alpha$ & Ångström exponent \\
\hline$\beta$ & Ångström turbidity \\
\hline$\Gamma$ & Day angle (degree) \\
\hline$\delta$ & Declination (degree) \\
\hline$\varepsilon$ & Temperature correction function \\
\hline$\lambda$ & Wavelength (nm) \\
\hline$\Lambda$ & Latitude (degree) \\
\hline$\mu_{0}$ & Cosine of the solar zenith angle \\
\hline$\rho_{\mathrm{w}}$ & Water density $\left(\mathrm{g} \mathrm{m}^{-3}\right)$ \\
\hline$\sigma$ & Absorption cross section of ozone $\left(\mathrm{cm}^{2}\right.$ molec $\left.^{-1}\right)$ \\
\hline$\tau$ & Total optical thickness \\
\hline$\tau_{\mathrm{a}, \mathrm{s}}$ & Absorption (a) and scattering (s) optical thickness \\
\hline$v$ & Frequency $\left(\mathrm{s}^{-1}\right)$ \\
\hline$\phi$ & Quantum yield of the ozone photodissociation (molec quanta ${ }^{-1}$ ) \\
\hline$\Phi$ & Solar azimuth angle (degree) \\
\hline$\omega_{0}$ & Single scattering albedo \\
\hline$\varpi$ & Solar hour angle (degree) \\
\hline A & Surface albedo \\
\hline $\operatorname{Ar}$ & Area \\
\hline AOT & Aerosol Optical Thickness \\
\hline $\mathrm{AOT}_{\lambda}$ & Aerosol Optical Thickness at a wavelength of $\lambda$ \\
\hline BEUVD & Biologically effective UV doses \\
\hline $\mathrm{CMF}$ & Cloud Modification Factor or cloud transmittance \\
\hline $\mathrm{CMF}_{\text {aer }}$ & Cloud Modification Factor for normal conditions (aerosol considered) \\
\hline $\mathrm{CMF}_{\text {DIFFUSE }}$ & Cloud Modification Factor for the diffuse component \\
\hline $\mathrm{CMF}_{\mathrm{F}}$ & Cloud Modification Factor for the actinic flux (global component) \\
\hline $\mathrm{CMF}_{\mathrm{GLOBAL}}$ & Cloud Modification Factor for the global component \\
\hline $\mathrm{CMF}_{\mathrm{I}}$ & Cloud Modification Factor for the irradiance (global component) \\
\hline $\mathrm{CMF}_{\mathrm{J}(\mathrm{O} 1 \mathrm{D})}$ & Cloud Modification Factor for the ozone photolysis rate \\
\hline $\mathrm{CMF}_{\text {Noaer }}$ & Cloud Modification Factor for an aerosol-free atmosphere \\
\hline $\mathrm{CMF}_{\mathrm{UVI}}$ & Cloud Modification Factor for the ultraviolet index \\
\hline CosCor & Cosine correction function \\
\hline COT & Cloud Optical Thickness \\
\hline CRE & Cloud Radiative Effect $\left(\mathrm{W} \mathrm{m}^{-2}\right)$ \\
\hline$d_{n}$ & Day number of the year \\
\hline $\mathrm{D}_{\mathrm{n}}$ & Downwelling diffuse cloud effect \\
\hline
\end{tabular}




\begin{tabular}{|c|c|}
\hline $\mathrm{E}_{0}$ & Sun-Earth distance correction \\
\hline $\mathrm{F}$ & Actinic flux (quanta $\mathrm{cm}^{-2} \mathrm{~s}^{-1}$, can be defined spectrally) \\
\hline g & Asymmetry factor \\
\hline $\mathrm{h}$ & Height (m) \\
\hline $\mathrm{h}_{\mathrm{cld}}$ & Height of the cloud base (m) \\
\hline I & Irradiance ( $\mathrm{W} \mathrm{m}^{-2}$, can be defined spectrally) \\
\hline $\mathrm{I}_{0}$ & $\begin{array}{l}\text { Radiation at the top of the atmosphere }\left(\mathrm{W} \mathrm{m}^{-2} \text {, can be defined }\right. \\
\text { spectrally) }\end{array}$ \\
\hline
\end{tabular}

$\mathrm{J}\left(\mathrm{O}^{1} \mathrm{D}\right) \quad$ Ozone photolysis rate $\left(\mathrm{s}^{-1}\right)$

$\mathrm{k}_{\mathrm{a}, \mathrm{e}, \mathrm{s}}$

Absorption (a), extinction (e) and scattering (s) coefficients $\left(\mathrm{m}^{-1}\right)$

$\mathrm{L}$

Radiance ( $\mathrm{W} \mathrm{m}^{-2} \mathrm{sr}^{-1}$, can be defined spectrally)

LWC

Liquid Water Content $\left(\mathrm{g} \mathrm{m}^{-3}\right)$

LWP Liquid Water Path $\left(\mathrm{g} \mathrm{m}^{-2}\right)$

$\mathrm{m}$

Relative optical air mass

$\mathrm{M}$

Number of UV-MFRSR channels

MBE

Mean Beas Error

n

Number of data

$\mathrm{P}$

Function of phase

$\mathrm{Q}_{\mathrm{e}}$

Mie scattering effienciency factor

$\mathrm{r}$

Correlation coefficient

$\mathrm{R}$

Mean Earth radius ( $6371 \mathrm{~km})$

$r_{\text {eff }}$

Effective radius of cloud droplets $(\mu \mathrm{m})$

RMSE

Root Mean Square Error

$\mathrm{T}$

Temperature $(\mathrm{K})$

TCO

Tropospheric Column Ozone (DU)

TOC

Total Ozone Column (DU)

$\mathrm{S}$

Action spectrum

$\mathrm{S}_{\mathrm{CV}}$

Fractional Sky Cover

SE

Standard error

$\mathrm{S}_{\mathrm{er}}$

Erythemal action spectrum

SW

Shortwave radiation ( $\mathrm{W} \mathrm{m}^{-2}$, can be defined spectrally)

SZA

Solar Zenith Angle (degree)

UV

UV-A

Ultraviolet radiation ( $\mathrm{W} \mathrm{m}^{-2}$, can be defined spectrally)

UV-B

Ultraviolet type A radiation ( $\mathrm{W} \mathrm{m}^{-2}$, can be defined spectrally)

UV-C

Ultraviolet type $\mathrm{B}$ radiation ( $\mathrm{W} \mathrm{m}^{-2}$, can be defined spectrally)

UVER

Ultraviolet type $\mathrm{C}$ radiation ( $\mathrm{W} \mathrm{m}^{-2}$, can be defined spectrally)

UVI

Erythemal Ultraviolet Radiation ( $\mathrm{W} \mathrm{m}^{-2}$, can be defined spectrally)

Ultraviolet Index 


\section{Summary}

Due to the decrease in total ozone recorded in recent decades, UV radiation levels at the surface have increased. This, together with the effects this radiation causes on atmospheric chemistry and the biosphere, has led to the need to monitor the UV radiation field (both irradiance and actinic flux). Spectral and integrated quantities of the two variables are usually employed. UV irradiance is usually represented with the UV index, UVI, which describes the UV radiation levels at the surface that produce erythema or sunburn on human skin. One key reaction in the chemistry of the troposphere is ozone photolysis, for which the rate of this reaction, $\mathrm{J}\left(\mathrm{O}^{1} \mathrm{D}\right)$, is used. The main factors involved in the attenuation of UV radiative flux on the Earth's surface are solar elevation, cloudiness, ozone, aerosol, surface albedo, and altitude. Cloud effect on solar UV radiative flux has only been partially explored due to the lack of measurements of cloud properties, which show a large temporal and spatial variability and determine the final levels of radiation at the surface. The main aim of this work is therefore to characterize radiative flux under overcast conditions.

A large number of instruments located at three different European stations were involved in the analysis described in this thesis. These instruments provided measurements of global and diffuse spectral irradiances and spectral actinic flux in the UV range, UVI, $\mathrm{J}\left(\mathrm{O}^{1} \mathrm{D}\right)$, cloud optical thickness (COT), liquid water path (LWP), effective radius of cloud droplets $\left(r_{\text {eff }}\right.$ ), total ozone column (TOC), cloud cover, cloud base and top heights, and aerosol optical thickness (as well as its vertical distribution). Radiative transfer simulations with the libRadtran library have been carried out as realistically as possible using input such as aerosol and cloud properties, temperature and pressure profiles, and surface albedo.

Characterization of UVI and $\mathrm{J}\left(\mathrm{O}^{1} \mathrm{D}\right)$ under overcast conditions was carried out by means of experimental and model data. The influence of solar zenith angle (SZA) and TOC is relevant under overcast conditions, while the aerosol effect is only relevant for the $\mathrm{J}\left(\mathrm{O}^{1} \mathrm{D}\right)$. As the cloud modification factor $(\mathrm{CMF})$ was calculated to investigate cloud effect, a good estimation under cloudless conditions was required. The CMFs for the UVI and $\mathrm{J}\left(\mathrm{O}^{1} \mathrm{D}\right)$ are studied as a function of COT. Experimental and model results are very similar, and no significant differences between $\mathrm{CMF}_{\mathrm{UVI}}$ and $\mathrm{CMF}_{\mathrm{J}(\mathrm{O} 1 \mathrm{D})}$ are observed. The relationship between CMF and COT can be approximated with $\mathrm{CMF}=\left(1+\mathrm{c}_{1} \mathrm{COT}\right)^{-1}$.

As regards spectral dependence (determined using COT and cloud microphysical properties separately), the CMFs for the global and diffuse irradiances and actinic flux exhibit different trends. The CMF for the global irradiance component increases up to 320 
$\mathrm{nm}$, and decreases beyond this wavelength with a weak SZA effect. Beyond $320 \mathrm{~nm}$, the CMF for the actinic flux shows three different behaviours: slightly increasing behaviour at low SZA, decreasing behaviour at moderate SZA, and a strongly decreasing behaviour at high SZA. The CMF for diffuse irradiance always increases with wavelength. The processes involved in UV radiation attenuation under cloud presence are scattering on molecules, and aerosol and cloud particles, and absorption by ozone. These processes lead to the following mechanisms: multiple reflections between the cloud and the atmosphere above; enhanced ozone absorption; dependence on SZA and wavelength in attenuation; and photons arriving from the zenith direction due to the Umkehr effect (more effectively for the shorter wavelengths). Finally, these effects have to be considered when biological effects are calculated using the CMF. If the CMF is taken as wavelength-independent, a notable overestimation of UV radiation occurs.

In the analysis considering cloud microphysical properties, droplets with a smaller effective radius cause higher attenuation in the overcast scenario. With regard to the different behaviour between irradiance and actinic flux, irradiance is more strongly attenuated at low SZA, and the actinic flux shows the smallest values of CMF at high SZA. These facts can be explained by the different weight of the direct and diffuse components.

A particular case with a desert dust layer below the cloud in overcast conditions is used to determine the impact of aerosol on cloud transmittance. Model simulations reproduce the experimental values of global and diffuse irradiance and actinic flux to within $\pm 5 \%$. The libRadtran model is used to perform a sensitivity analysis on aerosol properties. Results point out the single scattering albedo as a relevant parameter affecting both global and diffuse CMF. Cloud optical properties (cloud single scattering albedo and asymmetry factor) determine the values and spectral behaviour of CMFs (both global and diffuse), while other parameters such as cloud base altitude or cloud geometric thickness have less of an impact. 


\section{Resumen}

El descenso de la columna de ozono registrado en las últimas décadas ha provocado un aumento de los niveles de radiación UV en superficie. Debido a este hecho, y sabiendo que esta radiación produce efectos sobre la química de la atmósfera y sobre la biosfera, ha sido necesaria la monitorización del campo radiativo en el intervalo del UV, tanto del flujo actínico como de la irradiancia. Estas dos variables se han medido tanto en su régimen espectral como integrado. Una de las variables que representa la irradiancia UV es el índice UV, UVI, que describe los niveles de esta radiación en superficie que producen eritema o quemadura solar en la piel humana. Con respecto al flujo actínico, se estudia la velocidad de fotólisis del ozono, $\mathrm{J}\left(\mathrm{O}^{1} \mathrm{D}\right)$. Los principales factores que modulan el flujo radiativo en el UV que llega a la superficie terrestre son la elevación solar, la nubosidad, el ozono, el aerosol, al albedo superficial, y la altitud. Sin embargo, el efecto de las nubes sobre el flujo radiativo no es del todo conocido debido a la carencia de medidas de propiedades de nubes, que muestran una gran variabilidad tanto espacial como temporal, y que van a determinar los niveles finales de radiación en superficie. Por lo tanto, el principal objetivo de este trabajo es caracterizar el flujo radiativo bajo condiciones de cielos totalmente cubiertos.

Un gran número de instrumentos han sido necesarios en la realización de esta tesis doctoral en tres estaciones europeas. Se han realizado medidas de la irradiancia espectral (componente global y difusa), del flujo actínico espectral, del UVI y $\mathrm{J}\left(\mathrm{O}^{1} \mathrm{D}\right)$, del espesor óptico de las nubes (COT), del contenido de agua líquida (LWP), del radio efectivo de las gotas de las nubes ( $\mathrm{r}_{\mathrm{eff}}$ ), de la columna de ozono (TOC), de la cubierta, base y cima de las nubes, del espesor óptico de aerosoles (y su distribución vertical). Se han utilizado también simulaciones con el modelo de transferencia radiativa libRadtran, lo más precisas posibles considerando en las entradas propiedades de nubes y aerosoles, el tipo de atmósfera, el albedo superficial, entre otros.

La caracterización del UVI y $\mathrm{J}\left(\mathrm{O}^{1} \mathrm{D}\right)$ en condiciones de cielos totalmente cubiertos se ha realizado con datos experimentales y simulados. El ángulo cenital solar (SZA) y la TOC conservan un papel relevante en el escenario de cielos totalmente cubiertos, mientras que el aerosol solo muestra un efecto importante para el $\mathrm{J}\left(\mathrm{O}^{1} \mathrm{D}\right)$. Como el factor de modificación de nubes (CMF) se ha utilizado para investigar el efecto de éstas, ha sido necesaria una buena estimación bajo cielos despejados. Se ha estudiado la dependencia del CMF para el UVI y el $\mathrm{J}\left(\mathrm{O}^{1} \mathrm{D}\right)$ en función del COT. Los resultados obtenidos tanto experimentales como simulados son muy similares. Además, no hay diferencias 
significativas entre el $\mathrm{CMF}_{\mathrm{UVI}}$ y el $\mathrm{CMF}_{\mathrm{J}(\mathrm{O} 1 \mathrm{D})}$. La relación entre el CMF y el COT se puede establecer como $\mathrm{CMF}=\left(1+\mathrm{c}_{1} \mathrm{COT}\right)^{-1}$.

Con respecto a la dependencia espectral (determinada de dos formas distintas usando el COT y medidas de propiedades microfísicas de nubes), los CMFs para la irradiancia global y difusa y el flujo actínico tienen diferentes tendencias. El CMF para la componente global de la irradiancia aumenta hasta los $320 \mathrm{~nm}$, y decrece a partir de esta longitud de onda con un efecto del SZA no muy marcado. El CMF para el flujo actínico, por encima de los $320 \mathrm{~nm}$, presenta tres tendencias: un ligero aumento para bajos SZAs, un decrecimiento para moderados SZAs, y una fuerte tendencia decreciente para altos SZAs. El CMF para la irradiancia difusa aumenta con la longitud de onda. Los fenómenos involucrados en la atenuación de la radiación UV en presencia de nubes son la dispersión sobre moléculas y partículas de aerosol y nubes, y la absorción por el ozono. Estos procesos provocan los siguientes mecanismos: reflexiones múltiples entre la nube y la atmósfera de encima, una mayor absorción por ozono, una dependencia con el SZA y la longitud de onda en la atenuación, y fotones llegando desde el zenit por el efecto Umkehr (más efectivo para las longitudes de onda más pequeñas). Estos efectos se tienen que tener en consideración cuando se están calculando los efectos biológicos, puesto que si se supone un CMF constante con la longitud de onda, se produce una importante sobreestima de la radiación UV.

En el análisis realizado con las propiedades microfísicas de nubes, las gotas con un radio efectivo más pequeño van a producir una mayor atenuación de los flujos radiativos en el escenario de cielos totalmente cubiertos. Con respecto al diferente comportamiento entre la irradiancia y el flujo actínico, mientras que la irradiancia es más fuertemente atenuada para bajos SZAs, el flujo actínico muestra los valores más pequeños de CMF a altos SZAs. Esto se debe a la diferente definición de las dos variables, y por lo tanto, al diferente peso de las componentes directa y difusa.

Un caso particular que presenta una capa de aerosol desértico debajo de la capa de nubes (de 8 octas) se ha usado para determinar el impacto del aerosol en la transmitancia de la nube. El modelo libRadtran se ha usado para realizar un análisis de sensibilidad ante las propiedades de nubes y aerosol. Los resultados indican que el albedo de dispersión simple del aerosol es un factor muy relevante que afecta tanto a la componente global como a la difusa del CMF. Mientras que las propiedades ópticas de las nubes (el albedo de dispersión simple y el factor de asimetría) determinan los valores y la dependencia espectral del CMF (tanto global como difuso), otros parámetros como la altura de la base de la nube o el espesor geométrico de la capa de nubes toman un papel menos relevante. 


\section{Introduction, Objectives and Thesis Structure}

\section{I.1. Introduction}

The climate system is defined as an interactive system consisting of the atmosphere, land, snow, and ice surfaces, oceans and other bodies of water, and living things (IPCC, 2007). It is powered by solar radiation mainly in the shortwave range up to $3000 \mathrm{~nm}$. Yet, not all the radiation reaching the top of the Earth's atmosphere is absorbed; $\sim 30 \%$ is reflected back to space by clouds, aerosol particles or Earth's surfaces, mainly those with high albedo (snow, ice, and deserts). The other $\sim 70 \%$ is absorbed by the Earth's surface and the atmosphere. To balance incoming radiation, the same amount of energy is emitted from the Earth as longwave radiation. The energy is transported all around the Earth and is used for such purposes as water evaporation. Figure I.1 shows the main processes influencing this energy balance. As can be seen in the figure, clouds are the main factor involved in modulating the energy balance (Ramanathan et al., 1989). Clouds can affect the energy balance by reflecting solar radiation back to space (albedo effect of clouds) and by trapping infrared radiation emitted by the surface and the lower troposphere (greenhouse effect of clouds). The relationship between the two effects depends on many factors, including cloud microphysical properties (IPCC, 2007).

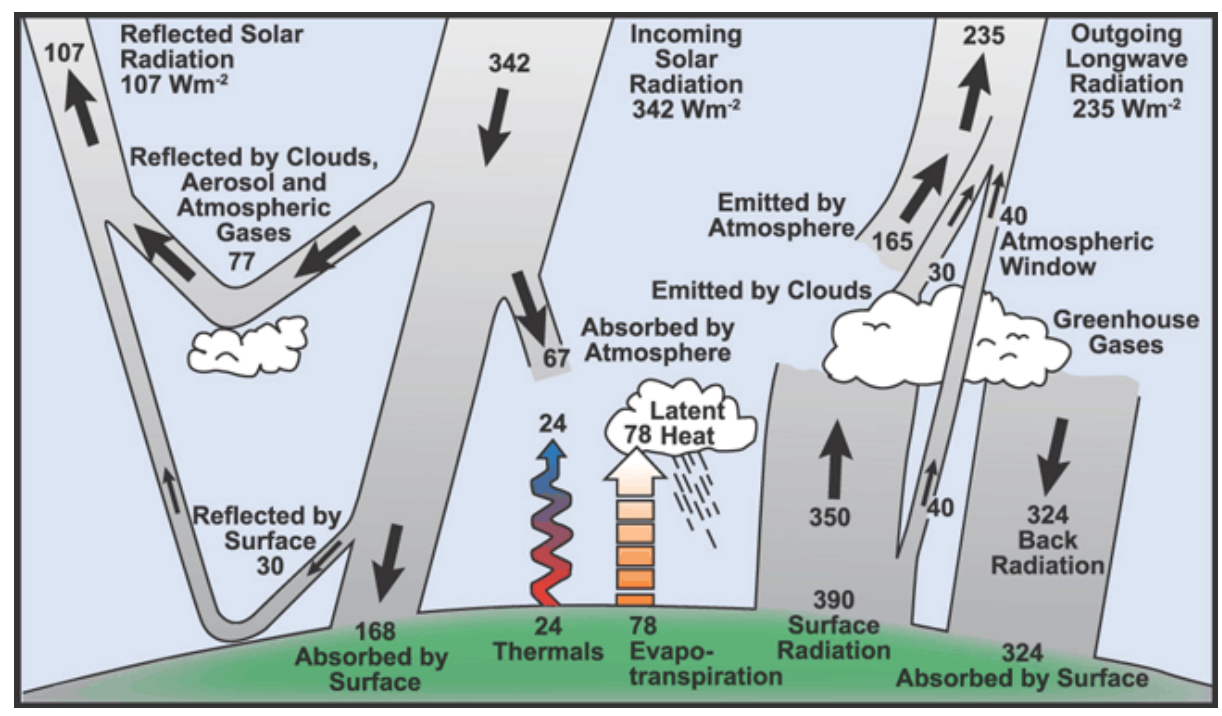

Figure I.1. Estimate of the Earth's annual and global mean energy balance. Taken from IPCC (2007). 
Solar ultraviolet (UV) radiation, 100-400 nm, represents only a small percentage of the total solar energy reaching the top of the atmosphere. Yet, UV is the most energetic radiation reaching the surface and exerts a significant influence on the biosphere. The ozone reduction reported in the early 1980s led to an increase in solar UV radiation at the surface. However, over the last 20 years a recovery in ozone values has been observed. Several studies have analyzed these trends and future scenarios (e.g., Weatherhead and Andersen, 2006; WMO, 2011). The UV-B range, 280-315 nm, is of great biological importance since photons from these wavelengths may damage deoxyribonucleic acid (DNA) molecules and certain proteins of living organisms. Not all effects are harmful, however. UV-B radiation is essential for the synthesis of vitamin D in the human body, which has beneficial effects and helps prevent certain diseases. UV radiation is also important for tropospheric chemistry as it is involved in important photochemical reactions, such as nitrogen dioxide photolysis, ozone, and formaldehyde. Changes in the tropospheric composition can influence the stratosphere through interactions between both layers. Finally, links have been established between changes in UV radiation and climate change (Bais et al., 2007).

Monitoring UV radiation at the Earth's surface requires detailed instrument characterization and accurate calibration in order to provide high quality UV radiation data. High maintenance costs mean that UV radiation measurement networks are confined to certain areas (e.g., Fioletov et al., 2002; Cede et al., 2004). In recent years, the use of instruments onboard satellites has also addressed the assessment of UV levels at the surface (e.g., Fioletov et al., 2004; Meloni et al., 2005; Ialongo et al., 2011). A study into the validation of satellite UV retrievals was carried out, although this topic was not one of the objectives of the thesis (Mateos et al., 2012a).

The main factors modulating UV radiation levels at the surface are: Sun-Earth geometry, clouds, ozone, aerosol, surface albedo, and altitude. In particular, clouds dominate any other atmospheric variable as a source of surface UV variability resulting in either a reduction or an increase in UV radiation. This depends on cloud cover and the position in relation to the Sun, cloud optical thickness, and microphysical properties. These variables present large temporal and spatial variability, which prevents cloud effect from being determined.

Results from different studies of cloud effects can be compared using the cloud modification factor (CMF), which is defined as the ratio between the measured UV radiation in a cloudy sky and the calculated radiation for a cloudless sky. Typical CMF values for overcast skies range from 0.3 to 0.8 , depending on cloud type and characteristics (Calbó et al., 2005). In general, clouds attenuate UV radiation less than 
total shortwave (e.g., Den Outer et al., 2005). This effect is explained by Rayleigh scattering that more efficiently redirects toward the surface the UV part of the radiation reflected by clouds (Kylling et al., 1997), and by radiance distribution at the cloud top (Bernhard et al., 2004; Lindfors and Arola, 2008). UV radiation levels at the surface under cloudy conditions may be higher than in a cloud-free sky. This is the so-called enhancement effect, which may occur when the solar disk is not occluded.

Despite these well-known effects under cloudy conditions, few cases of experimental data are reported in the literature, and these are mainly case studies with a limited number of spectra and atmospheric conditions. In addition, measurements of cloud properties are sparse and are only available in certain measurement campaigns. This thesis allows the UV radiative flux (irradiance and actinic flux) to be described with simultaneous measurements of cloud optical thickness and microphysical properties with relatively large data sets at three different stations. This also allows the dependence on the solar zenith angle to be investigated. To the best of our knowledge, this thesis presents the first analysis of spectral diffuse irradiance using experimental values under overcast conditions. Estimation of the UV effects on the biosphere under cloudy conditions proved the relevance of the findings obtained in this thesis.

\section{I.2. Objectives}

The main objective of this study is to provide a full description of the solar UV radiative flux under overcast conditions. This general objective gives the following specific objectives:

- To characterize the integrated values of the radiative flux under overcast conditions and the variables acting in this scenario.

- To investigate cloud transmittance for the UV radiative flux, both integrated and spectral, under overcast conditions as a function of cloud optical thickness.

- To analyze the effects that different cloud microphysical properties produce on UV cloud transmittance under overcast conditions.

- To ascertain the indirect effects caused by the presence of clouds on UV levels at the surface due to other atmospheric factors.

- To highlight the different behaviour of irradiance and actinic flux.

- To study diffuse cloud transmittance, establishing the parameters that influence it under overcast conditions. 


\section{I.3. Structure of the thesis}

The specific objectives mentioned before are distributed throughout six chapters, two annexes, and a bibliography section. An individual description of each chapter of the thesis follows.

Chapter 1 consists of an introduction of the radiative field, the phenomena and factors modulating its levels at surface. All the variables used in this thesis are defined in this chapter. Current knowledge of the interaction between clouds and UV radiative flux is presented.

Chapter 2 presents the instruments used for this thesis at three European stations: the Solar Radiometric Station at the University of Valladolid (SRSUVA), the station located at Lampedusa island managed by the UTMEA-TER Earth observation unit (LAMPEDUSA), and the two-month measurement campaign performed at the ENEATrisaia research centre in Southern Italy (TRISAIA). This chapter also includes details about: calibration processes, intercomparison studies, and retrievals of different parameters. Finally, a brief introduction to the radiative transfer theory is included, as well as a detailed description of the variables used as input to the libRadtran model.

Chapter 3 provides a full description of the UV index and ozone photolysis rate under overcast conditions, highlighting the impact of other atmospheric factors thereon. Both variables are modelled under cloudless conditions in order to evaluate their cloud transmittances or cloud modification factors, which are investigated as a function of cloud optical thickness.

Chapter 4 describes cloud effects on global and diffuse spectral irradiances and spectral actinic flux as a function of cloud optical thickness. It includes the analysis of enhanced ozone absorption under cloudy conditions. The different behaviours observed between irradiance and actinic flux, and between global and diffuse irradiance components are analyzed in detail. A physical interpretation of these phenomena is given at the end of the chapter.

Chapter 5 describes the UV radiative flux using microphysical cloud properties; liquid water path and the effective radius of cloud droplets having been used in the present work. For this purpose, UV index, ozone photolysis rate, global and diffuse spectral irradiances, and spectral actinic flux measurements are used. A detailed analysis of the different behaviours displayed by these variables is carried out. 
Chapter 6 explains the impact of aerosol load on cloud transmittance by analyzing a particular case. All the available measurements are used in order to obtain model simulations as accurately as possible. The case study presents overcast conditions with an aerosol dust layer below the cloud. The simulations reproduce the measurements of global and diffuse irradiance and actinic flux to within $\pm 5 \%$. Many options are changed in the set-up of the model to evaluate the relevance of the aerosol and cloud properties on cloud transmittances.

Finally, the main results and conclusions are summarized in Chapter 7. 



\section{Chapter 1}

1. The radiative field and the factors controlling its levels at the surface 
The main aim of this chapter is to present the radiative field by introducing concepts such as ultraviolet index and ozone photolysis rates. The effects of atmospheric and astronomical factors are analyzed in detail, highlighting the state of the art about the cloud - UV radiation interaction.

\subsection{Radiative Field}

\subsubsection{Introduction and definitions}

The Sun is the closest star to the Earth and is a completely gaseous body composed mainly of hydrogen. The Sun constitutes the main source of energy that reaches the Earth. The spectral distribution of the radiation arriving at the top of the atmosphere is known as extraterrestrial radiation which covers the spectral range, mainly, up to $3000 \mathrm{~nm}$ (the total shortwave, SW, range). This interval is classified into three main ranges: ultraviolet (UV) with the shortest wavelengths, visible (VIS) between 400 and $770 \mathrm{~nm}$, and infrared for wavelengths $>770 \mathrm{~nm} .95 \%$ of the Sun's energy falls in the range $300-2400 \mathrm{~nm}$. Solar UV radiation is defined as the part of the electromagnetic spectrum between 100 and $400 \mathrm{~nm}$. Figure 1.1 shows the part of the solar spectrum covered by the UV range. This radiation represents less than $8 \%$ of the total radiation at the top of the atmosphere; while the visible and infrared ranges constitute $39 \%$ and $53 \%$, respectively. UV radiation is usually divided into three ranges in relation to its biological effects:

- UV-C (100-280 $\mathrm{nm})$, this range is totally absorbed by molecular oxygen and ozone, and is therefore unable to reach the Earth's surface.

- UV-B (280-315 nm), stratospheric ozone absorbs most of the radiation at these wavelengths, although it is not totally blocked and does reach the surface. This radiation, which is the most energetic at the surface, can interact with living beings, causing damage as well as providing beneficial effects.

- UV-A (315-400 nm), this radiation is less affected by ozone absorption (absorption decreases rapidly towards $350 \mathrm{~nm}$, the Huggins absorption band). This type can represent almost $90 \%$ of UV radiation at the surface. 


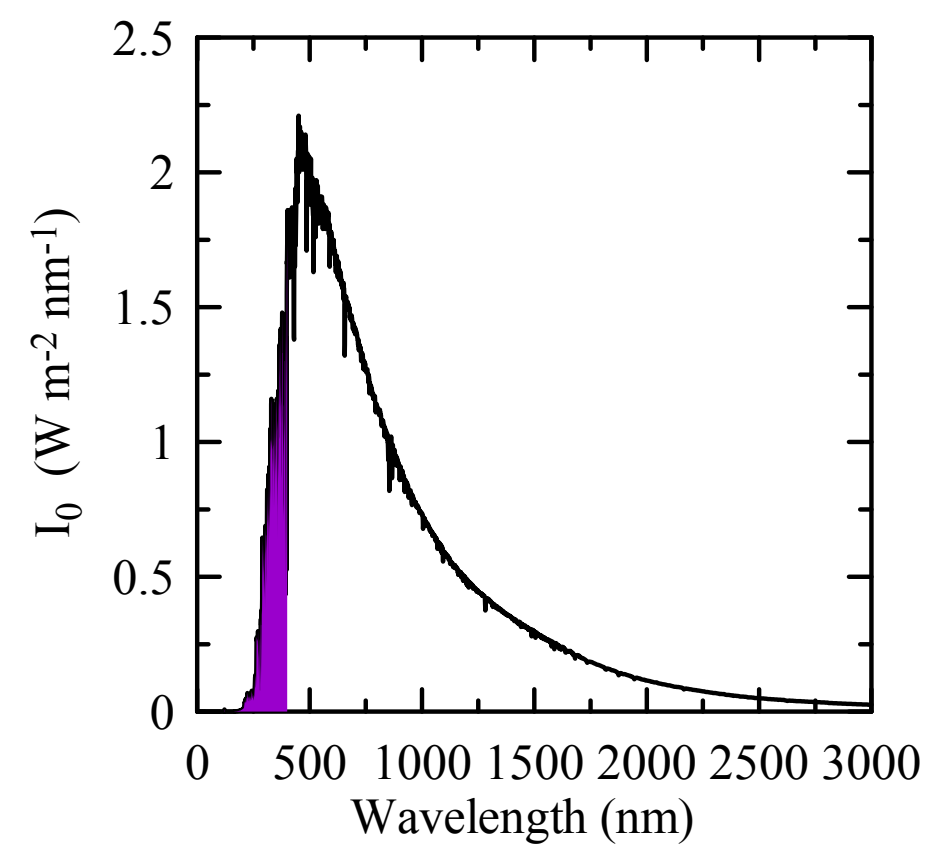

Figure 1.1. Dependence of radiation at the top of the atmosphere on wavelength following the spectrum given by Gueymard (2004).

The boundary between UV-B and UV-A is still not clear. Some authors set this limit at $320 \mathrm{~nm}$, although most international agencies agree to fix the boundary at 315 nm, viz., the World Meteorological Organization (WHO), the United Nations Environment Programme (UNEP), the World Meteorological Organization (WMO), the International Commission on Non-Ionizing Radiation Protection (ICNIRP), and the European Union's action COST 713, among others.

UV radiation is able to break up the chemical bonds of various molecules sinceit is the most energetic radiation in the lower troposphere. It therefore exerts a significant influence on the atmosphere and on living organisms (ICNIRP, 2004). In recent years, the following effects have been found:

- On human beings, UV radiation can produce sunburn on human skin (e.g., McKinlay and Diffey, 1987), and eye cataracts (e.g., WHO, 1995). Probably, the most dangerous effect is DNA damage (e.g., Diffey, 1992). However, not all of the effects are harmful, with synthesis of vitamin $\mathrm{D}$ being one of the main benefits of UV radiation (e.g., Webb, 2006; Turnbull et al., 2010). These different effects are not independent. In fact, Fioletov et al. (2009) found that the vitamin D action spectrum weighted UV is, under certain conditions, nearly proportional to erythemal action spectrum weighted UV.

- It affects plants and terrestrial ecosystems (e.g., Heisler et al., 2003). For instance, it impairs photosynthesis in many plant species and increases plant susceptibility 
to disease (Caldwell et al., 1998). It affects crop growth and development (Kakani et al., 2003), etc.

- It damages aquatic ecosystems. For example, it reduces phytoplankton production and induces changes in microbial and invertebrate communities, which may affect nutrient cycling in soil (Häder et al., 2007).

- It causes photo-degradation of polymers, pigments, and dyes, (e.g., Zhao et al., 2007).

- It induces alterations in atmospheric chemistry and biogeochemical cycles (see for instance, UNEP, 2007).

- It impacts energy balance and climate change since certain photochemical reactions can increase atmospheric temperature (e.g., Brühl and Crutzen, 1988).

Due to all of these effects, in past decades it has been common to measure spectral irradiance $\left(\mathrm{I}_{\lambda}\right)$, particularly in the UV range. $\mathrm{I}_{\lambda}$ describes the radiation that crosses a plane (usually horizontal) surface. Radiation from a specific solid angle is weighted with the cosine of the solar zenith angle (SZA); i.e., each photon contributes to irradiance with a weight determined by the cosine of its angle of incidence. However, as shown by Madronich (1987), photochemical processes are directly proportional to actinic flux $\left(\mathrm{F}_{\lambda}\right.$, also wavelength dependent). $F_{\lambda}$ is defined as the spherical flux density incident over all angles that is capable of producing photodissociation in photo-actively labile molecules, i.e., the radiation from all solid angles is equally weighted (all photons contribute equally, regardless of their angle of incidence). The two quantities are defined as follows:

$$
\begin{gathered}
\mathrm{I}_{\lambda}=\int_{0}^{2 \pi} \int_{0}^{\pi / 2} \mathrm{~L}_{\lambda}(\mathrm{SZA}, \Phi) \cos (\mathrm{SZA}) \sin (\mathrm{SZA}) \mathrm{dSZA} d \Phi \\
\mathrm{F}_{\lambda}=\int_{0}^{2 \pi} \int_{-\pi / 2}^{\pi / 2} \mathrm{~L}_{\lambda}(\mathrm{SZA}, \Phi) \sin (\mathrm{SZA}) \mathrm{dSZA} d \Phi
\end{gathered}
$$

where $\mathrm{L}$ is the radiance, and $\Phi$ the solar azimuth angle.

To highlight the difference between irradiance and actinic flux, Figure 1.2 shows a simple figure with the significance of both quantities. Figure 1.2.a shows how irradiance is related to a horizontal detection area, and Figure 1.2.b shows how the actinic flux is detected isotropically. 


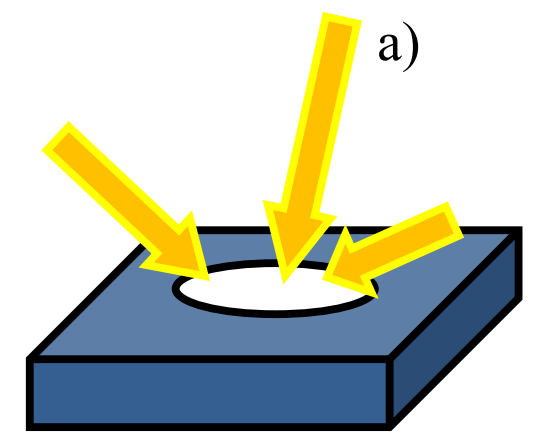

b)

Figure 1.2. Difference between irradiance (a) and actinic flux (b).

\subsubsection{Integrated radiation quantities}

The use of integrated quantities is also common. In this thesis, one integrated quantity of irradiance and another of actinic flux are used.

\section{UV index (UVI)}

As regards irradiance, the UV index (UVI) is formulated using the International Commission on Illumination (CIE) reference action spectrum for UV-induced erythema on human skin, $\mathrm{S}_{\text {er }}$ (ISO 17166:1999/CIES007/E-1998). This spectrum can be used to weight the spectral UV measurements, the result being termed erythemal UV radiation (UVER), Equations (1.3) and (1.4). The form of this spectrum and its application to radiation at the top of the atmosphere is shown in Figure 1.3.

$$
\text { UVER }=\int_{250 \mathrm{~nm}}^{400 \mathrm{~nm}} \mathrm{I}_{\lambda} \mathrm{S}_{\mathrm{er}}(\lambda) \mathrm{d} \lambda
$$

with

$$
\mathrm{S}_{\mathrm{er}}(\lambda)=\left\{\begin{array}{c}
1, \lambda<298 \mathrm{~nm} \\
10^{0.094(298-\lambda), 298 \leq \lambda<328 \mathrm{~nm}} \\
10^{0.015(139-\lambda), 328 \leq \lambda<400 \mathrm{~nm}} \\
0, \lambda \geq 400 \mathrm{~nm}
\end{array}\right.
$$



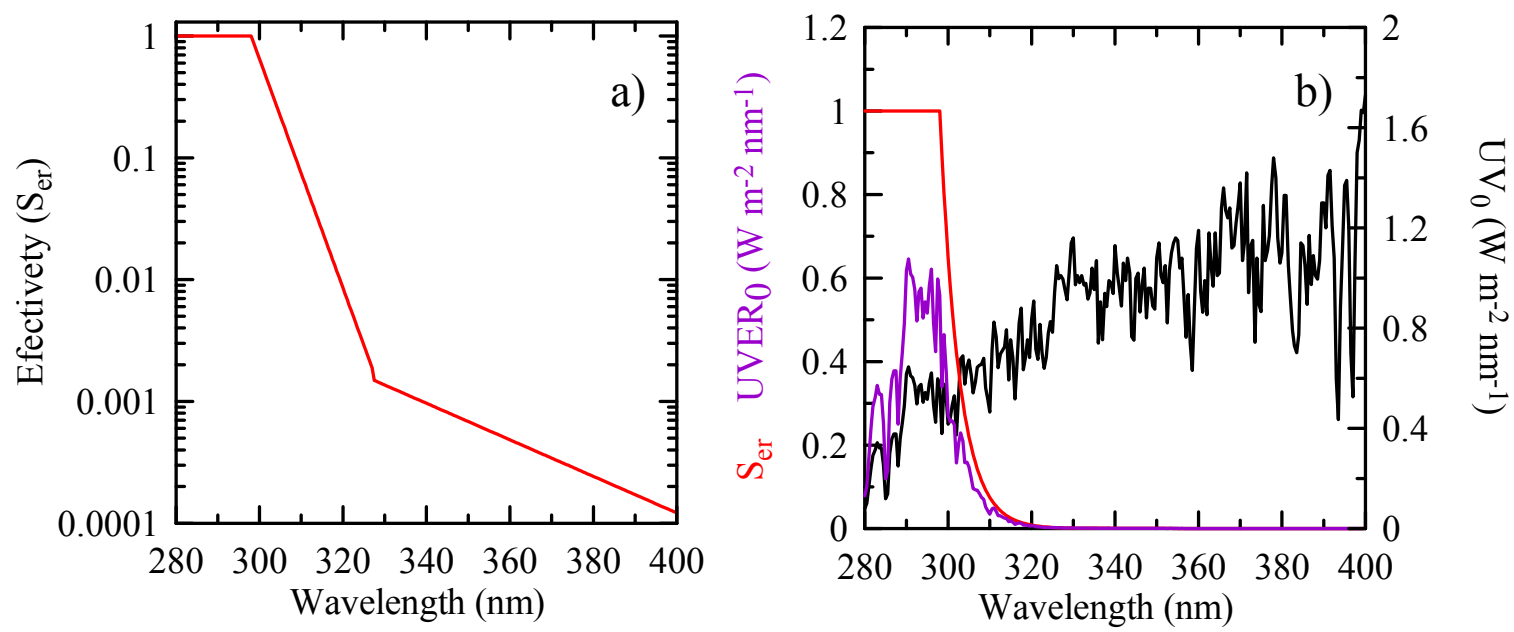

Figure 1.3. a) Erythemal Actium spectrum, $S_{e r}$; b) its application to obtain erythemal UV radiation, UVER, for the solar spectrum at the top of the atmosphere in the $U V, U V_{0}$.

The units for the measured UVER irradiance should be ' $\mathrm{W} \mathrm{m}$-2 effective'; although usual notation is ' $\mathrm{W} \mathrm{m} \mathrm{m}^{-2}$. Therefore, these should not be confused with the purely physical measurement of radiation in $\mathrm{W} \mathrm{m}^{-2}$, unweighted by a biological weighting function (Webb et al., 2006).

The decrease in the total ozone column (WMO, 2007) and the increase in the number of diseases related to UV radiation entailed the need to define an index that can convey information concerning UV radiation. International organisms such as WHO, WMO, and ICNIRP, among others, created the UV index (UVI) as an educational tool to foment the use of adopting the right protective measures for Sun exposure.

The UV Index (UVI) describes the levels of UVER radiation at the Earth's surface. The values of the index range from zero upward. The higher the index value, the greater the potential for damage to human health (WHO, 2002). It is a measure of UV radiation that is relevant to effects on the human skin and defined for a horizontal surface. The UVI is a unitless quantity defined by the following formula:

$$
\mathrm{UVI}=\mathrm{k}_{\mathrm{er}} \mathrm{UVER}=\int_{250 \mathrm{~nm}}^{400 \mathrm{~nm}} \mathrm{I}_{\lambda} \mathrm{S}_{\mathrm{er}}(\lambda) \mathrm{d} \lambda
$$

where $\mathrm{k}_{\mathrm{er}}$ is a constant equal to $40 \mathrm{~m}^{2} \mathrm{~W}^{-1}$. 
It is worth mentioning here that the UVI should be presented as a single integer value. However, the WHO recommends using a range of values when cloud cover is variable (WHO, 2002). As the studies carried out in this thesis are mainly conducted under cloudy conditions, the final decision concerning the representation of UVI is not a range of integer numbers. The real UVI (i.e., not rounded up) value is how this index is used in this thesis. UVI values are grouped into five exposure categories: low (1-2), moderate (3-5), high (6-7), very high (8-10), and extreme ( $\geq 11)$. These UVI values can also be split into three classes depending on the need to protect against outdoor exposure. These are shown in Figure 1.4.

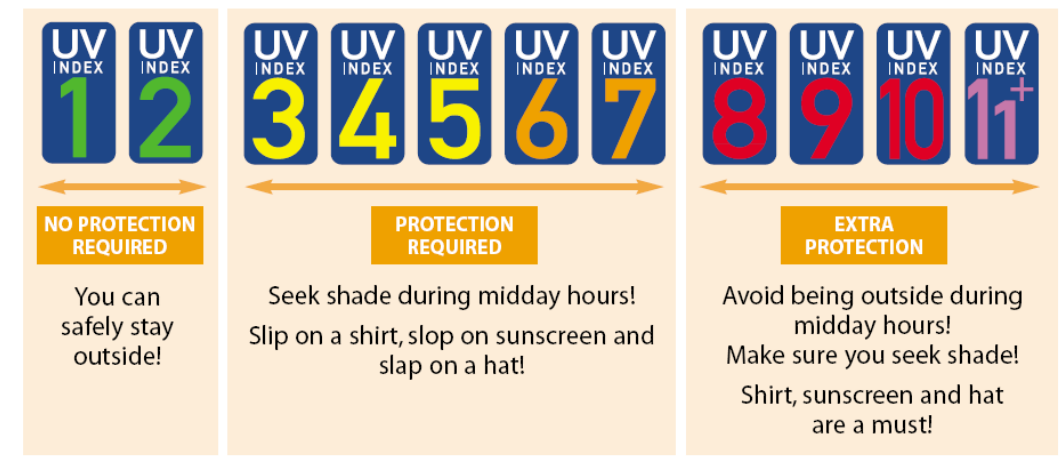

Figure 1.4. Recommended Sun protection scheme, taken from WHO (2002).

Ozone photolysis rate $\left(J\left(O^{l} D\right)\right)$

The UV radiative flux drives much of the chemistry in the stratosphere and troposphere dissociating molecules into reactive species. Table 1.1 shows some of the photochemical reactions occurring in the atmosphere at the ultraviolet wavelengths. One of the key reactions in tropospheric chemistry is the photolysis of ozone, $\mathrm{O}_{3}$, to form $\mathrm{O}\left({ }^{1} \mathrm{D}\right)$ and $\mathrm{O}_{2}$. Photochemical ozone production in the troposphere is given by photochemistry, namely (Edwards and Monks, 2003):

Table 1.1. Some photochemical reactions occurring in the atmosphere in the UV range.

\begin{tabular}{cc}
\hline \multicolumn{1}{c}{ Reaction } & Wavelength range (nm) \\
\hline $\mathrm{O}_{3}+\mathrm{hv} \rightarrow \mathrm{O}\left({ }^{1} \mathrm{D}\right)+\mathrm{O}_{2}$ & $\lambda<340 \mathrm{~nm}$ \\
$\mathrm{NO}_{2}+\mathrm{hv} \rightarrow \mathrm{NO}+\mathrm{O}\left({ }^{3} \mathrm{P}\right)$ & $\lambda<420 \mathrm{~nm}$ \\
$\mathrm{HONO}+\mathrm{hv} \rightarrow \mathrm{NO}+\mathrm{OH}$ & $\lambda<400 \mathrm{~nm}$ \\
$\mathrm{H}_{2} \mathrm{O}_{2}+\mathrm{hv} \rightarrow 2 \mathrm{OH}$ & $\lambda<360 \mathrm{~nm}$ \\
$\mathrm{CH}_{2} \mathrm{O}+\mathrm{hv} \rightarrow \mathrm{H}+\mathrm{HCO}$ & $\lambda<340 \mathrm{~nm}$ \\
$\mathrm{ClO}+\mathrm{hv} \rightarrow \mathrm{Cl}+\mathrm{O}\left({ }^{3} \mathrm{P}\right)$ & $\lambda<320 \mathrm{~nm}$ \\
\hline
\end{tabular}




$$
\begin{gathered}
\mathrm{NO}_{2}+\mathrm{h} v(\lambda<420 \mathrm{~nm}) \rightarrow \mathrm{NO}+\mathrm{O}\left({ }^{3} \mathrm{P}\right) \\
\mathrm{O}\left({ }^{3} \mathrm{P}\right)+\mathrm{O}_{2}+\mathrm{M} \rightarrow \mathrm{O}_{3}+\mathrm{M} \\
\mathrm{O}_{3}+\mathrm{h} v(\lambda<340 \mathrm{~nm}) \rightarrow \mathrm{O}\left({ }^{1} \mathrm{D}\right)+\mathrm{O}_{2} \\
\mathrm{O}\left({ }^{1} \mathrm{D}\right)+\mathrm{H}_{2} \mathrm{O} \rightarrow \mathrm{OH}+\mathrm{OH}
\end{gathered}
$$

where $\mathrm{M}$ is a catalyst.

The photolysis of nitrogen dioxide $\left(\mathrm{NO}_{2}\right)$ controls the photochemical production of ozone and the concentrations of the total peroxy radicals (e.g., Nicolet, 1965; Johnston, 1971). Once produced, $\mathrm{O}\left({ }^{1} \mathrm{D}\right)$ can react with $\mathrm{H}_{2} \mathrm{O}$ to form the hydroxyl radical $(\mathrm{OH})$, which is the primary oxidizing species in the low atmosphere (i.e. it determines the oxidizing capacity of the atmosphere and thus the lifetime of many tropospheric gases).

The precise determination of the photolysis frequencies, called $\mathrm{J}$ values, is essential to quantitative understanding of fast photochemistry in the troposphere. The $\mathrm{O}\left({ }^{1} \mathrm{D}\right)$ photolysis frequency of ozone represents the first-order rate constant quantifying the rate of this photolysis process, i.e. it represents the probability of photodissociation per second. The ozone photolysis rate, $\mathrm{J}\left(\mathrm{O}^{1} \mathrm{D}\right)$, is defined as:

$$
J\left(\mathrm{O}^{1} \mathrm{D}\right)=\int_{295 \mathrm{~nm}}^{340 \mathrm{~nm}} \mathrm{~F}_{\lambda} \sigma_{\lambda}(\mathrm{T}) \phi_{\lambda}(\mathrm{T})
$$

where $\sigma_{\lambda}(T)$ is the ozone absorption cross section, and $\phi_{\lambda}(T)$ is the ozone quantum yield, being both wavelength- and temperature- dependent. Details on these two functions will be given in Chapter 2. The units of $\mathrm{J}\left(\mathrm{O}^{1} \mathrm{D}\right)$ are $\mathrm{s}^{-1}$. 


\subsection{Factors controlling the UV radiative flux}

\subsubsection{Reflection, absorption and scattering}

When solar radiation reaches the top of the atmosphere, it is attenuated by atmospheric constituents. Solar radiation reaching the surface from the direction of the Sun is known as direct component. The diffuse component includes the radiation arriving from the other directions. The sum of the direct and the diffuse components gives the global radiation.

\section{Reflection}

When the radiative flux is received by a medium (incident flux, $R F_{i}$ ), part of the radiation is reflected (reflected flux, $\mathrm{RF}_{\mathrm{r}}$ ), in other words it returns into the medium from which it comes. In the case of the Earth's system, solar radiation can reach the Earth's surface. There are many types of reflections at the surface although in this thesis only the Lambertian reflectance, which produces reflected beams following a cosine relationship in their intensity, is considered (Figure 1.5.a). Reflection can also occur after some penetration into the atmosphere by backscattering by its constituents. For instance, Figure 1.5.b shows the diffuse reflection caused by the presence of clouds.

The albedo or reflectance, A, can be defined as the following ratio:

$$
\mathrm{A}=\frac{\mathrm{RF}_{\mathrm{r}}}{\mathrm{RF}_{\mathrm{i}}}
$$

Radiation not reflected by a medium is transmitted and/or absorbed.
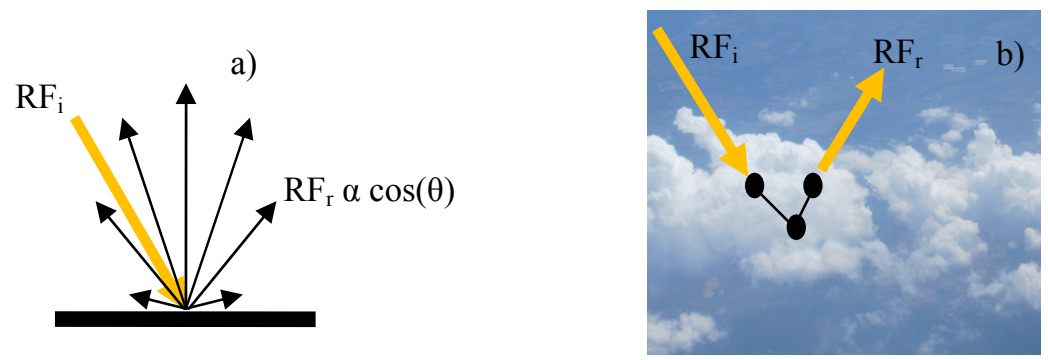

Figure 1.5. a) Lambertian reflectance; b) reflection by clouds 


\section{Absorption}

Solar radiation suffers some losses due to its conversion into other forms of energy (photochemical processes, heating, etc.) inside the atmosphere. With the geometry of Figure 1.6, the change in the radiance can be described as (Lenoble, 1993):

$$
\mathrm{dL}=-\mathrm{k}_{\mathrm{a}} \mathrm{L} \mathrm{dx}
$$

$\mathrm{k}_{\mathrm{a}}$ being the volume absorption coefficient $\left(\right.$ in $\left.^{-1}\right)$.

The integration of Equation (1.12) in a finite path between $\mathrm{x}_{1}$ and $\mathrm{x}_{2}$ produces the Beer-Bouguer-Lambert exponential extinction law which has the following form:

$$
\mathrm{L}\left(\mathrm{x}_{2}\right)=\mathrm{L}\left(\mathrm{x}_{1}\right) \exp \left(-\tau_{\mathrm{a}}\right)
$$

where $\tau_{\mathrm{a}}$ is the absorption optical thickness (in the atmosphere, measured vertically above a given level) between $\mathrm{x}_{1}$ and $\mathrm{x}_{2}$ :

$$
\tau_{\mathrm{a}}=\int_{\mathrm{x}_{1}}^{\mathrm{x}_{2}} \mathrm{k}_{\mathrm{a}}(\mathrm{x}) \mathrm{dx}
$$

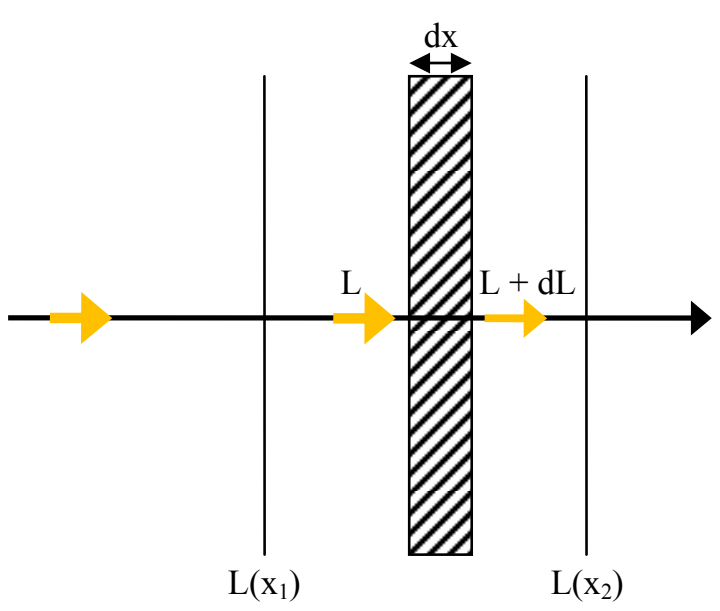

Figure 1.6. Definition of absorption: a radiation beam of radiance L crosses a perpendicular layer of thickness $d x$ (without scattering processes). Adapted from Lenoble (1993). 
Transmittance of the layer between $\mathrm{x}_{1}$ and $\mathrm{x}_{2}$ along the direction of propagation is defined by:

$$
\mathrm{T}_{\mathrm{a}}=\frac{\mathrm{L}\left(\mathrm{x}_{2}\right)}{\mathrm{L}\left(\mathrm{x}_{1}\right)}=\exp \left(-\tau_{\mathrm{a}}\right)
$$

The radiant energy not transmitted is absorbed, and the absorptance of the same $\left(\mathrm{x}_{1}, \mathrm{x}_{2}\right)$ layer is $1-\mathrm{T}_{\mathrm{a}}$.

In the real atmosphere, for instance, absorption in the UV-C range by molecular oxygen represents its main source of energy in the thermosphere. Ultraviolet absorption in the atmosphere is mostly due to the oxygen and ozone molecules, with other minor gases, such as $\mathrm{NO}_{2}$ also playing a role.

\section{Scattering}

When an electromagnetic wave strikes a particle, a part of the incident energy is scattered in all directions, in other words, the particle deviates the beam with regard to the incident direction. With the same geometry as in Figure 1.6 and assuming, in this case, that the layer does not absorb and only scatters radiation, it can be stated that:

$$
\mathrm{dL}=-\mathrm{k}_{\mathrm{s}} \mathrm{L} \mathrm{dx}
$$

where $\mathrm{k}_{\mathrm{s}}$ is the volume scattering coefficient (in $\mathrm{m}^{-1}$ ).

The scattering optical thickness of the layer between $\mathrm{x}_{1}$ and $\mathrm{x}_{2}$ thus takes the form:

$$
\tau_{\mathrm{s}}=\int_{\mathrm{x}_{1}}^{\mathrm{x}_{2}} \mathrm{k}_{\mathrm{s}}(\mathrm{x}) \mathrm{dx}
$$

The transmittance of the layer can be evaluated with Equation (1.15) with $\tau_{\mathrm{s}}$ instead of $\tau_{\mathrm{a}}$. 
If a beam of solar radiation reaches a small scattering volume dV (see Figure 1.7), the function controlling the angular distribution of the scattered photons is known as the scattering function $f(\theta), \theta$ being the angle of scattering. $\theta$ indicates the deviation of the scattered beam with respect to the direction of incidence.

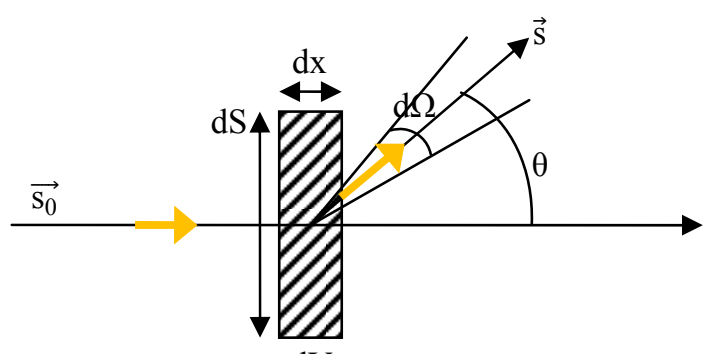

$\mathrm{dV}$

Figure 1.7. Scattering function. Adapted from Lenoble (1993).

The relationship between the scattering function and the scattering coefficient is given by (Lenoble, 1993):

$$
\mathrm{k}_{\mathrm{s}}=\iint_{\text {space }} \mathrm{f}(\theta) \mathrm{d} \Omega
$$

It is advisable to introduce a normalized phase function $p(\theta)$ related to the scattering function by:

$$
p(\theta)=4 \pi \frac{f(\theta)}{k_{s}}
$$

with the following boundary condition:

$$
\iint_{\text {space }} \mathrm{p}(\theta) \mathrm{d} \Omega=4 \pi
$$

In general, the phase function can be expanded as a series in Legendre polynomials of the form: 


$$
p(\theta)=\sum_{i=0}^{\infty} \eta_{i} P_{i}(\cos \theta)
$$

with $\eta_{0}=1$ from normalization. The others take the form

$$
\eta_{i}=\frac{2 i+1}{2} \int_{-1}^{1} p(\cos \theta) P_{i}(\cos \theta) d(\cos \theta)
$$

Among the $\eta_{i}$ coefficients, the first plays a particular role in distributing diffuse light. The asymmetry factor $(\mathrm{g})$ is defined from this first coefficient as follows:

$$
g=\frac{\eta_{1}}{3}
$$

and is usually used to simplify the details of the phase function in the multiple scattering processes. The asymmetry factor is an average cosine of the scattering angle weighted by the phase function:

$$
g=<\cos \theta>=\frac{\int_{-1}^{1} \mu p(\mu) d \mu}{\int_{-1}^{1} p(\mu) d \mu} \text {, with } \mu=\cos \theta
$$

The asymmetry factor takes values from -1 (perfect back-scattering) to +1 (perfect forward-scattering).

The relationship between the size of the atmospheric constituent and the wavelength determines the type of scattering:

- Rayleigh scattering: this scattering occurs when the molecules and particles are much smaller than the radiation wavelength, i.e., the field around the constituent can be assumed to be constant (Lenoble, 1993). The intensity of the scattered radiation varies inversely with the fourth power of the wavelength $\left(\lambda^{-4}\right)$. This type of scattering is produced by air molecules, most of which have a size $\sim 1 \AA$. In this process, scattering is identical and maximum in forward and backward directions. It is minimum at $90^{\circ}$ with regard to the line of incidence. In other words, the asymmetry factor $g$ is 0 because the phase function is symmetric. Since this effect 
is $\lambda^{-4}$-dependent, the radiation of shorter wavelengths is more scattered than at longer ones. In fact, global UV radiation at the surface is obtained from the direct and diffuse components in a proportion that can take values of $50 \%$ in each, although this percentage can increase or decrease depending on atmospheric conditions, wavelength, and solar position (e.g., Parisi et al., 2000; Utrillas et al., 2007).

- Mie Scattering: the Mie theory assumes the spherical shape of the particles with homogeneous composition. Mie scattering has no size limitations and converges to the limits of geometrical optics for large particles, and of Rayleigh scattering for $2 \pi r / \lambda<<1$ ( $r$ being the radius and $\lambda$ the wavelength). This type can be applied to scattering by aerosol and cloud particles. In this case, more energy is scattered in a forward than in a backward direction. Furthermore, if particle size increases, forward scattering increases (Iqbal, 1983).

Figure 1.8 shows the difference between Rayleigh and Mie modes of scattering. There is another type called the Raman scattering. In terms of radiant energy, this type is completely negligible compared with Rayleigh scattering. However, it can be used to identify a component, since it has a line structure characteristic of the molecule (high relevant in remote sensing).

(a)

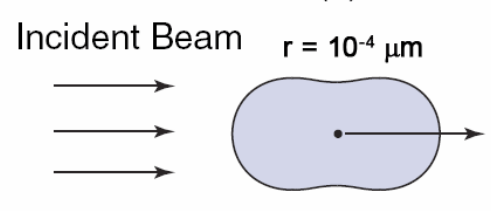

(b)

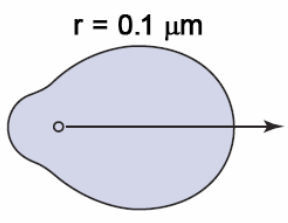

(c)

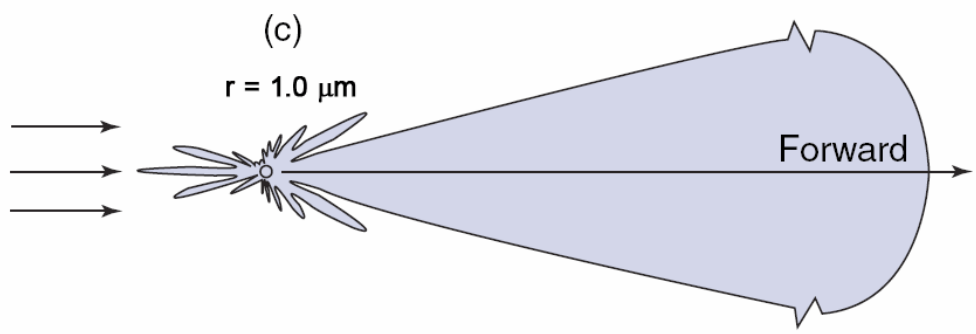

Figure 1.8. Rayleigh scattering (a), Mie scattering (b) and Mie scattering for larger particles (c). 


\section{Absorption and scattering}

In the real atmosphere, both absorption and scattering occur simultaneously. Attenuation of solar radiation is expressed by an extinction coefficient $\mathrm{k}_{\mathrm{e}}$ defined by the sum of the absorption and scattering coefficients:

$$
\mathrm{k}_{\mathrm{e}}=\mathrm{k}_{\mathrm{a}}+\mathrm{k}_{\mathrm{s}}
$$

The relationship between the incident extraterrestrial radiation (at the top of the atmosphere), $\mathrm{I}_{0}$, and the direct component reaching the surface, $\mathrm{I}_{\text {direct }}$, can be expressed by the Beer-Bouguer-Lambert Law, which may be written in simple terms as (Bodhaine et al., 1999):

$$
m \tau=-\ln \frac{I_{0}(\lambda)}{I_{\text {direct }}(\lambda)}
$$

where $\mathrm{m}$ is the relative optical air mass (defined in the following section), and $\tau$ is the total optical thickness also defined by the sum of the absorption and scattering optical thicknesses:

$$
\tau=\tau_{\mathrm{a}}+\tau_{\mathrm{s}}
$$

The relative importance of scattering and absorption is characterized by the single scattering albedo $\left(\omega_{0}\right)$ defined as the ratio:

$$
\omega_{0}=\frac{\mathrm{k}_{\mathrm{s}}}{\mathrm{k}_{\mathrm{e}}}=\frac{\mathrm{k}_{\mathrm{s}}}{\mathrm{k}_{\mathrm{a}}+\mathrm{k}_{\mathrm{s}}}, \text { with } 0 \leq \omega_{0} \leq 1
$$

This variable represents the fraction of radiation lost by scattering, while the coalbedo, defined as $\left(1-\omega_{0}\right)$, expresses the remaining fraction which has been transformed into other forms of energy. In the limiting cases, if $\omega_{0}=1$, there is no loss of radiative energy because the medium only scatters, and if $\omega_{0}=0$, the medium is a pure absorber. 


\subsubsection{Main factors affecting the solar radiative flux in the ultraviolet range}

In this section, the main factors that affect the UV radiative flux are described.

\section{Sun-Earth geometry}

There are two geometric factors affecting radiation levels at the surface: the SunEarth distance, and the solar zenith angle (SZA). The first is due to the non-constant distance between them, which can vary between 0.983 and $1.017 \mathrm{AU}$ ( $1 \mathrm{AU}=$ $149,597,870 \mathrm{~km})$. Although the change in this distance leads to small changes in radiation at the surface, it should be taken into account by means of the following equation (Iqbal, 1983):

$$
\begin{aligned}
\mathrm{E}_{0}= & 1.00011+0.034221 \cos \Gamma+0.001280 \sin \Gamma+ \\
& +0.000719 \cos 2 \Gamma+0.000077 \sin 2 \Gamma
\end{aligned}
$$

In this equation, $\Gamma$ is the day angle and it is evaluated as follows:

$$
\Gamma=2 \pi \frac{\mathrm{d}_{\mathrm{n}}-1}{365}
$$

where $d_{n}$ is the day number of the year, ranging from 1 on 1 January to 365 on 31 December.

The influence of the SZA is, however, much more relevant for three reasons: firstly, the variation of the obliquity of solar radiation over the Earth's surface, that changes according to astronomical motion (Iqbal, 1983); secondly, because of the different path that solar radiation takes for lower and higher SZAs, for instance at higher solar zenith angles (i.e. a longer path within the atmosphere) there is more intense attenuation of solar radiation by absorption and scattering (mainly due to gases and aerosol particles); and finally, solar radiation splitting into direct and diffuse is also notably affected by changes in solar elevation (Antón et al., 2009). Figure 1.9 shows the definition of this angle. Mathematically, this angle can be evaluated by: 


$$
\mathrm{SZA}=\arccos [\sin \delta \sin \Lambda+\cos \delta \cos \Lambda \cos \varpi]
$$

where $\Lambda$ is the geographic latitude, $\varpi$ is the hour angle (being 0 at noon, changing $15^{\circ}$ per hour and being positive in the morning), and $\delta$ indicates the declination angle which can be evaluated by (Iqbal, 1983):

$$
\begin{gathered}
\delta=0.006918-0.399912 \cos \Gamma+0.070257 \sin \Gamma-0.006758 \cos 2 \Gamma \\
+0.000907 \sin 2 \Gamma-0.002697 \cos 3 \Gamma+0.00148 \sin 3 \Gamma
\end{gathered}
$$

Another variable used to quantify the path followed by the photons through the atmosphere is the relative optical air mass (m) that is defined as the ratio between the optical air mass in a given direction and the optical air mass in the vertical direction. This variable is linked with the SZA and can be approximated by the following formula (Kasten and Young, 1989):

$$
\mathrm{m}=\frac{1}{\cos (\mathrm{SZA})+0.050572(96.07995-\mathrm{SZA})^{-1.6364}}
$$

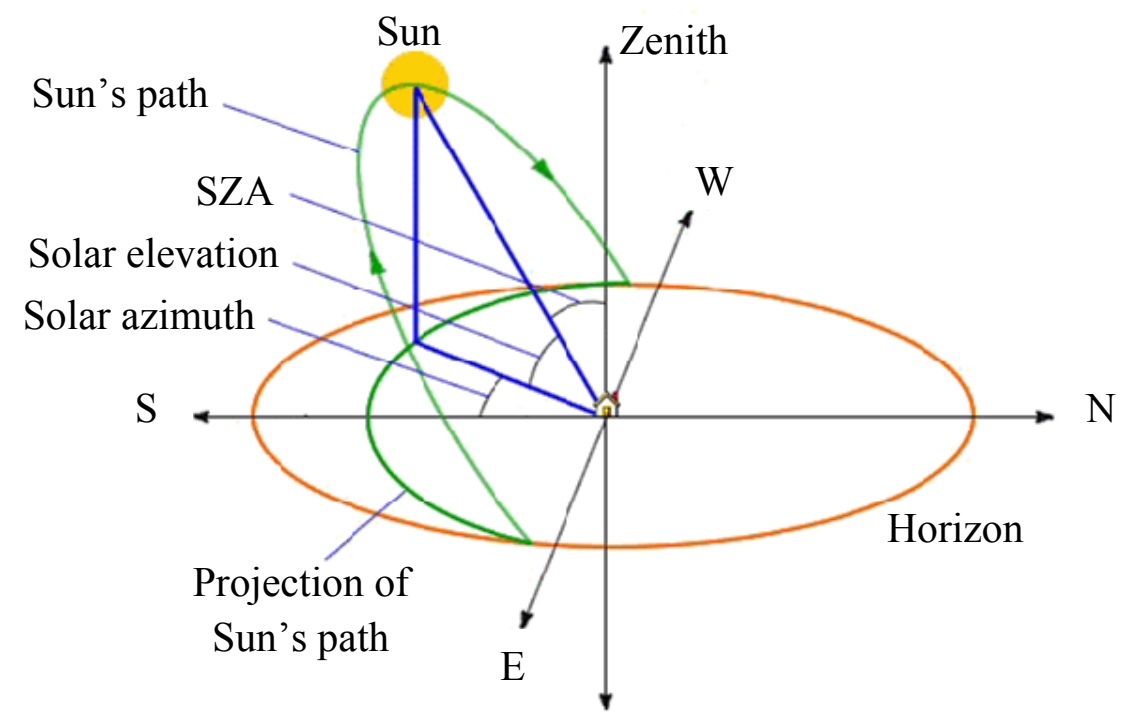

Figure 1.9. Definitions of Solar Zenith Angle (SZA) and other solar parameters. 


\section{Altitude}

Solar UV radiative flux increases with altitude in the atmosphere, due to the smaller optical path followed by the photons and the decreasing amounts of atmospheric constituents (i.e., molecules, ozone, clouds,...) above the relevant surface (Dvorkin and Steinberger, 1999). As a consequence of all these processes, the altitude effect shows both SZA and wavelength dependencies. Theoretically, the altitude effect is $\sim 10 \% \mathrm{~km}^{-1}$ at 300 $\mathrm{nm}$ and $\sim 5 \% \mathrm{~km}^{-1}$ at $330 \mathrm{~nm}$ at $\mathrm{SZA}=50^{\circ}$ (Krotkov et al., 1998). Most field measurements of the altitude effect are higher than these theoretical limits. For instance, simultaneous measurements of UV spectral irradiance showed coefficients of 9 and $24 \%$ $\mathrm{km}^{-1}$ at 370 and $300 \mathrm{~nm}$, respectively (Blumthaler et al., 1994). With regard to the altitude effect on UVI values, the coefficient can reached maxima of $14 \% \mathrm{~km}^{-1}$ at low solar zenith angles $\left(\mathrm{SZA}=16^{\circ}\right)$ depending on aerosol conditions (Sola et al., 2008).

\section{Surface albedo}

Surface albedo has an influence on UV radiative flux because it can produce an extra-upwelling-flux by scattering radiation at the surface that can be backscattered by the atmosphere to the ground. The UV radiation at a certain site is influenced by the surface albedo within $40 \mathrm{~km}$ of the site (Degünther et al., 1998). Since different surfaces present different reflectivity values, the behaviour and the influence of this parameter depend on the surface. For instance, snow can produce an increase in the experimental UV-B irradiance under cloudless conditions of about $30 \%$, with regard to the snow-free case (McKenzie et al., 1998). This percentage was also obtained by a model study comparing situations of albedo 0.0 and 0.8 (Schwander et al., 1999). Another effect linked to surface albedo is the multiple reflections that can occur under cloudy conditions between cloud and surface. Nichol et al. (2003) found that the cloud attenuation of solar radiation decreases from $40 \%$ to $10 \%$ when the surface albedo varies between 0.05 and 0.96 , respectively.

\section{Ozone}

Ozone is a greenhouse gas, with a maximum concentration of $0.0012 \%$ of the total of atmospheric constituents (Iqbal, 1983), although changes in its abundance may contribute to global climate change (WMO, 2007). While an increase in tropospheric ozone leads to warming of the troposphere, a decrease in stratospheric ozone leads to cooling in the stratosphere (Steinbrecht et al., 2003). 
Between the end of the 1970s and the beginning of the 1990s, a significant decreasing trend in ozone concentration values was observed due to the increase in chlorofluorocarbon (CFC) emission by anthropogenic activity. Successful implementations of the Montreal Protocol on substances that deplete the ozone layer have controlled the levels of these particles in the atmosphere, with the corresponding recovery of the ozone layer (Bais et al., 2007).

The highest concentration of ozone in the atmosphere is found in the stratosphere at an altitude of 12-35 km. In this layer, the ozone is both created and destroyed by photochemical reactions. These reactions are known as the Chapman Cycle (e.g., Velazquez, 2001). Figure 1.10 shows the four main steps in the formation and destruction of ozone. In the first step, an $\mathrm{O}_{2}$ molecule is dissociated by the absorption of a UV photon $(\lambda<242 \mathrm{~nm})$. The diatomic oxygen generated in this step interacts with molecular oxygen (usually in the presence of an oxygen or nitrogen molecule). The formation process is $3 \mathrm{O}_{2}$ $\rightarrow 2 \mathrm{O}_{3}$. Ozone destruction basically occurs as a result of two processes: the ozone can react with atomic oxygen to recover the stable configuration and can be photodissociated by UV radiation between 200 and $340 \mathrm{~nm}$ (as explained above for the troposphere).

The most important parameter for the effect of ozone on UV radiation is the total ozone column (TOC) defined as the thickness of the ozone vertical column of unit area if brought to standard temperature and pressure conditions (i.e. $0^{\circ} \mathrm{C}$ and $1 \mathrm{~atm}$ ). The natural units of TOC are atm-cm, although it is usually expressed in Dobson Units (DU), such as $1 \mathrm{~atm}-\mathrm{cm}=1000$ DU. 1 DU of ozone corresponds to $2.6910^{20}$ molecules per $\mathrm{m}^{2}$ in an ozone column.

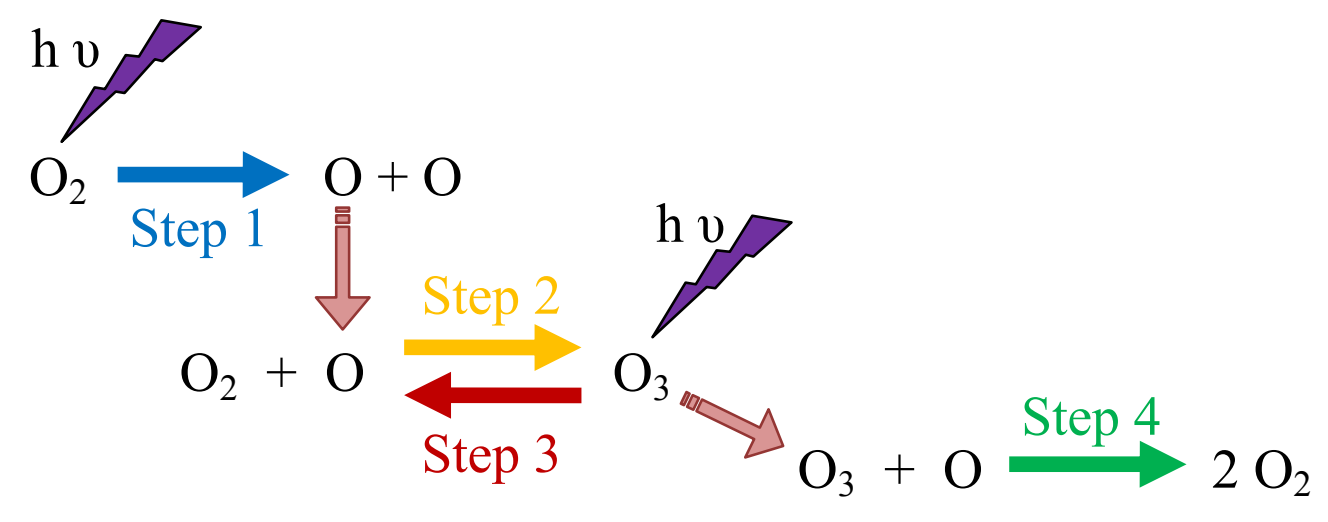

Figure 1.10. Ozone in the Chapman cycle. 
Since ozone absorption is wavelength-dependent, the effect of this gas on the UV range presents a clear dependence on this variable. For instance, at low SZA ( $\mathrm{SZA}=20^{\circ}$ ), di Sarra et al. (2002) observed that a $1 \%$ change in TOC value leads to changes of $\sim 3 \%$, $\sim 1.2 \%$, and $\sim 0.4 \%$ in radiation at 300,305 and $310 \mathrm{~nm}$, respectively. They also showed that the presence of tropospheric aerosols affects UV irradiance-ozone dependence. For the UVI case, a 10\% reduction in TOC causes an expected increase of between 11 and $13 \%$ (Vanicek et al., 2000). These percentages are in agreement with those obtained at the SRSUVA station in Valladolid (de Miguel et al., 2011a).

As regards the influence of ozone vertical distribution, a maximum $\sim 8 \%$ change in UVI simulated values is observed when a midlatitude ozone profile is replaced by a tropical one (Badosa, 2006).

\section{Aerosol}

Aerosol can be defined as a gaseous suspension of fine solid or liquid particles. These particles are able to absorb and scatter part of the solar radiation in the atmosphere. In fact, they are among the key parameters in the climate system since they influence the Earth's energy budget and act as cloud condensation nuclei modifying the structure and the properties of clouds (e.g., Forster et al., 2007). Aerosol can either be produced by ejection into the atmosphere, or by physical and chemical processes within the atmosphere. Aerosol particles affect the radiative field by attenuating the direct component and by enhancing (or reducing under a highly absorbent aerosol) the diffuse one. They also produce indirect effects, since aerosol particles perturb the Earthatmosphere radiation balance by modulating cloud albedo and cloud amount. It can be viewed as a series of processes linking various intermediate variables such as aerosol mass, cloud condensation nuclei concentration, ice nuclei concentration, water phase partitioning, cloud optical properties, etc. (Penner et al., 2001).

Aerosol optical thickness (AOT) is the main parameter to study the influence of aerosol on the radiative field. The AOT is a unitless quantity that accounts for both absorption and scattering at a certain wavelength. This variable in general depends on wavelength, and can be expressed by means of the Ångström formula (Ångström, 1964):

$$
\operatorname{AOT}_{\lambda}=\beta \lambda^{-\alpha}
$$

where $\alpha$ and $\beta$ are the Ångström coefficients and $\lambda$ the wavelength in $\mu \mathrm{m}$. $\alpha$ is mainly related to the size of the aerosol particles and is always in the range $(0,4)$. The larger the particles, the smaller the $\alpha$ value (i.e. the spectral dependence of extinction). $\beta$ 
is a constant that coincides with the aerosol optical thickness at the wavelength of $1 \mu \mathrm{m}$. Figure 1.11 shows the spectral dependence of the AOT for different combinations of values of the two Ångström coefficients.

Another key parameter in describing aerosol optical properties is the aerosol single scattering albedo. Knowledge of the aerosol $\omega_{0}$ is essential to estimate aerosol radiative effects and the impact on climate (e.g., Meloni et al., 2006). Typical values of this variable at $550 \mathrm{~nm}$ are $0.817,0.888$ and 0.997 for urban, desert, and maritime clean types of aerosol, respectively (Hess et al., 1998).

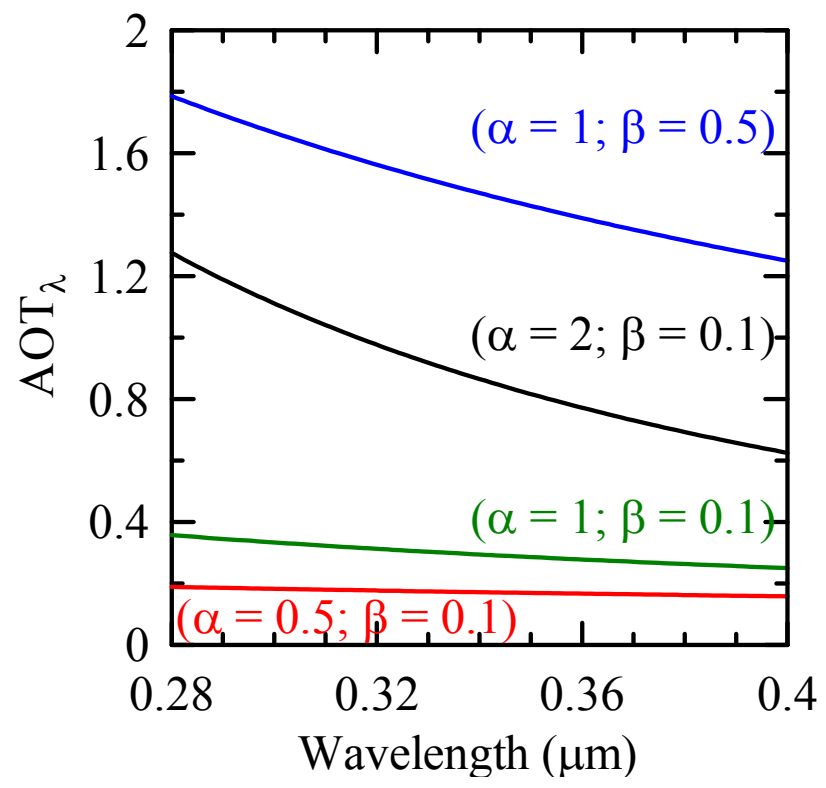

Figure 1.11. Spectral AOT dependence for different values of $\alpha$ and $\beta$ coefficients.

The aerosol asymmetry factor is also used to describe aerosol radiative properties and it depends on the aerosol type: for urban, desert, and maritime clean types, $g$ takes the following values at $550 \mathrm{~nm}$ : 0.689, 0.729 and 0.772, respectively (Hess et al., 1998).

The effects of aerosol on radiative levels at the surface have been reported by several authors. For instance, events of biomass burning can produce reductions of up to $35 \%$ compared to typical aerosol conditions at $340 \mathrm{~nm}$ (Arola et al., 2007); an urban aerosol event caused a maximum decrease of $37 \%$ at SZA $=60^{\circ}$ (Lorente et al., 1994); a strong desert dust event led to falls of around $40-50 \%$ in the global irradiance in the UV range (Antón et al., 2012). Using the AOT at $\lambda=440 \mathrm{~nm}$, Román et al. (2012) found a decrease of $28.4 \%$ for $\mathrm{AOT}_{440 \mathrm{~nm}}$ unity for the UVER radiation levels at the SRSUVA station in Valladolid. The impact of aerosol load is greater in the UV than for longer wavelengths (e.g., de Miguel et al., 2011b) 


\section{Clouds}

Clouds have a major impact on the radiative energy balance, and thereby on climate. Cloud microphysical properties and morphology are expected to change with the climate. In fact, the relationship between cloud microphysical processes and cloud radiative properties is the main tool used to assess the cloud-radiation-climate interaction. However, cloud effect on solar UV radiative flux has only been partially explored due to the lack of measurements of cloud properties, which show major temporal and spatial variability. In fact, only in recent years have new instrumentation and theoretical methods been applied to study this topic. Hence, simultaneous measurements of radiative flux and cloud properties are rarely found in the bibliography. Generally speaking, clouds can attenuate and enhance solar UV radiation on the surface depending on their amount, their optical depth, and their position in relation to the Sun (Pfeifer et al., 2006).

Cloud optical thickness (COT) is the most important parameter required to describe cloud radiative properties. COT can take values from just a few units up to several hundred. In a basic interpretation, Twomey (1976) noted that if the Sun's disc is not visible through the cloud, the COT should be about 10 or greater.

With the Mie theory, the scattering coefficient by particles can be expressed as

$$
\mathrm{k}_{\mathrm{e}}^{\mathrm{part}}=\pi \mathrm{r}^{2} \mathrm{Q}_{\mathrm{e}}
$$

The COT can be established as follows:

$$
\operatorname{COT}_{\lambda}=\int_{0}^{\Delta z} \int_{0}^{\infty} \mathrm{n}(\mathrm{r}) \mathrm{Q}_{\mathrm{e}}(\mathrm{x}) \pi \mathrm{r}^{2} \mathrm{dr} \mathrm{dz}
$$

where $\mathrm{x}=2 \pi \mathrm{r} / \lambda, \mathrm{n}(\mathrm{r})$ is the cloud droplet size distribution, $\mathrm{Q}_{\mathrm{e}}$ is the Mie scattering efficiency factor, and $\Delta \mathrm{z}$ is the geometric thickness of the cloud.

The variation of $\mathrm{Q}_{\mathrm{e}}$ with the size parameter $\mathrm{x}$ is small, particularly for large $\mathrm{x}$, and tends to a value of 2 (e.g., Stephens, 1978; Lenoble, 1993). Hence, the Equation (1.36) can be transformed for short wavelengths to: 


$$
\operatorname{COT} \approx \int_{0}^{\Delta z} 2 \pi\left[\int_{0}^{\infty} n(r) r^{2} d r\right] d z
$$

Given the droplet size distribution $\mathrm{n}(\mathrm{r})$, the effective radius is defined as the ratio of the third to the second moment of the size distribution, which for a spatially homogeneous cloud can take the form (Hansen and Travis, 1974):

$$
r_{\text {eff }}=\frac{\int_{0}^{\infty} n(r) r^{3} d r}{\int_{0}^{\infty} n(r) r^{2} d r}
$$

With this definition, and considering water density equal to 1 , the COT can be expressed by the simple relationship (Stephens, 1978):

$$
\mathrm{COT}=\frac{3 \mathrm{LWP}}{2 \rho_{\mathrm{w}} \mathrm{r}_{\mathrm{eff}}}
$$

where $\rho_{\mathrm{w}}$ is the water density in $\mathrm{g} \mathrm{m}^{-3}, \mathrm{r}_{\text {eff }}$ is in $\mu \mathrm{m}$ and LWP is the liquid water path in units of $\mathrm{g} \mathrm{m}^{-2}$. LWP is formally defined, assuming that the cloud is vertically uniform with regard to drop-size distribution, as (Stephens, 1978):

$$
\mathrm{LWP}=\int_{0}^{\Delta \mathrm{z}} \mathrm{LWC} \mathrm{dz} \rightarrow \mathrm{LWP}=\mathrm{LWC} \Delta \mathrm{z}
$$

where LWC is the liquid water content expressed in $\mathrm{g} \mathrm{m}^{-3}$.

Other cloud optical properties, such as the cloud single scattering albedo and the cloud asymmetry factor are used to describe the cloud radiative properties. The cloud $\omega_{0}$ is usually taken equal to 1 for water and ice clouds (Hess et al., 1998). The cloud g can vary between 0.757 and 0.868 for cirrus (ice clouds) and cumulus (water clouds) types at $550 \mathrm{~nm}$ (Hess et al., 1998).

The results obtained by authors studying the cloud-UV radiation interaction are presented in detail in the following section. 


\subsection{What is the effect of clouds on the UV radiative flux?}

This section describes current knowledge of cloud effects on the UV radiative flux.

In order to analyze the interaction between clouds and solar radiation, several authors have studied the relationships between UV and SW radiation. The works of FoyoMoreno et al. (2003), Martínez-Lozano et al. (1999), Jacovides et al. (2009), and Bilbao et al. (2011a) show that cloudy skies lead to higher values of the ratio between UV total (290-400 nm) and total shortwave radiation. Antón et al. (2008) found that the seasonal variability of the UVER/SW ratio is due to the variation of the slant ozone column and that cloudiness and aerosol cause notable day-to-day fluctuations. Using measured and modelled values of the UVER/SW ratio, de Miguel et al. (2011b) found different cloud cover dependences as a function of the SZA, as well as a determinant role of molecular and particulate absorbers (tropospheric ozone and aerosol particles) in the cloudy scenario.

Another variable used to investigate cloud effects is the clearness index or global hemispherical transmittance $\left(\mathrm{k}_{\mathrm{t}}\right)$, which is defined as the ratio between the radiation measured at the surface and the extraterrestrial radiation both on a horizontal surface and for the same time interval (e.g., Iqbal, 1983). This index can be evaluated for the SW and the UV ranges and their relationship has been studied by several authors. The UV total hemispherical transmittance is in the range of 50-70\% of hemispherical transmittance for the whole spectrum following the results obtained by authors such as Martínez-Lozano et al. (1999), Cañada et al. (2003), Ogunjobi and Kim (2004), and Bilbao et al. (2011a). The relationship between the clearness index in the UV and in the SW ranges can be used to obtain empirical models of UV radiation for predicting and estimating past missing data in databases (e.g. Foyo-Moreno et al., 1999; Mateos et al., 2010a).

In this thesis, the variable used to describe cloud effects is the so-called cloud transmittance or cloud modification factor (CMF). CMF is defined as the following ratio:

$$
\mathrm{CMF}=\frac{\mathrm{UV}_{\text {cloudy }}}{\mathrm{UV}_{\text {cloud-free }}}
$$

where $\mathrm{UV}_{\text {cloudy }}$ is the UV radiative flux (both irradiance and actinic flux) measured under a cloudy sky, and $\mathrm{UV}_{\text {cloud-free }}$ is the $\mathrm{UV}$ radiative flux simulated or estimated for the same atmospheric conditions, i.e. solar zenith angle, ozone column, aerosol, and atmospheric pressure and temperature, under a cloudless sky. CMF can be defined for both spectral and integrated radiative fluxes (Calbó et al., 2005). This factor provides an 
initial distinction of cloud radiative effects using the available database and has been introduced to reduce the effect of the most influential parameters on UV radiation (FoyoMoreno et al., 2001).

CMF values for integrated radiative fluxes have been studied by several authors. In a high mountain station, Blumthaler et al. (1994) found that the impact on radiation is negligible when the Sun is not covered by clouds. However, the UV-A and UV-B ranges are less attenuated than the total shortwave radiation when the Sun is totally covered. This suggests that attenuation is influenced more by scattering than by ozone. The dependence of CMF for the UV total and UVER ranges on cloud cover has been analyzed by such authors as Kasten and Czeplak (1980), Landelius and Josefsson (2000), Alados-Arboledas et al. (2003), Mateos et al. (2010a), Mateos et al. (2010b), and Esteve et al. (2010). These articles have in common the use of a potential fit between CMF and cloud cover (cc) as $\mathrm{CMF}_{\mathrm{UVER}}=1-\mathrm{A}(\mathrm{cc} / 8)^{\mathrm{B}}$. The obtained coefficients, A and B, do not significantly differ from station to station. The CMF evaluated for the eye cataract action spectrum shows a similar behaviour to the $\mathrm{CMF}_{\mathrm{UVER}}$ with values at eight octas around 0.4 (Parisi et al., 2007). A decrease of $7.7 \%$ in cloud transmission was observed when cloud cover increased by one octa in a campaign in the eastern Atlantic sector of the Southern Ocean (Chen et al., 2004). The role of cloud type in CMF values for the UV range was studied by Foyo-Moreno et al. (2001). Using non-linear fits between CMF and cloud cover, they found that low and mid-level clouds affect the UV-B more markedly than high-level clouds. Similar results were obtained by Adam and El Shazly (2007) in Egypt studying the three types of clouds, by Mateos et al. (2010b) comparing the dependence of CMF on total and low cloud covers and by Mateos et al. (2012b) with CMF calculations for mid and high-level clouds. One of the main applications of the CMF is the use of this factor to model UV radiation (e.g. Grant and Heisler, 2000; Krzýscin et al., 2003; Lindfors et al., 2007; Staiger et al., 2008; den Outer et al., 2010; Bilbao et al., 2011b).

Early modelling studies (e.g. Spinhirne and Green, 1978) revealed the existence of a wavelength dependence in the CMF, which was experimentally shown by, for example, Webb (1991), Seckmeyer et al. (1996), Mayer et al. (1998), Schwander et al. (2002), Crawford et al. (2003), Grant and Gao (2003), Bernhard et al. (2004), Winiecki and Frederick (2005), and López et al. (2009). In some cases, the CMF was found to monotonically decrease for increasing wavelengths (e.g., Seckmeyer et al. 1996; López et al., 2009), while it displayed a maximum of around 315-320 nm and decreased for longer wavelengths (Schwander et al., 2002; Bernhard et al., 2004). As suggested by López et al. (2009), different cloud types seem to produce different spectral effects. Several modelling analyses have shown that CMF wavelength dependence is due to superimposing of different mechanisms. For example, Kylling et al. (1997) showed that the wavelength dependence of the cloud transmissivity is caused by photons reflected upward by the 
cloud itself, and then scattered downward again by the atmosphere above the cloud. Molecular scattering strongly increases as the wavelength decreases $\left(\sim \lambda^{-4}\right)$, while the transmittance of the cloud alone has a very small wavelength dependence (see Figure 1.12). Hence, the cloud modification factor behaviour is determined by the combination of these two effects.

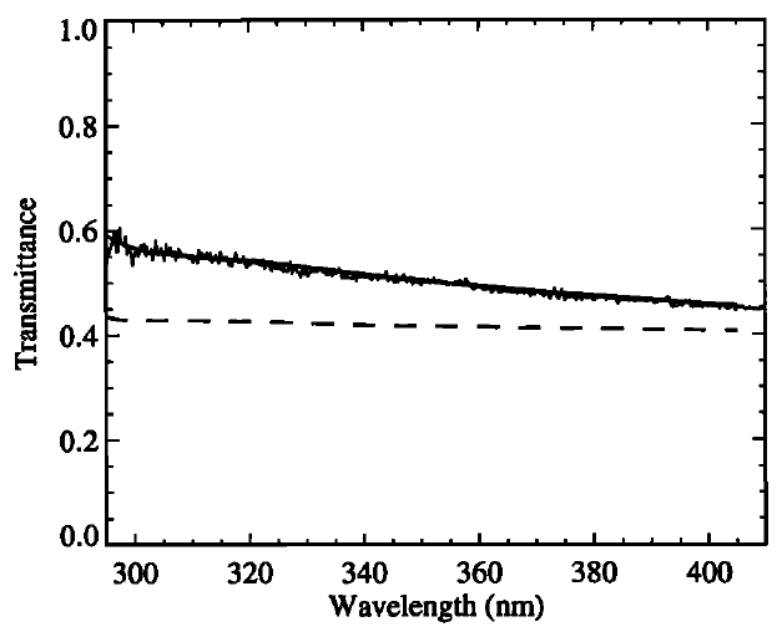

Figure 1.12. Transmittance of a homogeneous cloud layer at Garmisch-Partenkirchen on 22 October, 1995 as a function of wavelength (Seckmeyer et al.,1996; Kylling et al.,1997).

Bernhard et al. (2004) found a different behaviour in Antarctica for low Sun and high surface albedo. Under such conditions, clouds do not determine an additional component of the already large upward flux due to the high surface albedo. In this case, wavelength dependence is due to the radiance distribution on the cloud top and the dependence of cloud transmittance on the angle of incidence. Several studies suggest that reduced $\mathrm{CMF}$ at short wavelengths is caused by enhanced absorption by interstitial ozone molecules within the cloud layer along the extended photon path lengths in cloudy conditions (e.g. Mayer et al., 1998; Schwander et al., 2002; Kerr et al., 2005, Winiecki and Frederick, 2005). Lindfors and Arola (2008) carried out a model study to highlight the different behaviour of cloud attenuation at 320 and $400 \mathrm{~nm}$. They found that shorter wavelengths are, in general, less attenuated than longer ones with a strong dependence on solar zenith angle. In addition, they showed that both effects suggested by Kylling et al. (1997) and Bernhard et al. (2004) play an important role.

Focusing on actinic flux studies, Crawford et al. (2003) found for the spectral actinic flux at the surface that there is wavelength dependence which is stronger at high SZA $\left(\mathrm{SZA}>60^{\circ}\right)$. For these low Sun conditions, there are more substantial losses of the direct component that causes a decreasing trend in CMF values from 320 to $400 \mathrm{~nm}$. 
Figure 1.13 shows their results obtained with a radiative transfer model at COT $=15$ and several SZAs. Using spectral actinic flux, spectral irradiance, as well as aerosol and cloud property data, Kylling et al. (2005) found, for overcast situations, that 1D radiative transfer simulations reproduced the overall behaviour of the actinic flux measured by an aircraft. In this vertical distribution, they found that both the above-cloud enhancement ( $\sim 60-100 \%$ with regard to cloudless sky) and the below-cloud reduction $(\sim-55-65 \%$ compared with cloudless conditions) increased with COT. Palancar et al. (2011) studied the vertical profile of both down-welling and up-welling actinic fluxes with airborne measurements for different cloudy situations, and reported that the perturbations caused by clouds in these two components are not entirely independent.

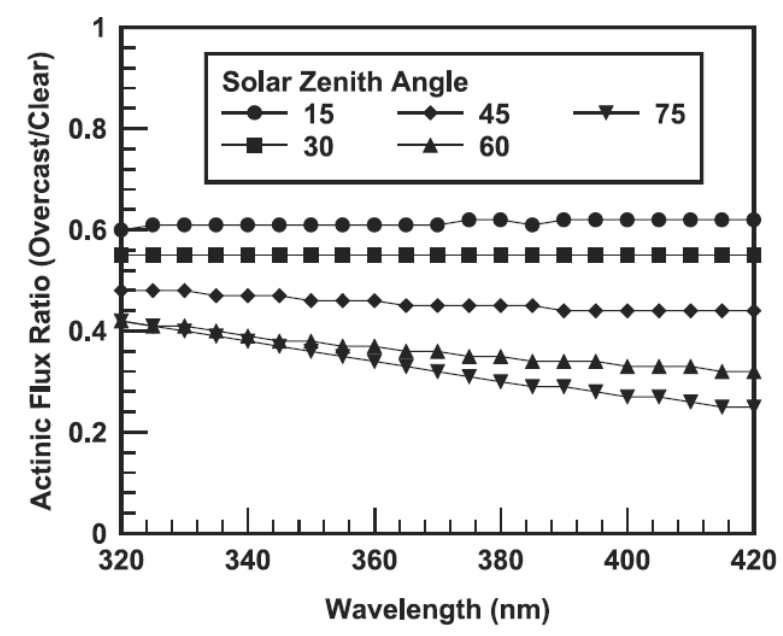

Figure 1.13. CMF for the actinic flux versus wavelength at several solar zenith angles obtained by Crawford et al. (2003) by a model study with COT $=15$

\subsection{Summary}

\subsubsection{English version}

Solar ultraviolet (UV) radiation is defined as the portion of the electromagnetic spectrum between 100 and $400 \mathrm{~nm}$. This radiation is about $8 \%$ of the energy that reaches the top of the atmosphere (39\% in the visible range and 53\% into the infrared region). UV radiation is divided into three ranges in relation to its biological effects: UV-C (100-280 $\mathrm{nm}$ ), UV-B (280-315 nm), and UV-A (315-400 nm). UV radiation is the most energetic radiation in the lower atmosphere, and is able to break up the chemical bonds of various molecules. UV radiation therefore exerts a significant influence on atmospheric chemistry and on living organisms. Spectral irradiance (radiation that crosses a horizontal surface, i.e. weighted with the cosine of the solar zenith angle) and the spectral actinic flux (the 
spherical flux density incident over all angles that is capable of producing photodissociation in photo-actively labile molecules, i.e. equally weighted from all solid angles) are measured at the surface, particularly, in the UV range. To quantify their values, it is common to work with integrated quantities such as UV index, UVI, and ozone photolysis rates, $\mathrm{J}\left(\mathrm{O}^{1} \mathrm{D}\right)$. The first describes $\mathrm{UV}$ radiation levels at the surface that are relevant to effects on the human skin, while the latter represents the probability of the ozone photodissociation per second, one of the key reactions in the chemistry of the troposphere. The main factors involved in the attenuation of UV radiation on the Earth's surface are: solar elevation, cloudiness, ozone, aerosol, surface albedo and altitude. One of the major uncertainties in the climate system is the role played by clouds, since they change radiative properties such as shortwave albedo, and infrared emission and absorption. The cloud effect on the solar UV radiative flux has only been partially explored due to the lack of cloud property measurements, which show major temporal and spatial variability and determine final radiation levels at the surface. Many studies have addressed the cloud-radiation interaction by using the ratio between ultraviolet and shortwave radiation, the clearness index (ratio between the value measured at the surface and the corresponding one at the top of the atmosphere), and the cloud modification factor (ratio between the value measured at surface and the simulated or calculated value under cloudless conditions). So far, it is known that UV radiation is less attenuated than shortwave radiation. Spectral dependence on cloud transmittance is found to increase at shorter wavelengths (280-315 nm), due to enhanced ozone absorption under cloudy conditions, and to decrease with wavelengths beyond $315 \mathrm{~nm}$, which is explained by the multiple reflections between cloud and the above atmosphere, and the wavelengthdependent directional distribution of the radiance (including the direct beam) at the cloud top.

\subsubsection{Spanish version}

La radiación solar ultravioleta (UV) está definida como la parte del espectro electromagnético entre 100 y $400 \mathrm{~nm}$. Representa cerca del 8\% de la energía que alcanza la cima de la atmósfera (un 39\% cae en el intervalo visible y un 53\% en el infrarrojo). La radiación UV se clasifica en tres intervalos, dependiendo de sus efectos biológicos: UV-C (100-280 nm), UV-B (280-315 nm), and UV-A (315-400 nm). Esta radiación, que es la más energética de la baja atmósfera, es capaz de romper los enlaces de varias moléculas $\mathrm{y}$, por lo tanto, ejercer una fuerte influencia en la química de la atmósfera y sobre los seres vivos. A causa de estos efectos, se han registrado medidas en superficie de la irradiancia y el flujo actínico, que difieren en la consideración o no del ángulo de incidencia. Para cuantificar estos efectos se pueden evaluar el índice UV y el índice de 
fotodisociación del ozono. El primero da cuenta de los niveles en superficie de radiación UV que afectan a la piel humana, y el segundo representa la probabilidad de fotodisociación del ozono por segundo, una de las reacciones fundamentales de la química de la troposfera. Los principales factores moduladores de la radiación UV en la superficie terrestre son la posición solar, la nubosidad, el ozono, la carga de aerosol, el albedo superficial y la altitud. Las nubes representan una de las mayores incertidumbres del sistema climático puesto que cambian propiedades radiativas como el albedo planetario, o la emisión y la absorción en el infrarrojo. El principal problema al estudiar el efecto de las nubes sobre la radiación solar es la falta de medidas de propiedades de las nubes, las cuales muestran una gran variabilidad tanto temporal como espacial y que van a determinar los valores finales de radiación en superficie. Algunos estudios han analizado la interacción de las nubes con la radiación por medio de tres variables, el cociente entre la radiación UV y la de onda corta, el índice de claridad (cociente entre el valor medido en superficie y el correspondiente en la cima de la atmósfera), y el factor de modificación de nubes (cociente entre el valor medido en superficie y el que llegaría a la superficie para las mismas condiciones atmosféricas pero considerando cielos despejados). En general, la radiación UV es menos atenuada por las nubes que la radiación de onda corta. La dependencia espectral encontrada para la transmitancia de las nubes en el intervalo del UV crece para longitudes de onda más cortas (intervalo 280-315 $\mathrm{nm}$ ) y decrece desde $315 \mathrm{~nm}$. Estas tendencias se han explicado debido a un realce en el efecto de absorción por parte del ozono en condiciones de cielos nublados, a las reflexiones múltiples que ocurren entre la nube y la atmósfera sobre ella, y a la distribución de la radiancia espectral (incluida la componente directa) en la cima de la nube. 



\section{Chapter 2}

\section{Instrumentation and Methodology}


In this chapter, all the instruments used in this thesis and the three measurement stations are described. The algorithms implemented to obtain parameters such as cloud optical thickness and cloud cover are explained, and the set-up used in the libRadtran radiative transfer model and each input are detailed.

\subsection{Instruments}

\subsubsection{Broadband UVI measurements: UVB-1}

Broadband UVER radiation is recorded by the Yankee Environmental Systems, Inc. (YES) UVB-1 pyranometer. This instrument, shown in Figure 2.1, is a precision meteorological instrument, whose spectral range covers UV-B and UV-A (280-400 nm) and which has a spectral response very close to the erythemal action spectrum. Both are shown in Figure 2.2.

The operating principle of the UVB-1 pyranometer is summarized in Figure 2.3. Solar radiation strikes the top of the dome where only ultraviolet radiation and a small amount of red light are transmitted by a UG-11 Schott filter (Lantz et al., 1999), i.e. all the visible wavelengths are blocked. After that, the radiation strikes an $\mathrm{MgWO}_{4}$ phosphor, UV-sensitive fluorescent, which scatters the red light and absorbs the UV-B light, reemiting it as visible light, predominantly in the green wavelengths. A green glass postfilter passes the fluorescent light from the phosphor while blocking the red line transmitted by the black glass.

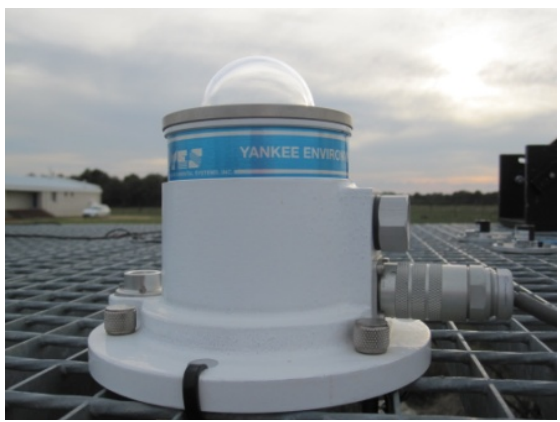

Figure 2.1. UVB-1 YES pyranometer. 


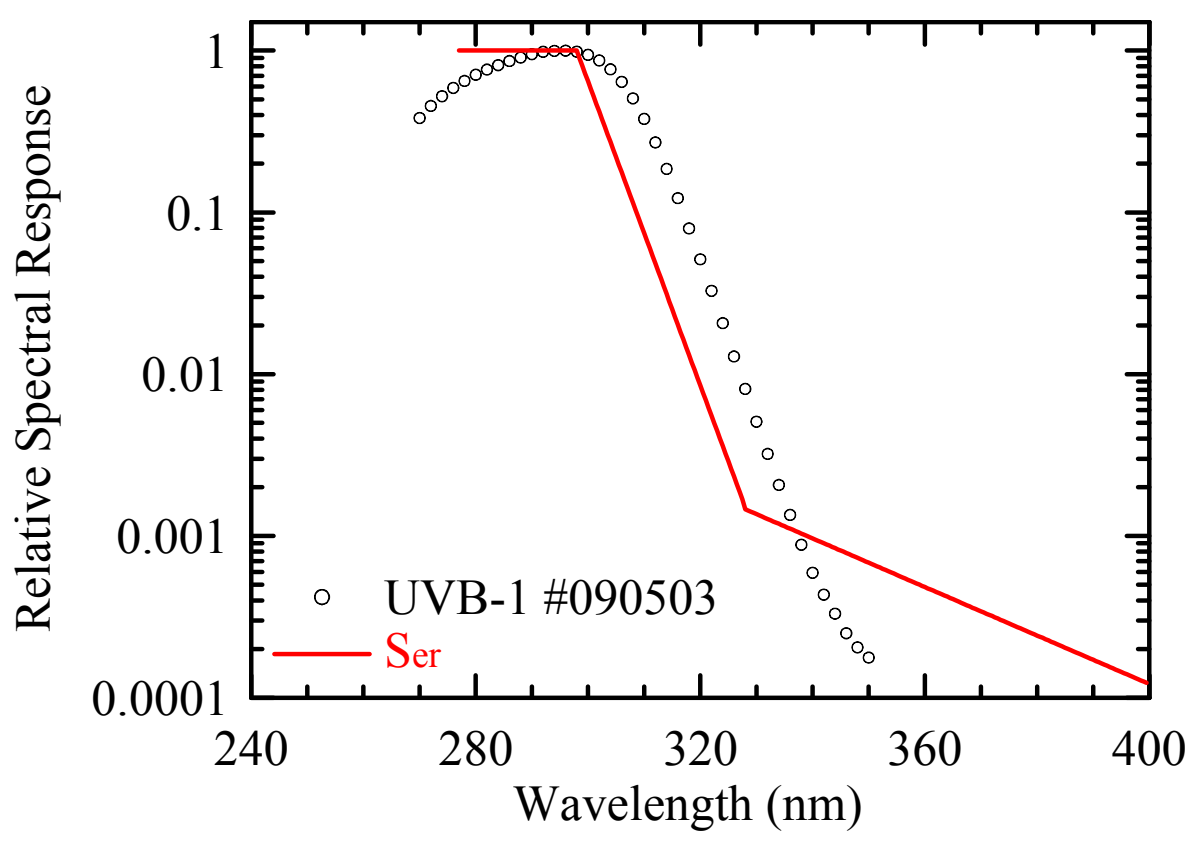

Figure 2.2. UVB-1 pyranometer (SN 090503) spectral response measured in one calibration on 1 October 2009 (black circles) and the erythemal actium spectrum $\left(S_{e r}\right.$, red line).

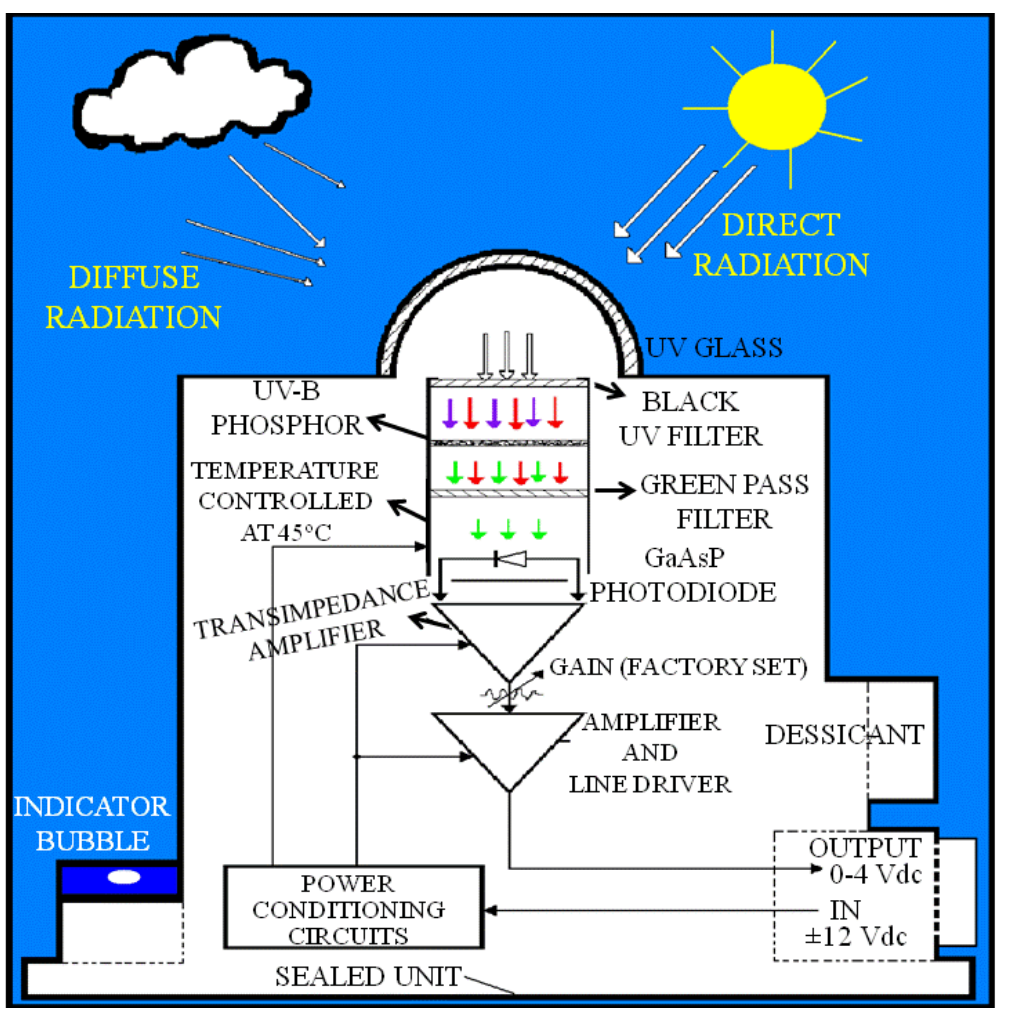

Figure 2.3. Schematic block diagram of the UVB-1 pyranometer. 
The intensity of the fluorescent light is measured by a solid state (GaAsP) photodiode whose peak spectral response is in the green light region, and which drops off rapidly at longer wavelengths (i.e. it is insensitive to red light).

The photodiode output current is converted into a voltage by a thermally stabilized transimpedance amplifier. The output signal is low impedance, 0 to $+4 \mathrm{Vdc}$. The glass filter, phosphor and photodiode are held at constant temperature $\left(45^{\circ} \mathrm{C}\right)$ inside the detector housing in order to ensure that the output signal is not sensitive to changes in ambient temperature.

Two other specifications of the UVB-1 pyranometer are its cosine response, which is better than $\pm 5 \%$ for $0^{\circ}-60^{\circ}$ of SZA, and a typical sensitivity of $2.0 \mathrm{~W} \mathrm{~m}^{-2} \mathrm{~V}^{-1}$. Further details about this instrument and each component are given by Dichter et al. (1993).

For the studies carried out in this thesis, two UVB-1 pyranometers are used. The first, \#010922, works continuously at the SRSUVA station, and the second, \#090503, was in operation in the three stations whose measurements are used in this thesis. Hence, to simplify the section on UVB-1 instruments, only the latter instrument is mentioned in the following lines. Details about the calibration of the \#010922 instrument are published by Bilbao et al. (2011b).

With regard to the calibration process, following the guidelines of the World Meteorological Organisation, Global Atmospheric Watch (GAW), and the COST 726 (Long Term changes and Climatology of UV Radiation over Europe), the instruments used to measure broadband UV radiation should be characterized at regular intervals for spectral response, angular response, and sensitivity to temperature. With this information, it is possible to convert the pyranometer's output signal (U) into units of erythemal irradiance ( $\mathrm{W} \mathrm{m}^{-2}$ effective) by applying the calibration factor. This factor can be obtained from the SZA and TOC values at the time of measurement. Erythemal effective irradiance (UVER) can be evaluated as follows (Webb et al., 2006; Hülsen and Gröbner, 2007):

$$
\mathrm{UVER}=\left(\mathrm{U}-\mathrm{U}_{\text {offset }}\right) C \mathrm{f}_{\mathrm{n}}(\mathrm{SZA}, \mathrm{TOC}) \varepsilon(\mathrm{T}) \operatorname{Coscor}(\mathrm{SZA})
$$

where:

- $U_{\text {offset }}$ is the electrical offset for dark conditions (when the Sun is more than $10^{\circ}$ below the horizon). 
- $\mathrm{C}$ is the calibration coefficient, a constant value determined for specific conditions, $\mathrm{SZA}=40^{\circ}$ and $\mathrm{TOC}=300 \mathrm{DU}$. It is calculated as the average from all the calibration factors obtained in an outdoor comparison between reference spectroradiometer scans and radiometer signals.

- $\quad \mathrm{f}_{\mathrm{n}}(\mathrm{SZA}, \mathrm{TOC})$ is a calibration matrix or Look-up-Table (LUT) derived as part of the calibration procedure (for several SZA and TOC conditions) to convert from detector weighted output to erythemal weighted irradiance. It is normalized at $\mathrm{SZA}=40^{\circ}$ and $\mathrm{TOC}=300 \mathrm{DU}$.

- $\quad \varepsilon(T)$ is the temperature correction function.

- Coscor(SZA) is the cosine correction function, which takes into account possible deviations of the angular response of the detector entrance optic from the nominal cosine response.

The new values of $\mathrm{C}, \mathrm{f}_{\mathrm{n}}(\mathrm{SZA}, \mathrm{TOC}), \varepsilon(\mathrm{T})$, and Coscor(SZA) in the calibration certificates are given by international laboratories such as the World Radiometric Centre (PMOD-WRC) in Davos, Switzerland, or the National Institute for Aerospace Technology (INTA), Huelva, Spain. As an example, Figure 2.4 shows the $f_{n}$ matrix, and cosine correction function for the calibration of the UVB-1 \#090503 carried out at Davos, Switzerland, on 1 October 2009. The spectral response is shown in Figure 2.2.

Following the methodology proposed by Hülsen and Gröbner (2007), well maintained and stable radiometers are calibrated with an expanded uncertainty of $7.2 \%$. This uncertainty includes uncertainty due to the calibration procedure itself $(\sim 3.1 \%)$, uncertainty in the conversion from detector weighted irradiance to erythemally weighted irradiance $(\sim 1.7 \%)$, and uncertainty due to the cosine correction which depends on the angular response of each individual radiometer and which can vary between $0.9 \%$ and $7.2 \%$.
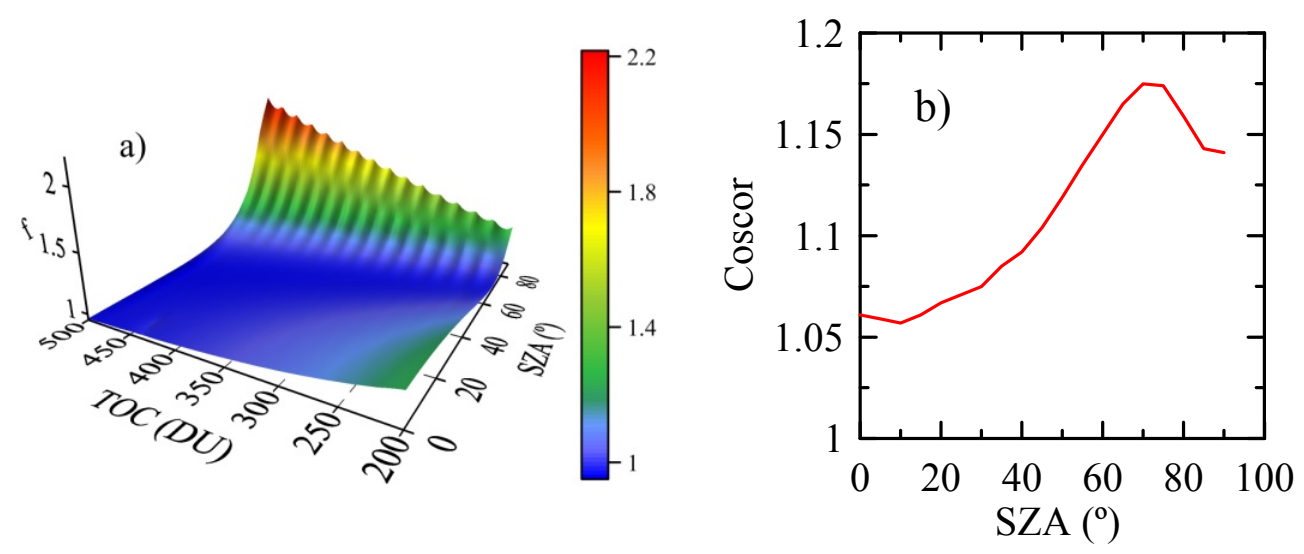

Figure 2.4. a) $f_{n}(S Z A, T O C)$ and b) Coscor(SZA) obtained in the calibration performed in the PMOD-WRC of the UVB-1 \#090503 on 1 October 2009. 
In addition to the calibrations performed at international institutes, a comparison campaign was carried out between the UVB-1 \#090503 pyranometer and the BREWER spectroradiometer (this instrument will be described in detail in Section 2.1.3) located on Lampedusa Island. Taking this spectroradiometer as a reference, inter-comparison between the two instruments was performed for 56 days from 14 July 2010 to 7 September 2010. This inter-comparison is carried out almost one year after the calibration conducted at the PMOD-WRC. As will be mentioned in Section 2.1.3, each scan of the Brewer takes eight minutes, therefore, 8-minute averages from the 1-minute UVB-1 measurements are calculated. The scatterplot between the two radiometric values is shown in Figure 2.5.

The linear fit (red line in Figure 2.5) has a slope of $1.02 \pm 0.04$ and an intercept of $0.0009 \pm 0.00005$. Hence, the fit has the following form:

$$
\begin{gathered}
\text { UVER }_{\text {UVB- } 1}=0.0009+1.02 \text { UVER }_{\text {BREWER }} \\
\text { with } \mathrm{r}=0.99
\end{gathered}
$$

The results are highly satisfactory because of the low intercept and the slope which is very close to 1 . In addition, the ratio between the two UVER measurements is calculated and its dependence on atmospheric factors such as SZA and TOC is shown in Figure 2.6. It can be seen that no dependencies are observed.

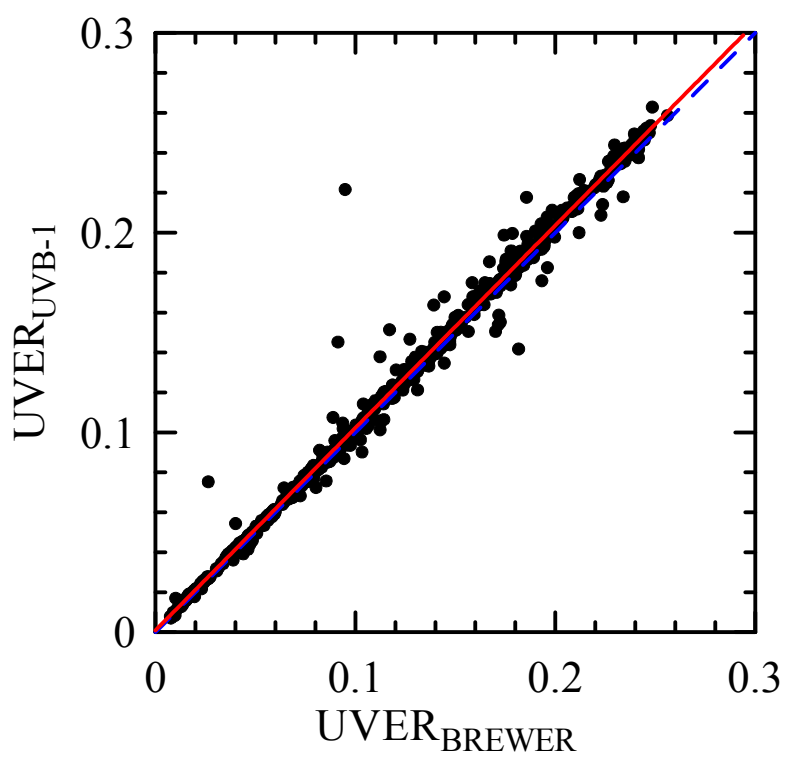

Figure 2.5. Comparison between UVER data obtained with the UVB-1 pyranometer and the BREWER spectroradiometer. 

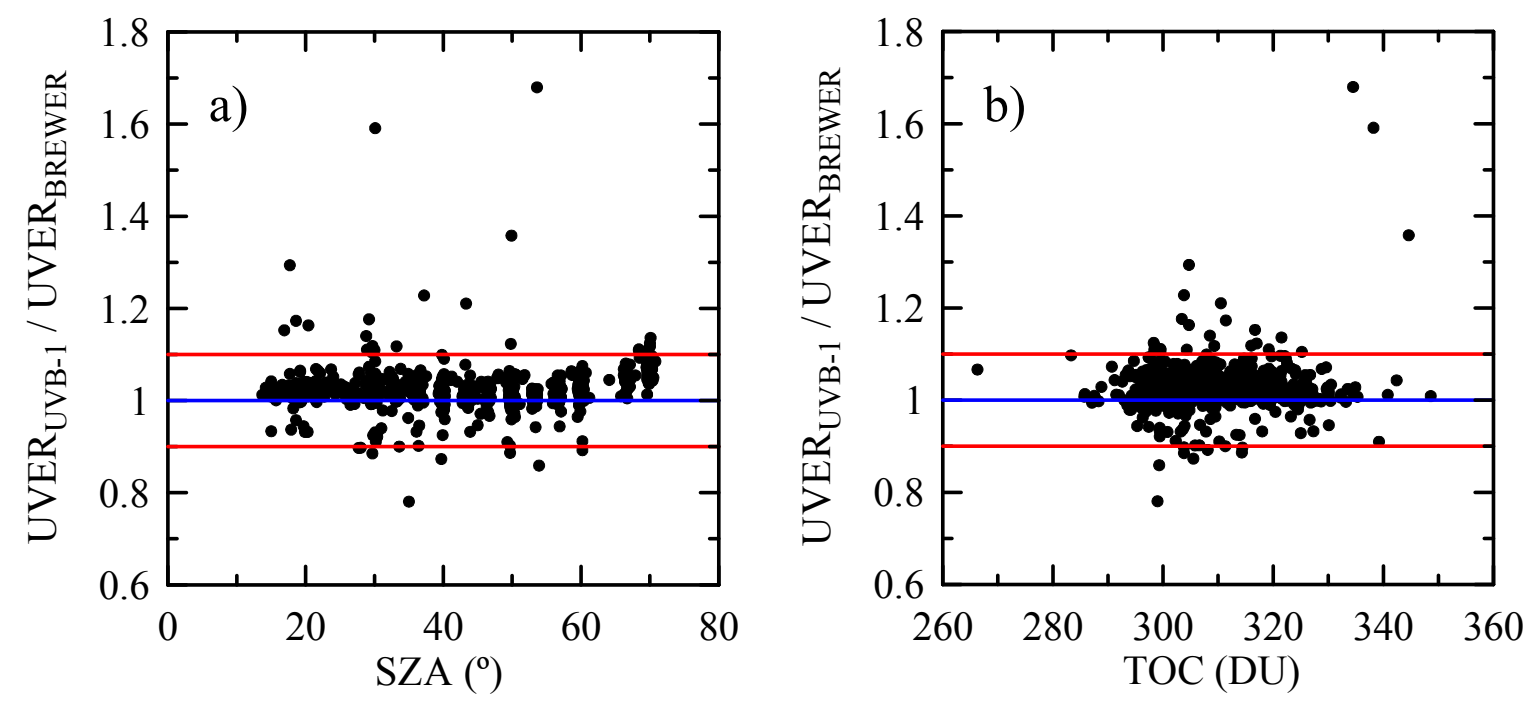

Figure 2.6. Dependence of the ratio between UVB-1 and BREWER measurements on SZA (a) and TOC (b) values. Blue lines indicate perfect agreement and red lines limit the area to within an error of $\pm 10 \%$.

Finally, some statistical indexes are evaluated and shown in Table 2.1. The definitions of the statistical indexes are explained in Annex A. Despite the high number of data used in the comparison $(n=789)$ and the wide variety of atmospheric conditions that occurred (particularly, cloudy and aerosol load conditions), almost $96 \%$ of the data evidence an error below $10 \%$, the average values measured by both instruments being similar, and the differences between them displaying low values of statistical estimators.

From the results obtained, the UVB-1 pyranometer presents a robust technique to measure UVER radiation, and therefore, the UV index.

Table 2.1. Statistical indexes of the comparison between UVB-1 and BREWER measurements of UVER carried out at Lampedusa Island in 2010 during 56 days: $n$ is the number of data, UVER ave represents the average of all the experimental data, MBE and RMSE are the mean bias error and the root mean square error, respectively, and $W_{i}$ is the percent of cases whose deviation falls below the $\pm i \%$ difference.

\begin{tabular}{cc}
\hline Variable & Value \\
\hline n & 789 \\
UVER $_{\text {ave }}$ - UVB-1 & $0.109 \mathrm{~W} \mathrm{~m}^{-2}$ \\
UVER $_{\text {ave }}$ - BREWER & $0.112 \mathrm{~W} \mathrm{~m}^{-2}$ \\
MBE & $3.0 \%$ \\
RMSE & $6.7 \%$ \\
average difference $^{\text {W }}$ & $2.7 \%$ \\
$\mathbf{W}_{\mathbf{1 0} \%}$ & $95.7 \%$ \\
$\mathbf{W}_{\mathbf{2 0} \%}$ & $98.9 \%$ \\
$\mathbf{W}_{\mathbf{3 0} \%}$ & $99.4 \%$ \\
\hline
\end{tabular}




\subsubsection{Spectral irradiance and UVI: UV-MFRSR}

\subsubsection{Spectral measurements}

The UV-MFRSR is a shadowband instrument that measures diffuse and global horizontal radiation with an automated rotating shadowband at seven narrowband channels (nominal wavelengths at 299.0, 304.7, 310.7, 316.8, 323.7, 331.7, and $367.2 \mathrm{~nm}$; each channel with about $2 \mathrm{~nm}$ Full Width at Half Maximum, FWHM, bandwidth). Once these two components are known, the direct-normal component can be derived. This instrument, shown in Figure 2.7, is capable of retrieving column ozone, aerosol optical thickness, as well as calibrated diffuse and global UV irradiance. The shadowband is a strip of metal shaped into a circular arc and mounted along a celestial meridian with the instrument's entrance aperture at the centre of the arc. The shadowband blocks a strip of sky with a $3.3^{\circ}$ umbral angle, sufficient to block the Sun. The motor housing is adjusted for the latitude of the instrument. At each measurement interval, a microprocessor computes the solar position using an approximation for the solar ephemeris. The first measurement is made with the band rotated to its nadir position (global horizontal irradiance). The band is then rotated to take three more measurements. One measurement is taken with the Sun completely blocked (diffuse horizontal irradiance) and the other two are taken with the band rotated to $9^{\circ}$ on either side of the Sun. The side measurements permit a correction for the "excess sky" that is blocked by the shadowband when the Sunblocking measurement is taken. To avoid errors caused by changes in ambient temperature, the instrument uses a computer-controlled thermal regulation circuit that maintains the detectors and filters above ambient temperature, thereby preventing thermal transients from affecting the solid state detectors. The solid state photodiodes, interference filters, and sensitive electronic components are all held inside a desiccated enclosure, further eliminating environmentally-induced measurement errors. More details about this instrument are given by Harrison et al. (1994) and Krotkov et al. (2005), among others.

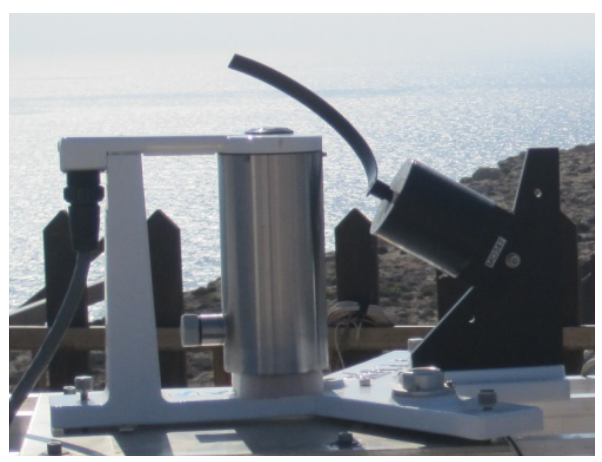

Figure 2.7. UV-MFRSR YES shadowband radiometer. 
All spectral channels are measured within $1 \mathrm{~s}$ by seven separate solid state detectors with interference filters sharing a common Teflon diffuser. The entire sequence is completed in less than 20 seconds. In this thesis, these values are averaged so as to obtain 1-minute values.

\subsubsection{Obtaining UVI values from spectral measurements}

Dahlback (1996) proposed a methodology to derive Biologically Effective UV Doses (BEUVD) from irradiance measurements with instruments with few bandwidth filters in the UV region. This author's methodology compares the exact BEUVD $\left(\right.$ BEUVD $\left._{\text {exact }}\right)$ obtained by a spectroradiometer with approximated BEUVD (BEUVD ${ }_{\text {approx }}$ ) obtained using a multichannel filter instrument of $M$ channels in the UV part of the spectrum. To determine the $\mathrm{BEUVD}_{\text {exact }}$, the spectral irradiance $\left(\mathrm{I}_{\lambda}\right)$ measured by the spectrometer has to be convolved with a biological action spectrum $\left(\mathrm{S}_{\lambda}\right)$ :

$$
\text { BEUVD }_{\text {exact }}=\int_{0}^{\infty} \mathrm{I}_{\lambda} \mathrm{S}_{\lambda} \mathrm{d} \lambda=\sum_{\lambda=0}^{\infty} \mathrm{I}_{\lambda} \mathrm{S}_{\lambda} \Delta \lambda
$$

where $\Delta \lambda$ is determined by the step in the wavelength measurements of the spectroradiometer. However, the multichannel filter instrument only has $M$ channels available. Hence, the UV dose rate obtained by this instrument can be determined by the linear combination of the irradiances (represented by the voltages $V_{i}$ ) measured by each channel:

$$
\text { BEUVD }_{\text {approx }}=\sum_{\mathrm{i}=1}^{\mathrm{M}} \mathrm{a}_{\mathrm{i}} \mathrm{V}_{\mathrm{i}} \Delta \lambda
$$

The relationship between Equations (2.3) and (2.4) is as follows:

$$
\mathrm{BEUVD}_{\text {exact }}=\mathrm{BEUVD}_{\text {approx }}[1+\varepsilon(\mathrm{SZA}, \mathrm{TOC})]
$$

where $\varepsilon(\mathrm{SZA}, \mathrm{TOC})=\left[\left(\mathrm{BEUVD}_{\text {exact }}-\mathrm{BEUVD}_{\text {approx }}\right) / \mathrm{BEUVD}_{\text {approx }}\right]$ is an error function which is SZA- and TOC-dependent. It can be calculated by radiative transfer simulations.

The goal is to determine a unique set of $M$ coefficients $\mathrm{a}_{\mathrm{i}}$. 
However, a new methodology which makes the presence of the error function unnecessary was proposed by the UTMEA-TER team. This new methodology is validated in this thesis.

With the same notation as used in the previous equations, the new methodology takes the form:

$$
\sum_{\lambda=0}^{\infty} \mathrm{I}_{\lambda} \mathrm{S}_{\lambda} \Delta \lambda=\sum_{\mathrm{i}=1}^{\mathrm{M}}\left(\mathrm{a}_{\mathrm{i}} \mathrm{V}_{\mathrm{i}}+\mathrm{b}_{\mathrm{i}} \mathrm{V}_{\mathrm{i}}^{2}\right) \Delta \lambda
$$

where the error function is replaced by the squared multichannel instrument signal.

The BREWER spectroradiometer (explained in Section 2.1.3) and the UVMFRSR measurements are employed to obtain the $2 \mathrm{M}$ coefficients $\mathrm{a}_{i}$ and $\mathrm{b}_{\mathrm{i}}$ of Equation (2.6). Data from $14 / 7 / 2010$ to $14 / 6 / 2011$ are used to obtain the coefficients, selecting the erythemal action spectrum as $S_{\lambda}$. Since the number of channels can produce differences in the results, two options are analyzed: $\mathrm{M}=7$ and $\mathrm{M}=4$, in other words, all the channels and only four of them $(304.7,310.7,316.8$, and $331.7 \mathrm{~nm})$. Table 2.2 shows all the coefficients obtained for both cases.

Having obtained the coefficients, the erythemal dose can be evaluated with the UV-MFRSR data. In order to assess the accuracy of this methodology, the 1-minute measurements of the UVB-1 pyranometer performed at Lampedusa from 14/7/2010 to $7 / 9 / 2010$ are used. In this way, two instruments with two different methods to record UVER radiation are analyzed in the validation process. Figure 2.8 shows the scatterplots for the UV-MFRSR database using all the channels and only four of them as a function of the UVB-1 data.

Table 2.2. Coefficients of Equation (2.6) obtained for the UV-MFRSR. $a_{i}$ coefficients are unitless, while $b_{i}$ are in $m^{2} n m W^{1}$.

\begin{tabular}{lcccccccccccccc}
\hline & $\mathbf{a}_{\mathbf{1}}$ & $\mathbf{a}_{\mathbf{2}}$ & $\mathbf{a}_{\mathbf{3}}$ & $\mathbf{a}_{\mathbf{4}}$ & $\mathbf{a}_{\mathbf{5}}$ & $\mathbf{a}_{\mathbf{6}}$ & $\mathbf{a}_{7}$ & $\mathbf{b}_{\mathbf{1}}$ & $\mathbf{b}_{\mathbf{2}}$ & $\mathbf{b}_{\mathbf{3}}$ & $\mathbf{b}_{\mathbf{4}}$ & $\mathbf{b}_{\mathbf{5}}$ & $\mathbf{b}_{\mathbf{6}}$ & $\mathbf{b}_{7}$ \\
\hline $\mathbf{M = 7}$ & -14.0 & 1.3 & 6.6 & -8.1 & 5.2 & -1.9 & 0.2 & -1048.4 & 86.0 & -7.7 & 3.4 & -9.8 & 6.8 & -0.7 \\
$\mathbf{M = 4}$ & -0.3 & 3.5 & -2.1 & 0.5 & - & - & - & 5.5 & 5.2 & -5.0 & 0.5 & - & - & - \\
\hline
\end{tabular}



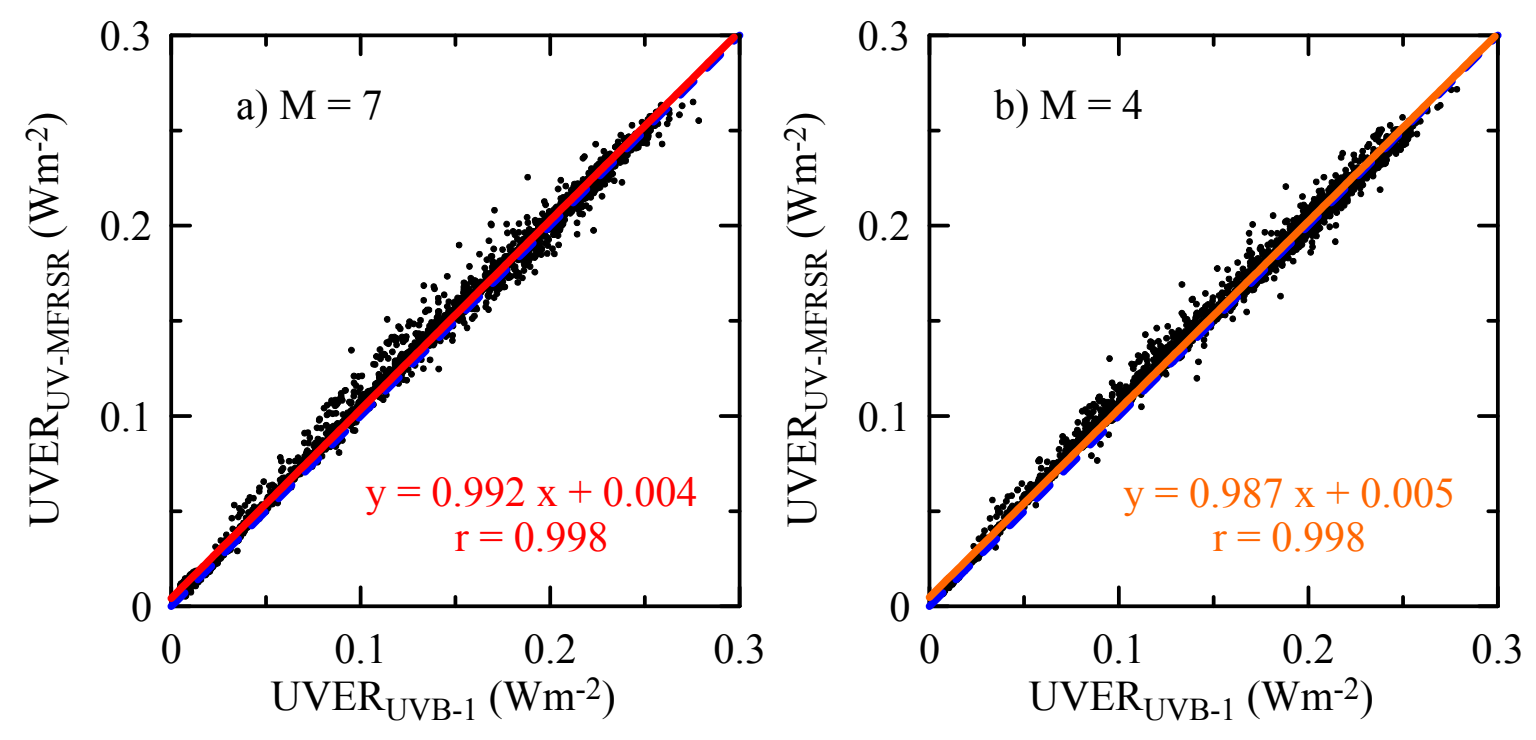

Figure 2.8. Comparison of UVER obtained by the UV-MFRSR using seven (a) and four (b) channels and UVB-1 instruments. Red and orange lines are the linear fits and blue dashed lines indicate the 1:1 line.

The results obtained are highly satisfactory because the two linear fits shown in Figure 2.8 present slopes and intercepts very close to 1 and 0 , respectively, with a high correlation coefficient. To complete the analysis, several statistical indexes are evaluated, the values obtained being shown in Table 2.3. Small, non-statistically significant differences are observed in the values of the statistical indexes despite the large dataset used in the validation (27049 data). Hence, the database obtained with the UV-MFRSR instrument is extremely accurate and can be used to obtain UV index values. In addition, using seven rather than four channels does not introduce any significant additional information in the calculation. Nevertheless, the database evaluated with the seven channels was chosen to describe erythemal UV at the LAMPEDUSA station because of the higher $\mathrm{W}_{10 \%}$ value with $\mathrm{M}=7$.

Table 2.3. Statistical indexes of the comparison between UVER data obtained by the UV-MFRSR using seven and four channels and the UVB-1 pyranometer. $n$ is the number of data, UVER ave represents the average of all the experimental data, MBE and RMSE are the mean bias error and the root mean square error, respectively, and $W_{i}$ is the number of cases falling below the $\pm i \%$ error.

\begin{tabular}{|c|c|c|}
\hline Variable & $\mathbf{M}=7$ & $M=4$ \\
\hline $\mathbf{n}$ & 27049 & 27049 \\
\hline UVER $_{\text {ave }}-$ UVB-1 $\left(\mathbf{W} \mathbf{m}^{-2}\right)$ & 0.116 & 0.116 \\
\hline $\operatorname{UVER}_{\text {ave }}-\mathbf{U V - M F R S R}\left(\mathbf{W} \mathbf{m}^{-2}\right)$ & 0.119 & 0.119 \\
\hline MBE (\%) & 7.5 & 6.7 \\
\hline RMSE (\%) & 5.3 & 5.1 \\
\hline average difference (\%) & 6.5 & 6.2 \\
\hline$W_{10 \%}(\%)$ & 81.5 & 76.1 \\
\hline$W_{20 \%}(\%)$ & 90.8 & 93.9 \\
\hline$W_{30 \%}(\%)$ & 94.2 & 97.3 \\
\hline
\end{tabular}




\subsubsection{Spectral irradiance: BREWER}

Spectral UV irradiance and total ozone column measurements are performed by the double monochromator Brewer MK III \#123 spectrometer (Figure 2.9). A description of the instrument and its routine mode of operation are given by Kerr et al. (1985). The double monochromator MKIII measurements below $305 \mathrm{~nm}$ are substantially better than for the single-monochromator instrument, due to better stray light suppression.

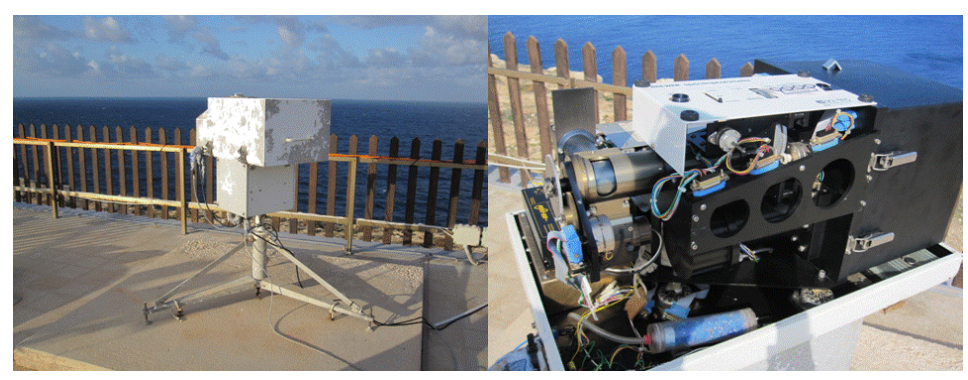

Figure 2.9. BREWER spectroradiometer.

The UV spectrum is measured in the $286.5-363.0 \mathrm{~nm}$ range at $0.5 \mathrm{~nm}$ steps, while the FWHM spectral resolution is $0.56 \mathrm{~nm}$. The whole interval is scanned by the Brewer within approximately eight minutes. This instrument was calibrated for ozone measurements in March 2002, March 2006, and in July 2009 through a comparison with travelling Brewer $\# 017$. No changes in instrumental calibration constants are required during this period.

The estimated uncertainty on total ozone from direct Sun measurements is $1 \%$. Spectral UV measurements are calibrated using a field calibrator described by Early et al. (1998), which uses US National Institute of Standards and Technology (NIST) traceable $1000 \mathrm{~W}$ FEL lamps. Changes in the instrumental response observed in the calibrations are taken into account. Figure 2.10 shows some details of this process in the calibration performed in November 2009 at the LAMPEDUSA station.

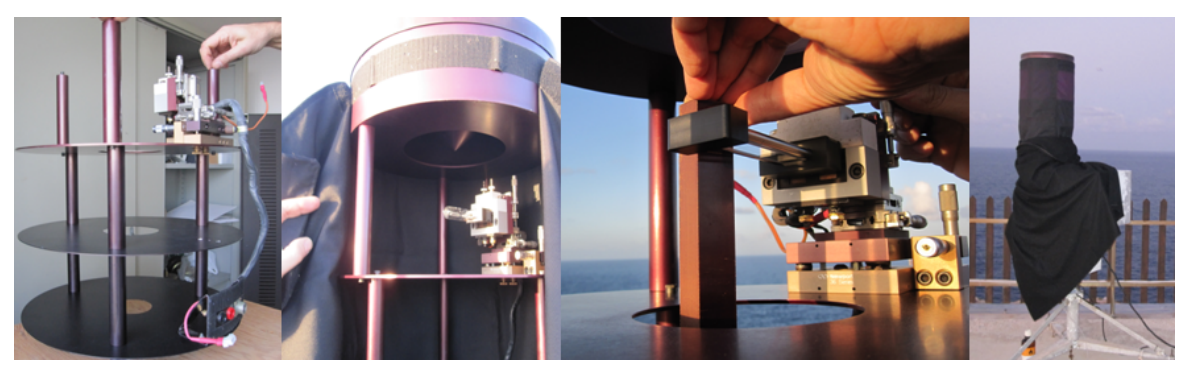

Figure 2.10. Several processes in BREWER calibration performed at LAMPEDUSA in November 2009. 
Measured spectra are referred to the mean Sun-Earth distance and corrected for the cosine error of the diffuser. The estimated expanded uncertainty on the spectral irradiance measurements decreases with wavelength and is below $10 \%$ throughout the Brewer spectral range (see for example Bernhard and Seckmeyer, 1999). For further details about the instrument and the calibration processes see di Sarra et al. (2008).

\subsubsection{Spectral actinic flux and $J\left(O^{1} D\right)$ : DAS}

Downward spectral actinic fluxes are measured using a METCON diode array spectrometer (DAS), which measures radiation between 280 and $700 \mathrm{~nm}$ with a FWHM bandwidth of about $2.5 \mathrm{~nm}$ at $0.83 \mathrm{~nm}$ steps. Figure 2.11 shows this instrument. The DAS is a fast, monolithic single monochromator spectral radiometer with a 512 pixel diode array detector. The spectrometer receives incident photons by using $2 \pi$ sr input optics (Volz-Thomas et al., 1996). A matt black shadow ring forms an artificial horizon to avoid detection of upwelling radiation. Collected photons pass through a quartz rod and a round to slit converter $(50 \times 2500 \mu \mathrm{m})$, reaching the entrance of the spectrometer. The signal detected by each pixel is acquired and then averaged at three different integration times, which is sufficient to perform $\mathrm{J}\left(\mathrm{O}^{1} \mathrm{D}\right)$ measurements in the conditions occurring in this thesis. Taking into account stray light contribution, the DAS is calibrated with three different lamps (1000 W FEL lamps from NIST) to guarantee accurate calibration and lamp stability, and multiple spectra are averaged to derive the final calibration curve.

Uncertainty in the responsivity is estimated to be between $1 \%$ and $2 \%$ for the 290 $350 \mathrm{~nm}$ spectral range. An extensive description of the instrument is given by Edwards and Monks (2003). Further details about the calibration processes, the method used to suppress stray light, and how to retrieve the actinic flux and photolysis rates are given by Casasanta et al. (2011).

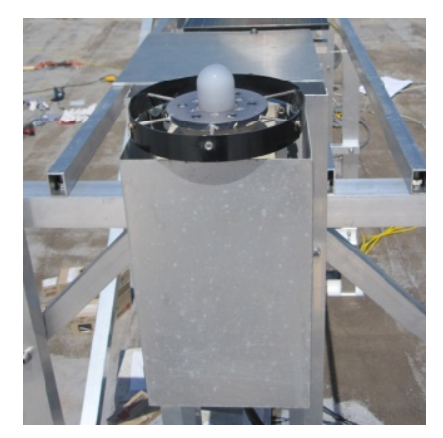

Figure 2.11. METCON-DAS actinometer. 
The quantum yields $(\phi)$ used to determine $\mathrm{J}\left(\mathrm{O}^{1} \mathrm{D}\right)$ are taken from Matsumi et al. (2002), while the ozone cross section $(\sigma)$ is derived from Daumont et al. (1992) and Malicet et al. (1995). Figure 2.12 shows the spectral dependence of both quantities at a temperature of $295 \mathrm{~K}$.

In order to highlight the radiative effects caused by atmospheric constituents (clouds, ozone and aerosol), $\mathrm{J}\left(\mathrm{O}^{1} \mathrm{D}\right)$ is calculated at a constant temperature. In this case, $\mathrm{T}$ $=295 \mathrm{~K}$ is set.
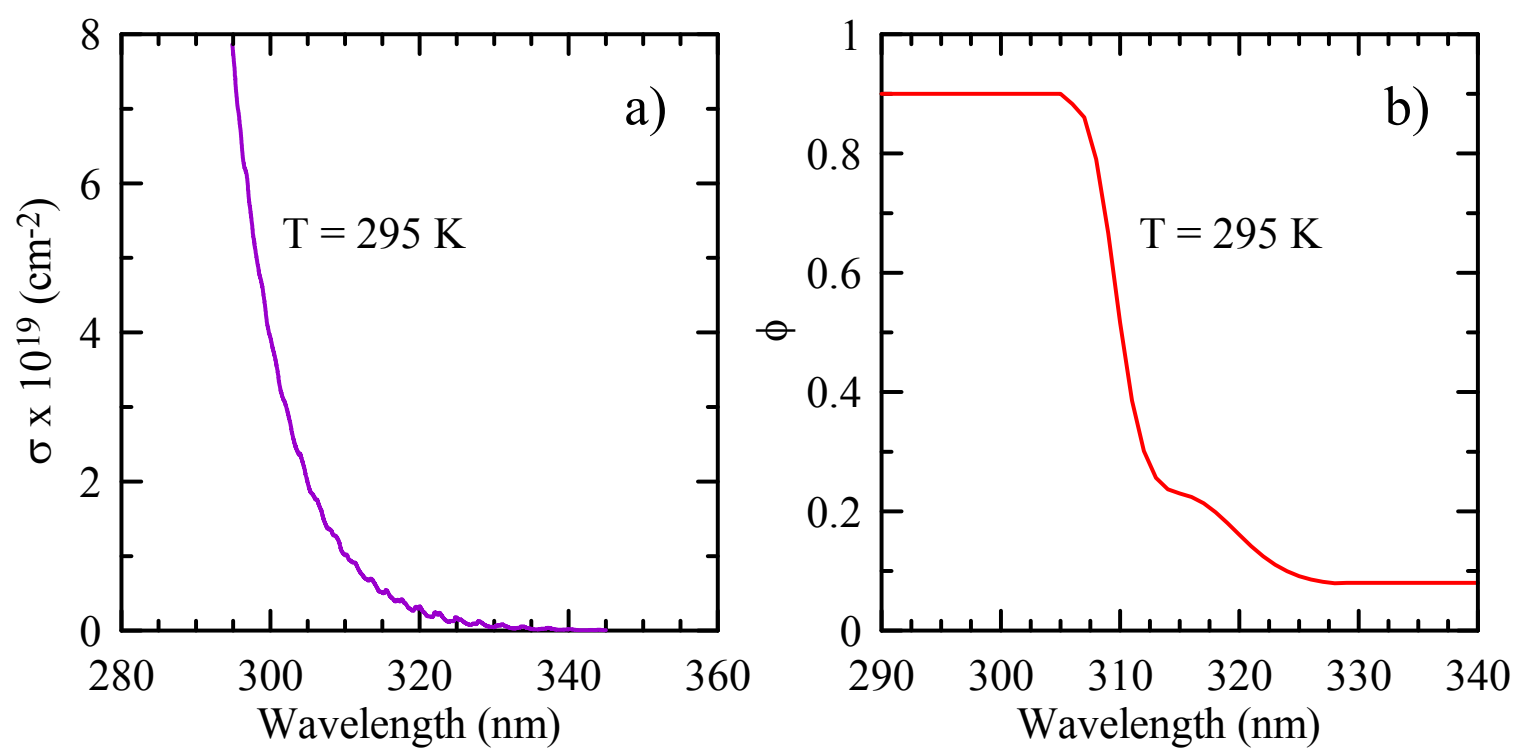

Figure 2.12. Spectral dependence of ozone cross section (a) and quantum yield (b) to determine $J\left(O^{l} D\right)$ at a fixed temperature of $295 \mathrm{~K}$.

\subsubsection{Cloud microphysical properties: HATPRO}

Continuous measurements of absolute humidity and temperature vertical profiles as well as integrated water vapour and liquid water content were provided by a Humidity And Temperature PROfiler (HATPRO) microwave radiometer developed by Radiometer Physics GmbH (RPG). This instrument, shown in Figure 2.13, measures the brilliance temperature at the high and low-frequency wings of the water vapour absorption lines and oxygen complex, centred at 22.235 and $60 \mathrm{GHz}$, respectively.

A statistical inversion methodology, similar to that described in Löhnert and Crewell (2003), is used to derive integrated water vapour and liquid water path as well as temperature and specific humidity profiles. Vertical profiles of specific humidity and 
temperature are calculated from quadratic and linear regressions, respectively. The coefficients used for the regressions are provided by RPG and derived by a group of radio-sounding data from the Mediterranean sites of Trapani and Cagliari. LWP accuracy depends on frequency combination, brightness temperature accuracy and observation angle. In this case it is $\sim 20 \mathrm{~g} \mathrm{~m}^{-2}$ (e.g. Löhnert and Crewell, 2003; Rose et al., 2005). A detailed description of this instrument's design is given by Rose et al. (2005), among others.

Using LWP measurements and transmissivity obtained by a VIS-MFRSR at 415 $\mathrm{nm}$ (explained in Section 2.1.10), Min and Harrison (1996) developed a methodology to estimate the COT and the effective radius by means of Look-up-Tables obtained from radiative transfer simulations. Using this methodology, Min et al. (2003) proved that $r_{\text {eff }}$ values agree with in situ measurements to within $5.5 \%$.

The cloud base height is measured by an infrared camera installed on one side of the HATPRO radiometer.

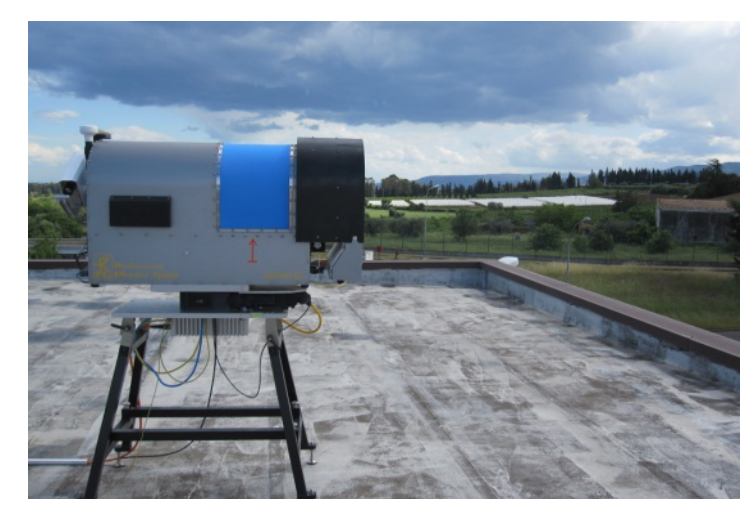

Figure 2.13. HATPRO radiometer.

\subsubsection{Total ozone column: MICROTOPS-II}

The Solar Light Company Microtops-II manual sun-photometer enables measurements of spectral direct radiation and retrieving total ozone column, precipitable water column, and aerosol optical thickness at $1020 \mathrm{~nm}$. This instrument is used in the three stations described later in Section 2.3. For instance, during the Trisaia campaign, Microtops-II was the source of columnar ozone measurements. This instrument (see Figure 2.14) is equipped with five accurately aligned optical collimators, capable of a full field view of $2.5^{\circ}$, to record measurements at the following nominal wavelengths: 305 , 
$312.5,320.5,936$, and $1020 \mathrm{~nm}$ with a FWHM of $2.4 \mathrm{~nm}$ in the UV, and $10 \mathrm{~nm}$ at longer wavelengths.

As this instrument is mainly used as an ozonometer in this thesis, the operating principle is only explained in the case of total ozone column retrievals. The principle governing measurements of column water vapour and aerosol optical thickness can be found in Morys et al. (2001).

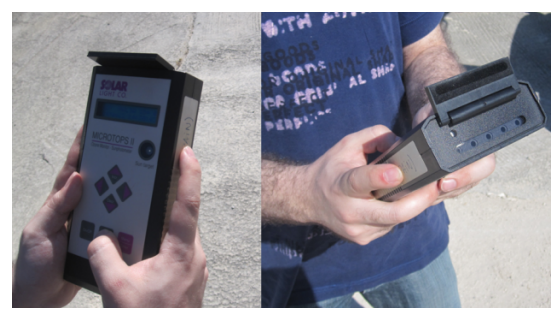

Figure 2.14. MICROTOPS-II photometer.

In order to measure TOC, the MICROTOPS-II records the signals at each wavelength in the UV range independently and assumes the validity of the Beer-BouguerLambert Law (Equation 1.26). When applied to ozone absorption and Rayleigh scattering by the atmosphere, it takes the form:

$$
\mathrm{I}=\mathrm{I}_{0} \mathrm{e}^{-\mathrm{a}_{\mathrm{o}} T O C \mathrm{~m}_{\mathrm{o}}-\mathrm{m}_{\mathrm{R}} \tau_{\mathrm{R}}}
$$

where $I$ and $I_{0}$ are the radiance at a particular wavelength at the surface and at the top of the atmosphere, respectively, $a_{o}$ is the ozone absorption coefficient at the specific wavelength, $m_{o}$ represents the ratio of the actual and vertical path lengths of the radiation through the ozone layer (i.e. the ozone relative optical air mass), $m_{R}$ indicates the corresponding Rayleigh relative optical air mass, and $\tau_{\mathrm{R}}$ is the Rayleigh scattering cross section. The aerosol effect is ignored in this equation because ozone retrievals are computed by two very closely spaced wavelengths. With this selection, the difference in the absorption coefficients at the two wavelengths is minimized, and the effect of aerosol is notably reduced. In fact, turbidity conditions have scarcely any impact on ozone retrievals (e.g. Basher and Thomas, 1979).

All these values are easily calculated, the ozone cross sections being derived by Molina and Molina (1986) with a fit proposed by Morys et al. (2001), the Rayleigh coefficients being obtained from Penndorf (1957), and the ozone and Rayleigh relative optical air mass being given by Kohmyr (1980) and Kohmyr et al. (1989) in the form: 


$$
\begin{gathered}
\mathrm{a}_{\mathrm{o}}(\lambda)=2.134910^{19} \mathrm{e}^{-0.14052 \lambda} \\
\mathrm{m}_{\mathrm{o}}=\frac{1}{\sqrt{1-\frac{\mathrm{R}+\mathrm{h}_{\mathrm{g}}}{\mathrm{R}+\mathrm{h}_{\mathrm{o}}} \sin ^{2}(\mathrm{SZA})}} \\
\tau_{\mathrm{R}}(\lambda)=\frac{\mathrm{p}}{\mathrm{p}_{0}}\left(16.407-8.528410^{-2} \lambda+1.152210^{-4} \lambda^{2}\right) \\
\mathrm{m}_{\mathrm{R}}=\sec (\mathrm{SZA})-1.816710^{-3}\left(\mathrm{~s}_{1}\right)-2.87510^{-3}\left(\mathrm{~s}_{1}\right)^{2}-8.08310^{-4}\left(\mathrm{~s}_{1}\right)^{3} \\
\mathrm{~s}_{1}=\sec (\mathrm{SZA})-1
\end{gathered}
$$

where $\mathrm{R}$ is mean Earth radius $(6371 \mathrm{~km}), \mathrm{h}_{\mathrm{g}}$ is the height of the instrument above sea level in kilometres, and $h_{o}$ is the height of the ozone layer above sea level which can be related with the latitude, $h_{0} \sim 26-0.1 \Lambda$ (degree).

With a pair of wavelengths, called $\lambda_{1}$ and $\lambda_{2}$ in the two possibilities of the MICROTOPS-II channels: $305-312.5 \mathrm{~nm}$ and $312.5-320 \mathrm{~nm}$, the total ozone column is obtained by:

$$
\mathrm{TOC}=\frac{\ln \left(\frac{\mathrm{I}_{0}\left(\lambda_{1}\right)}{\mathrm{I}_{0}\left(\lambda_{2}\right)}\right)-\ln \left(\frac{\mathrm{I}\left(\lambda_{1}\right)}{\mathrm{I}\left(\lambda_{2}\right)}\right)-\mathrm{m}_{\mathrm{R}}\left(\tau_{\mathrm{R}}\left(\lambda_{1}\right)-\tau_{\mathrm{R}}\left(\lambda_{2}\right)\right)}{\left(\mathrm{a}_{\mathrm{o}}\left(\lambda_{1}\right)-\mathrm{a}_{\mathrm{o}}\left(\lambda_{2}\right)\right) \mathrm{m}_{\mathrm{o}}}
$$

where TOC is expressed in atm. $\mathrm{cm}$. To convert these units to DU, a factor of 1000 has to be used.

The MICROTOPS-II instrument provides a third estimate of TOC. However, as the best results are obtained with the shortest wavelength channels, only the 305-312.5 $\mathrm{nm}$ pair is used to obtain retrievals of this parameter. Therefore, to simplify the section about TOC, no more details are given here about this third estimation. Figure 2.15 shows the daily averages of the TOC values recorded at the SRSUVA station. Since this instrument is a hand-held photometer, no continuous measurements are carried out at the SRSUVA station. In addition, the manufacturer only recommends using this photometer 
under cloudless conditions. When these conditions occur in the atmosphere, hourly measurements are recorded during the day. These are the main reasons for the large data gaps in the database since 2007.

A measure is obtained by averaging the experimental data of five samples carried out each measurement time. The standard deviation of the five measurements can be evaluated and when this variable shows values above $5 \mathrm{DU}$, the measurement is discarded. This methodology is also applied at the other stations when the MICROTOPSII worked in TRISAIA and LAMPEDUSA. In addition, measurements with SZA $>70^{\circ}$ are not taking into account in the analysis to minimize the dependence of ozone retrievals on airmass (Gómez-Amo et al., 2012).

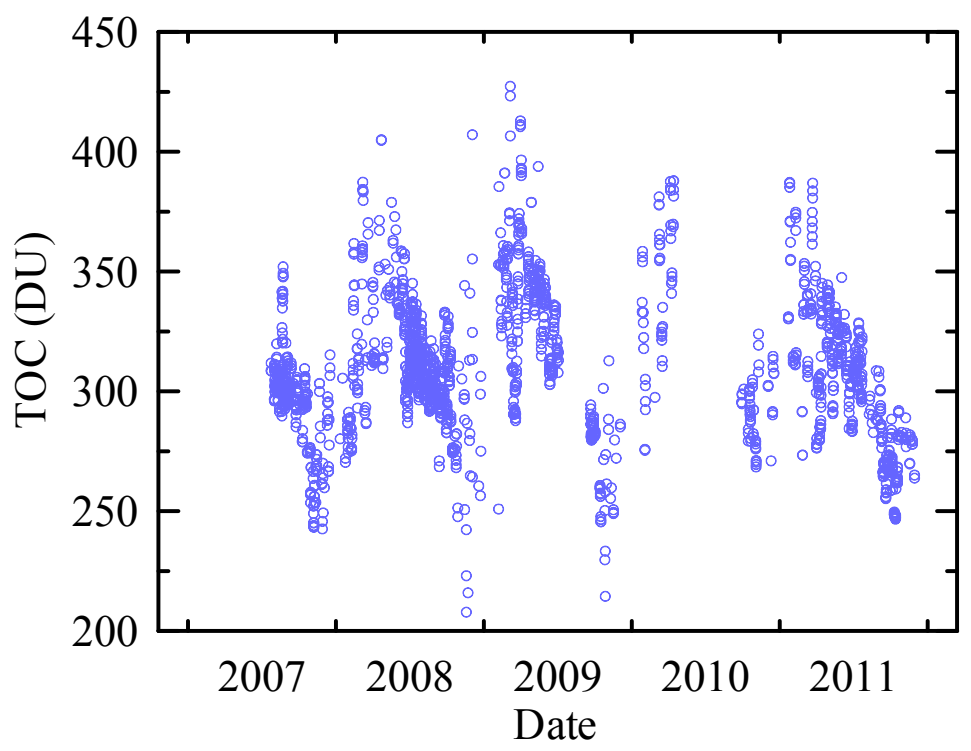

Figure 2.15. TOC database of MICROTOPS-II photometer at the SRSUVA station.

Moreover, MICROTOPS-II must be pointed directly at the Sun during use. Morys et al. (2001) carried out an analysis of possible error of using different Sun-Targeting methods. Their results indicate that a $1 \%$ standard deviation could be achieved when measurements are performed with the MICROTOPS-II only held by the operator's hands (without the help of any surface or tripod to support the instrument).

The MICROTOPS-II sun-photometer is calibrated each two years at the Manua Loa Observatory (Hawaii) and in the Solar Light Calibration Lab (Glenside, PA). The calibration method is based on comparisons against a Dobson spectrophotometer and a standard MICROTOPS ozonometer. In addition to these calibration campaigns, 
exhaustive control of MICROTOPS measurements is carried out. At the SRSUVA station, an inter-comparison with the satellite remote sensing measurements by the Ozone Monitoring Instrument (OMI, web available at http://disc.sci.gsfc.nasa.gov) is performed. As mentioned before, this instrument worked at the three stations used in this thesis. Hence, the ozone measurements of the MICROTOPS-II instrument are also compared with those of the BREWER spectroradiometer described previously at the LAMPEDUSA station. An inter-comparison of five days in July 2010, recording more than 50 data for different SZAs, was carried out. The scatterplot of the MICROTOPS-II-OMI measurements is shown in Figure 2.16 (the diagram for the MICROTOPS-II-BREWER comparison is not shown because of the low range of TOC values observed over the five days).

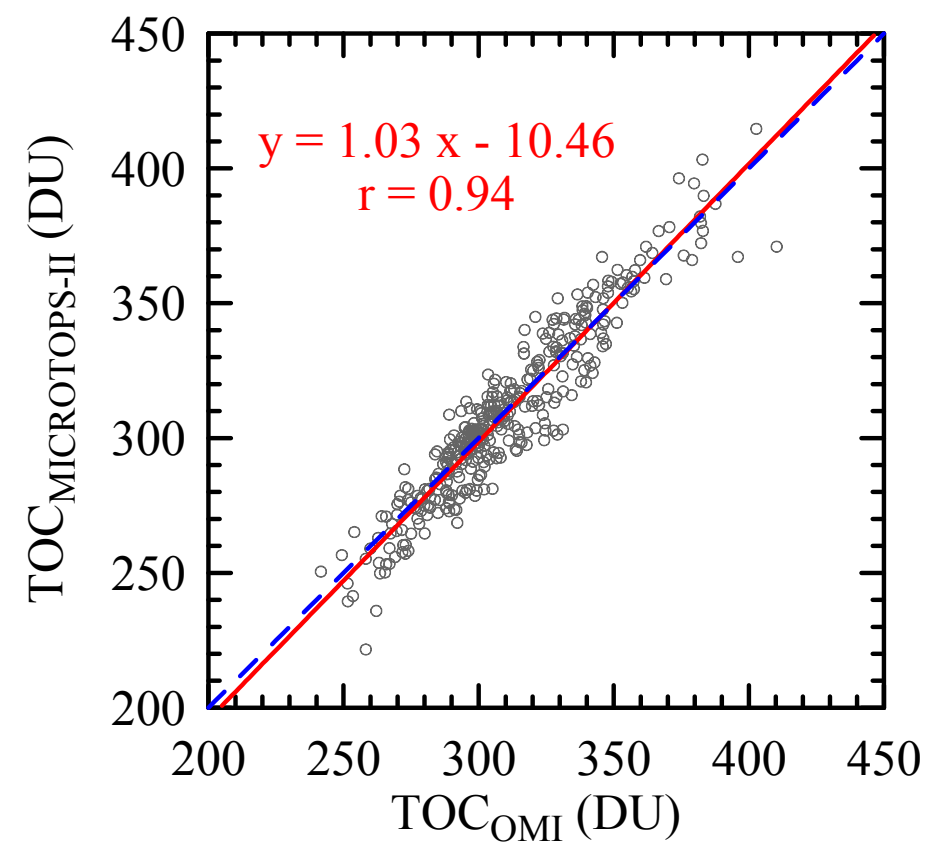

Figure 2.16. Comparison of TOC obtained by the MICROTOPS-II and OMI instruments. The red line is the linear fit and the blue dashed line indicates the 1:1 line.

To complete the analysis, the same statistical indexes as were calculated in the previous inter-comparisons are evaluated for the two studies on MICROTOPS-II ozone measurements. The results are shown in Table 2.4. As can be seen in the table, all the values show differences below $10 \%$, the same occurring for a $5 \%$ error in the MICROTOPS-II-BREWER comparison. The RMSE is low for both cases and is less than $1 \%$ for the study conducted at the LAMPEDUSA station. 
The percentage of data with differences below $1 \%$ is greater for the comparison with BREWER than with OMI because in the OMI case, its daily data are compared with the corresponding daily average recorded by the MICROTOPS-II. Differences in atmospheric conditions can occur when both instruments take their measurements. This happens, for instance, when there are local clouds around the time of OMI overpass, because the measurements of the MICROTOPS-II instrument are performed at other times of the day under cloudless conditions. This effect does not appear in the comparison at the LAMPEDUSA station because, as far as was possible, both ozone measurements (BREWER and MICROTOPS-II) were recorded simultaneously.

From the analysis, it can be concluded that the MICROTOPS-II instrument provides reliable TOC measurements.

Table 2.4. Statistical indexes of the comparison between TOC data obtained by the MICROTOPS-II and OMI and BREWER instruments. $n$ is the number of data, TOC ave represents the average of all the experimental data, MBE and RMSE are the mean bias error and the root mean square error, respectively, and $W_{i}$ is the number of cases falling below the $\pm i \%$ error.

\begin{tabular}{|c|c|c|}
\hline Variable & MICROTOPS-II vs OMI & MICROTOPS-II vs BREWER \\
\hline $\mathbf{n}$ & 371 & 51 \\
\hline TOC $_{\text {ave }}-$ MICROTOPS-II (DU) & 309.7 & 302.6 \\
\hline TOC $_{\text {ave }}-$ OMI (DU) & 308.7 & - \\
\hline TOC $_{\text {ave }}-$ BREWER (DU) & - & 303.3 \\
\hline MBE (\%) & -0.4 & 0.2 \\
\hline RMSE (\%) & 3.4 & 0.8 \\
\hline average difference $(\%)$ & -0.4 & 0.2 \\
\hline$W_{1 \%}(\%)$ & 24.8 & 76.5 \\
\hline$W_{5 \%}(\%)$ & 85.4 & 100.0 \\
\hline $\mathrm{W}_{10 \%}(\%)$ & 99.5 & 100.0 \\
\hline
\end{tabular}

\subsubsection{Cloud cover: TSI + visual observations}

Two different methods are used to record cloud cover. The first is the automatic instrument: the 440 Total Sky Imager (TSI) model by Yankee Environmental Systems. The TSI is setup to automatically capture sky images each five minutes during daylight and consists of a digital colour video camera mounted to look down on a convex mirror to provide a horizon-to-horizon view of the sky. This instrument has a solar-ephemeris guided shadow band to block direct-normal radiation from the Sun. Figure 2.17 shows a picture of this instrument located at the LAMPEDUSA station. 


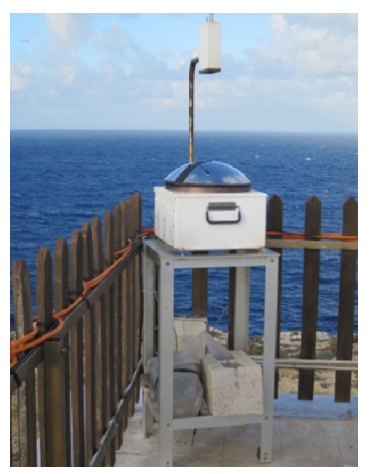

Figure 2.17. YES Total Sky Imager model 440.

Digital image processing provides cloud cover, cloud uniformity, cloud type (low or high) and information on Sun obstruction by clouds. In this thesis, only the cloud cover product is used. The fractional sky cover is in some cases overestimated due to the occurrence of white regions near the Sun and/or near the horizon for low solar elevation angles in the images. This phenomenon is due to strong forward scattering of visible light by aerosol and haze, and has required a visual inspection of all the images to assess the accuracy of the cloud cover evaluated by the automatic algorithm or to correct the data if there is an overestimation due to the presence of desert dust particles, among others. Figure 2.18 shows some examples of bad estimation by the automatic algorithm. Uncertainty on the corrected cloud cover determination is below 1 octa.

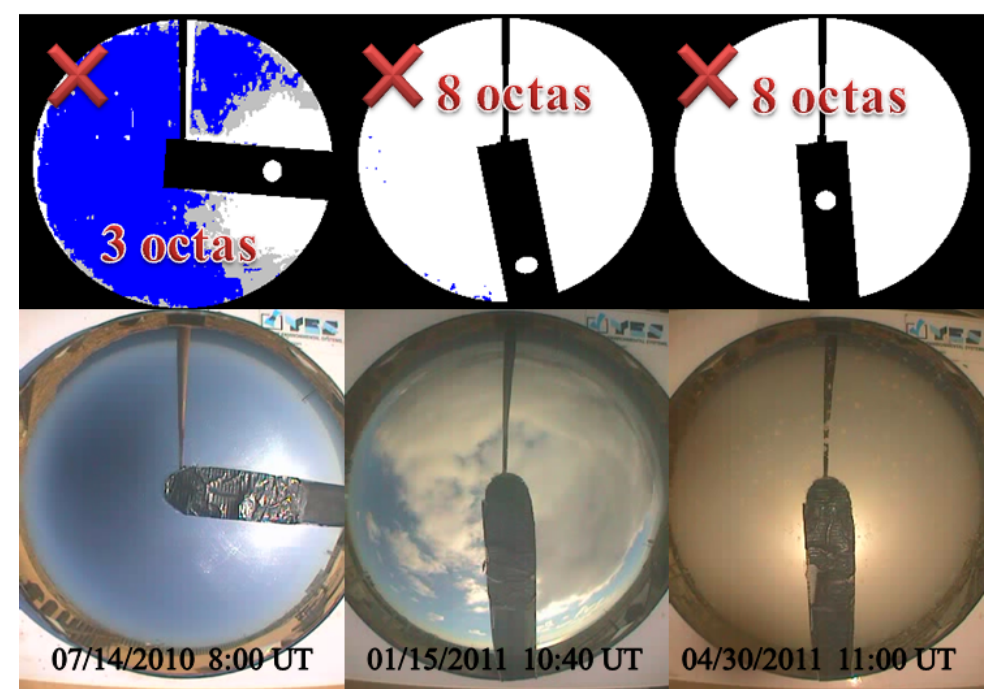

Figure 2.18. Three samples of bad estimation of cloud cover from the TSI's automatic algorithm. 
When this automatic instrument is not available, cloud cover estimations are obtained by visual observations. The cloud cover data of the SRSUVA station (three times per day: 7:00 h, 13:00 h, and 18:00 h GMT) are recorded by the trained staff at Valladolid Airport, which is $10 \mathrm{~km}$ away from the station, and distributed by the Spanish Meteorological Agency (AEMet). At the TRISAIA station, visual observations together with manual pictures of a convex mirror were used for this purpose with an hourly frequency when possible (Figure 2.19 shows three pictures for cloudless, cloudy and overcast conditions).

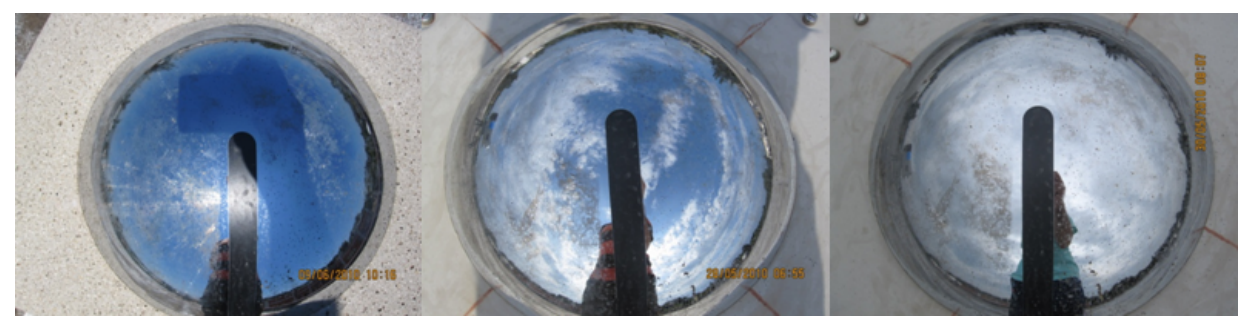

Figure 2.19. Three different pictures at the TRISAIA station.

\subsubsection{Total SW measurements: CMP21 / CM 6B / PSP}

Total shortwave radiation on a horizontal surface is measured by different instruments:

- Kipp \& Zonen CM-6B

- Eppley Precision Spectral Pyranometer (PSP)

- $\quad$ Kipp \& Zonen CMP 21

All these instruments are well calibrated and regularly maintained. More details concerning their calibrations and quality control are described by Di Biagio et al. (2009) and de Miguel et al. (2011b), among others. Figure 2.20 shows the three radiometers mentioned above. 


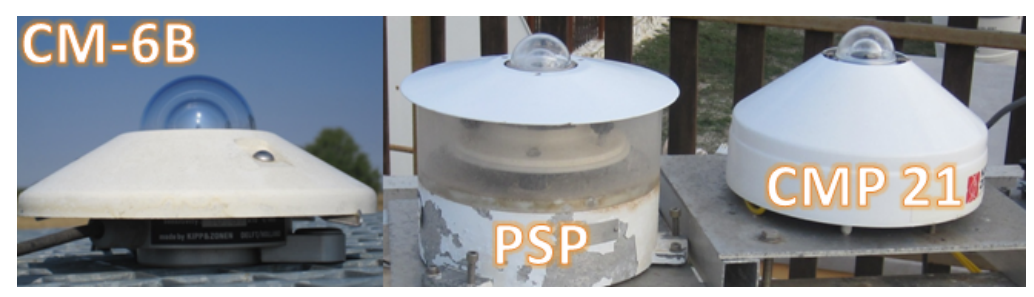

Figure 2.20. Three different models of pyranometers used in this thesis to record SW radiation.

\subsubsection{Aerosol and cloud vertical distribution: LIDAR}

The LIDAR (Light Detection and Ranging) is an optical remote sensing instrument to measure the optical properties of atmospheric constituents. The LIDAR used at the TRISAIA station is a Camper Born Lidar Experimenta (CaBLE) designed by the G-24 group of the Università Sapienza (Rome, Italy), and is shown in Figure 2.21.

This LIDAR source is a laser which sends radiation pulses into the atmosphere. Part of the radiation is scattered backwards and is received by telescopes, from which the LIDAR can estimate variables such as backscatter and extinction coefficients, optical depths, vertical profiles and depolarization ratio of aerosol, cloud geometric and optical thicknesses (for low and moderate COT), as well as structure and height of the planetary boundary layer (Casasanta, 2012).

CaBLE is able to perform measurements in the troposphere, from $600 \mathrm{~m}$ up to 10 $\mathrm{km}$. The source of radiation is a Nd:YAG laser emitting radiation at $1064 \mathrm{~nm}$, which is transformed by the second harmonic generator at $532 \mathrm{~nm}$ (the final wavelength sent to the atmosphere), with a repetition frequency of $10 \mathrm{~Hz}$, a pulse duration of $\sim 15 \mathrm{~ns}$, and a maximum energy at $532 \mathrm{~nm}$ of $\sim 85 \mathrm{~mJ}$. Radiation backscattered by atmospheric constituents is received by an optic system consisting of two telescopes and one lens. More details about the CaBLE instrument and its configuration are given by Casasanta (2012).

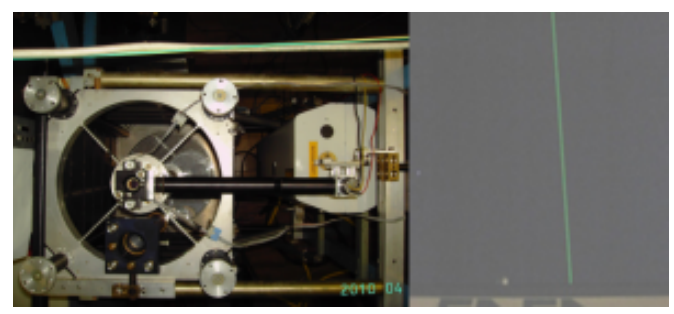

Figure 2.21. Top view of the LIDAR instrument used at the TRISAIA station: CaBLE 


\subsubsection{Aerosol optical properties: VIS-MFRSR}

Another MFRSR in the visible range (six channels at 415, 500, 615, 673, 870, and $940 \mathrm{~nm}$, nominal wavelengths, each with $10 \mathrm{~nm}$ FWHM bandwidths, plus one photodiode covering the 300-1040 nm spectral range) records (global and diffuse) irradiance and derives the direct component (Harrison et al., 1994). Using Langley regression techniques, retrieval of extraterrestrial irradiance can be obtained to evaluate optical thicknesses by means of the Beer-Bouguer-Lambert Law (see Equation 1.26). By using the VIS-MFRSR measurements, aerosol optical properties and cloud optical thickness can be derived (e.g. Harrison and Michalsky, 1994; Min and Harrison, 1996; Pace et al., 2006). This radiometer is shown in Figure 2.22.

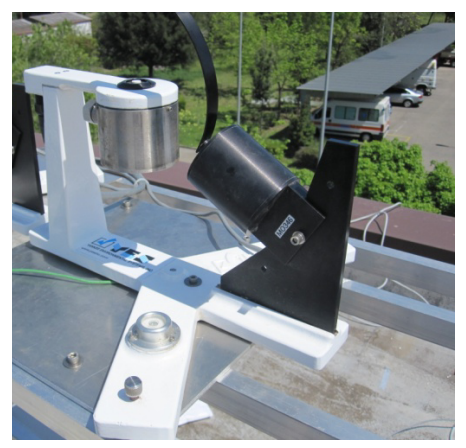

Figure 2.22. VIS-MFRSR YES shadowband radiometer.

\subsubsection{Remote sensing data: OMI - GOME/GOME2 - MODIS}

When ground-based data are not available, other sources of data are needed. Hence, satellite retrievals of different atmospheric factors are used.

\section{TOMS-OMI instruments}

The Total Ozone Monitoring System (TOMS) and the Ozone Monitoring Instrument (OMI) provide daily TOC values which are downloaded free from http://macuv.gsfc.nasa.gov/. The TOMS instrument was on board the Earth-Probe satellite till the end of 2004. OMI was installed on board Eos-Aura (OMI) and has been operational since the end of 2004. 
To download satellite data, GIOVANNI is an application which can be found at http://disc.sci.gsfc.nasa.gov/giovanni/overview/index.html. GIOVANNI data are obtained over an area of $0.2^{\circ}$ latitude x $0.2^{\circ}$ longitude around each measurement site. Daily Level 3 Global Gridded Products are used to obtain TOC data. This tool is used to download many of the satellite data used in this thesis.

\section{GOME-GOME2 instruments}

The Global Ozone Monitoring Experiment (GOME and GOME-2) data on board MetOp-A and ERS-2 satellites also provide daily TOC values. These values were supplied by the staff of the Remote Sensing Technology Institute (IMF) of the German Aerospace Centre (DLR).

\section{MODIS}

When aerosol properties are not available at the surface, the Moderate Resolution Imaging Radiometer (MODIS) AQUA Daily Level-3 can prove a good tool to obtain this information. This collection of data provides aerosol optical properties in $1^{\circ} \mathrm{x} 1^{\circ}$ grids and it is also available in the Giovanni application. For instance, the aerosol optical depth at $550 \mathrm{~nm}$ is the parameter used in Chapter 6.

\subsection{Algorithms}

\subsubsection{Cloudless data selection}

When available, visual observations are the most accurate form of ensuring cloudless conditions. The methodology developed by Long and Ackerman (2000) and modified by Biavati and di Sarra (2004) is implemented when visual criteria are not available to select cloud-free events. This is based on VIS-MFRSR global and diffuse broadband irradiance. The cloud screening algorithm uses the dependence on the solar zenith angle of the following quantities: diffuse-to-global irradiance, and the first and second derivative of global irradiance. These quantities are calculated from the acquired data, and compared with theoretical values obtained from simple reference clear-sky curves as in Long and Ackerman (2000), calculated for each day as a function of the solar zenith angle evolution. Data are selected as cloud-free if the measured quantities are close to the theoretical quantities within empirical intervals. Empirical intervals are determined by comparing the algorithm results with wide angle images of the sky. Cloud-free 
intervals of less than 20 minutes are discarded. The detection method tends to exclude data for solar SZA $>80^{\circ}$.

Having obtained the cloudless time periods, using the algorithm or visual observations, empirical cloudless models, fits and/or Look-up-Tables can be adopted and used in $\mathrm{CMF}$ evaluation.

\subsubsection{Algorithms to retrieve fractional sky cover}

In this section, two algorithms for estimating fractional sky cover from surface measurements are described. The first uses global and diffuse shortwave broadband data, while the other is based on spectral measurements.

Long et al. (2006) proposed a methodology based on surface measurements of downwelling global and diffuse SW radiation. A brief summary with the main steps of this algorithm is shown in Figure 2.23. As a first point, the algorithm described by Long and Ackerman (2000), explained in Section 2.2.1, is used to determine periods with cloudless conditions (sky fraction $=0$ ). In addition, in these periods it is possible to establish estimations for clear-sky global and diffuse SW radiations in the form $y=a$ $\cos (S Z A)^{b}, y$ being both global and diffuse SW. To minimize possible errors in the cloudless modelling, one fit is carried out for each cloudless period determined by the Long and Ackerman algorithm (2000).

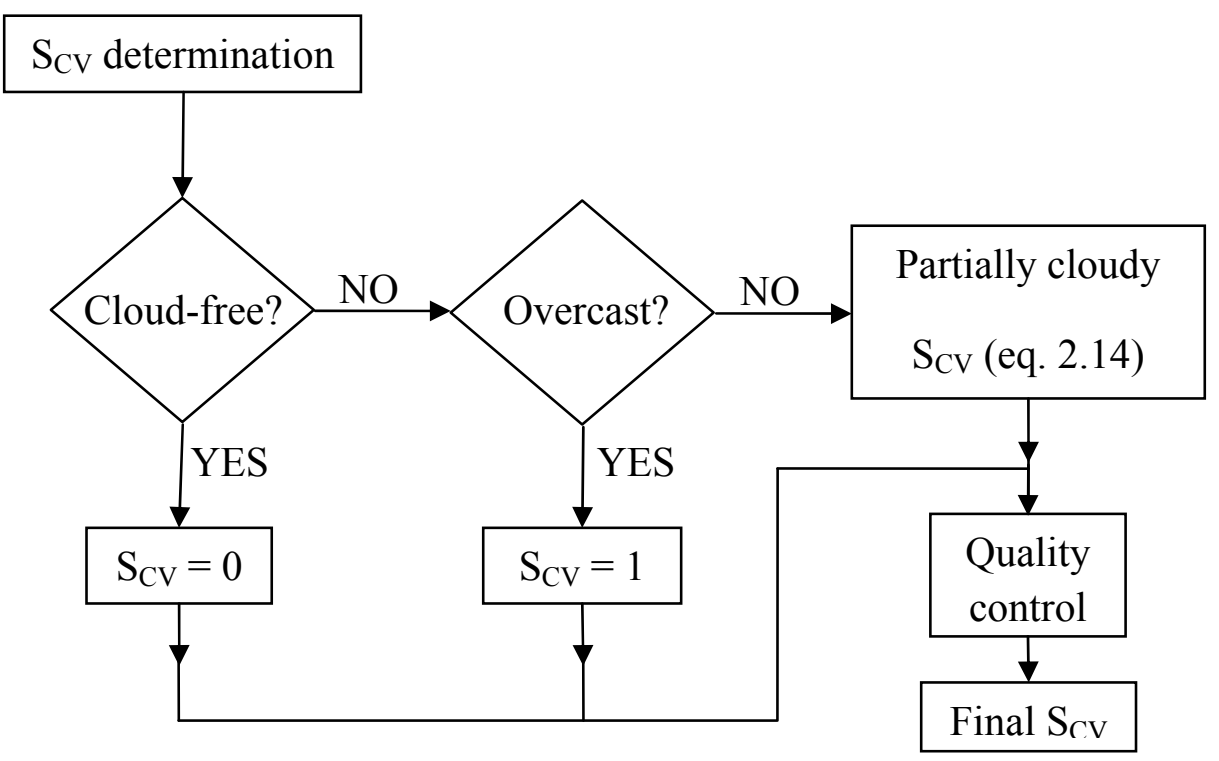

Figure 2.23. Main steps of the Long et al. (2006) algorithm. 
The estimations under cloudless conditions for the nearest cloudless time (with regard to the measurement time) are used to calculate the normalized downwelling diffuse cloud effect $\left(\mathrm{D}_{\mathrm{n}}\right)$ :

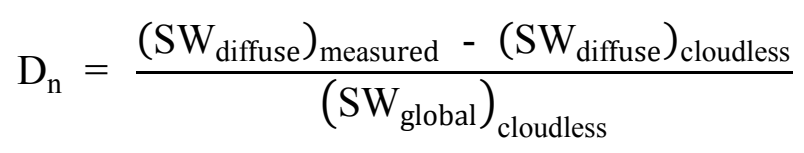

In other words, the diffuse cloud effect is normalized by clear-sky global SW estimated under cloudless conditions to help remove SZA dependence. Once this variable is evaluated, additional criteria have to be established because different conditions may produce values close to 1 . Two conditions have to be distinguished: optically thick overcast clouds and partly cloudy and optically thin overcast cases. For the former, the diffuse component is dominant (with a virtually zero direct $S W$ ), because of which $D_{n}$ can even become negative. To verify the occurrence of thick overcast cases, the CMF of SW radiation $\left(\mathrm{CMF}_{\mathrm{SW}}\right)$ may be analyzed. Cases showing $\mathrm{CMF}_{\mathrm{SW}}$ values between 0 and 0.4 are considered as overcast (sky fraction $=1$ ). Overcast conditions at other times can be detected by means of $\mathrm{D}_{\mathrm{n}}$ and the ratio between measured diffuse $\mathrm{SW}$ and measured global SW. If a limit of 0.9 is established for the diffuse ratio, at least $90 \%$ of the measured global SW must be coming from the diffuse field. In addition, to avoid problems with thin clouds, a limit of 0.37 in the $D_{n}$ values is applied, which corresponds to moderate to thick overcast clouds. Any data passing these conditions is declared to be overcast. For the rest of the data remaining after screening for overcast and cloudless conditions, an empirical formula (by a power law) is used to determine the fractional sky cover $\left(\mathrm{S}_{\mathrm{CV}}\right)$ value:

$$
\mathrm{S}_{\mathrm{CV}}=2.255\left(\mathrm{D}_{\mathrm{n}}\right)^{0.9381}
$$

An 11-point running average of sky coverage is calculated centred on the data sample of interest. After that, only data showing an average absolute deviation below 0.1 are retained to remove extreme oscillation cases. If at least one of the 11 data has been set to overcast in the previous tests, and if the absolute difference between the 11-point average and the data of interest is greater than the average absolute deviation and at least $4 \%$ in sky cover, a linear fit is calculated to retrieve a new estimation of $S_{C V}$ for the data of interest. To smooth the sky cover value over time, other anomalous data have to be detected. These are data which have at least $70 \%$ of the surrounding data (in the 11 points) as cloudless or partially cloudy, with at least two being cloud-free, and no more than two of the 11 points being assigned as overcast. For these cases, the $\mathrm{S}_{\mathrm{CV}}$ value in the analyzed point is weighted by the number of data classified as partially cloudy divided by 
the number of the 11 data that were either cloudless or partially cloudy. The validation results carried out by the authors of this technique show errors below $10 \%$ of the root mean square error in the fractional sky cover with respect to sky imager retrievals and human observations.

Min et al. (2008) expressed the fractional sky cover as a function of the transmittance ratio at two wavelengths. They used a ratio because this variable is less dependent on solar zenith angle. Wavelengths should be selected bearing in mind that a substantial contrast with aerosol optical depth is needed as well as minimal gaseous absorption interference, particularly water vapour due to cloud-water vapour interaction. In addition, using a ratio is both independent of the absolute calibration and not very sensitive to changes in cloud and aerosol optical properties. The authors apply this methodology to the VIS-MFRSR measurements in the 415 and $860 \mathrm{~nm}$ channels. The fractional sky cover may be obtained from:

$$
\left(\frac{I_{860 \mathrm{~nm}}}{\mathrm{I}_{415 \mathrm{~nm}}}\right)_{\text {measured }}=\left(1-\mathrm{S}_{\mathrm{CV}}\right)\left(\frac{\mathrm{I}_{860 \mathrm{~nm}}}{\mathrm{I}_{415 \mathrm{~nm}}}\right)_{\text {cloudless }}+\mathrm{S}_{\mathrm{CV}}\left(\frac{\mathrm{I}_{860 \mathrm{~nm}}}{\mathrm{I}_{415 \mathrm{~nm}}}\right)_{\text {cloudy }}
$$

where $\mathrm{I}_{860 \mathrm{~nm}}$ and $\mathrm{I}_{415 \mathrm{~nm}}$ are the irradiances at these wavelengths and where the label 'meas' refers to experimental data.

On the basis of a model study, the authors determined that the ratio under cloudy conditions is equal to 1 , the final expression for the fractional sky cover being the following:

$$
S_{C V}=\frac{\left(\frac{I_{860 n m}}{I_{415 n m}}\right)_{\text {measured }}-\left(\frac{I_{860 n m}}{I_{415 n m}}\right)_{\text {cloudless }}}{1-\left(\frac{I_{860 n m}}{I_{415 n m}}\right)_{\text {cloudless }}}
$$

They tested this method and found an uncertainty of about $10 \%$ in sensitivity and inter-comparison studies.

In this thesis, these two algorithms are tested at the TRISAIA station against the available visual observations. Figure 2.24 shows the comparison of the three methods considering visual observations as a reference. As can be seen in the figure, a high dispersion in each subset of cloud cover is observed. There are only nine subsets because the visual observations are performed in octas. Despite the variability of the results, the differences correlate with cloud cover. In the extreme case of 8 octas (overcast), the observed variability is the smallest. Therefore, these two algorithms, which are only 
applied at the TRISAIA station, can be used as a useful tool to identify overcast situations. This increases the selected cases which evidence these conditions, compared to the number of cases selected by visual observations. In addition, to ensure overcast conditions and to remove possible outliers, final selection of time periods presenting overcast conditions is made when both algorithms simultaneously gave a fraction sky cover in the range $(0.95,1.0)$. Comparing the time periods obtained with only visual observations to those from the algorithms, the number of hours with overcast conditions rises from 67 , using the former criterion, to 338 using the latter. This notable increase lies in the different time resolutions between the two methods: the algorithms are based on 1minute measurements, while visual observations, as mentioned above, have only an hourly frequency.

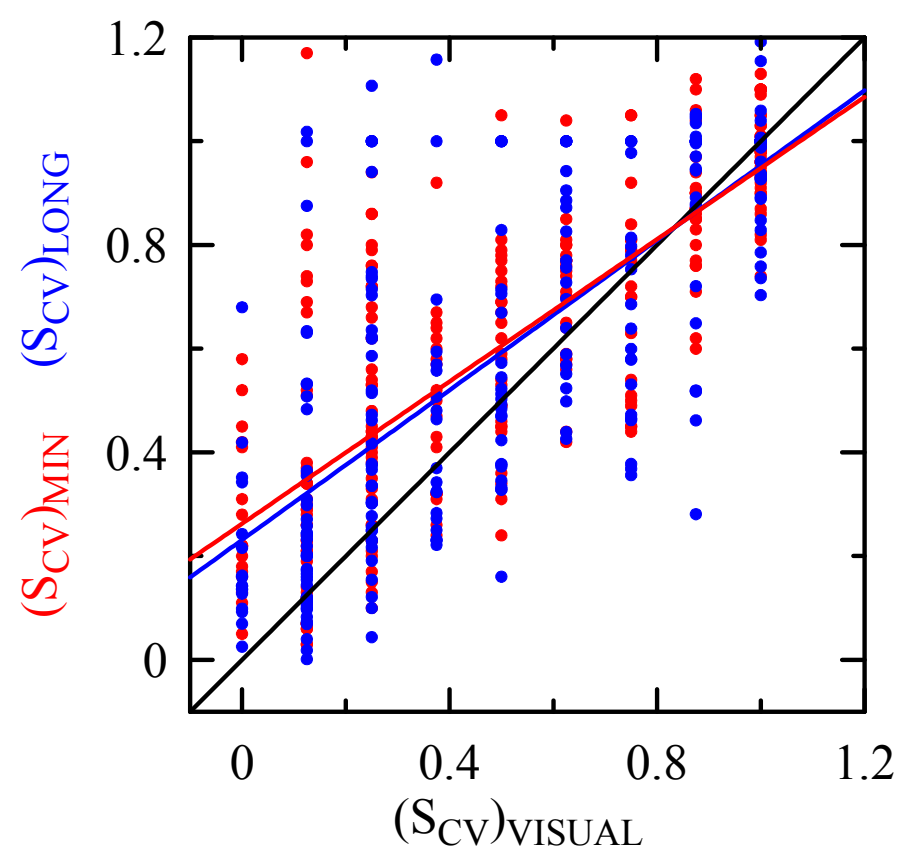

Figure 2.24. Comparison of the fractional sky cover obtained by the algorithms proposed by Long et al. (2006), $\left(S_{C V}\right)_{L O N G}$, by Min et al. (2008), $\left(S_{C V}\right)_{M I N}$, and the visual observations, $\left(S_{C V}\right)_{V I S U A L}$ at the TRISAIA station.

\subsubsection{Algorithm to retrieve Cloud Optical Thickness}

Following the algorithm proposed by Barnard et al. (2008), an estimation of the value of the cloud optical thickness (COT) can be obtained from surface broadband measurements of total shortwave irradiance. The main assumption in this algorithm is plane parallel conditions. Only cases with overcast skies should be considered in order to reduce errors. The authors expected a good performance only for optically thick clouds, 
although, surprisingly, the method also performs well for thin ice clouds (optical depth from 0.1 to 5 ). The validation performed by the authors shows good agreement with other COT retrieval methods.

The algorithm depends on surface albedo, asymmetry factor, and empirical cloudless estimation in the form:

$$
\begin{gathered}
\mathrm{COT}=\frac{\left(\frac{1.16}{\mathrm{r}_{1}}-1\right)}{(1-\mathrm{A})(1-\mathrm{g})} \\
\text { with } \mathrm{r}_{1}=\frac{\mathrm{SW}_{\text {meas }}}{\mathrm{C} \mu_{0}^{1 / 4}}
\end{gathered}
$$

where $\mathrm{A}$ is the surface albedo, $\mathrm{g}$ the asymmetry factor, $\mu_{0}$ is the cosine of the $\mathrm{SZA}, \mathrm{SW}_{\text {meas }}$ is the total shortwave irradiance measurement at surface, and $\mathrm{C}$ is an empirical fit for SW cloudless data in the form $\mathrm{C}=\mathrm{B} \mu_{0}^{1.25}$. The values of the $\mathrm{B}$ parameter, obtained by empirical $\mathrm{SW}_{\text {cloudless }}$ fits vs $\mu_{0}^{1.25}$, are 1095.38, 1053.60, and $1284.15 \mathrm{~W} \mathrm{~m}^{-2}$ for SRSUVA, TRISAIA, and LAMPEDUSA, respectively. A typical value of 0.17 is chosen for the SW surface albedo at SRSUVA. Airborne measurements at TRISAIA showed that ground albedo is around 0.20 (see Figure 2.25), so this value is chosen for Equation (2.18). Finally, a lower value is used for LAMPEDUSA. Di Biagio et al. (2009) carried out a detailed analysis of surface albedo at Lampedusa Island and found $28 \%$ and $72 \%$ contributions for land and ocean, respectively. As a result, in this case, surface albedo is fixed at 0.08 . 


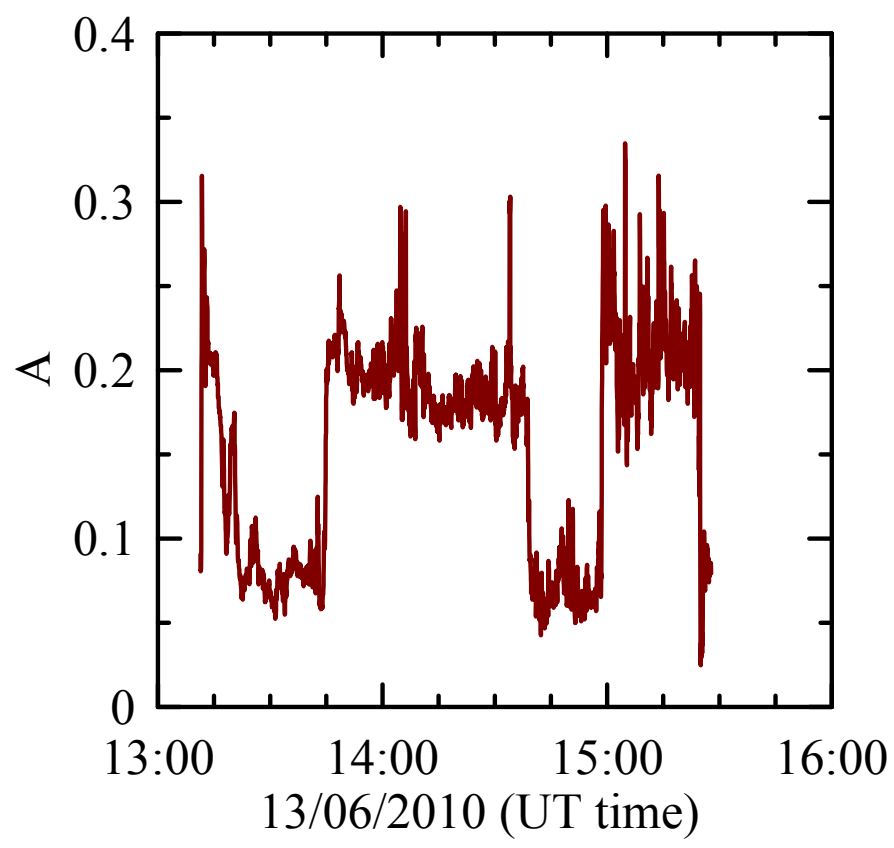

Figure 2.25. Surface albedo measurements by an aircraft at the TRISAIA station.

Finally, the asymmetry factor is set to the recommended values of 0.8 and 0.87 for water and ice clouds, respectively. In addition, Barnard et al. (2008) proposed a simple criterion to distinguish between ice and liquid clouds using the $\mathrm{CMF}_{\mathrm{SW}}$ as an indicator of ice clouds when its value is above 0.8 .

Following the authors' recommendation, this algorithm is only applied when overcast conditions are guaranteed so as to reduce errors caused by isolated clouds.

To verify the stability of the COT estimation formula, its sensitivity to changes in surface albedo and cloud asymmetry factor is tested with total shortwave measurements for a whole overcast day. One day of the TRISAIA database is selected. After that, the COT values are evaluated for two different surface albedos $(0.15$ and 0.20$)$ and two different cloud asymmetry factors $(0.8$ and 0.87 , the values for ice and water, respectively). The results obtained are shown in Figure 2.26. Figure 2.26.a shows that a $25 \%$ change in the surface albedo value only leads to a difference of around $6 \%$ in COT values. However, Figure 2.26.b shows how an $8 \%$ change in the cloud asymmetry factor leads to a difference of over $30 \%$ in the COT estimation. Therefore, the surface albedo value does not seem to be significant, while the classification between ice and water clouds proves to be the key factor in accurately estimating COT. Hence, the criteria to select between the two types of clouds explained by Barnard et al. (2008) are implemented so as to reduce possible errors in the asymmetry factor choice. 

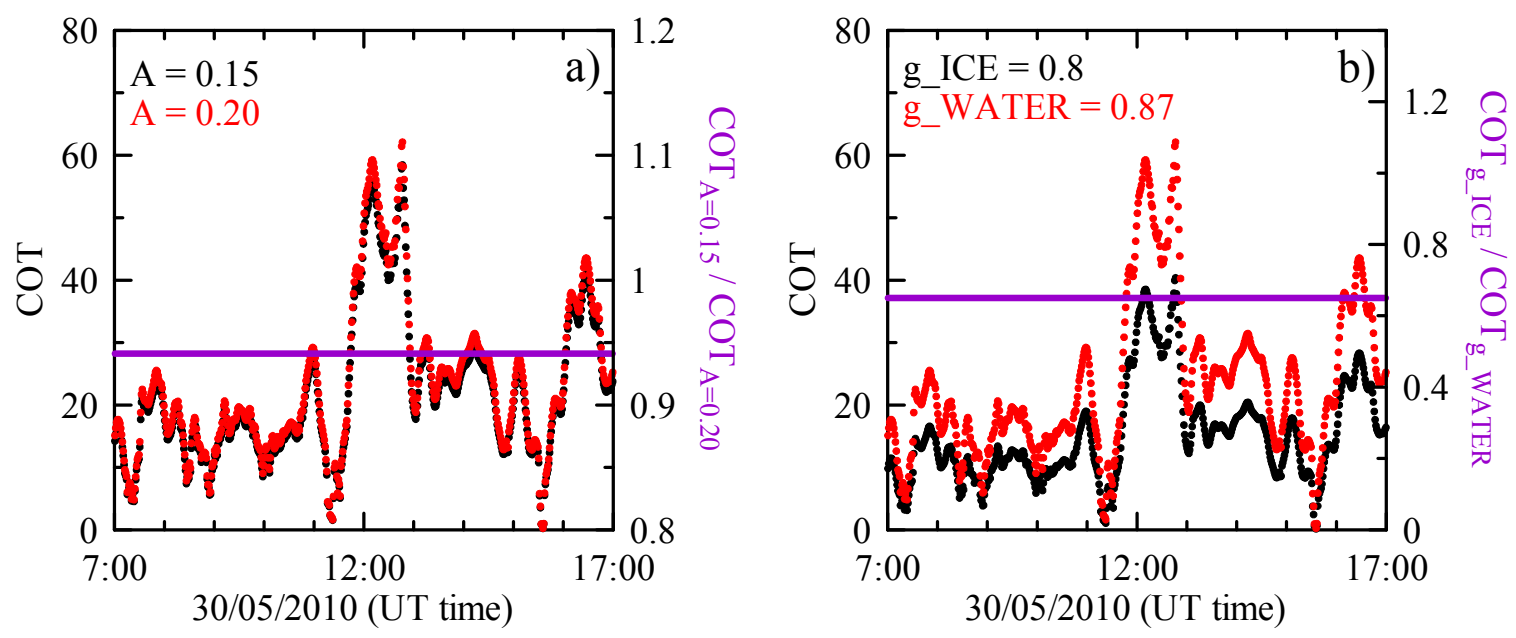

Figure 2.26. COT estimations by Equations (2.18) and (2.19) for different surface albedo (a) and cloud asymmetry factor (b).

\subsection{Stations}

All the instruments mentioned in Section 2.1 are located at different stations. Not all worked at the same station, hence, this section focuses on presenting each. As mentioned before, three European stations are used in this thesis: SRSUVA, TRISAIA and LAMPEDUSA. Their locations are shown in Figure 2.27.

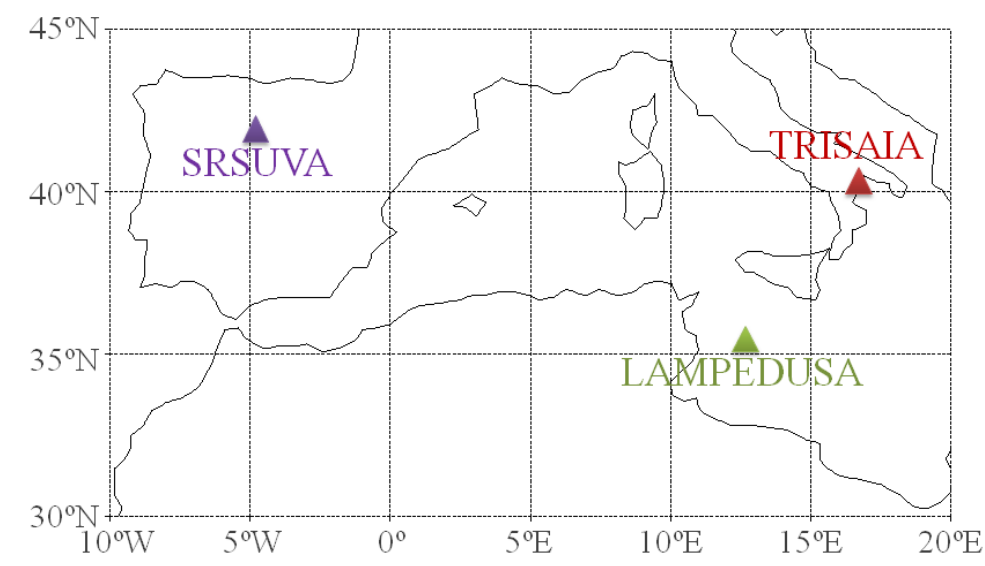

Figure 2.27. Location of the three stations used in this thesis. 


\subsubsection{SRSUVA}

The Solar Radiometric Station of the University of Valladolid (SRSUVA) is located in a rural area free from obstructions $\left(41^{\circ} 40^{\prime} \mathrm{N}, 4^{\circ} 50^{\prime} \mathrm{W}, 840 \mathrm{~m}\right.$ a.s.1.), about 35 $\mathrm{km} \mathrm{NW}$ of the city of Valladolid (Spain) in the autonomous community of Castilla $\mathrm{y}$ León, a region covering one fifth of the whole of Spain. The climate is continental, but is also influenced by the Mediterranean Sea, with dry and warm summers (maximum $\sim 38^{\circ} \mathrm{C}$ ) and cold and wet winters (minimum $\sim-7^{\circ} \mathrm{C}$ ). Cloudless skies are predominant in summer while cloudy skies are most frequent in autumn and winter. Typical annual rainfall averages about $580 \mathrm{~mm}$.

SRSUVA contains a large number of radiometric and meteorological sensors (see Figure 2.28): eight Kipp\&Zonen CM-6B record global shortwave radiation (global and diffuse component on horizontal, tilt, and vertical surfaces); for the UV range, there are two spectral ranges available (UV total and UV-B) measured by the Eppley TUVR and YES UVB-1 (three instruments) radiometers; a solar tracker with two CMP-21 and a CHP-1 which record data of global, diffuse, and direct components of the SW radiation; one MICROTOPS-II hand-held photometer; one albedometer CM-7B which records SW radiation from sky and ground surface; six photometric sensors LI-210SA which take measurements of visible radiation (illumination) with a spectral responsivity curve equal to the average human eye; two Eppley PIR record downward thermal radiation; and a LI190SA quantum sensor measures Photosynthetically Active Radiation (PAR). Other meteorological variables like temperature, pressure and humidity are recorded by several sensors such as Campbell Scientific HMP35AC and RPT410F, among others. All sensors are connected to two CR23X Campbell Dataloggers which are programmed to record measurements each 10 minutes as an average of 10 -second values.

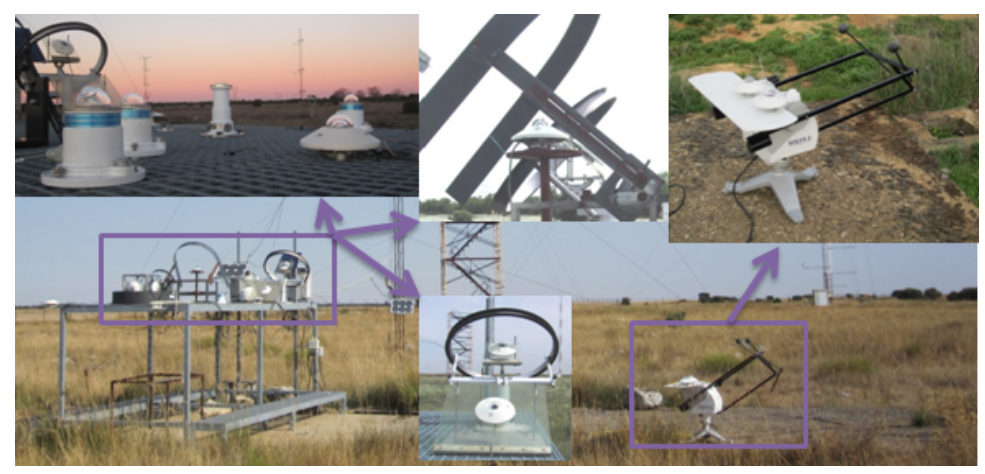

Figure 2.28. SRSUVA station and some of its instruments. 
Table 2.5. SRSUVA station instruments used, the variables they record and the time period used for the thesis.

\begin{tabular}{cccc}
\hline Instrument & Variable & Owner & Time period \\
\hline UVB-1 \#010922 & UVI & SRSUVA & $2002-2010$ \\
UVB-1 \#090503 & UVI & SRSUVA & $2009-2010$ \\
MICROTOPS-II & TOC & SRSUVA & $2007-2010$ \\
Visual observations & Cloud cover & AEMet & $2002-2010$ \\
CM-6B & SW & SRSUVA & $2002-2010$ \\
CMP-21 & SW & SRSUVA & 2010 \\
\hline
\end{tabular}

Table 2.5 shows the SRSUVA station instruments and information used in this thesis.

\subsubsection{LAMPEDUSA}

The LAMPEDUSA station is located on Lampedusa island $\left(35.5^{\circ} \mathrm{N}, 12.6^{\circ} \mathrm{E}, 40 \mathrm{~m}\right.$ a.s.1.) at the station for climate observations, run by ENEA (Agenzia Nazionale per le Nuove Tecnologie, l'Energia e lo Svilippo Economico Sostenibile). This station is located on a high plateau on the North-Eastern coast of the island. Lampedusa Island has a surface area of about $20 \mathrm{~km}^{2}$, and is located $\sim 100 \mathrm{~km}$ east of Tunisia and $\sim 200 \mathrm{~km}$ north of Libya. Annual average precipitation is about $320 \mathrm{~mm}$, and mainly occurs from October to February.

A variety of aerosol types from different sources reach Lampedusa: dust from the Sahara desert, mainly in summer, polluted and biomass burning aerosol from the European continent, and marine aerosol from the sea. Continuous observations of greenhouse gas concentration, aerosol properties, total ozone, ultraviolet irradiance, actinic flux, and other climatic parameters are carried out (see Figure 2.29).

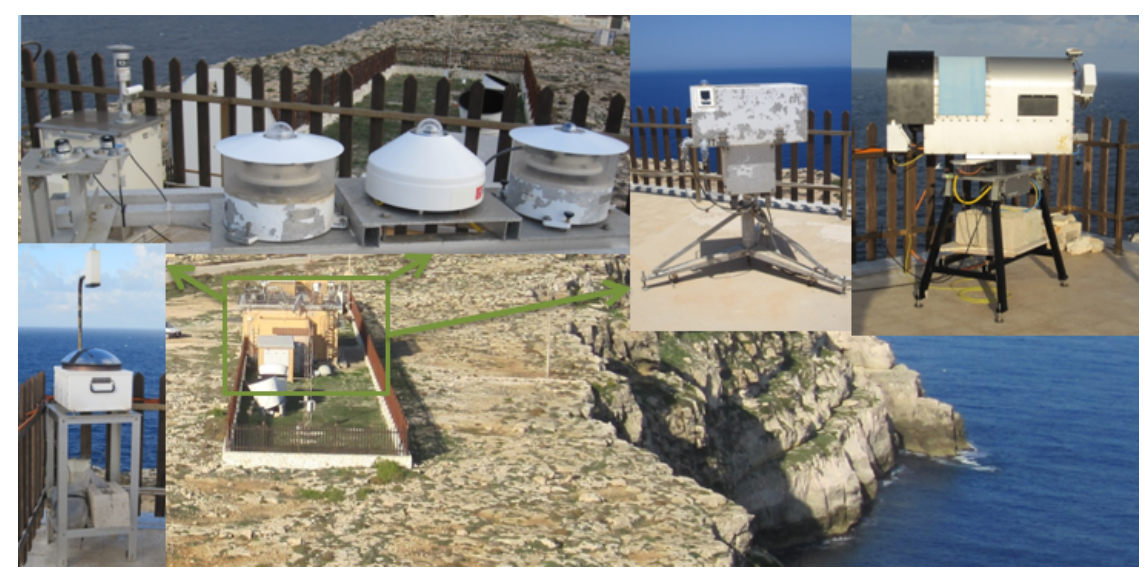

Figure 2.29. LAMPEDUSA station and some of its instruments. 
All instruments considered in this thesis are situated on the roof of the Station and have an obstruction-free horizon.

Table 2.6 shows the instruments in place at the LAMPEDUSA station that are used in this thesis. All radiometric data have a 1-minute resolution with the exception of the BREWER instrument, which needs eight minutes to perform one spectral scan. The ozone values obtained from this instrument are taken as daily values, except in the ozone comparison with the MICROTOPS-II instrument when the closest measurement is considered for the time of the manual record.

Table 2.6. LAMPEDUSA station instruments used, the variables they record and the time period used for the thesis.

\begin{tabular}{|c|c|c|c|}
\hline Instrument & Variable & Owner & Time period \\
\hline BREWER & UV irradiance / TOC & ENEA & $2005+2010 / 2011$ \\
\hline UV-MFRSR & UVI & ENEA & 2010/2011 \\
\hline TSI 440 & Cloud cover & ENEA & $2005+2010 / 2011$ \\
\hline PSP & SW irradiance & ENEA & 2005 \\
\hline VIS-MFRSR & $\begin{array}{c}\text { SW irradiance } \\
\text { Aerosol properties }\end{array}$ & ENEA & $2010 / 2011$ \\
\hline UVB-1 \#090503 & UVI & SRSUVA & 2010 \\
\hline MICROTOPS-II & TOC & SRSUVA & 2010 \\
\hline
\end{tabular}

\subsubsection{TRISAIA}

Observations at the TRISAIA station were made over a two-month measurement campaign carried out in May and June 2010 at the ENEA-Trisaia Research Centre $\left(40.16^{\circ} \mathrm{N}, 16.64^{\circ} \mathrm{E}, 40 \mathrm{~m}\right.$ a.s.1.) in Southern Italy. This campaign was possible thanks to two projects: MINNI (Modello Integrato Nazionale a supporto della Negoziazione Internazionale sui temi dell'Inquinamento Atmosferico) and MORE (Marine Ozone and Radiation Experiment). The first is an Italian project funded by the Italian Ministry of the Environment and ENEA collaborating with Arianet and IIASA. The main objective of the TRISAIA campaign was to analyze the accuracy of the MINNI model. Taking advantage of the campaign, the EUFAR (European Facility for Airborne Research) MORE project program enabled several flights with an aircraft under different conditions. The TRISAIA campaign involved several European groups: ENEA (from three different research centres: Casaccia, Bologna, and Trisaia), the University of Valladolid Atmosphere and Energy Lab, the G-24 group of the University of Rome, Institute of Meteorology and Climate Research - Atmospheric Environmental Research in Garmisch-Partenkirchen (Germany), the environmental consulting company Arianet in Milan (Italy), and the Italian Universities of Siena and Rome 3. 


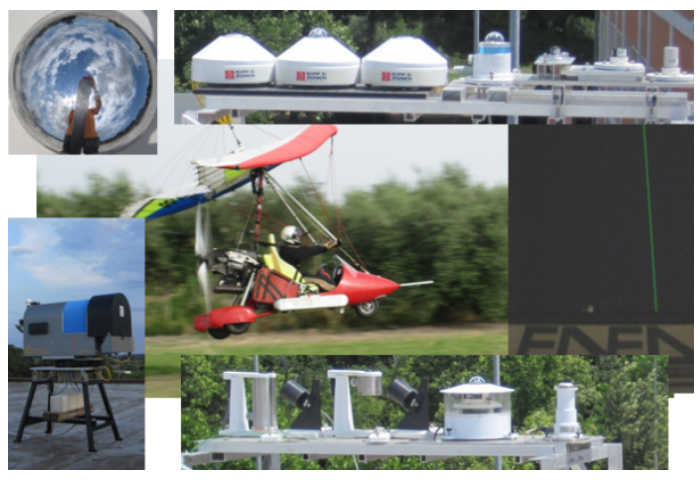

Figure 2.30. Some of the instruments at the TRISAIA station.

All the instruments considered (see Figure 2.30) were located on the roof of the two-floor building and had an obstruction-free horizon. The list of the instruments with measurements used in this thesis is shown in Table 2.7. All radiometric data were taken with a temporal resolution of one minute. The LIDAR recorded three profiles at the beginning of each hour in 15 minutes, with the exception of continuous profiles in the MORE campaign in correspondence with aircraft flights. Whenever possible, the frequencies of the 'manual' data, in other words, cloud cover visual observations and MICROTOPS-II instrument, were hourly.

Table 2.7. TRISAIA station instruments used, the variables they record and the time period used for the thesis.

\begin{tabular}{|c|c|c|c|}
\hline Instrument & Variable & Owner & Time period \\
\hline UV-MFRSR & $\begin{array}{c}\text { Spectral UV } \\
\text { (global and diffuse) }\end{array}$ & ENEA & 2010 \\
\hline UVB-1 \#090503 & UVI & SRSUVA & 2010 \\
\hline DAS & Actinic Flux / J $\left(\mathrm{O}^{1} \mathrm{D}\right)$ & ENEA & 2010 \\
\hline HATPRO & LWP & ENEA & 2010 \\
\hline VIS-MFRSR & $\begin{array}{c}\text { SW irradiance } \\
\text { Aerosol properties } \\
\text { Cloud effective radius }\end{array}$ & ENEA & 2010 \\
\hline LIDAR & $\begin{array}{l}\text { Cloud base } \& \text { top } \\
\text { Aerosol vertical distribution }\end{array}$ & G-24 & 2010 \\
\hline Visual observations & Cloud cover & SRSUVA & 2010 \\
\hline CMP 21 & SW irradiance & ENEA & 2010 \\
\hline MICROTOPS-II & TOC & SRSUVA & 2010 \\
\hline
\end{tabular}




\subsection{Radiative transfer model: libRadtran}

\subsubsection{Radiative Transfer Equation (RTE) and Discrete Ordinate Approximation}

In this section, a brief description of the radiative transfer equation and the method used to solve it is given.

Radiance $\left(\mathrm{L}_{\lambda}\right)$ is a radiometric measure that describes the amount of radiant energy $\left(\mathrm{dE}_{\lambda}\right)$ in a specified frequency interval $(\lambda, \lambda+\mathrm{d} \lambda)$ which is transported across an element of area $\mathrm{dAr}$ and in directions confined to an element of solid angle $\mathrm{d} \Omega$, oriented at an angle of $\theta$ from the normal direction to the surface, over a time dt (see Figure 2.31). Its units in the international system (SI) are $\mathrm{W} \mathrm{m}^{-2} \mathrm{sr}^{-1}$ and it is given by (Chandrasekhar, 1960; Lenoble, 1993):

$$
\mathrm{L}_{\lambda}=\frac{\mathrm{dE}_{\lambda}}{\cos \theta \mathrm{d} \lambda \mathrm{dAr} \mathrm{d} \Omega \mathrm{dt}}
$$

If a radiative field is characterized by its radiance $\mathrm{L}_{\lambda}$ with a propagation direction $\overrightarrow{\boldsymbol{s}}$ in a material of extinction coefficient $\mathrm{k}_{\mathrm{e}, \lambda}$ and a density equal to 1 (International System Units), the radiant energy entering a volume element dA ds (see Figure 2.32) per unit time in a solid angle $\mathrm{d} \Omega$ is:

$$
\Phi_{1}=\mathrm{L}_{\lambda} \mathrm{dAr} \mathrm{d} \Omega
$$

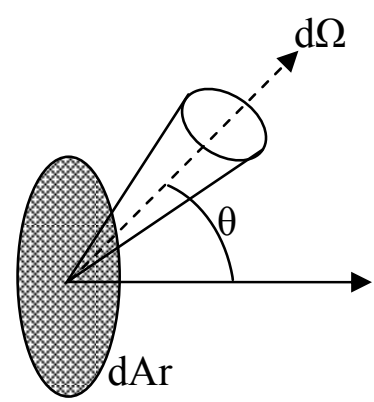

Figure 2.31. Definition of radiance, adapted from Lenoble (1993). 


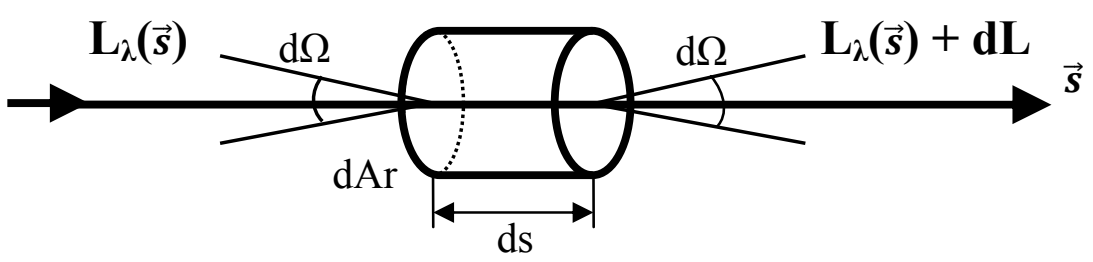

Figure 2.32. Establishing the radiative transfer equation, adapted from Lenoble (1993).

The dependence of $\mathrm{L}_{\lambda}$ on direction $\overrightarrow{\boldsymbol{s}}$ is suppressed in the notation used in the equations to facilitate reading.

The energy leaving the volume element is:

$$
\Phi_{2}=\left(L_{\lambda}+\frac{d L_{\lambda}}{d s} d s\right) d A r d \Omega
$$

The radiant flux lost by absorption and scattering along ds is:

$$
\Phi_{3}=-\mathrm{k}_{\mathrm{e}, \lambda} \mathrm{L}_{\lambda} \mathrm{dAr} \mathrm{d} \Omega \mathrm{ds}
$$

Some radiant flux is gained along ds by two processes, scattering from other directions into direction $\overrightarrow{\boldsymbol{s}}$ and thermal emission by the volume itself. The flux gained in the volume element is:

$$
\Phi_{4}=\mathrm{k}_{\mathrm{e}, \lambda} \mathrm{J}_{\lambda} \mathrm{dAr} \mathrm{ds} \mathrm{d} \Omega
$$

where $J_{\lambda}$ is the source function. This function is the sum of the scattering and emission source functions.

Therefore, energy conservation leads to:

$$
\Phi_{2}-\Phi_{1}=\Phi_{4}-\Phi_{3}
$$


With the Equations from (2.21) to (2.24), this equation can be transformed in the general radiative transfer equation, which fully defines the radiance $\mathrm{L}_{\lambda}$ in the medium:

$$
\frac{d L_{\lambda}}{d s}=-k_{e, \lambda}\left[L_{\lambda}-J_{\lambda}\right]
$$

The formal solution of this equation is (Chandrasekhar, 1960):

$$
\mathrm{L}_{\lambda}(\mathrm{s})=\mathrm{L}_{\lambda}(0) \mathrm{e}^{-\tau(\mathrm{s}, 0)}+\int_{0}^{\mathrm{s}} \mathrm{J}_{\lambda}\left(\mathrm{s}^{\prime}\right) \mathrm{e}^{-\tau\left(\mathrm{s}, \mathrm{s}^{\prime}\right)} \mathrm{k}_{\mathrm{e}, \lambda} d \mathrm{~s}^{\prime}
$$

where $\tau\left(\mathrm{s}, \mathrm{s}^{\prime}\right)$ is the optical thickness of the material between points $\mathrm{s}$ and $\mathrm{s}^{\prime}$ :

$$
\tau\left(\mathrm{s}, \mathrm{s}^{\prime}\right)=\int_{\mathrm{s}^{\prime}}^{\mathrm{s}} \mathrm{k}_{\mathrm{e}, \lambda} \mathrm{ds}
$$

The physical meaning of the solution evidences that the intensity at any point (s) and in a given direction results from the emission at all previous points ( $\left.\mathrm{s}^{\prime}\right)$ reduced by the factor $\mathrm{e}^{-\tau\left(\mathrm{s}, \mathrm{s}^{\prime}\right)}$ to take into account extinction by the intervening matter.

There are many methods to solve the radiative transfer equation. In this thesis, the DIScrete Ordinates Radiative Transfer 2.0, DISORT 2.0 (Stamnes et al., 2000) is chosen. DISORT considers the transfer of monochromatic unpolarized radiation in a scattering, absorbing and emitting plane parallel medium, with specified bidirectional reflectivity at the lower boundary. The medium can be forced by a parallel beam and/or diffuse incidence and/or Planck emission at either boundary. For this type of medium, the RTE is in the form:

$$
\mu_{0} \frac{\mathrm{dI}_{\lambda}^{\text {tot }}\left(\tau_{\lambda}, \mu_{0}, \Phi\right)}{\mathrm{d} \tau_{\lambda}}=\mathrm{I}_{\lambda}^{\mathrm{tot}}\left(\tau_{\lambda}, \mu_{0}, \Phi\right)-\operatorname{SF}_{\lambda}\left(\tau_{\lambda}, \mu_{0}, \Phi\right)
$$

where $\mathrm{I}_{\lambda}^{\text {tot }}$ is the specific intensity at vertical optical depth $\tau_{\lambda}$ (measured downward from the upper boundary) in a cone of unit solid angle along the direction given by $\mu_{0}$ and $\Phi$ ( $\Phi$ is the azimuthal angle and $\mu_{0}$ is the cosine of the polar angle), and $\mathrm{SF}_{\lambda}$ is the source function which has the internal source (Q) plus scattering into the direction given by $\mu_{0}$ 
and $\Phi$ from all other directions in the form (the wavelength dependence of all quantities is omitted in the rest of this section):

$$
\begin{gathered}
\operatorname{SF}\left(\tau, \mu_{0}, \Phi\right)=\mathrm{Q}\left(\tau, \mu_{0}, \Phi\right)+ \\
+\frac{\omega_{0}(\tau)}{4 \pi} \int_{0}^{2 \pi} \mathrm{d} \Phi^{\prime} \int_{-1}^{1} \mathrm{~d} \mu^{\prime} \mathrm{P}\left(\tau, \mu_{0}, \Phi ; \mu_{0}^{\prime}, \Phi^{\prime}\right) \mathrm{I}_{\lambda}^{\mathrm{tot}}\left(\tau, \mu_{0}^{\prime}, \Phi^{\prime}\right)
\end{gathered}
$$

where $\omega_{0}$ is the single scattering albedo, and $\mathrm{P}$ is the scattering phase function.

DISORT assumes that the scattering phase function depends only on the angle between the incident and scattered beams. This fact can be used to factor out the dependence of the azimuthal angle in Equations (2.29) and (2.30). Hence, the P function can be expanded in a series of $2 \mathrm{~N}$ Legendre polynomials and, finally, intensity can be expressed as a Fourier cosine series of $2 \mathrm{~N}$ terms, Equation (2.29) giving a system of $2 \mathrm{~N}$ independent integro-differential equations that can be approximated for the following system of ordinary differential equations:

$$
\mu_{\mathrm{i}} \frac{\mathrm{dI}^{\mathrm{m}}\left(\tau, \mu_{\mathrm{i}}\right)}{\mathrm{d} \tau}=\mathrm{I}^{\mathrm{m}}\left(\tau, \mu_{\mathrm{i}}\right)-\mathrm{SF}^{\mathrm{m}}\left(\tau, \mu_{\mathrm{i}}\right), \mathrm{i}= \pm 1, \ldots, \pm \mathrm{N}
$$

Each $\mu_{\mathrm{i}}$ in Equation (2.31) is called a stream.

To obtain analytic solutions, DISORT assumes the medium as $\mathrm{N}$ adjacent homogeneous layers. In other words, the single scattering albedo and phase function are assumed constant with each layer although they can vary from layer to layer.

\subsubsection{Inputs in the libRadtran model}

The libRadtran software package (Mayer and Kylling, 2005) is a suite of tools for radiative transfer calculations in the Earth's atmosphere. Its software package is available from http://www.libradtran.org. Its main tool is the uvspec program, and it may be used to compute radiances, irradiances and actinic fluxes. uvspec was originally designed to 
perform calculations in the ultraviolet and visible parts of the spectrum, and is therefore a useful model for this thesis.

The uvspec model comprises three essential parts: a) conversion from atmospheric properties into optical properties, b) radiative transfer equation solver, and c) postprocessing of the solver output. An overview of the uvspec model structure is shown in Figure 2.33 .

As described in the previous section, DISORT 2.0 is the method chosen to solve the RTE. The atmospheric description is made by an INPUT file with all the parameters influencing, in this case, the UV radiation levels. A description of the values used in the main input variables follows. If no comment is made about the stations, it means that the range is the same for all three stations.

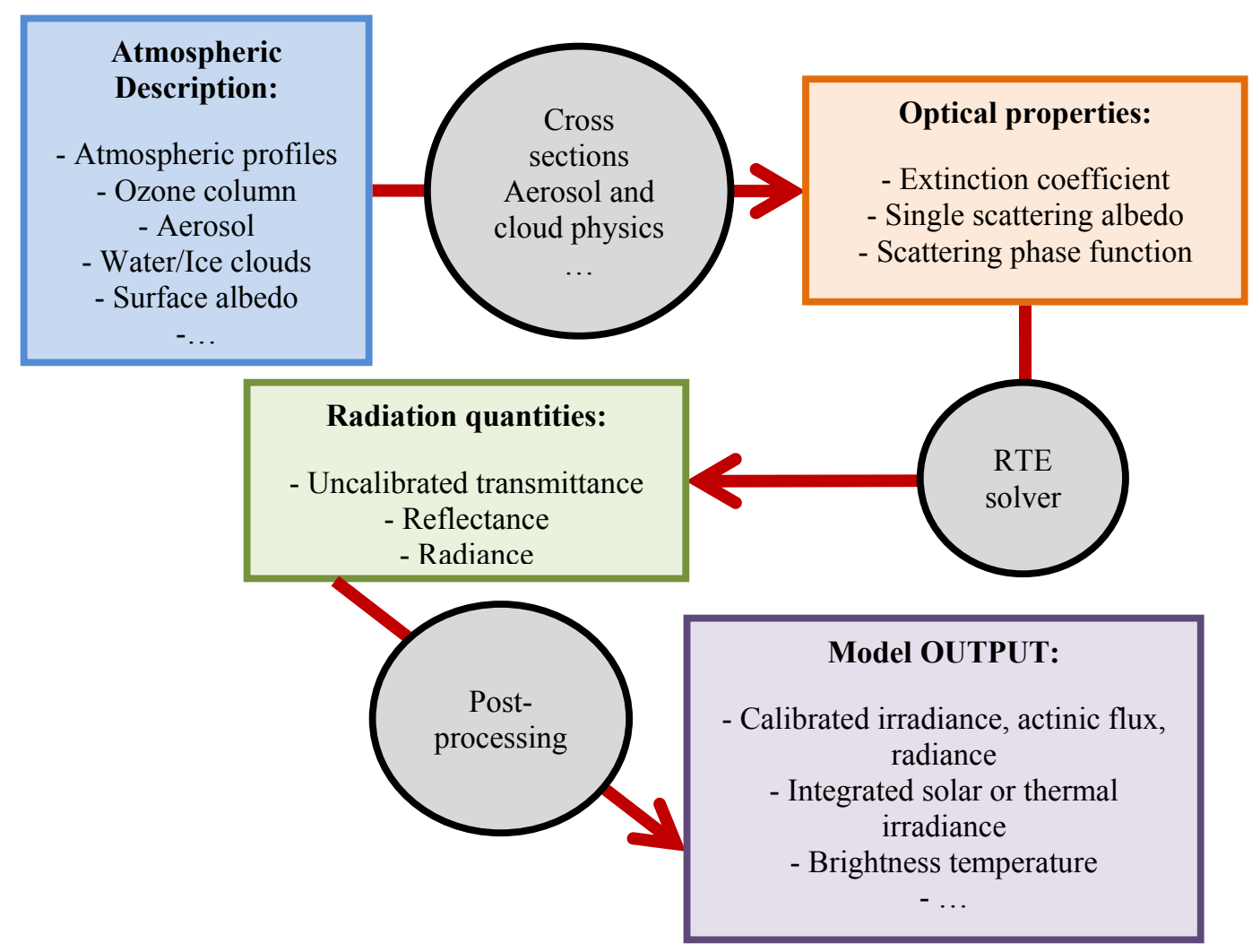

Figure 2.33. Structure of the uvspec model, adapted from Mayer and Kylling (2005). 


\section{Solar Zenith Angle}

In order to minimize the number of simulations, the SZA is set from $10^{\circ}$ to $80^{\circ}$ at $5^{\circ}$ steps. The command used is 'sza value'.

\section{Total Ozone Column}

TOC values within a wide interval between 200 and 500 DU at 20 DU steps are used in the simulation. The command used is 'dens_column O3 value DU'.

\section{Aerosol properties}

There numerous commands to change aerosol properties. In this section only the ones used in this thesis are explained.

The default configuration of aerosol takes the aerosol models proposed by Shettle (1989). Four commands have to be defined: a) 'aerosol_vulcan value' which controls the aerosol distribution above $2 \mathrm{~km}$ and is an integer number indicating background aerosol (1) up to extreme volcanic aerosols (4); b) 'aerosol_haze value' selects the type of aerosol particles in the lower $2 \mathrm{~km}$ of the atmosphere among rural (1), maritime (4), urban (5), and tropospheric (6); c) with 'aerosol_season value' the spring-summer (1) or autumnwinter (2) profiles can be chosen; and d) 'aerosol_visibility value' is the horizontal visibility in $\mathrm{km}$.

Once the default properties are fixed, the values of the aerosol optical thickness at $550 \mathrm{~nm}\left(\mathrm{AOT}_{550 \mathrm{~nm}}\right)$ are set with the values of $\alpha$ and $\beta$ Ångström coefficients ('aerosol_angstrom value $\alpha$ value $_{\beta}$ ') in order to obtain a wavelength dependent aerosol optical thickness. If further aerosol information is known, such as single scattering albedo ('aerosol_set_ssa value') and asymmetry factor ('aerosol_set_gg value'), it is included in the simulations.

As no information on aerosol content is available for the simulations at the SRSUVA station, the average values of $\mathrm{AOT}_{550 \mathrm{~nm}}$ and $\alpha$ Ångström coefficient are obtained from the nearest AERONET station (http://aeronet.gsfc.nasa.gov/), located in Palencia, Spain (see, Cachorro et al., 2008, among others). For this station, only this option is used: 'aerosol_angstrom 1.32000 .0481 ' which produces AOT $_{550 \mathrm{~nm}}=0.1059$. This value is the annual climatological average.

However, for the simulations carried out for the TRISAIA and LAMPEDUSA stations, where more aerosol information is available, variability on the $\mathrm{AOT}_{550 \mathrm{~nm}}$ must be extended. To do this, the $\alpha$ Ångström coefficient is set to an average value of 0.86 and the 
$\beta$ coefficient is varied in order to obtain an $\mathrm{AOT}_{550 \mathrm{~nm}}$ of between 0.05 and 0.85 at 0.2 steps. In addition, the values of the single scattering albedo and the asymmetry factor are set to a constant value for all wavelengths and altitudes. The selected values are established to 'aerosol_set_ssa 0.85 ' and 'aerosol_set_gg 0.73', typical values in the UV region for the aerosol type observed in the area (e.g. Pace et al., 2006).

\section{Cloud properties}

In this thesis, only simulations of water clouds are carried out and always with a cloud cover of 8 octas, in other words, overcast conditions.

The easiest way to define a water cloud in the uvspec model is to specify the liquid water content, the effective droplet radius, and the altitude at each layer in a file. A typical file, which is indicated in the general INPUT file with 'wc_file file', is as follows:

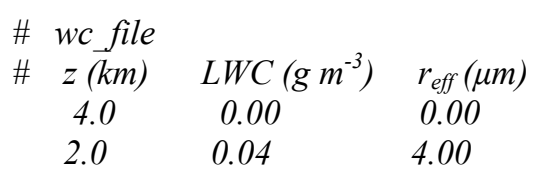

This configuration places a cloud layer between 2 and $4 \mathrm{~km}$ a.s.l. with an LWC of $0.04 \mathrm{~g} \mathrm{~m}^{-3}$ and an effective radius of $4.00 \mu \mathrm{m}$.

There are different ways to convert microphysical properties to optical properties. Exact determination by Mie calculations is extremely time-consuming. Hence, the $\mathrm{Hu}$ and Stamnes (1993) parameterization was chosen. This is based on the fact that there is a unique relation between cloud radiative properties and the equivalent radius in both the shortwave and longwave regions. The extinction coefficient, the single scattering albedo, and the asymmetry factor are expressed by a non-linear function in terms of the effective radius for three different ranges: 2.5-12.5 $\mu \mathrm{m}, 12.5-30 \mu \mathrm{m}$, and 30-60 $\mu \mathrm{m}$. These relationships are insensitive to the details of the drop size distribution, such as shape, width, and skewness. Experimentally, it implies that it is not necessary to measure the full size distribution to obtain the optical properties of the clouds. The great advantage of this parameterization is that it is almost as accurate and is more than thousands of times computationally faster than the "exact" Mie calculations.

In order to simulate many cloudy situations, different combinations of LWC and $r_{\text {eff }}$ values are used. 
The default configuration is selected to place a cloud layer between 2 and $3 \mathrm{~km}$ a.s.l., and the microphysical properties varied accordingly in order to have COT values from 1 to 100 .

\section{Surface albedo}

With regard to the surface albedo in the UV range, a different value is used at each station. For the simulations carried out for the SRSUVA station, a constant albedo of 0.03 (Staiger and Koepke, 2005; among others) is fixed, with the command 'albedo 0.03', because the different surface conditions around the station made it difficult to consider one/two unique types for spectral dependence. This decision is supported since spectral dependence is usually weak in the UV and does not generally exceed 0.02 (Blumthaler and Ambach, 1988; Schwander et al., 1999; among others).

Simplifying, for the LAMPEDUSA station, $22 \%$ of the land contribution mentioned before is ignored, and the spectral dependence of the ocean albedo is taken. Finally, the TRISAIA station surface albedo is calculated considering $50 \%$ of the surface covered by water and the other half by grass. Figure 2.34 shows the three surface albedos used in the simulations. The spectral dependencies of ocean and grass surfaces in the UV are taken from Doda and Green (1980) and Feister and Grewe (1995), respectively. The command used in this case is 'albedo_file name'.

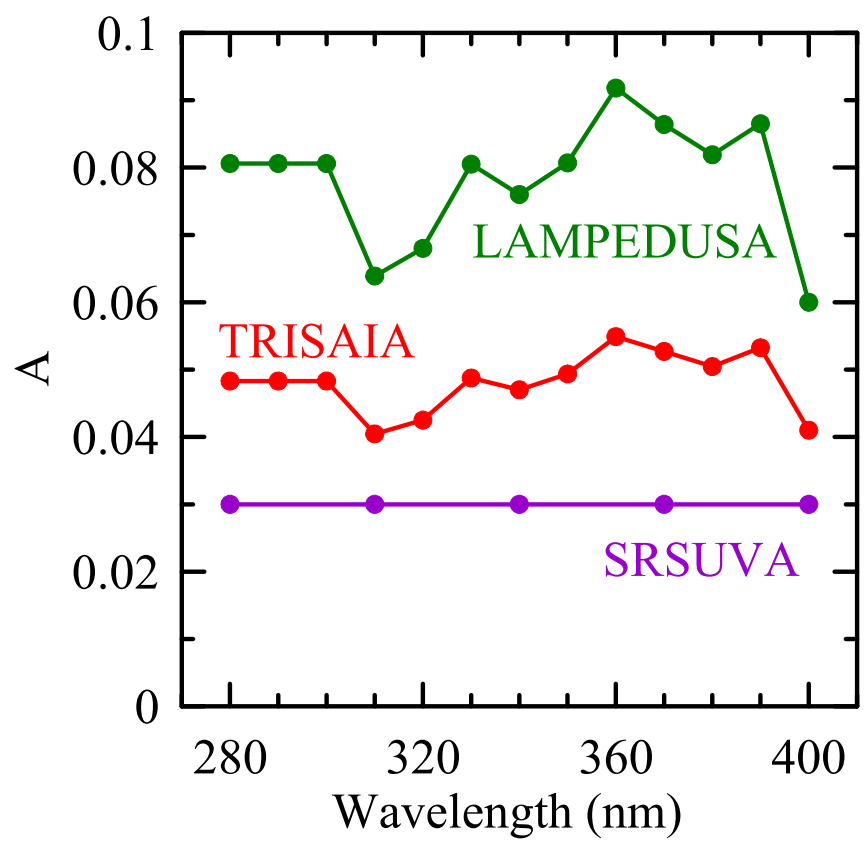

Figure 2.34. Surface albedo (A) values used in the radiative transfer simulations for each station. 
Atmospheric profiles

The altitude, pressure, and temperature vertical profiles must be defined. In addition, libRadtran provides several standard atmospheres (taken from Anderson et al., 1986) containing information on air, ozone, oxygen, water vapour, $\mathrm{CO}_{2}$, and $\mathrm{NO}_{2}$ densities that can be introduced with the command 'atmosphere_file name'.

The standard atmosphere defined for midlatitude summer is used in the LAMPEDUSA and TRISAIA simulations. The selection for the SRSUVA simulations is the US 1976 standard atmosphere $\left(45^{\circ} \mathrm{N}\right)$. Figure 2.35 shows the temperature and ozone density profiles for these two types of atmosphere.
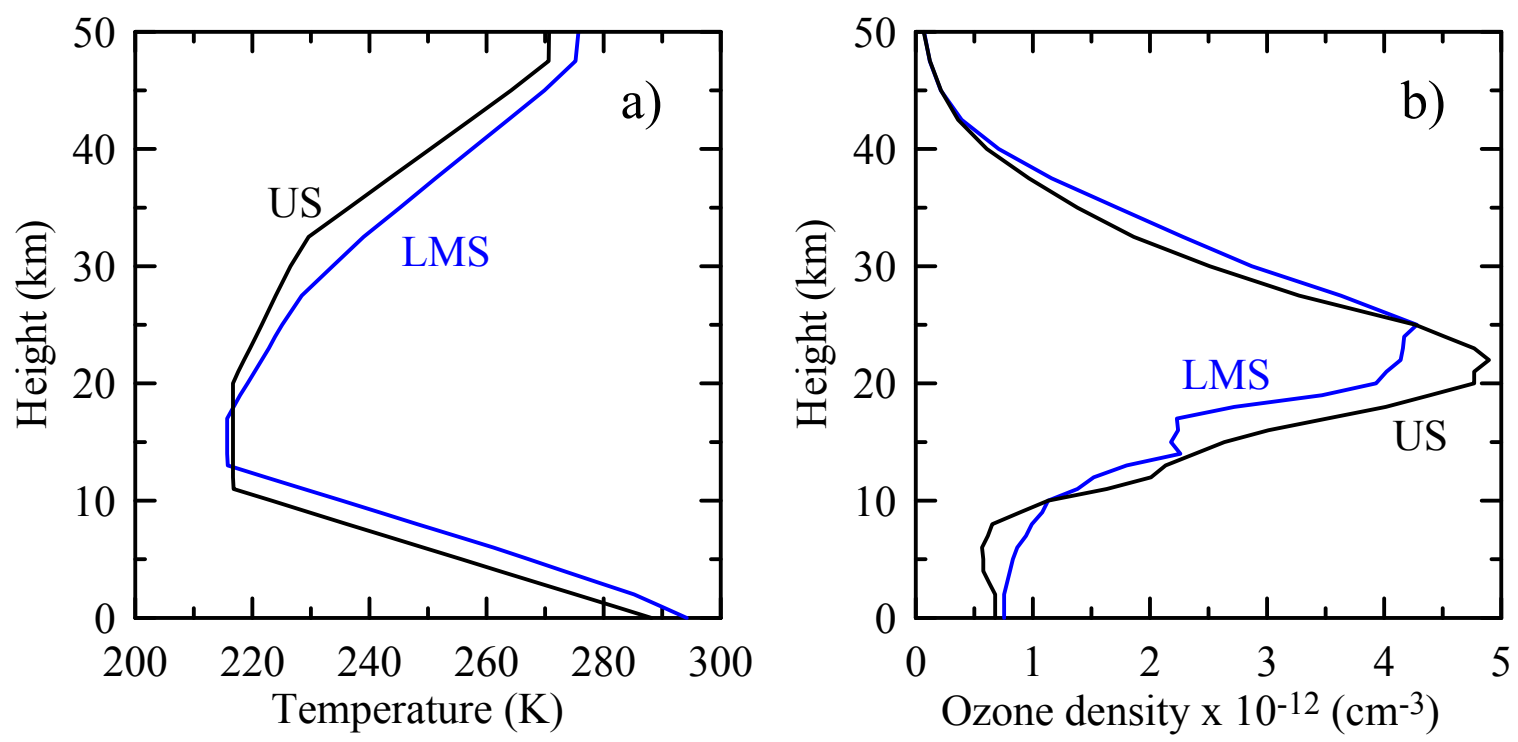

Figure 2.35. Temperature (a) and ozone density (b) profiles for the midlatitude summer (LMS) and standard atmosphere in the US (US).

\section{Extraterrestrial spectrum}

The ATLAS 3 (Woods et al., 1996) spectrum is selected as the extraterrestrial spectrum in the simulations. This spectrum shows a $0.05 \mathrm{~nm}$ resolution in the $200-407$ $\mathrm{nm}$ interval. For longer wavelengths, the ATLAS 2 (up to $419.9 \mathrm{~nm}$ ) and MODTRAN (> $419.9 \mathrm{~nm}$ ) spectra are used. The command for introducing this spectrum is 'solar_file atlas_plus_modtran per_nm' and is shown in Figure 2.36. 


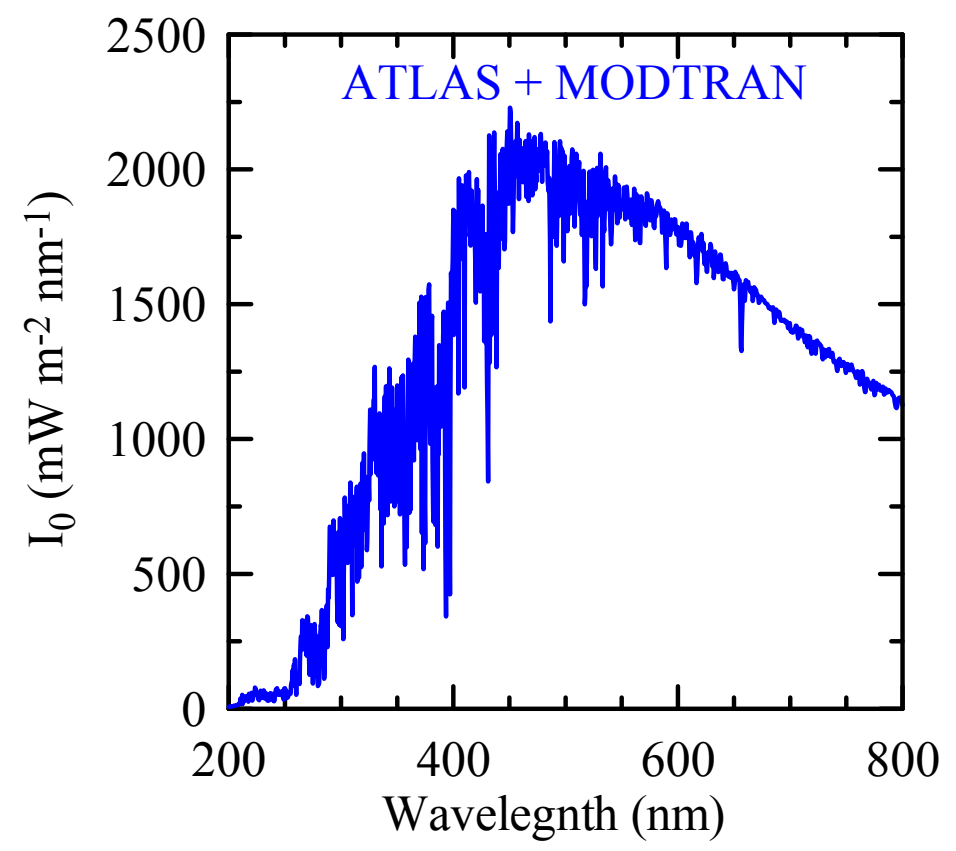

Figure 2.36. Radiation at the top of the atmosphere taken from ATLAS and MODTRAN spectra.

\section{Altitude}

The altitude of each station is set with the command 'altitude value (in $\mathrm{km}$ )'. Each station altitude mentioned in Section 2.3 is introduced.

RTE solver

RTE is solved using Disort 2.0 with 16 streams (in the default set-up) and is calculated between 280 and $400 \mathrm{~nm}$ at $0.5 \mathrm{~nm}$ steps. The commands to produce the output are: 'rte_solver disort2', 'nstr 16', 'wavelength 277.0 555.0', and 'spline 280.0400 .0 $0.5^{\prime}$.

With all these INPUT parameters, the configuration of an INPUT file for cloudy conditions at the SRSUVA station typically has the following form:

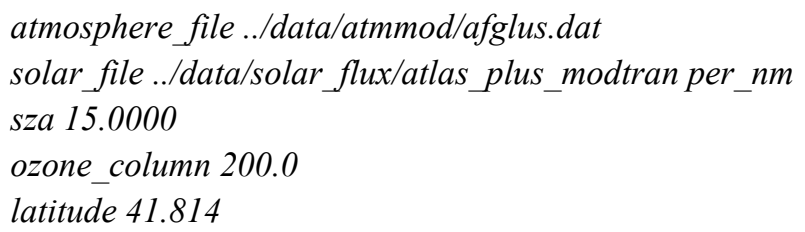




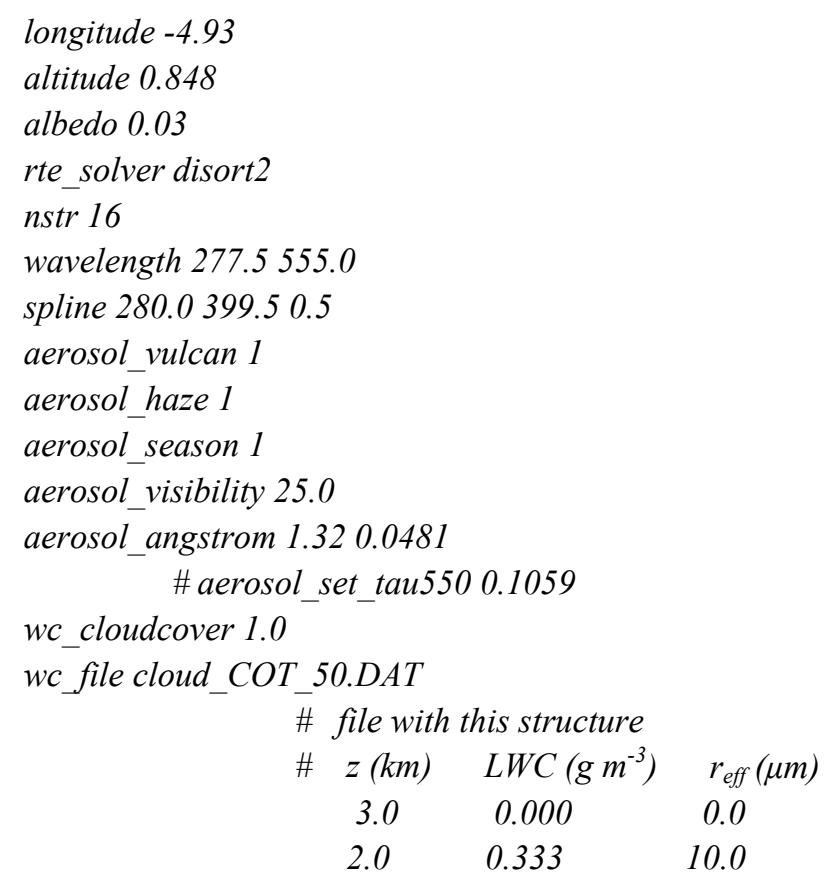

If the configuration used in some simulations is different from the one explained above, it will be discussed in the text.

As results of the simulations, several Look-up-Tables are obtained both for cloudless and overcast conditions that describe the dependence of UVI, J(O $\left.{ }^{1} \mathrm{D}\right)$, global and diffuse spectral irradiance, and spectral actinic flux in terms of the SZA, TOC, and $\mathrm{AOT}_{550 \mathrm{~nm}}$. Hence, the modelled CMFs for all the radiometric quantities could be evaluated for different values of SZA, TOC, $\mathrm{AOT}_{550 \mathrm{~nm}}$ and COT.

\subsection{Summary}

\subsubsection{English version}

A large number of instruments in place at three different European stations were involved in the analysis described in this thesis. Measurements were made at: the Solar Radiometric Station of the University of Valladolid (SRSUVA) in Central Spain, the station located at Lampedusa island (Central Mediterranean) managed by the UTMEATER unit of ENEA, and the measurement campaign carried out at the ENEA-Trisaia research centre (Southern Italy). Measurements of spectral irradiance in the UV range were recorded by BREWER and UV-MFRSR instruments, the latter also recording the diffuse component. UVB-1 pyranometers were used to obtain measurements of erythemal radiation, from which the UV index can be calculated. In addition, a new methodology 
for obtaining UVI values from multichannel instruments was implemented and validated in this thesis. With regard to the actinic flux, a METCON-DAS measured the downward spectral actinic flux which can be integrated to obtain the ozone photolysis rate. Cloud optical thickness was estimated by means of total shortwave measurements carried out with CMP-21, PSP or CM-6B pyranometers. The measurements obtained by the microwave radiometer HATPRO were used to derive the liquid water path. With this variable and the estimation of cloud optical thickness using spectral data from a VISMFRSR instrument, the effective radius of the cloud droplets was derived. Total ozone column measurements were obtained from a hand-held MICROTOPS-II ozonometer and the BREWER, and remote sensing data were used to fill gaps when surface data were not available. Cloud cover data were obtained from visual observations (SRSUVA and TRISAIA stations) and detected with an automatic TSI (LAMPEDUSA station), although the latter requires visual inspection to verify the behaviour of the detection algorithm. These experimental data were complementary to two algorithms using broadband and spectral shortwave measurements to obtain the fractional sky cover. These algorithms were implemented in order to accurately select time periods with overcast conditions. LIDAR profiles were useful to describe the aerosol and cloud vertical distributions. Finally, the experimental part of this thesis is complemented with the use of the libRadtran library to solve the radiative transfer equation numerically. Model inputs were selected as the most realistic in the simulations performed at each station. In particular, aerosol properties were described in detail, a wide variety of cloud conditions were simulated, and the type of the atmosphere and spectral dependence of the surface albedo were set close to actual values.

\subsubsection{Spanish versión}

Un alto número de instrumentos han sido utilizados en el desarrollo de esta tesis doctoral en tres estaciones europeas: la Estación Radiométrica Solar de la Universidad de Valladolid (SRSUVA), en el centro de la península ibérica, la estación situada en la isla italiana de Lampedusa (sector central del Mediterráneo) controlada por la unidad UTMEA-TER del ENEA, y la campaña de medidas realizada en el centro de investigación ENEA-Trisaia en el sur de Italia. Las medidas de irradiancia espectral en el intervalo del UV se han realizado con un BREWER y un UV-MFRSR (que también mide la componente difusa). Los radiométros UVB-1 se han utilizado para obtener medidas de radiación eritemática, con la que se puede calcular el índice UV. Se ha desarrollado y validado una nueva metodología para la obtención del UVI usando las medidas de instrumentos multicanal. El flujo actínico espectral ha sido medido con un METCONDAS, con el que se puede calcular el índice de fotodisociación del ozono. El espesor 
óptico de nubes se ha estimado usando las medidas de radiación solar de onda corta realizadas por piranómetros como el CMP-21, PSP, o CM-6B. Las medidas de un radiómetro de microondas HAPPRO han sido usadas para obtener el contenido de agua líquida de las nubes que, junto con una estimación de su espesor óptico usando los datos de irradiancia espectral de un VIS-MFRSR, permiten una estimación del radio efectivo de las gotas de las nubes. Las medidas de la columna total de ozono han sido efectuadas por los instrumentos MICROTOPS-II y BREWER, y por diversos instrumentos satelitales (que son de mucha utilidad cuando no se disponen de medidas desde la superficie). Observaciones visuales de la cubierta de nubes son registradas en las estaciones de SRSUVA y TRISAIA, mientras que una cámara de cielo TSI permite su obtención de una forma automática en la estación de LAMPEDUSA, aunque se requiere de una inspección visual de todas imágenes para su verificación. Junto con estos datos experimentales, se han utilizado dos algoritmos basados en las medidas de radiación solar de onda corta, integrada y espectral, para obtener una estima de la fracción de cielo cubierta por las nubes. Estos algoritmos se han implementado con el objetivo de seleccionar los periodos más amplios en los que se dan condiciones de cielos totalmente cubiertos. Los perfiles obtenidos con un LIDAR han sido utilizados para caracterizar las distribuciones verticales de aerosol y nubes. La parte experimental de esta tesis se ha complementado con el uso de la librería libRadtran para resolver de forma numérica la ecuación de transferencia radiativa. Las entradas a este modelo se han seleccionado como las más reales posibles en cada una de las estaciones. Esto ha sido llevado a cabo, por ejemplo, caracterizando las propiedades de los aerosoles, simulando una amplia variedad de condiciones de nubes, seleccionando un tipo de atmósfera acorde con la realidad y considerando un albedo superficial lo más real posible. 



\section{Chapter 3}

3. Characterization of UV Index and Ozone Photolysis Rate in the Cloudy Scenario 
This chapter provides a full description of UV index and ozone photolysis rate, highlighting the effects of other atmospheric factors under overcast conditions. Cloudless models for UVI and $\mathrm{J}\left(\mathrm{O}^{1} \mathrm{D}\right)$ are evaluated and validated. With these models, the CMFs for $\mathrm{UVI}$ and $\mathrm{J}\left(\mathrm{O}^{1} \mathrm{D}\right)$ are calculated and investigated as a function of cloud optical thickness.

\subsection{Dependence of UVI and $J\left(O^{1} D\right)$ on cloud cover}

In this section, the experimental values of the integrated quantities of UVI and $\mathrm{J}\left(\mathrm{O}^{1} \mathrm{D}\right)$ are classified according to cloud cover and solar zenith angle (SZA) using four intervals: a) $\mathrm{SZA} \leq 30^{\circ}$, b) $30^{\circ}<\mathrm{SZA}<45^{\circ}$, c) $45^{\circ}<\mathrm{SZA}<60^{\circ}$, and d) $60^{\circ}<\mathrm{SZA}<75^{\circ}$. Cloud cover is assumed constant during 5-minute intervals around the cloud time observations at the LAMPEDUSA and TRISAIA stations (radiometric data present a 1minute resolution). At the SRSUVA station in Valladolid, the average value of the two 10-minute radiometric measurements before and after the visual observation time (7:00, 13:00 and 18:00 h GMT) is associated with the cloud cover determination.

\subsubsection{UVI dependence on cloud cover and solar zenith angle}

Figure 3.1 depicts UVI dependence on cloud cover for each interval of SZA. Increased cloudiness obviously leads to a reduction in UVI values. Moreover, the following characteristics can be extracted:

Cloud effects are evident during cloudy (6-7 octas) or overcast (8 octas) skies, but less significant for cloud cover below 4 octas (clouds cannot be located between the Sun and the sensor).

The range of higher SZA, $60^{\circ}<\mathrm{SZA}<75^{\circ}$, is the least affected by cloud presence. In fact, this category evidences a change of about $-30 \%,-44 \%$, and $-22 \%$ between cloudless and overcast skies at SRSUVA, TRISAIA, and LAMPEDUSA, respectively. 

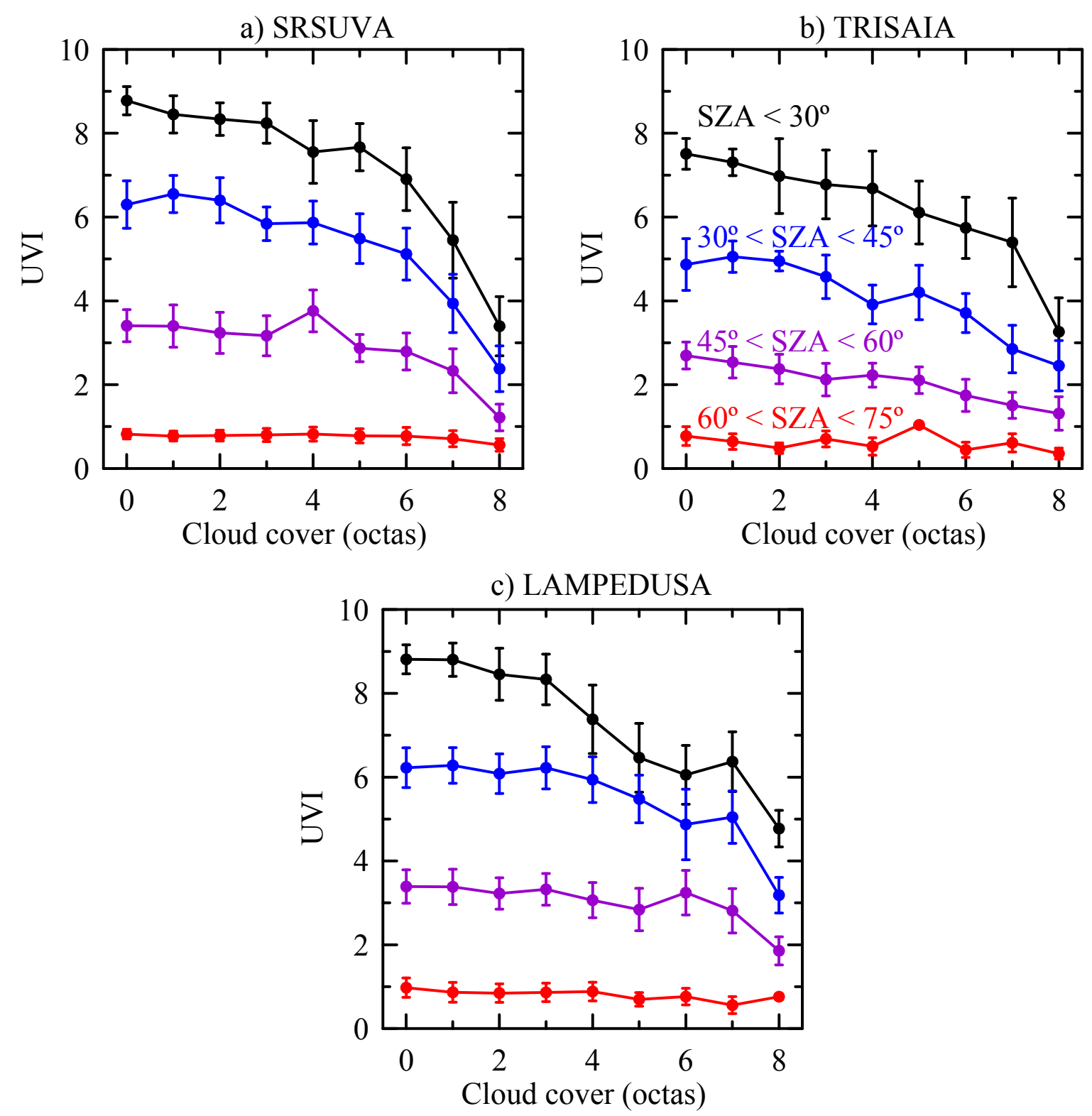

Figure 3.1. Dependence of UV index values on total cloud cover for different solar zenith angles (SZA $\leq$ $30^{\circ}$, in black, $30^{\circ}<S Z A<45^{\circ}$, in blue, $45^{\circ}<S Z A<60^{\circ}$, in purple, and $60^{\circ}<S Z A<75^{\circ}$, in red) at the SRSUVA (a), TRISAIA (b) and LAMPEDUSA (c) stations. The bars indicate the standard deviation.

Under overcast conditions (8 octas), the absolute differences among the different ranges of SZA are considerably lower. In fact, merging low SZA and overcast skies yields similar results to merging high SZA and cloudless skies. For instance, UVI values for $\mathrm{SZA}<30^{\circ}$ and 8 octas are similar to those recorded at $30^{\circ}<\mathrm{SZA}<45^{\circ}$ under cloudless conditions for the three stations in the figure.

As regards the different values at each station, the figure shows similar maximum values for the LAMPEDUSA and SRSUVA stations despite the latitude difference. This can be accounted for by the effects of aerosol and altitude. The aerosol load at the 
SRSUVA is usually weaker than that observed at LAMPEDUSA and TRISAIA because these are strongly affected by air masses intrusion from North Africa containing large dust concentrations. As concerns altitude, the SRSUVA station shows an altitude difference of $\sim 800 \mathrm{~m}$. As discussed in Chapter 1, this can lead to a major difference in UVI values at the surface.

The results obtained are influenced by the ozone column and the aerosol load at each station. With the largest database (SRSUVA station), which covers a long temporal period, another classification is created in order to minimize the ozone effect in Figure 3.1. Two groups of TOC values are used: (290, 310 DU) and (330, 350 DU). Figure 3.2 shows the dependence of UVI on total cloud cover for different solar zenith angle intervals and total ozone column values. The effect of TOC is stronger for low and intermediate SZAs under cloudless conditions (0-2 octas). In fact, this effect is confirmed by the smaller differences in the UVI values of the two TOCs in the group with the highest SZAs. However, the effect of ozone seems to diminish for cloudy (6-7 octas) and overcast ( 8 octas) conditions. The variability of cloud properties occurring at each point in the figure severely restricts the reliability of these results. Hence, the effects of SZA, ozone, and aerosol under overcast conditions are investigated in Section 3.3.

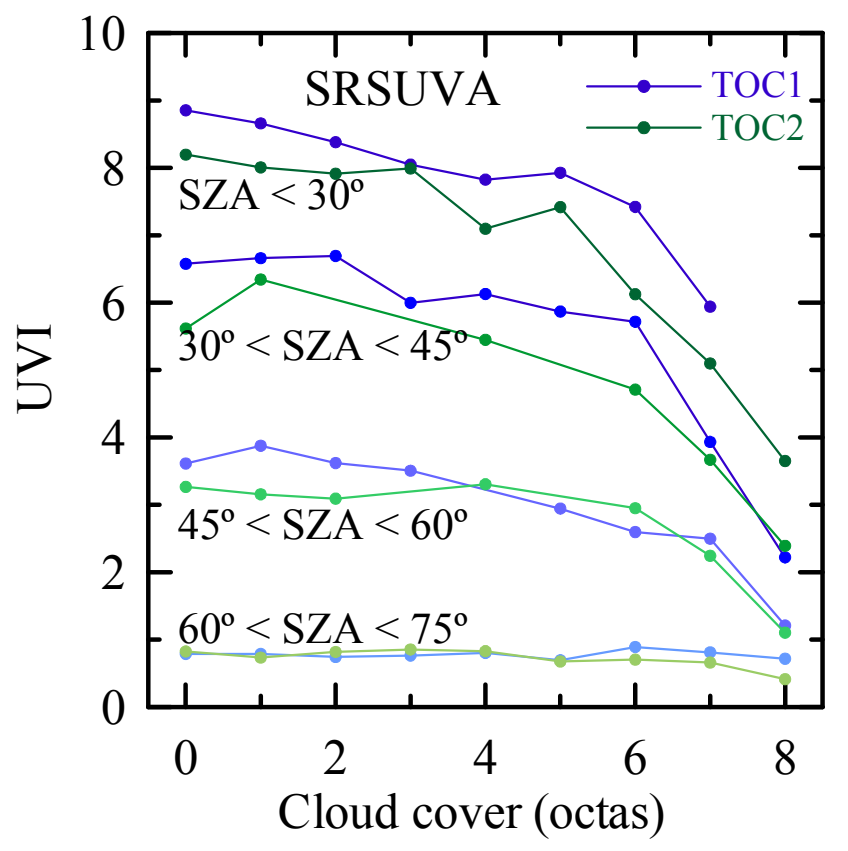

Figure 3.2. Dependence of UV index values on total cloud cover for different solar zenith angles (SZA $\leq$ $30^{\circ}, 30^{\circ}<S Z A<45^{\circ}, 45^{\circ}<S Z A<60^{\circ}$, and $\left.60^{\circ}<S Z A<75^{\circ}\right)$ and TOC values $(290 \mathrm{DU}<\mathrm{TOC} 1<310 \mathrm{DU}$ and $330 \mathrm{DU}<$ TOC2 $<350 \mathrm{DU})$ at the SRSUVA station. 


\subsection{2. $\mathrm{J}\left(\mathrm{O}^{1} \mathrm{D}\right)$ dependence on cloud cover and solar zenith angle}

The same classification created for UV Index is also applied to $\mathrm{J}\left(\mathrm{O}^{1} \mathrm{D}\right)$ data. Figure 3.3 shows its dependence on cloud cover for each SZA interval. Similar conclusions to the UVI case can be derived from the figure. The highest group of SZA is the least affected by cloud presence. The strongest reduction in ozone photolysis rates between 0 and 8 octas occurs at SZA $<30^{\circ}$ with $\sim-50 \%$. The differences between the four intervals decrease with cloudiness. $\mathrm{J}\left(\mathrm{O}^{1} \mathrm{D}\right)$ values at $\mathrm{SZA}<30^{\circ}$ and 8 octas are similar to those observed for higher SZA and cloudless conditions.

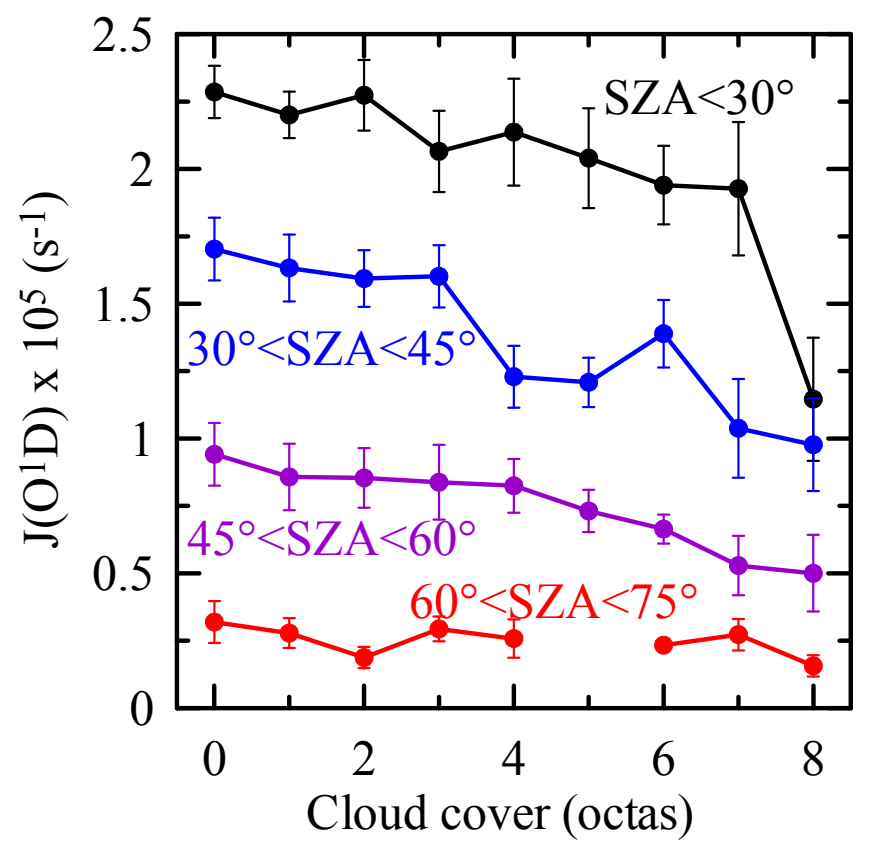

Figure 3.3. Dependence of $J\left(O^{I} D\right)$ values on total cloud cover for different solar zenith angles $\left(S Z A \leq 30^{\circ}\right.$, in black, $30^{\circ}<S Z A<45^{\circ}$, in blue, $45^{\circ}<S Z A<60^{\circ}$, in purple, and $60^{\circ}<S Z A<75^{\circ}$, in red) at the TRISAIA station. The bars indicate the standard deviation.

\subsection{Cloudless modelling of UVI and $\mathrm{J}\left(\mathrm{O}^{1} \mathrm{D}\right)$}

The variable used to characterize cloudy conditions is the CMF; hence a good estimation of UVI and $\mathrm{J}\left(\mathrm{O}^{1} \mathrm{D}\right)$ under cloudless conditions is needed. To this end, two methodologies are compared. The first is an empirical Look-up-Table (LUT) built with the UVI and $\mathrm{J}\left(\mathrm{O}^{1} \mathrm{D}\right)$ measurements classified as a function of TOC and SZA values. The second method is based on radiative transfer simulations performed with the libRadtran model, which are also classified as a function of TOC and SZA values. Both LUTs under cloudless conditions can be compared in order to ascertain the agreement between the two methods. 


\subsubsection{UVI under cloudless conditions: measurements vs simulations}

As explained in the previous paragraph, both measured and simulated UVI values are classified as a function of SZA and TOC. Classification criteria are selected based on data availability in each station. For the model simulations, SZA values varied from $10^{\circ}$ to $80^{\circ}$ at $5^{\circ}$ steps, TOC ranged from 200 to $500 \mathrm{DU}$ at $20 \mathrm{DU}$ steps, and $\mathrm{AOT}_{550 \mathrm{~nm}}$ was fixed at 0.25 for LAMPEDUSA and TRISAIA and 0.1059 for SRSUVA.

\section{SRSUVA station}

SRSUVA station UVI data under cloudless conditions are grouped and averaged for TOC values from 260 to 430 DU at 10 DU steps and for SZA values ranging from $18^{\circ}$ to $78^{\circ}$ at $4^{\circ}$ steps. This empirical LUT and the corresponding one obtained by the model are shown in Figure 3.4.

a) SRSUVA

UVI simulated LUT

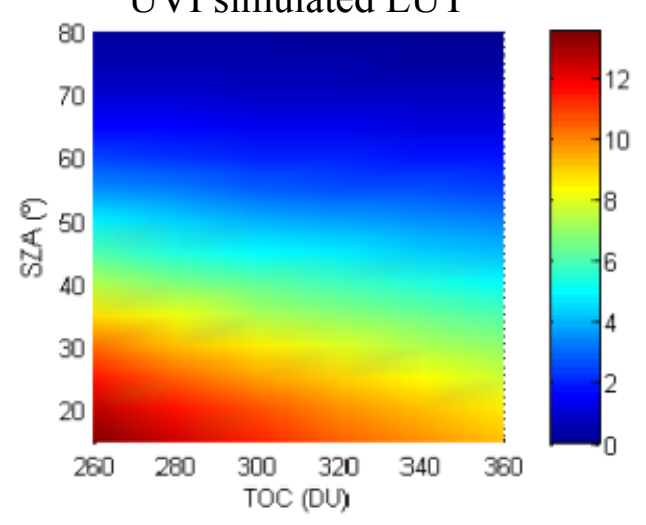

b) SRSUVA

UVI empirical LUT

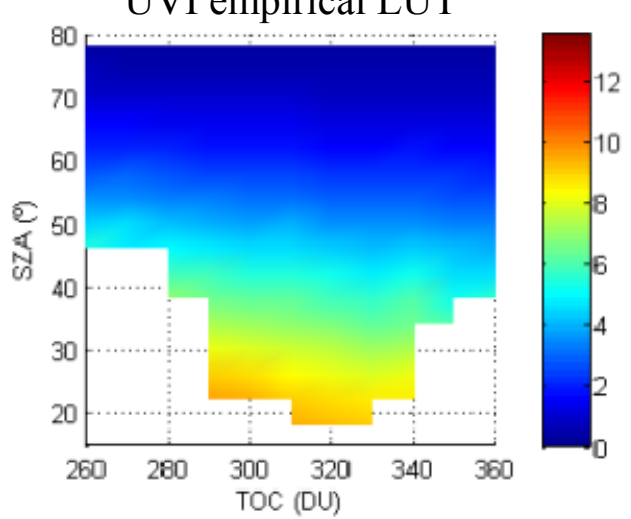

Figure 3.4. Look-up-Tables obtained by model (a) and experimental (b) data for UVI values under cloudless conditions at the SRSUVA station.

\section{TRISAIA station}

TRISAIA data under cloudless conditions are grouped and averaged for TOC values from 300 to $380 \mathrm{DU}$ at $20 \mathrm{DU}$ steps and for SZA values ranging from $17^{\circ}$ to $80^{\circ}$ at $1^{\mathrm{o}}$ steps. This empirical LUT and the corresponding one obtained by the model are shown in Figure 3.5. 
a) TRISAIA

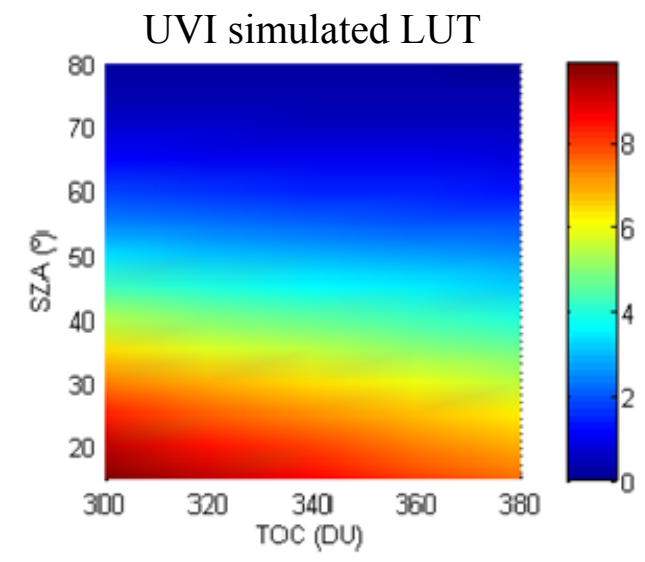

b) TRISAIA

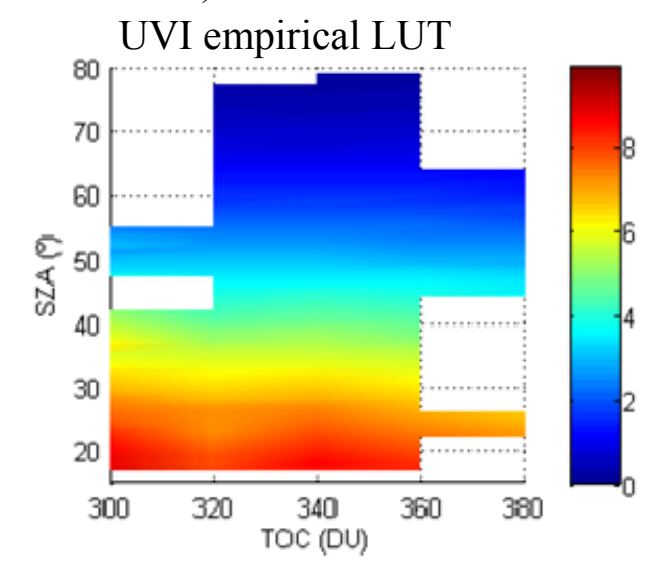

Figure 3.5. Look-up-Tables obtained by model (a) and experimental (b) data for UVI values under cloudless conditions at the TRISAIA station.

\section{LAMPEDUSA station}

Finally, the same process is applied at the LAMPEDUSA station with TOC values ranging from 250 to $340 \mathrm{DU}$ at $10 \mathrm{DU}$ steps and on SZA values ranging from $14^{\circ}$ to $80^{\circ}$ at $1^{\circ}$ steps. This empirical LUT and the corresponding one obtained by the model are shown in Figure 3.6.
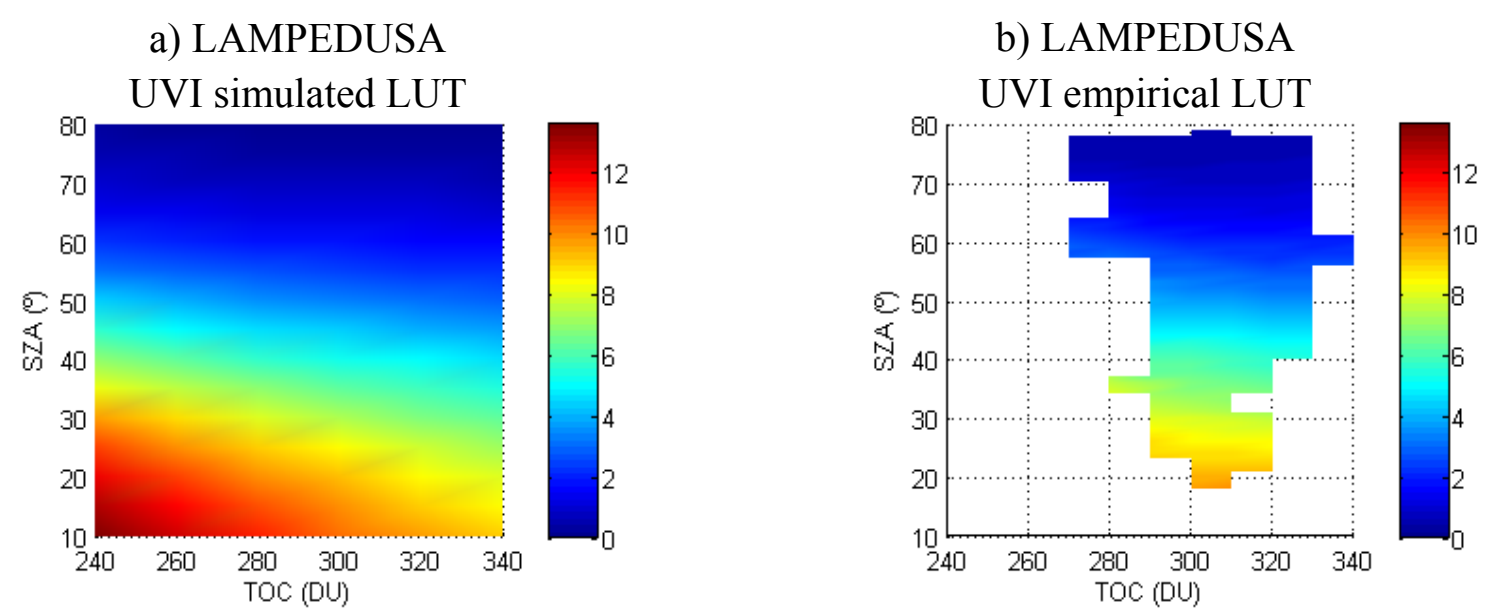

Figure 3.6. Look-up-Tables obtained by model (a) and experimental (b) data for UVI values under cloudless conditions at the LAMPEDUSA station. 


\section{Validation results}

A comparison between the experimental and simulated LUTs is performed for each station. In order to simplify this section, only the figures for the TRISAIA station are shown, although the results for the other two stations are also discussed and commented on.

The comparison between the estimated and measured values and the linear fit between them are shown in Figure 3.7. Two types of simulations are used in this figure. The first (Figure 3.7.a) takes a fixed $\mathrm{AOT}_{550 \mathrm{~nm}}$ value of 0.25 . For the second (Figure 3.7.b), the average $\mathrm{AOT}_{550 \mathrm{~nm}}$ value in each class of UVI(SZA, TOC) is calculated and used to obtain the UVI radiative transfer simulation to better reproduce the different conditions in each class. Despite the good agreement observed in the comparison with the LUT obtained for $\mathrm{AOT}_{550 \mathrm{~nm}}=0.25$, the results clearly improve when each average $\mathrm{AOT}_{550 \mathrm{~nm}}$ value for each class (SZA, TOC) is considered. This fact is more significant, particularly for the UVI maxima at low SZA.

Continuing with this analysis, the ratio between the UVI simulated with the libRadtran model and the UVI obtained from the measurements is evaluated and the dependence on SZA and TOC values is studied. The two panels of Figure 3.8 show the results obtained.
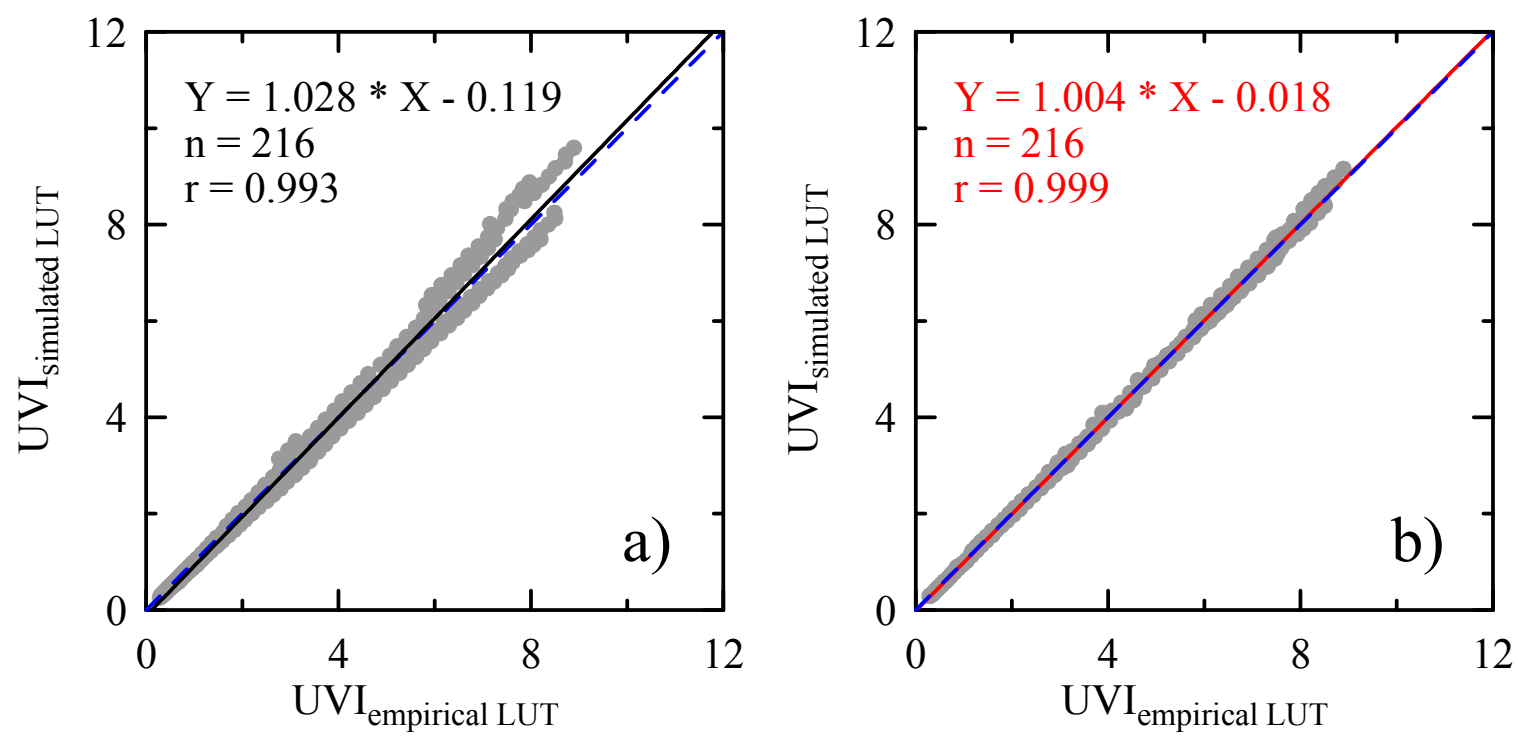

Figure 3.7. Comparison between UVI values obtained by the libRadtran Look-up-Table and experimental data under cloudless conditions at the TRISAIA station: a) considering a fixed $A O_{550 \mathrm{~nm}}$ of 0.25 in the model, b) using the average $A_{O T_{50 n m}}$ value for each point. The blue dashed lines indicate the 1:1 line; the black and red lines are the linear fits. 

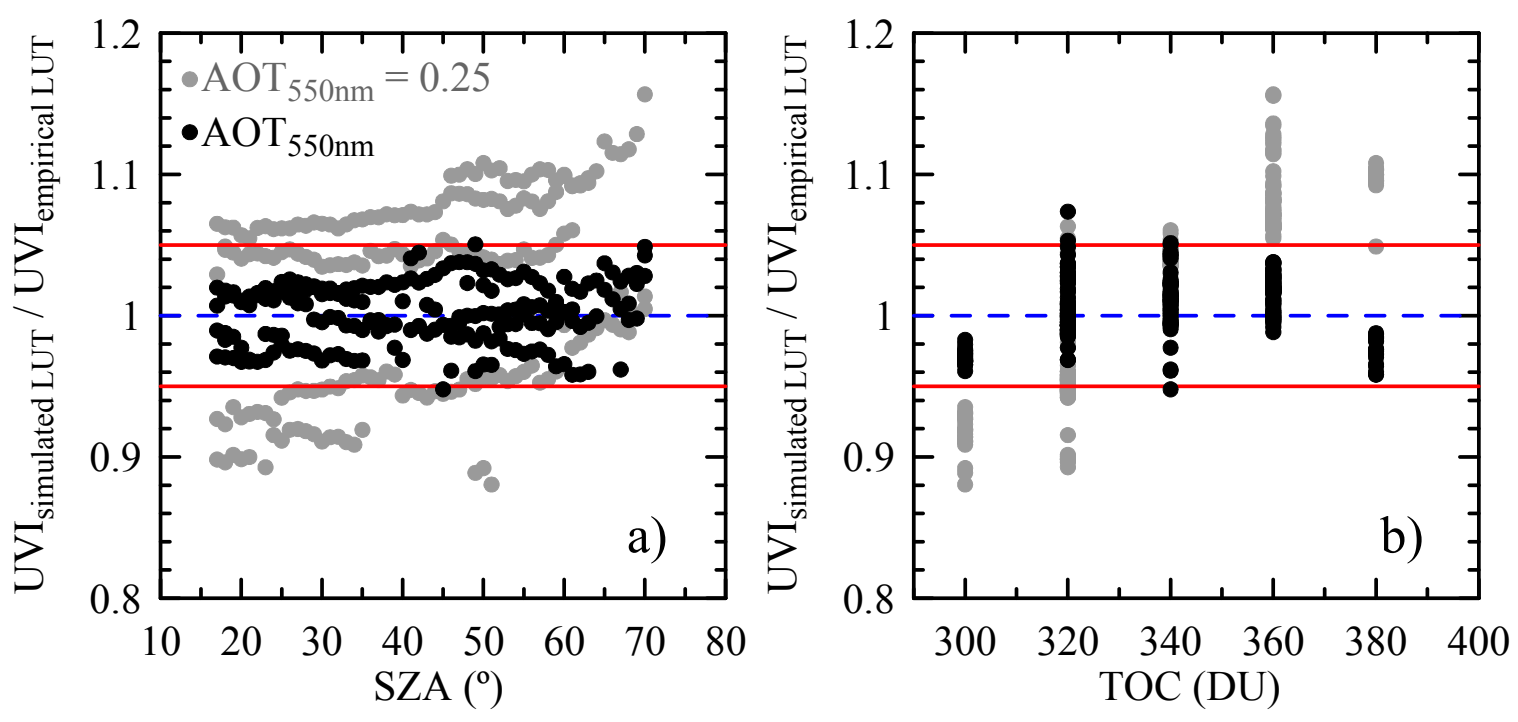

Figure 3.8. Dependence of ratio between the UVI estimated with the libRadtran model and that obtained by the measurements on SZA (a) and TOC (b), considering a fixed AOT $550 \mathrm{~nm}$ of 0.25 in the model (grey points), and using the average $A O T_{550 \mathrm{~nm}}$ value for each point (black points). The blue dashed lines indicate perfect agreement and the red ones a deviation of $\pm 5 \%$.

For the fixed $\mathrm{AOT}_{550 \mathrm{~nm}}$ in the simulations, in some cases the ratio shows a dependence on SZA, although the differences between the two UVI usually fall below $10 \%$. When the simulations take into account the average $\mathrm{AOT}_{550 \mathrm{~nm}}$ value in each class, this dependence disappears.

The dependence on SZA in Figure 3.8 is due to the different aerosol situations under cloudless conditions. The ozone case also shows dependence on ozone values which disappears when the actual value of the $\mathrm{AOT}_{550 \mathrm{~nm}}$ in each class (SZA,TOC) is considered, confirming that ozone and aerosol may be negatively correlated (e.g., di Sarra et al., 2002).

Similar results were obtained for SRSUVA and LAMPEDUSA. The role of aerosol leads to a dependence on SZA and TOC in the differences, despite which the agreement between cloudless measurements and simulations is also good for these stations. The slopes for the linear fits between the UVI simulated by the libRadtran model and the UVI cloudless measurements are 1.08 and 1.04 for the SRSUVA and LAMPEDUSA stations.

Cloudless simulations of UVI values should include the right aerosol load in the model. However, it is very difficult to acquire information concerning aerosol optical properties in cloudy conditions. As a good estimation of UVI can also be achieved by only taking into account SZA and TOC dependence, these models can be used in CMF evaluation in cloudy conditions. 


\subsection{2. $\mathrm{J}\left(\mathrm{O}^{1} \mathrm{D}\right)$ under cloudless conditions: measurements vs simulations}

$\mathrm{J}\left(\mathrm{O}^{1} \mathrm{D}\right)$ TRISAIA data in cloudless conditions are grouped and averaged for TOC values from 300 to $380 \mathrm{DU}$ at $20 \mathrm{DU}$ steps, and for SZA values ranging from $17^{\circ}$ to $80^{\circ}$ at $1^{\mathrm{o}}$ steps. This empirical LUT and the corresponding one obtained by the model are shown in Figure 3.9.

A similar analysis to the one carried out for the UVI is applied to the $\mathrm{J}\left(\mathrm{O}^{1} \mathrm{D}\right)$ data calculated in cloudless conditions. Figure 3.10 shows the scatter plots between simulations and measurements. First of all, calculations of ozone photolysis rates are carried out fixing the $\mathrm{AOT}_{550 \mathrm{~nm}}$ value $\left(\mathrm{AOT}_{550 \mathrm{~nm}}=0.25\right)$, and are represented in grey and black in the figure. The slope of the linear fit is 1.12 . In order to improve the results obtained, the average AOT $_{550 \mathrm{~nm}}$ value of each class (SZA, TOC) is calculated and the corresponding simulated values for these quantities are evaluated. For these conditions, the slope does not change, although the number of values above the 1:1 line in Figure 3.10 decreases. Some authors such as Brühl and Crutzen (1989) and Balis et al. (2002) point out that, particularly for small solar zenith angles, tropospheric ozone absorbs UV-B radiation more efficiently than stratospheric ozone because of an enhanced pathway through the atmosphere caused by Rayleigh and particle scattering. This effect is expected to be relevant when strong aerosol load conditions occur in the troposphere. New simulations are performed for double the amount of tropospheric column ozone (TCO). The results obtained are again compared with the empirical LUT and are shown in Figure 3.10 in purple. In this case, the results clearly improve, and a slope of 1.06 is obtained.

a) TRISAIA

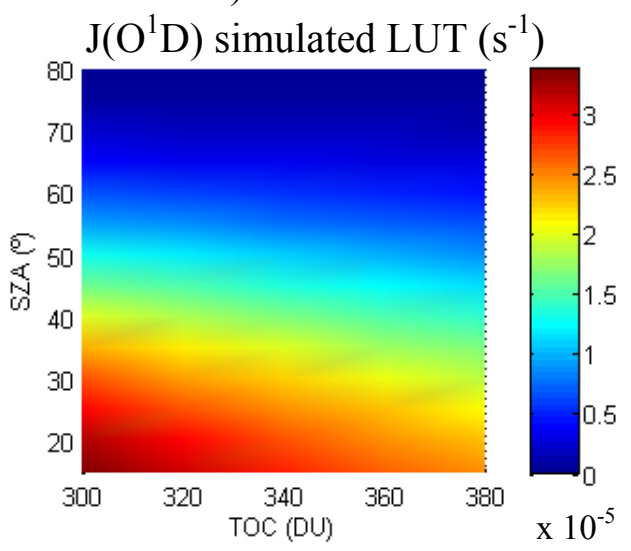

b) TRISAIA

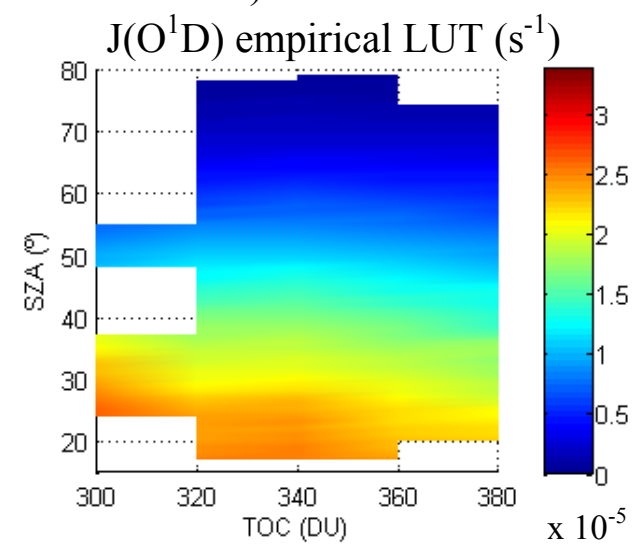

Figure 3.9. Look-up-Tables obtained by model (a) and experimental (b) data for $J\left(O^{l} D\right)$ values under cloudless conditions at the TRISAIA station. 


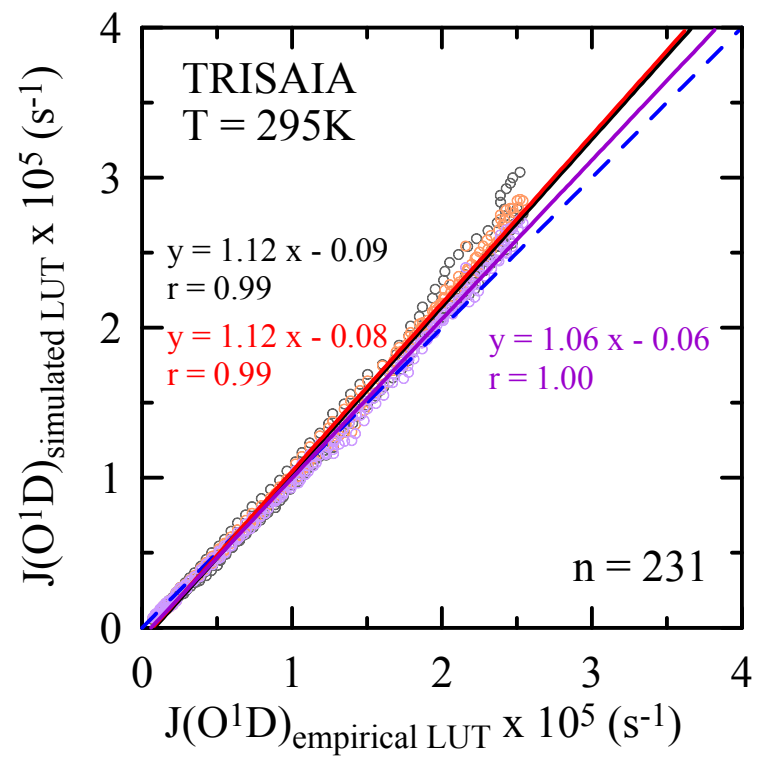

Figure 3.10. Comparison between $J\left(O^{I} D\right)$ values obtained by the libRadtran Look-up-Table and experimental data under cloudless conditions at the TRISAIA station for three different conditions (see text). The blue dashed line indicates the 1:1 line.

As for the UVI case, the ratio between $\mathrm{J}\left(\mathrm{O}^{1} \mathrm{D}\right)$ estimated with the libRadtran model and that obtained from the measurements is analyzed as a function of SZA and TOC. The results are shown in Figure 3.11 for the three types of simulations mentioned above.
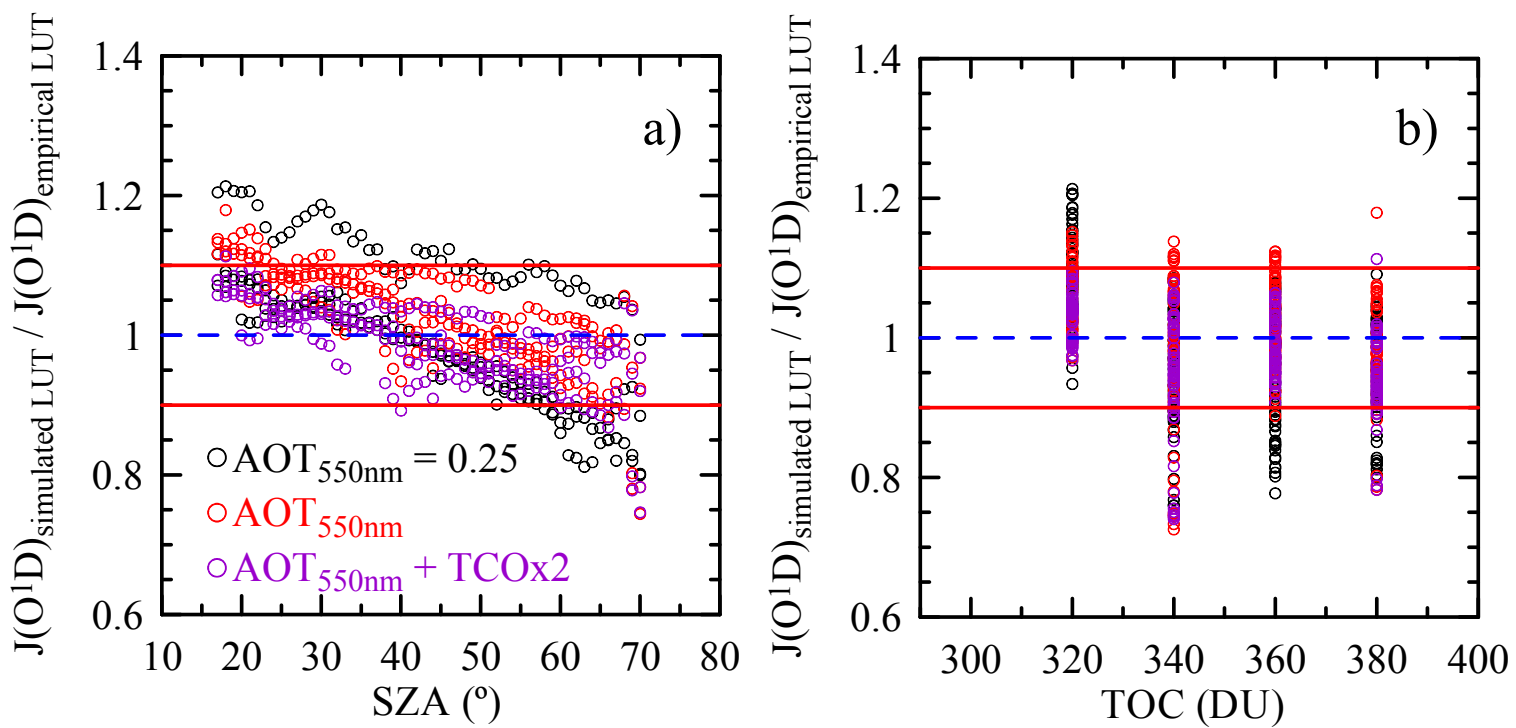

Figure 3.11. Dependence of the ratio between $J\left(O^{I} D\right)$ estimated with the libRadtran model and the measured one versus SZA (a) and TOC (b), considering in the model a fixed AOT ${ }_{550 \mathrm{~nm}}$ of 0.25 (black points), using the average $A O T_{550 \mathrm{~nm}}$ value for each point (red points), and considering twice the amount of tropospheric ozone (TCOx2, purple points). Blue dashed lines indicate perfect agreement and the red solid lines a deviation of $\pm 10 \%$. 
The evaluated ratios show a clear dependence on SZA which is stronger for the simulations with a fixed $\mathrm{AOT}_{550 \mathrm{~nm}}$ value. With the corresponding aerosol value for each (SZA, TOC) class and twice the amount of TCO, the relative differences remain practically below $\pm 10 \%$ for all SZA and TOC values. Similar or even higher differences in the estimation of the ozone photolysis rate are usually obtained in the literature. Palancar et al. (2005) obtained deviations below $\pm 10 \%$ up to $\mathrm{SZA}=70^{\circ}$ comparing a semi-empirical method with radiative transfer calculations. The maximum differences presented by Balis et al. (2002) for different ozone, altitude, and aerosol conditions ranged between 10 and $16 \%$. The estimation uncertainties of the photolysis rates of other species, such as $\mathrm{NO}_{2}, \mathrm{NO}_{3}, \mathrm{Cl}_{2}$, and others, can oscillate between 12 and $50 \%$ (Kanaya et al., 2003).

\subsection{UVI and $\mathrm{J}\left(\mathrm{O}^{1} \mathrm{D}\right)$ as a function of cloud optical thickness}

In this section, UVI and $\mathrm{J}\left(\mathrm{O}^{1} \mathrm{D}\right)$ values under a cloud cover of 8 octas are analyzed. The selection criteria for the SRSUVA database are based on visual inspections at Villanubla airport, and only cases with an observation of 8 octas are used. With regard to the TRISAIA station, the two algorithms described in Section 2.2.2 using radiometric measurements allow overcast periods with a radiative cloud fraction between 0.95 and 1.0 to be identified. Finally, the LAMPEDUSA station is equipped with a TSI, and a visual inspection of all the photos (each five minutes) is carried out to select the time periods with overcast conditions. In order to select periods that are as stable as possible, an additional criterion concerning duration is applied. Only when the cloud cover remains at 8 octas over 20 minutes is the time period considered for subsequent studies. UVI and $\mathrm{J}\left(\mathrm{O}^{1} \mathrm{D}\right)$ values are then plotted as a function of the COT. Once this dependence is defined, the influence of other atmospheric factors can be studied. 


\subsubsection{UVI under overcast conditions}

Figure 3.12 shows the dependence of UVI values under overcast conditions on cloud optical thickness for each station. The following general remarks can be established: with low COT values, high and very high UVI (ranging from 6 to 10) may still occur; for low COTs, high variability in the UVI values is observed which may be attributed to other parameters such as SZA, TOC and aerosol load. However, for moderate and large COTs, UVI values are notably lower, with maxima under UVI $=2$.
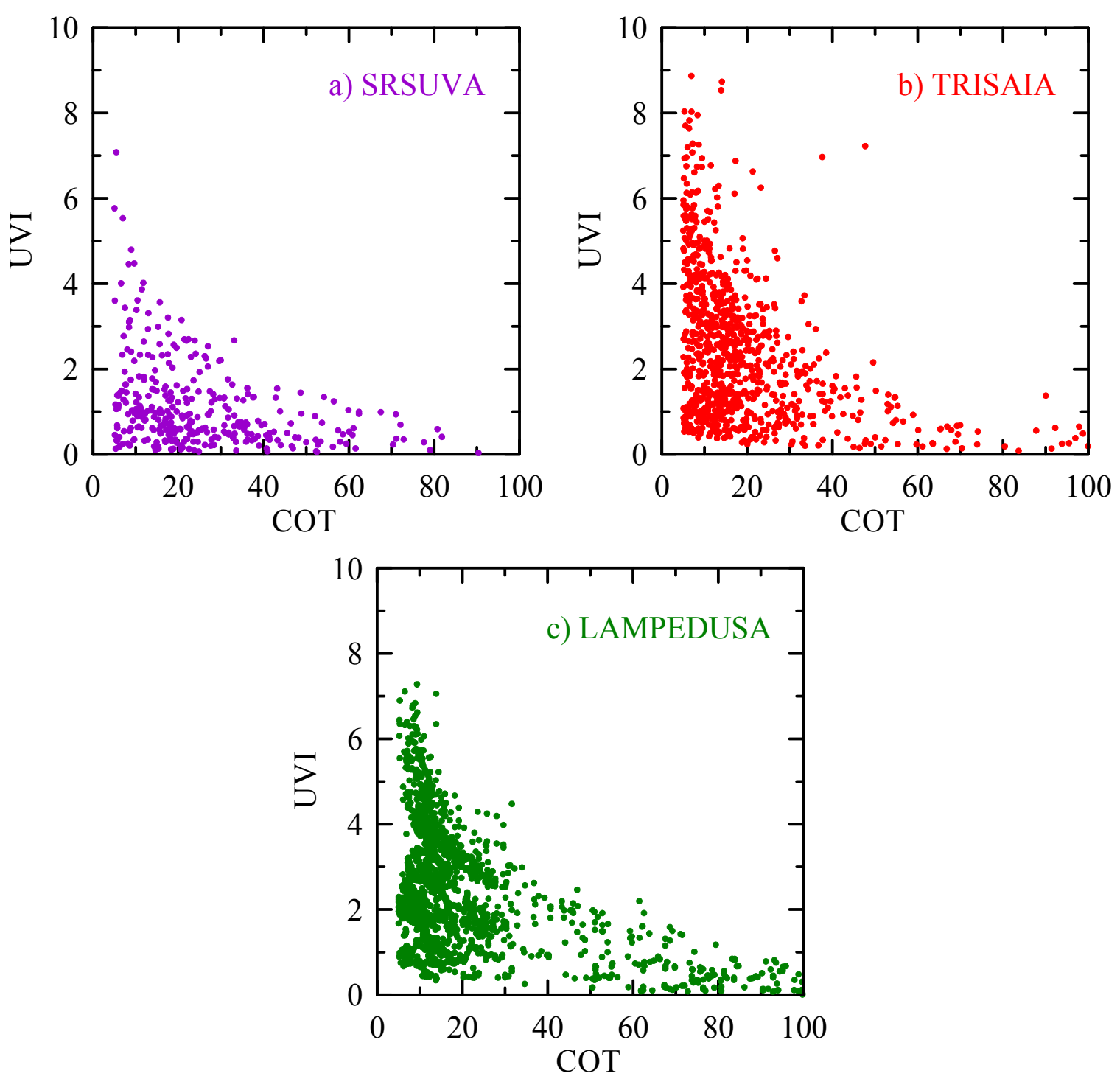

Figure 3.12. UVI values in overcast skies (8 octas) as a function of the cloud optical thickness for the SRSUVA (a), TRISAIA (b), and LAMPEDUSA (c) stations. 
A large number of data falling in the overcast case are identified at TRISAIA by automatic algorithms. Since SRSUVA offers visual observations of cloud cover and the images of the LAMPEDUSA station need a visual criterion to ensure 8 octas, in these two stations the more restrictive methodology reduces the number of cases. Therefore, only the TRISAIA database is used to analyze the effects of SZA, TOC and AOT under overcast conditions.

Figure 3.13 shows UVI dependence on SZA under overcast conditions for the TRISAIA database. To reduce the effects of other atmospheric factors, TOC is fixed in an interval of $20 \mathrm{DU}(350 \mathrm{DU}<\mathrm{TOC}<370 \mathrm{DU})$. The left panel indicates the measurements, while the right one shows the radiative transfer simulations. An increase in the COT value reduces UVI at surface although SZA influence remains highly significant (even for high COT). This behaviour is borne out by the simulations. To analyze variability in UVI values (simulated with the libRadtran) as a function of COT and SZA, the differences between the two extreme angles, $\mathrm{UVI}_{\mathrm{SZA}}=10^{\circ}-\mathrm{UVI}_{\mathrm{SZA}}=80^{\circ}$, are calculated. The absolute and relative differences are shown in Figure 3.14 as a function of COT.
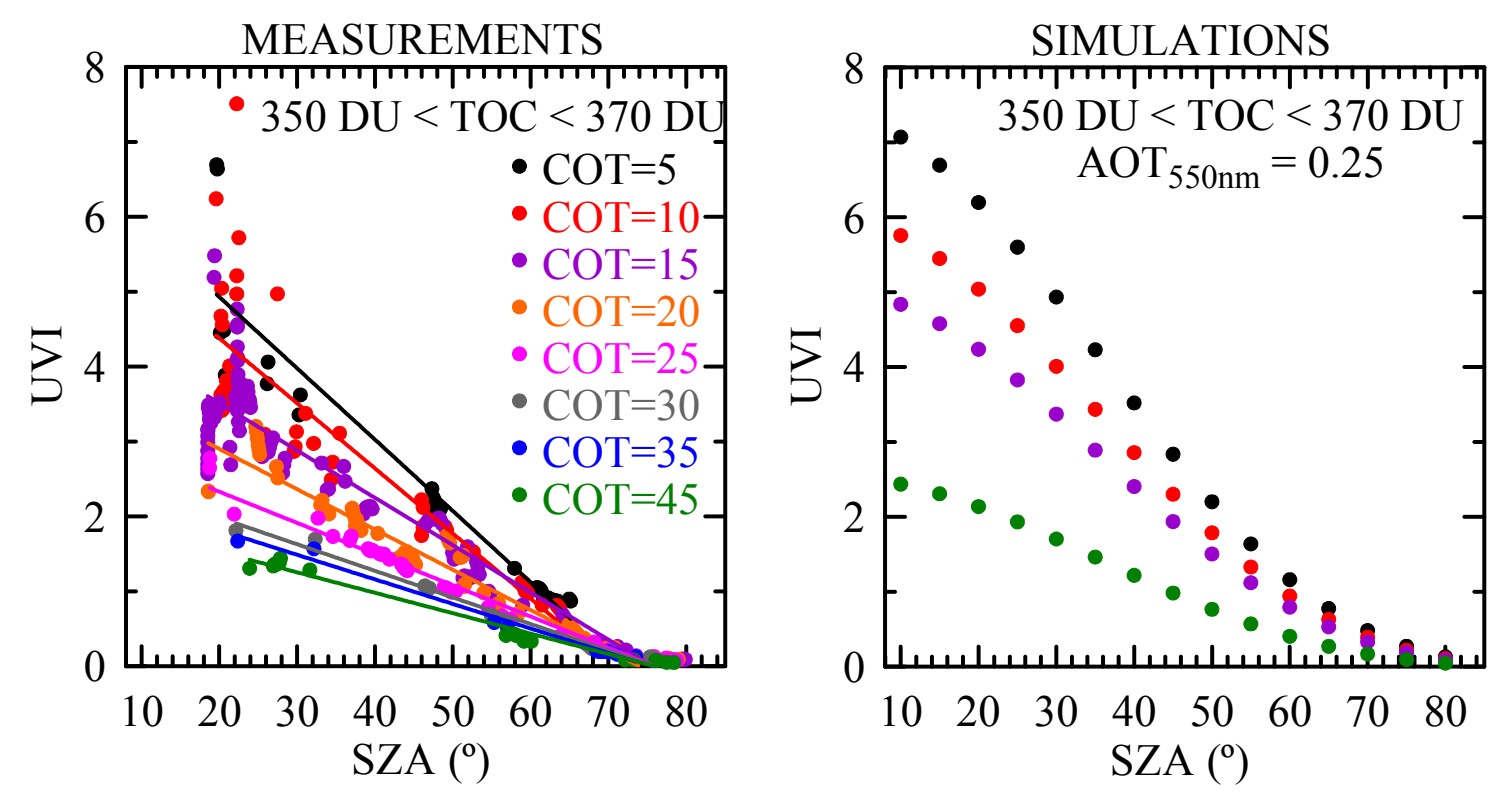

Figure 3.13. UVI values in overcast skies (8 octas) as a function of the solar zenith angle for different cloud optical thicknesses for measurements (left panel) and radiative transfer simulations (right panel) at a fixed interval of TOC for the TRISAIA database. 


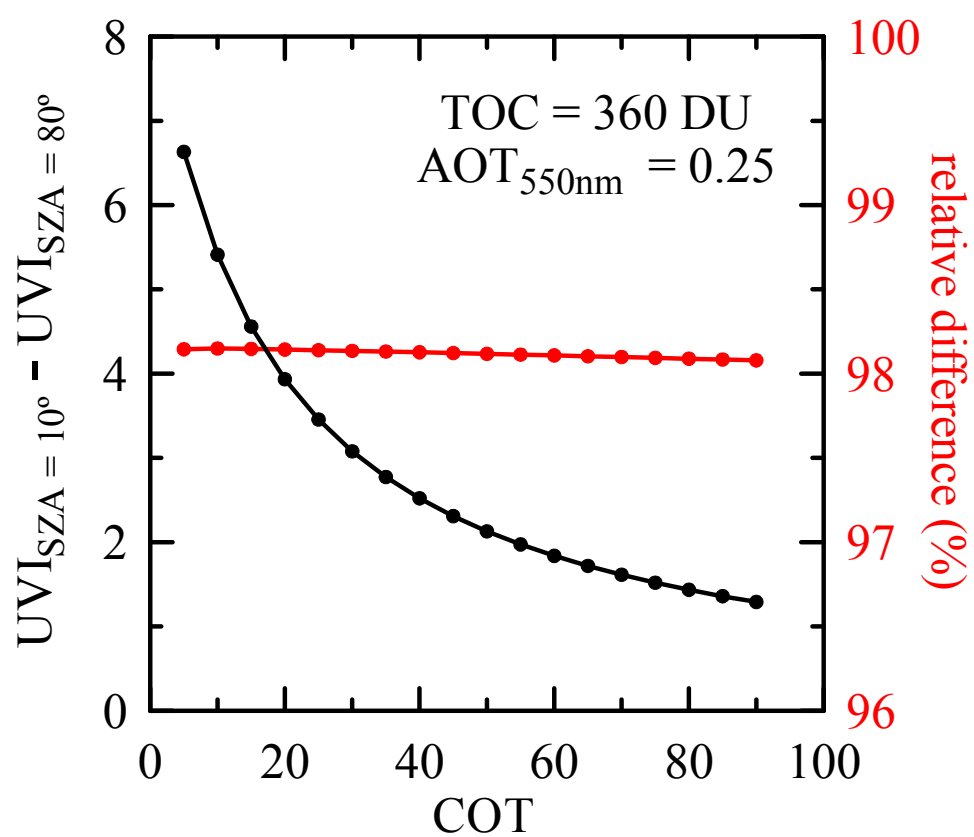

Figure 3.14. Absolute and relative differences between $U V I$ at $S Z A=10^{\circ}$ and $S Z A=80^{\circ}$ as a function of the COT obtained with radiative transfer simulations.

As can be seen in the figure, the absolute change in UVI between $\mathrm{SZA}=10^{\circ}$ and $\mathrm{SZA}=80^{\circ}$ is above five for COT $<10$ and less than two for COT $>60$, while the relative difference remains practically constant with $\mathrm{COT}(98.14 \%$ at $\mathrm{COT}=5$ and $98.08 \%$ at $\mathrm{COT}=90)$.

A similar study is carried out for the influence of TOC on UVI values in the cloudy scenario. In this case, to reduce the solar position effect, two different SZA intervals are fixed. Figure 3.15 shows the results obtained for $15^{\circ}<\mathrm{SZA}<25^{\circ}$ and $30^{\circ}<$ $\mathrm{SZA}<40^{\circ}$ intervals. As in the previous case, the simulations obtained with the libRadtran model are also plotted in the figure. The use of the model in this case gives the possibility to extend the range of TOC values in the analysis. From the measurements, only the dependence on COT can be established due to the low range of ozone values. 

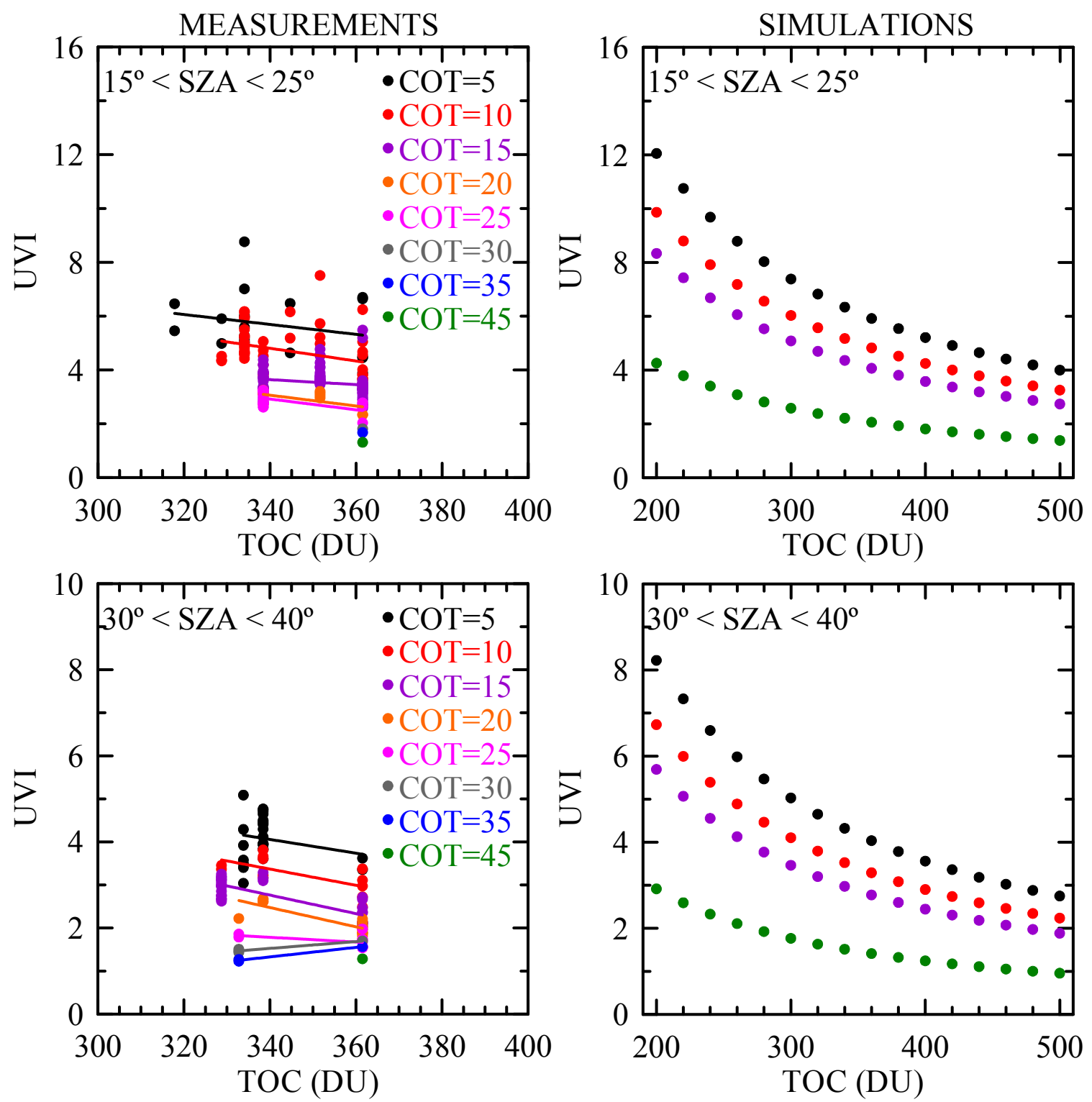

Figure 3.15. UVI values in overcast skies (8 octas) as a function of the total ozone column for different cloud optical thicknesses for measurements (left panels) and radiative transfer simulations (right panels) at two fixed intervals of SZA for the TRISAIA database.

When the TOC increases its value from 200 to 500 DU, the differences observed in the values of modelled UVI on TOC also show a dependence on SZA. As can be seen in the figure, ozone also contributes to the final levels of UVI at the surface under overcast conditions. To investigate this, the differences in the UVI values (both absolute and relative) between the two extreme TOC values, i.e. $\mathrm{UVI}_{\mathrm{TOC}}=200 \mathrm{DU}-\mathrm{UVI}_{\mathrm{TOC}}=500 \mathrm{DU}$, are calculated and plotted against the COT in Figure 3.16. The differences are calculated for two SZAs: $30^{\circ}$ and $60^{\circ}$. As mentioned before, the impact of ozone is clearly 
influenced by the SZA. The absolute differences at a low SZA show higher values at $\mathrm{COT}=5$ than at $\mathrm{COT}=90$. However, in the case of SZA $=60^{\circ}$, these differences are below 1 for $\mathrm{COT}>20$. The relative change in UVI values from TOC $=200 \mathrm{DU}$ to $\mathrm{TOC}=$ 500 DU exhibits an increasing trend with COT (for the two SZAs): i.e. the higher the COT, the stronger the impact of TOC on UVI. In addition, the increase in the SZA produces a weaker effect of ozone by a decrease of $\sim 3 \%$ in the relative differences.
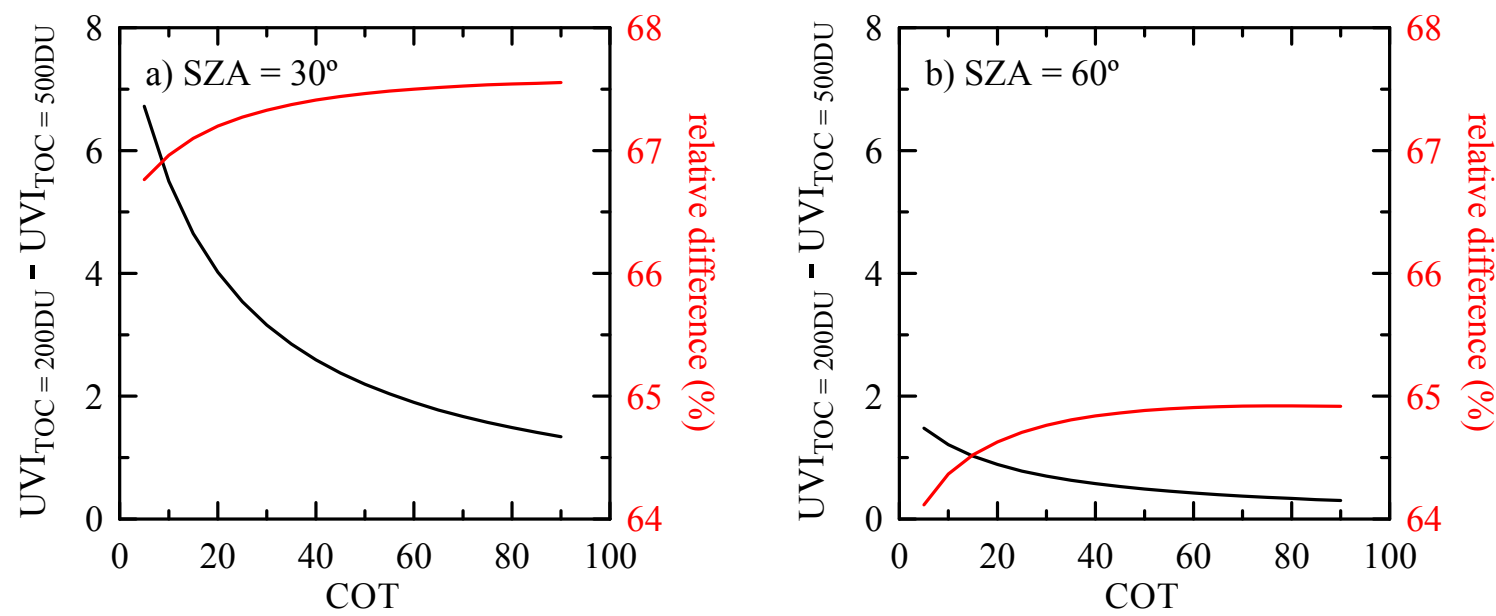

Figure 3.16. Absolute and relative differences between UVI at TOC $=200 \mathrm{DU}$ and TOC $=500 \mathrm{DU}$ as a function of the COT obtained with radiative transfer simulations at $S Z A=30^{\circ}\left(\right.$ a) and $S Z A=60^{\circ}(b)$, and with $A O T_{550 \mathrm{~nm}}=0.25$.

Finally, the effect of aerosol particles under cloudy conditions on the values of UVI is also studied using the model simulations. Figure 3.17 shows the dependence of UVI on the $\mathrm{AOT}_{550 \mathrm{~nm}}$ at TOC $=300 \mathrm{DU}$ and two different SZAs. For COT $=5$ and SZA $=30^{\circ}$, the increase in aerosol load produces changes in the UVI of about 1 . 

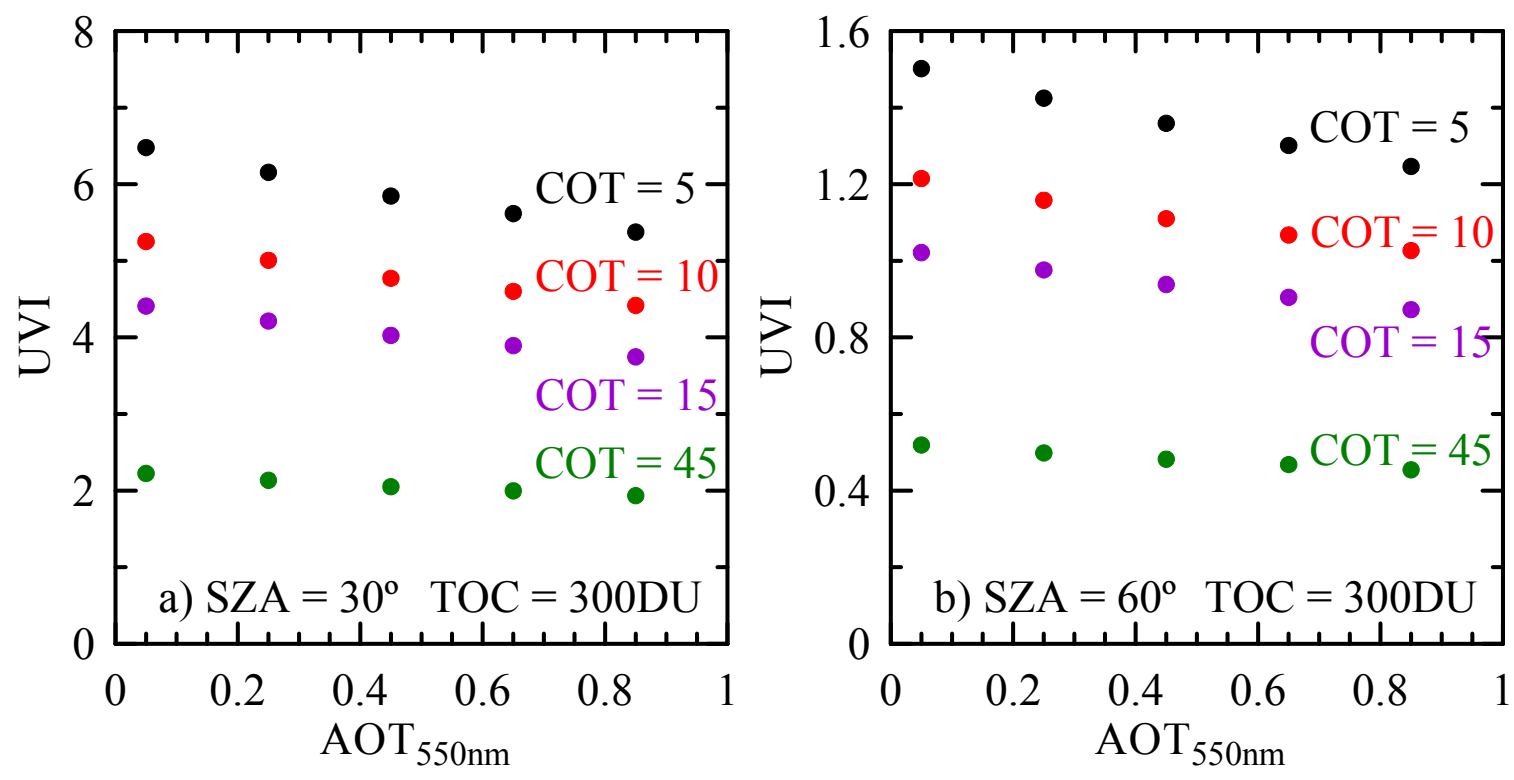

Figure 3.17. Simulated UVI values in overcast skies (8 octas) as a function of the aerosol optical thickness at $550 \mathrm{~nm}$ for different cloud optical thicknesses for the TRISAIA station at a fixed TOC $=300$ DU for two different SZAs: $30^{\circ}\left(\right.$ a) and $60^{\circ}(\mathrm{b})$.

As in the previous studies, the differences between the two extreme aerosol conditions, i.e. $\mathrm{UVI}_{\mathrm{AOT} 550 \mathrm{~nm}}=0.05-\mathrm{UVI}_{\mathrm{AOT} 550 \mathrm{~nm}=0.85}$, are calculated. Figure 3.18 shows the dependence of the absolute and relative differences on COT at two SZAs. Relative changes in UVI values between $\mathrm{AOT}_{550 \mathrm{~nm}}=0.05$ and $\mathrm{AOT}_{550 \mathrm{~nm}}=0.85$ are therefore influenced by SZA and COT. At low COT $($ COT $<10)$, similar relative differences $(>$ $15 \%)$ are observed for the two SZAs. However, the effect of aerosol load on the differences decreases with COT and is slightly stronger for low SZA.

Comparing Figures 3.14, 3.16, and 3.18, it can be concluded that the strongest effect on UVI values under overcast conditions is that caused by the SZA (and is almost independent on COT). The ozone effect also causes a major reduction in UVI, passing from 200 to 500 DU of about $\sim 68 \%$ at low SZA and high COT. Finally, the effect of aerosol is weaker than that caused by the other factors: $\sim 17 \%$ at low SZA and low COT comparing two scenarios with low and high aerosol load. 

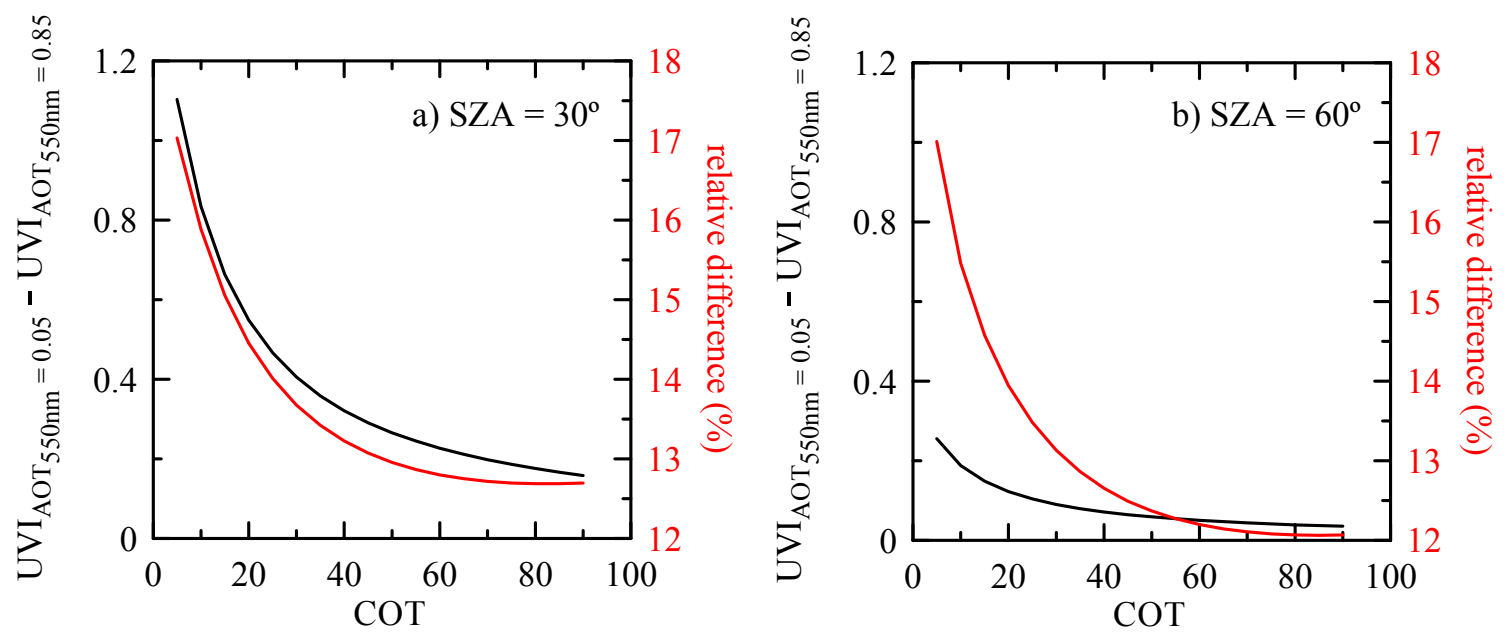

Figure 3.18. Absolute and relative differences between UVI at $A O T_{550 \mathrm{~nm}}=0.05$ and $A O T_{550 \mathrm{~nm}}=0.85$ as a function of the COT obtained with radiative transfer simulations at $S Z A=30^{\circ}(a)$ and $S Z A=60^{\circ}(b)$, and $T O C=300 \mathrm{DU}$.

\subsection{2. $\mathrm{J}\left(\mathrm{O}^{1} \mathrm{D}\right)$ under overcast conditions}

Following the same analysis as was carried out for the UVI case, Figure 3.19 shows the dependence of experimental $\mathrm{J}\left(\mathrm{O}^{1} \mathrm{D}\right)$ values under overcast conditions on cloud optical thickness at the TRISAIA station. As for the UVI case, high variability in the $\mathrm{J}\left(\mathrm{O}^{1} \mathrm{D}\right)$ values is observed at low COTs that can be attributed to other parameters such as SZA, TOC and aerosol load.

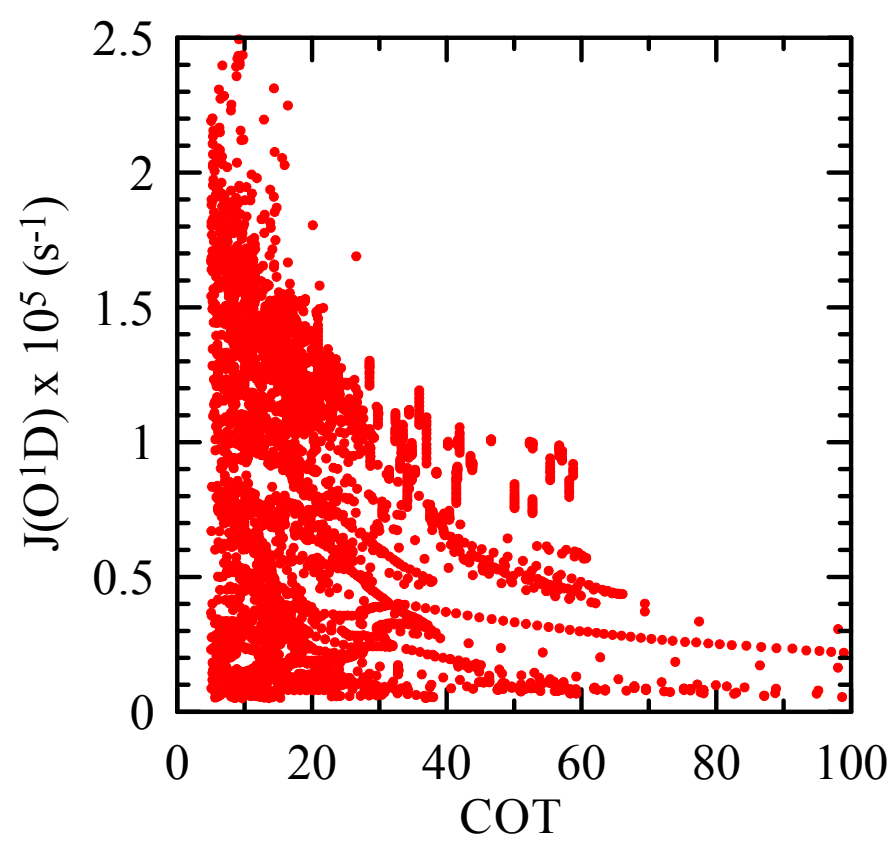

Figure 3.19. $J\left(O^{l} D\right)$ values in overcast skies (8 octas) as a function of the cloud optical thickness for the TRISAIA station. 
To determine the SZA effect on $\mathrm{J}\left(\mathrm{O}^{1} \mathrm{D}\right)$ values, the TOC is limited in the range between 350 and 370 DU in order to reduce ozone absorption influence. Figure 3.20 shows the dependence of both measured and simulated $\mathrm{J}\left(\mathrm{O}^{1} \mathrm{D}\right)$ on SZA for different cloud optical thicknesses. Again, at low COT values, a large variability in the ozone photolysis rate is observed with the SZA, and decreases when COT increases. This behaviour is confirmed by the simulations carried out by the libRadtran model.
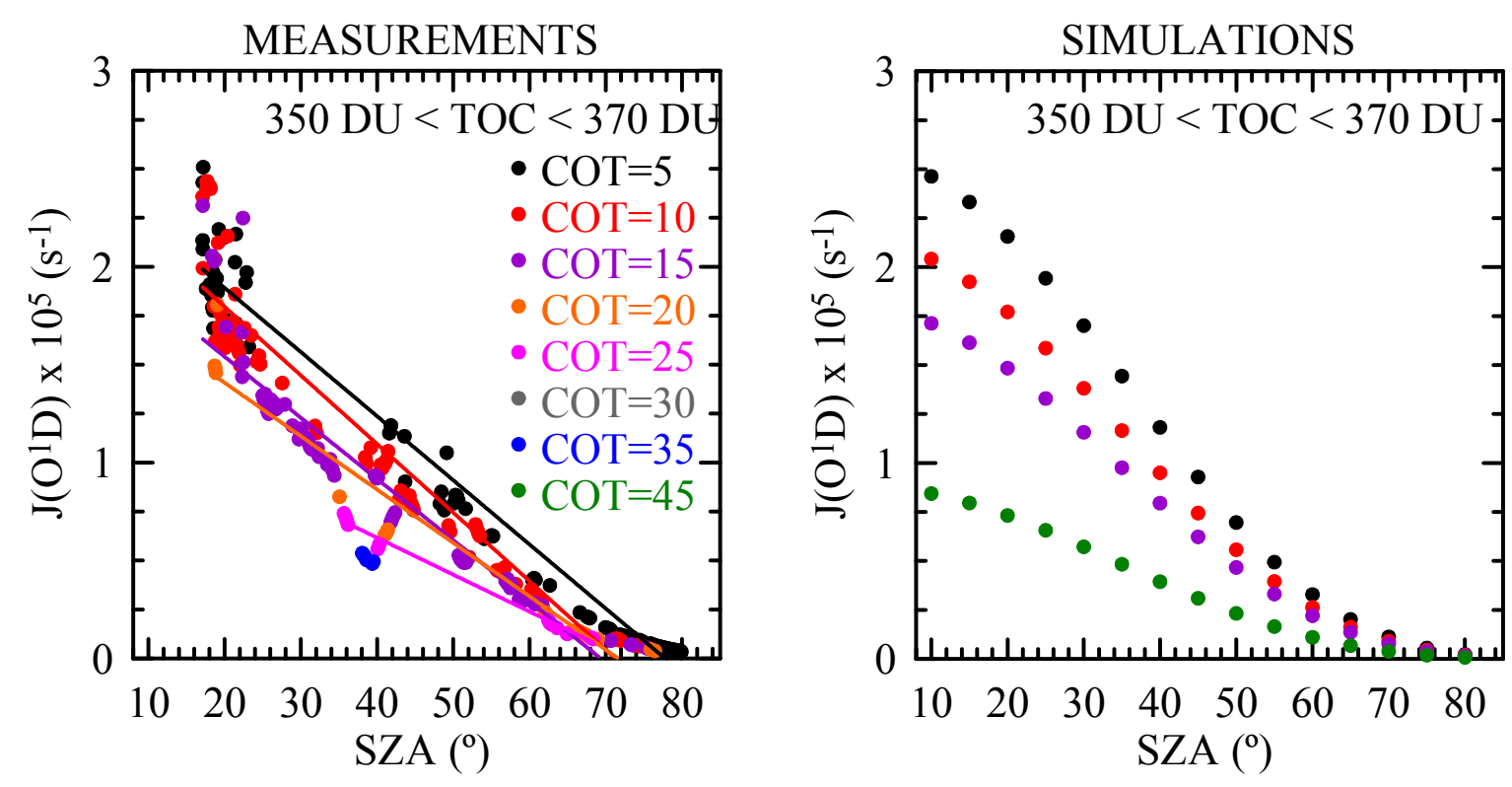

Figure 3.20. $J\left(O^{I} D\right)$ values in overcast skies (8 octas) as a function of the solar zenith angle for different cloud optical thicknesses for measurements (left panel) and radiative transfer simulations (right panel) at a fixed interval of TOC for the TRISAIA database.

To investigate the impact of TOC on $\mathrm{J}\left(\mathrm{O}^{1} \mathrm{D}\right)$ values under overcast conditions, the two SZA intervals fixed in the UVI case are again used $\left(15^{\circ}<\mathrm{SZA}<25^{\circ}\right.$ and $30^{\circ}<\mathrm{SZA}$ $<40^{\circ}$ ). Figure 3.21 shows the results obtained from the measurements and the simulations for $\mathrm{J}\left(\mathrm{O}^{1} \mathrm{D}\right)$. The following discussion is mainly with the model results because of the low range of TOC and the high dispersion obtained in the experimental plots. The variability observed in the values of the ozone photolysis rate for different COT decreases with TOC. The effect of ozone is SZA dependent. 

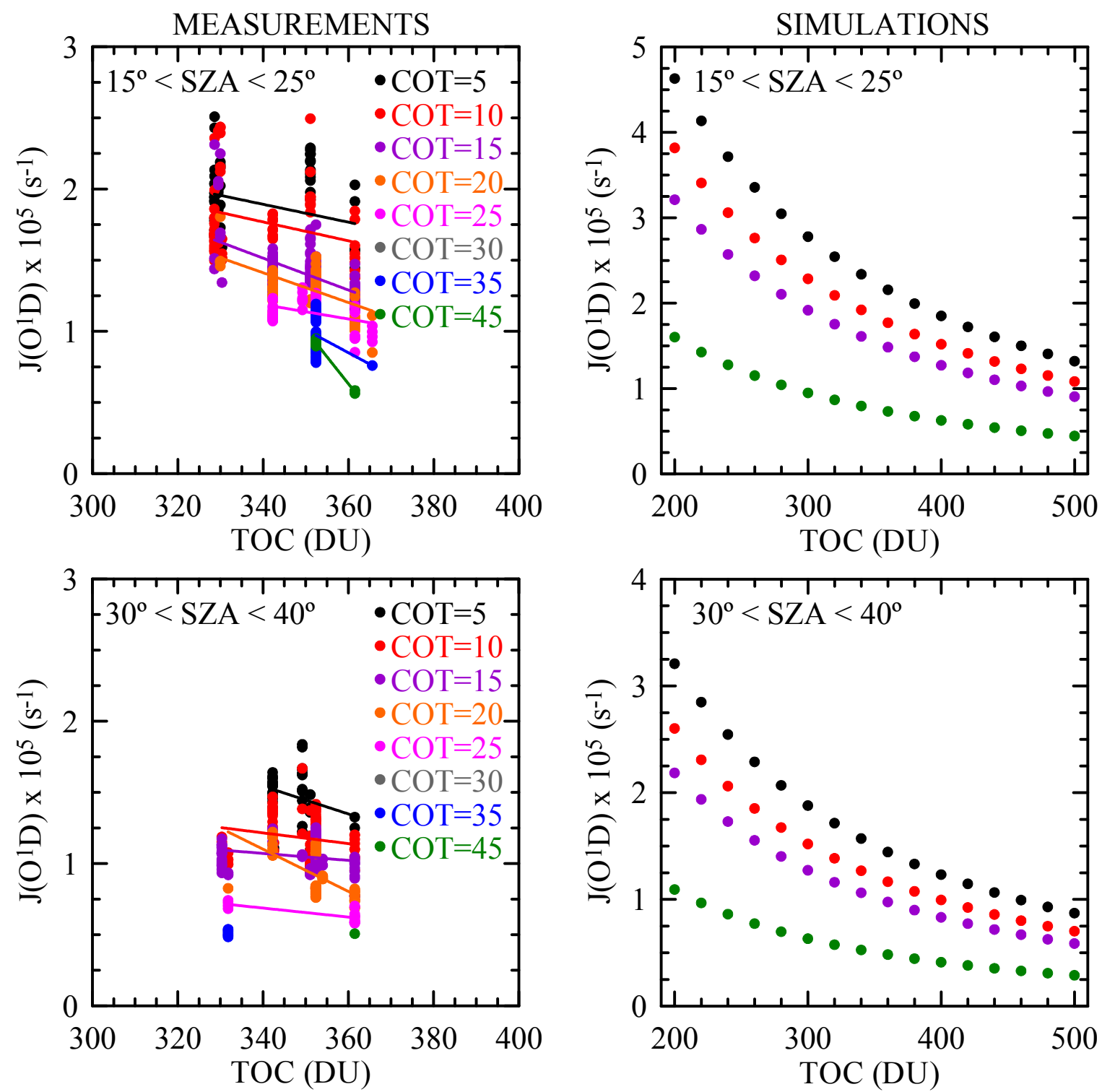

Figure 3.21. $J\left(O^{I} D\right)$ values in overcast skies (8 octas) as a function of total ozone column for different cloud optical thicknesses for measurements (left panels) and radiative transfer simulations (right panels) at two fixed intervals of SZA for the TRISAIA database.

The effect of aerosol under overcast conditions on $\mathrm{J}\left(\mathrm{O}^{1} \mathrm{D}\right)$ values is analyzed using model simulations. Figure 3.22 shows this dependence at $30^{\circ}$ and $60^{\circ}$ of SZA and TOC $=$ 300 DU. As can be seen in the figure, the aerosol effect on $\mathrm{J}\left(\mathrm{O}^{1} \mathrm{D}\right)$ seen to be determinant under overcast conditions, with even high COT. 

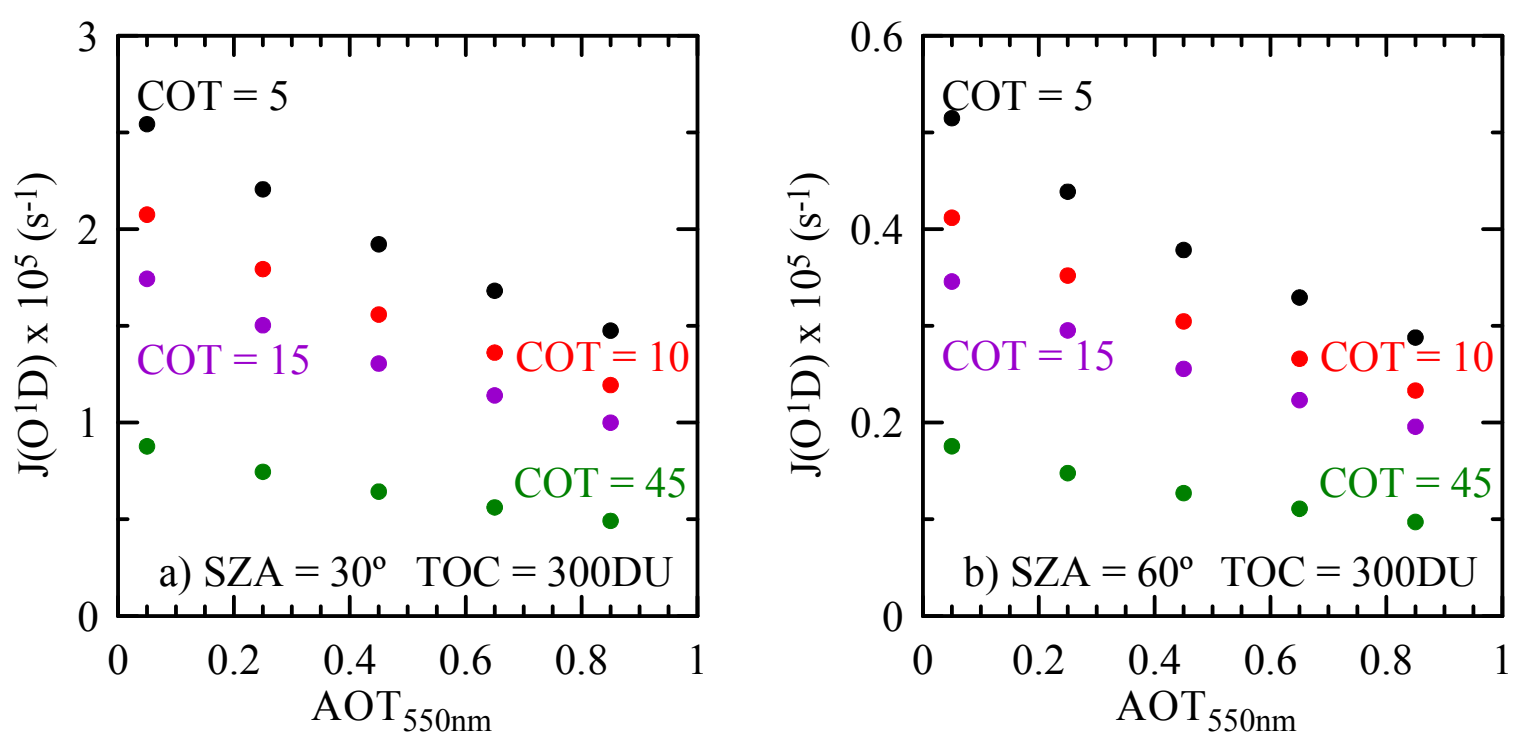

Figure 3.22. Simulated $J\left(O^{I} D\right)$ values in overcast skies (8 octas) as a function of aerosol optical thickness at $550 \mathrm{~nm}$ for different cloud optical thicknesses for the TRISAIA station at a fixed TOC $=300 \mathrm{DU}$ for two different SZAs: $30^{\circ}(a)$ and $60^{\circ}(b)$.

As for the UVI case, variability in $\mathrm{J}\left(\mathrm{O}^{1} \mathrm{D}\right)$ values (simulated with the libRadtran) as a function of COT and SZA, TOC, and $\mathrm{AOT}_{550 \mathrm{~nm}}$ is analyzed. In this case, all the results are plotted together in Figure 3.23. The difference (in the figure represented by the symbol $\Delta$ ) between the two extreme angles, i.e. $\mathrm{J}\left(\mathrm{O}^{1} \mathrm{D}\right)_{\mathrm{SZA}}=10^{\circ}-\mathrm{J}\left(\mathrm{O}^{1} \mathrm{D}\right)_{\mathrm{SZA}}=80^{\circ}$, is shown in Figure 3.23.a. The difference between the two extreme TOC values, i.e. $\mathrm{J}\left(\mathrm{O}^{1} \mathrm{D}\right)_{\mathrm{TOC}}=$ $200 \mathrm{DU}-\mathrm{J}\left(\mathrm{O}^{1} \mathrm{D}\right)_{\mathrm{TOC}}=500 \mathrm{DU}$, is shown in Figure 3.23.b, and the difference between the two extreme values of the aerosol load, i.e. $\mathrm{J}\left(\mathrm{O}^{1} \mathrm{D}\right)_{\mathrm{AOT} 550 \mathrm{~nm}}=0.05-\mathrm{J}\left(\mathrm{O}^{1} \mathrm{D}\right)_{\mathrm{AOT} 550 \mathrm{~nm}}=0.85$ is shown in Figure 3.23.c.

The relative change in the ozone photolysis rate between $\mathrm{SZA}=10^{\circ}$ and $\mathrm{SZA}=$ $80^{\circ}$ is almost COT-independent with a percentage of $\sim 99 \%$ (slightly higher than was obtained for the UVI study). With regard to ozone, a higher relative change is again observed for the $\mathrm{J}\left(\mathrm{O}^{1} \mathrm{D}\right)$ case, with percentages between 72 and $77 \%$ for $30^{\circ}<\mathrm{SZA}<60^{\circ}$. In addition, a significant difference is observed compared to the Figure 3.16. The change in $\mathrm{J}\left(\mathrm{O}^{1} \mathrm{D}\right)$ values passing from $\mathrm{TOC}=200 \mathrm{DU}$ to $\mathrm{TOC}=500 \mathrm{DU}$ is greater the higher the SZA (the opposite behaviour to the UVI case). In other words, the maximum percentages of relative changes are reached at higher SZAs. The behaviour shared with the UVI is the increasing trend in the relative differences with COT. 

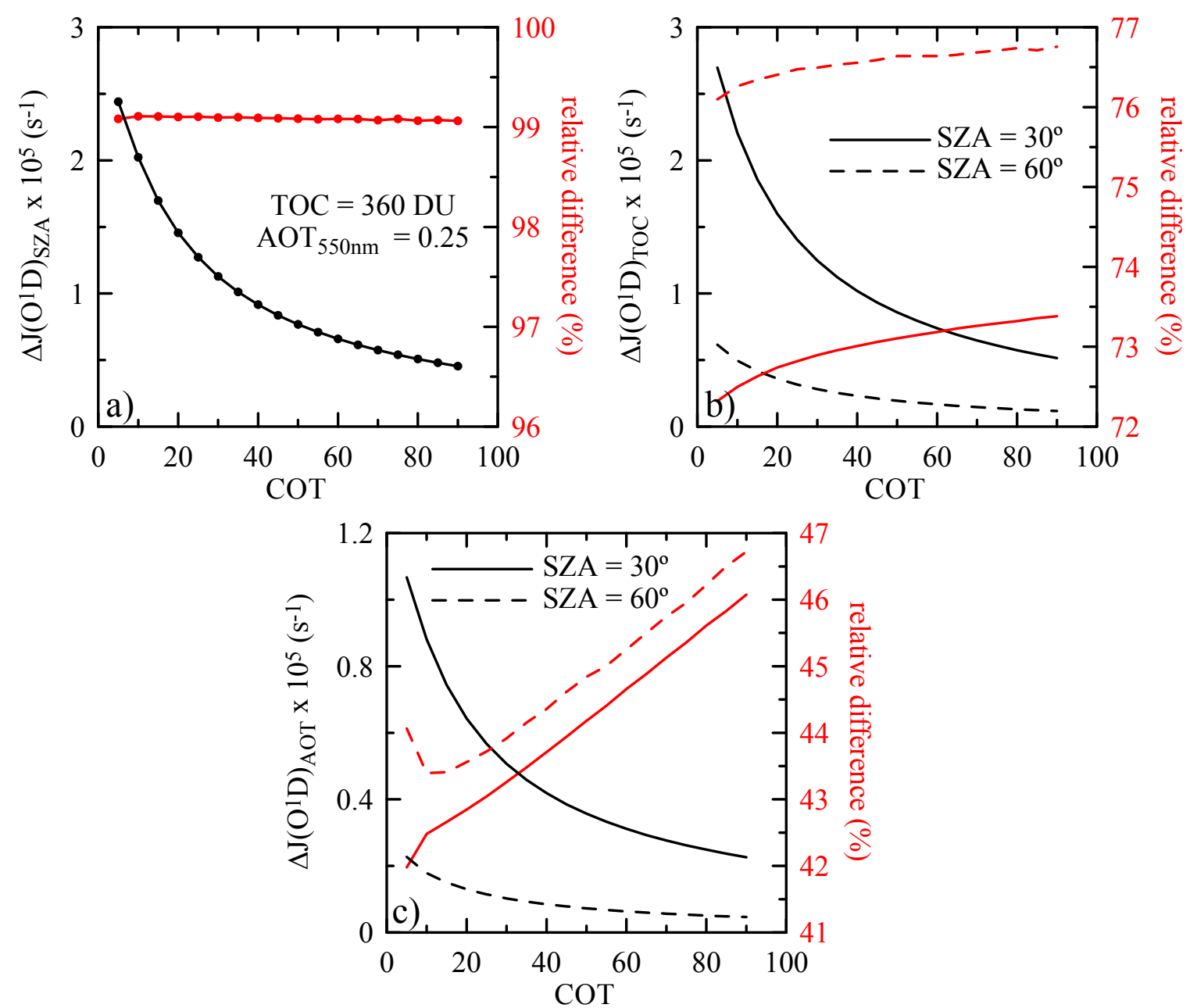

Figure 3.23. Absolute and relative differences between $J\left(O^{I} D\right)$ at $S Z A$ of $10^{\circ}$ and $80^{\circ}(\mathrm{a})$, TOC of 200 and $500 \mathrm{DU}(\mathrm{b})$, and $A O T_{550 \mathrm{~mm}}$ of 0.05 and 0.85 (c) as a function of the COT obtained with radiative transfer simulations.

Finally, the aerosol effect on $\mathrm{J}\left(\mathrm{O}^{1} \mathrm{D}\right)$ under overcast conditions is stronger than for the UVI case. The relative difference on the ozone photolysis rates between two scenarios of low and high turbidity can reach differences of over $40 \%$. In addition, a clear increasing trend of the relative differences with COT is observed (different from the UVI discussion in Figure 3.18). The curves' dependence on SZA leads to a $\sim 1 \%$ change comparing SZAs of $30^{\circ}$ and $60^{\circ}$, the aerosol effect in this case proving stronger for higher SZAs. 


\subsection{Evaluation of cloud modification factors for UVI and $J\left(O^{1} D\right)$ and their dependence on cloud optical thickness}

The effects of clouds on UV radiation are usually expressed by the cloud modification factor (CMF), defined in Chapter 1 (see Equation 1.41) as the ratio between the measurement (at any condition) and the estimated value under cloudless conditions. The models established in Section 3.2 are used to evaluate the CMFs with the SZA and the TOC values at the time of the measurement, which are introduced into the Look-upTables to obtain the corresponding UVI or $\mathrm{J}\left(\mathrm{O}^{1} \mathrm{D}\right)$ estimations under cloudless conditions. A bilinear interpolation between the four appropriate elements of the table (for the two closest SZA and TOC values) is carried out to determine the output.

Figure 3.24 shows CMF dependence for UVI values $\left(\mathrm{CMF}_{\mathrm{UVI}}\right)$ as a function of cloud optical thickness for both measurements and simulations in each station. The agreement between both techniques is good. As expected, lower COT values lead to larger $\mathrm{CMF}_{\mathrm{UVI}}$ than the higher ones. 

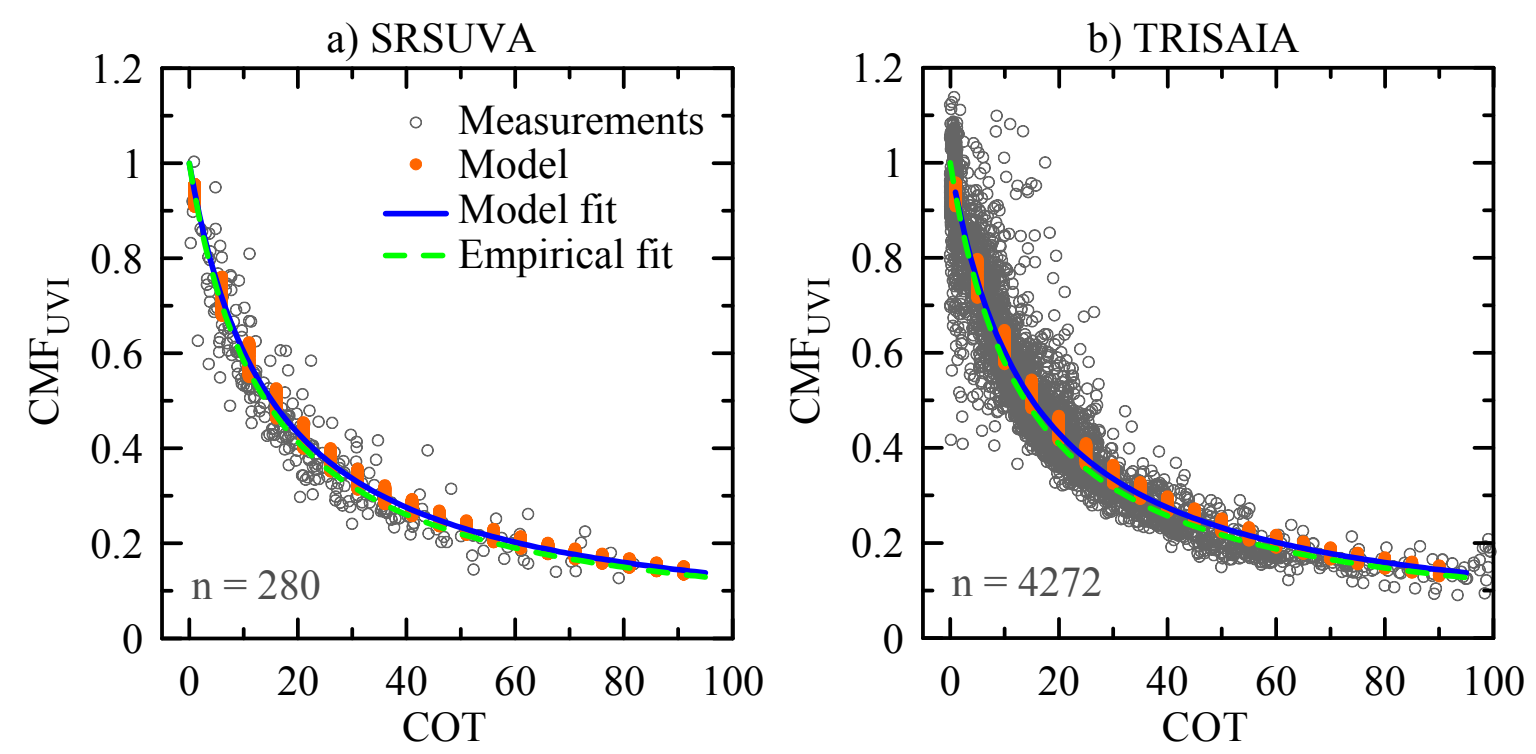

c) LAMPEDUSA

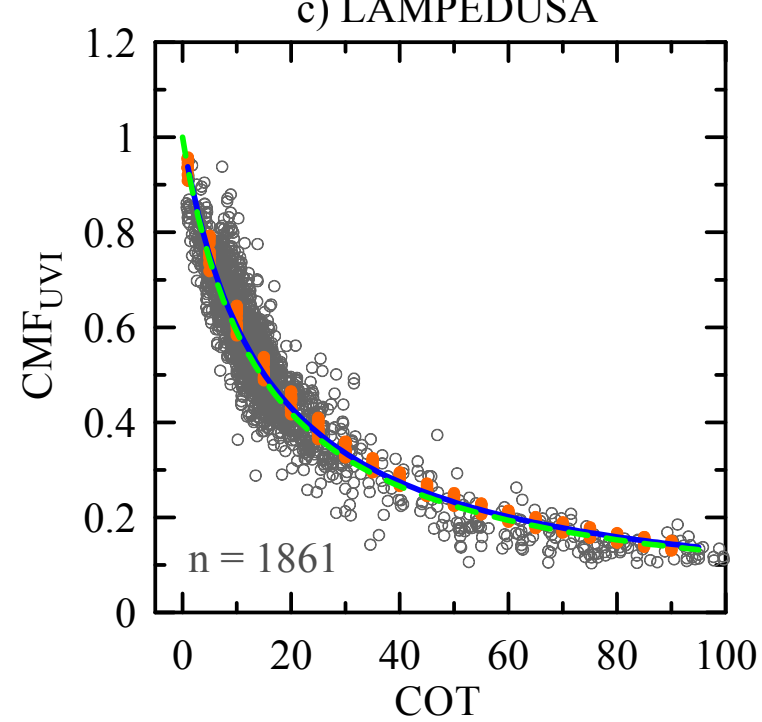

Figure 3.24. $C M F_{U V I}$ values (measurements and simulations in grey and orange, respectively) in overcast skies (8 octas) as a function of cloud optical thickness at the SRSUVA (a), TRISAIA (b), and LAMPEDUSA (c) stations. The green dash and the blue solid lines are fits made with the measured and modelled data, respectively.

There is much more variability in the CMF values at low COT, and with highly optically thick clouds the effects of other atmospheric factors almost disappear.

The fits shown in Figure 3.24 present the following form:

$$
\mathrm{CMF}_{\mathrm{UVI}}=\frac{1}{1+\mathrm{c}_{1} \mathrm{COT}}
$$


The values and the corresponding standard errors of the obtained $\mathrm{c}_{1}$ coefficient for the three stations are reported in Table 3.1.

Table 3.1. $c_{1}$ coefficient of Equation (3.1), its standard error (SE), and correlation coefficient (r) for the three stations.

\begin{tabular}{ccccc}
\hline Station & Type & $\mathbf{c}_{1}$ & SE & $\mathbf{r}$ \\
\hline \multirow{2}{*}{ SRSUVA } & Empirical & 0.0710 & 0.0009 & 0.962 \\
& Model & 0.06573 & 0.00004 & 0.998 \\
\multirow{2}{*}{ TRISAIA } & Empirical & 0.0723 & 0.0004 & 0.944 \\
& Model & 0.06610 & 0.00010 & 0.998 \\
\multirow{2}{*}{ LAMPEDUSA } & Empirical & 0.0692 & 0.0002 & 0.963 \\
& Model & 0.06610 & 0.00010 & 0.998 \\
\hline
\end{tabular}

Despite the numerical differences in the table coefficients, the curves are very similar. All of them are plotted in Figure 3.25, the three empirical fits being on top of each other. The same happens for the two model curves. Therefore, CMF dependence on COT seems to be site-independent (or with a very weak effect on local characteristics), and the calculated fits appear to have a general applicability.

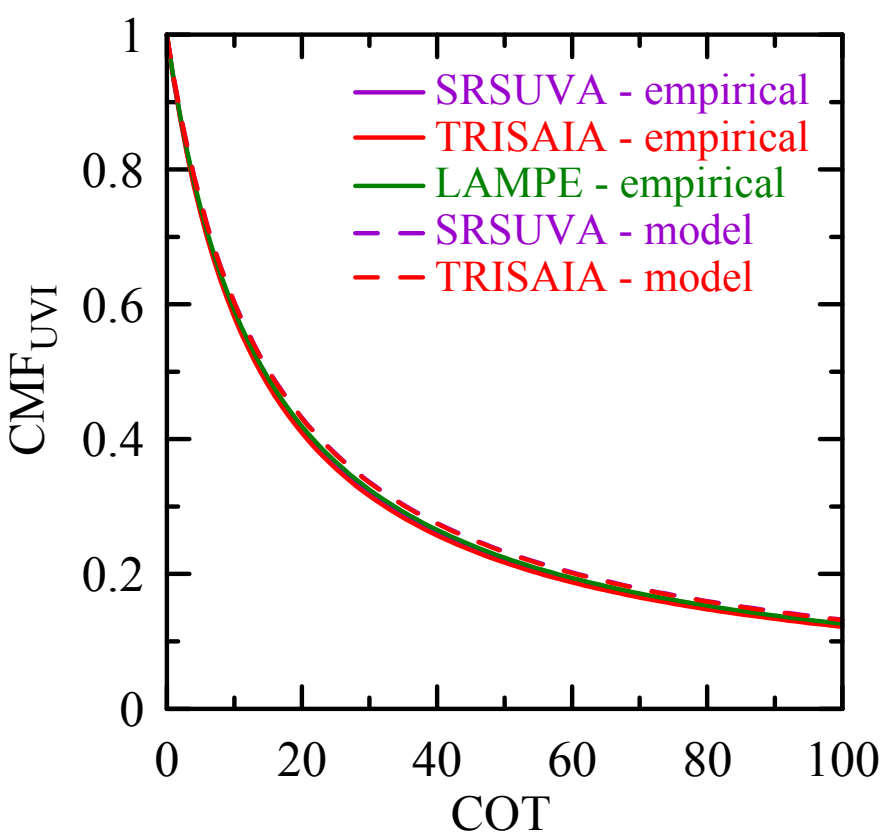

Figure 3.25. $C M F_{U V I}=\left(1+c_{1} C O T\right)^{-1}$ with the coefficients of Table 3.1 for the three stations (SRSUVA, TRISAIA and LAMPEDUSA, labelled LAMPE in the legend), for both experimental (solid lines) and model (dashed lines) results. 
Hence, the fits proposed in Equation 3.1 and Table 3.1 could be used to estimate cloud optical thickness under overcast conditions from UVI measurements, since the CMF calculation only needs the UV index estimate in a cloud-free sky.

Finally, the CMFs for the ozone photolysis rates $\left(\mathrm{CMF}_{\mathrm{J}(\mathrm{O} 1 \mathrm{D})}\right)$ are also calculated. Measurements and simulations are used and the results are shown in Figure 3.26. As can be seen in the figure, the $\mathrm{CMF}_{\mathrm{J}(\mathrm{O} 1 \mathrm{D})}$ values (both measurements and simulations) show a wide dispersion for all COTs. Regarding the linear fits of the figure, their equations have the same form as Equation (3.1), and their coefficients are shown in Table 3.2.

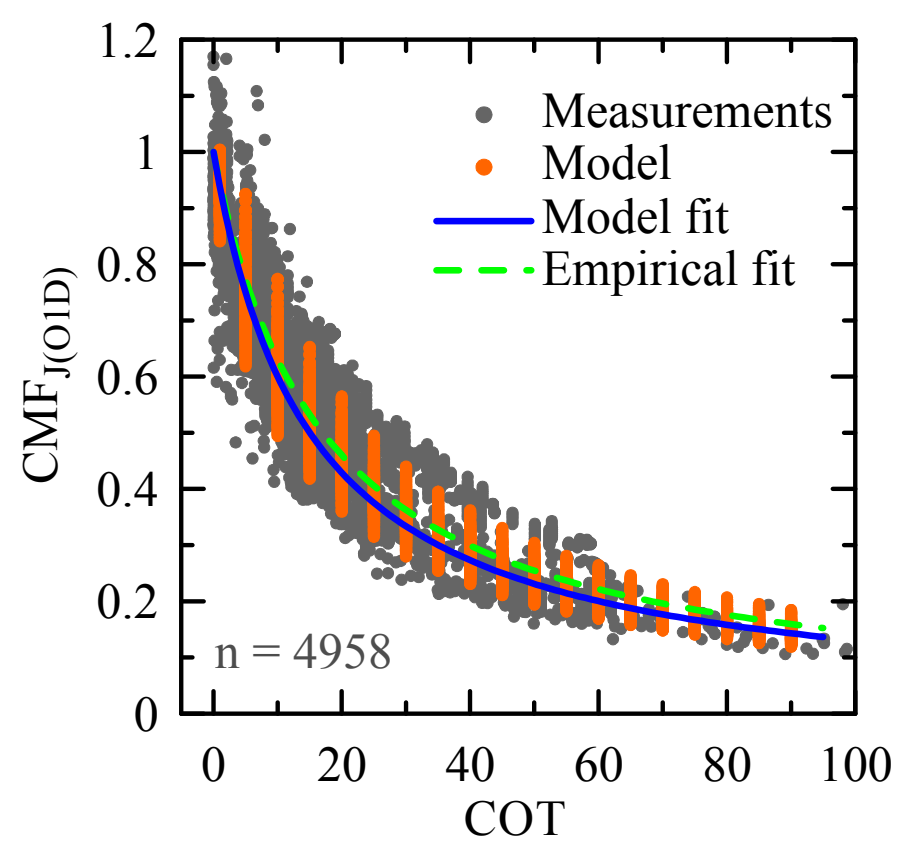

Figure 3.26. CMF $F_{J(O I D)}$ values (measurements and simulations in grey and orange, respectively) in overcast skies (8 octas) as a function of cloud optical thickness at the TRISAIA station. The green dash and the blue solid lines are fits made with the measured and modelled data, respectively.

Table 3.2. $c_{1}$ coefficient of Equation (3.1) but for the $C M F_{J(O I D)}$, its standard error (SE), and the correlation coefficient (r) at the TRISAIA station.

\begin{tabular}{ccccc}
\hline Station & Type & $\mathbf{c}_{\mathbf{1}}$ & $\mathbf{S E}$ & $\mathbf{R}$ \\
\hline \multirow{2}{*}{ TRISAIA } & Empirical & 0.0586 & 0.0003 & 0.913 \\
& Model & 0.06658 & 0.00005 & 0.987 \\
\hline
\end{tabular}


From the results obtained, no significant differences between the dependences on COT of $\mathrm{CMF}_{\mathrm{UVI}}$ and $\mathrm{CMF}_{\mathrm{J}(\mathrm{O} 1 \mathrm{D})}$ can be found, since the fits are very similar, particularly for the simulations. This can be seen in Figure 3.27 with the results for the TRISAIA station. $\mathrm{CMF}_{\mathrm{J}(\mathrm{O} 1 \mathrm{D})}$ however, shows a larger variability than $\mathrm{CMF}_{\mathrm{UVI}}$.

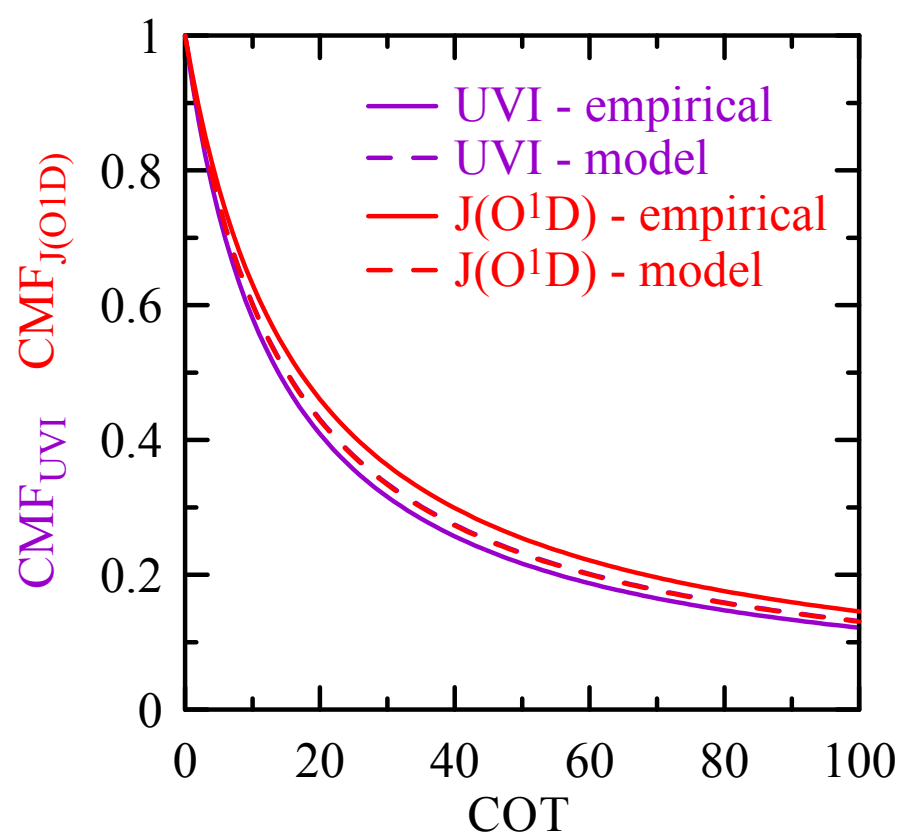

Figure 3.27. $C M F=\left(1+c_{1} C O T\right)^{-1}$ for UVI and $J\left(O^{I} D\right)$ with the coefficients of Table 3.1 and Table 3.2 of the TRISAIA station for both experimental (solid lines) and model (dashed lines) results.

Another possibility for analyzing the effect that clouds have on solar radiation is to calculate the cloud radiative effect, defined as the difference between the cloudy and the cloud-free sky radiative flux. Annex B shows the cloud radiative effect for erythemal radiation, calculated at the three measurement stations used in this thesis. The dependence of the UVER cloud radiative effect on cloud properties is also shown. This study is the first step in further determining the cloud net effect on UV radiative flux. 


\subsection{Summary}

\subsubsection{English version}

Solar integrated irradiance and actinic flux were analyzed as a function of cloudy conditions using experimental measurements at three different stations and radiative transfer simulations. The dependence of the UV index and ozone photolysis rates on cloud cover is similar. For instance, the largest solar zenith angles are the least affected by cloud presence. The scenario of overcast conditions was analyzed in detail. UVI and $\mathrm{J}\left(\mathrm{O}^{1} \mathrm{D}\right)$ measured at the three stations show a strong dependence on cloud optical thickness. The influence of other parameters under overcast conditions was also analyzed. The SZA produces an effect on UVI and $\mathrm{J}\left(\mathrm{O}^{1} \mathrm{D}\right)$ which is COT-independent, while the impact of ozone increases with COT and is SZA-dependent. The effect of aerosol under these conditions is weak for UVI (decreasing with COT), and more relevant for $\mathrm{J}\left(\mathrm{O}^{1} \mathrm{D}\right)$ with an increasing trend with COT. A good estimation of UVI and $\mathrm{J}\left(\mathrm{O}^{1} \mathrm{D}\right)$ under cloudless conditions must be achieved to calculate the corresponding cloud modification factor (CMF). Empirical Look-up-Tables obtained by averaging the values falling into the same conditions of SZA and TOC were developed. The main source of uncertainty of this UVI cloudless model is aerosol load, particularly for the highest UVI values (in summer months with a high probability of large particle concentration events). However, as experimental data of aerosol load under cloudy conditions are not available, this information has not been taken into account in the cloudless modelling. $\mathrm{J}\left(\mathrm{O}^{1} \mathrm{D}\right)$ modelling under cloudless conditions highlights the role of aerosol influence together with a possible enhanced role of tropospheric ozone. CMFs were evaluated for the UVI and $\mathrm{J}\left(\mathrm{O}^{1} \mathrm{D}\right)$ variables and their dependences on COT were determined. The experimental results are very close to those obtained by using radiative transfer simulations. In addition, no significant differences between $\mathrm{CMF}_{\mathrm{UVI}}$ and $\mathrm{CMF}_{\mathrm{J}(\mathrm{O} 1 \mathrm{D})}$ are observed, with the exception of a higher variability in the $\mathrm{J}\left(\mathrm{O}^{1} \mathrm{D}\right)$ case. Fits with the form $\mathrm{CMF}=\left(1+\mathrm{c}_{1}\right.$ $\mathrm{COT})^{-1}$ were calculated for CMF dependence on COT resulting in a new methodology, which allows COT to be easily obtained using only a reliable estimation under cloudless conditions.

\subsubsection{Spanish version}

La caracterización de la radiación solar, irradiancia y flujo actínico, en régimen integrado se ha realizado en condiciones de cielo nuboso usando las medidas en tres estaciones europeas y simulaciones con un modelo de transferencia radiativa. La dependencia con la cubierta de nubes del índice UV, UVI, y del índice de fotodisociación 
del ozono, $\mathrm{J}\left(\mathrm{O}^{1} \mathrm{D}\right)$, presenta conclusiones similares: por ejemplo, para ángulos cenitales altos, estas variables resultan ser menos afectadas por la presencia de nubes, y la combinación de bajos SZAs y cielos totalmente cubiertos produce los mismos valores que para altos SZAs y cielos despejados. El escenario de cielos totalmente cubiertos ha sido analizado en detalle. Las medidas realizadas de UVI y $\mathrm{J}\left(\mathrm{O}^{1} \mathrm{D}\right)$ presentan una fuerte dependencia del espesor óptico de nubes. También se ha estudiado la influencia de otros parámetros en condiciones de cielos totalmente cubiertos. El SZA produce un efecto sobre el UVI y el $\mathrm{J}\left(\mathrm{O}^{1} \mathrm{D}\right)$ que es independiente del COT, mientras que el impacto del ozono aumenta con el COT y es, además, dependiente del SZA. El efecto del aerosol en estas condiciones es débil en el caso del UVI (disminuyendo con el COT) y más relevante para el $\mathrm{J}\left(\mathrm{O}^{1} \mathrm{D}\right)$ con una tendencia creciente con el COT. Como la variable para estudiar los efectos radiativos de las nubes es el factor de modificación de nubes (CMF), es necesario tener una buena estimación del UVI y el $\mathrm{J}\left(\mathrm{O}^{1} \mathrm{D}\right)$ en condiciones de cielos despejados. Para ello, se evalúan una serie de tablas empíricas promediando todos los valores que presenten las mismas condiciones de SZA y TOC. La principal fuente de incertidumbre en la modelización del UVI resulta ser el papel que juega el aerosol atmosférico, particularmente para los valores más altos del UVI que suelen ocurrir en los meses de verano cuando hay más probabilidad de eventos con una mayor carga de aerosol. Como no hay disponibilidad de datos experimentales de espesor óptico de aerosoles en condiciones de cielos nubosos, esta información no se ha considerado en la modelización de cielos despejados. En el caso del $\mathrm{J}\left(\mathrm{O}^{1} \mathrm{D}\right)$, no solo se observa la influencia del aerosol, sino que además se puede producir un aumento de absorción por parte del ozono troposférico en determinadas situaciones. Con los modelos de cielos despejados, se calculan los factores de modificación de nubes para el UVI y $\mathrm{J}\left(\mathrm{O}^{1} \mathrm{D}\right)$ y se determina su dependencia con el COT. Los resultados experimentales coinciden con los obtenidos usando un modelo de transferencia radiativa. No se han encontrado diferencias significativas entre el $\mathrm{CMF}_{\text {UVI }}$ y el $\mathrm{CMF}_{\mathrm{J}(\mathrm{O} 1 \mathrm{D})}$, a excepción de la alta variabilidad observada en los valores de este último. Se han calculado ajustes de la forma $\mathrm{CMF}=(1+$ $\left.\mathrm{c}_{1} \mathrm{COT}\right)^{-1}$, que constituyen una nueva y sencilla metodología para poder obtener valores del COT en función únicamente de una estimación robusta de lo que ocurre en cielos despejados. 


\section{Chapter 4}

4. Characterization of Spectral Cloud Modification Factors as a function of Cloud Optical Thickness 
The spectral effects produced under the presence of clouds are investigated in this chapter using the LAMPEDUSA and TRISAIA databases. First, the BREWER spectroradiometer measurements collected at Lampedusa Island are used to obtain spectral CMF dependence as a function of cloud optical thickness and solar zenith angle, using simulations from a radiative transfer model. Measurements from the UV-MFRSR and diode array spectrometer performed during the TRISAIA campaign are then used to examine CMFs for actinic flux as well as for global and diffuse irradiances as a function of COT and SZA.

\subsection{Dependence of global irradiance CMF on cloud cover, cloud optical thickness and solar zenith angle}

In this section, global UV irradiance spectra obtained by the Brewer spectrometer at the LAMPEDUSA station during 2005 are used to investigate CMF wavelength dependence. The experimental data are classified according to the WMO classification (http://worldweather.wmo.int/oktas.htm) as a function of cloud cover in four categories from $0-2$ octas (cloudless) to 8 octas (overcast). In this section, only the extreme categories are used due to the low number of cases which comply with the selection criteria on COT and total ozone for the year 2005. All measured spectra are referred to the mean Sun-Earth distance to allow comparison throughout the year.

As a first step for calculating the CMF, UV spectra in cloud-free conditions are detected. To do so, all the Brewer spectra measured under 0 octas are identified and grouped for different classes of total ozone column (from 250 to $400 \mathrm{DU}, 5 \mathrm{DU}$ steps) and SZA (from $20^{\circ}$ to $70^{\circ}, 10^{\circ}$ steps). The obtained cloud-free UV spectra are averaged in order to obtain cloudless reference spectra as a function of total ozone column and SZA. To calculate the CMF, each UV spectrum in cloudy conditions is divided by the corresponding UV spectrum in cloud-free conditions at the same SZA and TOC. Moreover, all spectra displaying a change in cloudiness in three consecutive TSI images (i.e., over a 10 minute interval) are discarded. 


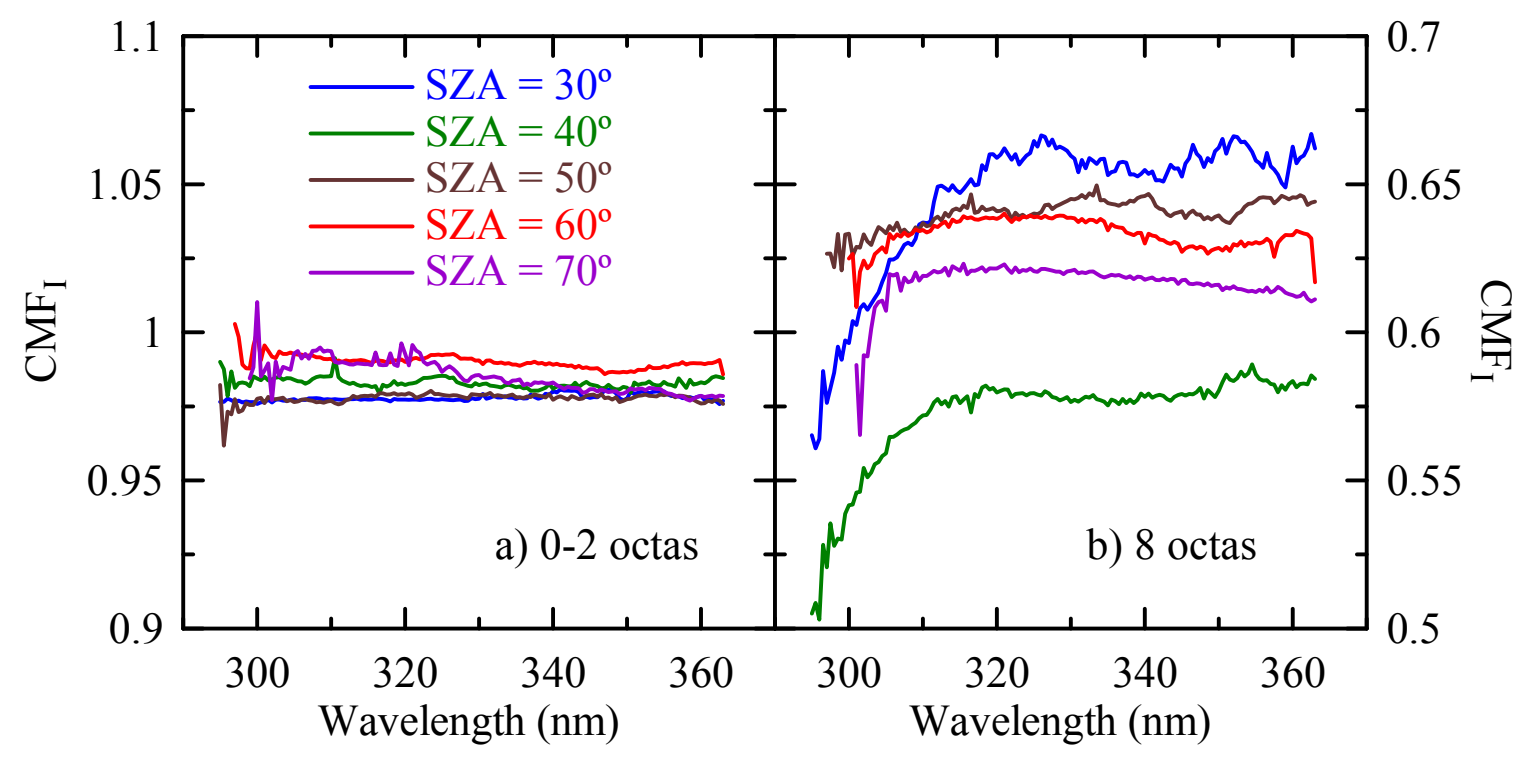

Figure 4.1. Irradiance CMF spectral dependence for 0-2 octas (a), and overcast (8 octas, b) cloud cover as a function of the solar zenith angle (SZA) at the LAMPEDUSA station.

The CMF dependence on SZA for low cloudiness (0-2 octas), and for overcast skies is shown in Figure 4.1. As expected, CMF values for low cloudiness are between 0.97 and 1 for all SZA, and do not significantly depend on wavelength. Relatively large variability is still present, and is attributed to the number of cases with a cloud cover of 1 and 2 octas which comply with the selection method, and the intrinsic high variability of cloud optical properties. The overall behaviour is, however, determined by the dominant role of cloud-free conditions in this class. The absence of wavelength dependence suggests that the total ozone effect is efficiently removed by the methodology used.

The CMF depends on SZA and on wavelength under overcast conditions (Figure 4.1.b). Also in this case, significant variability can be observed. The CMF curves at $\mathrm{SZA}=30^{\circ}$ and $40^{\circ}$ are, respectively, the largest and lowest between 320 and $360 \mathrm{~nm}$. Large variability and solar zenith angle dependence are mostly due to the fact that clouds with different COT and optical properties are included for each SZA. At SZA $=30^{\circ}, \mathrm{CMF}$ shows major wavelength variability, mainly due to the limited number of overcast cases in this class, including summertime spectra. At low solar zenith angles (30-40 ), the CMF increases with wavelength up to $320 \mathrm{~nm}$, while it only increases up to $305 \mathrm{~nm}$ at large solar zenith angles. One possible explanation for this effect is that the enhancement of the photon path length under cloudy conditions compared to clear sky is larger at small solar zenith angles. At the shortest wavelengths, the diffuse component of the irradiance is also dominant for clear skies at large solar zenith angles. In some cases, CMF shows a decrease with wavelength above $310-320 \mathrm{~nm}$. This decrease seems to be more evident at 
$60^{\circ}$ and $70^{\circ}$ solar zenith angles. As mentioned above, the variability of cloud optical thickness strongly limits the reliability of these results. Hence, an investigation as a function of COT is needed.

Only cases of overcast skies are considered to study CMF dependence on cloud optical thickness. Three COT ranges are taken into account: 10-20, 20-30, and 40-50. Table 4.1 shows the number of spectra falling into each of the three COT ranges as a function of the solar zenith angle. Although a large number of spectra are used in this thesis, only few comply with the selection criteria because of the major temporal variability in cloud properties and distribution, and the relatively long time required to acquire UV spectra using the Brewer. Figure 4.2 (left panels: a, c, and e) shows CMF dependence on wavelength and on SZA for the three COT ranges.

The CMF decreases with increasing COT, from about 0.5 for $10<\mathrm{COT}<20$ to 0.25 for $40<\mathrm{COT}<50$. Dependence on SZA is smooth. A weak decrease in CMF for increasing wavelengths can be observed above $315-320 \mathrm{~nm}$, which seems to be more evident at large solar zenith angles. These results are consistent with the mechanism proposed by Kylling et al. (1997), see Chapter 1 - Section 1.3, which is expected to produce a wavelength dependent CMF. Part of the observed variability in CMF behaviour may also be due to effects of different aerosol types and amount.

With the aim of interpreting the observed results, spectral CMFs have been calculated from the simulated spectra for the central COT value of each interval. The results are also shown in Figure 4.2 (right panels: b, d, and f). The ozone column is the same for measured and modelled CMFs. Differences between the curves on the left and right hand sides of Figure 4.2 can be attributed to the variability of COT within the intervals in the measured CMF spectra and, to a lesser extent, to the variability of aerosol optical properties. Consistent with observations, dependence on the solar zenith angle appears stronger for $\mathrm{COT}=15$, and weaker for larger COT values. The agreement between model and measurements is good at longer wavelengths, while differences mainly appear below $310 \mathrm{~nm}$. Based on a modelling study, Brühl and Crutzen (1989) suggested that tropospheric ozone may play a key role in modulating UV-B radiation $(280-315 \mathrm{~nm})$ in the presence of elevated amounts of aerosol, due to the enhanced photon path lengths in the troposphere. This effect is expected to be more evident when clouds are present, because of their large optical thickness, as discussed by Mayer et al. (1998), Wienicki and Fredrick (2005), and others. 


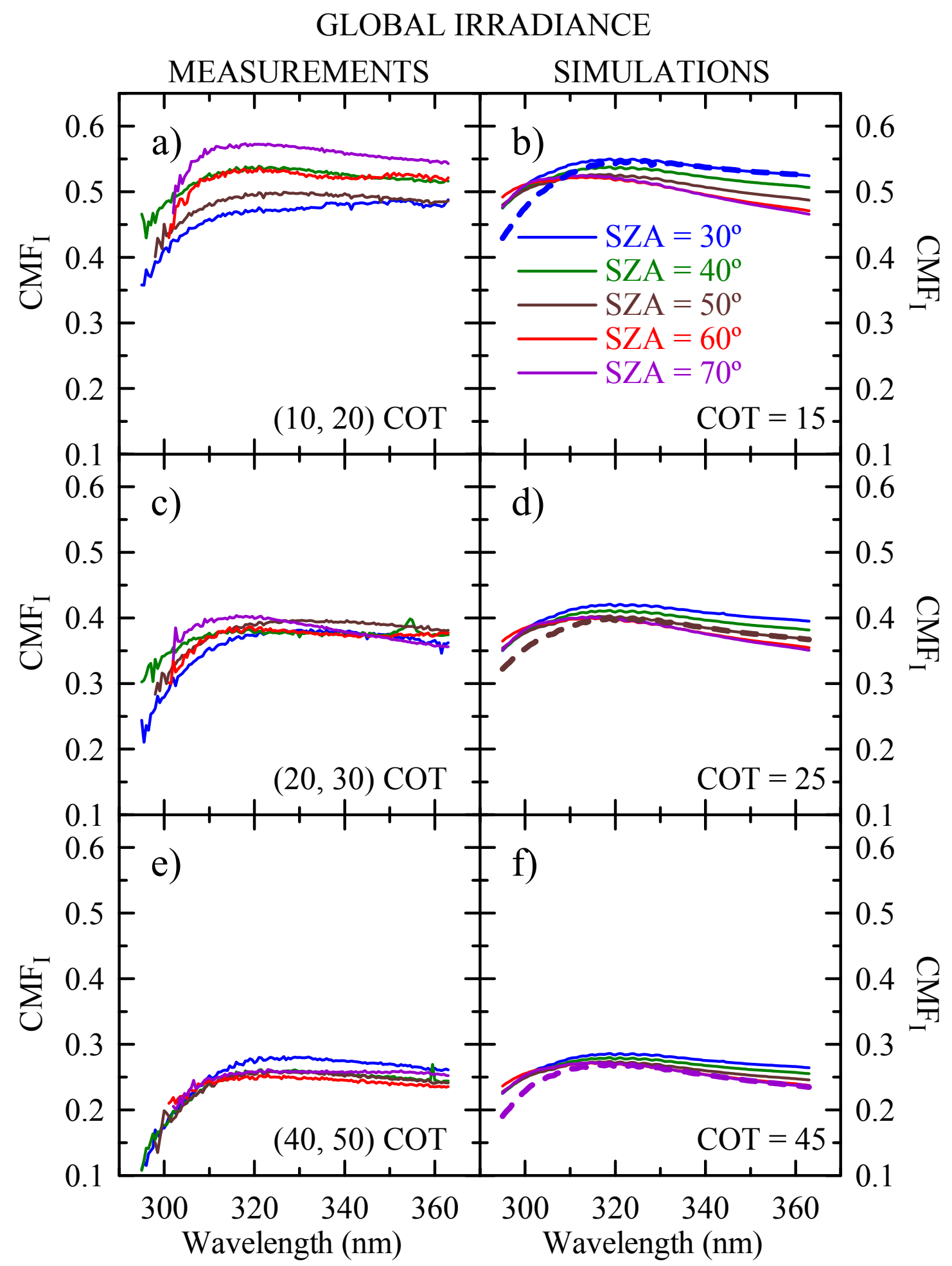

Figure 4.2. Measured ( $a, c, e)$ and modelled ( $b, d, f) C M F$ versus wavelength as a function of the solar zenith angle for different cloud optical thickness values. Dashed bold lines in the right panels relate to simulations with twice the amount of tropospheric ozone at $30^{\circ}, 50^{\circ}$, and $70^{\circ} \mathrm{SZA}$, respectively in b), d), and $f$ ). 
Table 4.1. Number of UV spectra at 8 octas for the three ranges of cloud optical thickness (COT) as a function of the solar zenith angle (SZA) at the LAMPEDUSA station.

\begin{tabular}{cccccc}
\hline COT range $\backslash$ SZA & $\mathbf{3 0}^{\mathbf{0}}$ & $\mathbf{4 0}^{\mathbf{o}}$ & $\mathbf{5 0}^{\mathbf{0}}$ & $\mathbf{6 0}^{\mathbf{0}}$ & $\mathbf{7 0}^{\mathbf{0}}$ \\
\hline $\mathbf{1 0 - 2 0}$ & 5 & 9 & 7 & 1 & 2 \\
$\mathbf{2 0 - 3 0}$ & 2 & 5 & 4 & 1 & 6 \\
$\mathbf{4 0 - 5 0}$ & 2 & 2 & 2 & 1 & 3 \\
\hline
\end{tabular}

The ozone vertical distribution used in the model calculations is typical of a midlatitude profile, which is scaled to match the measured TOC. For this profile, the amount of tropospheric ozone is about $10 \%$ of the total column, and the surface mixing ratio is about $30 \mathrm{ppb}$. However, the contribution of tropospheric ozone may be above $10 \%$ at Northern mid- and high-latitudes (e.g., Fishman et al., 2003).

The ozone vertical profile used in the model is modified, without changing the total ozone column, to verify whether CMF behaviour for wavelengths below $310 \mathrm{~nm}$ is regulated by tropospheric ozone. Model calculations are thus repeated with a tropospheric fraction (from 0 to $10 \mathrm{~km}$ ) twice as large as in the standard profile (surface ozone mixing ratio of about $60 \mathrm{ppb}$ ). Obtained CMFs are reported in Figure 4.2 as dashed bold lines for $\mathrm{SZA}=30^{\circ}$ and $\mathrm{COT}=15, \mathrm{SZA}=50^{\circ}$ and $\mathrm{COT}=25$, and $\mathrm{SZA}=70^{\circ}$ and $\mathrm{COT}=45$. Lower $\mathrm{CMF}$ values are found below $320 \mathrm{~nm}$, and a steeper increase with wavelength is observed, which gives a better reproduction of measured CMF for all classes of COT, although it still overestimates it. Several studies suggest that elevated ozone is common at the surface over the Mediterranean, particularly in summer (e.g., Nolle et al., 2002; Kalabokas et al., 2008; Kulkarni et al., 2011). Elevated ozone levels may also be found throughout the troposphere (e.g., Kourtidis et al., 2002). Surface ozone measurements performed at Lampedusa in spring and summer, not available in 2005, show that tropospheric ozone is generally larger than in the standard mid-latitude profile. A larger reduction of diffuse irradiance at the surface due to enhanced tropospheric ozone has been observed and explained by Meloni et al. (2003). A reliable description of the ozone vertical profile is thus needed for an accurate determination of the cloud modification factor by model at short wavelengths. 


\subsection{Spectral dependence of actinic flux CMF on cloud optical thickness and solar zenith angle}

The same analysis conducted for irradiance is carried out for the actinic flux measured at the TRISAIA station. Once the cloudless periods are identified by the algorithm mentioned in Chapter 2, the classification of the data is performed at $1^{\mathrm{o}}$ steps of SZA and 20 DU of TOC. The spectral CMF of the actinic flux $\left(\mathrm{CMF}_{\mathrm{F}}\right)$ is evaluated. A cloud optical thickness value is assigned to each CMF when the algorithms described in Section 2.2.2 indicate overcast conditions. Figure 4.3 shows the spectral dependence of the CMF for different SZA and COT values. The left panels (a, c, and e) are the experimental data and the right ones ( $b, d$, and $f)$ are the simulations obtained in the configuration of the model explained in Section 2.4.2. Table 4.2 shows the number of spectra falling into each COT value as a function of the solar zenith angle. Each value of COT is fixed as an interval of 1.5 units centred in COT $=10,15$ and 20, and the values of the SZA are considered in $1^{\circ}$ intervals centred at SZA $=20^{\circ}, 30^{\circ}, 40^{\circ}, 50^{\circ}, 60^{\circ}$ and $70^{\circ}$.

As can be seen in the figure, SZA remains the main factor in determining spectral CMF curves above $320 \mathrm{~nm}$. For low SZAs (e.g., SZA=20 ${ }^{\circ}$ ) and for the three COT values, $\mathrm{CMF}$ increases slightly with wavelength.

For intermediate SZAs (e.g., $\mathrm{SZA}=40^{\circ}$ ), spectral behaviour is very similar to that obtained for the irradiance case, with a decrease with wavelength. Finally, for high SZAs (e.g., $\left.\mathrm{SZA}=70^{\circ}\right)$, a stronger decrease is observed. In fact, at these SZAs $\left(60^{\circ}\right.$ and $\left.70^{\circ}\right)$, less attenuation of the shorter wavelengths $(<320 \mathrm{~nm})$ is observed, while the other curves displayed the typical ozone absorption effect. This effect for the shorter wavelengths and high SZA is discussed in Section 4.4 and is attributed to photons arriving from the zenith direction. There are visible differences in the measured and simulated curves at SZA = $60^{\circ}$ and SZA $=70^{\circ}$. Despite this, similar conclusions can be established from the figure. The curve of SZA $=70^{\circ}$ at the shorter wavelengths is above other SZA curves, for instance, in the panel of $\mathrm{COT}=15$, the $\mathrm{SZA}=70^{\circ}$ curve reaches the curve of $\mathrm{SZA}=30^{\circ}$ in the two cases (measurements and simulations).

Table 4.2. Number of actinic flux spectra at 8 octas for the three values of COT as a function of the SZA at the TRISAIA station.

\begin{tabular}{ccccccc}
\hline COT $\backslash$ SZA & $\mathbf{2 0}^{\mathbf{0}}$ & $\mathbf{3 0}^{\mathbf{0}}$ & $\mathbf{4 0}^{\mathbf{0}}$ & $\mathbf{5 0}^{\mathbf{o}}$ & $\mathbf{6 0}^{\mathbf{0}}$ & $\mathbf{7 0}^{\mathbf{0}}$ \\
\hline $\mathbf{1 0}$ & 9 & 7 & 4 & 13 & 7 & 6 \\
$\mathbf{1 5}$ & 20 & 4 & 3 & 9 & 3 & 8 \\
$\mathbf{2 0}$ & 18 & 11 & 7 & 3 & 1 & 5 \\
\hline
\end{tabular}




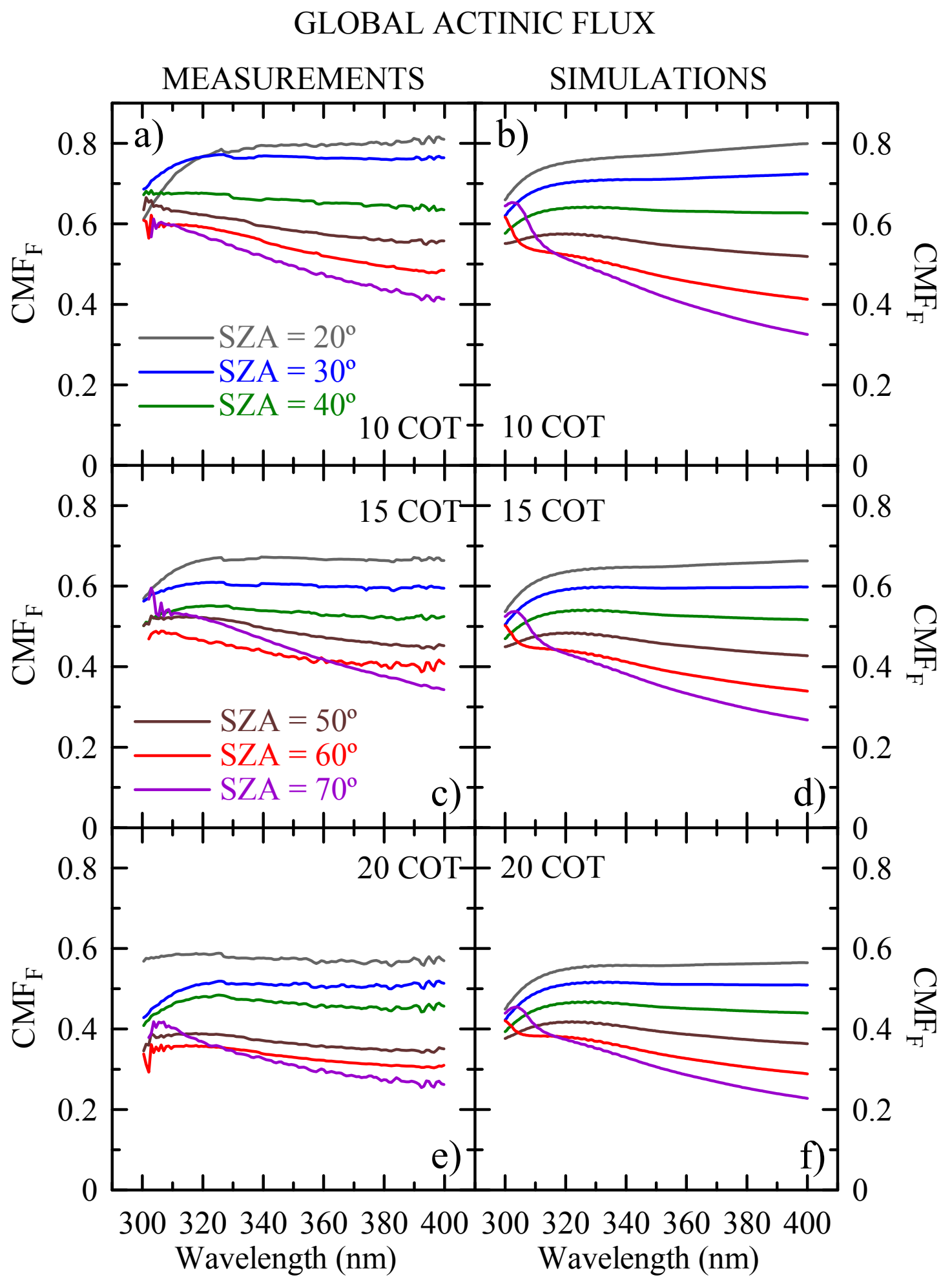

Figure 4.3. Measured (left panels) and modelled (right panels) values of actinic flux CMF versus wavelength as a function of the solar zenith angle for different cloud optical thickness values. 
The model results obtained here are consistent with those obtained by Crawford et al. (2003) for the actinic flux in the interval $(320,400 \mathrm{~nm})$ considering COT $=15$ and several SZAs (see Section 1.3 - Figure 1.13).

With regard to the CMF values, their variability at $400 \mathrm{~nm}$ varies with COT from $(0.4,0.8)$ at $\mathrm{COT}=10$ to $(0.2,0.6)$ at $\mathrm{COT}=20$ both depending on SZA with the higher values for low SZAs. This trend is confirmed through the radiative transfer simulations.

In order to analyze the different behaviour of the CMFs for actinic flux $\left(\mathrm{CMF}_{\mathrm{F}}\right)$ and for irradiance $\left(\mathrm{CMF}_{\mathrm{I}}\right)$, Figure 4.4 shows the results obtained in the model calculations for conditions of COT $=15$, TOC $=300 \mathrm{DU}$ and $\mathrm{AOT}_{550 \mathrm{~nm}}=0.25$ at several SZAs. Significant differences can be observed between the two variables. At low SZA, the values of the $\mathrm{CMF}$ for the actinic flux are higher than the corresponding ones for the irradiance. However, the opposite behaviour occurs at high SZA where $\mathrm{CMF}_{\mathrm{I}}>\mathrm{CMF}_{\mathrm{F}}$ for SZA $>50^{\circ}$. The observed CMF decrease between 320-400 $\mathrm{nm}$ is stronger in the case of actinic flux at high SZA. CMF dependence for the actinic flux on SZA causes noticeable changes in the $\mathrm{CMF}_{\mathrm{F}}$ curves, while $\mathrm{CMF}_{\mathrm{I}}$ shows a weaker dependence on this variable.

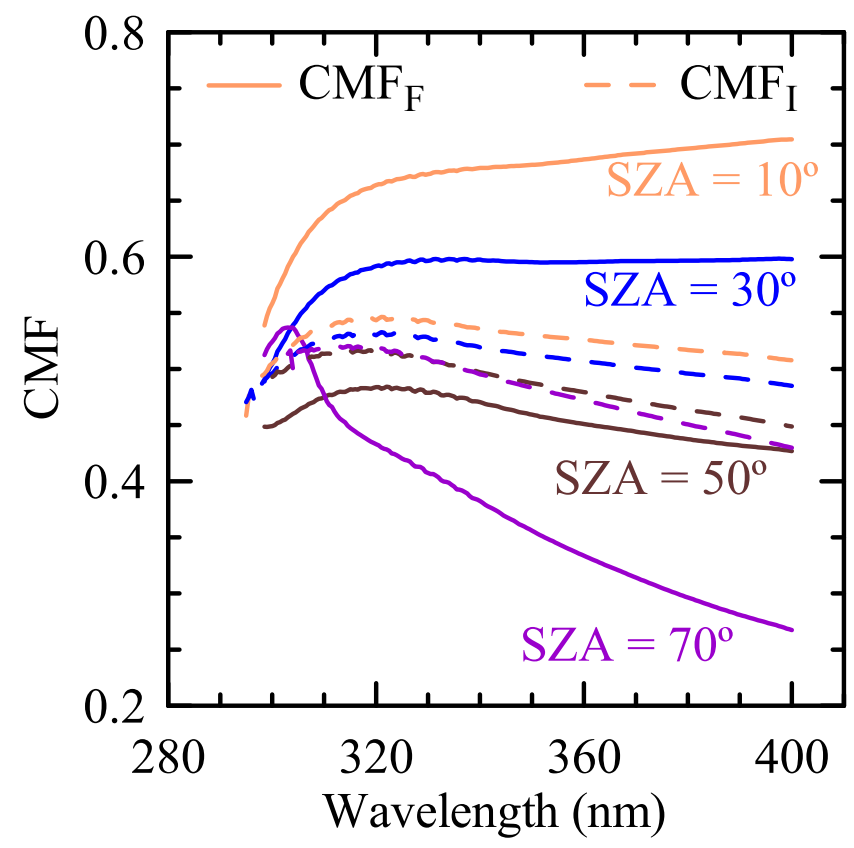

Figure 4.4. $C M F$ for the irradiance $\left(C M F_{1}\right.$, dashed lines) and the actinic flux $\left(C M F_{F}\right.$, solid lines) calculated with the libRadtran model for COT $=15, T O C=300 \mathrm{DU}$ and $A O T_{550 \mathrm{~nm}}=0.25$ at several SZAs. 


\subsection{Spectral CMF of global and diffuse irradiances as a function of cloud optical properties and solar zenith angle}

The study of the global and diffuse cloud transmittances can be carried out at the TRISAIA station with the measurements of the UV-MFRSR instrument. The CMF evaluation for the global and diffuse components is achieved using cloudless data classified and averaged at $1^{\circ}$ steps of SZA and 20 DU of TOC.

Table 4.3 shows the number of spectra falling into each COT value as a function of the solar zenith angle. Again, each value of COT is fixed as an interval of 1.5 units centred in $\mathrm{COT}=10,15$ and 20 , and the values of the SZA are considered in $1^{\circ}$ intervals centred at SZA $=20^{\circ}, 30^{\circ}, 40^{\circ}, 50^{\circ}, 60^{\circ}, 65^{\circ}$ and $70^{\circ}$.

Table 4.3. Number of irradiance (global and diffuse) spectra at 8 octas for the three values of COT as a function of the SZA at the TRISAIA station.

\begin{tabular}{cccccccc}
\hline COT $\backslash$ SZA & $\mathbf{2 0}^{\mathbf{o}}$ & $\mathbf{3 0}^{\mathbf{0}}$ & $\mathbf{4 0}^{\mathbf{0}}$ & $\mathbf{5 0}^{\mathbf{0}}$ & $\mathbf{6 0}^{\mathbf{0}}$ & $\mathbf{6 5}^{\circ}$ & $\mathbf{7 0}^{\mathbf{0}}$ \\
\hline $\mathbf{1 0}$ & 7 & 10 & 5 & 4 & - & - & 7 \\
$\mathbf{1 5}$ & 13 & 4 & - & 9 & 7 & 9 & - \\
$\mathbf{2 0}$ & 13 & 8 & 7 & 4 & - & - & 6 \\
\hline
\end{tabular}

Figure 4.5 shows the spectral dependence of the global and diffuse CMF for different SZA and COT values.

The experimental curves of the $\mathrm{CMF}_{\mathrm{GLOBAL}}$ confirm the previous results obtained with the BREWER spectroradiometer, i.e. the decreasing trend beyond 315-320 $\mathrm{nm}$ and the effect of ozone absorption dominating for the shorter wavelengths are observed. In fact, the values of the CMF at COT $=15$ in the middle panels of Figure 4.5 coincide with those obtained at the LAMPEDUSA station in panels a) and b) of Figure 4.2. In both cases, the $\mathrm{CMF}_{\mathrm{GLOBAL}}$ is around 0.5 for the longer wavelengths (both measurements and simulations). 


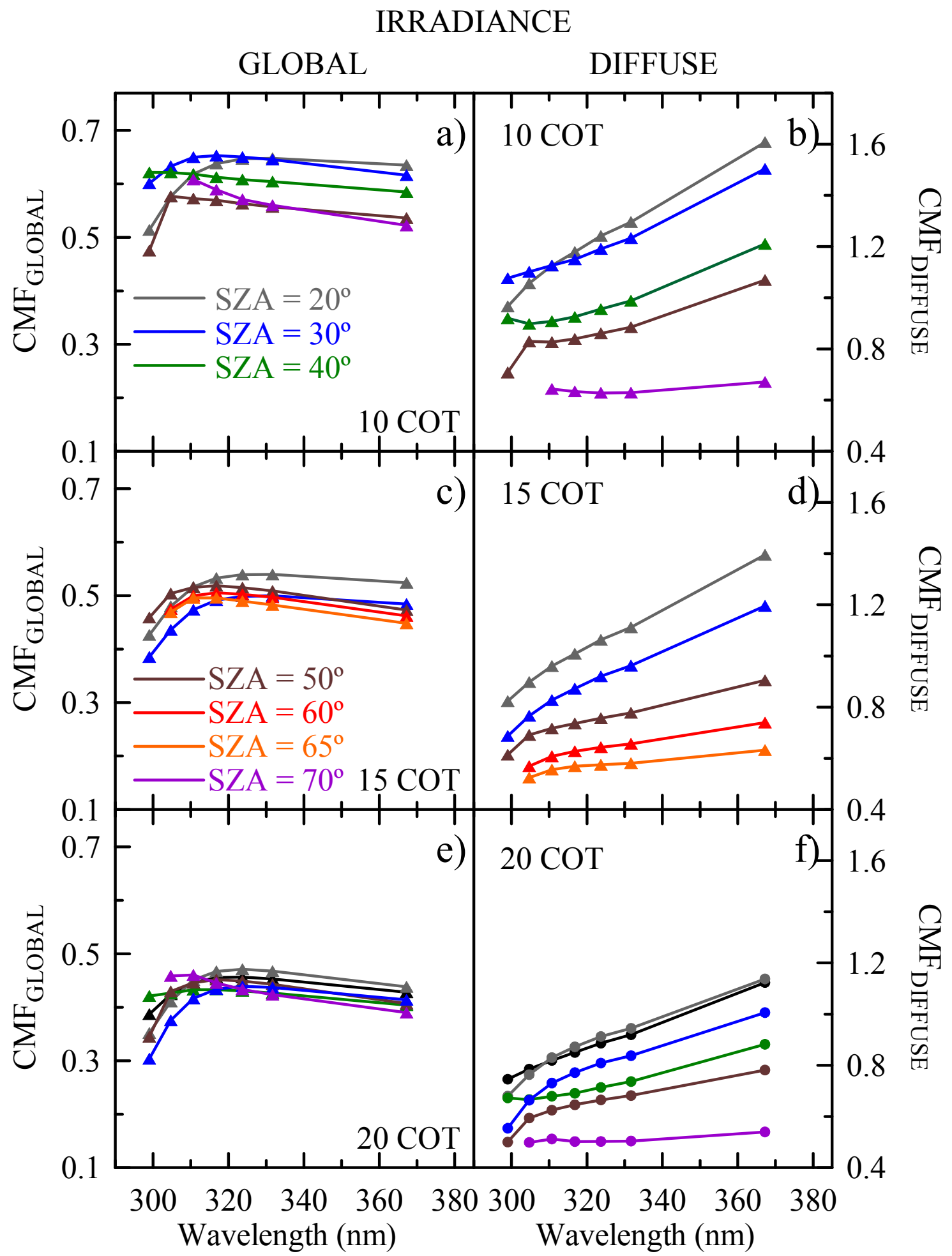

Figure 4.5. Global (left panels) and diffuse (right panels) experimental values of irradiance CMF versus wavelength as a function of the solar zenith angle for different cloud optical thickness values. 
The variability of the $\mathrm{CMF}_{\mathrm{GLOBAL}}$ at $367.2 \mathrm{~nm}$ for the TRISAIA station is $(0.5$, $0.65)$ for $\mathrm{COT}=10$ and $(0.35,0.5)$ for $\mathrm{COT}=20$. These values again reflect the different behaviour between global irradiance and actinic flux (as discussed in the previous section).

However, the $\mathrm{CMF}_{\text {DIFFUSE }}$ always increases with wavelength for all SZA and COT values. As expected, $\mathrm{CMF}_{\mathrm{DIF} \text { USE }}$ values are higher than $\mathrm{CMF}_{\mathrm{GLOBAL}}$ ones because of the dominant role of the diffuse component under overcast conditions (the direct beam is completely blocked). This effect means that, under certain conditions, there is a high frequency of data showing $\mathrm{CMF}_{\text {DIFFUSE }}>1$. For instance, for COT $=10$ and $\mathrm{SZA}<40^{\circ}$, the diffuse irradiance reaching the surface for all wavelengths is higher under overcast conditions than under a cloudless sky. At a fixed SZA of $20^{\circ}$, the spectral CMF DIFFUSE values vary between 0.99 and 1.63 at 299.0 and $367.2 \mathrm{~nm}$ at $\mathrm{COT}=10$, while at COT $=$ 20 the values fall to 0.82 and 1.23 . This reduction with COT is similar for other SZAs. For example, at SZA $=50^{\circ}$ the spectral values of 299 and $367.2 \mathrm{~nm}$ are in the ranges $(0.72,1.11)$ and $(0.5,0.73)$ for $\mathrm{COT}=10$ and $\mathrm{COT}=20$, respectively.

In order to verify $\mathrm{CMF}_{\text {DIFFUSE }}$ behaviour, simulations obtained with the libRadtran model using the set-up described in Chapter 2 are used. In this case, only the results for $\mathrm{TOC}=300 \mathrm{DU}$ and $\mathrm{AOT}_{550 \mathrm{~nm}}=0.25$ are considered. The model results (for both $\mathrm{CMF}_{\mathrm{GLOBAL}}$ and $\mathrm{CMF}_{\mathrm{DIFFUSE}}$ ) are shown in Figure 4.6 for the same three COT values as Figure 4.5. The simulations evidence a spectral dependence which increases with wavelength for all SZAs, and is stronger for low SZA (as occurs in the measurements). The curves of both CMFs show similar behaviours to in Figure 4.5. For instance, the model also predicts $\mathrm{CMF}_{\text {DIFFUSE }}>1$ for low SZAs and COT $=10$. In addition, at high SZAs (e.g., $\mathrm{SZA}=70^{\circ}$ ) the differences between $\mathrm{CMF}_{\mathrm{GLOBAL}}$ and $\mathrm{CMF}_{\text {DIFFUSE }}$ are smaller. 


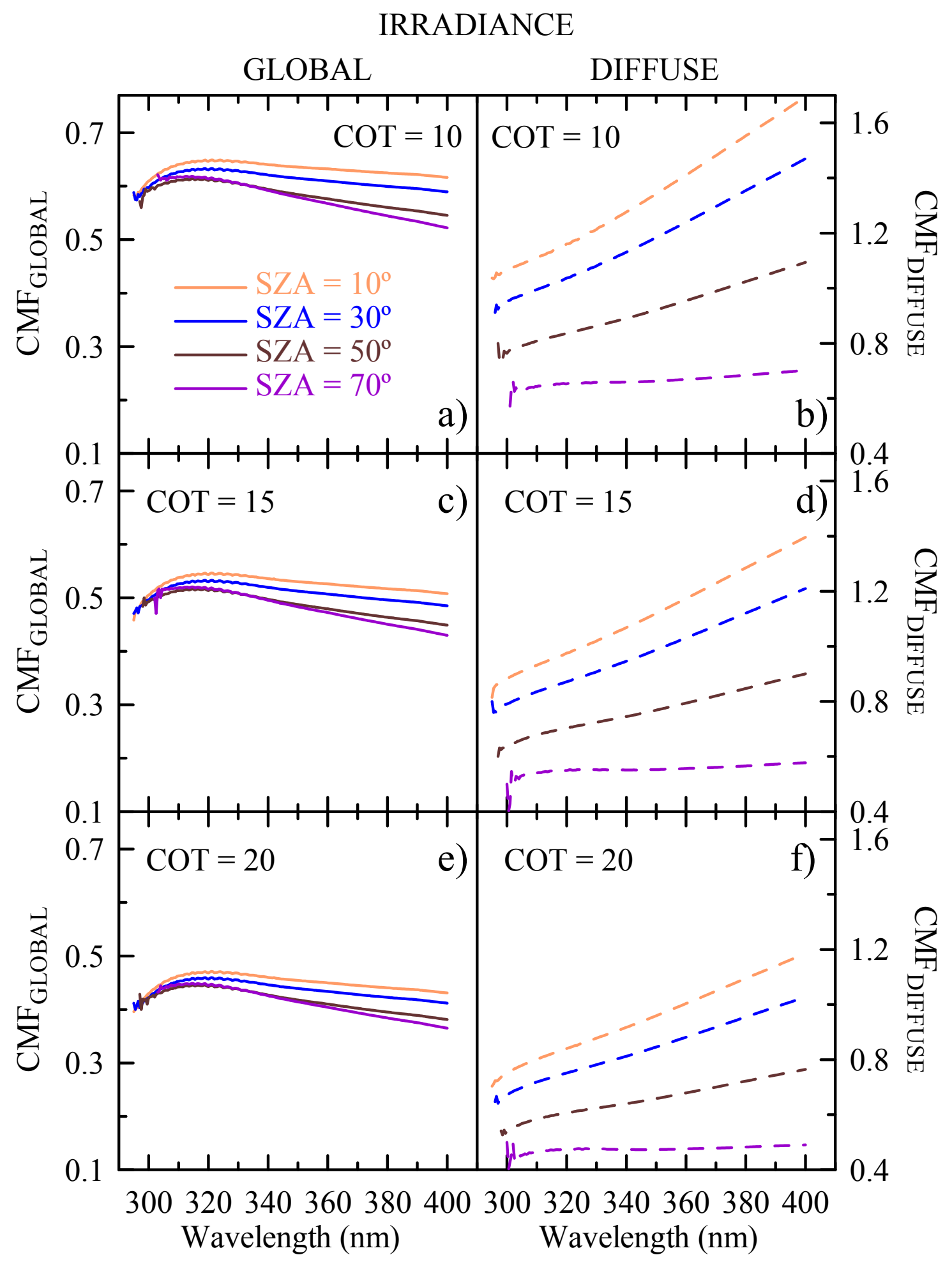

Figure 4.6. Global (solid lines, right panels) and diffuse (dashed lines, left panels) values of irradiance CMF versus wavelength as a function of the solar zenith angle for different cloud optical thickness values evaluated using the libRadtran model. 
A significant difference between global and diffuse cloud transmittances is their dependence on SZA. This is visible in the measured and modelled data. $\mathrm{CMF}_{\mathrm{GLOBAL}}$ also displayed a relatively small dependence on wavelength, while $\mathrm{CMF}_{\text {DIFFUSE }}$ is clearly controlled by this parameter. The difference between the two variables can be obtained from their definitions, assuming that direct irradiance under overcast conditions is negligible:

$$
\begin{gathered}
\mathrm{CMF}_{\mathrm{GLOBAL}}=\frac{\left(\mathrm{UV}_{\text {DIFFUSE }}(\lambda)\right)_{\text {overcast }}}{\left(\mathrm{UV}_{\text {DIRECT }}(\lambda)+\mathrm{UV}_{\text {DIFFUSE }}(\lambda)\right)_{\text {cloudless }}} \\
\mathrm{CMF}_{\text {DIFFUSE }}=\frac{\left(\operatorname{UV}_{\text {DIFFUSE }}(\lambda)\right)_{\text {overcast }}}{\left(\operatorname{UV}_{\text {DIFFUSE }}(\lambda)\right)_{\text {cloudless }}} \\
\mathrm{CMF}_{\text {DIFFUSE }}=\mathrm{CMF}_{\text {GLOBAL }}\left[1+\left(\frac{\mathrm{UV}_{\text {DIRECT }}(\lambda)}{\operatorname{UV}_{\text {DIFFUSE }}(\lambda)}\right)_{\text {cloudless }}\right]
\end{gathered}
$$

The term inside the brackets of the Equation (4.3) is responsible for the difference between $\mathrm{CMF}_{\mathrm{GLOBAL}}$ and $\mathrm{CMF}_{\text {DIfFuse. The evolution of the simulated }}$ $\mathrm{UV}_{\text {DIRECT }}(\lambda) / \mathrm{UV}_{\text {DIFFUSE }}(\lambda)$ ratio is shown in Figure 4.7 for cloud-free conditions.

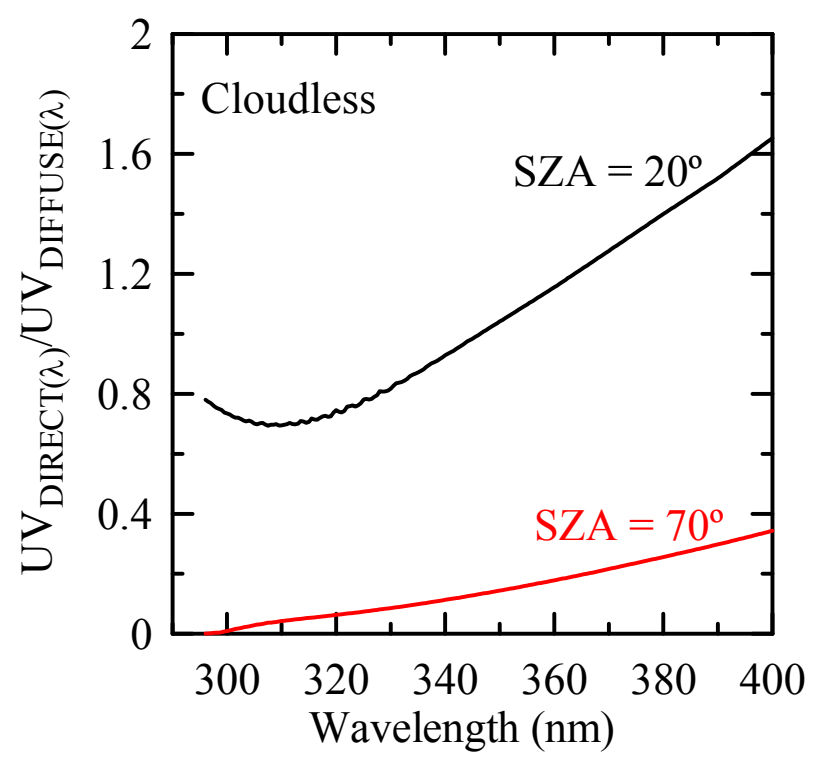

Figure 4.7. Evolution of the $U V_{\text {DIRECT }}(\lambda) / U V_{\text {DIFFUSE }}(\lambda)$ ratio under cloudless conditions for two different solar zenith angles. 
As mentioned before, at $\mathrm{SZA}=70^{\circ}$ the diffuse component is the dominant one and, therefore, the difference between $\mathrm{CMF}_{\mathrm{GLOBAL}}$ and $\mathrm{CMF}_{\mathrm{DIFFUSE}}$ is smaller. However, the direct component is relevant for low SZA (e.g., SZA $=20^{\circ}$ case), particularly for longer wavelengths. Hence, the maximum differences between global and diffuse CMFs occur at low SZAs. The role of the diffuse component is dominant at short wavelengths $(<320 \mathrm{~nm})$ where ozone absorption is relevant.

\subsection{Physical interpretation of the spectral effects under overcast conditions}

As mentioned in Chapter 1, Kylling et al. (1997) explained spectral CMF dependence as being caused by photons reflected upward by the cloud itself, and then scattered downward by the atmosphere above the cloud. This effect, which is governed by Rayleigh scattering $\left(\sim \lambda^{-4}\right)$, means that radiation at short wavelengths is more effectively redirected downwards and, therefore, appears less attenuated. However, in this thesis diffuse transmittance does not show this spectral behaviour (in fact it increases with wavelength). A more detailed explanation should be given.

Lindfors and Arola (2008) studied the variation of the different contributions to the $\mathrm{CMF}$ at the surface (in their configuration, $\mathrm{CMF}_{\mathrm{AE}}$ ) with the SZA (see Figure 4.8). To analyze wavelength dependence of the cloud effect, they used the ratio between the CMF at 320 and $400 \mathrm{~nm}$, defined as:

$$
\mathrm{R}_{\mathrm{CMF}}=\frac{\mathrm{CMF}_{320 \mathrm{~nm}}}{\mathrm{CMF}_{400 \mathrm{~nm}}}=\mathrm{R}_{\mathrm{AB}} \mathrm{R}_{\mathrm{BC}} \mathrm{R}_{\mathrm{CD}} \mathrm{R}_{\mathrm{DE}}
$$

where the variables $\mathrm{R}$ are the ratio of irradiances for each $\mathrm{XY}$ pair of points in the form

$$
\mathrm{R}_{X Y}=\frac{\mathrm{I}_{Y}(320 \mathrm{~nm}) \mathrm{I}_{X}(320 \mathrm{~nm})}{\mathrm{I}_{\mathrm{Y}}(400 \mathrm{~nm}) \mathrm{I}_{\mathrm{X}}(400 \mathrm{~nm})}
$$

and $\mathrm{A}, \mathrm{B}, \mathrm{C}, \mathrm{D}$, and $\mathrm{E}$ are the points shown in Figure 4.8. 
$\mathrm{B}$
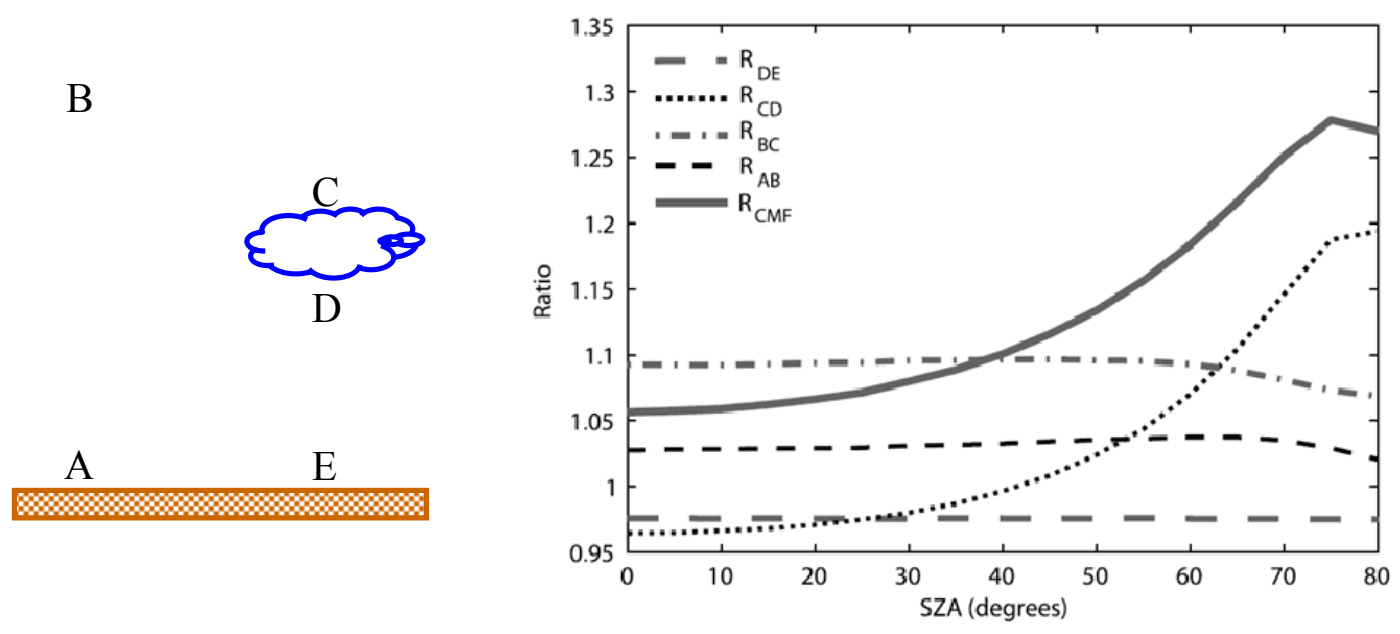

Figure 4.8. Figure 2 at Lindfors and Arola (2008) and the analyzed scenario.

Figure 4.8 shows the main results obtained by their model study. It can be seen that the terms $R_{A B}$ and $R_{D E}$, which represent the altitude effect of the atmosphere, are not important for $\mathrm{R}_{\mathrm{CMF}}$ because they are not SZA-dependent and their product is close to 1 . The effect described by Kylling et al. (1997) is represented in the term $\mathrm{R}_{\mathrm{BC}}$ and shows weak SZA dependence. Therefore, the term $R_{C D}$ is responsible for SZA dependence on $\mathrm{R}_{\mathrm{CMF}}$. This term is connected to processes governing how radiation of different wavelengths penetrates the cloud: a) directional distribution of radiance at the cloud top and its dependence on both wavelength and SZA; and b) transmittance of the cloud alone as a function of the angle of incidence, which shows no wavelength dependence (e.g., Hu and Stamnes, 1993). Lindfors and Arola (2008) attributed the differences in $\mathrm{R}_{\mathrm{CD}}$ at 320 and $400 \mathrm{~nm}$ to the strongly wavelength-dependent Rayleigh scattering $\left(\sim \lambda^{-4}\right)$. As can be seen in the figure, the effect is stronger at high SZA. At these angles, the diffuse part of the radiation incident at the cloud top contributes increasingly to the transmitted radiation, and the influence of the wavelength dependent Rayleigh scattering means that shorter wavelengths are less attenuated by clouds.

The same physical effect was used by Crawford et al. (2003) to explain the CMF behaviour of the spectral actinic flux. Their results (see Figure 1.13 for the simulations) can be described by differences in the direct and diffuse components of solar UV radiation. Since the direct component is greatest at longer wavelengths, these undergo larger relative reductions in global actinic flux. Since there are more substantial losses of the direct component as at larger SZAs, cloud effects at these angles are stronger. 
In order to understand the physical processes involved under overcast conditions, in this thesis new simulations have been carried out using the model configuration of the TRISAIA station. The ozone vertical profile is modified following the methodology in Section 4.1 attaching greater importance to tropospheric ozone. For standard conditions, i.e. $\mathrm{TOC}=300 \mathrm{DU}$ and $\mathrm{AOT}_{550 \mathrm{~nm}}=0.25$, two different scenarios are simulated assuming a cloud layer between 3 and $4 \mathrm{~km}$ a.s.l. with $\mathrm{COT}=15$. The first is the 'normal case' (labelled 'NORMAL') with all the standard profiles (except the modification explained previously for ozone), and the second is the 'new density case' (labelled 'DENS') with a new vertical particle density distribution characterized by low values just over the cloud top (i.e. the normal density has been divided by a $10^{3}$ factor). The latter density distribution leads to a different pressure profile, assuming that temperature does not change. Figure 4.9 shows the air density and pressure profiles for both scenarios.

With these two scenarios, the CMFs are calculated at two different solar zenith angles: $\mathrm{SZA}=20^{\circ}$ and $\mathrm{SZA}=70^{\circ}$. Figure 4.10 shows the obtained results. Outside intense ozone absorptions bands $(\lambda>320 \mathrm{~nm})$, at $\mathrm{SZA}=20^{\circ}$ the effect of shorter wavelengths which are less attenuated than longer ones is still observed for both scenarios in the $\mathrm{CMF}_{\mathrm{GLOBAL}}$ (Figure 4.10.a). Although the relative decrease is more effective for the normal case $(\sim 6.8 \%)$, the new density profile led to a $3.3 \%$ decrease between 320 and 400 $\mathrm{nm}$. It is worth mentioning here that the reduction in the number of particles above the cloud not only reduces multiple scattering between the top of the cloud and the atmosphere but also changes the distribution of the incoming radiation, since the direct beam remains almost unaltered up to the cloud top.
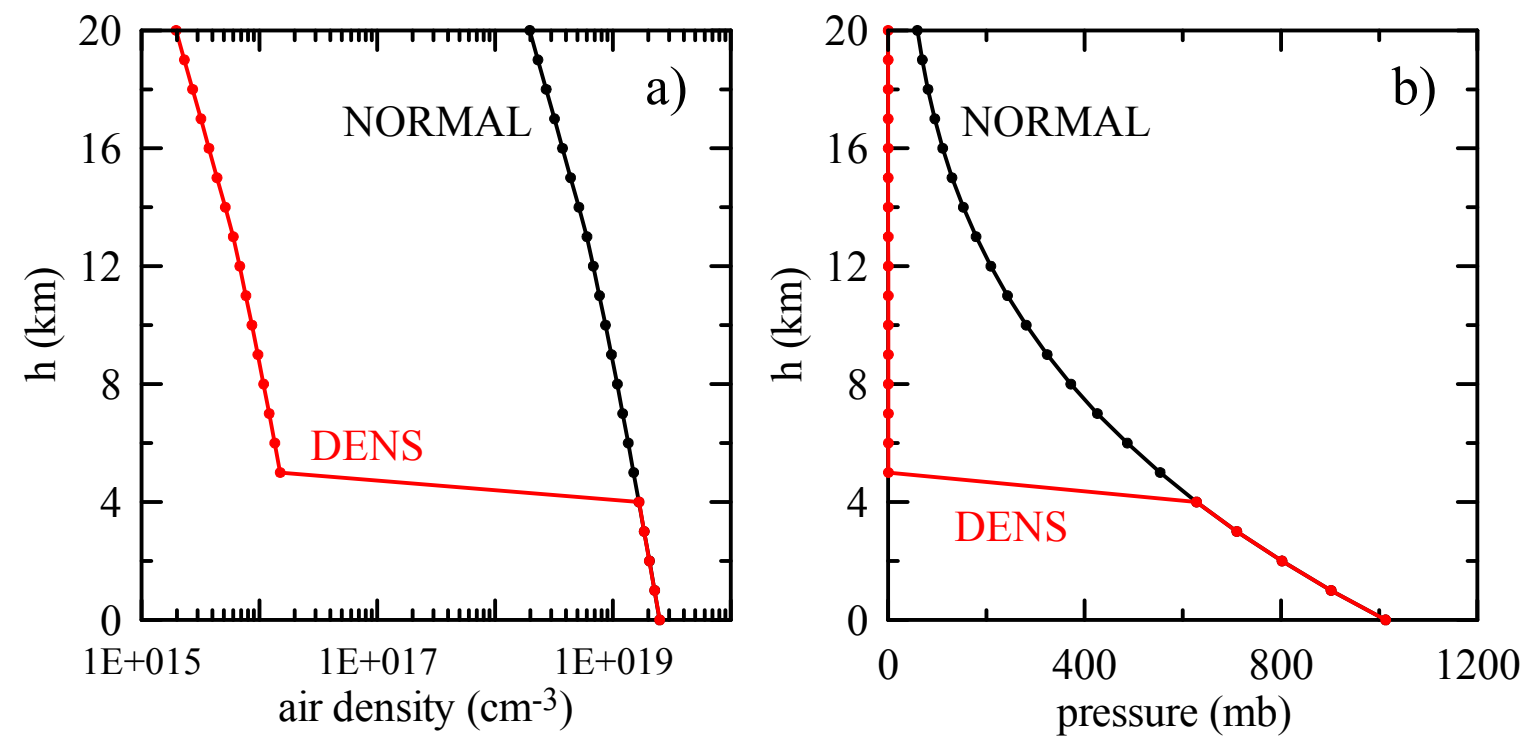

Figure 4.9. Profiles of air density (a) and pressure (b) for the normal scenario and the DENS option (see text). 

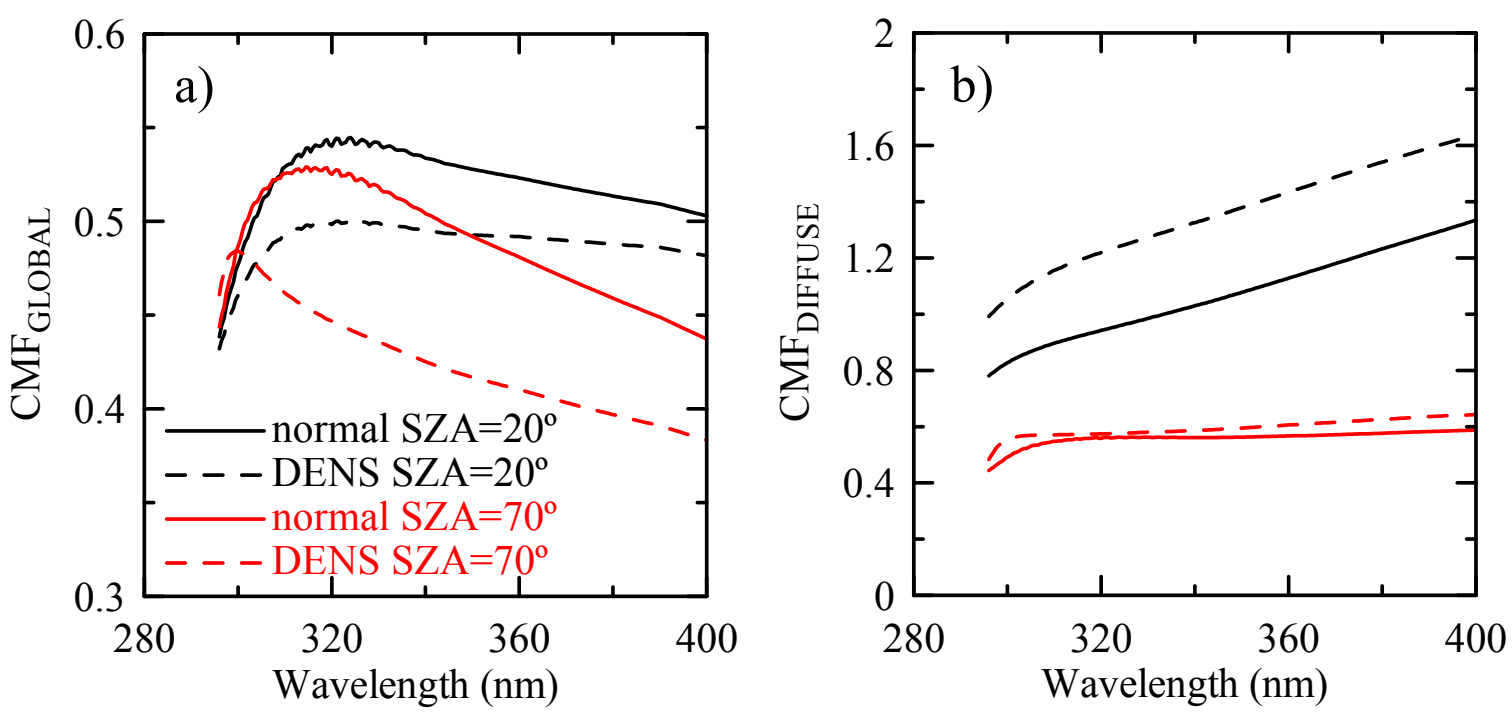

Figure 4.10. Spectral CMF of global (a) and diffuse (b) components for two different scenarios: normal case and the new density profile explained in the test for two different solar zenith angles.

Hence, the decrease in CMF curves between 320 and $400 \mathrm{~nm}$ is due to two effects: multiple reflections between cloud and the above atmosphere (Kylling et al., 1997), and total attenuation of the direct component under overcast conditions which, however, remains in the CMF denominator under cloud-free conditions, and is wavelengthdependent (greater at longer wavelengths).

The same occurred at $\mathrm{SZA}=70^{\circ}$, although in this case the $\mathrm{CMF}_{\text {DIFFUSE }}$ did not significantly change in the two scenarios. Rayleigh scattering contribution from the molecular atmosphere is therefore the factor controlling the spectral response of $\mathrm{CMF}_{\text {DIFFUSE }}$ with the lower values at shorter wavelengths, which coincides with the interpretation given by Lindfors and Arola (2008) for processes occurring in the cloud layer. In conclusion, cloud transmittance shows that shorter wavelengths are, in general, less attenuated by clouds than longer ones. However, the diffuse component evidences the opposite behaviour, this effect not being evident when the global component (with a great importance of the direct term) is studied.

Similar considerations may be applied to the CMF for the actinic flux, with the exception of large SZA and short wavelengths, where the typical ozone absorption effect does not appear in the CMF curves. At theses angles, the larger optical path followed by the photons causes scattering phenomena more easily than for other SZAs. The photons arriving from the zenith, where the optical path is shorter, are less attenuated once they have been scattered in this direction. This effect was first noticed by Götz (1931) and called the Umkehr effect. In the irradiance case, the Umkehr effect is weaker than that observed for the actinic flux, and is more noticeable when the density profile is changed 
in the model study, showing a spectral behaviour similar to the actinic flux in the case of $\mathrm{SZA}=70^{\circ}$ (see Figure 4.10.a).

To highlight the relevance of the photons arriving from the zenith direction, the radiances from different directions of the principal plane are calculated for the normal scenario with the libRadtran. Radiances are calculated at $5^{\circ}$ steps from $0^{\circ}$ (zenith) to $90^{\circ}$ polar angle, i.e. in 19 directions. In this case, radiances are calculated for an azimutal angle of $0^{\circ}$. For each wavelength, the direction showing the maximum radiance value is detected and used to normalize the other radiance values. This calculation is carried out at two different SZAs, SZA $=20^{\circ}$ and SZA $=70^{\circ}$. The normalized radiances of the zenith and one other direction under cloudless and overcast conditions are presented in Figure 4.11. The zenith and $20.5^{\circ}$ of polar angle are shown in the case of SZA $=20^{\circ}$, Figure 4.11.a. Under cloudless conditions, radiance at $20.5^{\circ}$ is the maximum value observed for $\lambda$ $>305 \mathrm{~nm}$. It is worth mentioning here that $20^{\circ}$ is not the maximum value because libRadtran cannot estimate the radiance at this angle with an azimuth of $0^{\circ}$, i.e. looking directly at the Sun (Mayer and Kylling, 2005). The zenith direction shows normalized radiances for $\lambda<305 \mathrm{~nm}$ close to $50 \%$ of the maximum. When overcast conditions are analyzed (Figure 4.11.b), the maximum radiance is achieved from the zenith direction for all wavelengths, although the radiance at $20.5^{\circ}$ of polar angle is only $\sim 5 \%$ smaller than the radiance from the zenith. Different conclusions may be drawn in the case of SZA = $70^{\circ}$, Figures 4.11.c and 4.11.d. The direction of the zenith and $70.5^{\circ}$ of polar angle are presented in the figure. Under cloudless conditions (Figure 4.11.c), directions below $35^{\circ}$ display the maximum irradiance values for $\lambda<303 \mathrm{~nm}$. This can be understood by the Umkehr effect. Beyond this wavelength, the normalized radiance from the zenith strongly reduces its values and the maximum radiance values are shifted to higher angles. For instance, the maxima are achieved: for $305 \mathrm{~nm} \leq \lambda \leq 322 \mathrm{~nm}$ at a polar angle of $65^{\circ}$, and for $322.5 \mathrm{~nm} \leq \lambda \leq 400 \mathrm{~nm}$ at a polar angle of $70.5^{\circ}$. However, in the overcast scenario (Figure 4.11.d), as in the $\mathrm{SZA}=20^{\circ}$ case, the radiance from the zenith is the maximum (regardless of the wavelength).

Therefore, when cloudy conditions occur, the role of the zenith radiance is enhanced compared to the cloud-free case. Hence, this fact introduces stronger wavelength dependence on the CMF at higher SZAs. Considering the Umkehr effect is essential if wavelength dependent attenuation by clouds is to be understood correctly, particularly at higher SZA. 

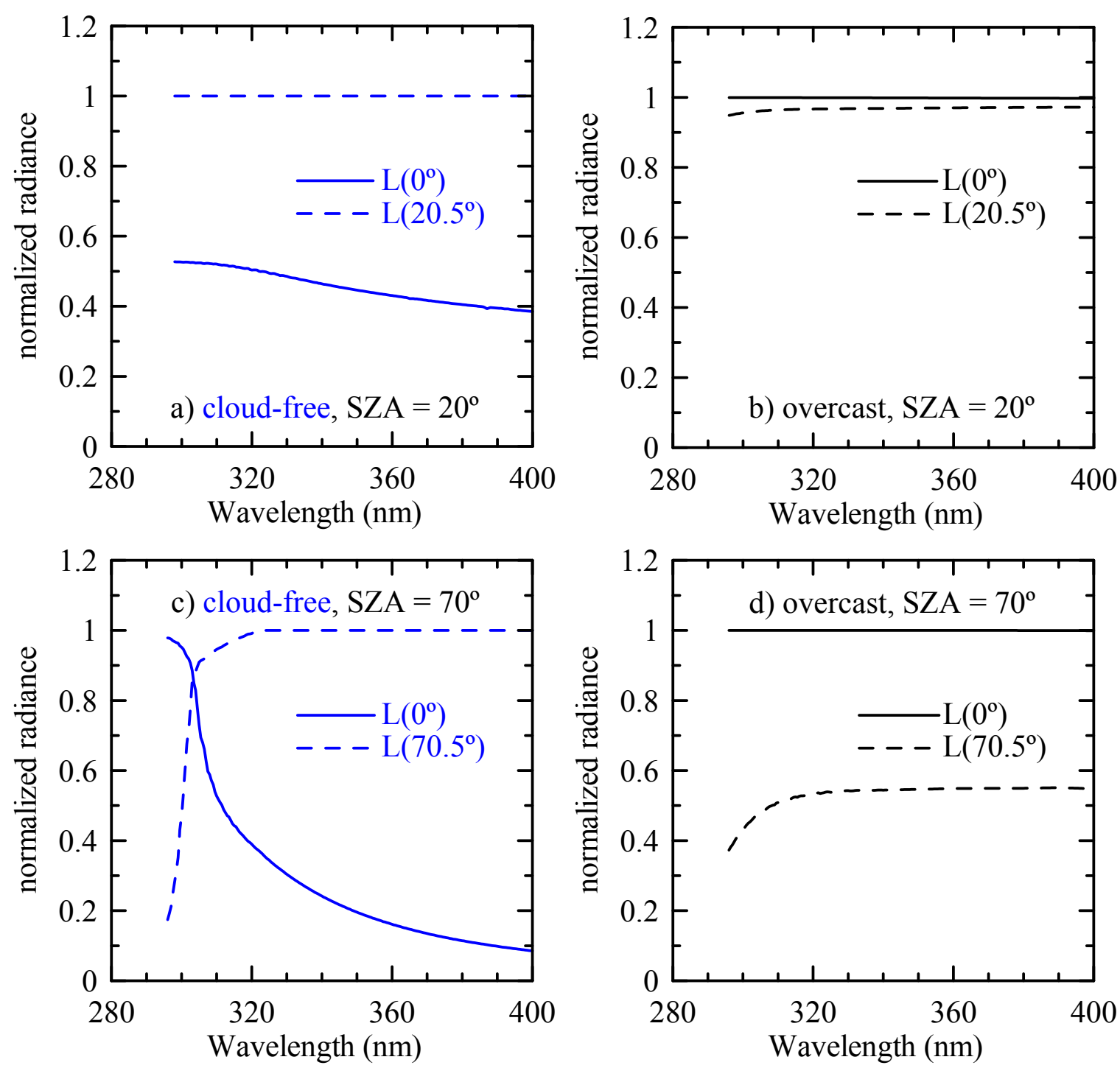

Figure 4.11. Normalized radiance compared to the maximum value among all the directions between $0^{\circ}$ and $90^{\circ}$ polar angle at the zenith (solid lines) and $20.5^{\circ}$ and $70.5^{\circ}$ (dashed lines) of polar angle at $S Z A=20^{\circ}(a$, b) and $S Z A=70^{\circ}(c, d)$, respectively. Cloud-free $(a, c)$ and overcast $(b, d)$ conditions are considered.

Other theoretical (e.g., Sobolev, 1975; Mayer and Kylling, 2005) and empirical (e.g., Grant and Heisler, 1997; Kuchinke et al., 2004) studies have also proved that sky radiance under overcast conditions is non-isotropic and reaches its maximum in the zenith direction. 


\subsection{Biological effects}

An empirical relationship linking UV fluxes and cloud cover, independent of wavelength, is used in several studies (e.g., Calbó et al., 2005).

In this section, errors associated with the use of a wavelength-independent CMF are estimated when calculating the effects of UV radiation on biological systems. Several action spectra are considered; the weighted UV dose rate for the selected effects is calculated using both a wavelength independent CMF, and the CMF determined from the observations made with the BREWER instrument at Lampedusa in 2005, i.e., with the data from Section 4.1.

The biologically effective UV dose (BEUVD) is calculated as:

$$
\text { BEUVD }=\int_{\lambda=286.5 \mathrm{~nm}}^{\lambda=363 \mathrm{~nm}} \mathrm{I}_{\text {cloudless, } \lambda} \mathrm{S}_{\lambda} \mathrm{CMF}_{\lambda} \mathrm{d} \lambda
$$

where $I_{\text {cloudless, } \lambda}$ is the spectral irradiance under cloud-free conditions and $S_{\lambda}$ is the action spectrum for a specific process.

Five different action spectra relevant for health and plants are considered in this thesis:

- the erythemal action spectrum (mentioned in Chapter 1),

- DNA damage (Setlow, 1974),

- $\quad$ synthesis of vitamin D (CIE, 2006),

- plant damage (Flint and Caldwell, 2003), and

- phytoplankton inhibition (Cullen et al., 1992).

These five action spectra are shown in Figure 4.12. 


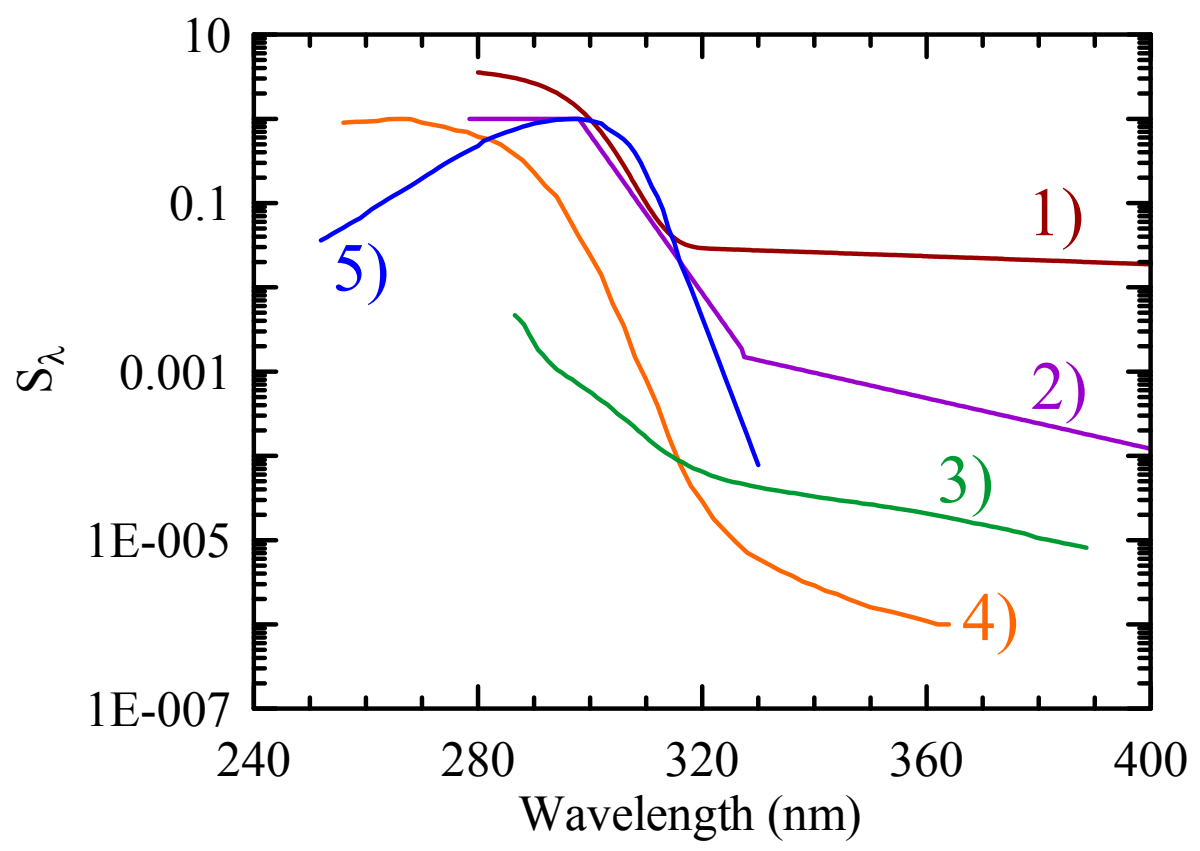

Figure 4.12. The five action spectra used to calculate the BEUVD dose: plant damage (1), erythemal (2), phytoplankton inhibition (3), DNA damage (4), and vitamin D synthesis (5).

The BEUVD for all five action spectra is calculated from measured cloud-free UV irradiance spectra (i.e., with $\mathrm{CMF}=1$ ) with $310 \mathrm{DU}$ of ozone, and for different values of the solar zenith angle. The BEUVD under cloudy conditions for different values of SZA and COT is then calculated using both the spectral CMFs displayed in Figure 4.2 $\left(B_{E U V D}\right)$, and a wavelength-independent $\mathrm{CMF}\left(\mathrm{BEUVD}_{\mathrm{C}}\right)$. The latter $\mathrm{CMF}$ value is chosen equal to the CMF at $320 \mathrm{~nm}$ in Figure 4.2.

Two sets of UV index, $\mathrm{UVI}_{\lambda}$ and $\mathrm{UVI}_{\mathrm{C}}$, are derived by multiplying the erythemal $\operatorname{BEUVD}_{\lambda}$ and $\mathrm{BEUVD}_{\mathrm{C}}$, respectively, by $40 \mathrm{~m}^{2} \mathrm{~W}^{-1}$ (see Equation 1.5). It is worth mentioning here that the spectral range used in this section reaches $363 \mathrm{~nm}$, and the integral is limited to this wavelength. However, the UV index is defined up to $400 \mathrm{~nm}$. In order to take into account the missing fraction of the spectrum, which slightly underestimates UVI values (e.g., $<5 \%$ for SZA $<50^{\circ}$ and TOC $=300 \mathrm{DU}$ ), a factor dependent on SZA was applied to UVI calculation. This factor is evaluated at different solar zenith angles as the ratio between the UVI calculated using simulated spectra up to $400 \mathrm{~nm}$, and the UVI obtained from modelled spectra up to $363 \mathrm{~nm}$. The evaluated factors are shown in Table 4.4. 
Table 4.4. Correction factors for taking into account the 363.5-400 nm range in UVI calculations.

\begin{tabular}{cc}
\hline SZA & Factor \\
\hline $\mathbf{2 0}$ & 1.03 \\
$\mathbf{3 0}$ & 1.03 \\
$\mathbf{4 0}$ & 1.04 \\
$\mathbf{5 0}$ & 1.05 \\
$\mathbf{6 0}$ & 1.07 \\
\hline $\mathbf{7 0}$ & 1.10 \\
\hline
\end{tabular}

Figure 4.13 shows the retrieved values of $\mathrm{UVI}_{\lambda}$ and $\mathrm{UVI}_{\mathrm{C}}$ and the percentage difference between the two determinations. Assuming a constant CMF in the whole UV range leads to systematically higher UVI values than those obtained by means of the observed spectral dependence. $\mathrm{UVI}_{\mathrm{C}}$ always overestimates $\mathrm{UVI}_{\lambda}$. At solar zenith angles of $30^{\circ}, 40^{\circ}$, and $50^{\circ}$ the difference between $\mathrm{UVI}_{\mathrm{C}}$ and $\mathrm{UVI}_{\lambda}$ increases with cloud optical thickness. At large COT, the difference may be up to $10 \%$. The differences are always below $5 \%$ at $\mathrm{SZA}=70^{\circ}$.

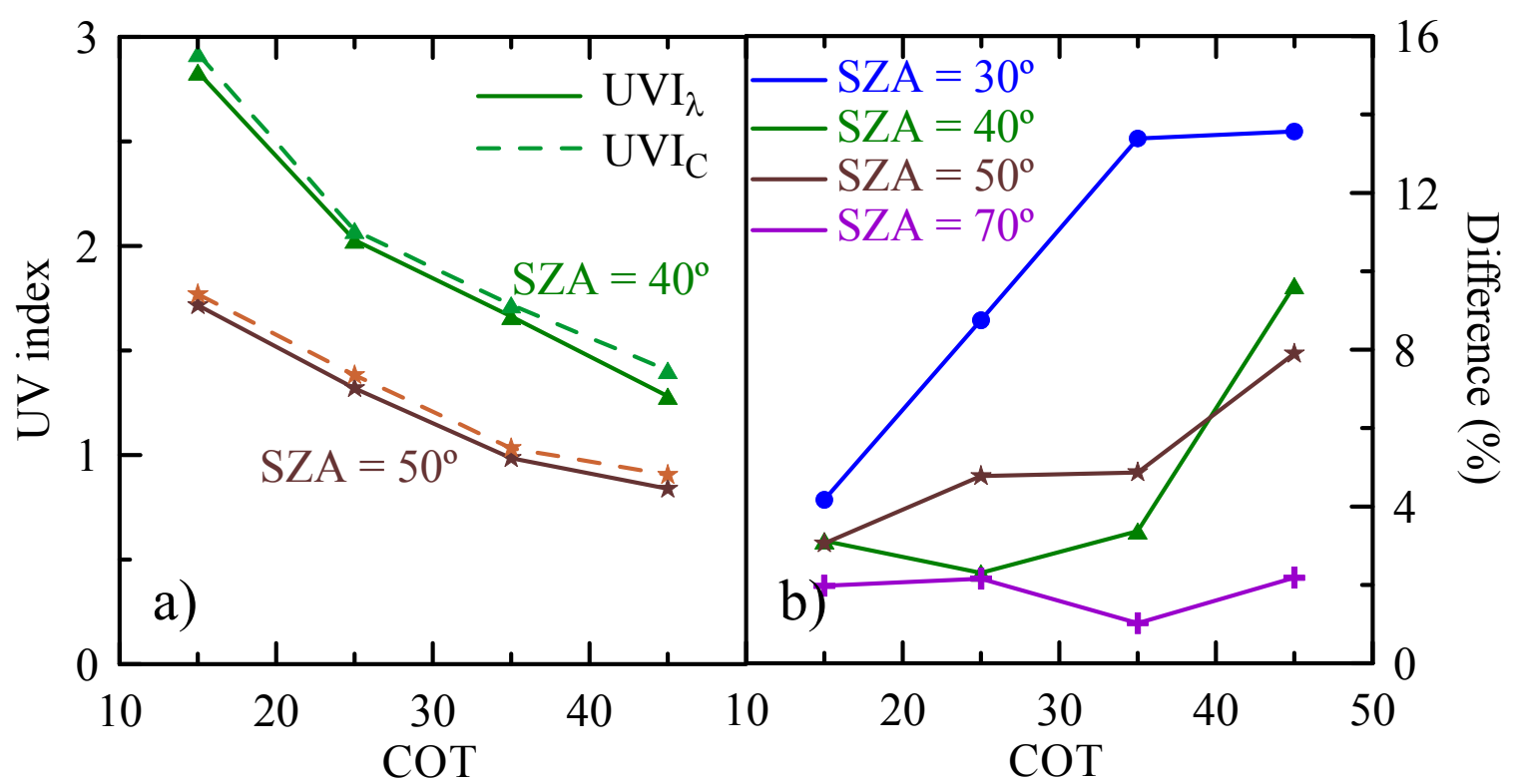

Figure 4.13. (a) Dependence of UV index on cloud optical thickness at two solar zenith angles. Solid lines reflect the real case, and the dashed ones the assumption of constant CMF. (b) Differences between the two derived values of UVI versus COT. 


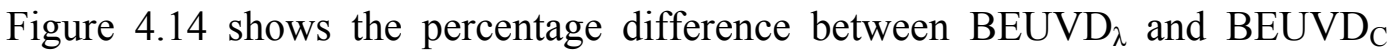
using the other action spectra for different solar zenith angles and cloud optical thicknesses. The differences are positive in practically all. The difference between $\operatorname{BEUVD}_{\lambda}$ and $\mathrm{BEUVD}_{\mathrm{C}}$ is up to $30 \%$ when considering DNA damage, $20 \%$ for vitamin $\mathrm{D}$ synthesis, $12 \%$ for plant damage, and $8 \%$ for phytoplankton inhibition. The differences obtained for all action spectra display a dependence on cloud optical thickness, except at $\mathrm{SZA}=70^{\circ}$, where the differences become smaller and do not appear to depend on COT.

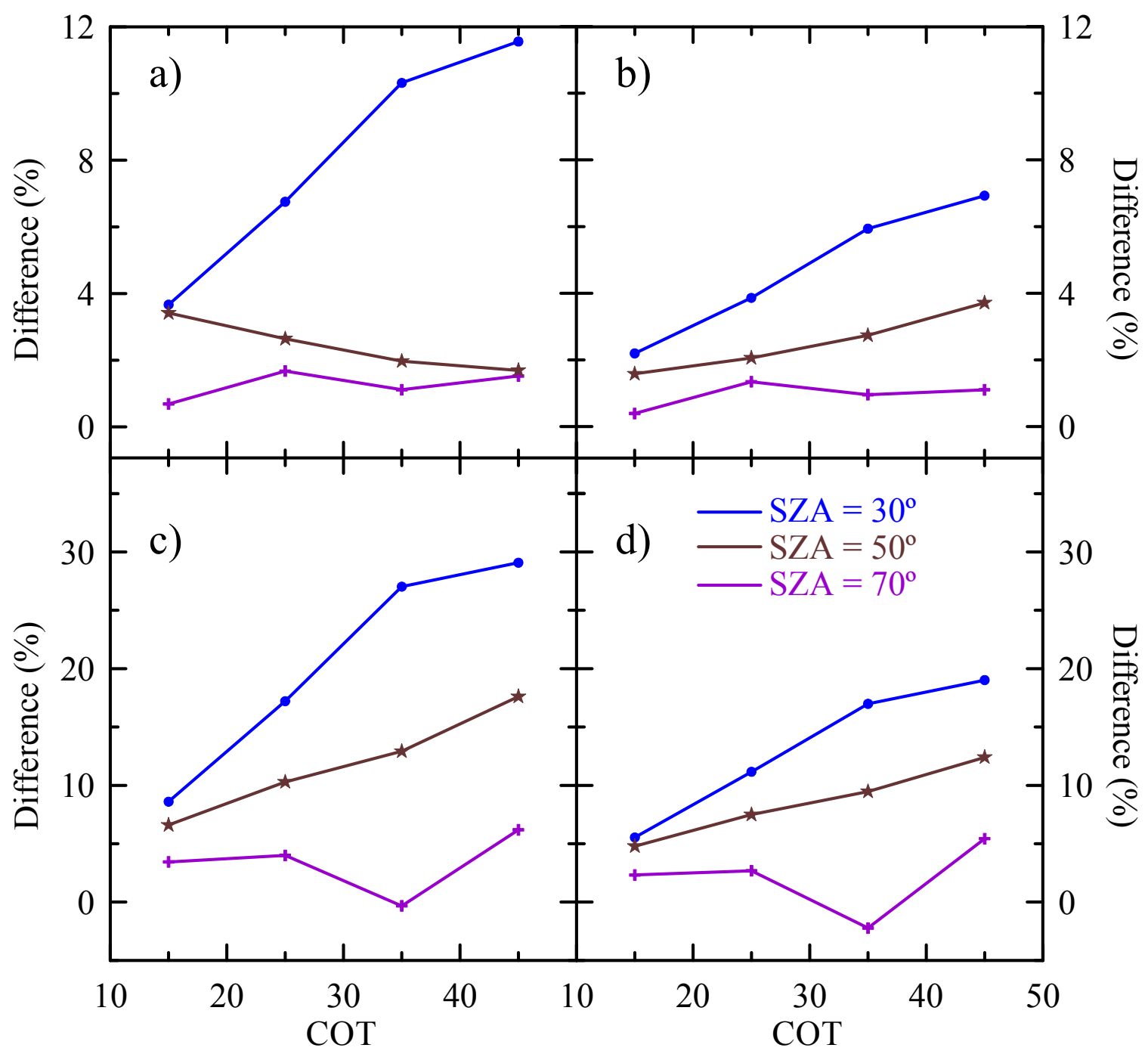

Figure 4.14. Differences between the UV irradiance weighted for various biological action spectra calculated with the derived CMF and with constant CMF: (a) plant damage, (b) inhibition of phytoplankton, (c) DNA damage, and (d) vitamin D synthesis. 


\subsection{Summary}

\subsubsection{English version}

Measurements of irradiance (global and diffuse components) and actinic flux spectra, cloud cover, cloud optical thickness, and total ozone column were combined in order to study the wavelength dependence of the cloud modification factor and the implications for the estimated weighted UV irradiation effects on biological systems. Simulations carried out with the libRadtran model were also used. The CMF for the global irradiance component decreases with increasing wavelength above $320 \mathrm{~nm}$. This effect, already shown by previous studies, was explained by multiple scattering between the cloud top and the atmosphere above, and by wavelength-dependent radiance distribution at the cloud top together with the transmittance of the cloud alone as a function of the angle of incidence. Hence, shorter wavelengths are generally less attenuated than longer ones. However, from 295 to $320 \mathrm{~nm}$ the CMF increases, and is more evident at large COT and SZA. This effect is attributed to absorption of diffuse irradiance by tropospheric ozone as a result of longer photon path lengths in cloudy conditions. The CMF for the spectral actinic flux shows more variable behaviour, and a strong dependence on the solar zenith angle. It displays a small increasing trend above $320 \mathrm{~nm}$ at low SZA, and a decreasing trend beyond moderate SZA $\left(\mathrm{SZA}>50^{\circ}\right)$. For shorter wavelengths, ozone absorption is the dominant effect, except at high SZAs (SZA $>60^{\circ}$ ). At high SZA, the 'Umkehr effect' has a major impact on the CMF. Analysis of the CMF for diffuse irradiance shows the opposite behaviour to the global component. In other words, $\mathrm{CMF}_{\mathrm{DIFFUSE}}$ shows an increasing trend with wavelength which occurs for all SZAs. The difference between $\mathrm{CMF}_{\text {DIFFUSE }}$ and $\mathrm{CMF}_{\mathrm{GLOBAL}}$ can be obtained from their definitions, and the $\operatorname{UV}_{\text {DIRECT }}(\lambda) / \operatorname{UV}_{\text {DIFFUSE }}(\lambda)$ ratio for cloudless conditions is the main factor causing the differences observed. Since the diffuse component is dominant in relation to the direct component at high SZA, the difference between the two CMFs decreases, the opposite occurring at low SZA, when the direct component is prevalent and the maximum differences are observed. As a numerical result, the CMF at COT $=15$ and $367 \mathrm{~nm}$ takes values between $(0.45,0.5),(0.35,0.7)$, and $(0.6,1.4)$ for global irradiance, actinic flux, and diffuse irradiance, respectively. Finally, using a wavelength independent CMF instead of the experimentally determined spectral curves leads to overestimation of the biological weighted UV irradiation effects, which has been estimated as being up to $30 \%$ for DNA damage, $20 \%$ for vitamin D synthesis, $12 \%$ for plant damage, $8 \%$ for phytoplankton inhibition, and $14 \%$ for erythema. Overestimation is greater at low solar zenith angle and large cloud optical thickness. 


\subsubsection{Spanish version}

Medidas de irradiancia (tanto la componente global como difusa) y flujo actínico espectral en el intervalo del UV, cubierta de nubes, espesor óptico de nubes, y ozono en columna han sido combinadas para analizar la dependencia espectral del factor de modificación de nubes y las implicaciones para la irradiancia UV pesada por espectros de acción sobre sistemas biológicos. Se han utilizado conjuntamente las simulaciones realizadas con la librería libRadtran. El CMF para la componente global de la irradiancia decrece al aumentar la longitud de onda por encima de los $320 \mathrm{~nm}$. Este efecto ha sido atribuido por estudios anteriores a la dispersión múltiple entre la cima de la nube y la atmósfera de encima, y a la distribución de la radiancia espectral en la cima de la nube junto con la dependencia de la transmitancia de la nube con el ángulo de incidencia. Por esto, las longitudes de onda corta son, en general, menos atenuadas que las de onda larga. Sin embargo, el CMF crece desde 295 hasta $320 \mathrm{~nm}$, siendo más evidente la tendencia para SZAs y COTs altos. Este efecto es atribuido a un realce en la absorción por parte del ozono troposférico, como resultado de un mayor recorrido óptico por parte de los fotones en condiciones nubosas. El CMF calculado para el flujo actínico muestra un comportamiento más variable, en especial muestra más dependencia con el SZA. Presenta una tendencia ligeramente creciente por encima de los $320 \mathrm{~nm}$ para bajos SZA, que se transforma en una tendencia decreciente para moderados SZA $\left(\mathrm{SZA}>50^{\circ}\right)$. Para las longitudes de onda más cortas, el efecto de absorción del ozono es el dominante, excepto para altos SZAs $\left(\mathrm{SZA}>60^{\circ}\right)$, cuando el efecto Umkehr dirige el comportamiento del CMF. Analizando el CMF para la componente difusa de la irradiancia, se observa un comportamiento contrario. Es decir, el CMF $\mathrm{CIFUSA}_{\text {p }}$ presenta una tendencia creciente con la longitud de onda que ocurre para todo SZA. La diferencia entre los dos CMF (CMF $\mathrm{CIFUSA}_{\text {A }}$ y $\left.\mathrm{CMF}_{\mathrm{GLOBAL}}\right)$ se obtiene de sus definiciones, resultando que el cociente $\mathrm{UV}_{\text {DIRECTA }}(\lambda) / \mathrm{UV}_{\text {DIFUSA }}(\lambda)$, evaluado en condiciones de cielo despejado, es el responsable de las diferencias. Como a altos SZAs la componente difusa es la predominante (con respecto a la directa), las diferencias entre ambos CMFs son más pequeñas. Sin embargo, para bajos SZAs, la componente directa domina y se observan las mayores diferencias entre los CMF. Como resultado numérico, para un COT $=15$, el CMF a $367 \mathrm{~nm}$ toma valores entre $(0.45,0.5),(0.35,0.7)$ y $(0.6,1.4)$ para la irradiancia global, flujo actínico, e irradiancia difusa, respectivamente. Finalmente, el uso de un CMF independiente con la longitud de onda, en lugar de uno con la forma determinada experimentalmente, produce una sobreestimación de la irradiancia UV pesada por espectros de acción, que puede llegar a tomar valores máximos del 30\% para el daño al ADN, el 20\% para la síntesis de vitamina $\mathrm{D}$, el $12 \%$ para el daño a las plantas, el $8 \%$ para la inhibición del fitoplancton, y el 14\% para la quemadura solar en la piel humana. La sobreestimación es mayor para los ángulos cenitales bajos y para un espesor óptico de nubes alto. 


\section{Chapter 5}

5. Dependence of UV Cloud Modification Factors on Water Cloud Microphysical Properties 
In this chapter, the CMFs for the UV radiative fluxes (both irradiance and actinic flux) are investigated as a function of cloud microphysical properties. The entire chapter is only referred to the TRISAIA database. HATPRO measurements of liquid water path (LWP) and cloud droplet effective radius ( $\mathrm{r}_{\mathrm{eff}}$ ) retrieved using HATPRO and VISMFRSR instruments (see Chapter 2) are used. In addition, radiative transfer simulations help to explain the obtained behaviours.

\subsection{Dependence of integrated UV radiative flux on water cloud microphysical properties}

\subsubsection{UVI}

The CMF evaluated for the UVI range $\left(\mathrm{CMF}_{\mathrm{UVI}}\right)$ explained in Section 3.4 is analyzed as a function of the experimental values of LWP and the $r_{\text {eff. }}$ Using the set-up of the libRadtran model for the TRISAIA station described in Chapter 2, the simulated $\mathrm{CMF}_{\text {UVI }}$ values are also obtained for different values of the cloud microphysical properties.

Three groups of particle radius are used in the calculations: $(2.5,5 \mu \mathrm{m}),(5,10$ $\mu \mathrm{m})$, and $(10,15 \mu \mathrm{m})$. To exclude ice clouds from the analysis, only cases with cloud base $\left(\mathrm{h}_{\text {cld }}\right)$ below $5000 \mathrm{~m}$ are selected.

It is worth mentioning that in the previous chapters all the data from the TRISAIA station are 1-minute values. However, the algorithm to retrieve the $r_{\text {eff }}$ from HATPRO and VIS-MFRSR instruments needs a longer integration time. This is due to the different field of view of the instruments: the microwave radiometer looks at the zenith, while the multichannel radiometer has a field of view of $\sim 160^{\circ}$. Thus, in some cases, the cloud viewed by HATPRO may have different properties to the whole cloud layer observed by VIS-MFRSR. Min and Harrison (1996) derived retrievals of the effective radius for 5 and 30-minute averaged data. In these periods, the cloud properties are treated as stationary properties. In this thesis, the 5-minute integration data are used to analyze the influence of cloud properties on cloud transmittance. However, calculations with 1-minute measurements were also carried out, and the model reproduced the experimental data as accurately as for the 5-minute data. 5-minute averages for cloud optical properties have already been used by Min et al. (2003) and Nzeffe et al. (2008), among others. This interval allows cloud variations to be monitored on a cloud lifetime scale. 
Figure 5.1 shows the results for measurements and simulations. The model calculations are shown for $\mathrm{SZA}=18^{\circ}$ and $\mathrm{SZA}=75^{\circ}$, the smallest and the highest in the overcast data series. As can be seen in the figure, the simulated values reproduced the measurements well with a clear separation of radius size. This is particularly significant due to the large number of days with overcast conditions analyzed in this thesis. The three classes of radii include 16, 20, and 16-day data, respectively. The points out of the model curve can represent situations with different conditions in the HATPRO and VIS-MFRSR field of views. In addition, the model curves indicate that there is weak dependence on SZA. Both observations and simulations show that smaller size particles cause the smaller $\mathrm{CMF}_{\mathrm{UVI}}$ values, i.e. scattering phenomena occurring in the cloudy atmosphere are more effective for smaller radii. For instance, at $\mathrm{LWP}=0.1 \mathrm{~kg} \mathrm{~m}^{-2}$, the $\mathrm{CMF}_{\mathrm{UVI}}$ values ranged between 0.2 and 0.35 for the smallest particles $\left(2.5 \mu \mathrm{m}<\mathrm{r}_{\text {eff }}<5 \mu \mathrm{m}\right)$. When the radius increases $\left(5 \mu \mathrm{m}<\mathrm{r}_{\text {eff }}<10 \mu \mathrm{m}\right), \mathrm{CMF}_{\mathrm{UVI}}$ presents values in the range $(0.35,0.55)$. For the largest particles considered in this thesis $\left(10 \mu \mathrm{m}<\mathrm{r}_{\text {eff }}<15 \mu \mathrm{m}\right)$, the $\mathrm{CMF}_{\mathrm{UVI}}$ values varied from 0.55 to 0.65 .

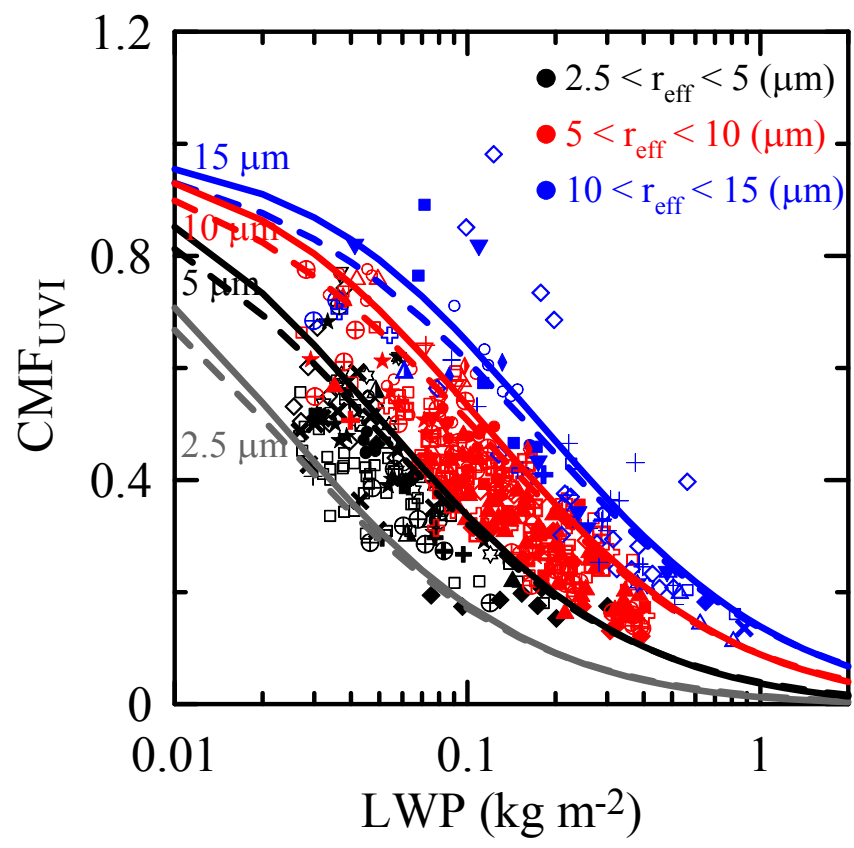

Figure 5.1. $C M F_{U V I}$ as a function of the LWP for different cloud droplet radii. Dots are the experimental data (different symbols correspond to different days) and lines are the radiative transfer simulations at SZA $=18^{\circ}$ (solid lines) and $S Z A=75^{\circ}$ (dashed lines).

Hence, CMF variability decreases for larger particles. This effect is to be expected since, for a vertically uniform cloud, cloud optical thickness is defined as COT $=(3$ LWP) / (2 $\left.\rho_{\mathrm{w}} \mathrm{r}_{\mathrm{eff}}\right)$ (Equation 1.39). Smaller particles correspond to a higher COT for a 
fixed LWP. Using measurements and theoretical methods, Kim et al. (2003) obtained a linear relationship between COT and LWP, which is inversely proportional to $r_{\text {eff }}$. Hence, $\mathrm{CMF}_{\mathrm{UVI}}$ dependence on LWP clearly depends on $\mathrm{r}_{\text {eff. }}$.

Experimental LWP values are limited to a range between $0.03 \mathrm{~kg} \mathrm{~m}^{-2}$ and $0.4 \mathrm{~kg}$ $\mathrm{m}^{-2}$ for $2.5 \mu \mathrm{m}<\mathrm{r}_{\text {eff }}<10 \mu \mathrm{m}$. This range ensures non-precipitating and cloudy cases (Löhnert and Crewell, 2003). However, larger concentrations of LWP are observed for cloud droplet radius between 10 and $15 \mu \mathrm{m}$. Löhnert and Crewell (2003) stated that raindrops will occur at LWP $>0.4 \mathrm{~kg} \mathrm{~m}^{-2}$. Thereby, experimental values falling into this range could be associated with drizzle conditions.

Figure 5.2 shows $\mathrm{CMF}_{\text {UVI }}$ dependence on LWP and $\mathrm{r}_{\text {eff }}$ for four different cloud base heights: $h_{\text {cld }}<2000 \mathrm{~m}$ (Figure 5.2.a), $2000 \mathrm{~m}<\mathrm{h}_{\text {cld }}<3000 \mathrm{~m}$ (Figure 5.2.b), $3000 \mathrm{~m}$ $<\mathrm{h}_{\text {cld }}<4000 \mathrm{~m}$ (Figure 5.2.c), and $4000 \mathrm{~m}<\mathrm{h}_{\text {cld }}<5000 \mathrm{~m}$ (Figure 5.2.d). WMO (2008) proposed a classification of clouds in terms of the level at which they are usually encountered. Three types exist: high, in the range 6-12 km; middle, from the surface up to $6 \mathrm{~km}$; and low, from the surface to $1.5 \mathrm{~km}$. The high clouds are cirrus, cirrocumulus and cirrostratus; the middle clouds are altocumulus and altostratus (the latter often extending higher) and nimbostratus (usually extending both higher and lower); and the low clouds are stratocumulus, stratus, cumulus and cumulonimbus (the last two often also reaching middle and high levels). With this classification, the first group ( $\left.\mathrm{h}_{\mathrm{cld}}<2000 \mathrm{~m}\right)$ corresponds to low clouds, while the others are medium level clouds, the last group (4000 $\mathrm{m}<\mathrm{h}_{\mathrm{cld}}<5000 \mathrm{~m}$ ) being close to the boundary of high clouds. As expected, it can be deduced that the clouds with their base closest to the surface (Figures 5.2.a and 5.2.b) show the highest concentrations of liquid water. As can be seen in the four panels, the group with the maximum number of data is the medium cloud group between 2 and $3 \mathrm{~km}$.

The solid lines plotted in Figure 5.2 reflect the radiative transfer simulations at $\mathrm{SZA}=18^{\circ}$ for a cloud layer between 2 and $3 \mathrm{~km}$ (the case of SZA $=75^{\circ}$ is omitted because of the small difference between the two SZA, see Figure 5.1). Although the model is run with fixed cloud height, the overall behaviour of the model reproduces well the four groups of cloud base height. This is an early indicator that cloud base height is not a decisive parameter in CMF characterization. This effect will be discussed in detail in Chapter 6. 
- $2.5<\mathrm{r}_{\mathrm{eff}}<5(\mu \mathrm{m})$

- $5<\mathrm{r}_{\text {eff }}<10(\mu \mathrm{m})$

- $10<\mathrm{r}_{\text {eff }}<25$ ( $\left.\mu \mathrm{m}\right)$
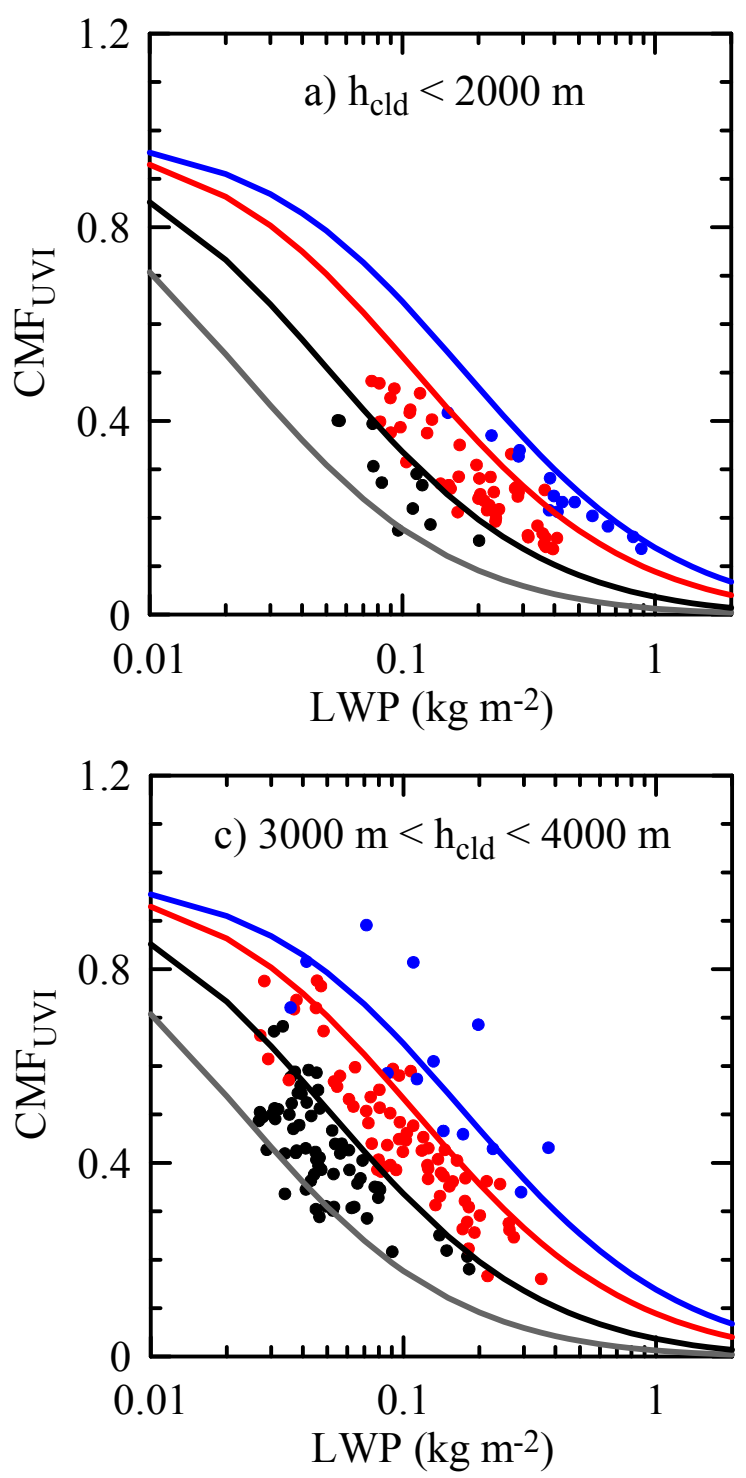

$-\mathrm{r}_{\text {eff }}=2.5 \mu \mathrm{m}$

$-\mathrm{r}_{\mathrm{eff}}=5 \mu \mathrm{m}$

$\longrightarrow \mathrm{r}_{\text {eff }}=10 \mu \mathrm{m}$

$\longrightarrow \mathrm{r}_{\mathrm{eff}}=15 \mu \mathrm{m}$
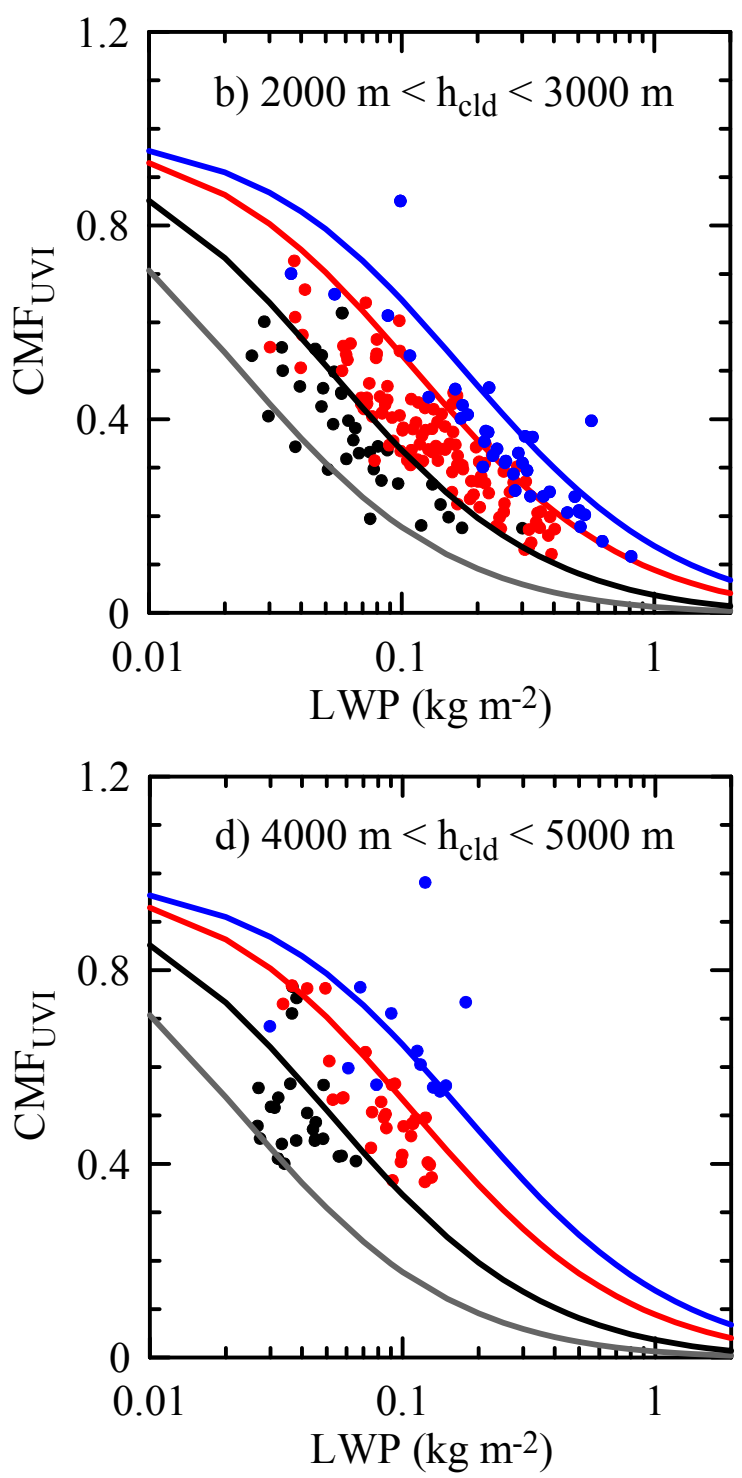

Figure 5.2. $C M F_{U V I}$ as a function of $L W P$ for different cloud droplet radii and for different cloud base heights. Dots are the experimental data and solid lines are the radiative transfer simulations at SZA $=18^{\circ}$. 


\subsection{2. $\mathbf{J}\left(\mathrm{O}^{1} \mathrm{D}\right)$}

Previous studies (e.g., Crawford et al., 2003; Chapters 3 and 4 of this thesis) suggest a strong dependence of cloud transmittance for actinic flux on SZA. Three groups of SZA are selected for $\mathrm{CMF}_{\mathrm{J}(\mathrm{O} 1 \mathrm{D})}$ analysis: $\left(18^{\circ}, 30^{\circ}\right),\left(42^{\circ}, 54^{\circ}\right)$, and $\left(63^{\circ}, 75^{\circ}\right)$. Each interval is $12^{\circ}$ wide. The results are shown in Figure 5.3. The simulations are plotted at the boundaries of each SZA interval, i.e. $18^{\circ}-30^{\circ}, 42^{\circ}-54^{\circ}$, and $63^{\circ}-75^{\circ}$.
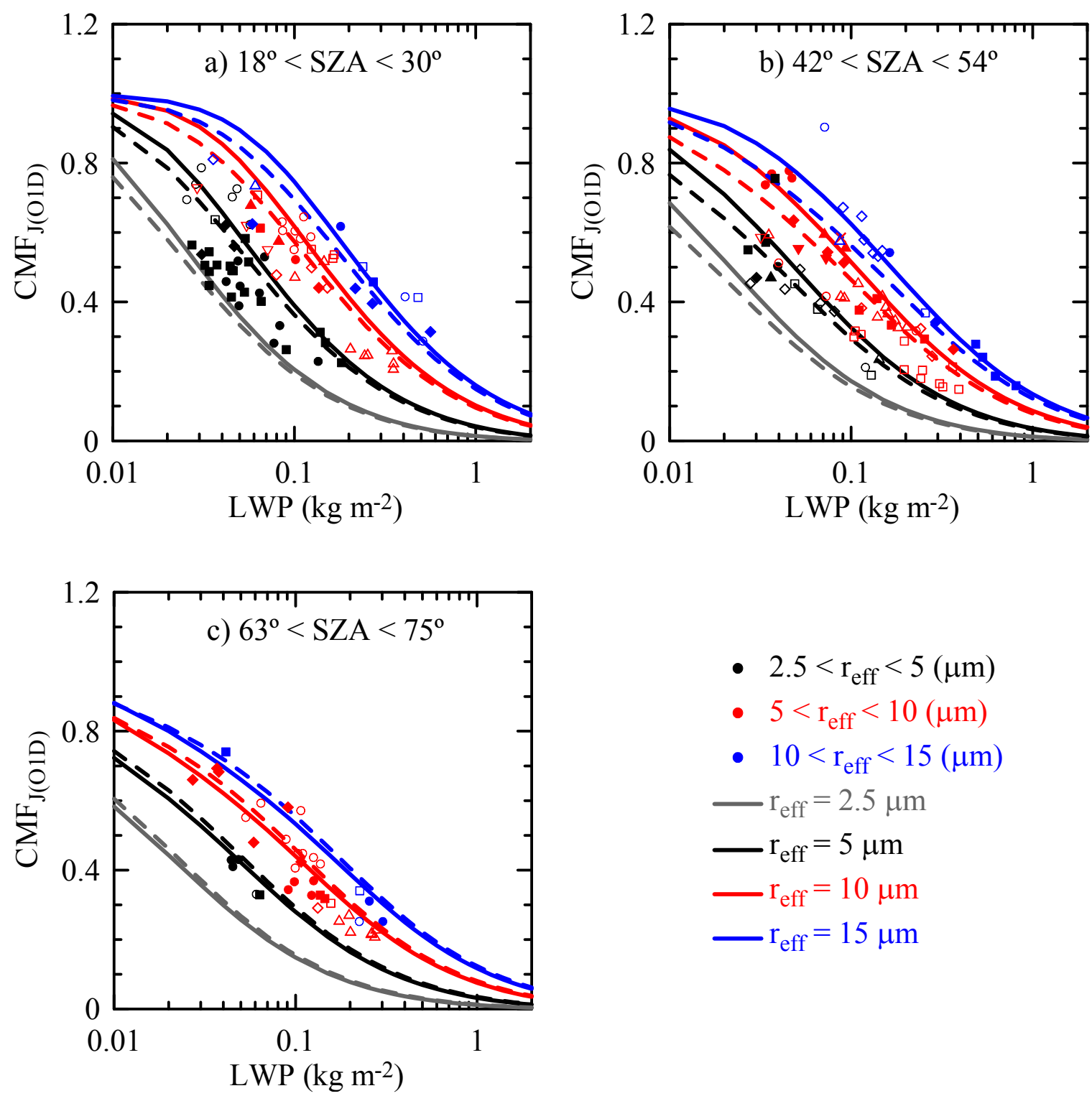

- $2.5<\mathrm{r}_{\mathrm{eff}}<5(\mu \mathrm{m})$

- $5<\mathrm{r}_{\text {eff }}<10(\mu \mathrm{m})$

- $10<\mathrm{r}_{\mathrm{eff}}<15(\mu \mathrm{m})$

$-\mathrm{r}_{\mathrm{eff}}=2.5 \mu \mathrm{m}$

$-\mathrm{r}_{\mathrm{eff}}=5 \mu \mathrm{m}$

$-\mathrm{r}_{\mathrm{eff}}=10 \mu \mathrm{m}$

$-\mathrm{r}_{\mathrm{eff}}=15 \mu \mathrm{m}$

Figure 5.3. $C M F_{J(O I D)}$ as a function of the LWP for different cloud droplet radii for three SZA intervals. Dots are the experimental data (different symbols correspond to different days). In each plot, solid lines refer to results of simulations at the smallest SZA in the range $\left(18^{\circ}\right.$ in graph a; $42^{\circ}$ in graph $b ; 63^{\circ}$ in graph c), and dashed lines refer to simulations at the largest SZA in the range. 
In this case, slightly more variability can be observed in the experimental data. Despite this, the overall agreement between measurements and simulations is also quite good. For the case of $18^{\circ}<\mathrm{SZA}<30^{\circ}$, the different days used for the three groups of radii are 5,9 , and 7 , in ascending order of size; 8,11 , and 7 , respectively, are used at $42^{\circ}$ $<\mathrm{SZA}<54^{\circ}$; and finally, 3, 7, and 4, respectively, at $63^{\circ}<\mathrm{SZA}<75^{\circ}$. As occurred in the $\mathrm{CMF}_{\mathrm{UVI}}$ case, smaller particles cause stronger attenuation of the radiative flux. If the LWP is fixed at $0.1 \mathrm{~kg} \mathrm{~m}^{-2}$, at $\mathrm{SZA}=18^{\circ} \mathrm{CMF}_{\mathrm{J}(\mathrm{O} 1 \mathrm{D})}$ varies between $(0.2,0.4),(0.4,0.6)$, and $(0.6,0.75)$ for effective radii in the ranges $(2.5,5 \mu \mathrm{m}),(5,10 \mu \mathrm{m})$, and $(10,15 \mu \mathrm{m})$, respectively. These $\mathrm{CMF}_{\mathrm{J}(\mathrm{O} 1 \mathrm{D})}$ intervals at $\mathrm{SZA}=42^{\circ}$ are $(0.15,0.35),(0.35,0.55)$, and $(0.55,0.65)$, respectively, and at $\mathrm{SZA}=63^{\circ}$ are $(0.15,0.3),(0.3,0.45)$, and $(0.45,0.55)$, respectively.

The maximum values of each interval decrease with SZA, and the variability within the intervals is smaller for the case of larger particles. A stronger dependence on SZA than for $\mathrm{CMF}_{\mathrm{UVI}}$ is observed, which is in agreement with model simulations, predicting a $\mathrm{CMF}_{\mathrm{J}(\mathrm{O} 1 \mathrm{D})}$ decreasing trend with SZA (Figures 5.3.a and 5.3.b), with the exception of high SZA when there is a slight increase from $63^{\circ}$ to $75^{\circ}$ (Figure 5.3.c).

A large difference is evident between $\mathrm{CMF}_{\mathrm{J}(\mathrm{O} 1 \mathrm{D})}$ behaviours shown in the three panels of Figure 5.3. For the actinic flux, $\mathrm{CMF}_{\mathrm{J}(\mathrm{O} 1 \mathrm{D})}$ dependence on LWP and $\mathrm{r}_{\mathrm{eff}}$ is clearly SZA-dependent too. To highlight this dependence, Figure 5.4 shows $\mathrm{CMF}_{\mathrm{J}(\mathrm{O} 1 \mathrm{D})}$ dependence on SZA for three fixed values of LWP, 0.01, 0.1 and $0.5 \mathrm{~kg} \mathrm{~m}^{-2}$, and two different values of $r_{\text {eff. }}$ All the cases display maximum values at $\mathrm{SZA}=18^{\circ}$ and minimum values at $\mathrm{SZA}=63^{\circ}$. The case of $\mathrm{r}_{\mathrm{eff}}=2.5 \mu \mathrm{m}$ (Figure 5.4.a) shows the highest SZA dependence for the lowest LWP values $\left(0.01\right.$ and $\left.0.1 \mathrm{~kg} \mathrm{~m}^{-2}\right)$ with a relative decrease of $\sim 28 \%$ between the maximum and minimum values. At LWP $=0.5 \mathrm{~kg} \mathrm{~m}^{-2}$, the percentage of difference between the two extreme values is $\sim 23 \%$. However, for larger particles $\left(\mathrm{r}_{\text {eff }}\right.$ $=10 \mu \mathrm{m}$, Figure 5.4.b), the decrease between maximum and minimum values is $\sim 27-29 \%$ for the highest values of LWP $\left(0.1\right.$ and $\left.0.5 \mathrm{~kg} \mathrm{~m}^{-2}\right)$, and $\sim 17 \%$ at LWP $=0.01 \mathrm{~kg} \mathrm{~m}^{-2}$. Therefore, each class of $r_{\text {eff }}$ and LWP evidences a different dependence on SZA. 


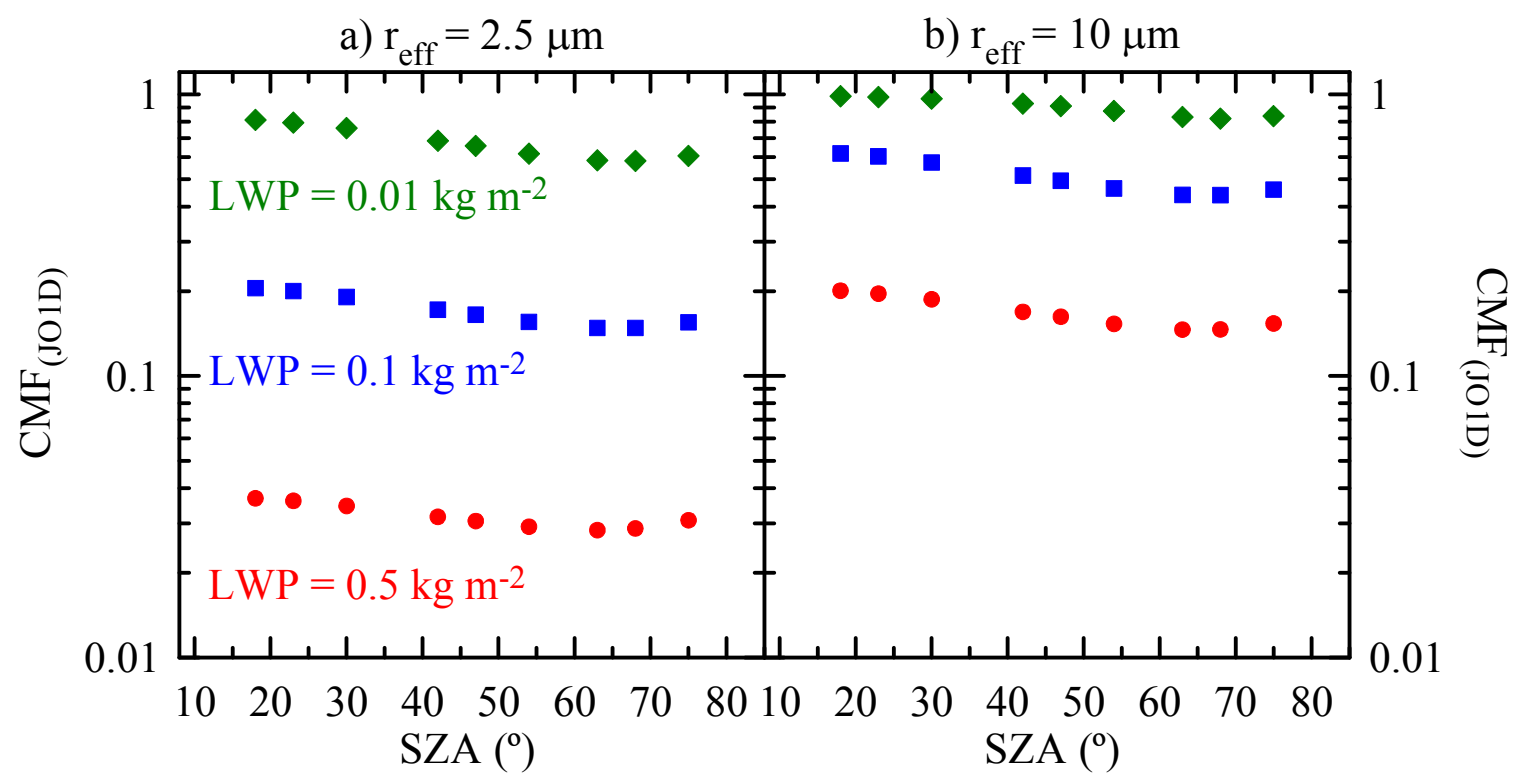

Figure 5.4. Dependence of modelled $C M F_{J(O I D)}$ on solar zenith angle for three values of LWP and two different effective radii: a) $2.5 \mu \mathrm{m}$, and b) $10 \mu \mathrm{m}$.

In order to analyze the different behaviour of CMF for UVI and $\mathrm{J}\left(\mathrm{O}^{1} \mathrm{D}\right)$, Figure 5.5 shows the simulations for radii of 2.5 and $10 \mu \mathrm{m}$ at $18^{\circ}$ and $75^{\circ}$ of SZA. The $\mathrm{CMF}_{\mathrm{UVI}}$ exhibits weak dependence on SZA for low LWP and no significant differences in the curve shape. For instance, the values of $\mathrm{CMF}_{\mathrm{UVI}}$ in Figures 5.5.a and 5.5.b at the lowest LWP $\left(0.01 \mathrm{~kg} \mathrm{~m}^{-2}\right)$ decrease by 0.04 units from $\mathrm{SZA}=18^{\circ}$ to $\mathrm{SZA}=75^{\circ}$. However, as discussed before, the $\mathrm{CMF}_{\mathrm{J}(\mathrm{O} 1 \mathrm{D})}$ shows relevant differences for the two radii (change $\sim 0.2$ units at $0.01 \mathrm{~kg} \mathrm{~m}^{-2}$ between the two SZAs). In addition, the shape of the curves changes with SZA. 

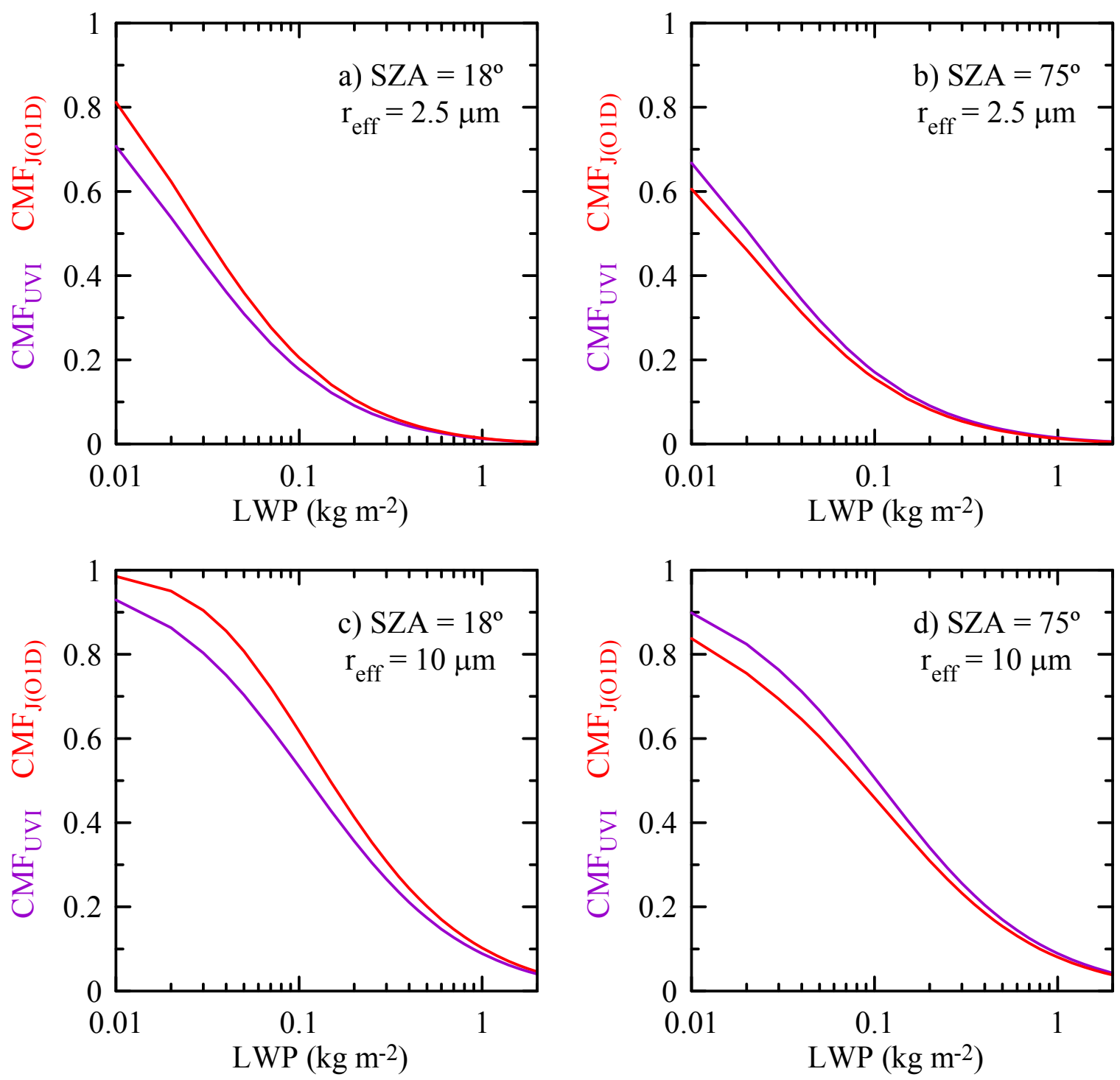

Figure 5.5. Dependence of $C M F_{U V I}$ (purple lines) and $C M F_{J(O I D)}$ (red lines) on $L W P$ at $18^{\circ}$, a) and c), and $75^{\circ}$, b) and d), of SZA for two fixed cloud droplet radii of $\left.2.5 \mu \mathrm{m}, a\right)$ and b), and $\left.10 \mu \mathrm{m}, c\right)$ and d).

For small particles $\left(\mathrm{r}_{\mathrm{eff}}=2.5 \mu \mathrm{m}\right), \mathrm{CMF}_{\mathrm{UVI}}$ is smaller than $\mathrm{CMF}_{\mathrm{J}(\mathrm{O} 1 \mathrm{D})}$ at $\mathrm{SZA}=18^{\circ}$ (Figure 5.5.a), while the $\mathrm{CMF}_{\mathrm{UVI}}$ values are higher than the $\mathrm{CMF}_{\mathrm{J}(\mathrm{O} 1 \mathrm{D})}$ ones for all the LWP at large SZA (SZA $=75^{\circ}$, Figure 5.5.b). The same behaviour is observed for larger particles $\left(\mathrm{r}_{\mathrm{eff}}=10 \mu \mathrm{m}\right.$, Figures 5.5.c and 5.5.d), although CMF dependence on LWP differs somewhat. The physical reason for this different behaviour lies in the different role played by the direct and diffuse components at each SZA.

To clarify this point, simulations of the two components for the UVI and $J\left(O^{1} D\right)$ variables for cloud-free conditions are analyzed. The simulations are carried out with the set-up described in Chapter 2, with TOC $=300 \mathrm{DU}$ and $\mathrm{AOT}_{550 \mathrm{~nm}}=0.25$. Figure 5.6 
shows the ratio between the diffuse and global components versus the SZA. The direct to global ratio can be evaluated as 1 - diffuse/global. At low SZA, the direct component of the UVI is almost half of the global, while this fraction decreases to $35 \%$ in the case of $\mathrm{J}\left(\mathrm{O}^{1} \mathrm{D}\right)$. Therefore, the presence of clouds blocking the direct component affects the UVI much more effectively, and the $\mathrm{CMF}_{\mathrm{UVI}}$ values are smaller than the $\mathrm{CMF}_{\mathrm{J}(\mathrm{O} 1 \mathrm{D})}$ at these solar zenith angles. However, at high SZA, the fraction of $\mathrm{J}\left(\mathrm{O}^{1} \mathrm{D}\right)$ due to the diffuse component is slightly lower than for UVI: while the diffuse/global ratio for the ozone photolysis rate increases $\sim 43 \%$ from $18^{\circ}$ to $75^{\circ}$ of SZA, this change is $\sim 81 \%$ in the case of UVI. The different definition of the irradiance and actinic flux means that for high SZA, the CMF values for the UVI are in this case higher than the CMF values for the $J\left(O^{1} D\right)$.

As a conclusion, at low SZAs, UVI is attenuated more effectively by clouds than $\mathrm{J}\left(\mathrm{O}^{1} \mathrm{D}\right)$, while the opposite occurs at high SZAs. This behaviour does not depend on cloud droplet radius and occurs for all LWP values in the range between 0.01 and $2 \mathrm{~kg} \mathrm{~m}^{-2}$.

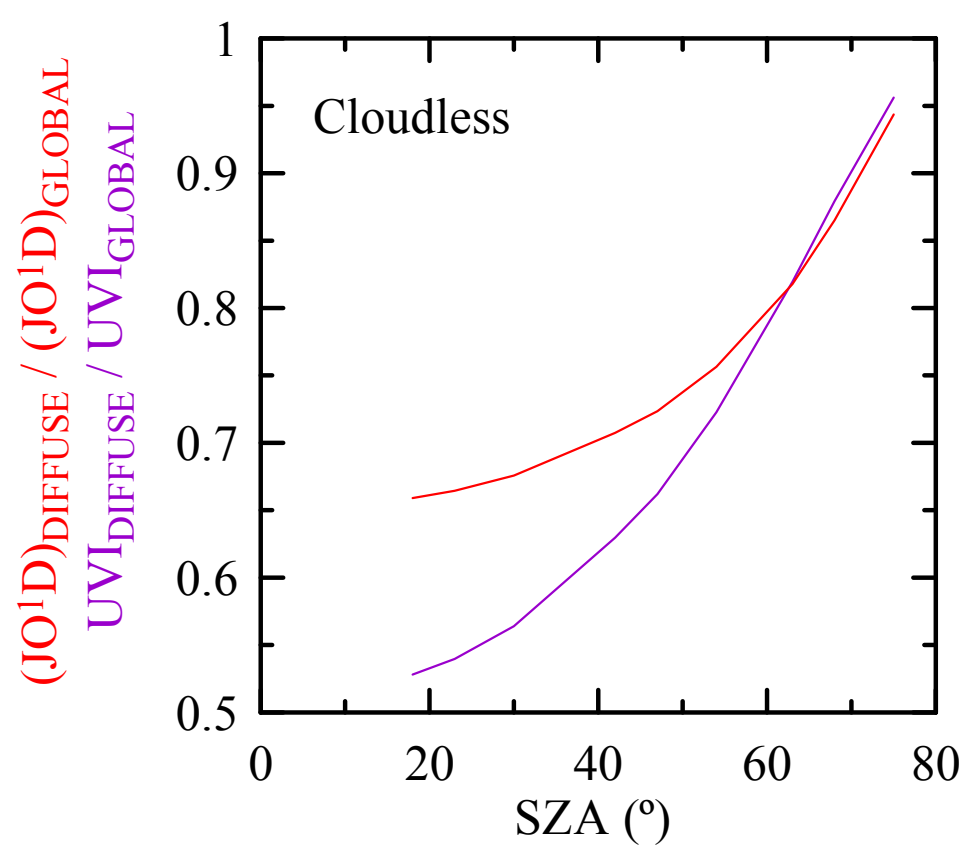

Figure 5.6. Dependence on SZA of the ratio between diffuse and global components for the UVI (purple line) and $J\left(O^{I} D\right)$ (red line) calculated with the libRadtran model for cloudless conditions. 


\subsection{Dependence of spectral UV radiative flux on water cloud microphysical properties}

Having analyzed the dependence of integrated CMF on cloud microphysical properties, spectral behaviour is also investigated.

It is worth mentioning here that the spectral behaviours obtained in Chapter 4 using cloud optical thickness to characterize cloudy conditions should not vary with the use of cloud microphysical properties. The spectral dependence caused by two (LWP, $\mathrm{r}_{\text {eff }}$ ) obtained from the HATPRO and VIS-MFRSR instruments is the same as that caused by their corresponding COT value.

\subsubsection{Global and diffuse irradiances}

The spectral irradiance measured by the UV-MFRSR instrument is used to study the behaviour of global and diffuse irradiances. Two wavelengths are selected: one in the UV-B range $(304.7 \mathrm{~nm})$ and the other in the UV-A $(367.2 \mathrm{~nm})$. Following the classification mentioned in Section 5.1, three groups of particle radii are established. In addition, due to the strong dependence of the $\mathrm{CMF}_{\text {DIFFUSE }}$ on SZA, three intervals of angles are fixed: $\left(18^{\circ}, 30^{\circ}\right),\left(42^{\circ}, 54^{\circ}\right)$ and $\left(63^{\circ}, 75^{\circ}\right)$, which are all $12^{\circ}$ in width. Figure 5.7 shows the results obtained for the interval $18^{\circ}<\mathrm{SZA}<30^{\circ}$. The model simulations are plotted for the smallest and highest SZAs, i.e. $\mathrm{SZA}=18^{\circ}$ and $\mathrm{SZA}=30^{\circ}$. The agreement between measurements and simulations is quite good, and is slightly better for the longest wavelength.

Smaller particles produce stronger attenuation of both global and diffuse spectral irradiance, as occurred in the case of UVI (integrated irradiance).

The CMF of the global component did not display significant differences between the two wavelengths. At 304.7 and $367.2 \mathrm{~nm}$, the variability of the $\mathrm{CMF}_{\mathrm{GLOBAL}}$ for LWP $=0.1 \mathrm{~kg} \mathrm{~m}^{-2}$ is similar, with values falling into the intervals: $(0.15,0.35),(0.35,0.55)$, and $(0.55,0.65)$ for $2.5 \mu \mathrm{m}<\mathrm{r}_{\text {eff }}<5 \mu \mathrm{m}, 5 \mu \mathrm{m}<\mathrm{r}_{\text {eff }}<10 \mu \mathrm{m}$, and $10 \mu \mathrm{m}<\mathrm{r}_{\text {eff }}<15 \mu \mathrm{m}$, respectively (values relative to the smallest SZA). However, when the diffuse component is investigated, the CMF values at $367.2 \mathrm{~nm}$ are always higher than those at $304.7 \mathrm{~nm}$. The increasing trend in the diffuse CMF values with wavelength observed in Section 4.3 is confirmed. Analyzing the same intervals of effective radius, the $\mathrm{CMF}_{\text {DIFFUSE }}$ takes the following values (for SZA $=18^{\circ}$ and $\left.\mathrm{LWP}=0.1 \mathrm{~kg} \mathrm{~m}^{-2}\right)$ : $(0.3,0.6),(0.6,1.0),(1.0,1.2)$, and $(0.45,0.85),(0.85,1.4),(1.4,1.7)$ at 304.7 and $367.2 \mathrm{~nm}$, respectively, increasing with particle radius size. 
In addition, a particular case occurs for very low LWP in the $\mathrm{CMF}_{\text {DIFFUSE }}$ case. When the LWP is $0.01 \mathrm{~kg} \mathrm{~m}^{-2}$, the curves of $r_{\text {eff }}=10 \mu \mathrm{m}$ are above those of $r_{\text {eff }}=15 \mu \mathrm{m}$. This effect is more relevant at $\lambda=367.2 \mathrm{~nm}$. One important point is that the results suggested by the model cannot be verified against observations because the HATPRO microwave radiometer does not allow very low values of LWP to be measured (this LWP value is in the same order of magnitude as the experimental error, see Chapter 2). In addition, a case of homogeneous cloud with very low LWP and high $r_{\text {eff }}$ is not easily observable.

The same study is performed for higher SZAs in the intervals $\left(42^{\circ}, 54^{\circ}\right)$ and $\left(63^{\circ}\right.$, $75^{\circ}$ ). The results are shown in Figures 5.8 and 5.9, respectively.

The curves of the diffuse irradiance changed substantially compared to the case of the $\mathrm{SZA}=\left(18^{\circ}, 30^{\circ}\right)$. The effect mentioned before of stronger attenuation with $\mathrm{r}_{\text {eff }}=15$ $\mu \mathrm{m}$ than with $\mathrm{r}_{\text {eff }}=10 \mu \mathrm{m}$ is weaker in the case of SZA $=\left(42^{\circ}, 54^{\circ}\right)$ and totally disappears in the highest SZA interval. In fact, Figure 5.9 shows how the curve of $\mathrm{CMF}_{\text {DIFFUSE }}$ at $367.2 \mathrm{~nm}$ with $\mathrm{r}_{\text {eff }}=15 \mu \mathrm{m}$ is always above the curve of $\mathrm{r}_{\mathrm{eff}}=10 \mu \mathrm{m}$.

The $\mathrm{CMF}_{\mathrm{GLOBAL}}$ shows a very slight decreasing trend with wavelength between 304.7 and $367.2 \mathrm{~nm}$ in the $\left(12^{\circ}, 30^{\circ}\right)$ and $\left(42^{\circ}, 54^{\circ}\right) \mathrm{SZA}$ intervals. However, for higher SZAs (Figure 5.9), between $63^{\circ}$ and $75^{\circ}$, a decreasing trend in the values is observed, this effect being more evident for the larger particles (cases of 10 and $15 \mu \mathrm{m}$ ). For instance, in the upper panels of Figure 5.9, at a fixed LWP of $0.1 \mathrm{~kg} \mathrm{~m}^{-2}$, a reduction of $\sim 0.05$ units in the $\mathrm{CMF}_{\mathrm{GLOBAL}}$ values is recorded with $\mathrm{r}_{\text {eff }}=15 \mu \mathrm{m}$ between 304.7 and $367.2 \mathrm{~nm}$, while the reduction is $\sim 0.025$ units in the case of $r_{\text {eff }}=2.5 \mu \mathrm{m}$. The observed stronger attenuation of the longer wavelengths confirms the results reported by authors who use cloud optical thickness to characterize the cloud layer (e.g., Seckmeyer et al., 1996; Bernhard et al., 2004; Chapter 4 of this thesis). 

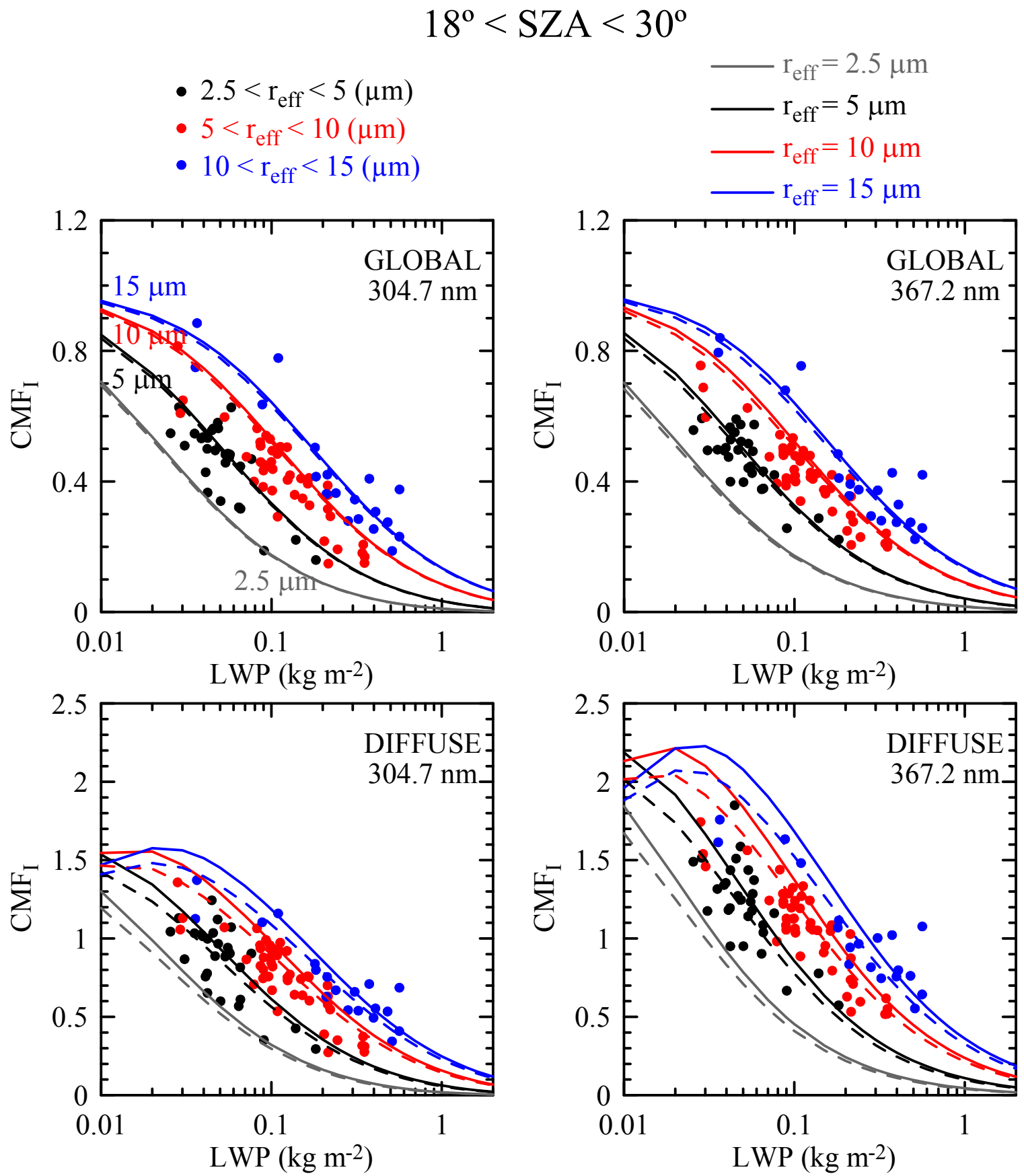

Figure 5.7. CMF for the global and diffuse spectral irradiances at two wavelengths as a function of LWP for different cloud droplet radii in the $S Z A$ interval $\left(18^{\circ}, 30^{\circ}\right)$. Dots are the experimental data and lines are the radiative transfer simulations at $S Z A=18^{\circ}$ (solid lines) and $S Z A=30^{\circ}$ (dashed lines). 


$$
42^{\circ}<\mathrm{SZA}<54^{\circ}
$$

$$
\begin{aligned}
& -2.5<\mathrm{r}_{\text {eff }}<5(\mu \mathrm{m}) \\
& \text { - } 5<\mathrm{r}_{\text {eff }}<10(\mu \mathrm{m}) \\
& \text { - } 10<\mathrm{r}_{\text {eff }}<15(\mu \mathrm{m})
\end{aligned}
$$
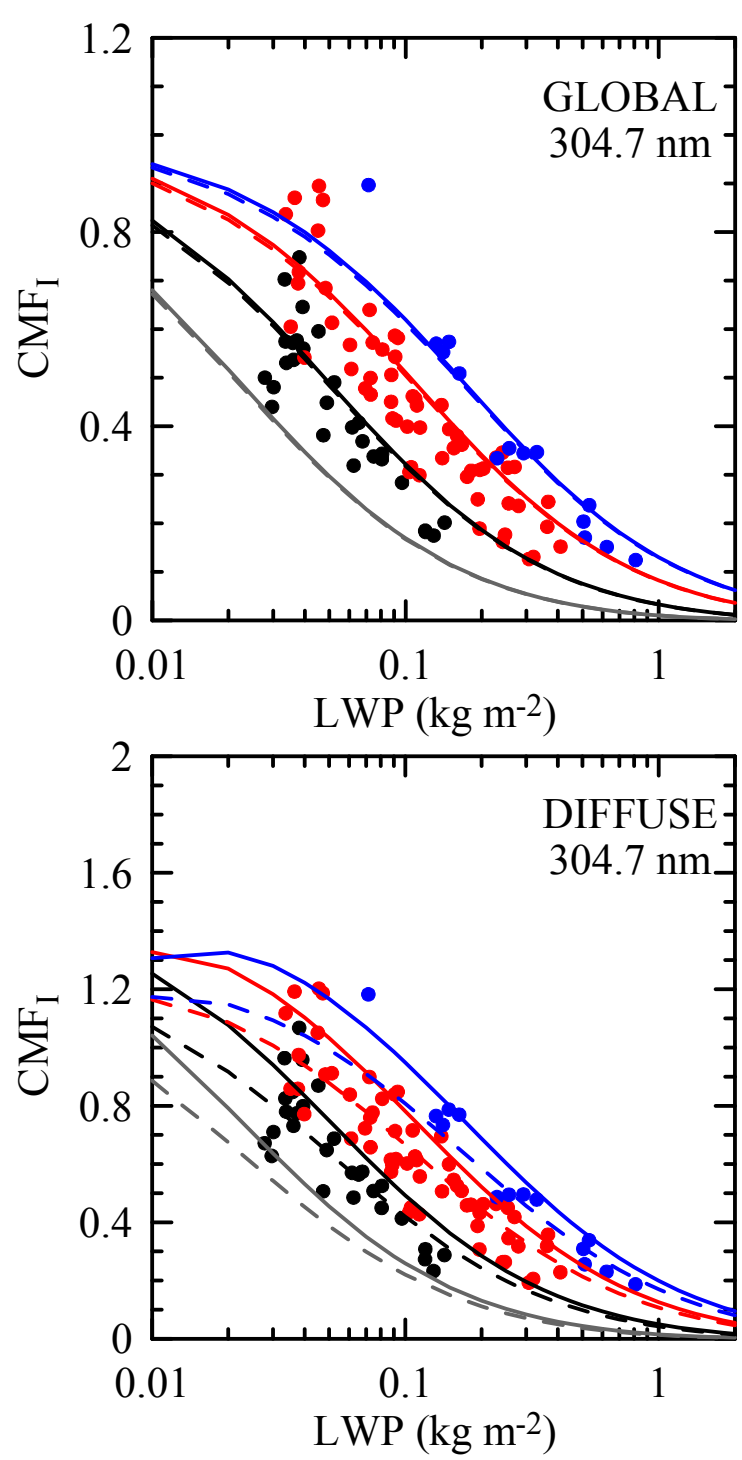
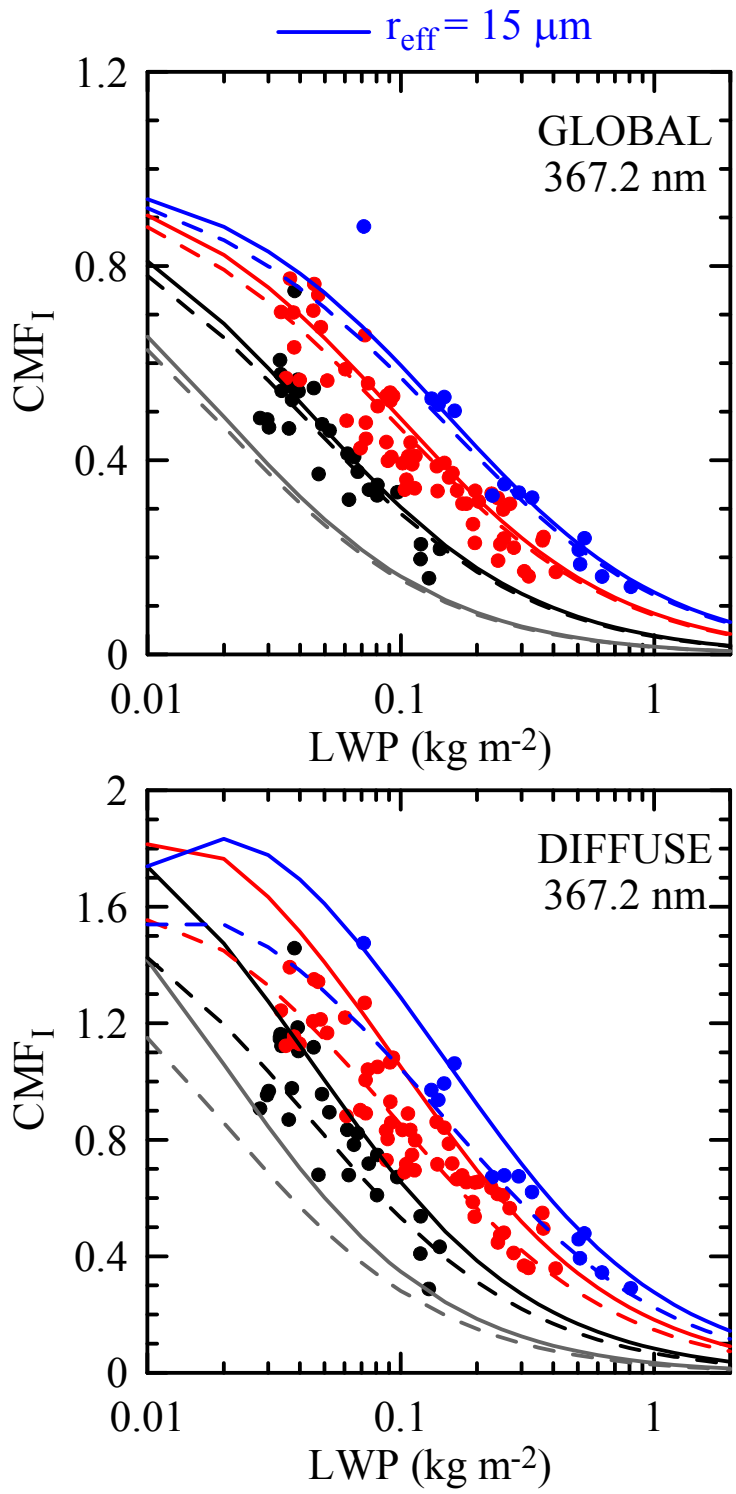

Figure 5.8. CMF for the global and diffuse spectral irradiances at two wavelengths as a function of LWP for different cloud droplet radii in the SZA interval $\left(42^{\circ}, 54^{\circ}\right)$. Dots are the experimental data and lines are the radiative transfer simulations at $S Z A=42^{\circ}$ (solid lines) and $S Z A=54^{\circ}$ (dashed lines). 

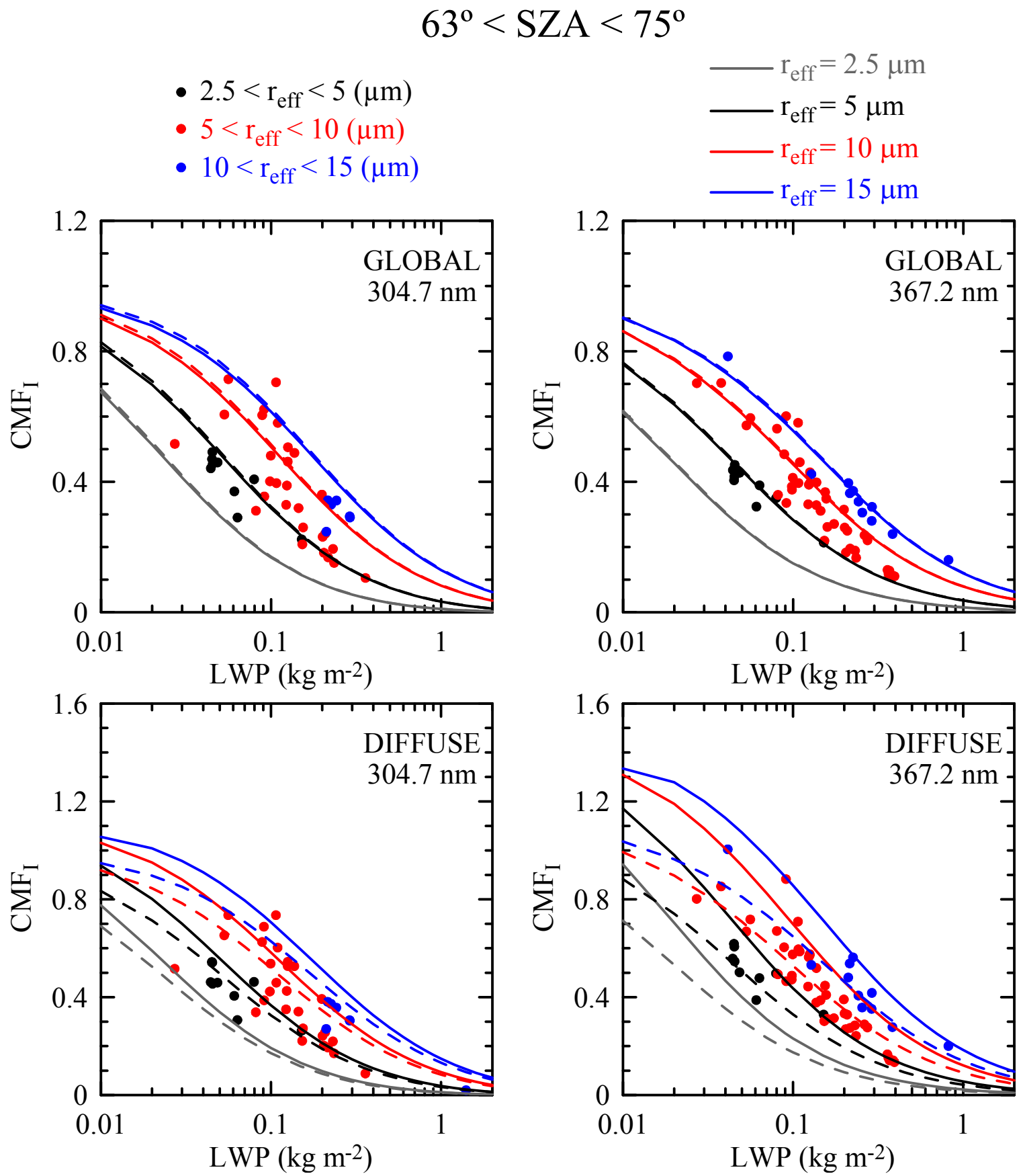

Figure 5.9. CMF for the global and diffuse spectral irradiances at two wavelengths as a function of LWP for different cloud droplet radii in the $S Z A$ interval $\left(63^{\circ}, 75^{\circ}\right)$. Dots are the experimental data and lines are the radiative transfer simulations at $S Z A=63^{\circ}$ (solid lines) and $S Z A=75^{\circ}$ (dashed lines). 


\subsubsection{Actinic flux}

A similar study is carried out with regard to the actinic flux. Figure 5.10 shows $\mathrm{CMF}_{\mathrm{F}}$ dependence on LWP for the same three groups of $r_{\text {eff }}$ and intervals of SZA used in the previous figures. The wavelengths shown in the figure were chosen in order to match those used in the irradiance study.

By way of general remarks, it can be said that $\mathrm{CMF}_{\mathrm{F}}$ values decrease with SZA at 305.4 and $367.51 \mathrm{~nm}$ for all the radii. At $305.4 \mathrm{~nm}$, the $\mathrm{CMF}_{\mathrm{F}}$ for the group of $5 \mu \mathrm{m}<\mathrm{r}_{\text {eff }}$ $<10 \mu \mathrm{m}$ is in the ranges $(0.4,0.6),(0.35,0.5)$, and $(0.3,0.45)$ at $\mathrm{LWP}=0.1 \mathrm{~kg} \mathrm{~m}^{-2}$ and $\mathrm{SZA}=18^{\circ}, 42^{\circ}$, and $63^{\circ}$, respectively. The CMFs display the following values in the case of $\lambda=367.51 \mathrm{~nm}$ : $(0.4,0.65),(0.3,0.5)$, and $(0.25,0.35)$, respectively. At low SZAs $\left(\mathrm{SZA}=18^{\circ}\right)$ there is a small increase in the $\mathrm{CMF}_{\mathrm{F}}$ values from 305.4 to $367.51 \mathrm{~nm}$, at intermediate SZAs $\left(\mathrm{SZA}=42^{\circ}\right)$ no spectral dependence is evident, and at the highest SZAs $\left(\mathrm{SZA}=63^{\circ}\right)$ a strong decrease occurs in the $\mathrm{CMF}_{\mathrm{F}}$ for all radii. These results corroborate those obtained in Chapter 4, when cloud optical thickness was used to characterize the cloud layer. 


$$
\begin{array}{rr}
\bullet 2.5<\mathrm{r}_{\text {eff }}<5(\mu \mathrm{m}) & -\mathrm{r}_{\text {eff }}=2.5 \mu \mathrm{m} \\
\bullet 5<\mathrm{r}_{\text {eff }}<10(\mu \mathrm{m}) & -\mathrm{r}_{\text {eff }}=5 \mu \mathrm{m} \\
\bullet 10<\mathrm{r}_{\text {eff }}<15(\mu \mathrm{m}) & -\mathrm{r}_{\text {eff }}=10 \mu \mathrm{m} \\
18^{\circ}<\mathrm{SZA}<30^{\circ} & \mathrm{r}_{\text {eff }}=15 \mu \mathrm{m}
\end{array}
$$

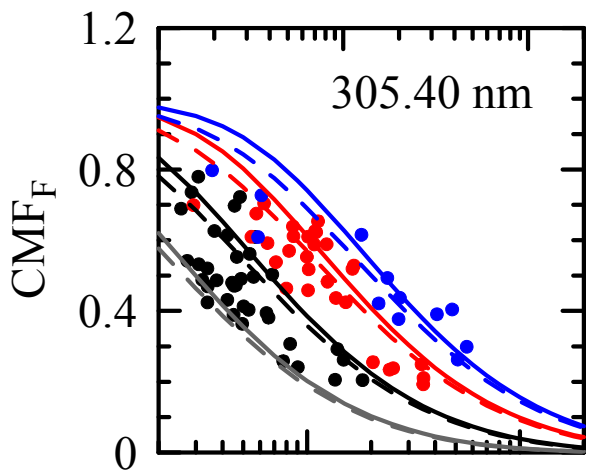

0.1

LWP $\left(\mathrm{kg} \mathrm{m}^{-2}\right)$

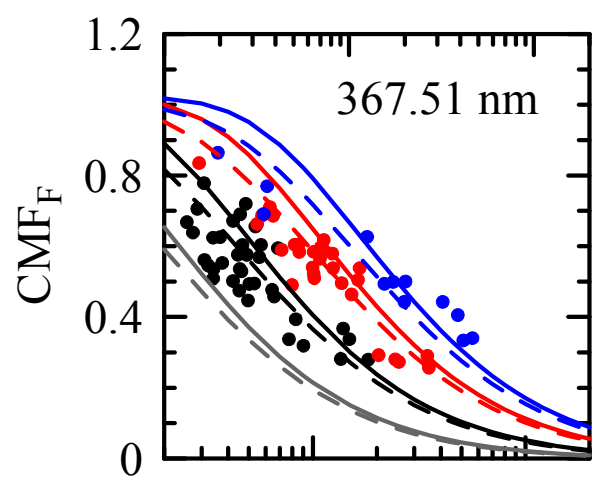

0.1

LWP (kg m-2)

$$
42^{\circ}<\mathrm{SZA}<54^{\circ}
$$
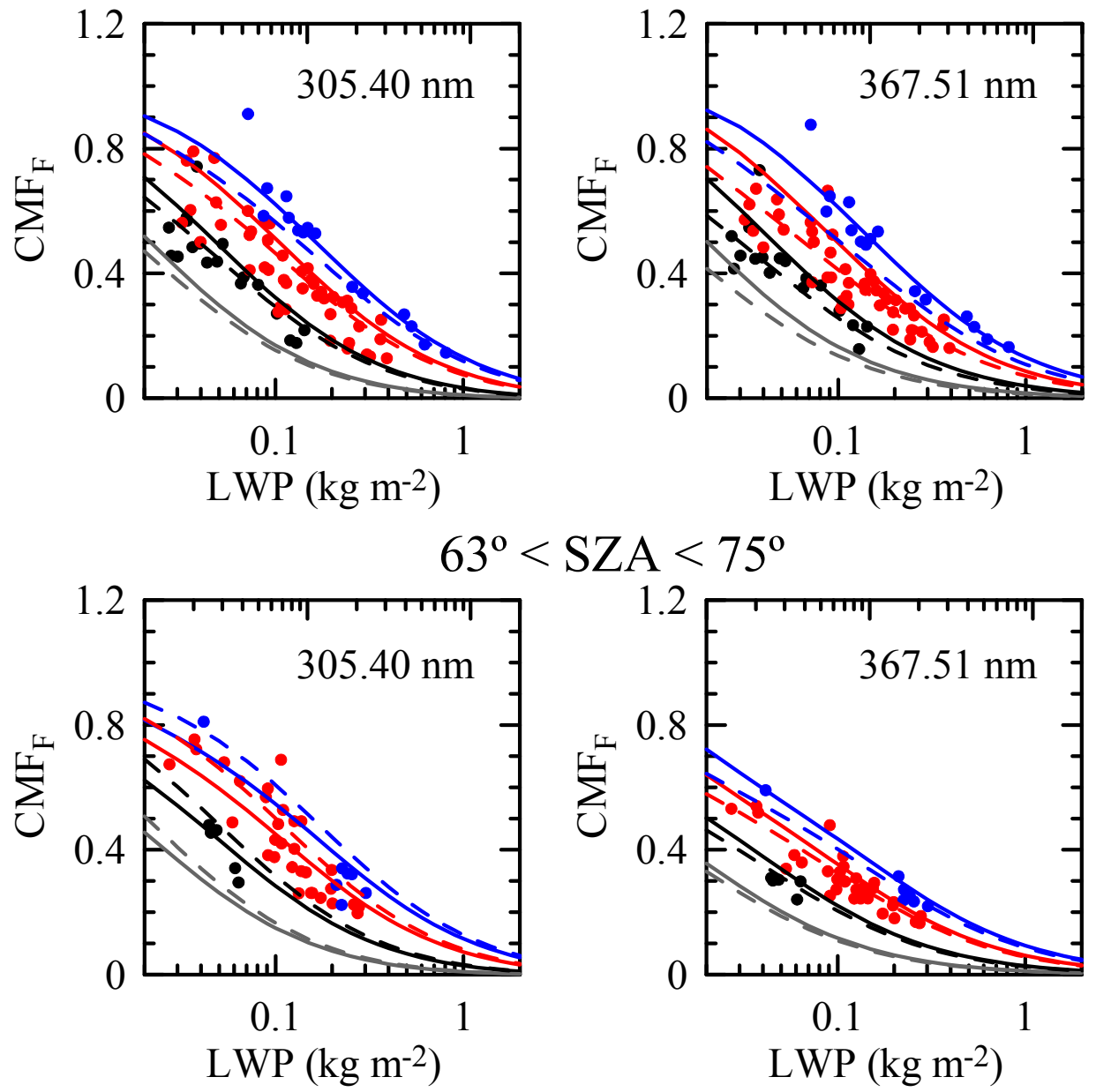

Figure 5.10. CMF for the actinic flux at two wavelengths as a function of LWP for different cloud droplet radii in the three SZA intervals. Dots are the experimental data and lines are the radiative transfer simulations at the smallest (solid lines) and highest (dashed lines) SZAs in each panel. 
Differences between spectral irradiance and actinic flux are also observed and analyzed using model calculations. The model results can be obtained for 'almost continuous' values of LWP for each case. Figure 5.11 shows the behaviour of $\mathrm{CMF}_{\mathrm{I}}$ and $\mathrm{CMF}_{\mathrm{F}}$ for the two wavelengths selected for the irradiance case $(304.7$ and $367.2 \mathrm{~nm})$ and a fixed cloud droplet radius of 2.5 and $10 \mu \mathrm{m}$. Calculations are made at the minimum and maximum values of the solar zenith angle used in this chapter. At $\mathrm{SZA}=18^{\circ}$, the $\mathrm{CMF}_{\mathrm{F}}$ values are higher than $\mathrm{CMF}_{\mathrm{I}}$. However, at $\mathrm{SZA}=75^{\circ}$ the opposite behaviour is found (i.e., $\mathrm{CMF}_{\mathrm{I}}>\mathrm{CMF}_{\mathrm{F}}$ ).
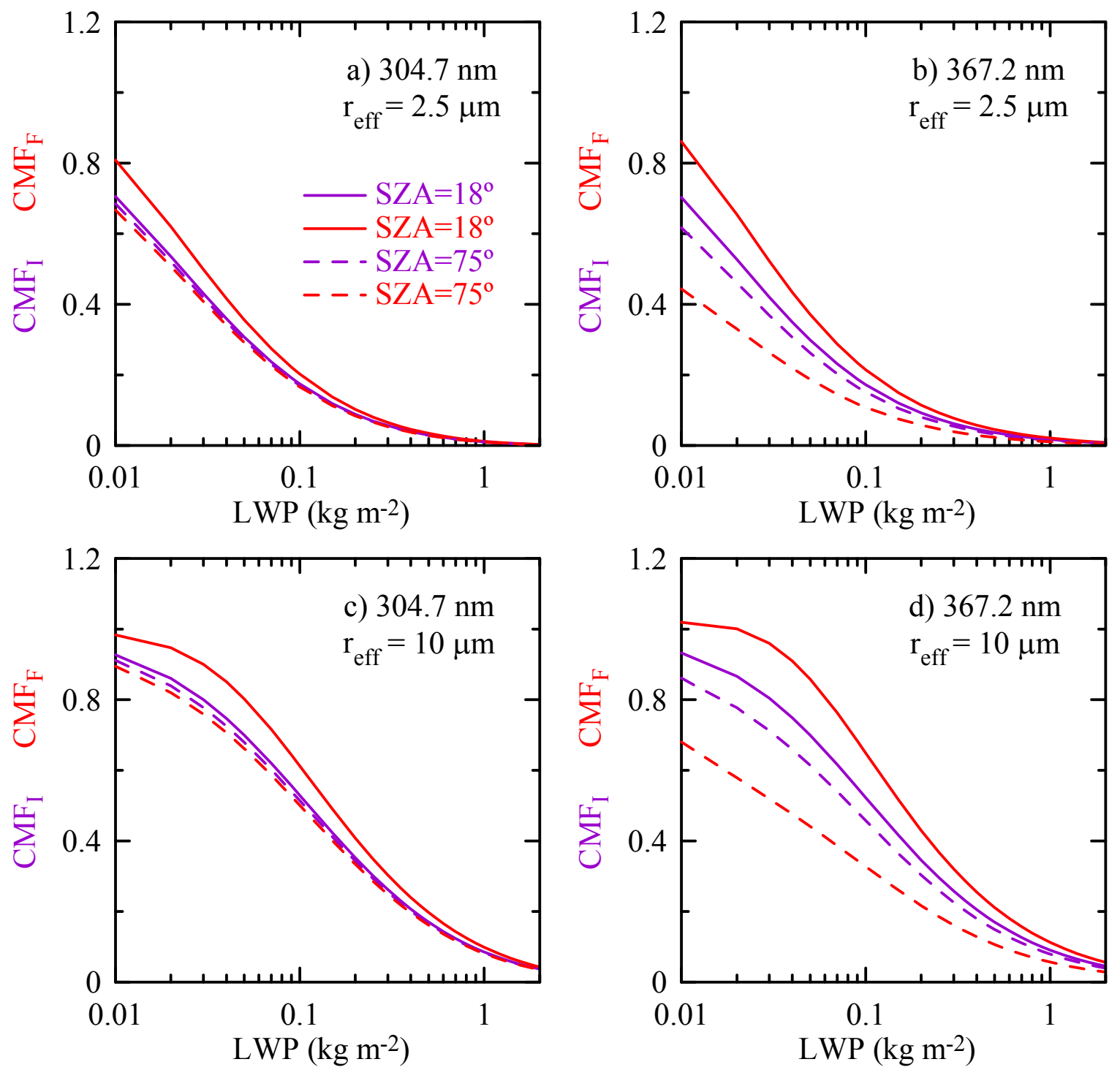

Figure 5.11. CMF for the global irradiance (CMF, purple lines) and actinic flux (CMF $F_{F}$, red lines) at $S Z A$ $=18^{\circ}$ (solid lines) and $S Z A=63^{\circ}$ (dashed lines) at $304.7 \mathrm{~nm}$, a) and c), and $367.2 \mathrm{~nm}$, b) and d), for fixed $r_{\text {eff }}$ of $5, a$ ) and b), and $15, c$ ) and d), $\mu \mathrm{m}$. 
As mentioned before, the actinic flux evidences a stronger dependence on SZA, which can be seen in the figure. These results corroborate the findings obtained in Figure 5.5 where the $\mathrm{CMF}_{\mathrm{UVI}}$ and $\mathrm{CMF}_{\mathrm{J}(\mathrm{O} 1 \mathrm{D})}$ are analyzed. In fact, the reason behind this different behaviour can again be explained by the different roles of the direct and the diffuse component under cloudless conditions.

Figure 5.12 shows the spectral dependence of the ratio between the diffuse components of the irradiance and actinic flux with regard to the global component obtained by the radiative transfer model at two different SZAs. The atmospheric conditions used in the simulations are the same as those explained in Chapter 2, with $\mathrm{TOC}=300$ and $\mathrm{AOT}_{550 \mathrm{~nm}}=0.25$. The spectral direct to global ratio can be evaluated as 1 - diffuse/global. As can be seen in the figure, at low SZA the direct component is dominant for the irradiance, and the diffuse component for the actinic flux. Hence, the $\mathrm{CMF}_{\mathrm{I}}$ is more strongly attenuated than $\mathrm{CMF}_{\mathrm{F}}$. However, the diffuse to global ratio increases substantially at high SZA both for irradiance and actinic flux. As can be deduced from the figure, the diffuse contribution for the irradiance is higher than for the actinic flux. Hence, the $\mathrm{CMF}_{\mathrm{I}}$ is less attenuated than $\mathrm{CMF}_{\mathrm{F}}$.

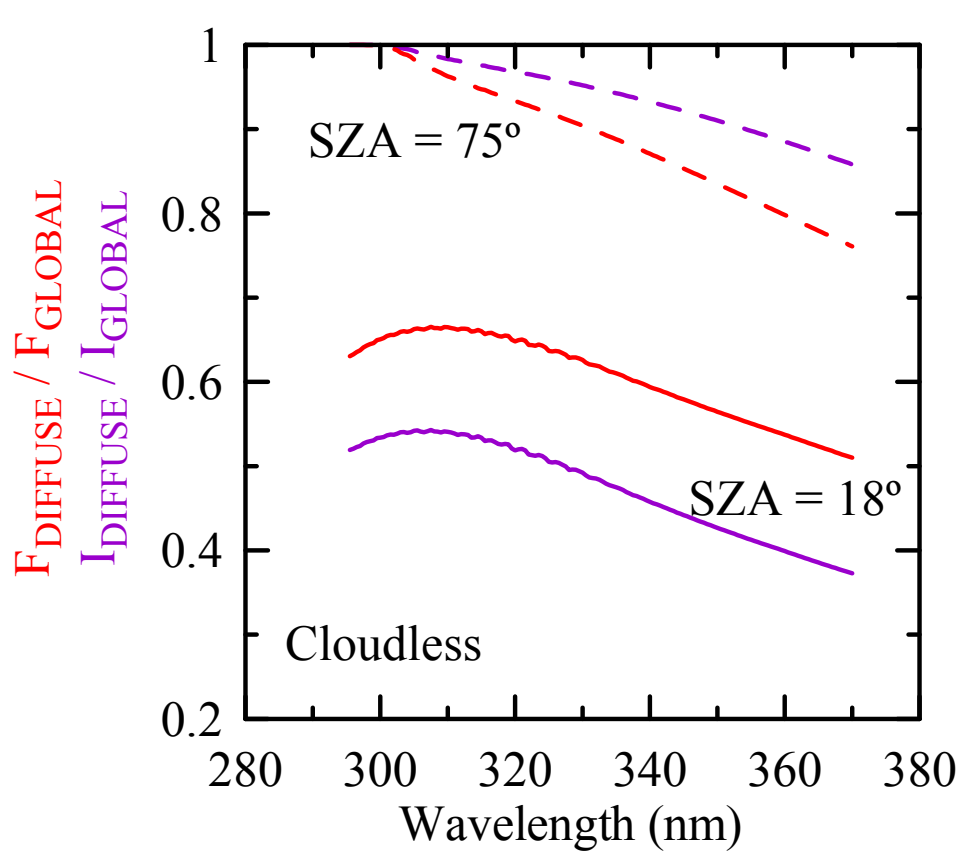

Figure 5.12. Spectral ratios between diffuse and global components for the irradiance (purple lines) and actinic flux (red lines) at $18^{\circ}$ (solid lines) and $75^{\circ}$ (dashed lines) calculated with the libRadtran model for cloudless conditions. 
Comparing the modelled results at the two wavelengths (304.7 and $367.2 \mathrm{~nm}$ ), at $\mathrm{SZA}=18^{\circ}$, the $\mathrm{CMF}$ for the global irradiance displays very similar values (since its spectral dependence reaches a maximum after $304.7 \mathrm{~nm}$ and then decreases towards longer wavelengths), while those for the actinic flux at $367.2 \mathrm{~nm}$ are slightly higher than the values at $304.7 \mathrm{~nm}$. Both effects remain for the whole LWP range used in this thesis. At high SZA $\left(\mathrm{SZA}=75^{\circ}\right)$, both radiative quantities evidence the decreasing trend with wavelength for all LWP values. This supports the results shown in Chapter 4 (with regard to COT). The cloud droplet radius determines the form of the curve in the cloud transmittance dependence on LWP, but does not add any spectral difference in the modelled study carried out in this thesis.

\subsection{Summary}

\subsubsection{English version}

Characterization of the radiative flux (UV index, ozone photolysis rates, and irradiance, global and diffuse, and actinic flux spectra) by means of the cloud transmittance was carried out using experimental values of the cloud microphysical properties. From microwave radiometer HATPRO and VIS-MFRSR instruments, the liquid water path and the cloud effective radius were derived. The libRadtran model was also used in this characterization. In general, smaller particles produce higher attenuation of radiative fluxes in the overcast scenario. While UVI and global spectral irradiance present very weak dependence on the SZA, the actinic flux (both integrated and spectral) and the diffuse spectral irradiance show clear dependence on this parameter. The CMF values of these variables decrease with SZA. The different behaviour between irradiance and actinic flux is analyzed using both integrated and spectral variables. It can be concluded that the irradiance is more attenuated at low SZA, while the actinic flux is more attenuated at high SZA. These effects can be understood by the different weight of the direct and diffuse components. At low SZA, the direct component of the irradiance is higher than for the actinic flux. This is extremely important under cloudy conditions since clouds tend to totally block the direct component (and partially attenuate the diffuse radiation). Hence, smaller CMF values occur for irradiance. However, the direct contribution of the actinic flux is higher than the irradiance contribution at high SZA. Therefore, at these angles, the CMF values for the actinic flux are smaller than those for the irradiance case. Global irradiance CMF displays a decreasing trend from 304.7 to $367.2 \mathrm{~nm}$, which is more evident at large SZA and for small particles. The diffuse irradiance CMF always increases between 304.7 and $367.2 \mathrm{~nm}$. In addition, $\mathrm{CMF}_{\mathrm{DIFFUSE}}$ also shows values $>1$ (i.e. there is more diffuse irradiance than in the cloudless scenario) 
with maxima for larger particles under certain conditions, for instance, at low LWP and, practically, all SZAs. Comparing the actinic flux CMF at 305.4 and $367.51 \mathrm{~nm}$, a small increasing trend in CMF values is observed at low SZA, while there is no variation at moderate SZA, and a clear decreasing trend at high SZA.

\subsubsection{Spanish version}

La caracterización del campo radiativo (índice UV, índice de fotodisociación, e irradiancia, global y difusa, y flujo actínico espectrales) a través de la transmitancia de la nube se ha realizado usando valores experimentales de las propiedades microfísicas de las nubes. El contenido de agua líquida y el radio efectivo de las gotas de agua han sido derivados de las medidas proporcionadas por los radiómetros HAPTRO y VIS-MFRSR. El modelo libRadtran también se ha empleado en la caracterización. Como resultado general, las partículas más pequeñas producen una mayor atenuación de los flujos radiativos en el escenario de cielos totalmente cubiertos. Mientras que el índice UV y la irradiancia espectral global presentan una dependencia con el SZA muy débil, tanto el flujo actínico (tanto en régimen integrado como espectral) como la irradiancia espectral difusa presentan una clara influencia con el SZA. El distinto comportamiento entre irradiancia y flujo actínico se ha analizado usando tanto los valores integrados como los espectros. Se puede concluir que la irradiancia es más atenuada que el flujo actínico para bajos SZAs, mientras que este último lo es para altos SZA. Estos efectos se pueden entender por el diferente peso de las componentes directa y difusa. Para bajo SZA, la componente directa de la irradiancia es más relevante que para el flujo actínico. Este hecho toma importancia en el escenario nuboso porque las nubes generalmente bloquean la componente directa, atenuando de forma menos efectiva la componente difusa. Lo que provoca valores más bajos del CMF en el caso de la irradiancia. Sin embargo, para alto SZA, la componente directa del flujo actínico tiene un mayor peso que la de la irradiancia, lo que produce una mayor contribución de la difusa en la irradiancia. Por lo tanto, a estos ángulos, los valores de CMF para el flujo actínico son más pequeños que aquellos obtenidos para la irradiancia. El CMF de la irradiancia global presenta un ligero aumento desde 304.7 a $367.2 \mathrm{~nm}$, resultando más evidente para un alto SZA y partículas con un radio más pequeño. El CMF de la irradiancia difusa aumenta su valor entre 304.7 y $367.2 \mathrm{~nm}$, presentando valores de CMF mayores que la unidad (es decir, hay más irradiancia que en el caso de cielos despejados), para partículas de radio grande y para, por ejemplo, bajo LWP y casi todos los SZAs. Comparando el CMF del flujo actínico entre 305.4 y 367.51 una ligera tendencia creciente en el CMF es observada a bajos SZAs, que pasa a ser una tendencia constante para moderados SZAs, y una clara tendencia decreciente para altos SZAs. 



\section{Chapter 6}

6. Case Study: Role of an Aerosol Layer below the Cloud. Model Sensitivity Analysis on Aerosol and Cloud Properties 
This chapter investigates the dependence of cloud transmittance on aerosol properties under overcast conditions by analyzing a particular case with an aerosol dust layer below the cloud. Sensitivity analyses are carried out to evaluate the impact of the aerosol and cloud properties on CMFs.

\subsection{Case study and inputs to the radiative transfer model}

During the two-month Trisaia campaign, a variety of atmospheric conditions occurred. With regard to the overcast conditions, events with constant cloud cover of 8 octas were not too long. Analyzing only cloudiness visual observations, Figure 6.1 shows that 17 events are shorter than three hours, three are between five and seven hours, and only two cases are longer than nine hours. Only two cases present overcast conditions the whole day: 20 and 30 May 2010. However, the first was under rainy conditions, and for instance, instruments such as LIDAR did not perform measurements. On 30 May 2010, some intervals of rain were occasionally observed. Hence, data from this day can be used to investigate aerosol effects under a cloud layer. Figure 6.2 shows the vertical profiles measured by LIDAR for this day. As can be seen in the figure, the aerosol layer is observed below the cloud. Radiative transfer simulations with the libRadtran library will be used in this chapter. In order to obtain simulations that are as realistic as possible, conditions which are easily reproducible with the model have been selected.

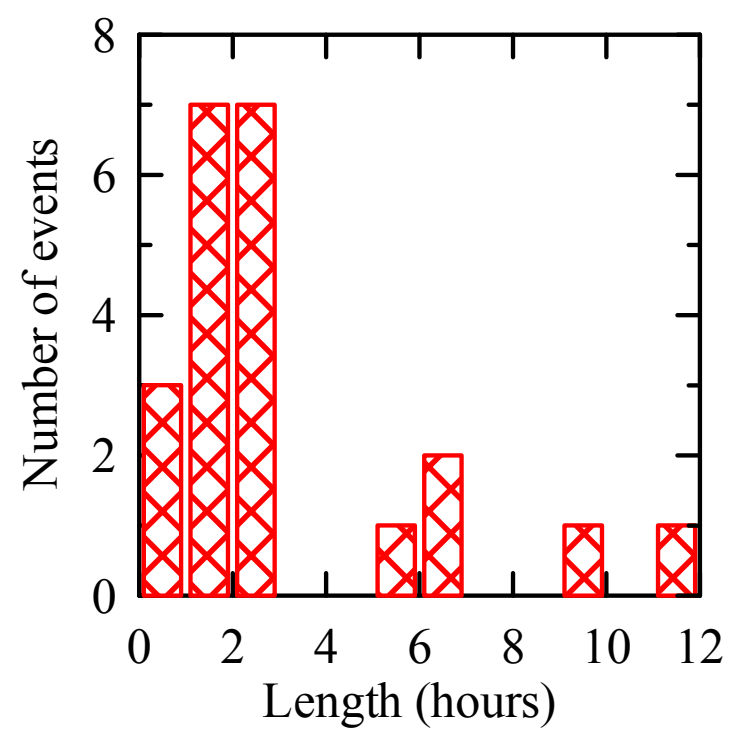

Figure 6.1. Frequency of overcast events as a function of their length in hours. 


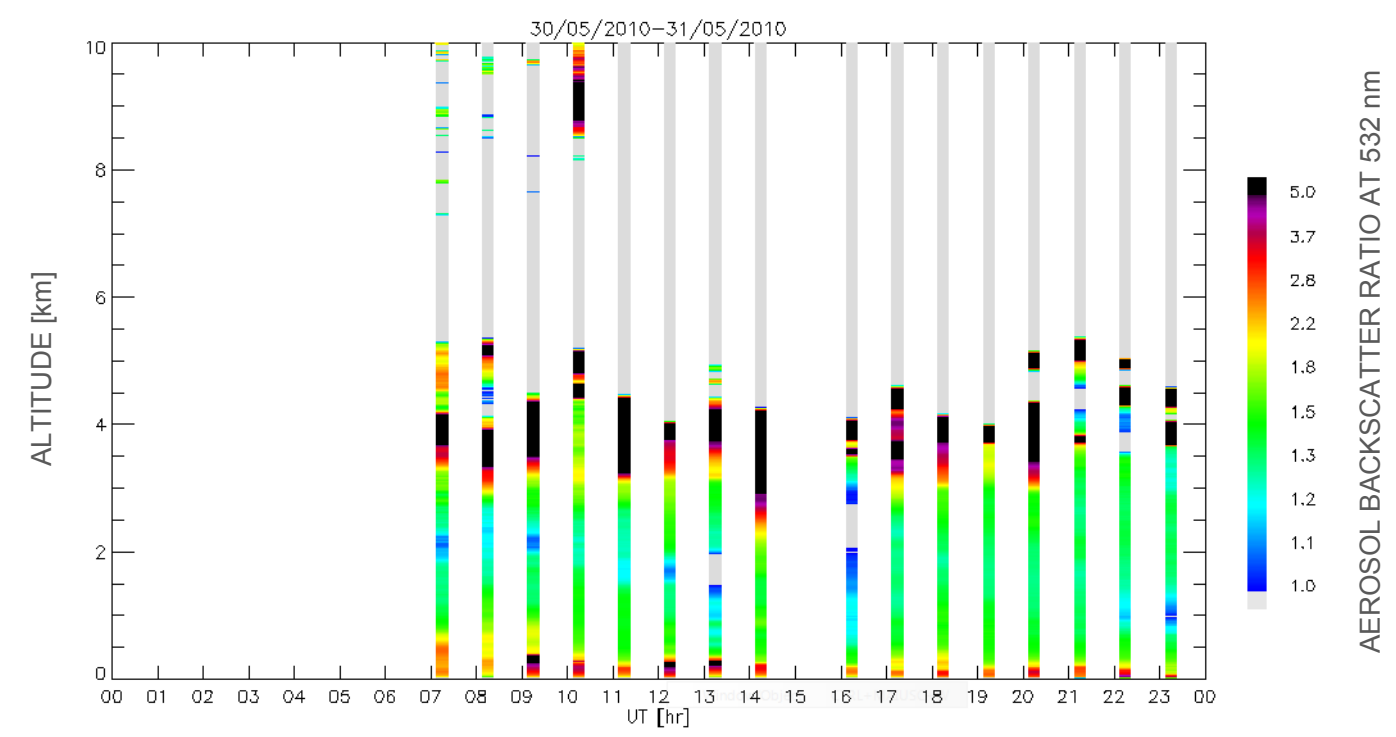

Figure 6.2. Vertical distribution of Aerosol Backscatter Ratio at $532 \mathrm{~nm}$ on 30 May 2010 at the TRISAIA station.

Hence, the profile measured at 14:00 UT is chosen (corresponding to a SZA of $45.7^{\circ}$ ). In this case, the aerosol is confined in the first two kilometres, while the cloud starts at this height. This configuration matches the default aerosol distribution used in the model.

Table 6.1 provides information on the atmospheric situation for the date and time of the case study. As cloudy conditions occurred throughout the day, the measurements of the Microtops-II and VIS-MFRSR instruments are not available to obtain TOC and aerosol load data, respectively. With regard to LIDAR observations, the base and top heights of the clouds are available, although it was not possible to obtain a good estimation of the aerosol optical thickness. The OMI and MODIS remote-sensing instruments are used instead of surface measurements to obtain daily ozone and aerosol data, respectively.

Cloud properties are defined using the estimation of the cloud optical thickness obtained from total shortwave irradiance (see Section 2.2.3), the measurements of the liquid water path by the HATPRO instrument, and the retrieved effective radius by VISMFRSR and HATPRO observations. 
Table 6.1. Atmospheric and meteorological conditions recorded at 14:00h UT 30 May 2010 at the TRISAIA station.

\begin{tabular}{ccc}
\hline Variable & Instrument & Value \\
\hline SZA & - & $45.7^{\circ}$ \\
Surface pressure & HATPRO & $1007.1 \mathrm{mb}$ \\
Surface temperature & HATPRO & $294.2 \mathrm{~K}$ \\
AOT $_{\text {550nm }}$ & MODIS & 0.2 \\
TOC $^{\text {TOC }}$ & OMI & $361.5 \mathrm{DU}$ \\
Surface O $_{3}$ & $49 \mathrm{C}$ & $43 \mathrm{ppb}$ \\
Cloud base height & LIDAR & $2190 \mathrm{~m}$ \\
Cloud top height & LIDAR & $4327 \mathrm{~m}$ \\
COT & CMP-21 & 30.1 \\
LWP & HATPRO & $177.2 \mathrm{~g} \mathrm{~m}^{-2}$ \\
$\mathbf{r}_{\text {eff }}$ & HATPRO & $7.6 \mu \mathrm{m}$ \\
\hline
\end{tabular}

The surface measurement of ozone concentration shown in Table 6.1 is higher than the corresponding value of the ozone standard profile in the mid-latitude summer atmosphere. This measurement was recorded by a model 49C Thermo Environmental Instruments Inc. ozone analyzer which has a dynamic range of 0.05-200 ppb and a precision of $1 \mathrm{ppb}$. For this reason, the vertical ozone profile is modified in order to reproduce the measured surface concentration. The new profile and the standard one are shown in Figure 6.3.

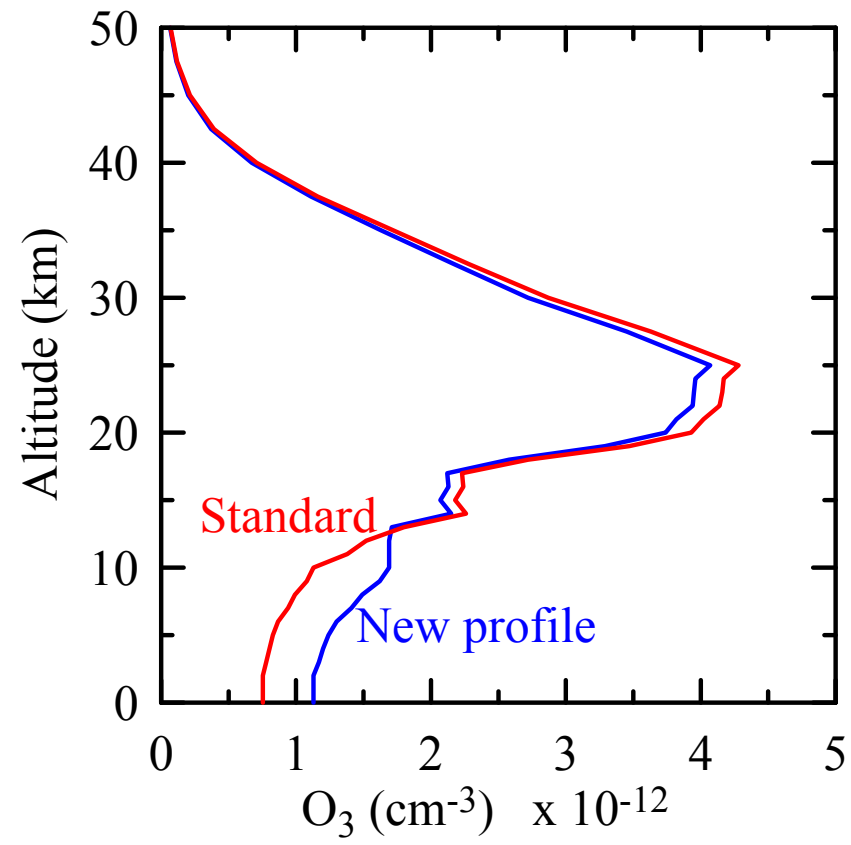

Figure 6.3. Ozone profiles in the standard mid-latitude summer atmosphere (red line) and in the new profile to produce more realistic values of ozone at surface (blue line). 
The temperature measured at the surface is very similar to that of the standard profile $(294.0 \mathrm{~K}$ vs $294.2 \mathrm{~K})$ and no corrections are applied to the model. The surface pressure showed a small difference $(\sim 6 \mathrm{mb})$, and $1007.1 \mathrm{mb}$ and $1013 \mathrm{mb}$ are the measured value and the surface value in the standard profile, respectively. Hence, the experimental value of the surface pressure is introduced into the model in order to scale the profiles of pressure, air, $\mathrm{O}_{2}$, and $\mathrm{CO}_{2}$ accordingly.

In addition, the day of the year is also introduced to take into account the SunEarth distance correction.

One important question is the type of aerosol in the atmosphere. With the HYbrid Single Particle Lagrangian Integrated Trajectory (HYSPLIT) model (Draxler and Rolph, 2012), the air mass back-trajectories are calculated. Figure 6.4 shows the obtained $72-$ hour back-trajectories at 500, 1500, and $2500 \mathrm{~m}$ a.s.1., ending at the time of the surface measurements. The three trajectories come from North Africa, and the presence of desert dust is plausible. This hypothesis is also supported with the LIDAR polarization measurements. Therefore, the aerosol type chosen for model simulations for the case study is desert dust.

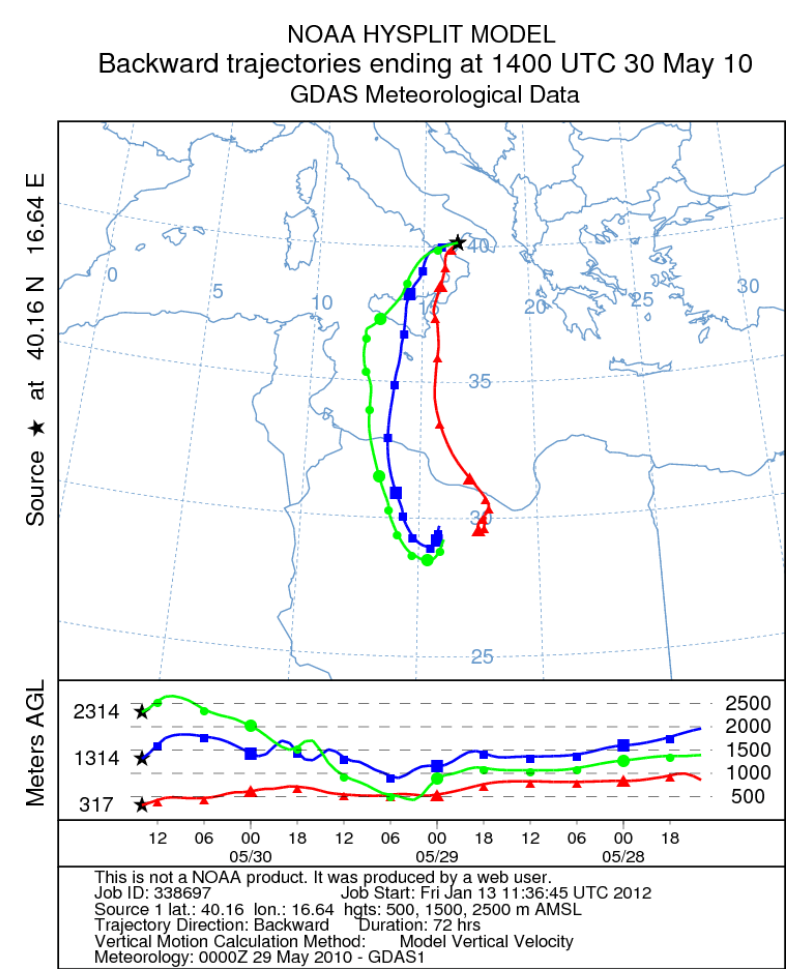

Figure 6.4. Three-day trajectories ending at the TRISAIA station at 14:00 UT 30 May 2010 for three different heights: 500 (red), 1500 (blue), and 2500 (green) m a.s.l. Source: NOAA Air Resources Laboratory (ARL) and READY website (http://ready.arl.noaa.gov) 
Optical Properties of Aerosols and Clouds (OPAC) software package (Hess et al., 1998), which provides optical properties in the solar spectral range of atmospheric constituents, is installed with the libRadtran. This additional module can be freedownloaded from the libRadtran website (http://www.libradtran.org). With regard to water clouds and aerosol particles, OPAC presents the microphysical and optical properties of six water clouds and ten aerosol components, which are calculated under the assumption of spherical particles. Typical mixtures of aerosol components as well as typical height profiles are proposed as default values: desert, maritime (clean, polluted, and tropical), continental (clean, polluted, and average), and urban, among others. The desert dust optical properties from the OPAC dataset are selected, for which a spectral dependence as well as variation with altitude is taken into account.

The libRadtran input file to obtain UV spectral irradiance and actinic flux outputs is described below:

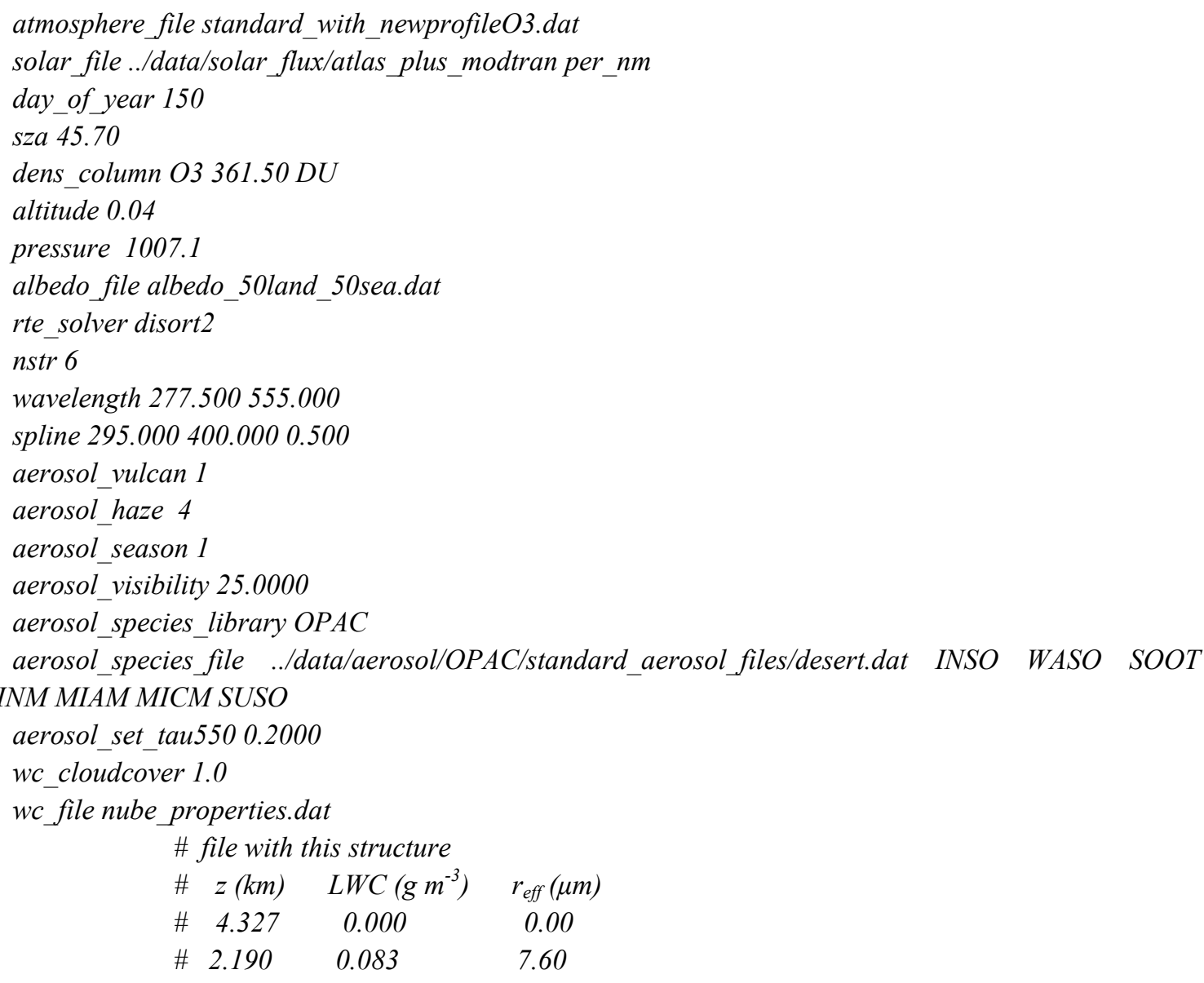
wc_set_tau550 30.1 


\subsection{Case study: Measured vs Modelled CMF}

With all the inputs described in the previous section, simulations for cloudless and overcast conditions are carried out. Modelled CMFs are compared with those obtained by experimental data at 14:00 UT 30 May 2010. CMF is evaluated for both global and diffuse irradiances and for global actinic flux.

The spectral global and diffuse CMFs derived by measurements and model simulations are shown in Figure 6.5. The agreement between measurements and simulations is very good, showing relative differences always below 5\%. As discussed in the previous chapters, at the shorter wavelengths, enhanced ozone absorption leads to an increase in the global CMF. However, this behaviour changes above $320 \mathrm{~nm}$, when CMF decreases with wavelength. The diffuse CMF always increases with wavelength.
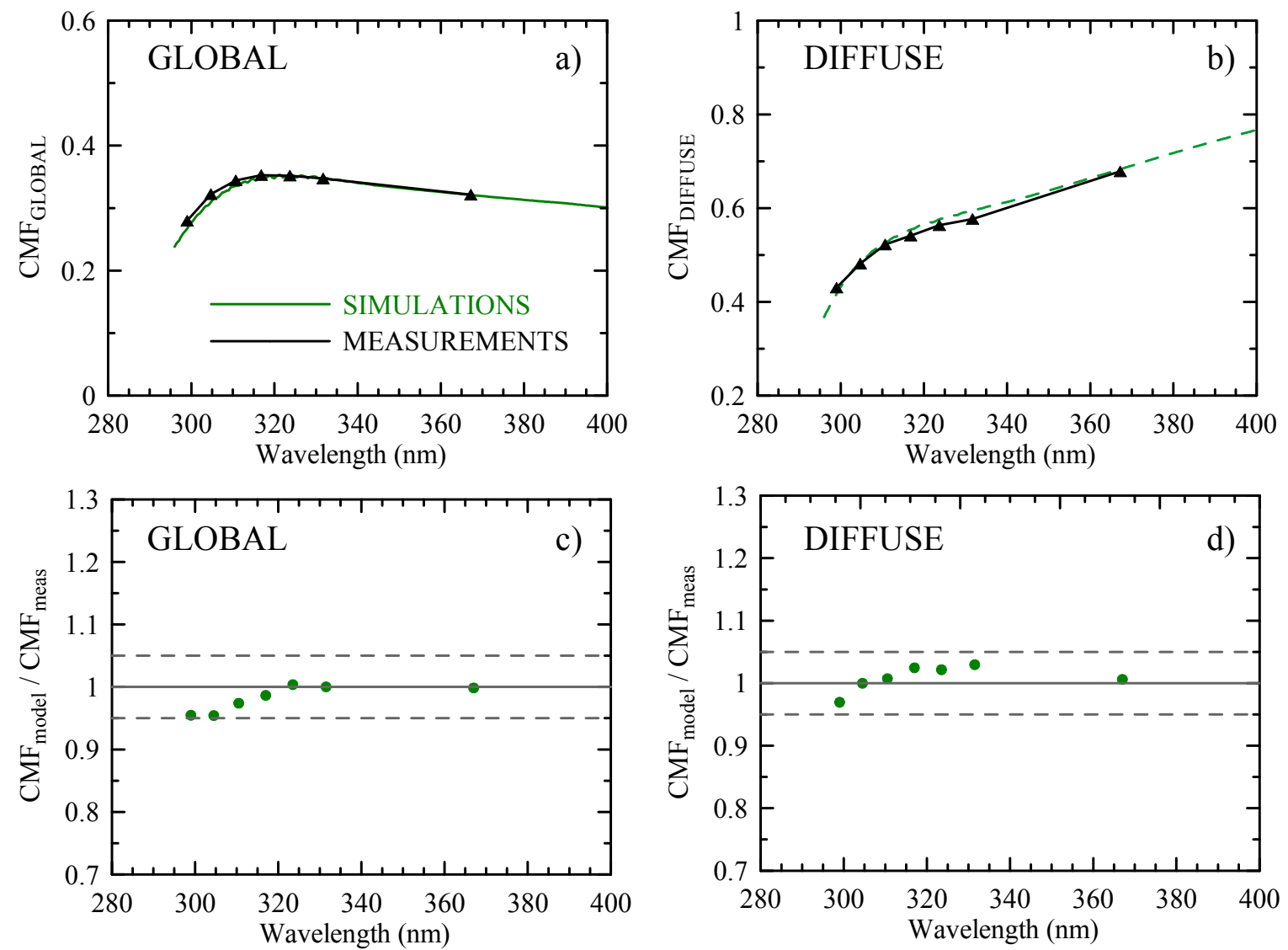

Figure 6.5. a-b) Comparison between modelled (green lines) and measured (black lines) spectral CMF values. $c$-d) Spectral ratios between CMF calculated by the libRadtran model and experimental data; horizontal grey lines indicate a difference of $5 \%$ (dashed) and perfect agreement (solid). Left and right panels correspond to global and diffuse components, respectively. 

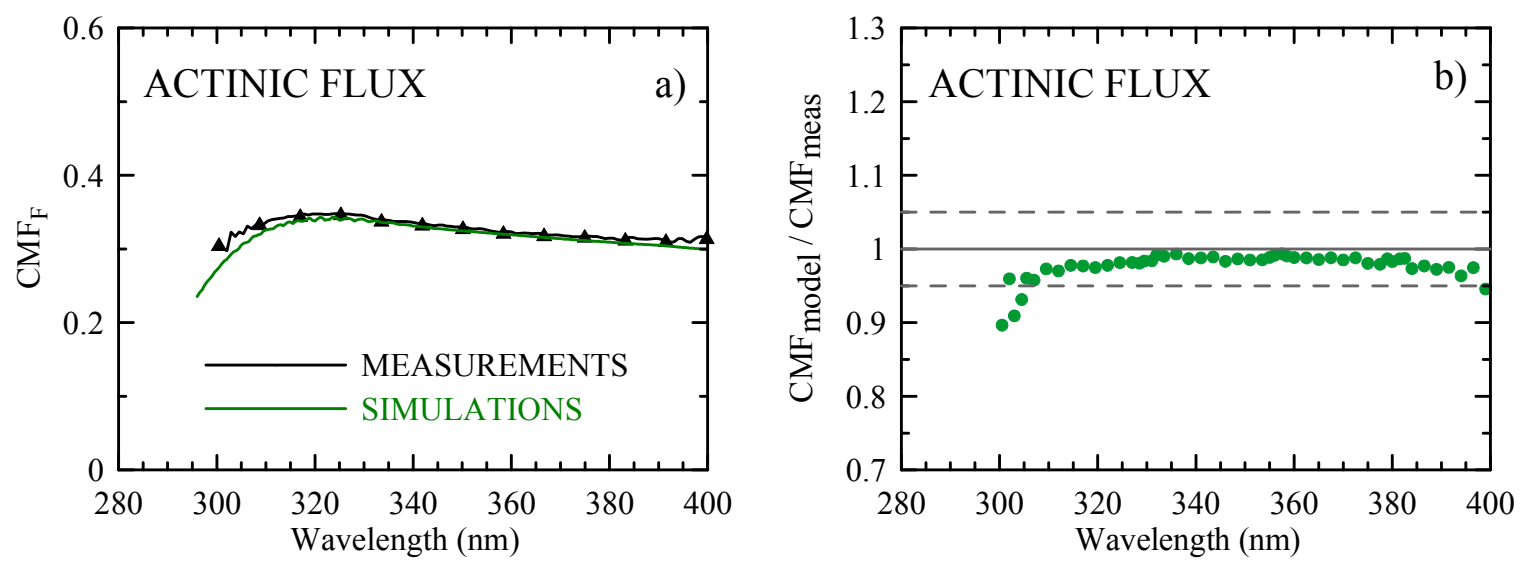

Figure 6.6. a) Comparison between measured (black lines) and modelled (green lines) spectral actinic flux $C M F$ values. b) Spectral ratios between CMF calculated by the libRadtran model and experimental data; horizontal grey lines indicate a difference of 5\% (dashed) and perfect agreement (solid).

The measured and modelled actinic flux CMFs are shown in Figure 6.6. The radiative transfer model reproduces the experimental CMF to within an error of 5\%. The curves of the CMF for the actinic flux are very similar to those of the global irradiance. $\mathrm{CMF}_{\mathrm{F}}$ was shown to be much more SZA-dependent than $\mathrm{CMF}_{\mathrm{I}}$, see, e.g., Figure 4.4. However, the SZA of the case study does not lead to significant differences between $\mathrm{CMF}_{\mathrm{F}}$ and $\mathrm{CMF}_{\mathrm{I}}$. Figure 6.7 shows this fact with experimental and model data. Hence, to simplify the notation and results of this chapter, only the irradiance case will be presented in the following figures.
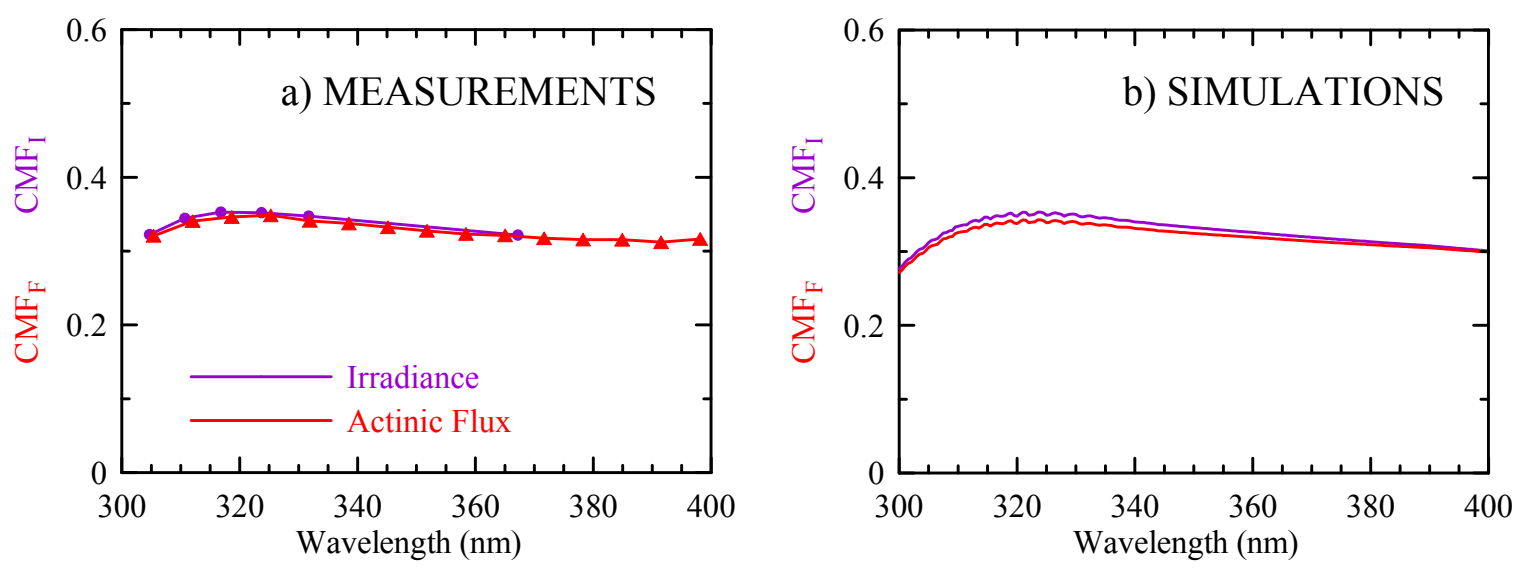

Figure 6.7. Spectral CMF for the irradiance (purple line) and the actinic flux (red line) obtained by experimental (a) and model (b) data. 


\subsection{Impact of the aerosol layer below the cloud on CMF}

Case study: desert dust

One way to study the aerosol effect under overcast conditions is to evaluate the ratio between the irradiance $\mathrm{CMF}$ for the actual atmospheric situation $\left(\mathrm{CMF}_{\mathrm{aer}}\right)$ and the irradiance $\mathrm{CMF}$ evaluated under aerosol-free conditions $\left(\mathrm{CMF}_{\mathrm{NO}}\right.$ aer $)$, i.e. $\mathrm{AOT}=0$ for all wavelengths. As the $\mathrm{CMF}$ alone gives cloud radiative effects, the $\mathrm{CMF}_{\text {aer }} / \mathrm{CMF}_{\mathrm{NOar}}$ ratio provides information about the impact of aerosol on cloud radiative effects. For instance, if the ratio takes a value of 1 , the effect of aerosol could be considered negligible. In addition, to better understand the aerosol effect, the $\mathrm{CMF}_{\mathrm{aer}}$ and $\mathrm{CMF}_{\mathrm{NOaer}}$ are also derived at five different heights in the atmosphere: at the surface, in the middle point between the cloud base and surface, just below the cloud, in the middle of the cloud and over the cloud top. Figure 6.8 presents the approximate location of the five heights and the names used to refer to each.

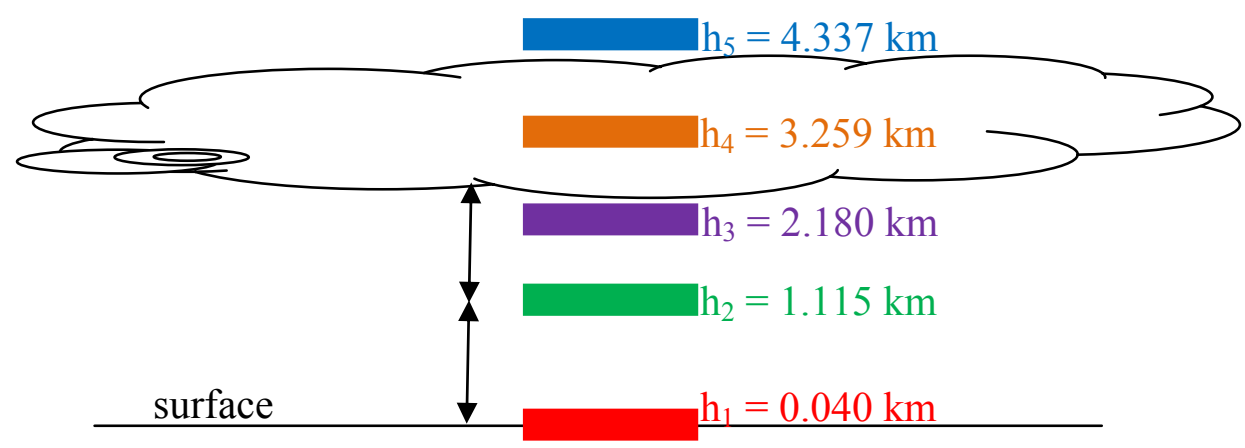

Figure 6.8. Heights at which irradiances are simulated with the libRadtran for the case study.

The obtained results are shown in Figure 6.9. The $\mathrm{CMF}_{\mathrm{aer}} / \mathrm{CMF}_{\mathrm{NOaer}}$ ratio of the global component is 1 at all selected heights, while the diffuse component shows the strongest effects at the two first heights (since the aerosol distribution is mainly in the $0-2$ $\mathrm{km}$ layer). 

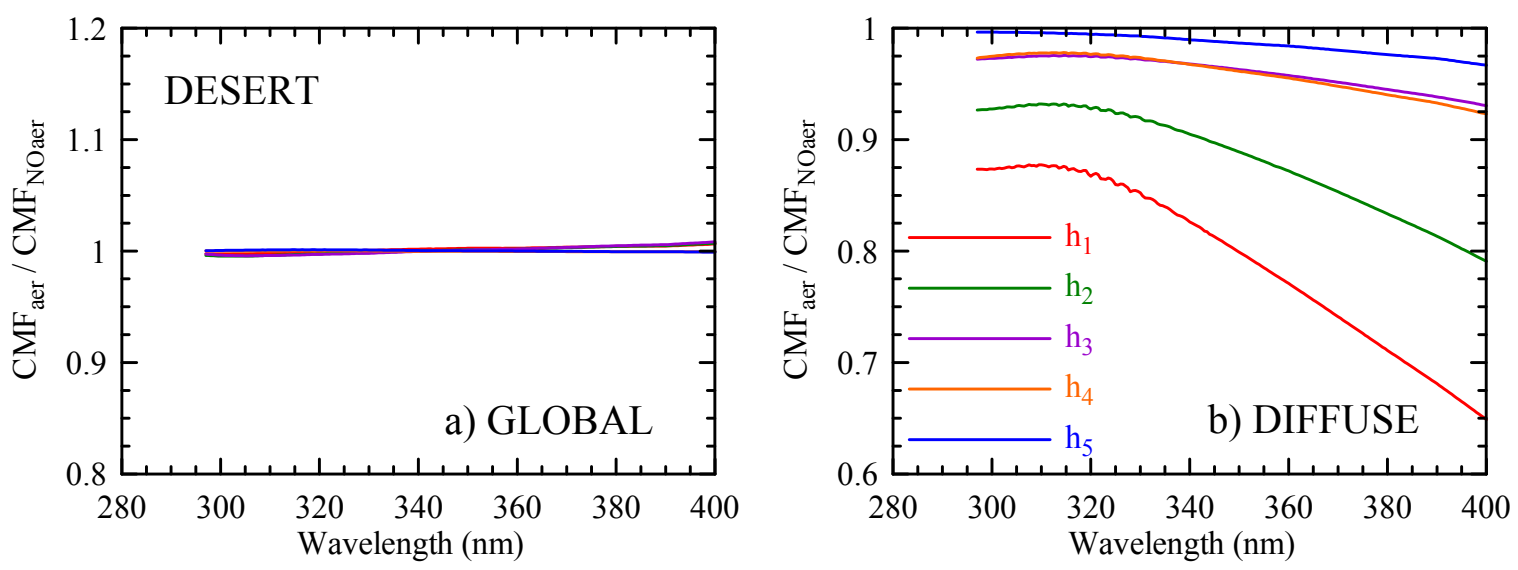

Figure 6.9. Spectral $C M F_{a e r} / C M F_{\text {NOaer }}$ ratio for global (a) and diffuse (b) components at five different heights.

In order to better understand the $\mathrm{CMF}_{\text {aer }} / \mathrm{CMF}_{\text {NOaer }}$ ratio plotted in Figure 6.9 , the various terms in the ratio are re-arranged:

$$
\begin{gathered}
\frac{\mathrm{CMF}_{\text {aer }}}{\mathrm{CMF}_{\text {NOaer }}}=\frac{\left(\frac{\mathrm{I}_{\text {cloudy }}}{\mathrm{I}_{\text {cloudless }}}\right)_{\text {aer }}}{\left(\frac{\mathrm{I}_{\text {cloudy }}}{\mathrm{I}_{\text {cloudless }}}\right)_{\text {NOaer }}}= \\
=\frac{\left(\mathrm{I}_{\text {cloudy }}\right)_{\text {aer }}}{\left(\mathrm{I}_{\text {cloudy }}\right)_{\text {NOaer }}} \frac{\left(\mathrm{I}_{\text {cloudless }}\right)_{\text {NOaer }}}{\left(\mathrm{I}_{\text {cloudless }}\right)_{\text {aer }}}=\text { rat }_{1} \text { rat }_{2}
\end{gathered}
$$

where $I$ is wavelength dependent solar irradiance. Figure 6.10 shows the spectral evolution of the two ratios defined in Equation (6.1). The rat ${ }_{1}$ ratio reflects the effects of aerosol in the cloudy scenario, while rat ${ }_{2}$ does likewise in the cloudless one. As can be seen in the figure, rat $_{1}$ and rat $_{2}$ ratios evaluated for the global component (Figure 6.10.a) display the opposite behaviour. The term under aerosol-free conditions is the dominant in the two ratios. This explains the constant value of 1 for the $\mathrm{CMF}_{\text {aer }} / \mathrm{CMF}_{\mathrm{NOaer}}$ ratio shown in Figure 6.9.a.

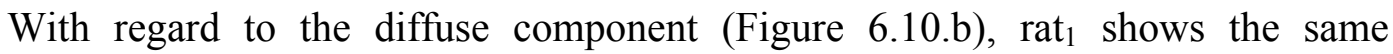
behaviour observed for the global component, because all the global radiation comes from the diffuse component under overcast conditions. Consequently, the behaviour observed in the right panel of Figure 6.9 is determined by rat $_{2}$ (under cloudless conditions). 

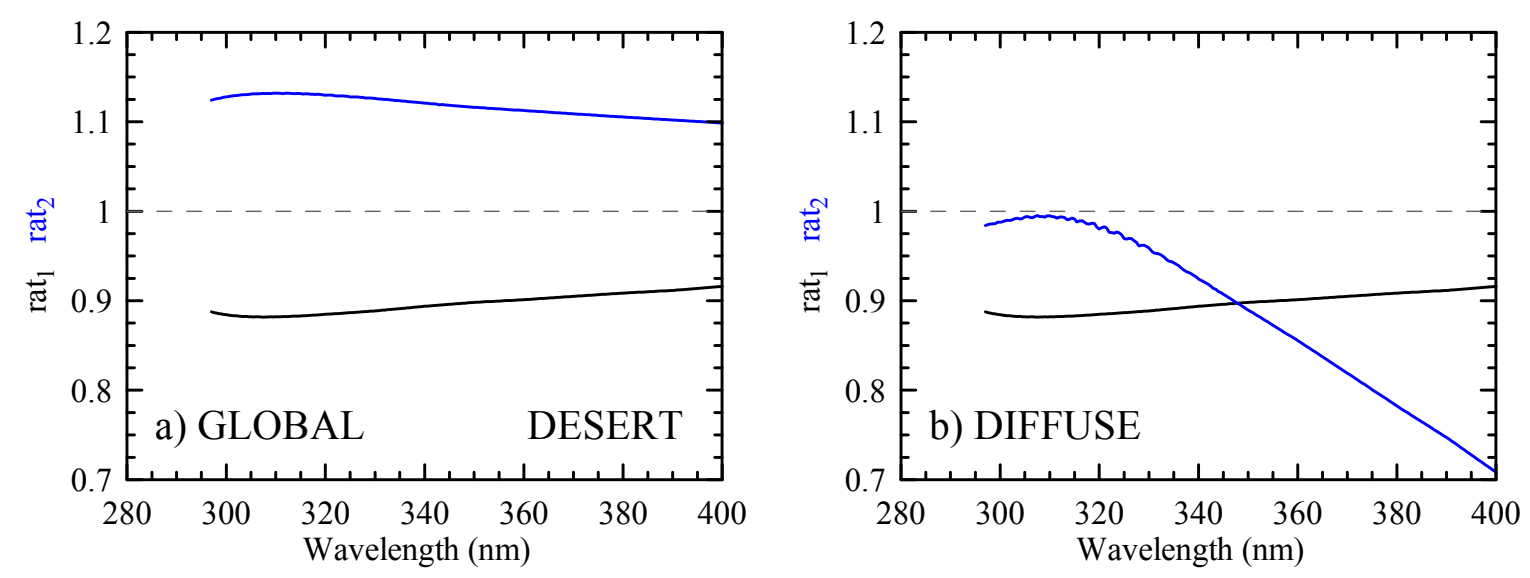

Figure 6.10. Spectral ratios of Equation (6.1) for global (a) and diffuse (b) components at the surface for a desert dust aerosol layer.

The rat $_{2}$ ratio has, by definition, the aerosol contribution in the denominator. Hence, rat ${ }_{2}$ always evidences values below 1, since the presence of aerosol particles

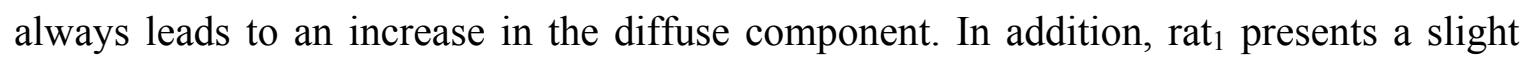
spectral dependence, while rat $_{2}$ is almost 1 at the shorter wavelengths and decreases rapidly beyond $310 \mathrm{~nm}$.

\section{Maritime clean aerosol layer}

In order to understand the role of the aerosol layer below the cloud, model simulations are carried out assuming a maritime clean aerosol type. Figure 6.11 shows the results obtained for this type. Significant differences can be observed with regard to the desert dust case: the $\mathrm{CMF}_{\text {aer }} / \mathrm{CMF}_{\mathrm{NOaer}}$ ratio calculated for the global component is $>1$ for the first three heights and the diffuse $\mathrm{CMF}_{\text {aer }} / \mathrm{CMF}_{\mathrm{NOaer}}$ ratio shows smaller values than for the desert dust case. 

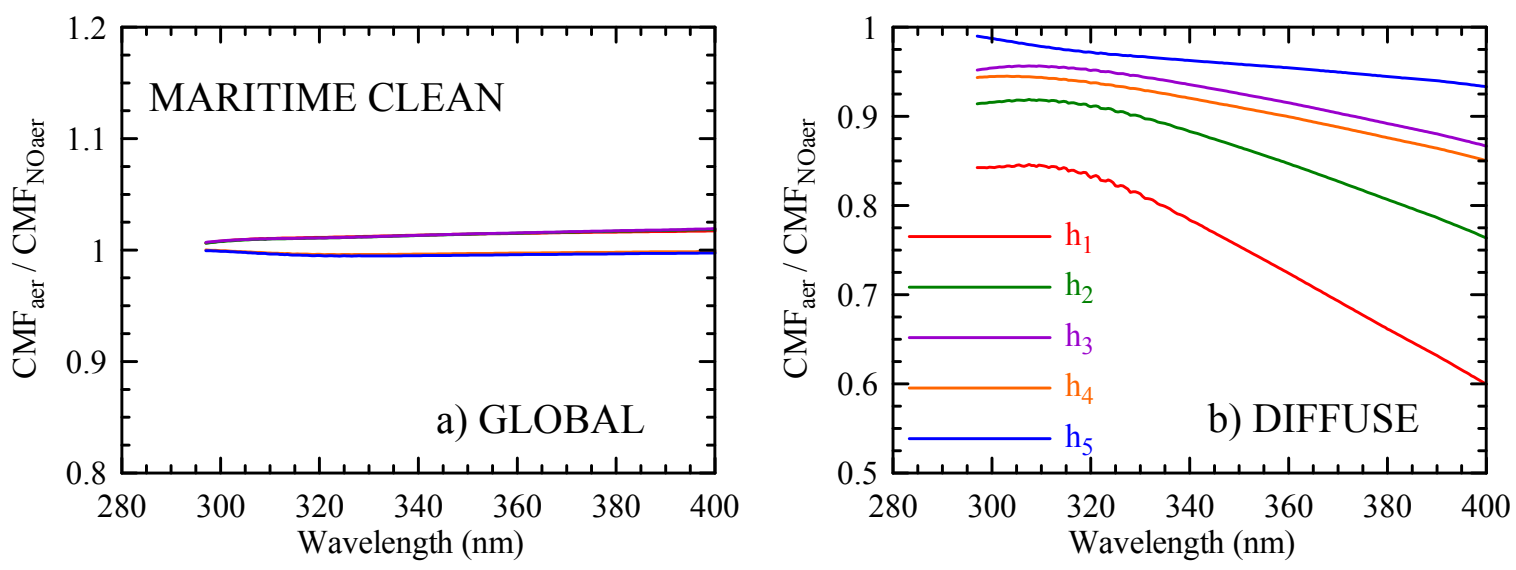

Figure 6.11. Spectral CMF aer $/ C M F_{\text {NOaer }}$ ratio for global (a) and diffuse (b) components at five different heights considering a maritime clean aerosol layer.

In order to compare the results with the desert type, rat $_{1}$ and rat $_{2}$ ratios are also calculated and are shown in Figure 6.12. This figure shows that $\mathrm{rat}_{2}$ is again the term controlling the behaviour of the $\mathrm{CMF}_{\mathrm{aer}} / \mathrm{CMF}_{\mathrm{NOaer}}$ ratio. In this case, the global

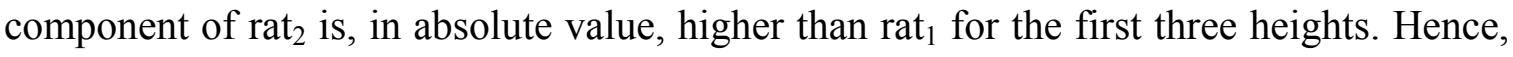
the ratio of the global CMFs shows values $>1$ in Figure 6.11. In the diffuse component, the values of rat $_{2}$ are notably lower than those obtained in the desert dust case.
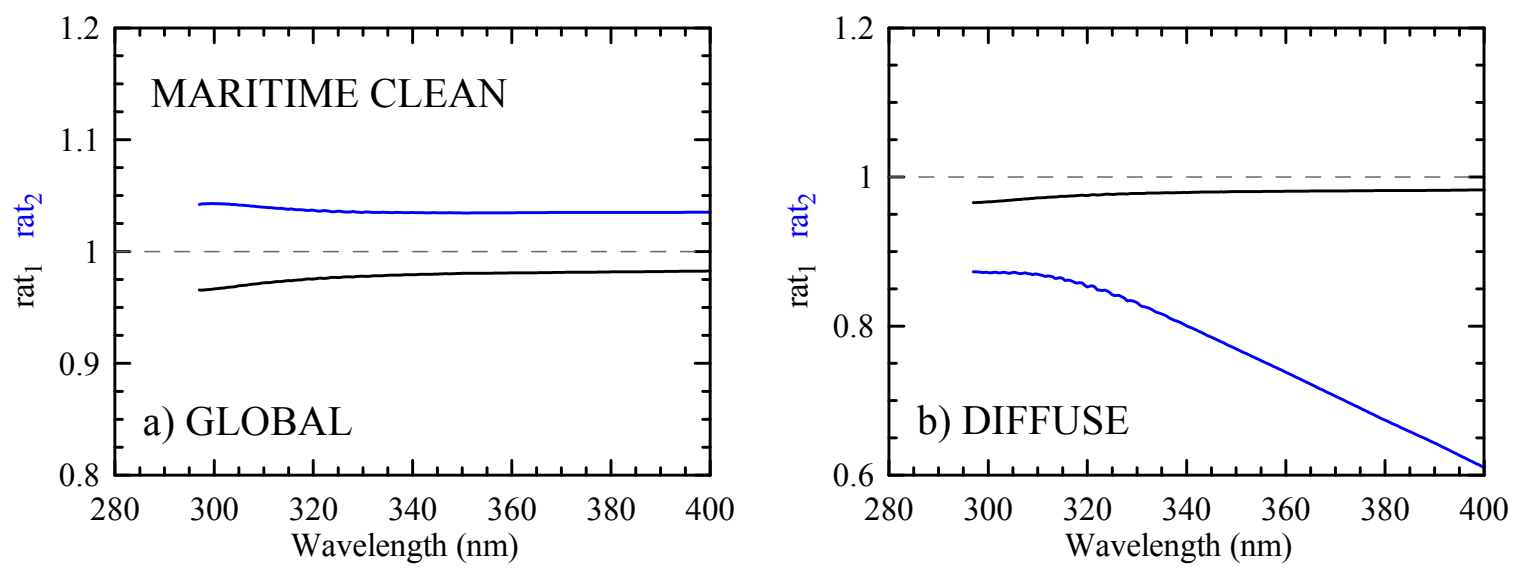

Figure 6.12. Spectral ratios of Equation (6.1) for the global (a) and diffuse (b) components at the surface for a maritime clean aerosol layer. 


\section{Urban aerosol layer}

The same study is performed for an urban aerosol. The results are plotted together in Figure 6.13. For this type, the aerosol effect on the diffuse component is confined to the first two kilometres (this can be understood by the different vertical profiles of aerosol load discussed in the following lines). The global component of the $\mathrm{CMF}_{\mathrm{aer}} / \mathrm{CMF}_{\mathrm{NOaer}}$ ratio is again slightly above 1 . Again, cloudless ratios $\left(\mathrm{rat}_{2}\right)$ are dominant in the behaviours obtained.
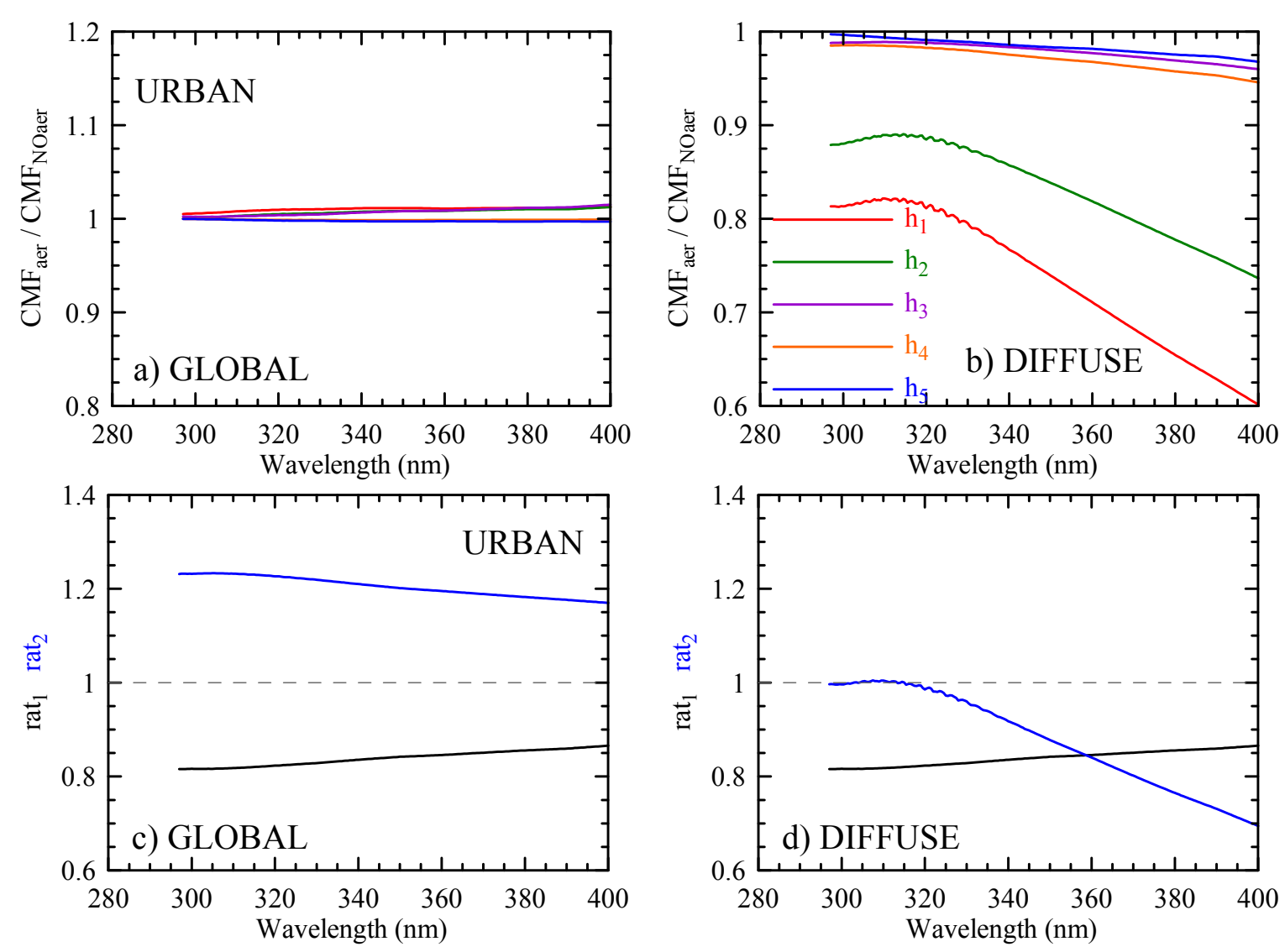

Figure 6.13. a-b) Spectral CMF aer/CMF NOaer ratio for global (a) and diffuse (b) components at five different heights for an urban aerosol layer. c-d) Spectral ratios of Equation (6.1) for global (c) and diffuse (d) components at surface for an urban aerosol layer.

To clarify the differences in the optical properties among the three types of aerosol, Table 6.2 shows the integrated values of the aerosol optical thickness and single scattering albedo (at two wavelengths), as well as the Ångström exponent. Figure 6.14 presents their profiles obtained by libRadtran outputs using the OPAC software package configuration. The values of these variables help to understand the behaviours obtained. 
For instance, the urban case, which presents the highest AOT at $305 \mathrm{~nm}$, takes the smallest values of the diffuse $\mathrm{CMF}_{\mathrm{aer}} / \mathrm{CMF}_{\text {Noaer }}$ at the surface at these wavelengths. At $400 \mathrm{~nm}$, the values under the maritime clean and urban aerosol particles are similar, and the value under desert dust type is higher than the previous ones. This could be explained by the combination of AOT and $\omega_{0}$ at this wavelength: the desert type has approximately the same AOT as the maritime case with a lower $\omega_{0}$, and a smaller AOT than the urban type with similar $\omega_{0}$. The values of the diffuse rat $_{2}$ ratio for absorbing particles are close to 1 up to $320 \mathrm{~nm}$, while the maritime clean type leads to a strong reduction. Hence, the effects of aerosol particles under cloudy conditions on diffuse cloud transmittance are stronger for purely scattering particles.

The observed differences beyond the $2 \mathrm{~km}$ level are due to the different aerosol load which depends on the AOT in the 0-2 km layer. The libRadtran model scales the default value to the one introduced by the user. Hence, as the maritime clean presents the smallest values of the AOT in the first two kilometres, there is a higher aerosol load in the upper layer and the effects are stronger than in the other two types.

Table 6.2. Integrated values of aerosol optical properties considering three different aerosol types in the 0$2 \mathrm{~km}$ and free tropospheric type in the 2-12 km height range.

\begin{tabular}{cccccc}
\hline Aerosol type 0-2 km & $\left(\boldsymbol{\omega}_{\mathbf{0}}\right)_{\mathbf{5 5 0} \mathbf{n m}}$ & $\left.\mathbf{( \omega}_{\mathbf{0}}\right)_{\mathbf{3 0 5} \mathbf{n m}}$ & $\mathbf{A O T}_{\mathbf{5 5 0} \mathbf{n m}}$ & $\mathbf{A O T}_{\mathbf{3 0 5} \mathbf{n m}}$ & $\boldsymbol{\alpha}_{\mathbf{3 0 5}-550 \mathbf{n m}}$ \\
\hline Desert & 0.90 & 0.72 & 0.20 & 0.23 & 0.22 \\
Maritime clean & 0.99 & 0.99 & 0.20 & 0.24 & 0.27 \\
Urban & 0.76 & 0.77 & 0.20 & 0.40 & 1.17 \\
\hline
\end{tabular}



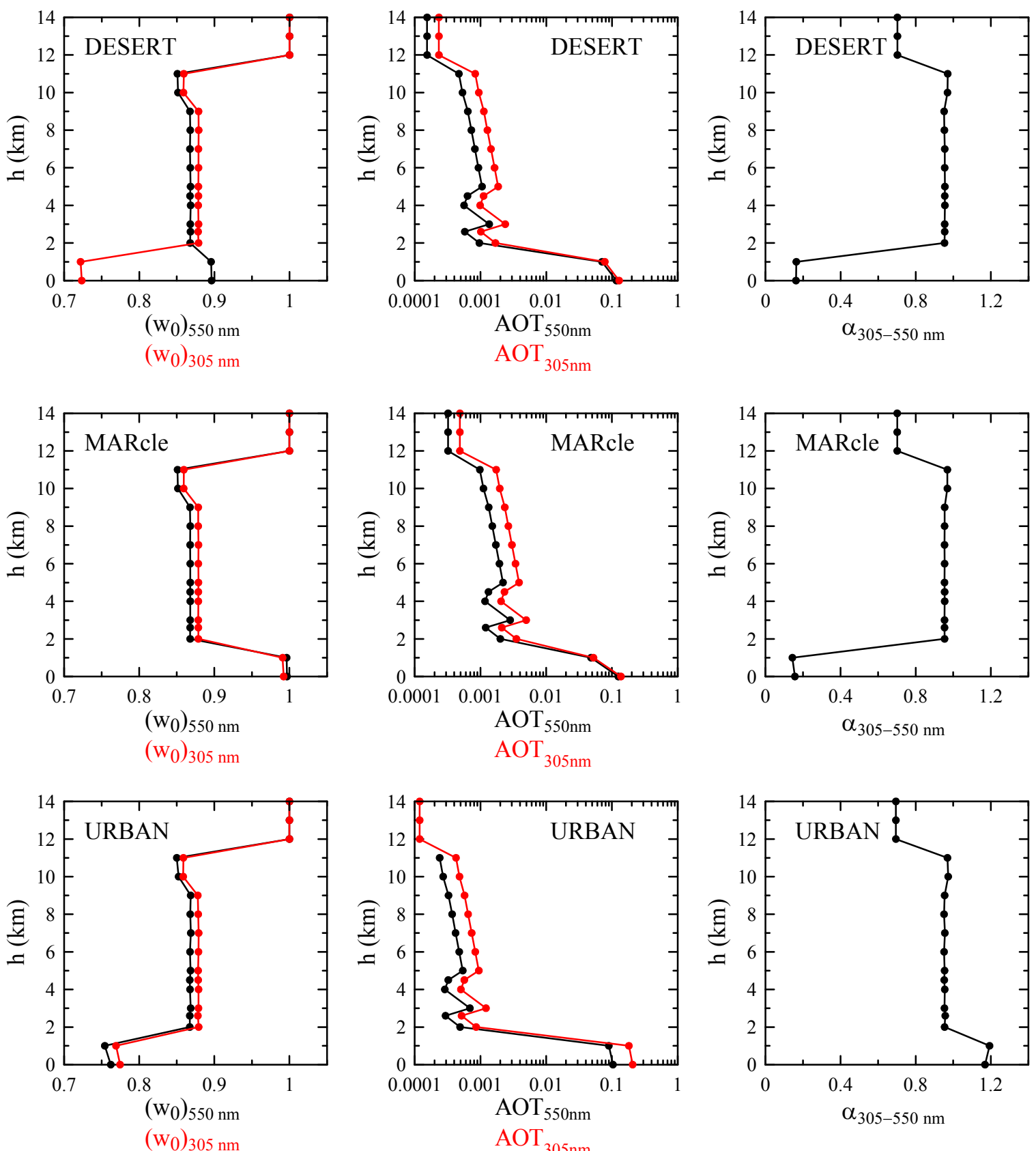

Figure 6.14. Profiles of single scattering albedo, aerosol optical thickness and $\alpha$ Ängström exponent for two wavelengths, 550 (black lines) and 305 (red lines) for three different types of aerosol: desert dust (DESERT, upper panels), maritime clean (MARcle, middle panels), and urban (URBAN, lower panels). 


\subsection{CMF sensitivity on aerosol optical properties}

A sensitivity analysis on aerosol optical properties is performed in order to highlight the importance of also understanding the aerosol load in the atmosphere in cloudy conditions.

For this purpose, all the aerosol parameters are fixed (wavelength independent) to avoid the spectral dependences shown in the previous section. In addition, the cloud properties are also fixed.

The configuration of the simulations for this study is as follows (the ' $*$ ' indicates the variables to be modified in each sensitivity analysis):

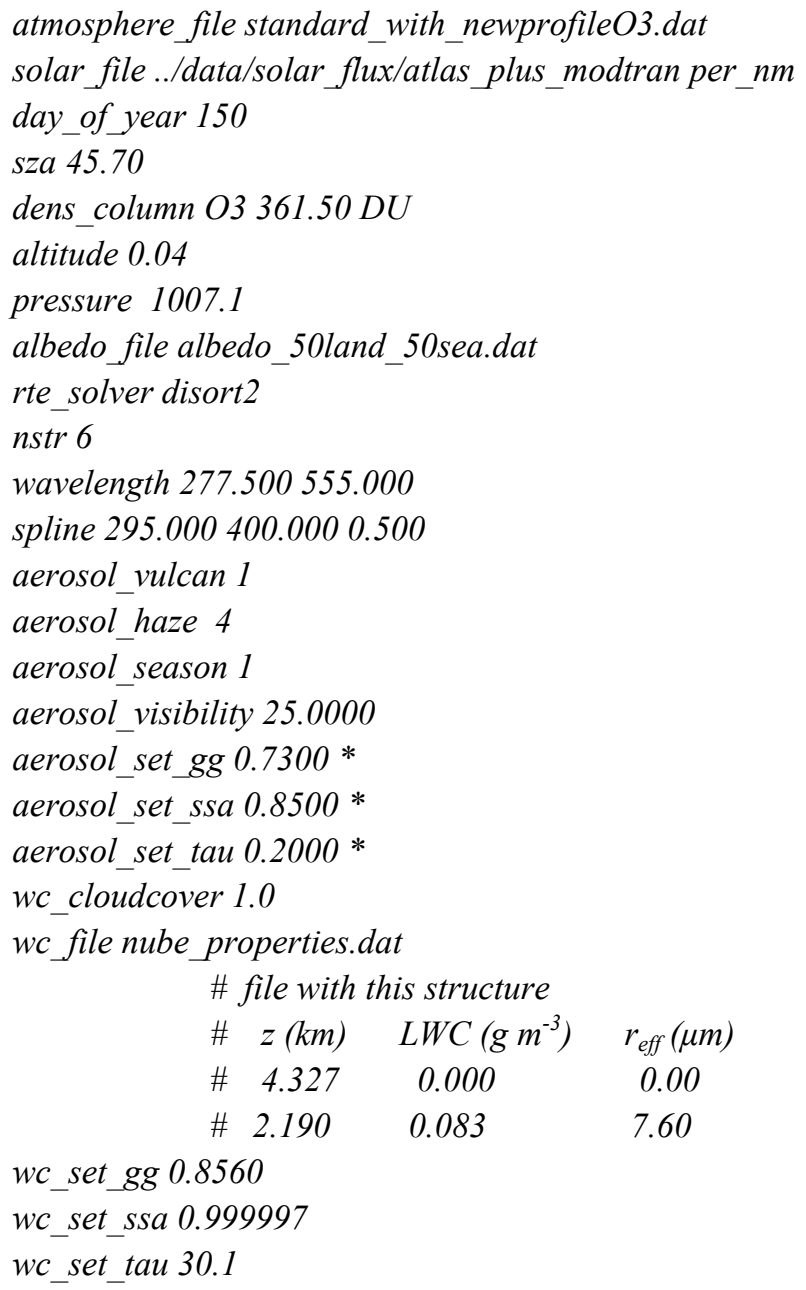

wc_set_gg 0.8560

wc_set_ssa 0.999997

wc_set_tau 30.1 


\section{Aerosol optical thickness}

To understand the role of columnar aerosol, simulations without aerosol and with an $\mathrm{AOT}_{550 \mathrm{~nm}}$ of 0.40 are compared. Figure 6.15 shows the results. In this case, the global CMF shows only a slight variation (maximum $\sim 6 \%$ in the range between 305 and 400 $\mathrm{nm}$ ) with smaller values for $\mathrm{AOT}_{550 \mathrm{~nm}}=0.40$, because of stronger attenuation under high turbidity conditions. Moreover, the diffuse component is more sensitive to the aerosol load, the $\mathrm{CMF}_{\text {DIFFUSE }}$ being almost half the value in the aerosol-free atmosphere for the longer wavelengths. In the aerosol-free case, $\mathrm{CMF}_{\text {DIFFUSE }}>1$ occurs for $\lambda>379 \mathrm{~nm}$. In addition, the shorter wavelengths, e.g. $305 \mathrm{~nm}$ and $320 \mathrm{~nm}$, exhibit less attenuation with

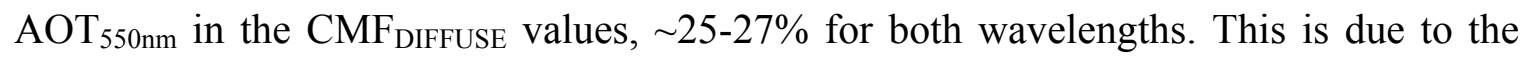
strong wavelength-effect of Rayleigh scattering caused by atmospheric particles.

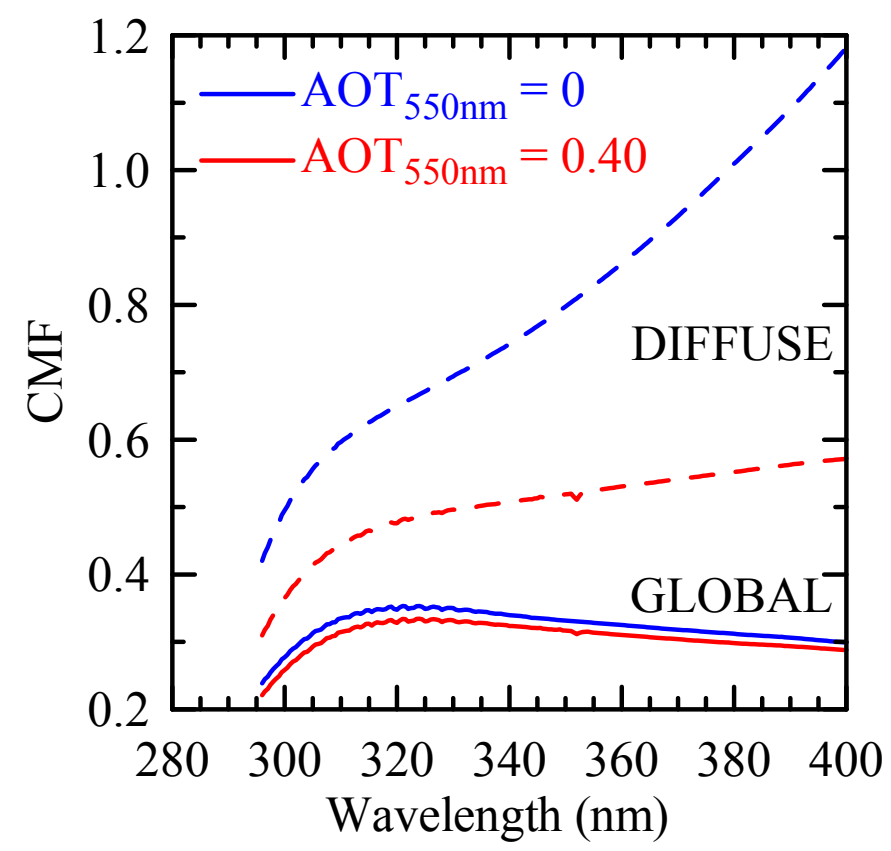

Figure 6.15. Sensitivity analysis of the CMF for global (solid lines) and diffuse (dashed lines) components for two aerosol optical thickness values.

\section{Aerosol asymmetry factor}

The aerosol asymmetry factor ( $\mathrm{g}$ ) is varied from 0.65 to 0.95 (when almost all radiation is scattered in the forward direction). Figure 6.16 shows the results. In this case, the $\mathrm{CMF}$ for the global component does not change (a slight change of $\sim 2 \%$ is observed), while the diffuse one decreases for the increasing aerosol $\mathrm{g}$. The effect is most noticeable 
at longer wavelengths with the maximum reductions $(\sim 6 \%)$ in the $\mathrm{CMF}_{\text {DIFFUSE }}$ values at $400 \mathrm{~nm}$. Shorter wavelengths, e.g. 305 and $320 \mathrm{~nm}$, show a reduction close to $3 \%$.

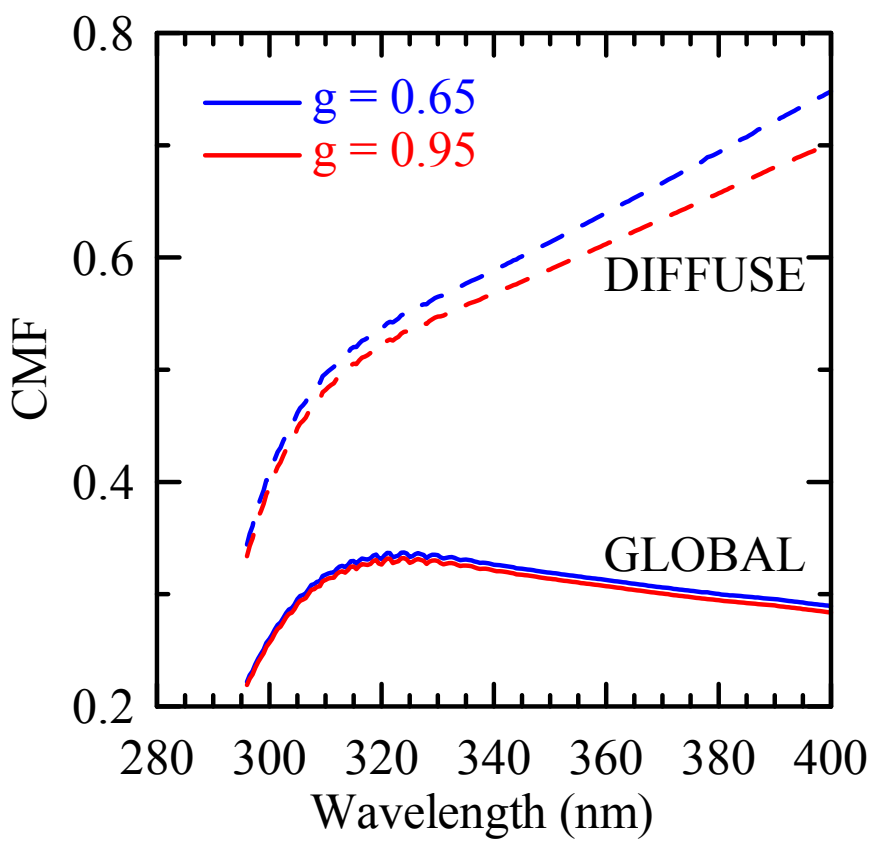

Figure 6.16. Sensitivity analysis of the CMF for global (solid lines) and diffuse (dashed lines) components for two aerosol asymmetry factor values.

To understand the effect of the aerosol asymmetry factor on CMF values, the impact that this parameter has on global and diffuse irradiance components is discussed. To this aim, the ratios between the simulated irradiances (both global and diffuse) for $\mathrm{g}=$ 0.65 and $g=0.95$ are calculated. Figure 6.17 shows the results obtained under cloudless and overcast conditions. As the g value increases the diffuse irradiance, both global and diffuse irradiances are higher in the case of $g=0.95$. However, the relative increase between $\mathrm{g}=0.65$ and $\mathrm{g}=0.95$ in the cloudless diffuse irradiance is higher than in the overcast case. The cloud above the aerosol layer redirects upward radiation to the surface and, therefore, the different effect caused by aerosol $\mathrm{g}$ is minimized. Thus, a higher cloudless diffuse irradiance with $\mathrm{g}=0.95$ leads to $\mathrm{CMF}_{\text {DIFFUSE }}$ with $\mathrm{g}=0.95$ being smaller than the $\mathrm{CMF}_{\text {DIFFUSE }}$ with $\mathrm{g}=0.65$. As can be deduced from the figure, this effect is weaker for the $\mathrm{CMF}_{\mathrm{GLOBAL}}$. 

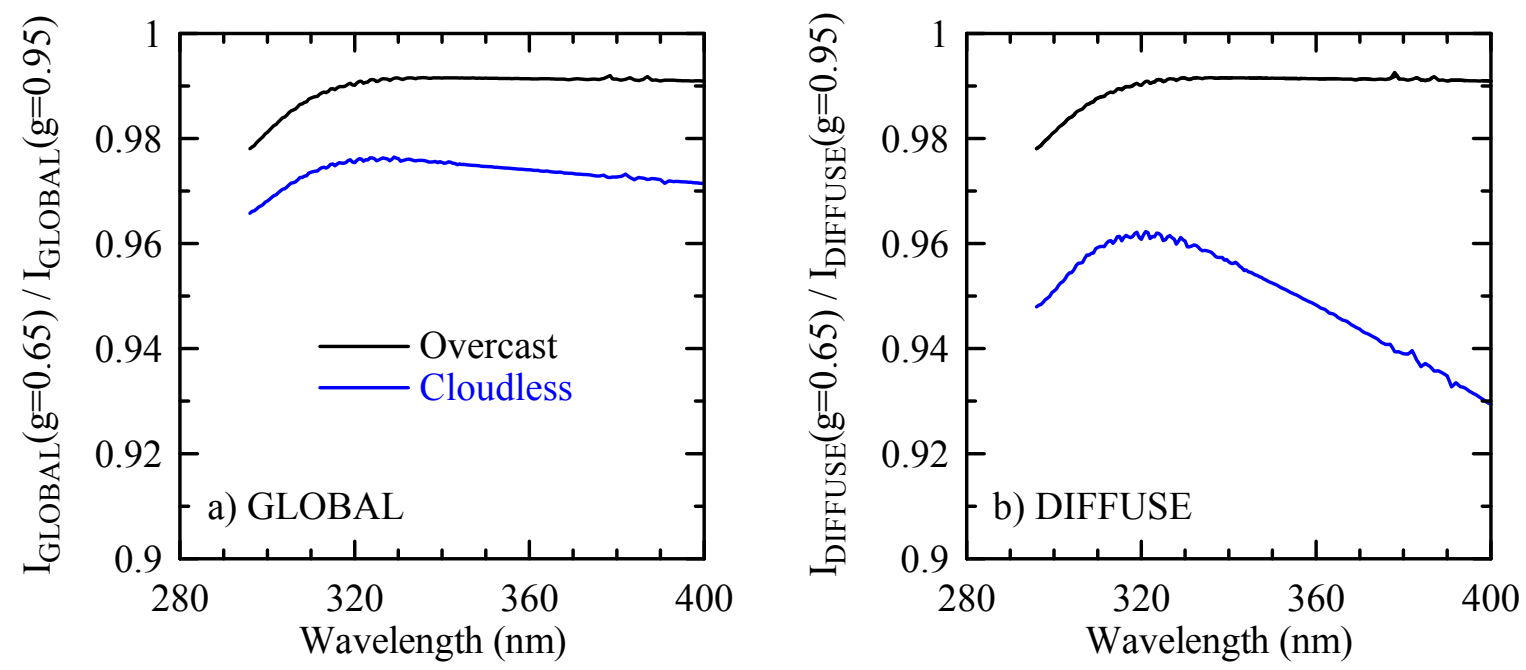

Figure 6.17. Ratios between the simulated irradiances, global (a) and diffuse (b), for $g=0.65$ and $g=$ 0.95 in cloudless (blue lines) and overcast (black lines) conditions.

Aerosol single scattering albedo

The sensitivity analysis on aerosol single scattering albedo is shown in Figure 6.18. In this case, CMFs for both components (global and diffuse) vary when aerosol $\omega_{0}$ rises from 0.60 to 0.99 . The change in aerosol $\omega_{0}$ causes a slight wavelength dependence of the $\mathrm{CMF}_{\mathrm{GLOBAL}}$ with relative differences between the two cases of aerosol $\omega_{0}$ ranging between $\sim 4-5 \%$ at shorter wavelengths $(<305 \mathrm{~nm})$ and $\sim 5.5-6 \%$ for $\lambda>312 \mathrm{~nm}$.

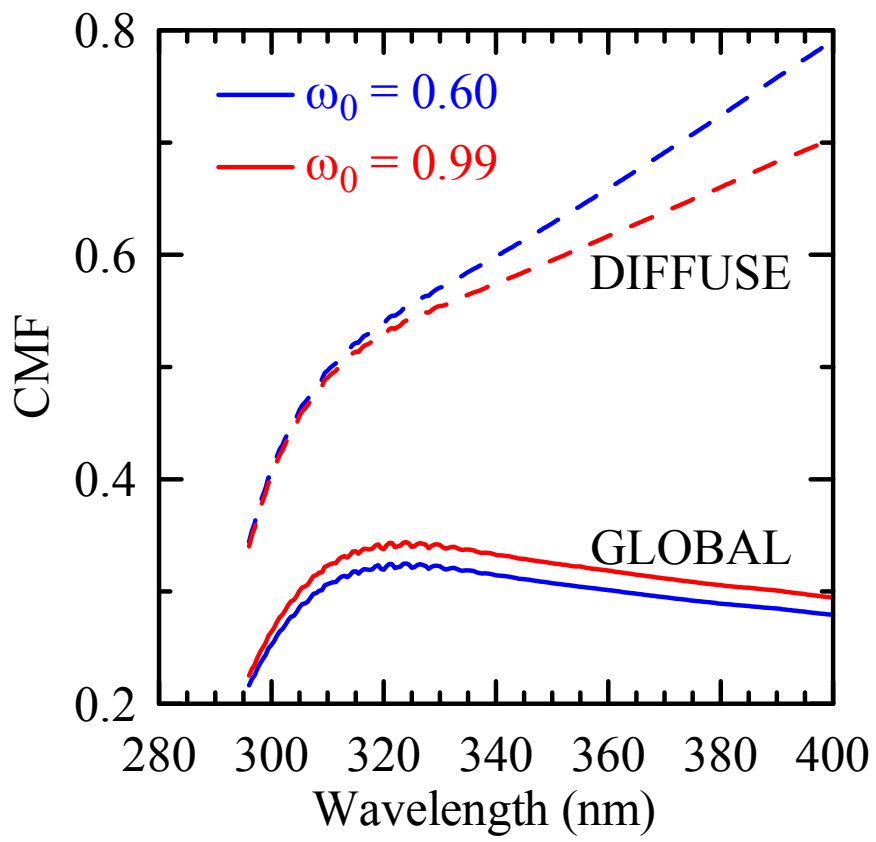

Figure 6.18. Sensitivity analysis of the CMF for global (solid lines) and diffuse (dashed lines) components for two aerosol single scattering albedo values. 
However, $\mathrm{CMF}_{\text {DIFFUSE }}$ at $305 \mathrm{~nm}$ suffers a weak reduction by $\sim 1 \%$ while at 400 $\mathrm{nm}$ this increases up to $\sim 11 \%$. It should be noted that the increase in the single scattering albedo values has a different effect on the global and diffuse components: the latter undergoing a stronger attenuation with purely absorbing aerosol particles, while the global component is less attenuated under these conditions.

In order to explain the aerosol single scattering albedo effect on the $\mathrm{CMF}$, the ratios between the simulated irradiances (both global and diffuse) for $\omega_{0}=0.6$ and $\omega_{0}=$ 0.99 are calculated in cloudless and overcast conditions. Figure 6.19 shows the results obtained. In this case, the impact of aerosol $\omega_{0}$ on the diffuse irradiance is notably higher than that observed for the asymmetry factor. Under cloudless conditions (blue lines of the figure), the diffuse ratio shows values between 0.75 and 0.85 , while the global ratio takes values from 0.88 to 0.91 . This notable increase is due to the direct contribution, which is still relevant at $\mathrm{SZA}=45.7$. Under overcast conditions (black lines of the figure), the cloud effect of the diffuse ratio reduces the difference between the two $\omega_{0}$ scenarios. Since all the variables are fixed with wavelength, aerosol attenuation in the $\omega_{0}=0.6$ case is stronger at longer wavelengths. However, diffuse cloud transmittance increases with wavelength as shown in this thesis (e.g., Figure 6.5.b). Therefore, combining these two effects produces an almost constant diffuse ratio for $\lambda>320 \mathrm{~nm}$ under overcast conditions.
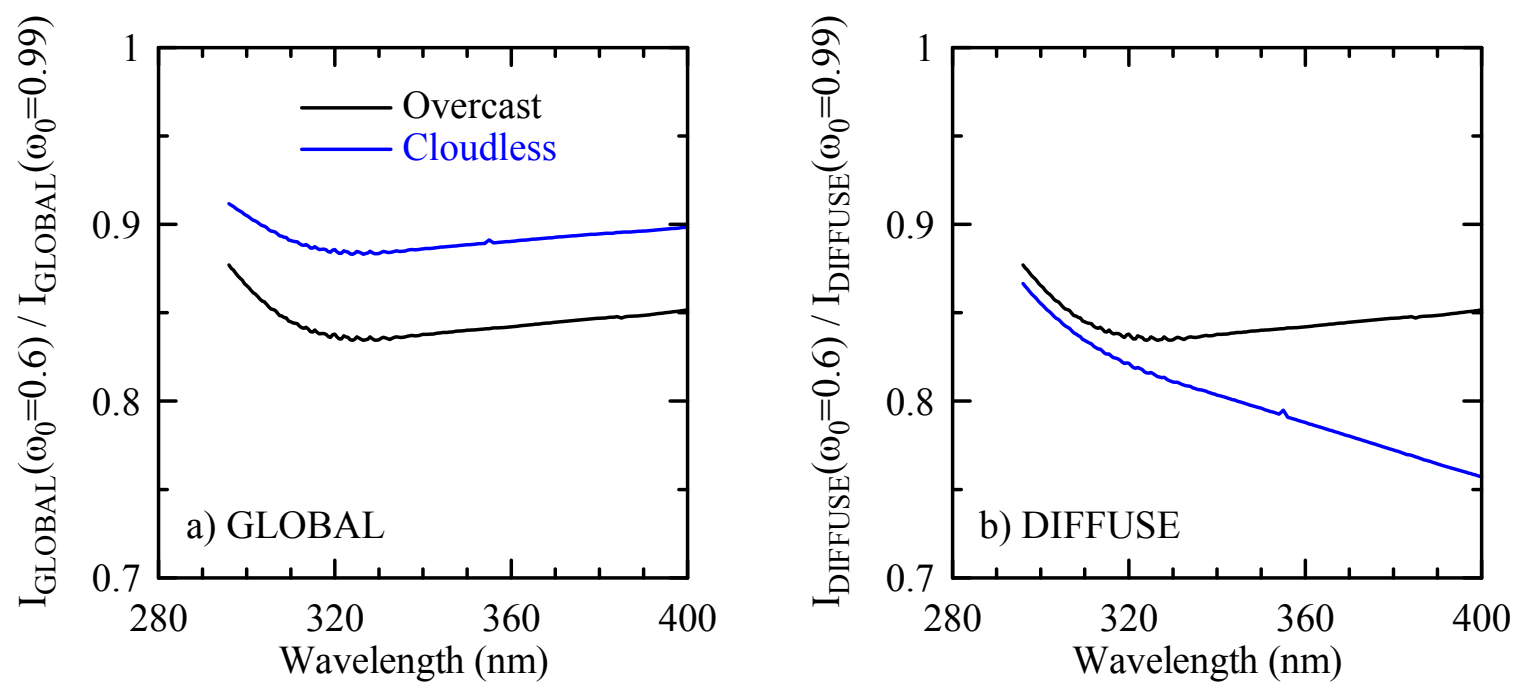

Figure 6.19. Ratios between the simulated irradiances, global (a) and diffuse (b), for $\omega_{0}=0.6$ and $\omega_{0}=$ 0.99 in cloudless (blue lines) and overcast (black lines) conditions. 
For shorter wavelengths $(\lambda<320 \mathrm{~nm})$, strong aerosol absorption in the $\omega_{0}=0.6$ case is the dominant effect under cloudless and overcast conditions. As a conclusion, the different behaviour observed for $\mathrm{CMF}_{\mathrm{DIFFUSE}}$ and $\mathrm{CMF}_{\mathrm{GLOBAL}}$ is explained by the strong impact on diffuse irradiance caused by the $\omega_{0}$ of the aerosol particles.

From the results observed in this section, describing the aerosol load is seen to be decisive when the spectral effects of global and, particularly, diffuse components are analyzed under cloudy conditions.

\subsection{CMF sensitivity on cloud properties}

Because this thesis is mainly based on describing overcast conditions, a sensitivity analysis is also performed by varying several cloud properties. The input in the radiative transfer model is similar to what was explained in the previous section. The configuration is as follows (the '*' indicates the variables to be modified in each sensitivity analysis):

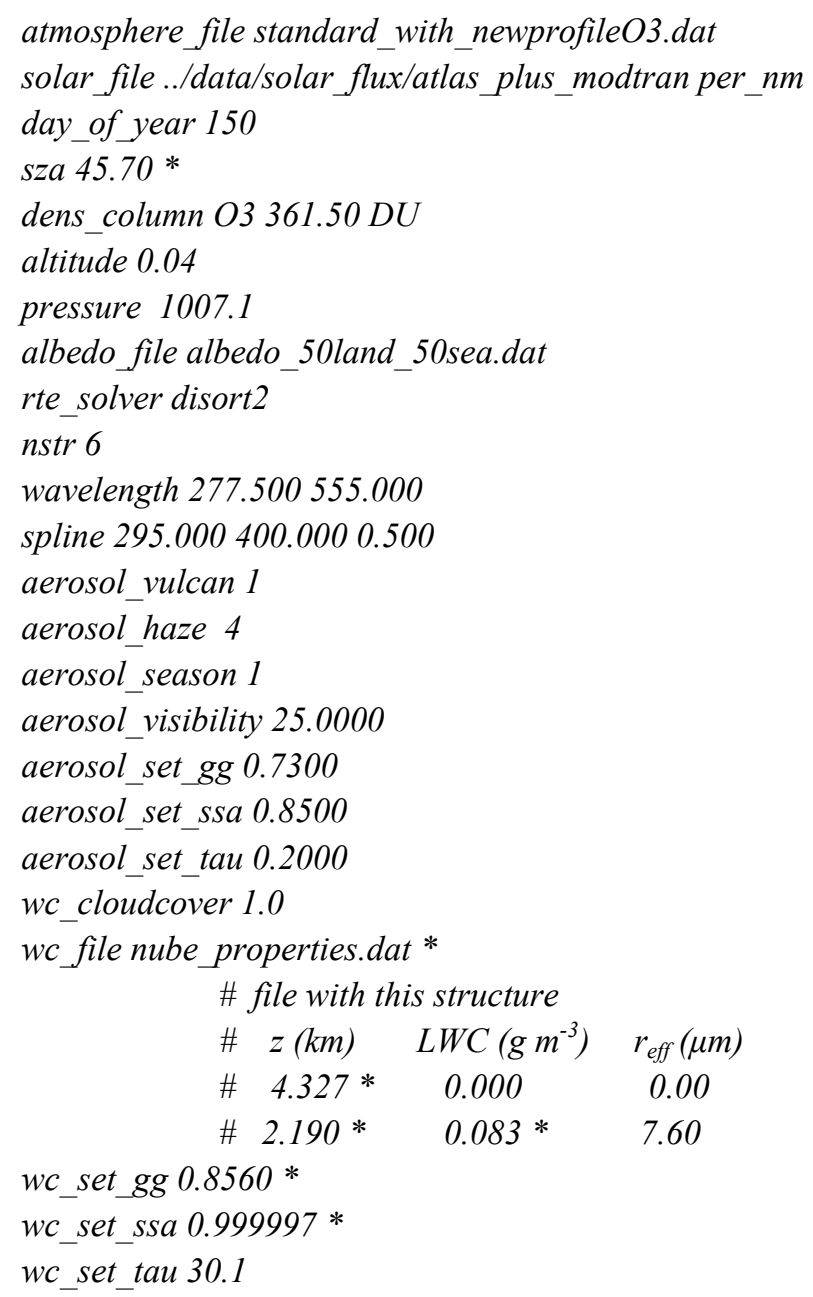




\section{Cloud asymmetry factor}

Calculations are made for 0.75 and 0.90 cloud asymmetry factor values, with all other properties fixed. These values are chosen to consider all the typical $g$ values of clouds, between 0.76 and 0.87 , typical for cirrus and cumulus, respectively (Hess et al., 1998). The CMFs obtained for these asymmetry factor values are shown in Figure 6.20. From the figure, it can be deduced that stronger scattering in the forward direction causes higher CMF values, and that when forward scattering is lower, the cloud attenuation of the solar irradiance increases substantially (with smaller CMF values). In this case, both $\mathrm{CMF}_{\mathrm{GLOBAL}}$ and $\mathrm{CMF}_{\mathrm{DIFFUSE}}$ undergo an increase $\sim 110 \%$ at $305 \mathrm{~nm}$, while this increase is smaller at longer wavelengths ( $\sim 95 \%$ at $400 \mathrm{~nm})$.

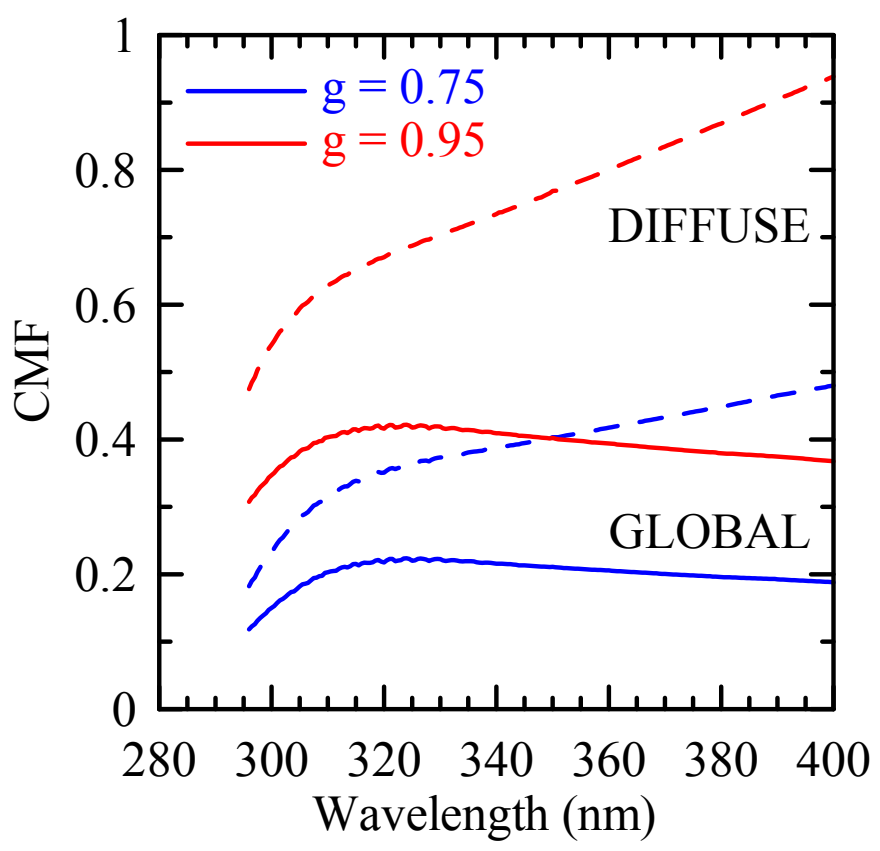

Figure 6.20. Sensitivity analysis of the CMF for global (solid lines) and diffuse (dashed lines) components for two cloud asymmetry factor values.

\section{Cloud single scattering albedo}

The role of cloud particle absorption is studied in this section, varying the cloud single scattering albedo. The default value in the model is usually equal to 1 . For the sensitivity analysis, cloud $\omega_{0}$ is varied between 0.99 and 1.0. The results are shown in Figure 6.21. The slight change in this parameter leads to a strong reduction in CMF values, i.e. an increase in the attenuation of the radiation reaching the surface. As a 
numerical result, a $1 \%$ decrease in cloud $\omega_{0}$ leads to a near $\sim 200 \%$ decrease in $\mathrm{CMF}$ values. In fact, $\mathrm{CMF}_{\mathrm{GLOBAL}}$ and $\mathrm{CMF}_{\mathrm{DIFFUSE}}$ decrease by up to $165 \%, 183 \%$ and $169 \%$ at 305,320 and $400 \mathrm{~nm}$, respectively.

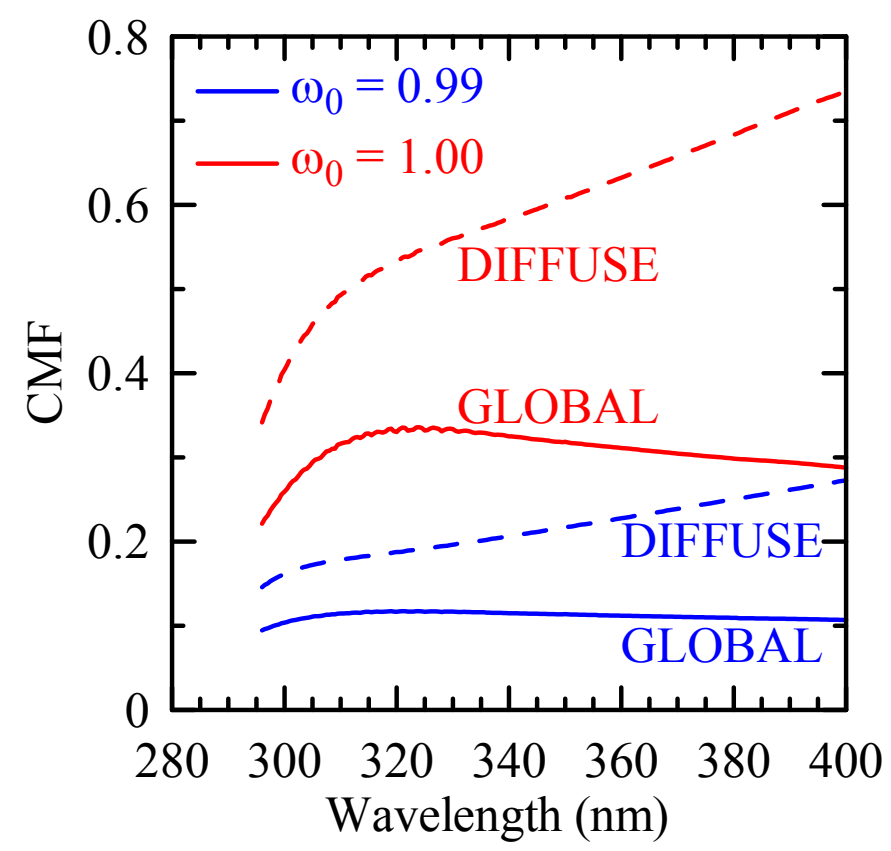

Figure 6.21. Sensitivity analysis of the CMF for global (solid lines) and diffuse (dashed lines) components for two cloud single scattering albedo values.

\section{Cloud geometric thickness}

In this section, the influence of cloud geometric thickness is investigated. The cloud in the case study in this chapter is divided into two cloud layers of smaller geometric thickness. Figure 6.22 presents the two configurations and the seven heights analyzed in this section. Total cloud optical thickness is the same for both cases, while the geometric thickness of the cloud differs by over $1 \mathrm{~km}$. The effective radius of the cloud droplets is assumed equal to that used in the single layer case $\left(\mathrm{r}_{\mathrm{eff}}=7.6 \mu \mathrm{m}\right)$, and the LWP is set to obtain COT $=15.05$ in each of the two layers, using the formula COT $=3$ LWP / $\left(2 \rho_{\mathrm{w}} \mathrm{r}_{\mathrm{eff}}\right)$ (Equation 1.39). 


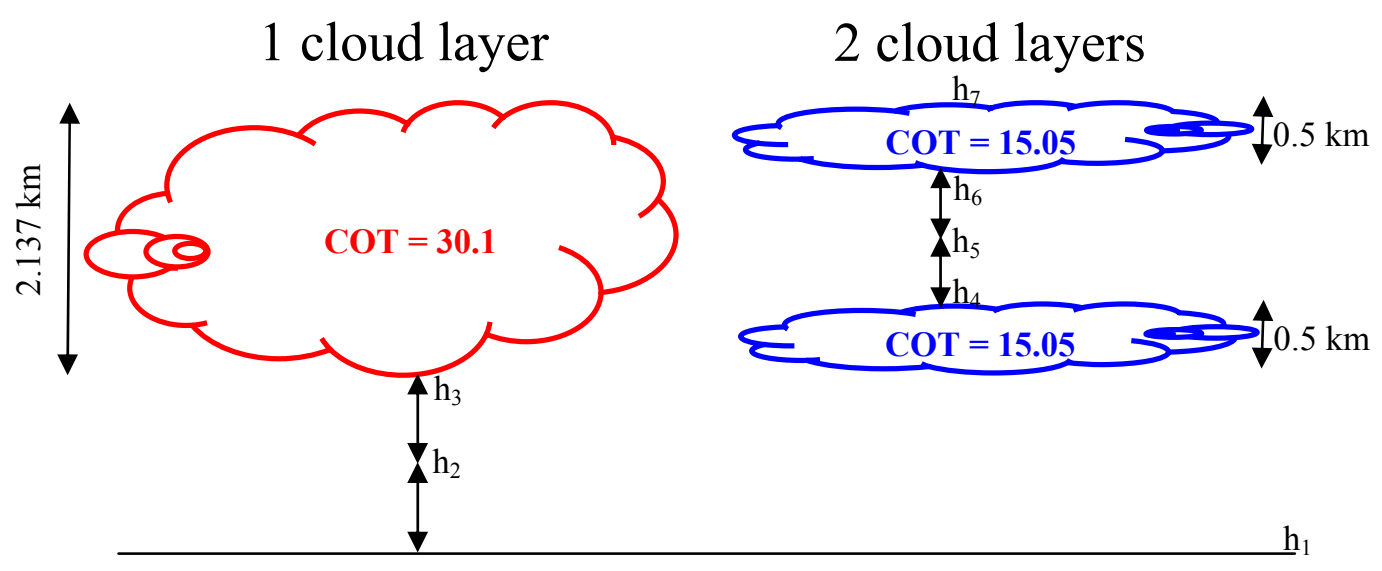

Figure 6.22. Diagram for the two situations analyzed with regard to cloud geometric thickness.

The CMFs for both scenarios are calculated for the seven heights indicated in Figure 6.22. Figure 6.23 shows the results for all of them. Comparing the results for $\mathrm{h}_{1}$ and $h_{7}$, no differences can be observed between both scenarios. Only two heights, $h_{4}$ and $\mathrm{h}_{6}$ show significant differences. At these heights, the CMF values differ, and are higher at $\mathrm{h}_{6}$ for two-layer clouds, and at $\mathrm{h}_{4}$ for one-layer clouds. Hence, COT is the main parameter in cloud characterization, because different geometric thicknesses with the same COT produce identical results above and below the cloud. Wang et al. (2011) investigated the effects of cloud properties and atmospheric factors on shortwave irradiance. They found the COT to be the most important factor determining SW irradiance at the surface. 

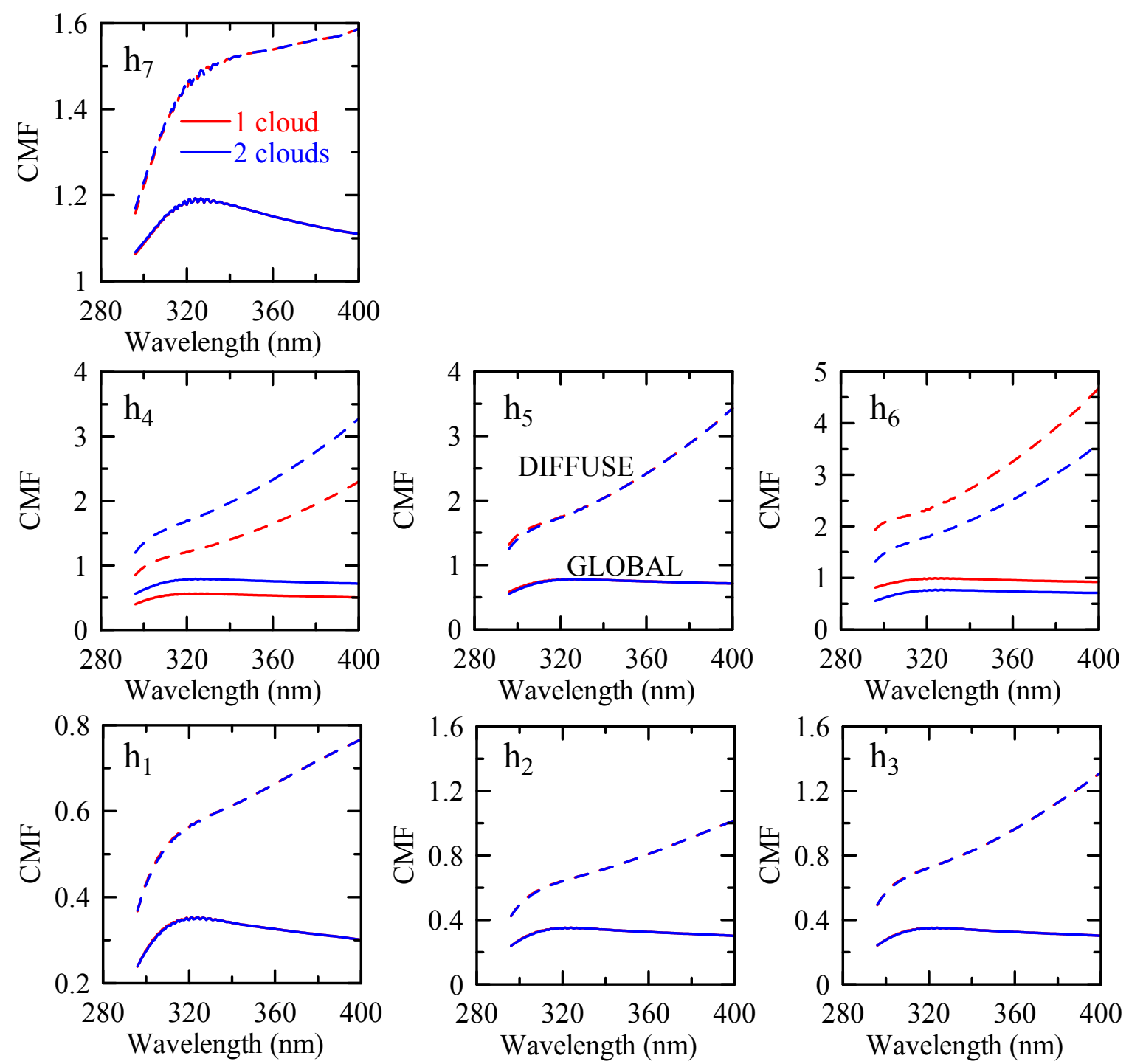

Figure 6.23. Spectral CMF dependence for global (solid lines) and diffuse (dashed lines) components for one (red lines) and two (blue lines) cloud layers at the seven heights indicated in Figure 6.22.

\section{Cloud base height}

Finally, the role of cloud height is also analyzed. In this case, all the previous parameters are fixed at the values mentioned before while $h_{\text {cld }}$ varied between 2500 and $5500 \mathrm{~m}$. The smaller limit is selected in order to avoid the aerosol layer (which is located between $0-2 \mathrm{~km}$ ). In order to analyze the cloud altitude effect as a function of the solar position, $20^{\circ}$ and $70^{\circ} \mathrm{SZA}$ are also studied. 

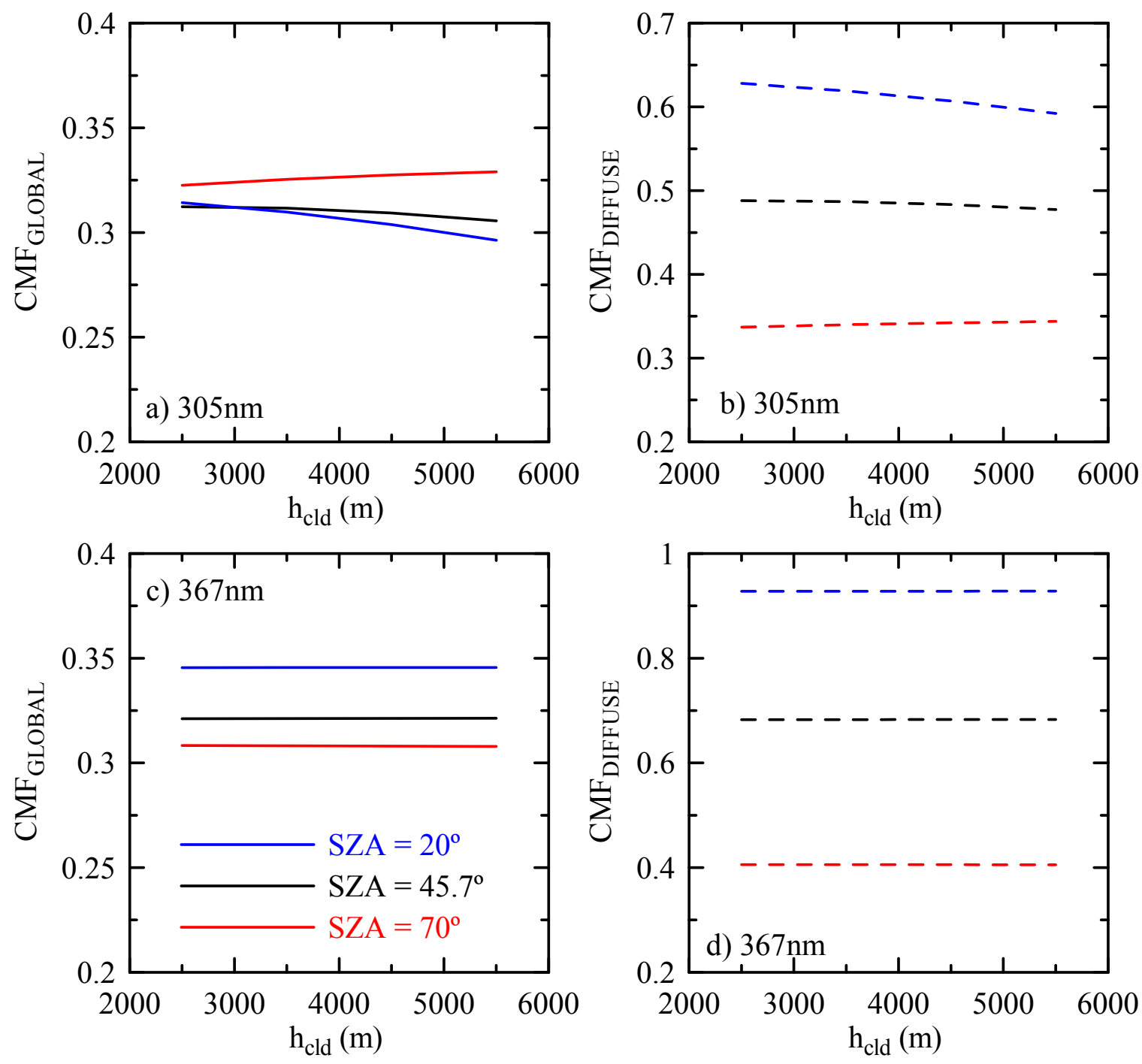

Figure 6.24. Effect of cloud base height on spectral CMF for global (solid lines) and diffuse (dashed lines) components for three different SZAs at $305(a-b)$ and $367(c-d) \mathrm{nm}$.

The CMF calculation is carried out at the surface and is shown in Figure 6.24 for two wavelengths: 305 and $367 \mathrm{~nm}$ (values very close to the UV-MFRSR wavelengths used in previous chapters). As can be seen in the figure, the CMFs at $367 \mathrm{~nm}$ do not show any dependence on cloud base height. However, CMFs at $305 \mathrm{~nm}$ exhibit a dependence on this parameter which is also SZA-dependent both for global and diffuse components. At $\mathrm{SZA}=20^{\circ}$, the CMFs decrease with $\mathrm{h}_{\mathrm{cld}}$, while the opposite occurs at $\mathrm{SZA}=70^{\circ}$. This different behaviour can be attributed to the different optical path followed by the radiation in each situation. For the smallest SZA, the direct component is predominant up to the cloud top. Below this height, the diffuse component and the attenuation it undergoes in the low troposphere play the dominant role. The situation changes at $\mathrm{SZA}=70^{\circ}$, when the radiation undergoes more scattering processes and the diffuse component reaches the 
cloud as the predominant component. This different relevance of the phenomena occurring above the cloud causes the small effects shown in Figure 6.24. In conclusion, cloud altitude plays a minor role in cloud-radiation interaction and only for shorter wavelengths.

\subsection{Summary}

\subsubsection{English version}

A special case presenting overcast conditions and an aerosol layer of dust below the cloud is analyzed. With all the available measurements (surface pressure, aerosol optical thickness, total ozone column, surface ozone concentration, cloud base and top heights, cloud optical thickness, liquid water path and cloud droplet effective radius), an INPUT file for the libRadtran library was built. Since the aerosol type is desert dust, optical and microphysical property dependences on wavelength and height were taken into account by means of the OPAC software installed with the libRadtran. Simulations with the introduced INPUT data can reproduce the experimental values of the irradiance (global and diffuse) and actinic flux to within $\pm 5 \%$. The spectral behaviours obtained support the dependences shown in previous chapters. The cloud modification factor for global irradiance shows an increase up to $320 \mathrm{~nm}$ and beyond this wavelength a small decrease up to $400 \mathrm{~nm}$, which are also observed for the CMF evaluated for the actinic flux. However, the diffuse CMF for irradiance shows an increasing trend with wavelength. At the solar zenith angle of the case study $\left(\mathrm{SZA}=45.7^{\circ}\right)$, global irradiance and actinic flux CMFs are very similar; hence, only the irradiance is mentioned in the following lines. To analyze the impact of the aerosol layer below the cloud, the aerosol type is switched to maritime clean and urban cases with the OPAC information. Comparing the results obtained for the three types, it can be deduced that the variation of the cloud modification factor for the global component is negligible. However, the diffuse CMF is strongly affected by the properties of the aerosol layer despite the large cloud optical thickness $(\mathrm{COT} \approx 30)$ in the case study. The ratio between the CMF for each aerosol type and the CMF for an aerosol-free atmosphere was evaluated. The observed spectral behaviour is determined by the ratio between the irradiances under cloudless conditions for an aerosol-free atmosphere and for the case with aerosol. This ratio is smaller for highly scattering particles (e.g., maritime clean). To confirm these results, a sensitivity analysis on aerosol optical properties was carried out: an increase in the aerosol load or the asymmetry factor strongly affects the diffuse CMF, while the global one remains almost constant, and a rise in the single scattering albedo leads to an increase and a decrease in $\mathrm{CMF}_{\mathrm{GLOBAL}}$ and $\mathrm{CMF}_{\mathrm{DIFFUSE}}$, respectively, the effect being stronger for 
the latter at longer wavelengths in the UV. Another sensitivity analysis was carried out relative to cloud properties. A minor $1 \%$ change in the cloud single scattering albedo can bring about changes of over 100\% in the CMF (both global and diffuse). The cloud asymmetry factor also strongly impacts $\mathrm{CMF}_{\mathrm{GLOBAL}}$ and $\mathrm{CMF}_{\text {DIFFUSE. Cloud geometric }}$ thickness does not influence CMFs. The cloud base height displays a weak effect, which is dependent on the solar zenith angle because of the different relevance of the phenomena occurring above or below the cloud.

\subsubsection{Spanish version}

Un caso particular de condiciones de cielos totalmente cubiertos con una capa de aerosol desértico debajo de la nube se ha analizado. Con todas las medidas disponibles (presión superficial, espesor óptico de aerosoles, ozono en columna y en superficie, altura de la base y la cima de la nube, espesor óptico de nubes, contenido de agua líquida, y radio efectivo de las gotas de las nubes), se ha construido un archivo de INPUT para el modelo libRadtran lo más cercano posible a la realidad. Para ello, como se conoce que el tipo de aerosol es desértico, se han considerado las propiedades ópticas y microfísicas del aerosol ambas dependientes con la longitud de onda y con la distribución vertical del software OPAC instalado con el libRadtran. Las simulaciones, con el archivo de INPUT, pueden reproducir las observaciones experimentales de la irradiancia (tanto la componente global como la difusa) y del flujo actínico con un error del $\pm 5 \%$. Los resultados obtenidos en cuanto a la dependencia espectral corroboran lo explicado en anteriores capítulos: el factor de modificación de nubes para la irradiancia global muestra un aumento hasta los $320 \mathrm{~nm}$, para ir decreciendo hasta los 400nm, dichas tendencias se observan también para el CMF del flujo actínico; por el contrario, el CMF de la irradiancia difusa presenta siempre una tendencia creciente con la longitud de onda. El ángulo cenital del caso estudio $\left(\mathrm{SZA}=45.7^{\circ}\right)$ provoca que no existan diferencias entre la irradiancia y el flujo actínico, por lo tanto, en lo sucesivo solo se hará mención de la irradiancia. Para poder analizar el impacto de una capa de aerosol debajo de la nube, el tipo de aerosol es cambiado a marítimo limpio y urbano usando el software OPAC. Comparando todos los resultados para los tres tipos de aerosoles, se puede deducir que la variación del CMF para la componente global es prácticamente inapreciable, mientras que el CMF difuso está fuertemente afectado por las propiedades ópticas de los aerosoles a pesar del elevado espesor óptico de nube del caso estudio (COT $\approx 30)$. Se ha evaluado el cociente entre el CMF para cada caso y el correspondiente valor para una atmósfera sin partículas de aerosol, obteniendo que su dependencia espectral queda determinada por el cociente de las irradiancias de cielo despejado cuando se dan condiciones sin aerosoles y con ellos. Dicho cociente presenta los valores más bajos para un medio dispersivo (como 
el marítimo limpio). Para confirmar estos resultados, se ha realizado un estudio de sensibilidad en función de las propiedades ópticas del aerosol con los siguientes resultados: un aumento en la carga de aerosol o su factor de asimetría afecta fuertemente al $\mathrm{CMF}_{\text {DIFUSA }}$ mientras que el $\mathrm{CMF}_{\mathrm{GLOBAL}}$ queda prácticamente inalterado, y un aumento en el albedo de dispersión simple produce un aumento y un decrecimiento del CMF global y difuso, respectivamente, siendo el efecto más fuerte para este último a longitudes de onda larga en el UV. También se ha realizado un análisis de sensibilidad atendiendo a las propiedades de las nubes. Un cambio del 1\% en el albedo de dispersión simple de las nubes puede producir cambios en los CMFs (global y difuso) de más del 100\%. Ambos CMFs también se ven afectados por el valor del factor de asimetría. El espesor geométrico de las nubes, como tal, no presenta influencia en los CMFs puesto que estos están controlados por el espesor óptico de las nubes. La altura de la base de la nube presenta un efecto débil que además es dependiente con el ángulo cenital debido a la distinta transcendencia de los fenómenos que ocurren encima y debajo de la nube. 



\section{Chapter 7}

7. Conclusions and Outlook 


\subsection{Conclusions}

This thesis provides a full description of the radiative field under overcast conditions. For this purpose, measurements at three different European stations (SRSUVA, Trisaia, and Lampedusa) and radiative transfer simulations using the libRadtran library are analyzed. Experimental values of the following variables are used: UVI, J $\left(\mathrm{O}^{1} \mathrm{D}\right)$, global and diffuse spectral irradiances, spectral actinic flux, liquid water path, effective radius of cloud droplets, cloud optical thickness, cloud base and top heights, total ozone column, cloud cover, aerosol optical thickness, total shortwave irradiance (global and diffuse), and ozone concentration at the surface. The main results and conclusions obtained in this thesis are:

1. A new methodology to obtain retrievals of the UV index from multichannel instruments was validated showing that only four channels are required to obtain UVI data. This method involves using a quadratic regression with regard to the measured signals.

2. UVI dependence on cloud cover is stronger at small SZA, ranging between seven and nine under cloudless conditions, and between three and five with overcast situations at the three stations. $\mathrm{J}\left(\mathrm{O}^{1} \mathrm{D}\right)$ values ranged between $\sim 2.2510^{-5} \mathrm{~s}^{-1}$ and $\sim 1.2510^{-5} \mathrm{~s}^{-1}$ from cloudless to overcast conditions at small SZA at the TRISAIA station. Under cloudless conditions, differences in UVI and $\mathrm{J}\left(\mathrm{O}^{1} \mathrm{D}\right)$ values for different SZA intervals are evident, although this effect is weaker with 8 octas of cloud cover.

3. Experimental and model values of UVI and $\mathrm{J}\left(\mathrm{O}^{1} \mathrm{D}\right)$ exhibit a strong dependence on cloud optical thickness under overcast conditions. The influence of other parameters is analyzed for these conditions. The influence of SZA is COT independent, while the impact of ozone increases with COT and is SZAdependent. The effect of aerosol under overcast conditions is weak for the UVI, and more relevant for the $\mathrm{J}\left(\mathrm{O}^{1} \mathrm{D}\right)$ with an increasing trend with COT.

4. Cloudless modelling of UVI and $\mathrm{J}\left(\mathrm{O}^{1} \mathrm{D}\right)$ is carried out using empirical Look-upTables as a function of SZA and TOC. A comparison with the simulations of libRadtran validates this methodology, although the results improve when aerosol optical thickness is considered. However, aerosol is not included in the cloudless model as it is difficult to obtain good measurements of the aerosol load under cloudy conditions. $\mathrm{J}\left(\mathrm{O}^{1} \mathrm{D}\right)$ modelling under a cloud-free sky also shows an enhanced role of tropospheric ozone due to the enhanced pathway through the atmosphere. This may be caused by Rayleigh and particle scattering under high turbidity conditions and low SZAs. 
5. The dependence of the cloud modification factors for the UVI and $\mathrm{J}\left(\mathrm{O}^{1} \mathrm{D}\right)$ on COT is studied using measured and modelled data. Observations and model simulations show very good agreement. Fits in the form $\mathrm{CMF}=\left(1+\mathrm{c}_{1} \mathrm{COT}\right)^{-1}$ are a simple way to retrieve COT values once CMFs are calculated.

6. The CMF spectral behaviours for the global and diffuse irradiances and the actinic flux are different using the COT to characterize the cloud layer. The CMF for the global irradiance component increases up to $320 \mathrm{~nm}$, decreases for longer wavelengths, and evidences a weak dependence on SZA. The CMF for the diffuse component always increases with wavelength and is SZA-dependent. Under certain conditions ( such as $\mathrm{COT}=10$ and $\mathrm{SZA}<40^{\circ}$ ), irradiance at the surface under overcast conditions is higher than that recorded under a cloud-free sky (i.e. $\left.\mathrm{CMF}_{\text {DIFFUSE }}>1\right)$. The CMF for the actinic flux increases at shorter wavelengths $(<$ $320 \mathrm{~nm}$ ) up to moderate SZAs and decreases at high SZAs, while beyond $320 \mathrm{~nm}$, actinic flux $\mathrm{CMF}$ increases for SZA $<30^{\circ}$, decreases for $30^{\circ}<\mathrm{SZA}<50^{\circ}$, and strongly decreases for $\mathrm{SZA}>50^{\circ}$ with wavelength.

7. Radiative transfer model calculations (by libRadtran) reproduce well the spectral behaviors of empirical CMFs.

8. The decrease in $\mathrm{CMF}_{\mathrm{GLOBAL}}$ with wavelength above $320 \mathrm{~nm}$ is essentially induced by normalization with regard to clear sky irradiance; molecular scattering processes above the clouds appear to play a minor role in determining the observed spectral behaviour of the $\mathrm{CMF}_{\mathrm{GLOBAL}}$, since $\mathrm{CMF}_{\text {DIFFUSE }}$ displays a different trend. Radiation at wavelengths $<320 \mathrm{~nm}$ is strongly modulated by ozone absorption because of the longer optical path under cloudy conditions. The Rayleigh scattering contribution $\left(\sim \lambda^{-4}\right)$ from the molecular atmosphere is the factor which controls the spectral response of CMF $\mathrm{DIFFUSE}_{\text {. }}$

9. Similar considerations may be applied to the behaviour of the actinic flux CMF, with the exception of large SZAs and short wavelengths. The Umkehr effect leads to maximum radiance arriving from the zenith, and to the photons of this direction being less attenuated under overcast conditions due to the shorter optical path.

10. Using a wavelength independent CMF instead of the experimentally determined spectral curves causes an overestimation of biological weighted UV irradiation effects. Overestimation is $30 \%$ for DNA damage, $20 \%$ for vitamin D synthesis, $12 \%$ for plant damage, $8 \%$ for phytoplankton inhibition, and $14 \%$ for erythema. Overestimation is greater at low solar zenith angles and large cloud optical thicknesses.

11. Cloud droplets of small effective radius cause stronger attenuation of radiative fluxes in the overcast scenario than larger ones. This dependence is shown by experimental and model data. 
12. The CMFs for global irradiance and for actinic flux show different behaviours: irradiance is more efficiently attenuated at low SZA than actinic flux, while the situation changes at high SZAs. These effects can be understood by the different weight of the direct and diffuse components.

13. The spectral behaviours obtained using the liquid water path and the effective radius of the cloud droplets are: $\mathrm{CMF}$ for global irradiance decreases slightly from 304.7 to $367.2 \mathrm{~nm}$, while CMF for diffuse irradiance always increases with wavelength; and CMF for actinic flux between 305.4 and $367.51 \mathrm{~nm}$ increases slightly at low SZA, remains constant at moderate SZA, and clearly decreases at high SZA. These results support the trends observed while using the COT.

14. The CMFs for UVI and global spectral irradiance display very weak dependence on the SZA, while the CMFs for actinic flux (both integrated and spectral) and diffuse spectral irradiance decrease with SZA. This dependence is determined by the values of the LWP and $r_{\text {eff }}$, because different cloud properties display different behaviours.

15. A special case with overcast conditions and an aerosol layer of dust below the cloud is simulated, with differences in the range $\pm 5 \%$ with regard to the measurements being obtained.

16. The configuration of the case study allows the impact of different aerosol properties on the irradiance $\mathrm{CMF}$ to be investigated. While the global CMF remains almost constant, the diffuse CMF displays a clear dependence on the aerosol properties despite the large COT in the case study (COT $\approx 30$ ).

17. A sensitivity study of CMF on aerosol properties is carried out using model simulations. If the $\mathrm{AOT}_{550 \mathrm{~nm}}$ changes from 0 to 0.4 , the $\mathrm{CMF}_{\text {DIFFUSE }}$ decreases $\sim 50 \%$ at long wavelengths. When the aerosol asymmetry factor rises from 0.65 to 0.95 , the $\mathrm{CMF}_{\text {DIFFUSE }}$ shows a maximum reduction of $6 \%$ at long wavelengths. Finally, the aerosol single scattering albedo leads to a decrease in $\mathrm{CMF}_{\text {DIFFUSE }}$ values of around $11 \%$ at $400 \mathrm{~nm}$ when it increases from 0.60 to 0.99 , the effect being weaker at shorter wavelengths (for instance, $\sim 1 \%$ at $305 \mathrm{~nm}$ ).

18. Another sensitivity study is carried out by varying the cloud properties. A variation as small as $1 \%$ in the cloud single scattering albedo may cause changes of over $100 \%$ in the CMF (both global and diffuse). The cloud asymmetry factor also evidences a strong impact on the two CMFs: e.g., a change from 0.75 to 0.90 leads to an increase of over $100 \%$ in the $\mathrm{CMF}_{\text {DIFFUSE }}$ at $305 \mathrm{~nm}$. Cloud geometric thickness does not influence the CMFs, which are controlled by cloud optical thickness. The cloud base height shows a weak effect which is dependent on the solar zenith angle. 


\subsection{Conclusiones}

En esta tesis se ha realizado una completa caracterización del campo radiativo, particularmente en condiciones de cielo totalmente cubierto, usando las medidas experimentales de tres estaciones europeas (SRSUVA, Trisaia y Lampedusa) y el modelo de transferencia radiativa libRadtran. Se han utilizado las siguientes variables: el UVI, el $\mathrm{J}\left(\mathrm{O}^{1} \mathrm{D}\right)$, la irradiancia espectral global y difusa, el flujo actínico espectral, el contenido de agua líquida, el radio efectivo de las gotas de las nubes, el espesor óptico de las nubes, la altura de la base y de la cima de las nubes, la columna total de ozono, la cobertura de nubes, el espesor óptico de aerosol, la irradiancia total de onda corta (global y difusa), y la concentración de ozono en superficie. Los principales resultados y conclusiones que se han obtenido a lo largo de esta tesis doctoral son:

1. Se ha desarrollado una nueva metodología para obtener el índice UV desde instrumentos multicanal que demuestra que con solo 4 canales se pueden obtener valores de UVI de alta fiabilidad. La metodología consiste en el uso de una regresión cuadrática de las señales medidas.

2. La dependencia del índice UV con la cubierta de nubes es más fuerte para bajos SZAs con valores en las tres estaciones analizadas entre 7 y 9 en condiciones de cielos despejados, y entre 3 y 5 en cielos totalmente cubiertos. Los valores para el $\mathrm{J}\left(\mathrm{O}^{1} \mathrm{D}\right)$ oscilaron entre $\sim 2.2510^{-5} \mathrm{~s}^{-1}$ and $\sim 1.2510^{-5} \mathrm{~s}^{-1}$ pasando de cielos despejados a totalmente cubiertos para bajos SZAs en la estación de TRISAIA. En cielos despejados, las diferencias entre los distintos grupos del SZA para el UVI y del $\mathrm{J}\left(\mathrm{O}^{1} \mathrm{D}\right)$ son evidentes y se reducen en el caso de 8 octas.

3. Los valores medidos y simulados del UVI y del $\mathrm{J}\left(\mathrm{O}^{1} \mathrm{D}\right)$ presentan una fuerte dependencia con el espesor óptico de nubes en cielos totalmente cubiertos. Se han analizado los efectos de otros factores en estas condiciones de 8 octas. La influencia del SZA es independiente del COT, mientras que la del ozono aumenta con el COT y además es dependiente con el SZA. El efecto del aerosol en condiciones nubosas es débil para el UVI y más fuerte para el $\mathrm{J}\left(\mathrm{O}^{1} \mathrm{D}\right)$ presentando una tendencia creciente con el COT.

4. Se han evaluado una serie de 'Look-up-Tables' usando las medidas en cielos despejados para modelizar en estas condiciones el UVI y el $\mathrm{J}\left(\mathrm{O}^{1} \mathrm{D}\right)$ en función del SZA y del TOC. La validación de estas tablas se ha realizado mediante una comparación con otras tablas obtenidas con el modelo de transferencia libRadtran. Aunque los resultados son buenos, mejoran cuando se considera el espesor óptico de aerosol, sin embargo, no se ha incluido este parámetro en la modelización al resultar difícil obtener una estima del mismo en condiciones de cielos nubosos. La modelización del $\mathrm{J}\left(\mathrm{O}^{1} \mathrm{D}\right)$ en cielos despejados también presenta un papel relevante del ozono troposférico, debido a un aumento del camino óptico de los fotones causado por la dispersión de Rayleigh y de las partículas en condiciones, por ejemplo, de alta turbiedad y bajo SZA. 
5. Se analizado la dependencia del factor de modificación de nubes con el espesor óptico de nubes, encontrando un buen acuerdo entre los datos experimentales y los simulados con el modelo de transferencia radiativa. Se ha realizado una parametrización de la forma $\mathrm{CMF}=\left(1+\mathrm{c}_{1} \mathrm{COT}\right)^{-1}$, que puede utilizarse para la obtención de los valores de COT una vez que se han calculado los CMFs.

6. Usando el COT para caracterizar la capa de nubes, la dependencia espectral de los CMFs para la irradiancia global y difusa y el flujo actínico resulta ser distinta. El CMF espectral de la irradiancia global aumenta hasta los $320 \mathrm{~nm}$, decrece para longitudes de onda más grandes y tiene una débil dependencia con el SZA. E1 CMF de la irradiancia difusa aumenta con la longitud de onda y es dependiente con el SZA; en determinadas condiciones, por ejemplo COT $=10$ y SZA $<40^{\circ}$, la irradiancia en superficie en condiciones de 8 octas es mayor que la que se registra con cielos despejados (es decir, $\mathrm{CMF}_{\text {DIFUSA }}>1$ ). Por último, la dependencia del CMF del flujo actínico aumenta en las longitudes de onda más cortas $(<320 \mathrm{~nm})$ hasta moderados SZAs y decrece para altos SZAs; mientras que por encima de los $320 \mathrm{~nm}$, el CMF del flujo actínico aumenta para SZA $<30^{\circ}$, decrece para $30^{\circ}<$ $\mathrm{SZA}<50^{\circ}$, y decrece fuertemente para $\mathrm{SZA}>50^{\circ}$ con la longitud de onda.

7. Las simulaciones hechas con el modelo de transferencia radiativa libRadtran reproducen correctamente los comportamientos espectrales de los CMFs.

8. El decrecimiento de $\mathrm{CMF}_{\mathrm{GLOBAL}}$ con la longitud de onda a partir de los $320 \mathrm{~nm}$ está inducido por la normalización con respecto a la irradiancia en cielos despejados. Los procesos de dispersión molecular que ocurren encima de la nube parecen tener una menor importancia en determinar el comportamiento espectral de $\mathrm{CMF}_{\mathrm{GLOBAL}}$ puesto que $\mathrm{CMF}_{\mathrm{DIFUSA}}$ no muestra este comportamiento. La radiación de longitudes de onda $<320 \mathrm{~nm}$ está modulada por la absorción del ozono, cuyo papel está reforzado en condiciones nubosas ya que se aumenta el camino óptico. La dispersión de Rayleigh $\left(\sim \lambda^{-4}\right)$ controla la respuesta espectral del CMF DIFUSA.

9. Fundamentos similares pueden ser aplicados al comportamiento espectral del flujo actínico, con la excepción de altos SZAs y longitudes de onda corta. El efecto Umkehr conlleva que la radiancia que llega desde el zenit sea la radiancia máxima. Además, debido a un menor camino óptico, los fotones de esta dirección resultan menos atenuados bajo condiciones de cielos totalmente cubiertos.

10. El uso de un CMF independiente con la longitud de onda, en lugar de las curvas obtenidas experimentalmente, produce una sobrestimación de los efectos biológicos de la radiación UV que se ha estimado del orden del 30\% para el daño al $\mathrm{ADN}$, del $20 \%$ para la síntesis de la vitamina $\mathrm{D}$, del $12 \%$ para el daño a las plantas, del 8\% para la inhibición del fitoplancton y del 14\% para la producción de eritema en la piel humana. La sobrestimación es mayor para bajos SZAs y grandes COTs. 
11. Las gotas de las nubes con radios efectivos más pequeños producen una mayor atenuación del flujo radiativo. Este hecho ha sido probado con las medidas y las simulaciones.

12. Los CMFs de la irradiancia global y del flujo actínico muestran comportamientos distintos: la irradiancia es más atenuada a bajos SZAs, mientras que para altos SZAs lo es el flujo actínico. Esto se puede explicar por el diferente peso de las componentes directa y difusa en cada caso.

13. La dependencia espectral obtenida usando el espesor óptico de nubes ha sido corroborada cuando se han utilizado el contenido de agua líquida y el radio efectivo de las gotas de nubes: el CMF para la irradiancia global muestra una ligera caída entre 304.7 y $367.2 \mathrm{~nm}$, mientras que el CMF para la irradiancia difusa siempre aumenta con la longitud de onda; y el CMF para el flujo actínico entre 305.4 y $367.51 \mathrm{~nm}$ presenta un ligero aumento a bajos SZAs, permanece constante para SZAs intermedios, y tiene una fuerte tendencia decreciente a altos SZAs.

14. Mientras que los CMFs para el UVI y la irradiancia global espectral muestran una leve dependencia con el SZA, los CMFs para el flujo actínico (tanto integrado como espectral) y para la irradiancia difusa decrecen con el SZA. Esta dependencia está determinada por los valores de LWP y $r_{\text {eff, }}$ ya que propiedades de nubes diferentes producen distintas tendencias.

15. Las simulaciones de un caso estudio con 8 octas y una capa de polvo desértico debajo de la nube han reproducido las medidas con una diferencia de $\pm 5 \%$.

16. La configuración del caso estudio ha permitido investigar el impacto de diferentes propiedades de aerosoles sobre los CMFs. Mientras que el CMF para la irradiancia global permanece casi constante, el CMF para la irradiancia difusa muestra una clara dependencia con las propiedades de los aerosoles a pesar de tener un elevado espesor óptico de nubes (COT $\approx 30$ ).

17. Se ha realizado un análisis de sensibilidad de los CMFs a las propiedades del aerosol usando las simulaciones del modelo de transferencia radiativa. Cuando el $\mathrm{AOT}_{550 \mathrm{~nm}}$ cambia desde 0 a 0.4 , el $\mathrm{CMF}_{\text {DIFUSA }}$ decrece hasta un $50 \%$ para las longitudes de onda más largas. Cuando el factor de asimetría aumenta desde 0.65 a 0.95 , el $\mathrm{CMF}_{\text {DIFUSA }}$ muestra una reducción máxima del $6 \%$ a las longitudes de onda mayores. Por último, el albedo de dispersión simple produce una caída en el $\mathrm{CMF}_{\text {DIFUSA }}$ sobre el $11 \%$ cuando este aumenta desde 0.60 a 0.99 ; el efecto es más débil a las longitudes de onda más cortas (por ejemplo, $1 \%$ a $305 \mathrm{~nm}$ ). 
18. Se ha analizado también la sensibilidad de los CMFs a las propiedades de las nubes. Un cambio del 1\% en el valor del albedo de dispersión simple de las nubes puede producir cambios en el CMF (tanto para la global como para la difusa) de más del $100 \%$. El factor de asimetría de las nubes ejerce también una fuerte influencia en los dos CMFs: por ejemplo, un aumento del 0.75 al 0.90 provoca un cambio del más del $100 \%$ en el $\mathrm{CMF}_{\text {DIFUSA }}$ a $305 \mathrm{~nm}$. El espesor geométrico de las nubes no muestra influencia en los CMFs, que están controlados por el valor del espesor óptico éstas. La altura de la base de la nube produce un débil efecto que además es dependiente con el ángulo cenital solar.

\subsection{Outlook}

The findings obtained in this thesis offer a wide range of options for future research. Some points which may prove interesting are the following:

1. With the methodology validated to retrieve the UV index from UV-MFRSR measurements, diffuse UVI can be evaluated from the same instrument. Therefore, the diffuse/global ratio can be determined for UVI and its dependence on, for instance, cloud properties can be estimated.

2. This thesis is based on overcast conditions. However, broken clouds which are more complex situations may also be analyzed. This might be achieved by means of the microwave radiometer and cloud property estimations from shortwave and spectral radiometers.

3. The spectral enhancement effect could be analyzed using the data from the Trisaia campaign. Using this database, cloud microphysical properties for cases showing higher levels of radiation than under cloudless conditions can be analyzed.

4. The retrievals of COT from CMF calculations of the UVI and $J\left(\mathrm{O}^{1} \mathrm{D}\right)$ proposed in this thesis should be tested and validated.

5. More in-depth analysis into the impact of aerosol on diffuse cloud transmittance should be performed. A case study of a day with both cloudless and overcast periods, obtaining surface measurements of AOT and TOC, may help to improve the characterization of the atmospheric state also under cloudy conditions.

6. Gaining further insights into the cloud radiative effect in the UV range, analyzing the factors that influence it under overcast conditions and establishing the relationship between the UV CRE and the net CRE at the surface. 


\section{Annex A: Definitions of the statistical parameters used in the comparison between two data series}

Average

The average (ave) value of a dataset is:

$$
\text { ave }=\frac{\sum_{\mathrm{i}=1}^{\mathrm{n}} \mathrm{x}_{\mathrm{i}}}{\mathrm{n}}
$$

where $x_{i}$ is each value of the variable and $n$ is the number of data.

Mean Bias Error

The mean bias error (MBE) between two data series $\left(\mathrm{x}_{\mathrm{i}}\right.$ and $\left.\mathrm{y}_{\mathrm{i}}\right)$ is calculated as follows:

$$
\operatorname{MBE}(\%)=\frac{100}{\operatorname{ave}_{\mathrm{x}}} \frac{\sum_{\mathrm{i}=1}^{\mathrm{n}}\left(\mathrm{y}_{\mathrm{i}}-\mathrm{x}_{\mathrm{i}}\right)}{\mathrm{n}}
$$

where ave $e_{x}$ is the average value of the data series $\mathrm{x}$ taken as reference.

Average difference

The average difference between two data series can be evaluated as:

$$
\text { average difference }(\%)=\frac{100}{n} \sum_{i=1}^{n} \frac{y_{i}-x_{i}}{\left(y_{i}+x_{i}\right) / 2}
$$




\section{Root Mean Square Error}

The Root Mean Square Error (RMSE) is defined by the following expression:

$$
\operatorname{RMSE}(\%)=\frac{100}{\operatorname{ave}_{\mathrm{x}}} \sqrt{\frac{\sum_{\mathrm{i}=1}^{\mathrm{n}}\left(\mathrm{y}_{\mathrm{i}}-\mathrm{x}_{\mathrm{i}}\right)^{2}}{\mathrm{n}}}
$$

$W_{P \%}$

The variable $\mathrm{W}_{\mathrm{P} \%}$ determines the percentage of the data of one series that agrees within $\pm \mathrm{P} \%$ with the reference data. In this thesis the following variables are calculated: $\mathrm{W}_{1 \%}, \mathrm{~W}_{5 \%}, \mathrm{~W}_{10 \%}, \mathrm{~W}_{20 \%}$, and $\mathrm{W}_{30 \%}$.

\section{Linear fit}

The linear fit is one way to evaluate the agreement between two data series. The least-squares method is used. The coefficients of the linear fits and their errors are calculated as follows (the subscript ' $i$ ' is omitted in all the summations):

$$
\begin{gathered}
\mathrm{y}=\mathrm{a}+\mathrm{b} \mathrm{x} \\
\mathrm{a}=\frac{\sum \mathrm{y}_{\mathrm{i}} \sum \mathrm{x}_{\mathrm{i}}^{2}-\sum \mathrm{x}_{\mathrm{i}} \sum \mathrm{x}_{\mathrm{i}} \mathrm{y}_{\mathrm{i}}}{\mathrm{n} \sum \mathrm{x}_{\mathrm{i}}^{2}-\left(\sum \mathrm{x}_{\mathrm{i}}\right)^{2}} \\
\mathrm{~b}=\frac{\mathrm{n} \sum \mathrm{x}_{\mathrm{i}} \mathrm{y}_{\mathrm{i}}-\sum \mathrm{x}_{\mathrm{i}} \sum \mathrm{y}_{\mathrm{i}}}{\mathrm{n} \sum \mathrm{x}_{\mathrm{i}}^{2}-\left(\sum \mathrm{x}_{\mathrm{i}}\right)^{2}} \\
\sigma_{\mathrm{a}}=\sqrt{\mathrm{MSE}\left[\frac{1}{\mathrm{n}}+\frac{\mathrm{ave}_{\mathrm{x}}^{2}}{\mathrm{~S}_{\mathrm{xx}}}\right]} \\
\sigma_{\mathrm{b}}=\sqrt{\frac{M S E}{\mathrm{~S}_{\mathrm{xx}}}}
\end{gathered}
$$


where MSE is the mean squared error and $\mathrm{S}_{\mathrm{xx}}$ are defined as:

$$
\begin{aligned}
\mathrm{MSE} & =\frac{\sum\left(\mathrm{y}_{\mathrm{i}}-\mathrm{a}-\mathrm{b} \mathrm{x}_{\mathrm{i}}\right)^{2}}{\mathrm{n}-2} \\
\mathrm{~S}_{\mathrm{xx}} & =\sum\left(\mathrm{x}_{\mathrm{i}}-\mathrm{ave}_{\mathrm{x}}\right)^{2}
\end{aligned}
$$

The correlation coefficient ( $r$ ) of the linear fit is calculated as:

$$
r=\frac{\sum\left(x_{i}-\operatorname{ave}_{x}\right)\left(y_{i}-a_{y e}\right)}{\sqrt{\sum\left(x_{i}-\operatorname{ave}_{x}\right)^{2} \sum\left(y_{i}-a_{y}\right)^{2}}}
$$





\section{Annex B: Cloud radiative effect for erythemal radiation}

The cloud radiative effect (CRE) is defined as the difference between all-sky and clear-sky irradiances (e.g. Ebell et al., 2011). To retrieve the CRE, the Look-up-Tables shown in Section 3.2 for UVI cloudless estimations are divided by $40 \mathrm{~m}^{2} \mathrm{~W}^{-1}$ so as to obtain UVER estimations under cloudless conditions. Hence, the CRE can be evaluated under overcast conditions. Figure B.1 shows the frequency distribution of the CRE values evaluated at the three stations used in this thesis. CRE is mostly negative due to the strong scattering of cloud particles (e.g. Chen et al., 2000).
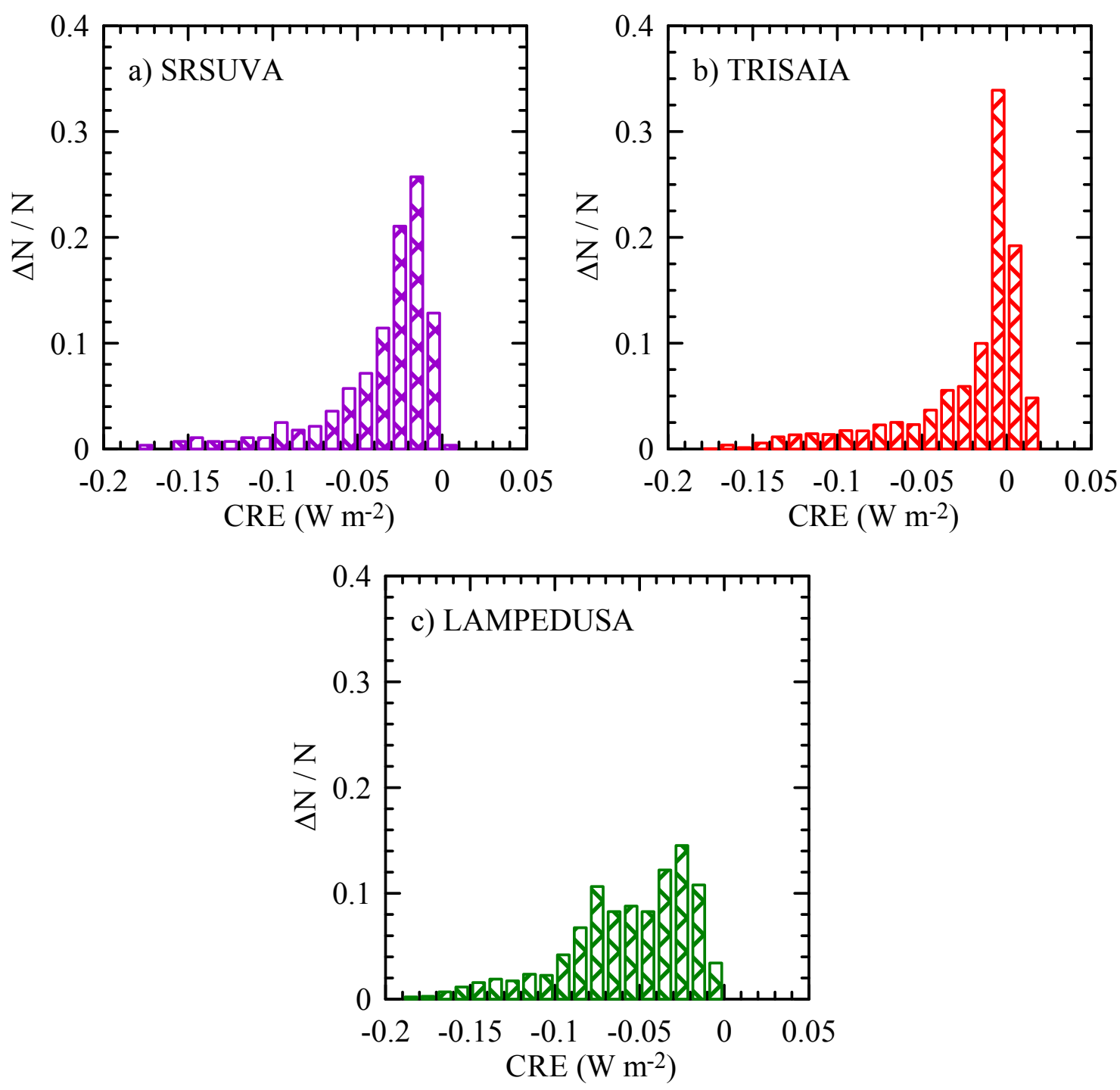

Figure B.1. Distributions of the UVER cloud radiative effect for the SRSUVA (a), TRISAIA (b), and LAMPEDUSA (c) stations. 
UVER CRE maxima are close to $-0.20 \mathrm{Wm}^{-2}$ at the three stations. As can be seen in the figure, each station presents a different frequency distribution, as occurred in the study carried out by Oreopoulos and Rossow (2011) for various cloud regimes or weather states.

The most frequent CRE values at the SRSUVA station are between -0.02 and $0.03 \mathrm{Wm}^{-2}$, while at TRISAIA they are about $-0.01 \mathrm{Wm}^{-2}$, and at LAMPEDUSA there is a more homogeneous distribution between 0 and $-0.1 \mathrm{Wm}^{-2}$. With regard to total shortwave $\mathrm{CRE}$, as an example, the main results of two early studies are described in the following lines. Chen et al. (2000) evaluated global annual mean shortwave CRE at the surface under overcast conditions for different cloud types. They found values of $-88,-35$, and $22 \mathrm{Wm}^{-2}$ for stratus, cumulus, and cirrus, respectively. Ebell et al. (2011) found monthly values of SW CRE ranging between -50 and $-200 \mathrm{Wm}^{-2}$ depending on solar isolation hours.

As the effects of all atmospheric factors are inside Figure B.1, a detailed analysis of the UVER CRE dependence on cloud optical thickness is performed selecting a $1^{\circ}$ interval of SZA and a 10 DU interval of TOC using the 5-minute TRISAIA database. Figure B.2 shows the results obtained for three different SZAs and the TOC interval centred at 360 DU. At low SZA, the difference between the cloudy and cloud-free scenarios strongly decreases with COT. This dependence is weaker for higher SZAs, and is below $-0.01 \mathrm{~W} \mathrm{~m}^{-2}$ at $\mathrm{SZA}=75^{\circ}$ and all COT values.

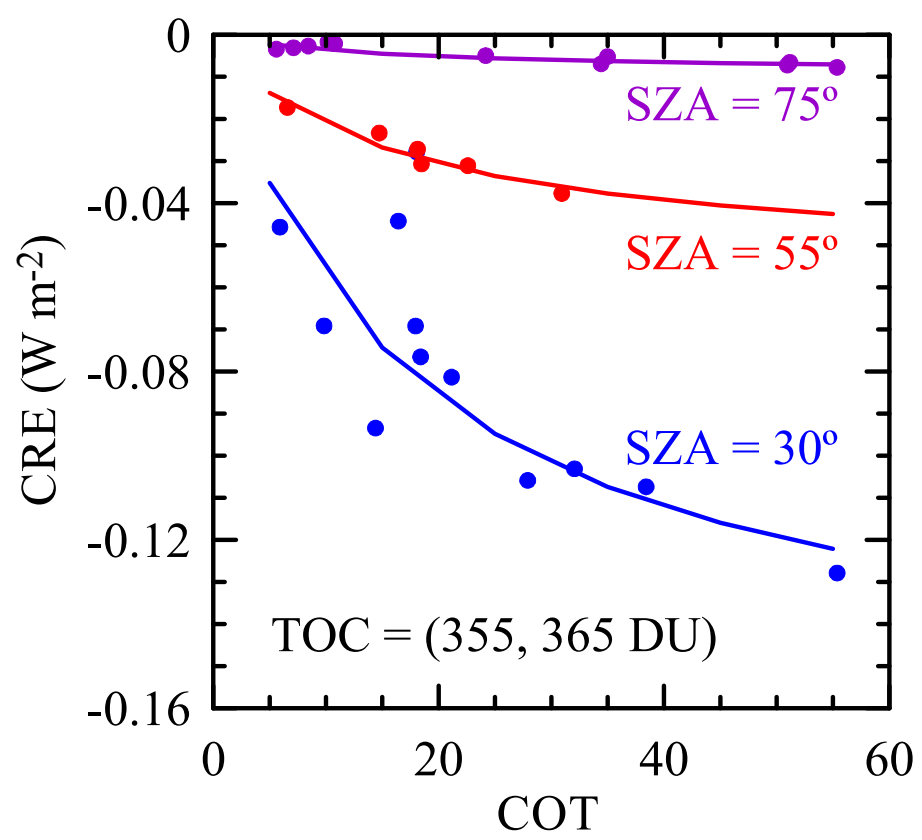

Figure B.2. Dependence of UVER CRE on COT for different SZAs for measured (dots) and simulated (lines) data at the TRISAIA station. 
The experimental data and the simulations obtained with the libRadtran model show good agreement, the latter being obtained for $\mathrm{AOT}_{550 \mathrm{~nm}}=0.25$.

Finally, the effect of cloud microphysical properties on UVER CRE values is analyzed in Figure B.3. As occurred with the CMF case, smaller particles cause stronger radiation attenuation, i.e. higher absolute $\mathrm{CRE}$ values. In the intervals considered in the figure $\left(20^{\circ}<\mathrm{SZA}<30^{\circ}\right.$ and $340 \mathrm{DU}<\mathrm{TOC}<360 \mathrm{DU}$ for the measurements), CRE exhibits strong $\mathrm{r}_{\text {eff }}$ dependence at low LWP, which decreases with increasing LWP.

Using the normalized CRE, defined as the absolute CRE divided by the cloudless estimation, Sengupta et al. (2003) proved that the variation of the SW CRE is much less sensitive to changes in cloud drop effective radius. These results were supported by, for example, Ebell et al. (2011). Hence, uncertainties in CRE determination are dominated by uncertainty in LWP for low LWP values.

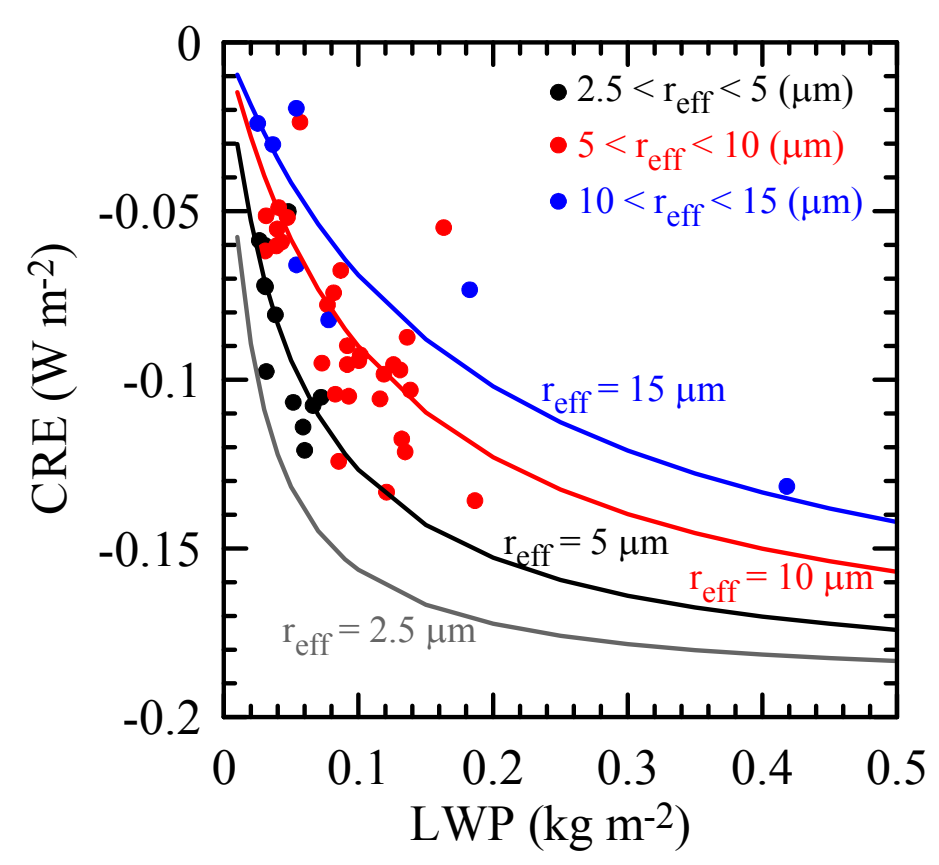

Figure B.3. Dependence of UVER CRE on LWP for different cloud droplet effective radii for measured (dots, with $20^{\circ}<S Z A<30^{\circ}$, and $340 \mathrm{DU}<\mathrm{TOC}<360 \mathrm{DU}$ ) and simulated (lines, only shown at SZA = $30^{\circ}$, TOC $=360 \mathrm{DU}$, and $\left.A O T_{550 \mathrm{~mm}}=0.25\right)$ data at the TRISAIA station. 



\section{References}

Adam, M.E.N., and El Shazly, S.M., 2007, Attenuation of UV-B radiation in the atmosphere: Clouds effect at Quena (Egypt), Atmos. Env. 41, 4856-4864.

Alados-Arboledas, L., Alados, I., Foyo-Moreno, I., Olmo, F.J., and Alcantara, A., 2003, The influence of clouds on surface UV erythemal irradiance, Atmos. Res. 66, $273-$ 290, doi:10.1016/S0169-8095(03)00027-9.

Anderson, G., Clough, S., Kneizys, F., Chetwynd, J., and Shettle, E., 1986, AFGL atmospheric constituent profiles $(0-120 \mathrm{~km})$, Tech. Rep. AFGL-TR-86-0110, Air Force Geophys. Lab., Hanscom Air Force Base, Bedford, Mass.

Ångström, A.K., 1964, The parameters of atmospheric turbidity, Tellus 16, 64-76.

Antón, M., Serrano, A., Cancillo, M.L., and García, J.A., 2008, Relationship between erythemal irradiance and total solar irradiance in South-Western Spain, J. Geophys. Res. 113, D14208, doi:10.1029/2007JD009627.

Antón, M., Serrano, A., Cancillo, M.L., and García, J.A., 2009, Influence of the relative optical air mass on ultraviolet erythemal irradiance, J. Atmos. Sol.-Terr. Phys. 71, 2027-2031, doi:10.1016/j.jastp.2009.09.009.

Antón, M., Sorribas, M., Bennouna, Y.S., Vilaplana, J.M., Cachorro, V.E., Gröbner, J., and L. Alados-Arboledas, 2012, Effects of an extreme desert dust event on the spectral ultraviolet irradiance at 'El Arenosillo' (Spain), J. Geophys. Res. 117, D03205, doi:10.1029/2011JD016645.

Arola, A., Lindfors, A., Natunen, A., and Lehtinen, K.E.J., 2007, A case study on biomass burning aerosols: effects on aerosol optical properties and surface radiation levels, Atmos. Chem. Phys. 7, 4257-4266.

Badosa, J., 2006, UV index measurement and model agreement: uncertainties and limitations, Doctoral Thesis, Universitat de Girona, ISBN: 84-689-6849-8.

Bais, A.F., and others., 2007, Surface ultraviolet radiation: past, present, and future, Chapter 7, in: Scientific Assessment of Ozone Depletion: 2006, Global Ozone Research and Monitoring Project, Report No 50, World Meteorological Organization, Geneva, Switzerland. 
Balis, D.S., Zerefos, C.S., Kourtidis, K., Bais, A.F., Hofzumahaus, A., Kraus, A., Schmitt, R., Blumthaler, M., and Gobbi, G.P., 2002, Measurements and modelling of photolysis rates during the Photochemical Activity and Ultraviolet Radiation (PAUR) II campaing, J. Geophys. Res. 107, D18, 8138, doi:10.1029/2000JD000136.

Barnard, J.C., Long, C.N., Kassianov, E.I., McFarlane, S.A., Comstock, J.M., Freer, M., and McFarquhar, G.M., 2008, Development and Evaluation of a Simple Algorithm to Find Cloud Optical Depth with Emphasis on Thin Ice Clouds, Open Atmos. Sci. J. 2, 46-55.

Basher, R.E., and Thomas, R.W.L., 1979, Atmospheric aerosol effect on Dobson total ozone measurements: A simple approach, Appl. Opt. 18, 3361-3362.

Bernhard, G., and Seckmeyer, G., 1999, Uncertainty of measurements of spectral solar UV irradiance, J. Geophys. Res. 104, 14,321-14,345.

Bernhard, G., Booth, C.R., and Ehramjian, J.C., 2004, Version 2 data of the National Science Foundation's Ultraviolet Radiation Monitoring Network: South Pole, J. Geophys. Res. 109, D21207, doi:10.1029/2004JD004937.

Biavati, G., and di Sarra, A., 2004, Identification of cloud-free periods from global and diffuse radiation observations, ENEA Report RT/2004/66/CLIM, Ente per le Nuove Tecnologie, l'Energia e l'Ambiente, Rome (in Italian).

Bilbao, J., Mateos, D., and de Miguel, A., 2011a, Analysis and cloudiness influence on UV total irradiation, Int. J. Climatol. 31 (3), 451-460, doi:10.1002/joc.2072.

Bilbao, J., Román, R., de Miguel, A., and Mateos, D., 2011b, Long-term solar erythemal UV irradiance data reconstruction in Spain using a semiempirical method, J. Geophys. Res. 116, D22211, doi:10.1029/2011JD015836.

Blumthaler, M., and Ambach W., 1988, Solar UVB-albedo of various surfaces, Photochem. Photobiol. 48, 85-88.

Blumthaler, M., Webb, A.R., Seckmeyer, G., Bais, A.F., Huber, M., and Mayer, B., 1994, Simultaneous spectroradiometry: A study of solar UV irradiance at two altitudes, Geophys. Res. Lett., 21, 2805-2808, doi:10.1029/94GL02786.

Bodhaine, B.A., Wood, N.B., Dutton, E.G., and Slusser, J.R., 1999, On Rayleigh Optical Depth Calculations, J. Atmos. Ocean. Tech. 16, 1854-1861. 
Brühl, C., and Crutzen, P., 1988, Scenarios of possible changes in atmospheric temperatures and ozone concentrations due to man's activities, estimated with a one-dimensional coupled photochemical climate model, Clim. Dynam. 2, 173-203.

Brühl, C., and Crutzen, P., 1989, On the disproportionate role of tropospheric ozone as a filter against solar UV-B radiation, Geophys. Res. Lett. 16, 703-706.

Cachorro, V., Toledano, C., Prats, N., Sorribas, M., Mogo, S., Berjón, A., Torres, B., Rodrigo, R., de la Rosa, J., and de Frutos, A.M., 2008, The strongest desert dust intrusion mixed with smoke over the Iberian Peninsula registered with Sun photometry. J. Geophys. Res. 113(D14), D14S04, doi:10.1029/2007JD009582.

Calbó, J., Pages, D., and Gonzalez, J., 2005, Empirical studies of cloud effects on UV radiation: a review, Rev. Geophys 43, RG2002, doi:10.1029/2004RG000155.

Caldwell, M.M., Bjorn, L.O., Bornman, J.F., Flint, S.D., Kulandaivelu, G., Teramura, A.H., and Tevini, M., 1998, Effects of increased solar ultraviolet radiation on terrestrial ecosystems, J. Photochem. Photobiol. B 46, 40-52.

Cañada, J., Pedros, G., and Bosca, J.V., 2003, Relationships between UV (0.290-0.385 $\mu \mathrm{m})$ and broad band solar radiation hourly values in Valencia and Córdoba, Spain, Energy 28, 199-217.

Casasanta, G., di Sarra, A., Meloni, D., Monteleone, F., Pace, G., Piacentino, S., and Sferlazzo, D., 2011, Large aerosol effects on ozone photolysis in the Mediterranean, Atmos. Env. 45, 3937-3943, doi:10.1016/j.atmosenv.2011.04.065.

Casasanta, G., 2012, Caratterizzazione dello strato limite planetario con diversi strumenti di telerilevamento, Doctoral Thesis, Universittà della Sapienza, Roma, Italy.

Cede, A., Luccini, E., Nuñez, L., Piacentini, R.D., Blumthaler, M., and Herman, J.R., 2004, TOMS-derived erythemal irradiance versus measurements at the stations of the Argentine UV Monitoring Network, J. Geophys. Res. 109, D08109, doi: 10.1029/2004JD004519.

Chandrasekhar, S., 1960, Radiative Transfer, Dover, New York, USA.

Chen, T., Rossow, W.B., and Zhang, Y., 2000, Radiative effects of cloud-type variations, J. Climate 13, 264-286.

Chen, D., Wängberg, S.Å., Wulff, A., and Borne, K., 2004, Attenuation of biologically effective UV doses under overcast skies: a case study from the eastern Atlantic sector of the Southern Ocean, Deep-See Res. II 51, 2673-2682. 
CIE, 2006, Action spectrum for the production of previtamin D3 in human skin, CIR 174, 2006.

Crawford, J., Shetter, R. E., Lefer, B., Cantrell, C., Junkermann, W., Madronich, S., and Calvert, J., 2003, Cloud impacts on UV spectral actinic flux observed during the International Photolysis Frequency Measurement and Model Intercomparison (IPMMI), J. Geophys. Res. 108(D16), 8545, doi:10.1029/2002JD002731.

Cullen, J.J., Neale, P.J., and Lesser, M.P., 1992, Biological weighting function for the inhibition of phytoplankton photosynthesis by ultraviolet radiation, Science 25, 646-649.

Dahlback, A., 1996, Measurements of biologically effective UV doses, total ozone abundances, and cloud effects with multichannel, moderate bandwidth filter instruments, Appl. Optics 35, 6514-6521.

Daumont, D., Brion, J., Charbonnier, J., and Malicet, J., 1992, Ozone UV spectroscopy I: absorption cross-sections at room temperature, J. Atmos. Chem. 15(2), 145-155.

de Miguel, A., Román, R., Bilbao, J., and Mateos, D., 2011a, Evolution of erythemal and total shortwave solar radiation in Valladolid, Spain: Effects of atmospheric factors, J. Atmos. Sol. Terr. Phys. 73, 578-586, doi:10.1016/j.jastp.2010.11.021.

de Miguel, A., Mateos, D., Bilbao, J., Román, R., 2011b, Sensitivity analysis of ratio between ultraviolet and total shortwave solar radiation to cloudiness, ozone, aerosols and precipitable water, Atmos. Res. 102, 136-144, doi:10.1016/j.atmosres.2011.06.019.

Degünther, M., Meerkötter, R., Albold, A., and Seckmeyer, G., 1998, Case study on the influence of inhomogeneous surface albedo on UV irradiance, Geophys. Res. Lett. $25,3587-3590$.

den Outer, P.N., Slaper, H., and Tax, R.B., 2005, UV radiation in the Netherlands: Assessing long-term variability and trends in relation to ozone and clouds, J. Geophys. Res. 110, D02203, doi: 10.1029/2004JD004824.

den Outer, P. N., Slaper, H., Kaurola, J., Lindfors, A., Kazantzidis, A., Bais, A.F., Feister, U., Junk, J., Janouch, M., and Josefsson, W., 2010, Reconstructing of erythemal ultraviolet radiation levels in Europe for the past 4 decades, J. Geophys. Res., 115, D10102, doi:10.1029/2009JD012827. 
Di Biagio, C., di Sarra, A., Meloni, D., Monteleone, F., Piacentino, S., and Sferlazzo, D., 2009, Measurements of Mediterranean aerosol radiative forcing and influence of the single scattering albedo, J. Geophys. Res. 114, D06211, doi:10.1029/2008JD011037.

di Sarra, A., Cacciani, M., Chamard, P., Cornwall, C., DeLuisi, J.J., Di Iorio, T., Disterhoft, P., Fiocco, G., Fuà, D., and Monteleone, F., 2002, Effects of desert dust on ozone on the ultraviolet irradiance at the Mediterranean island of Lampedusa during PAURII, J.Geophys. Res. 107 (D18), 8135. doi:10.1029/2000JD000139.

di Sarra, A., Fuà, D., Cacciani, M., Di Iorio, T., Disterhoft, P., Meloni, D., Monteleone, F., Piacentino, S., and Sferlazzo, D., 2008, Determination of ultraviolet cosinecorrected irradiances and aerosol optical thickness by combined measurements with a Brewer spectrophotometer and a multifilter rotating shadowband radiometer, Appl. Opt. 47(33), 6142-6150.

Dichter, B.K., Beaubien, A.F., and Beaubien, D.J., 1993, Development and Characterization of a New Solar Ultraviolet-B Irradiance Detector, J. Atmos. Ocean. Tech. 10, 337-344.

Diffey, B.L., 1992, Tables of Ambient Solar Ultraviolet Radiation for use in Epidemiological Studies of Malignant Melanoma.

Doda, D.D., and Green, A.E.S., 1980, Surface reflectance measurements in the UV from an airborne platform. Part 1, Appl. Opt., 19(13), 2140-2145.

Draxler, R.R. and Rolph, G.D., 2012, HYSPLIT (HYbrid Single-Particle Lagrangian Integrated Trajectory) Model access via NOAA ARL READY Website (http://ready.arl.noaa.gov/HYSPLIT.php), NOAA Air Resources Laboratory, Silver Spring, MD.

Dvorkin, A.Y., and Steinberger, E.H., 1999, Modeling the altitude effect on solar UV radiation, Sol. Energy 65(3), 181-187.

Early, E.A., Thompson, E.A., and Disterhoft, P., 1998, Field calibration unit for ultraviolet spectroradiometers, Appl. Optics 37, 6664-6670.

Ebell, H., Crewell, S., Löhnert, U., Turner, D.D., and Connor, E.J., 2011, Cloud statistics and cloud radiative effect for a low-mountain site, Q. J. R. Meteorol. Soc. 137, 306304, doi:10.1002/qj.748 
Edwards, G.D., and Monks, P.S., 2003, Performance of a single-monochromator diode array spectroradiometer for the determination of actinic flux and atmospheric photolysis frequencies, J. Geophys. Res. 108(D16), 8546, doi:10.1029/2002JD002844.

Esteve, A.R., Marin, M.J., Tena, F., Utrillas, M.P., and Martínez-Lozano, J.A., 2010, Influence of cloudiness over the values of erythemal radiation in Valencia, Spain, Int. J. Climatol. 30, 127-136, doi:10.1002/joc.1883.

Feister, U., and Grewe, R., 1995, Spectral albedo measurements in the UV and visible region over different types of surfaces, Photochem. Photobiol. 62, 736-744.

Fioletov, V.E., Kerr, J.B., Wardle, D.I., Krotkov, N., and Herman, J.R., 2002, Comparison of Brewer ultraviolet irradiance measurements with total ozone mapping spectrometer satellite retrievals, Opt. Eng. 41(12) 3051-3061.

Fioletov, V.E., Kimlin, M.G., Krotkov, N., McArthur, L.J.B., Kerr, J.B., Wardle, D.I., Herman, J.R., Meltzer, R., Mathews, T.W., and Kaurola, J., 2004, UV index climatology over the United States and Canada from ground-based and satellite estimates, J. Geophys. Res. 109, D22308, doi: 10.1029/2004JD004820.

Fioletov, V.E., McArthur, L.J.B., Mathews, T.W., and Marrett, L., 2009, On the relationship between erythemal and vitamin $\mathrm{D}$ action spectrum weighted ultraviolet radiation, J. Photochem. Photobiol. B95, 9-16, doi:10.1016/j.jphotobiol.2008.11.014.

Fishman, J., Wozniak, A.E., and Creilson, J.K., 2003, Global distribution of tropospheric ozone from satellite measurements using the empirically corrected tropospheric ozone residual technique: identification of the regional aspects of air pollution, Atmos. Chem. Phys. 3, 893-907.

Flint, S.D., and Caldwell, M.M., 2003, A biological spectral weighting function for ozone depletion research with higher plants, Physiol. Plantarum 117, 137-144.

Forster, P., and others, 2007, Changes in atmospheric constituents and in radiative forcing, in Climate Change 2007: The Physical Science Basis. Contribution of Working Group I to the Fourth Assessment Report of the Intergovernmental Panel on Climate Change, edited by S. Solomon et al., 129- 234, Cambridge Univ. Press, Cambridge, U. K.

Foyo-Moreno, I., Vida, J., Alados-Arboledas, L., 1999, A simple all weather model to estimate ultraviolet solar radiation (290-385nm), J. Appl. Meteorol. 38(3), 10201026. 
Foyo-Moreno, I., Vida, J., and Alados-Arboledas, L., 2001, On the use of a cloud modification factor for solar UV (290-385 nm) spectral range, Theor. Appl. Climatol. 38, 1183-1892.

Foyo-Moreno, I., Alados, I., Olmo, F.J., and Alados-Arboledas, L., 2003, The influence of cloudiness on UV global irradiance (295-385 nm), Agric. Forest Meteorol. 120, 101-111.

Gómez-Amo, J.L., Estellés, V., di Sarra, A., Pedrós, R., Utrillas, M.P., Martínez- Lozano, J.A., González-Frias, C., Kyrö, E., and Vilaplana, J.M., 2012, Operational considerations to improve total ozone measurements with a Microtops II ozone monitor, Atmos. Mes. Tech. 5, 759-769, doi:10.5194/amt-5-759-2012.

Götz, F.W.P., 1931, Zum Strahlungsklima des Spitzbergen Sommers, Gerlands Beiträge zur Geophys. 31, 119-154.

Grant, R., and Heisler, G., 1997, Obscured overcast sky radiance distributions for ultraviolet and photsyntetically active radiation, J. Appl. Meteorol. 36, 1336-1345.

Grant, R.H., and Heisler, G.M., 2000, Estimation of ultraviolet-B irradiance under variable cloud conditions, J. Appl. Meteorol. 39, 904-916.

Grant, R.H., and Gao, W., 2003, Diffuse fraction of UV radiation under partly cloudy skies as defined by the Automated Surface Observation System (ASOS), J. Geophys. Res. 108(D2), 4046, doi:10.1029/2002JD002201.

Gueymard, C., 2004, The sun's total and spectral irradiance for solar energy applications and solar radiation models, Sol. Energy, 76, 423-453.

Häder, D.P., Kumar, H.D., Smith, R.C., and Worrest, R.C., 2007, Effects of solar UV radiation on aquatic ecosystems and interactions with climate change, Photochem. Photobiol. Sci. 6, 267-285.

Hansen, J.E., and Travis, L.D., 1974, Light scattering in planetary atmospheres, Space Sci. Rev. 16, 527-610.

Harrison, L., and Michalsky, J., 1994, Objective algorithms for the retrieval of optical depths from ground-based measurements, Appl. Opt. 33(22), 5126-5132.

Harrison, L., Michalsky, J., and Berndt, J., 1994, The Automated multifilter rotating shadow-band radiometer: an instrument for optical depth and radiation measurements, Appl. Opt. 33(22), 5118-5125. 
Heisler, G.M., Grant, R.H., Gao, W., and Slusser, J.R., 2003, Ultraviolet radiation and its impacts on agriculture and forests, Agric. Forest Meteorol. 120, 3-7.

Hess, M., Koepke, P., and Schult, I. 1998, Optical Properties of Aerosols and Clouds: The Software Package OPAC, Bull. Am. Meteorol. Soc. 79, 831-844.

Hu, Y., and Stamnes, K., 1993, An accurate parameterization of the radiative properties of water clouds suitable for use in climate models, J. Climate 6, 728-742.

Hülsen, G., and Gröbner, J., 2007, Characterization and calibration of ultraviolet broadband radiometers measuring erythemally weighted irradiance, Appl. Optics 46 (23), 5877-5886.

Ialongo, I., Arola, A., Kujanpää, J., and Tamminen, J., 2011, Use of satellite erythemal UV products in analysing the global UV changes, Atmos. Chem. Phys. 11, 96499658, doi:10.5194/acp-11-9649-2011.

ICNIRP, 2004, Guidelines on limits of exposure of UV radiation, Health Phys. 87, 171186.

IPCC, 2007, Contribution of Working Group I to the Fourth Assessment Report of the Intergovernmental Panel on Climate Change 2007, Solomon, S., D. Qin, M. Manning, Z. Chen, M. Marquis, K.B. Averyt, M. Tignor and H.L. Miller (eds.), Cambridge University Press, Cambridge, United Kingdom and New York, NY, USA.

Iqbal, M., 1983, An introduction to solar radiation, Academic Press, London, UK.

Jacovides, C.P., Tymvios, F.S., Asimakopoulos, D.N., Kaltsounides, N.A., Theoharatos, G.A., and Tsitouri, M., 2009, Solar global UVB (280-315 nm) and UVA (315-380 $\mathrm{nm})$ radiant fluxes and their relationships with broadband global radiant flux at an eastern Mediterranean site, Agric. Forest Meteorol. 149, 1188-1200. doi:10.1016/j.agrformet.2009.02.009.

Johnston, H., 1971, Reduction of Stratospheric Ozone by Nitrogen Oxide Catalysts from Supersonic Transport Exhaust, Science 173, 3996, 517-522, doi: 10.1126/science.173.3996.517.

Kakani, V.G., Reddy, K.R., Zhao, D., and Sailaja, K., 2003, Field crop responses to ultraviolet-B radiation: a review, Agr. Forest Meterol. 120, 191-218. doi:10.1016/j.agrformet.2003.08.015. 
Kalabokas, P.D., Mihalopoulos, N., Ellul, R., Kleanthous, S., and Repapis, C.C., 2008, An investigation of the meteorological and photochemical factors influencing the background rural and marine surface ozone levels in the Central and Eastern Mediterranean, Atmos. Environ. 42 (34), 7894-7906.

Kanaya, Y., Kajii, Y., and Akimoto, H., 2003, Solar actinic flux and photolysis frequency determinations by radiometers and a radiative transfer model at Rishiri Island: comparisons, cloud effects, and detection of an aerosol plume from Russian forest fires, Atmos. Env. 37, 2463-2475, doi:10.1016/S1352-2310(03)00183-3.

Kasten, F., and Czeplak, G., 1980, Solar and terrestrial radiation dependent on the amount and type of cloud, Sol. Energy 24, 177-189.

Kasten, F., and Young, A.T., 1989, Revised optical air mass tables and approximation formula, Appl. Optics 28, 4735-4738.

Kerr, J.B., McElroy, C.T., Wardle, D.I., Olafson R.A., and Evans, W.F.J., 1985, The automated Brewer spectrophotometer, in Atmospheric Ozone, C.S. Zerefos and A. Ghazi, eds (Reidel, 1985), 396-401.

Kerr, J.B., 2005, Understanding the factors that affect surface ultraviolet radiation, Optical Engineering 44(4), 041002.

Kim, B.G., Schwartz, S.E., Miller, M.A. and Min, Q., 2003, Effective radius of cloud droplets by ground-based remote sensing: Relationship to aerosol, J. Geophys. Res. 108, D23, 4740, doi:10.1029/2003JD003721.

Kohmyr, D., 1980, Operations handbook: Ozone observations with a Dobson spectrometer, World Meteorol. Organ., Geneva, 1980.

Kohmyr, D., Grass, R.D., and Leonard, R.K., 1989, Dobson Spectrophotometer 83: A standard for total ozone measurement, 1962-1987, J. Geophys. Res. 94, 9847-9861.

Kourtidis, K., and others, 2002, Regional levels of ozone in the troposphere over Eastern Mediterranean, J. Geophys. Res. 107 (D18), 8140, doi:10.1029/2000JD000140.

Krotkov, N.A., Bhartia, P.K., Herman, J.R., Fioletov, V., and Kerr, J., 1998, Satellite estimation of spectral surface UV irradiance in the presence of tropospheric aerosols: 1. Cloud-free case, J. Geophys. Res. 103, 8779-8793, doi:10.1029/98JD00233. 
Krotkov, N.A., Bhartia, P.K., Herman, J.R., Slusser, J., Scott, G., Jason, G., Labow, G., Eck, T.F., and Holben, B.N., 2005, Aerosol ultraviolet absorption experiment (2002 to 2004), part 1: ultraviolet multifilter rotating shadowband radiometers calibration and intercomparison with CIMEL sunphotometers, Opt. Eng. 44, 041004, doi: $10.1117 / 1.1886818$.

Krzýscin, J.W., Jaroslawski, J., and Sobolewski, P.S., 2003, Effects of clouds on the surface erythemal UV-B irradiance at northern midlatitudes: estimation from the observations taken at Belsk, Poland (1999-2001), J. Atmos. Sol.-Terr. Phys. 65, $457-467$.

Kuchinke, C., Fienberg, K., and Nunez, M., 2004, The angular distribution of UV-B sky radiance under cloudy conditions: A comparison of measurements and radiative transfer calculations using a fractal model, J. Appl. Meteorol. 43, 751-761.

Kulkarni, P.S., Bortoli, D., Salgado, R., Antón, M., Costa, M.J., and Silva, A.M., 2011, Tropospheric ozone variability over the Iberian Peninsula, Atmos. Environ. 45, 174-182, doi:10.1016/j.atmosenv.2010.09.029.

Kylling, A., Albold, A., and Seckmeyer, G., 1997, Transmittance of a cloud is wavelength-dependent in the UV-range: Physical interpretation, Geophys. Res. Lett. 24, 397-400.

Kylling, A., and others, 2005, Spectral actinic flux in the lower troposphere: measurement and 1-D simulations for cloudless, broken cloud and overcast situations, Atmos. Chem. Phys. 5, 1975-1997, doi:10.5194/acp-5-1975-2005.

Landelius, T., and Josefsson, W., 2000, Methods for cosine correction of broadband UV data and their effect on the relation between UV irradiance and cloudiness, J. of Geophys. Res. 105(D4), 4795-4802.

Lantz, K.O., Disterhoft, P., DeLuisi, J.J., Early, E., Thompson, A., Bigelow, D., Slusser, J., 1999, Methodology for Deriving Clear-Sky Erythemal Calibration Factors for UV Broadband Radiometers of the U.S. Central UV Calibration Facility, J. Atmos. Oceanic Technol. 16, 1736-1752, doi: http://dx.doi.org/10.1175/15200426(1999)016<1736:MFDCSE $>2.0 . \mathrm{CO} ; 2$.

Lenoble, J., 1993, Atmospheric radiative transfer, A. Deepak Publishing, Hampton, Virginia, USA. 
Lindfors, A., Kaurola, J., Arola, A., Koskela, T., Lakkala, K., Josefsson, W., Olseth, J.A., and Johnsen, B., 2007, A method for reconstruction of past UV radiation based on radiative transfer modeling: Applied to four stations in northern Europe, J. Geophys. Res. 112, D23201, doi:10.1029/2007JD008454.

Lindfors, A., and Arola, A., 2008, On the wavelength-dependent attenuation of UV radiation by clouds, Geophys. Res. Lett. 35, L05806, doi:10.1029/2007GL032571.

Löhnert, U., and Crewell, S., 2003, Accuracy of cloud liquid water path from groundbased microwave radiometry: 1 . Dependence on cloud model statistics, Radio Science 38(3), 8041, doi:10.1029/2002RS002654.

Long, C.N., and Ackerman, T.P., 2000, Identification of clear skies from broadband pyranometer measurements and calculation of downwelling shortwave cloud effects, J. Geophys. Res. 105(D12), 15609-15626.

Long, C.N., Ackerman, T.P., Gaustad, K.L., and Cole, J.N.S., 2006, Estimation of fractional sky cover from broadband shortwave radiometer measurements, J. Geophys. Res. 111, D11204, doi:10.1029/2005JD006475.

López, M.L., Palancar, G.G., and Toselli, B.M., 2009, Effect of different types of clouds on surface UV-B and total solar irradiance at southern mid-latitudes: CMF determination at Córdoba, Argentina, Atmos. Environ. 43, 3130-3136, doi:10.1016/j.atmosenv.2009.02.065.

Lorente, J., Redaño, A., and De Cabo, X., 1994, Influence of Urban Aerosol on Spectral Solar Irradiance, J. Appl. Meteorol. 33, $406-415$.

Madronich, S., 1987, Photodissociation in the atmosphere 1. Actinic flux and the effect of ground reflections and clouds, J. Geophys. Res., 92, 9740-9752.

Malicet, J., Daumont, D., Charbonnier, J., Parisse, C., Chakir, A., and Brion, J., 1995, Ozone UV spectroscopy. II. Absorption cross-sections and temperature dependence, J. Atmos. Chem. 21 (3), 263-273.

Martínez-Lozano, J.A., Tena, F., and Utrillas, M.P., 1999, Ratio of UV to global broad band irradiation in Valencia, Spain, Int. J. Climatol. 19, 903-911.

Mateos, D., de Miguel, A., and Bilbao, J., 2010a, Empirical models of UV total radiation and cloud effect study, Int. J. Climatol. 30, 1407-1415, doi:10.1002/joc.1983. 
Mateos, D., Bilbao, J., de Miguel, A., and Pérez-Burgos, A., 2010b, Dependence of ultraviolet (erythemal and total) radiation and CMF values on total and low cloud covers in Central Spain, Atmos. Res. 98, 21-27, doi:10.1016/j.atmosres.2010.05.002.

Mateos, D., Bilbao, J., Kudish, A.I., Parisi, A.V., Carbajal, G., di Sarra, A., Román, R., and de Miguel, A., 2012a, Validation of satellite erythemal radiation retrievals using ground-based measurements in five Countries, Rem. Sen. Environ., Under Review.

Mateos, D., Román, R., Bilbao, J., de Miguel, A., and Pérez-Burgos, A., 2012b, Cloud modulation of shortwave and ultraviolet solar irradiances at surface, Óptica Pura y Aplicada 45(1), 29-32.

Matsumi, Y., Comes, F.J., Hancock, G., Hofzumahaus, A., Hynes, A.J., Kawasaki, M., and Ravishankara, A.R., 2002, Quantum yields for production of O(1D) in the ultraviolet photolysis of ozone: recommendation based on evaluation of laboratory data, J. Geophys. Res. 107, D3, 4024, doi:10.1029/2001JD000510.

Mayer, B., Kylling, A., Madronich, S., and Seckmeyer, G., 1998, Enhanced absorption of UV radiation due to multiple scattering in clouds: Experimental evidence and theoretical explanation, J. Geophys. Res. 103, D23, 31241-31254.

Mayer, B., and Kylling, A., 2005, Technical note: The libRadtran software package for radiative transfer calculations - description and examples of use, Atmos. Chem. Phys. 5, 1855-1877.

McKenzie, R.L., Paulin, K.J., and Madronich, S., 1998, Effects of snow cover on UV irradiance and surface albedo: A case study, J. Geophys. Res. 103, 28785-28792.

McKinlay, A.F., and Diffey, B.L., 1987, A reference action spectrum for ultraviolet induced erythema in human skin, Commission Internationale de l' Eclairage (CIE) $6,17-22$.

Meloni, D., di Sarra, A., DeLuisi, J., Di Iorio, T., Fiocco, G., Junkermann, W., and Pace, G., 2003, Trospospheric aerosols in Mediterranean: 2. radiative effects trough model simulations and measurements, J. Geophys. Res. 108 (D10), 4217, doi:10.1029/2002JD002807.

Meloni, D, di Sarra, A., Herman, J.R., Monteleone, F., and Piacentino, S., 2005, Comparison of ground-based and Total Ozone Mapping Spectrometer erythemal UV doses at the island of Lampedusa in the period 1998-2003: Role of tropospheric aerosols, J. Geophys. Res. 110, D01202, doi:10.1029/2004JD005283. 
Meloni, D., di Sarra, A., Pace, G., and Monteleone, F., 2006, Aerosol optical properties at Lampedusa (Central Mediterranean): 2. Determination of single scattering albedo at two wavelengths for different aerosol types, Atmos. Chem. Phys. 6, 715-727.

Min, Q., and Harrison, L.C., 1996, Cloud properties derived from surface MFRSR measurements and comparison with GOES results at the ARM SGP site, Geophys. Res. Lett. 23(13), 1641-1644.

Min, Q., Duan, M., and Marchand, R., 2003, Validation of surface retrieved cloud optical properties with in situ measurements at the Atmospheric Radiation Measurement Program (ARM) South Great Plains site, J. Geophys. Res. 108, D17, 4547, doi: 10.1029/2003JD003385.

Min, Q., Wang, T., Long, C.N., and Duan, M., 2008, Estimating fractional sky cover from spectral measurements, J. Geophys. Res. 113, D20208, doi:10.1029/2008JD010278.

Molina, L. T., and Molina, M.J., 1986, Absolute absorption cross sections of ozone in the 185- to 350-nm wavelength range, J. Geophys. Res. 91, 14,501-14,508.

Morys, M., Mims III, F.M., Hagerup, S., Anderson, S.E., Baker, A., Kia, J., and Walkup, T., 2001, Design, calibration, and performance of MICROTOPS II handheld ozone monitor and Sun photometer, J. Geophys. Res. 106, D3, 14,573-14,582.

Nichol, S.E., Pfister, G., Bodeker, G.E., Mckenzie, R.L., Wood, S.W., and Bernhard, G., 2003, Moderation of Cloud Reduction of UV in the Antarctic Due to High Surface Albedo, J. Appl. Meteorol. 42, 1174-1183.

Nicolet, M., 1965, Nitrogen Oxides in the Chemosphere, J. Geophys. Res. 70(3), 679689, doi:10.1029/JZ070i003p00679.

Nolle, M., Ellul, R., Heinrich, G., and Güsten, H., 2002, A long-term study of background ozone concentrations in the central Mediterranean-diurnal and seasonal variations on the island of Gozo, Atmos. Environ. 36 (8), 1391-1402.

Nzeffe, F., Joseph, E., and Min, Q., 2008, Surface-based observation of aerosol indirect effect in the Mid-Atlantic region, Geopohys. Res. Lett. 35, L22814, doi:10.1029/2008GL036064.

Ogunjobi, K, and Kim, Y., 2004, Ultraviolet (0.280-0.400) and broadband solar hourly radiation at Kwangju, South Korea: analysis of their correlation with aerosol optical depth and clearness index, Atmos. Res. 71, 193-214. 
Oreopoulos, L., and Rossow, W.B., 2011, The cloud radiative effects of International Satellite Cloud Climatology Project weather states, J. Geophys. Res. 116, D12202, doi:10.1029/2010JD015472.

Pace, G., di Sarra, A., Meloni, D., Piacentino, S., and Chamard, P., 2006, Aerosol optical properties at Lampedusa (Central Mediterranean) - 1 . influence of transport and identification of different aerosol types, Atmos. Chem. Phys. 6, 697-713.

Palancar, G.G., Fernández, R.P., and Toselli, B.M., 2005, Photolysis rate coefficients calculations from broadband UV-B irradiance: model-measurement interaction, Atmos. Env. 39, 857-866, doi:10.1016/j.atmosenv.2004.10.033.

Palancar, G.G., Shetter, R.E., Hall, S.R., Toselli, B.M., and Madronich, S., 2011, Ultraviolet actinic flux in clear and cloudy atmospheres: model calculations and aircraft-based measurements, Atmos. Chem. Phys. 11, 5457-5469.

Parisi, A., Kimlin, M., Wong, J., and Wilson, M., 2000, Diffuse component of solar ultraviolet radiation in tree shade, J. Photochem. Photobiol. B-Biol. 54, 116-120.

Parisi, A.V., Turnbull, D.J., and Turner, J., 2007, Calculation of cloud modifications factors for the horizontal plane eye damaging ultraviolet radiation, Atmos. Res. 86, 278-285, doi:10.1016/j.atmosres.2007.06.003.

Penndorf, R., 1957, Tables of the refractive index for standard air and the Rayleigh scattering coefficient for the spectral region between 0.2 and $20 \mathrm{~mm}$ and their application to atmospheric optics, J. Opt. Soc. Am. 47, 176-182.

Penner, J. E., Andreae, M., Annegarn, H., Barrie, L., Feichter, J., Hegg, D., Jayaraman, A., Leaitch, R., Murphy, D., Nganga, J., and Pitari, G., 2001, Aerosols, their Direct and Indirect Effects, in: Climate Change 2001: The Scientific Basis, edited by: Houghton, J. T., Ding, Y., Griggs, D. J., Noguer, M., Van der Linden, P. J., Dai, X., Maskell, K., and Johnson, C. A., Report to Intergovernmental Panel on Climate Change from the Scientific Assessment Working Group (WGI), Cambridge University Press, 289-416.

Pfeifer, M.T., Koepke, P., and Reuder, J., 2006, Effects of altitude and aerosol on UV radiation. J. Geophys. Res. 111, D01203, doi:10.1029/2005JD006444.

Ramanathan, V., Cess, R. D., Harrison, E. F, Minnis, P., Barkstrom, B.R., Ahmad, E., and Hartmann, D., 1989, Cloud-Radiative Forcing and Climate: Results from the Earth Radiation Budget Experiment, Science 243, 4887, 57-63. 
Román, R., Mateos, D., de Miguel, A., Bilbao, J., Pérez-Burgos, A., Rodrigo, R., and Cachorro, V.E., 2012, Atmospheric effects on the ultraviolet erythemal and total shortwave solar radiation in Valladolid, Spain, Óptica Pura y Aplicada 45(1), 17-21.

Rose, T., Crewell, S., Löhnert, U., and Simmer, C., 2005, A network suitable microwave radiometer for operational monitoring of the cloudy atmosphere, Atmos. Res. 75, 183-200, doi:10.1016/j.atmosres.2004.12.005.

Schwander, H., Mayer, B., Ruggaber, A., Albold, A., Seckmeyer, G., and Koepke, P., 1999, Method to determine snow albedo values in the ultraviolet for radiative transfer modelling, Appl. Optics 38(18), 3869-3875.

Schwander, H., Koepke, P., Kaifel, A., and Seckmeyer, G., 2002, Modification of spectral UV irradiance by clouds, J. Geophys. Res. 107, D16, 4296, doi:10.1029/2001JD001297.

Seckmeyer, G., Erb, R., and Albold, A., 1996, Transmittance of a cloud is wavelengthdependent in the UV-range, Geophys. Res. Lett. 23, 2753-2755.

Sengupta, M., Clothiaux, E.E., Ackerman, T.P., Kato, S., and Min, Q., 2003, Importance of accurate liquid water path for estimation of solar radiation in warm boundary layer clouds: An observational study, J. Climate 16, 2997-3009.

Setlow, R.B., 1974, The wavelengths in sunlight effective in producing skin cancer: a theoretical analysis, Proc. Natl. Acad. Sci. 71, 3363-3366.

Shettle, E.P., 1989, Models of aerosols, clouds and precipitation for atmospheric propagation studies. In AGARD Conference Proceedings $\mathrm{N}^{\circ} 454$, Atmospheric propagation in the uv, visible, ir and mm-region and related system aspects.

Sobolev, V., 1975, Light Scattering in Planetary Atmospheres, Pergamon Press, Oxford, New York, Toronto, Sydney, Braunschweig.

Sola, Y., and others, 2008, Altitude effect in UV radiation during the Evaluation of the Effects of Elevation and Aerosols on the Ultraviolet Radiation 2002 (VELETA2002) field campaign, J. Geophys. Res. 113, D23202, doi:10.1029/2007JD009742.

Spinhirne, J.D., and Green, A.E.S., 1978, Calculation of the relative influence of cloud layers on received ultraviolet and integrated solar radiation, Atmos. Environ. 12, 2449-2454.

Staiger, H., and Koepke, P., 2005, UV Index forecasting on a global scale, Meteorologische Zeitschrift 14(2), 259-270, doi:10.1127/0941-2948/2005/0029 
Staiger, H., den Outer, P.N., Bais, A.F., Feister, U., Johnsen, B., and Vuilleumier, L., 2008, Hourly resolved cloud modification factors in the ultraviolet, Atmos. Chem. Phys. 8, 2493-2508.

Stamnes, K., Tsay, S.C., Wiscombe, W., and Laszlo, I., 2000, DISORT, a GeneralPurpose Fortran Program for Discrete-Ordinate-Method Radiative Transfer in Scattering and Emitting Layered Media: Documentation of Methodology, Tech. rep. Dept. of Physics and Engineering Physics, Stevens Institute of Technology, Hoboken, NJ 07030.

Steinbrecht, W., Hassler, B., Claude, H., Winkler, P., and Stolarski, R.S., 2003, Global distribution of total ozone and lower stratospheric temperature variations, Atmos. Chem. Phys. 3(5), 1421-1438.

Stephens, G.L., 1978, Radiation profiles in extended water clouds. II: Parameterization schemes, J. Atmos. Sci. 35, 2123-2132.

Turnbull, D.J., Parisi, A.V., and Schouten, P.W., 2010, Empirical Evaluation of Global Vitamin D Effective Ultraviolet Irradiances under Cloudy Conditions for a Subtropical Southern Hemisphere Site, Rad. Res. 173(5), 703-708, doi:http://dx.doi.org/10.1667/RR1936.1

Twomey, S., 1976, The influence of aerosols on radiative properties of clouds, Climatic change and Variability: A Southern Perspective, Pittock et al., Eds., 455pp.

UNEP, 2007, UNEP Report on Environmental Effects of Ozone Depletion, Photochem. Photobiol. Sci. 6, 201-332.

Utrillas, M.P., Marín, M.J., Esteve, A.R., Tena, F., Cañada, J., Estellés, V., and MartínezLozano, J.A., 2007, Diffuse UV erythemal radiation experimental values, J. Geophys. Res. 112, D24207, doi:10.1029/2007JD008846.

Vanicek, K., Frei, T., Litynska, Z., and Schmalwieser, A., 2000, UV-Index for the public, COST-713 Action, Brussels.

Velazquez, F., 2001, El ozono: ¿Cuándo protege y cuándo destruye?, McWraw-Hill.

Volz-Thomas, A., Lerner, A., Pfitz, H.-W., Schultz, M., McKenna, D.S., Schmitt, R., Madronich, S., and Roth, E.P., 1996, Airborne measurements of the photolysis frequency of NO2, J. Geophys. Res. 101 (D13), 18,613-18,627.

Wang, P., Knap, W.H., and Stammes, P., 2011, Cloudy sky shortwave radiative closure for a Baseline Surface Radiation Network site, J. Geophys. Res. 116, D08202, doi:10.1029/2010JD015141. 
Weatherhead, E.C., and Andersen, S.B., 2006, The search for signs of recovery of the ozone layer. Nature 441, 39-45, doi:10.1038/nature04746.

Webb, A.R., 1991, Solar ultraviolet-radiation in Southeast England - The case for spectral measurements, Photochem. Photobiol. 54, 789-794.

Webb, A.R., 2006, Who, what, where and when influences on cutaneous vitamin D synthesis, Prog. Biophys. Mol. Biol. 92, 17-25.

Webb, A., Gröbner, J., and Blumthaler, M., 2006, A practical guide to operating broadband instruments measuring erythemally weighted irradiance, COST726, 22595.

WHO, 1995, Protection against exposure to ultraviolet radiation, Tech. Rep. 17, Joint publication by World Health Organization, United Nations Environment Programme, WHO/EHG/95.17, Geneva, Switzerland.

WHO, 2002, Global Solar UV Index: a practical guide, World Health Organization, World Meteorological Organization, United Nations Environment Programme, and International Commission on Non-Ionizing Radiation Protection, Geneva, Switzerland.

Winiecki, S., and Frederick, J.E., 2005, Ultraviolet radiation and clouds: Couplings to tropospheric air quality, J. Geophys. Res. 110, D22202, doi:10.1029/2005JD006199.

WMO, 2007, Scientific assessment of ozone depletion: 2006, Global ozone research and monitoring project, Tech. Rep. 50, Geneva, Switzerland.

WMO, 2008, Guide to Meteorological Instruments and Methods of Observation, WMO No. 8, Geneva, Switzerland.

WMO, 2011, Scientific Assessment of Ozone Depletion: 2010, Global ozone research and monitoring project, Tech. Rep. 52, Geneva, Switzerland.

Woods, T.N., and others, 1996, Validation of the UARS solar ultraviolet irradiances: Comparison with the ATLAS 1 and 2 measurements, J. Geophys. Res. 101(D6), 9541-9569, doi:10.1029/96JD00225.

Zhao, X., Zongwei, L., Chen, Y., Shi, L., and Zhu, Y., 2007, Solid-phase photocatalytic degradation of polyethylene plastic under UV and solar light irradiation, J. Molec.

Catal. A, Chem. 268, 101-106. 